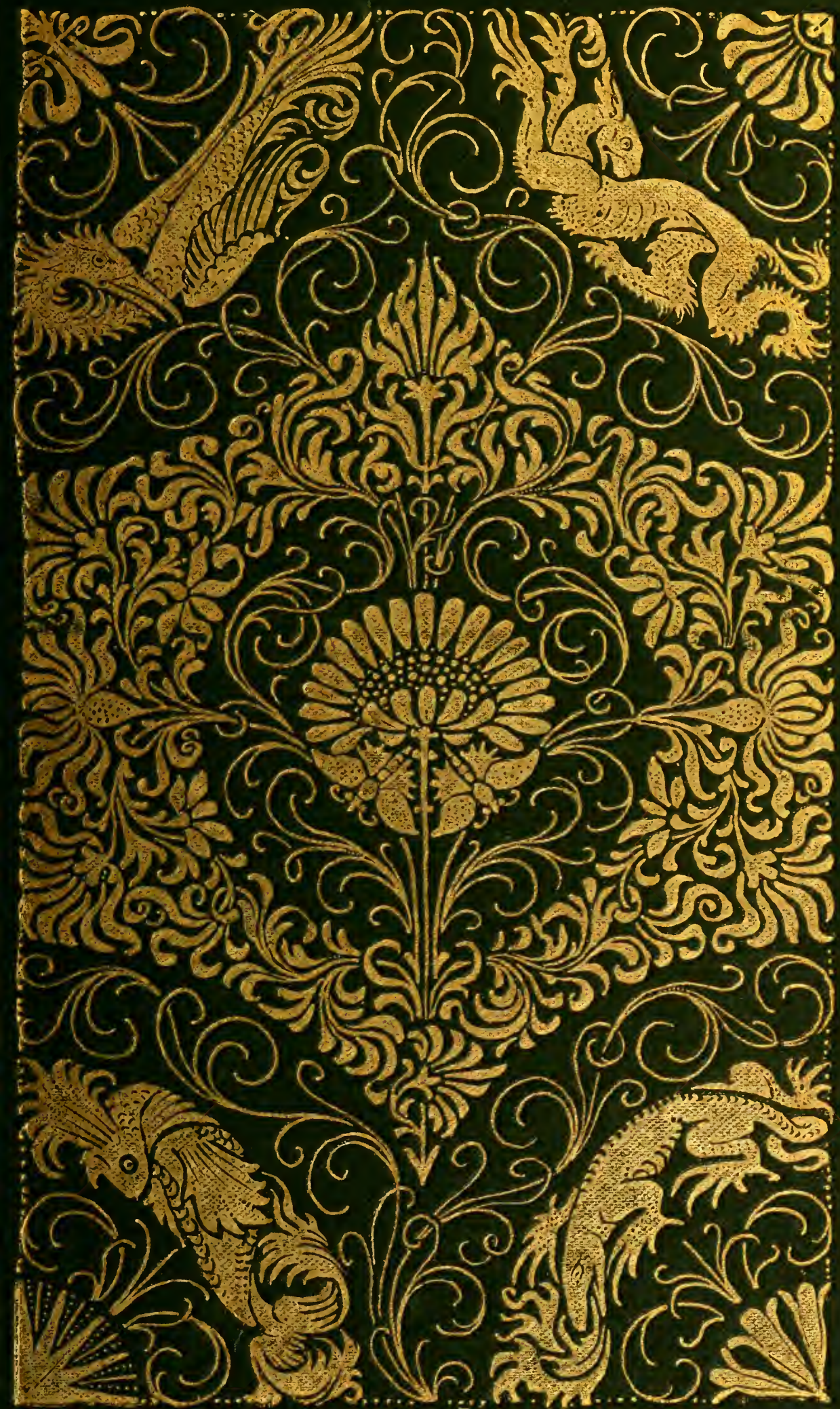





NATURE IN ORNAMENT.

BY LEWIS F. DAY. 
WORKS BY THE SAME AUTHOR.

SOME PRINCIPLES OF EVERY-DAY ART. Second Edition.

THE ANATOMY OF PATTERN.

Fourth Edition.

THE PLANNING OF ORNAMENT.

Third Edition.

THE APPLICATION OF ORNAMENT.

Fourth Edition.

WINDOWS; A BOOK ABOUT STAINED AND PAINTED GLASS.

ALPHABETS, OLD AND NEW.

Third Impression.

ART IN NEEDLEWORK; A BOOK ABOUT EMBROIDERY.

Second Edition.

LETTERING IN ORNAMENT. 

Pate

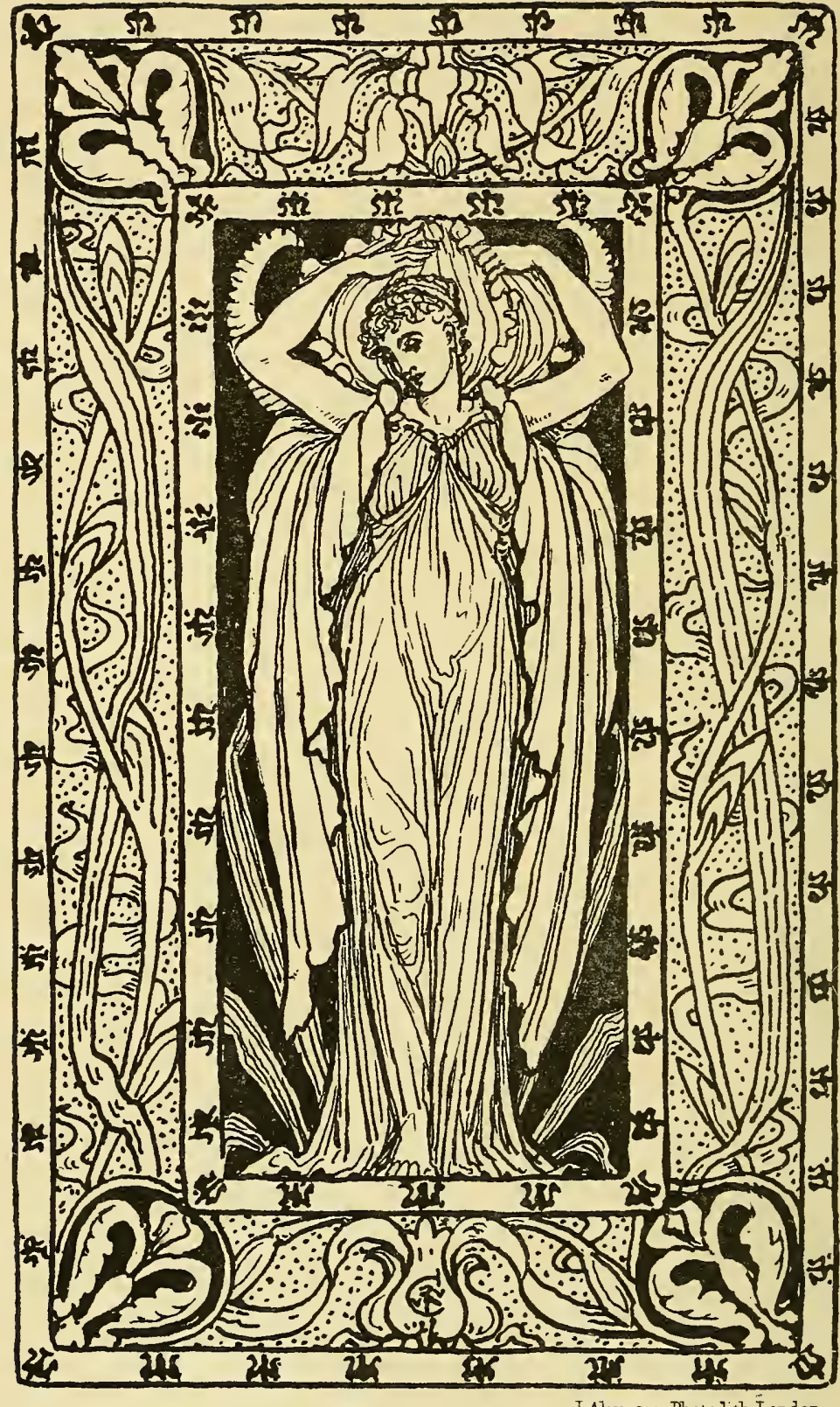

Fleur-de-Luce 


\section{NATURE IN ORNAMENT}

AN ENQUIRY INTO THE NATURAL ELEMENT IN ORNAMENTAL DESIGN \& A SURVEY OF THE ORNAMENTAL TREATMENT OF NATURAL FORMS.

BY

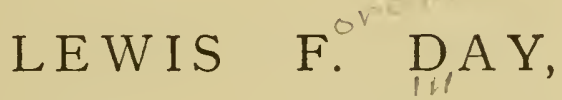

AUTHOR OF 'WINDOWS,' 'ART IN NEEDLEWORK,' 'LETTERING

IN ORNAMENT,' 'ALPHABETS,' \& C.

WITH NUMEROUS ILLUSTRATIONS OF DESIGN AND TREATMENT IN ORNAMENT, OLD AND NEW.

$$
\begin{array}{lr}
\text { THIRD } & \text { EDITION } \\
\text { SIXTH } & \text { THOUSAND. }
\end{array}
$$

L O N D N :

B. T. BATSFORD, $94 \mathrm{HIGH}$ HOLBORN 1902. 


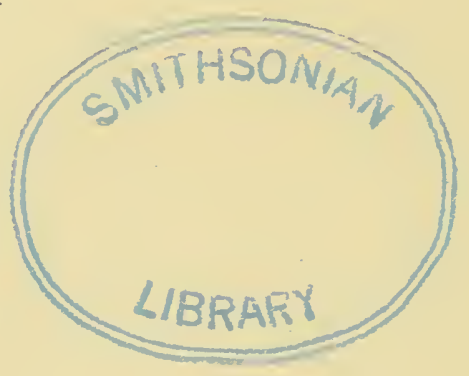




\section{MHT}

\section{PREFACE}

\section{TO THE THIRD EDITION.}

IT was explained in the Preface to the First Edition that the aim of this book was not merely to show the adaptability of plant form to the purposes of ornament. That is selfobvious: were it not, others have already called attention to the fact. The purpose is rather to demonstrate the natural development of ornament, to show its constant relation to natural form, and to deduce from the practice of past-masters of the craft of design something like principles, which may put the student in the way of turning nature to account in ornament of his own.

A Third Edition gives me the opportunity not only of once more carefully revising the text, but of adding a copious Index of Illustrations; which, as these are invariably to be found as near the reference to them as the pages would allow, should make general reference easy.

LEWIS F. DAY.

I3 Mecklenburg Square, London, Fanuary 12 th, I 896. 



\section{TABLE OF CONTENTS.}

I. INTRODUCTORY ..

II. Ornament in Nature $\ldots$..

III. Nature in ORnament ..

IV. The Simplification of Natural Forms 52

V. The Elaboration of Natural Forms .. 69

VI. Consistency in the Modification of

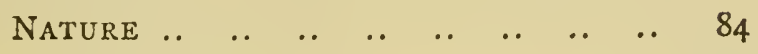

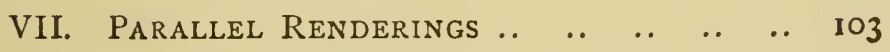

VIII. More Parallels

iX. Tradition in Design $\ldots$..

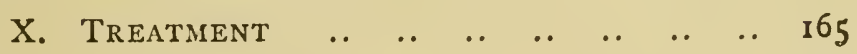

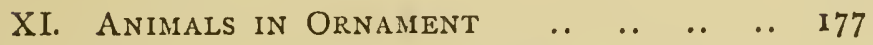

XiI. The Element of the Grotesque .. .. 195

XIII. Still Life in Ornament

XIV. Symbolic Ornament

INDEX TO ILLUSTRATIONS $\quad . . \quad \ldots \quad$.. 



\section{LIST OF PLATES.}

I. FLEUR DE LUCE-treatment of the Iris, by Walter Crane.

2. JAPANESE ROSES-from various Japanese printed books.

3. BUDDING BRANCHES-drawn from nature.

4. NATURAL LEAF-SHEATHS-from a Japanese botany book.

5. VARIOUS BERRIES-drawn from nature.

6. SOME SEED-VESSELS-from a Japanese botany book.

7. PODS-drawn from nature.

8. FLOWER AND LEAF BUDS-drawn from nature.

9. OAK AND OAK GALLS-tile panel, L.F.D.

IO. NATURAL GROWTH-from a Japanese botany book.

II. GREEK SCROLLS.

I2. ROMAN SCROLLS.

I 3 ACANTHUS SCULPTURE AND BRUSH-WORK-illustrative diagram.

14. TWO VERSIONS OF THE SAME FRIEZE DESIGN-L.F.D.

15. DETAILS OF ROMAN MOSAIC-from Carthage, B.M.

I6. TRANSITIONAL SCROLL-German, by D. Hopfer.

17. PAinted WALL PANEL-from the Palazzo del $T$, by Giulio Romano. 
r8. LUSTRE DISHES - of the sixteenth century-V.\& A.M.

I9. GERMAN GOTHIC SCROLL-from tapestry in the museum at Nuremberg.

20. ARAB-ESQUE RENAISSANCE ORNAMENT-German.

21. ORNAMENTAL BOUQUET-Of the seventeenth centurydesign for goldsmith's work.

22. BOoK-COVER-designed by Owen Jones.

23. SUNFLOWERS AND ROSES-wall-paper by B. J. Talbert. 24. DETAILS OF GREEK TERRA-COTTA-from vases at Naples and at the B.M.

25. DETAILS OF ANCIENT COPTIC EMBROIDERIES-V.\& A.M. 26. DETAIL FROM AN INDIAN KINKAUB-modern traditional design.

27. DETAILS FROM POMPEII-wall painting and mosaic.

28. CARVED CABINET DOOR-from Cairo-V.\&A.M.

29. ENGLISH GOTHIC DETAILS-from various sources.

30. INDIAN RENDERINGS OF THE IRIS-painting and damascening.

31. INLAID FLOWER-PANELS-L.F.D.

32. LYONS SILK-WEAVING OF THE SEVENTEENTH OR EIGHTEENTH CENTURY-Dresden Museum.

33. Details of eighteenth Century Foliage-from old English silks.

34. SILK DAMASK OF THE SIXTEenth CENTURY-Italian.

35. OLD LACE-ivory point, Munich Museum.

36. Details of hammered WORK-German Gothic.

37. WALL-PAPER-conventional growth-L.F.D.

38. WALl-PAPER FOUNDED UPON NATURE-L.F.D. 


$$
\text { List of Plates. }
$$

39. TILE PANEL BASED ON THE LILY-L.F.D.

40. CHRYSANTHEMUM PATTERN-comparatively naturalL.F.D.

41. ARCHAIC GREEK FOLIAGE-from a bronze cup-B.M.

42. MODERN GOTHIC LILY PANEL-B. J. Talbert.

43. LILY ORNAMENT-Italian inlay, Siena.

44. EIGHTEENTH CENTURY FLOWER RENDERINGS-from , old English silks.

45. A RENAissance MEDley-S. Croce, Florence.

46. PEA-POD ORNAMENT-pilaster by Brunellesco.

47. DUTCH AND GERMAN CONVENTIONS-of the seventeenth century.

48. SCROLL AND FOLIAGE-L.F.D.

49. ANCIENT COPTIC EMBROIDERY-V.\&A.M.

50. VINE AND OLIVE PANEL-Lateran Museum, Rome.

5I. ITAlian Gothic vine-from Giotto's Tower, Florence

52. VINE AND APPLE-TREE FRIEZE-L.F.D.

53. CLASSIC RENDERINGS OF THE VINE-B.M.

54. ARAB VINE PANEL-showing one-half of the design.

55. VINE SCULPTURE-Lateran Museum.

56. STENCILled Vine deCORATion-Heywood Sumner.

57. COPTIC VINE ORNAMENT-from ancient embroideriesV.S A.M.

58. ENGLISH GOTHIC VINE-stall-end, from Christchurch Priory.

59. VINE IN STAINED GLASS-L.F.D.

60. VINE BY DÜRER-from a woodcut.

6I. Conventional Vine-LEAF PATtERn-L.F.D. 
62. ARTIFICIAL RENDERINGS OF THE ROSE-from English silks of the eighteenth century.

63. TUDOR ROSE-from the bronze doors to Henry VII.'s chapel.

64. TUDOR ROSE-from a stall-arm, Henry VII.'s chapel.

65. ITALIAN VERSION OF A PERSIAN CARPET-rose and tulip-V.\&A.M.

66. MARBLE INLAY-from the Taj Mahal, India.

67. INDIAN LOTUS PANEL-stone-carving, from the Buddhist Tope at Amarivati.

68. DETAILS OF BUDDHIST STONE-CARVING-lotus flowers, \&c., from Amarivati.

69. THE PINK-various renderings of the flower.

70. EighteENTH CENTURY VERSiONS OF THE PINKEnglish.

7I. POPPY BY GHIBERTI-from the bronze doors of the Baptistery at Florence.

72. POPPY PATTERN-wall-paper, L.F.D.

73. pomegranates-Chinese colour-printing and German incising.

74. GOTHIC OAK ORNAMENT-after Pugin.

75. COMParatively Natural Lily PANEL-L.F.D.

76. ORCHID AND FUNGUS PATTERN-old Chinese embroidery.

77. CONVENTIONAL TREE WORK-Indian stone carving.

78. PERSIAN FOLIAGE-silk-weaving of the sixteenth century, Lyons Museum.

79. Details of egYPtian SCUlPtuRE-B.M.

80. DETAILS OF NINEVITE SCULPTURE-B.M. 
81. DETAILS OF GREER VASE-PAINTING-B.M.

82. ROMAN SCULPTURF-lemon and apple trees-Lateran Museum.

83. SiXTEENTH CENTURY GERMAN DESIGN-Peter Quentel.

84. LATE GOTHIC "PINE" ORNAMENTS-from various textiles.

85. CONVENTIONAL TULIP FRIEZE-L.F.D.

86. PEONY FRIEZE-by W. J. Muckley.

87. FRUIT PATTERN-wall-paper by Wm. Morris.

88. CHINESE LOTUS-porcelain painting.

89. СОВ๕A SCANDENS-linen damask-L.F.D.

9. CONVENTIONAL DANDELION-L.F.D.

91. GERMAN GOTHIC THISTLE-SCROLL - wood-carving, V.\&A.M.

92. JAPANESE CRANES-from a printed book.

93. JAPANESE TORTOISES-from a printed book.

94. PERUVIAN ECCENTRICITIES-from fragments of stuffs.

95. SICILIAN SILK PATTERNS- of about the thirteenth century.

96. SiXteENTH CENTURY WOOD-CARving - S. Pietro, Perugia.

97. CONVENTIONAL BUTTERFLIES-Chinese and Japanese.

98. MODERN GERMAN RENAISSANCE-by Anton Seder.

99. SEVENTEENTH CENTURY SCROLL-WORK-from a book of designs, published 1682, by S. Gribelin.

100. SIXTEENTH CENTURY ARABESQUE-Italian.

101. LATE GOTHIC FOLIAGE-tempera painting, 
102. LUSTRE PLAQUES-L.F.D.

103. STUDIES IN ORNAMENTAL FIGURE-WORK-by Holbein. 104. GROTESQUE PANEL-by Sansovino.

IO5. GROTESQUE FIGURE-by Marco Dente da Ravenna.

106. GROTESQUE SCROLI-cretonne, L.F.D.

107. KELTIC INTERLACED ORNAMENT-from a MS. in the B.M.

108. CONVENTIONAL WING FORMS - sixteenth century Italian carving.

I09. DIAPERS WITH A MEANING-Japanese.

IIO. EARLY GREEK WAVE AND LOTUS DIAPER-twelfth or thirteenth century B.C.

III. SEAWEED BORDERS-L.F.D.

112. SEAWEED PATTERN-L.F.D.

I13. PEACOCK-FEATHER PATTERN-Japanese.

II4. PEACOCK-FEATHER DIAPERS-from various sources.

115. PEACOCK-FEATHER PATTERN-Turkish embroidery.

116. ROCOCO SCROLL-WORK-by Philippo Passarini.

II7. SEVENTEENTh CENTURy SCROLL-WORK - German, by Nicolaus Drusse.

iI8. POMPEIAN WALL PAINTING.

119. INDIAN NAJA-stone-carving from the Amarivati Tope. 120. CONVENTIONAL TREES-from various sources.

121. LATE GOTHIC FLEUR-DE-LIS TRACERY-from woodcarvings at V.\& A.M.

122. MARGUERITE PANELS-wood-carving.

123. SYMBOLIC ORNAMENT-book-cover-L.F.D. 


\section{LIST OF ILLUSTRATIONS IN THE TEXT.}

PAGE

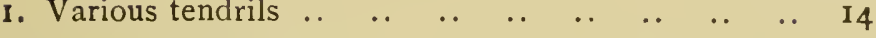

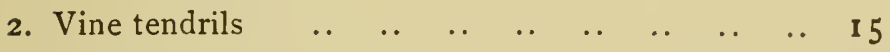

3. Romanesque ornamentation of the stem-Ely _. I8

4. Part of a Pompeian candelabrum--B.M. $\quad$.. $\quad$.. $\quad$ I9

5. Renaissance use of pea-pods (Prato Cathedral) .. 20

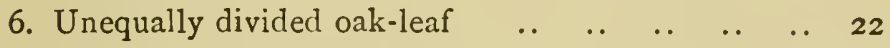

7. Chinese rendering of Wistaria-old embroidery .. 29

8. Acanthus leaves reduced to brush-work $\quad$.. $\quad . .34$

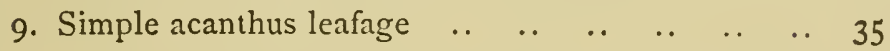

10. Step between wave and acanthus scroll-Roman $\begin{array}{llllllllll}\text { mosaic, B.M. } & \text {. } & \text {. } & \text {.. } & \text {. } & \text {. } & \text {.. } & \text {. } & 36\end{array}$

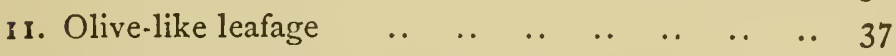

12. Oak-like leafage $\quad \ldots \quad$.

13. Vine-like acanthus leafage, from the Jubé at

$\begin{array}{llllllllllll}\text { Limoges } & . & \ldots & \ldots & \ldots & \ldots & \ldots & \ldots & \ldots & \ldots & 38\end{array}$

14. Crocket-like foliage, from Limoges $\quad \ldots \quad$.. $\quad . .38$

I5. Modern modification of Classic leafage .. $\quad . . \quad$.. 39

I6. Seventeenth century scroll-Boulle $\quad . \quad \ldots \quad \ldots \quad 4$ I

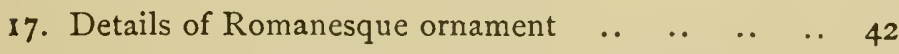

I8. Details of early Gothic ornament-stained glass $\quad . \quad 43$ 
xvi List of Illustrations in the Text.

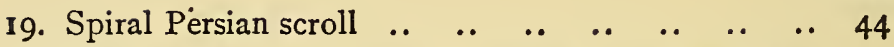

20. Iris-like details of Persian ornament--sixteenth and

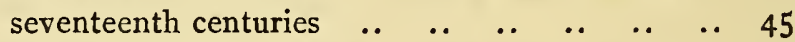

21. Details of Early Persian ornament-tenth to $\begin{array}{lllllllll}\text { twelfth century } & \text {.. } & \text {.. } & \text {.. } & \text {.. } & \text {.. } & \text {.. } & \text {.. } & 46\end{array}$

22. Sixteenth century arabesque details-German $\quad . .47$

23. Rosette in Rouen faïence ..

24. Chinese foliage, not easy to identify $\quad$.. $\quad$.. $\quad$.. 48

25. Bouquet of conventional ornament-Persian porce$\begin{array}{lllllllll}\text { lain, V.\& A.M. } & . . & . . & . . & . . & . . & . . & . & 48\end{array}$

26. Abstract ornament, not free from foliation $\quad . \quad$.. 49

27. Conventional Chinese flower forms ..

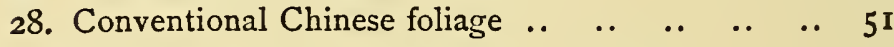

29. Rectangular acorn patterns-old German $\quad . . \quad$.. 53

30. Simplified thistle-by the late G. E. Street, R.A. 54

31. Gothic leaf border, wood-carving-Maidstone .. 55

32. Rosette or rose ?-German Gothic .. $\quad$.. $\quad$.

33. Gothic leaf-and-flower border-wood-carving $\quad . .55$

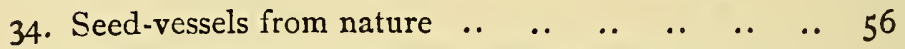

35. Conventional buds, or seed-vessels ?-marble inlay,

$\begin{array}{llllllllll}\text { Florence .. } & \text {.. } & \text {.. } & \text {.. } & \text {.. } & \text {.. } & \text {.. } & \text {.. } & \text {.. } & 57\end{array}$

36. Conventional Greek ivy leaves and berries $\quad . . \quad$.. 57

37. Japanese border, buds or fruits?

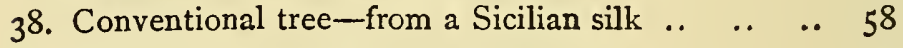

39. Simple Roman tree-mosaic, B.M... $\quad$.. $\quad$.. $\quad$.. 59

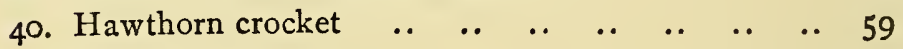

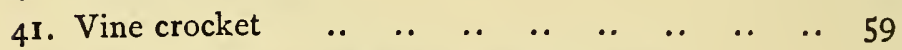

42. Late Gothic pomegranate-stencil pattern ..

43-4. Indian renderings of the poppy-nielle $\quad . . \quad$.. 6 I 


\section{List of Illustrations in the Text. xvii}

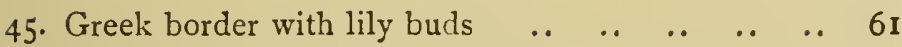

46. Early Gothic foliated ornament-pavement tiles .. 62

47. Natural and ornamental foliage-Early French .. 63

48. Bud-like ornamental forms-Gothic wood-carving.. 63

49. Peony simplified to form a stencil-by H. Sumner 64

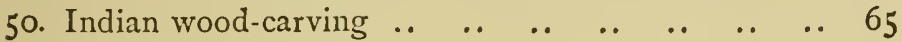

5 r. Gothic wood-carving ..

52. Greek that might be Gothic-stone-carving .. .. 65

53. Persian details which might be Gothic-porcelain of the sixteenth or seventeenth century $\quad . . \quad$.. $\quad . .666$

54. Japanese treatment of the iris-embroidery $\quad$. $\quad$.. 66

55. Wheat-ears, simplified or elaborated?-seventeenth

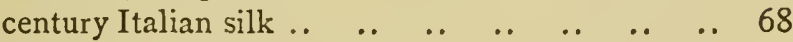

56. Floral forms within floral forms-Italian velvet, $\begin{array}{llllllllll}\text { Persian design .. } & \text {. } & \text {.. } & \text {.. } & \text {. } & \text {.. } & \text {.. } & \text {.. } & 73\end{array}$

57. Pomegranate berries arranged in bud-form-Per$\begin{array}{lllllllllll}\text { sian silk } & . . & . . & \text {.. } & \text {.. } & \text {.. } & \text {.. } & \text {. } & \text {.. } & \text {.. } & 74\end{array}$

58. Ornamental pomegranates-Italian velvet $\quad . \quad$.. 75

59. Ornamental pomegranate-eighteenth century silk 76

60. Ornamental pomegranate-old German embroi$\begin{array}{llllllllllll}\text { dery } & . & . . & . . & . & . . & . . & . . & . . & . . & . & 77\end{array}$

61. Foliated forms geometrically diapered-Japanese .. $\quad 78$

62. Elaborated flower-from an embroidered Gothic

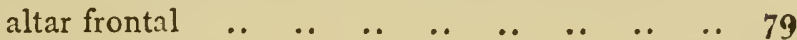

63. Elaborated flower-from a table-cover of German

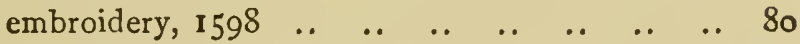

64. Bulbous hop-leaves-German Gothic wood-carving 8I

65. Indian corn adapted to ornament-Italian wood$\begin{array}{lllllllllll}\text { carving } & . . & . . & . & . . & . . & . & . . & . & . . & 88\end{array}$ 
xviii List of Illustrations in the Text.

PAGE

66. Rigid lines of the growth of corn turned to ornamental account-by the late C. Heaton $\quad . \quad$.. $\quad 89$

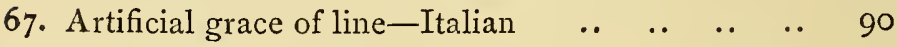

68. Quasi-natural rendering of the lily-by Sammicheli $9 \mathrm{r}$

69. Quattro-cento lily-S. Bernardino, Perugia .. .. 92

70. Narcissus compelled into the way of ornament

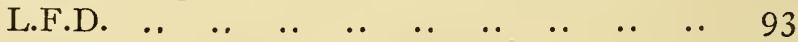

7 I. Incongruous treatment of the oak-Roman $\quad . . \quad$.. 94

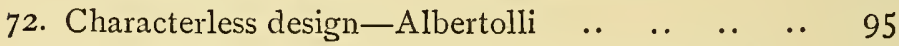

73. Inconsistency between flower and leaf-Japanese 96

74. Graceful artificiality-Lyons silk, about I700 $\quad . .997$

75. De-naturalised floral details-by Gribelin, 1682 .. $\quad 98$

76. Confusion of eifect without confusion of growth-

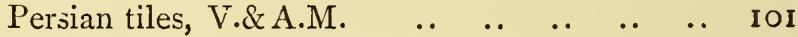

77. The vine in Assyrian sculpture-B.M. .. $\quad . . \quad$.. $\quad$ I06

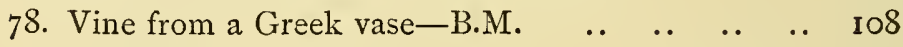

79. Pompeian vine border-silver on bronze-Naples 109

So. Italian wood-carving-hop or vine ?-V.\& A.M. .. I IO

8I. Conventional Gothic vine and grapes-York .. II I

82. Gothic vine with mulberry-like grape-bunches-

$\begin{array}{lllllllllll}\text { York } & . . & \text {.. } & \text {.. } & \text {.. } & \text {.. } & \text {. } & \text {.. } & \text {.. } & \text {.. } & \text { II } 2\end{array}$

83. Conventional vine, from Toledo-more or less

$\begin{array}{llllllllll}\text { Moorish .. } & \text {.. } & \text {.. } & \text {.. } & . . & . . & \text {.. } & \text {.. } & \text {.. } & \text { II } 3\end{array}$

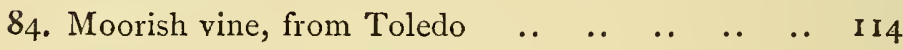

85. Naïve Byzantine vine-Ravemna ..

86. Early French Gothic vine-Notre Dame, Paris .. I I6

87. Square-shaped vine-leaves - scratched earthen-

ware, B.M.

88 Diamond-shaped vine-leaves -Gothic $\quad$.. $\quad$.. $\quad$. 


\section{List of Illustrations in the Text. xix}

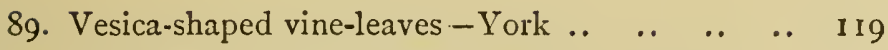

90. Diagram of Italian Gothic treatment-Padua .. I20

9I. Transitional vine scroll-German linen damask .. I2 I

92. Italian quattro-cento vine scroll-Venice $\quad . . \quad \ldots \quad$ I23

93. German Renaissance foliage-by Aldegrever .. $\quad$ I24

94. Vine in Gothic glass-painting-Malvern _. . $\quad$ I26

95. Quasi-Persian rose - Italian velvet, sixteenth $\begin{array}{llllllllll}\text { century .. } & \text {. } & \text {. } & \text {. } & \text {.. } & \text {. } & \text {.. } & \text {.. } & \text {.. } & \text { I } 30\end{array}$

96. Oriental rose border-embroidered in silk and

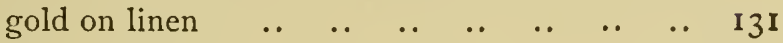

97. Rhodian rose-from a fä̈ence dish $\quad \ldots \quad \ldots \quad$.. $\quad$ I 32

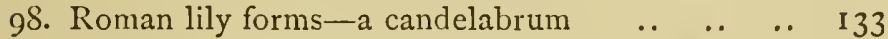

99. Indian lotus-Buddhist stone-carving, B.M. .. 134

I00. Seventeenth century iris-appliqué embroidery, $\begin{array}{llllllll}\text { Italian, V.\& A.M. } & \ldots & \ldots & \ldots & \ldots & \ldots & \text {. } & \text { I } 35\end{array}$

IOI. Renaissance pinks-needlework $\quad \ldots \quad \ldots \quad \ldots \quad$.. $\quad$ I 36

I02. Modern Gothic ponegranate-by the late B. J.

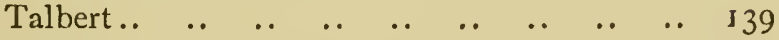

I03. Pomegranate-Spanish brocatelle.. $\quad \ldots \quad \ldots \quad$.. $\quad$ I 40

I04. Oak-from the Cathedral of Toledo .. $\quad . . \quad$.. I4I

105. Assyrian tree of life ..

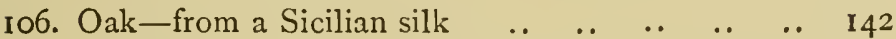

I07. Romanesque tree of life-from a painted roof at

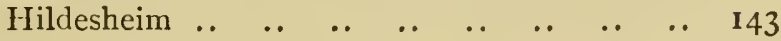

108. Renaissance silk-showing Persian influence .. 149

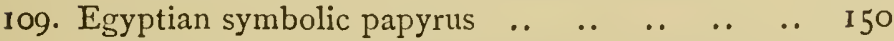

I IO. Assyrian symbolic ormament-glazed earthenware,

B.M. ..

I I I. Abstract Greek ornament-from a vase $\quad . \quad \ldots \quad$ I 52 
I 12. Later Greek ornament-from a vase $\quad . \quad$. $\quad$.. $\quad$ I 53

I I3. Assyrian rosette of lotus flowers and buds .. $\quad$.. $\quad$ I 55

I I4. Gothic ornament-from Notre Dame, Paris .. I 56

I I5. Fifteenth century fir-cone ornaments $\quad . \quad \ldots \quad$.. $\quad$ I 57

I 16. Chinese flower forms $\quad$.

I I 7. Etruscan and Greek anthemion shapes $\quad . . \quad \ldots \quad$ I 58

I I8. Japanese diaper $\quad$.

I I9. Japanese diaper $\quad \ldots \quad$.

120. Lily-like Greek details-from various sources .. I60

I2 I. Romanesque detail approaching to the fleur-de-lis I60

I 22. Gothic pattern-Early fleur-de-lis _. . . . . I60

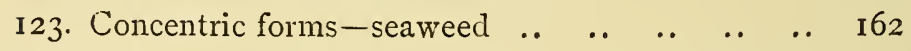

I24 Gothic-anthemion shape-from the nimbus of

a figure in one of the stained-glass windows at

$\begin{array}{llllllllll}\text { Fairford } & \text {. } & \text {. } & \text {. } & \text {. } & \text {. } & \text {. } & \text {. } & \text {.. } & \mathbf{1} 62\end{array}$

I25. Gothic diaper-radiating-from a painted screen $\quad$ I62

$\left.\begin{array}{l}\text { I26. } \\ \text { I27. }\end{array}\right\}$ Renaissance ormament-Italian wood-carving $\quad \ldots \quad$ I63

I28. Renaissance anthemion-by Mino da Fiesole, $\begin{array}{llllllllll}\text { Florence } & \text {. } & \text {. } & \text {.. } & \text {. } & \text {. } & \text {. } & \text {.. } & \text {. } & \text { I64 }\end{array}$

I29. Abstract foliage-Persian inlay, V.\& A.M... .. I69

I30. Would-be ornamental celandine-Albertolli .. I

I3I. Chinese rendering of "kiss-me-quick" - em$\begin{array}{llllllllll}\text { broidery } & \ldots & \ldots & \ldots & \ldots & \ldots & \ldots & \ldots & \text {. } & \text { I } 7 \text { I }\end{array}$

I32. Comparatively natural treatment of poppy$\begin{array}{llllllllll}\text { L.F.D. .. } & \ldots & \ldots & \ldots & \ldots & \ldots & \ldots & \ldots & \text {. } & \text { I } 72\end{array}$

I33. Comparatively natural treatment of fig-L.F.D... I73

I34. Ornamental treatment of strawberry-L.F.D. .. I74

I35. Dolphins used as ornament-by George Fox .. I8o 


\section{List of Illustrations in the Text. xxi}

PAGE

136. Circular bird (and flower) crest

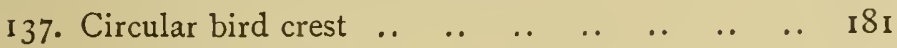

I38. Ornamental indication of birds in flight $\quad . \quad \ldots \quad$ I 8 I

I39. Diaper of storks and chrysanthemum flowers

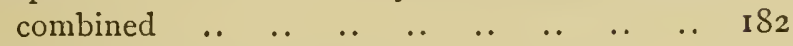

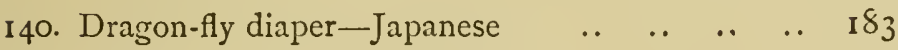

I4I. Diaper of conventional bats

I42. Bird diaper by the late Wm. Burgess, A.R.A. .. I85

143. Repeating figure pattern.. $\quad$..

I44. Conventional peacock border-Indian embroidery $\quad$ I 87

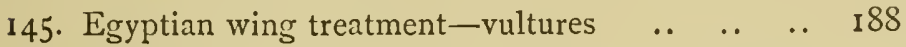

I46. Egyptian wing treatment-hawk in cloisonné $\begin{array}{lllllllllll}\text { enamel .. } & . . & . . & . & . & . . & . . & . & . & 189\end{array}$

I47. Bat diaper-old Japanese $\quad$..

148. Embroidered bat-Chinese

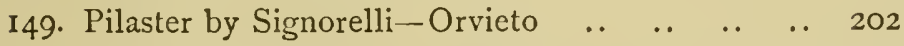

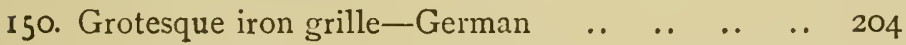

I5I. Wings reduced to ornament-Italian wood-carving 209

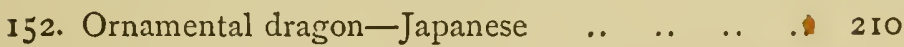

153. Arctic American grotesquerie-embroidered cloth 2 I I

I 54. Spring blossoms on the stream-Japanese .. $\quad . .213$

155. Diaper of spiders' webs ..

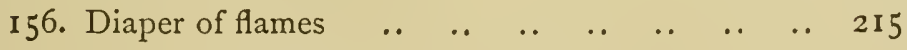

I57. Cloud and bat pattern

158. Cloud pattern ..

I59. Wave pattern

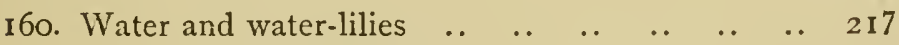

Í́. '. Wave patiern and water-fowl 


\section{xxii List of Illustrations in the Text.}

I62. Wave pattern-Japanese porcelain $\quad$..

I63. Wave pattern-Japanese.lacquer

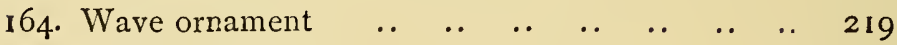

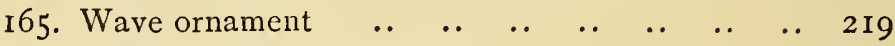

I66. Wave and spray pattern..

I67. Decorative rendering of incoming wave-Japanese 221

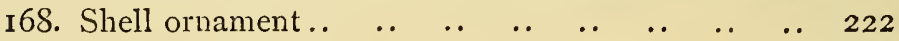

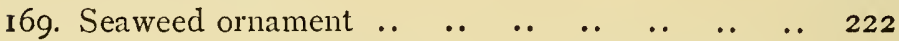

I70. Heraldic mantling-part of a painted frieze-

$\begin{array}{llllllllll}\text { L.F.D. .. } & \text {.. } & \text {.. } & \text {. } & \text {.. } & \text {.. } & \text {.. } & \text {. } & \text {.. } & 223\end{array}$

I7I. Heraldic mantling - German Gothic wood. $\begin{array}{llllllllll}\text { carving .. } & \text {.. } & \text {.. } & \text {.. } & \text {.. } & \text {.. } & \text {.. } & \text {.. } & \text {.. } & 224\end{array}$

172. Inlaid peacock-feather ornament-by B. J. Talbert 226

I73. Coptic feather border-V.\& A.M... $\quad$.. $\quad$.. $\quad$.. 227

I74. Coptic feather diaper-V.\& A.M. .. $\quad$.. $\quad$.

175. Persian peacock feather pattern-painted tiles,

$\begin{array}{llllllllll}\text { V.\& A.M. } & \text {. } & \text {.. } & \text {.. } & \text {.. } & \text {.. } & \text {.. } & \text {.. } & \text {.. } & 228\end{array}$

I76. Trophy panel-Renaissance $\quad$..

177. François $I^{\text {er }}$ skull ornament-wood-carving, Fon-

$\begin{array}{llllllllll}\text { tainebleau } & . . & . . & . . & . . & . . & . . & . . & . . & 230\end{array}$

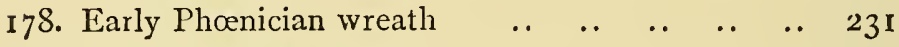

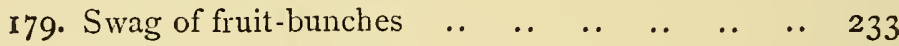

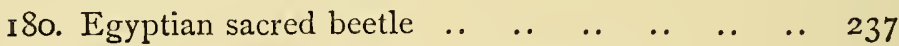

I8r. Diaper of waves, clouds, and sacred birds .. $\quad . .238$

I82. Cross of fleurs-de-lis-thirteenth century .. $\quad . \quad 238$

I83. Assyrian sacred tree $\quad$..

I84. Assyrian sacred tree-B.c. $885-860 \quad$.. $\quad$.. $\quad$.. 239

185. Iris or fleur-de-lis? - Seventeenth century Vene-

tian velvet $\begin{array}{lllllllll} & . . & . . & . . & . & . . & \text {.. } & \text {.. } & 240\end{array}$ 


\section{List of Illustrations in the Text. xxiii}

PAGE

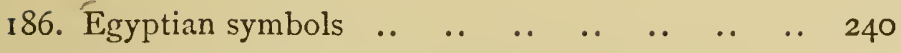

187. Gothic fleurs-de-lis-from old glass, Lincoln .. 241

188. Heraldic badges--Sixteenth century, Mantua .. 242

I89. Symbolic eye-Egyptian $\quad$..

190. Segment of Greek border of eyes-painted terra$\begin{array}{lllllllllll}\operatorname{cotta} & \text {.. } & . . & . . & . . & . . & . . & \text {. } & \text {.. } & \text {.. } & 243\end{array}$

191. Symbolic burder of seed-vessels-L.F.D. .. $\quad . . \quad 245$

192. Heraldic oak-Italian Renaissance $\quad . . \quad$.. $\quad$.. 246

ABBREVIATIONS.

B.M.-British Museum.

V.\& A.M.-Victoria \& Albert Museum.

L.F.D.-Lewiz F. Day. 



\section{NATURE IN ORNAMENT.}

I.

INTRODUCTORY.

THE bias of the natural man is not unnaturally in the direction of nature. Almost alone in the history of art, the Greeks and the Moors appear to have been content with ornament which was ornament pure and simple. It is not too much to say, even in these days of supposed interest in things decorative, that the Englishman generally speaking neither knows nor cares anything about the subject. He is in most cases absolutely out of sympathy with it. Possibly he has even a sort of contempt for the "ornamental," as something opposed to that utility which he so highly esteems-never so much as apprehending the fact that ornamental art is art applied to some useful purpose.

The forms of ornament he most admires are those most nearly resembling something 
in nature, and it is because of that resemblance he admires them : abstract ornament is quite outside his sympathies and beyond his understanding. He begins, for example, to take a feeble interest in Greek pattern-work only when he sees in it a likeness to the honeysuckle. Show him some purely ornamental form, and it is neither its beauty, nor its character, nor its fitness that strikes him; he is perplexed only to know what it is meant to represent. To him every form of ornament must have its definite relation to some natural object, and therein lies all its interest.

Relation to nature there must be indeed, and every one will acknowledge the interest with which we trace such relationship; but no one who really cares for ornament at all will allow that it depends upon that for its charm.

When ornament has gone astray, it has been more often in the direction of what one may call rusticity than of that artificiality which is at the other end of the scale.

Art passes through periods of affectation, when it becomes before all things urgent that opinion should be led back again to the forgotten, grass-grown paths of nature. That is not our urgency just now. If there was at one time within our memory some fear of artificiality in art, the danger now lies in the 


\section{Introductory.}

opposite direction of literalism; a literalism which assumes a copy of nature to be not only art, but the highest form of art; which ignores, if it does not in so many words deny, the necessity of anything like imagination or invention on the part of the artist, and accepts the imitative faculty for all in all.

To venture upon the sweeping assertion that all art whatsoever is, and must be, conventional, would be very likely to lay oneself open to the rebuke of judging all art by the decorative standard; but with regard to ornament, it is no more than the bare truth to say that more or less conventional it must be, or it would not be ornamental.

Not, of course, that the ornamentist denies in the least the supreme beauty of natural form and colour, or thinks for a moment to improve upon it, as some seem to imagine, who insinuate that he proposes to surpass nature, presumes to "paint the lily," and so on. On the contrary, he is modest enough to recognise the impossibility of even approximately copying anything without the sacrifice of something which is more immediately to his purpose than any fact of nature-consistency namely, fitness, breadth, repose ; and is content, therefore, to take only so much of natural beauty as he can turn to use. He regulates his 
appetite, that is to say, according to his digestion.

Such self-denial on his part is not by any means a shirking of the difficulties of the situation. In art nothing is easy, except to such as have a natural faculty that way. It is not every one who finds it easy to make a striking study from nature; but that comparatively elementary accomplishment does demand ability of a lesser kind than the production of a picture in which there is design, unity, style, and whatever else may distinguish a masterwork of the Renaissance from a study of to-day.

In like manner, the mere painting or carving of a sprig of foliage is within the reach of every amateur; but to adapt such foliage to a given position and purpose, to design it into its place, to treat it after the manner of wood, stone, glass, metal, textile fabric, earthenware, or what not, demands not only intelligence and inborn aptitude, but training and experience too.

It is the easiest thing in the world to ridicule such decorative treatment; but it would puzzle the scoffer if he were asked to pause a moment in his merriment and point out a single instance of even moderately satisfactory decoration in which a more or less non-natural 


\section{Introductory.}

treatment has not been adopted. The fact is, the artist has not yet arrived at a point where he is able to dispense altogether with art.

It is his misfortune (more so nowadays than ever it was) that it is extremely difficult for him to make up his mind precisely as to the relation of art to nature. That it is dependent upon nature, more or less, is obvious. Only by way of paradox is it possible to contend, like Mr. Whistler, that "nature is very seldom right." Nature is our one and constant model. The question is as to how freely or how painfully, how broadly or how literally, how individually or how slavishly, we shall render the model before us, how much of it, and what of it, we shall depict. And this is a question which, if not quite beyond solution, must be solved by each man according to his idiosyncrasy, and that only after much anxiety and doubt and difficult self-questioning.

It is the good fortune of the decorator, the ornamentist, the worker in any of the more dependent arts, to be comparatively free from such incubus of doubt. In his art there is much less room for hesitation. For him to adopt the realistic creed would be to deny his calling, and to cut himself off from the art of his adoption: for the very idea of 
ornament implies something to be ornamented, and accordingly to be taken into account.

A man is bound, by the very adoption of any one of the applied arts, to draw the line at realism so soon as ever it is opposed to the application of his art. In other words, the purpose to which his art is put indicates to him the limits of possible realism. And so, while the dispute about realism is still at its height so far as literature, the drama, and even painting are concerned, the question as to the adaptation of natural forms to ornamental design has resolved itself, for all who know anything of the subject, into inquiry as to the degree and kind of modification calculated to render natural forms applicable to ornament and the various purposes to which it is put.

This modification of natural form to ornamental purpose we are accustomed to call "conventional." In accepting this term, however, we must be careful to distinguish convention from convention, and especially from that academic acceptation of the term which would give us to understand that the modification of nature has been done for us, and that we have only to accept the Classic Mediæval, Renaissance, or other more or less obsolete rendering at hand. As though the 


\section{Introductory.}

tombs of buried peoples were heaven-sent habitations for live men!

The one thing to be insisted upon in reference to convention is that it has not been done for us once and for all, that we have to do our own conventionalising; and not only that, but that we have to do it again and again, each time afresh, according to the work in hand. It is only by this means that art in ornament subsists and grows: when it ceases to grow, decay sets in of course.

To accept a convention ready-made is to compromise your own invention; to go on copying the accepted types, be they never so beautiful, is just to stifle it. But one must be familiar with them : one must be aware of what has been already done in the way of art, as well as conversant with nature. Simply to study nature is not enough. We have to know how artists of all times have interpreted nature; how the same artist, or artists of the same period, treated natural form differently, according to the material employed, conformably with the position of the work, in view of the use it was to serve. Knowing all this, and being perfectly at home in the world of nature, one may set to work to conventionalise on one's own account-and with the best possible chance of success. 
Those who most keenly feel the need in ornament of a quality which the modern nature-worshipper delights to disparage, will be inclined to pray that they may be preserved from some of their allies. There is, or was not long ago, a class of ornament in vogue, which appears to have originated in the idea that you have only to flatten out any kind of natural detail, and arrange it symmetrically upon arbitrary lines, and the end of ornament is achieved.

Decorative design is not so easy as all that. To emasculate a natural form is not to fit it for ornamental use, and to distribute detail according to diagram is not to design. The result may be conventional, but it is not the kind of convention here advocated; one touch of nature is worth all the mechanical and lifeless stuff of that kind that ever was done.

One hopes, and tries to think, that this sort of thing is dying out, if not quite dead already; but then one flatters oneself so readily that what has been proved absurd must be extinct, or moribund at least; until, perhaps, an enforced stay among the Philistines brings us face to face with the evidence how very much it is alive. We have only weeded it out of our little garden plot; about us is a wide world where it is rampant. There 
is no hiding it from ourselves, there is life in the old dogma yet; and, alas, in many another.

It is still as necessary as ever to deny the claim of merely geometric reconstruction to represent the due adaptation of natural forms to decorative needs. It is no more fair to take this ridiculously childish work to represent conventional design than it would be to instance the immature studies of some raw student as examples of naturalistic treatment. Compare the best with the best. Compare the ceramic painting of Sèvres with that of ancient Greece, China, or Japan; compare the work of Palissy with that of the potters of Persia and Moresque Spain; compare the finest Aubusson carpet with a Persian rug of the best period; compare the earlier Arras (such as we have at Hampton Court) with the most illusive of modern Gobelins tapestry; compare the traditional Swiss wood-carving on the châlet fronts at Meyringen and thereabouts with the most ingenious model produced in the same district for the English and American tourist; compare the peasant jewellery of almost any country except our own (we never seem to have had any) with the modern gewgaws which have taken its place; and who would hesitate to choose the more conventional art? 
Conventional treatment, it will be seen, is no mere stopping short of perfect rendering, no bald excuse for incompetence. It is purposed presently to show that, if it does not on the one hand consist in the substitution of the diagram of a thing instead of its life and growth, neither does it mean the mere distortion of natural details, nor yet that mechanical repetition of ancient conventions which is a weariness to every one concerned in it. Our rendering of natural form must be our own, natural to us; but without some sort of conventionality (if we must use the word) decoration is impossible. There is no art without convention; and your most determined realist is in his way as conventional as the best, or worst, of us.

It is not the word conventional for which contention is made, but that fit treatment of ornament which folk seem agreed to call by the title, more especially when they want to abuse it. By whatever name it is called, we cannot afford to let go our hold of that something which distinguishes the decorative art of every country, period, and master, from the crude attempts of such as have not so much as grasped the idea that there is in art something more than a dishing up of the raw facts of nature. 
Work as nearly natural as man can make it, though not in itself decorative, may be at times available in decoration. But forms denaturalised by men alike ignorant of the principles and unskilled in the practice of ornament, and more than half contemptuous of design to boot, are of no interest to any one but their authors, if even to them. Nature and art are not on such bad terms that to be unnatural is to be ornamental. 


\section{II.}

ORNAMENT IN NATURE.

NATURE being admittedly the primal source of all our inspiration, it is rather curious to observe the limited range within which we have been content to seek ideas, how we have gone on reflecting reflections of reflections, as though we dared not face the naked light of nature.

With all the wealth of suggestion in the world about us, and the never-ending variety of natural detail, the types which have sufficed for the ancient and mediæval world, and for that matter for ourselves too, are, comparatively speaking, very few indeed. How largely the ornament of Egypt and Assyria is based upon the lotus, the papyrus, and the palm! The vine, the ivy, and the olive, the fir-tree and the oak, together with the merest reminiscence of the acanthus, went far to satisfy not only the Greeks but their Roman and Renaissance imitators as well.

Gothic art went further afield, and gathered 
Plate ?

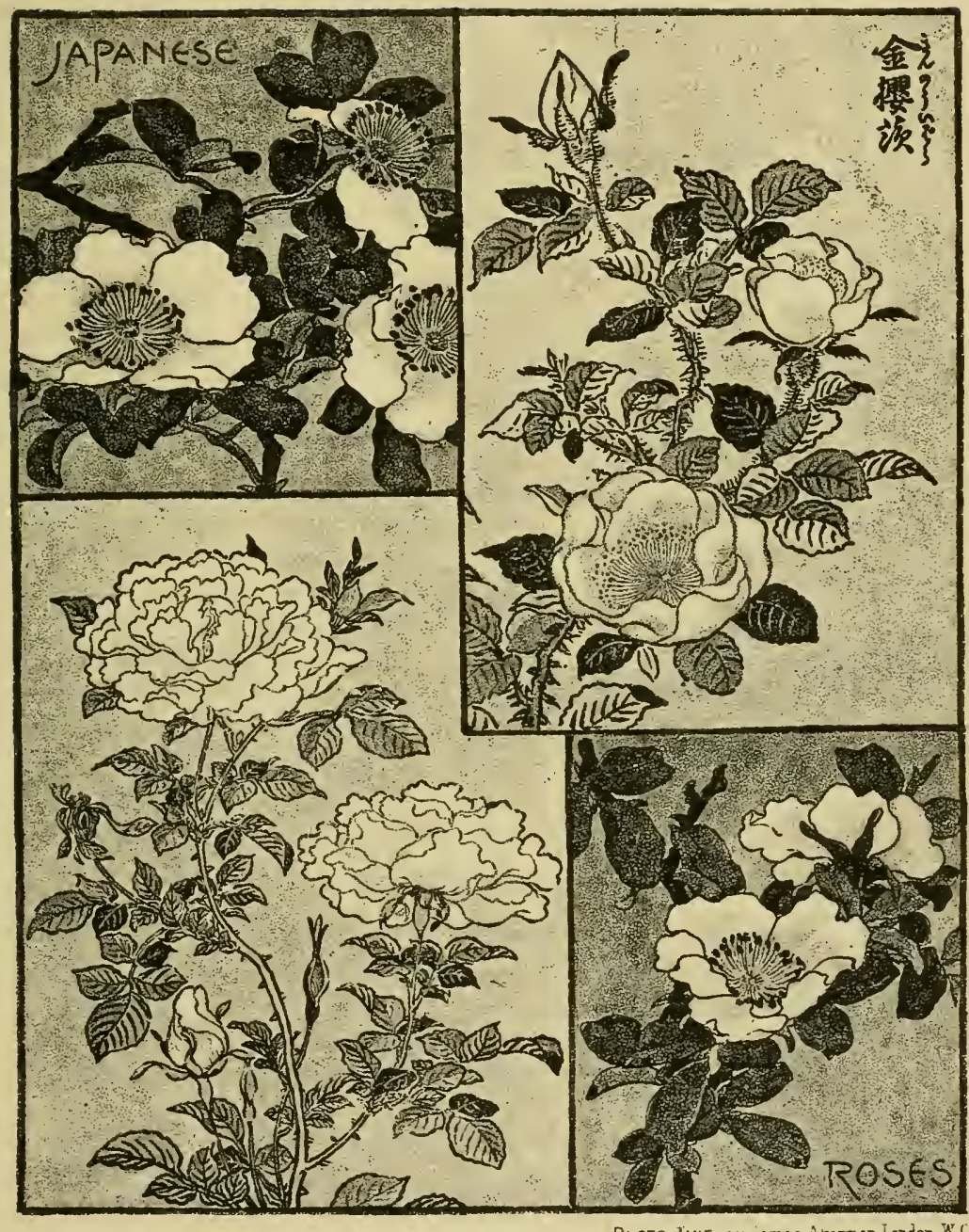

Japanese Roses 

into its posy the lily and the rose, the pomegranate and the passion flower, the maple and the trefoil, but still only a comparatively small selection of the plants a-growing and a-blowing within sight of the village church. Oriental art is more conservative still; in it a very few types recur continually, with a monotony which becomes at last tedious. One wonders what Chinese art would have been without the aster and the peony, or Japanese without the almond blossom and bamboo, what Arab ornament would be but for the un-leaf-like leaf peculiar to it.

One is struck sometimes by the degree of variety in the treatment which a single type may undergo in different hands; more often it is the sameness of the renderings which impresses us.

Probably in the case of no single plant have the possibilities in the way of ornamental adaptation been exhausted, and in many instances the very plainest hints in the way of design have not been taken.

The rose, for example, has been very variously treated; but comparatively little use has been made of the fruit, or of the thorns, or of the broad stipules at the base of the leaves. We have to be grateful when the buds, with their boldly pronounced sepals, are 


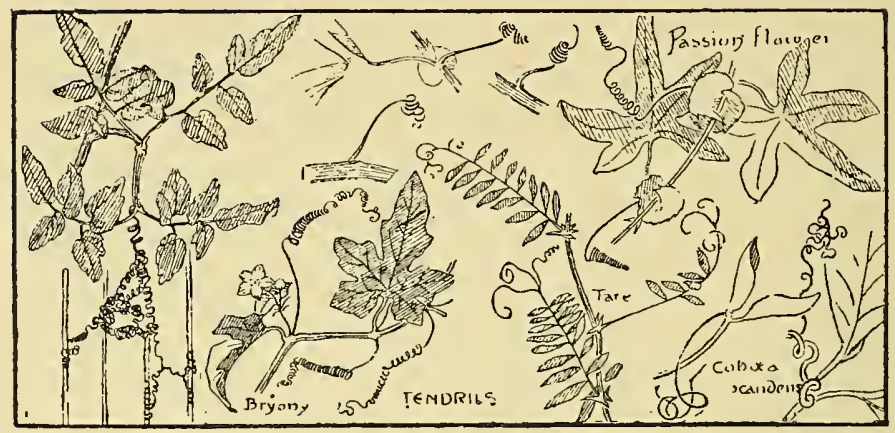

I. Various tendrils, from nature.

once in a way, turned to ornamental account (Plate 65 and pp. I3I, I 32).

The Japanese roses on Plate 2 are somewhat directly inspired by nature, but then they are not very ornamentally treated. They might almost have been drawn directly from nature. It is mainly the simplicity and directness with which they are rendered which gives them some decorative quality.

Take the conventional vine again, with its stereotyped leaves and prim grapes. And its tendrils, how seldom they have suggested more than a rather meaningless wriggle, useful, no doubt, to fill an awkward gap in the composition, but without either character or beauty.

Probably no feature of flower growth has been more badly treated than the tendril. Artists have thought themselves free to add a tendril to any plant whatsoever, and whereso- 


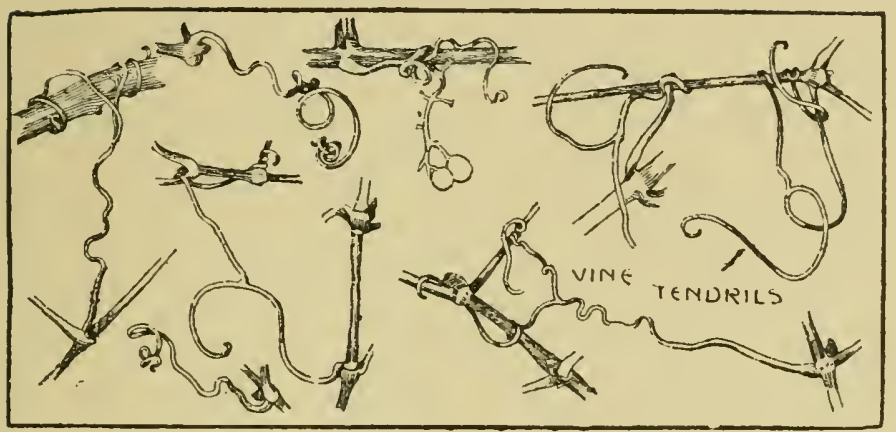

2. Vine tendrils, from nature.

ever it pleased them. The clinging character of the bindweed, the hop, and plants of that kind, has suggested to artists who look without their eyes the necessity of support of some kind, and they have accordingly provided the tendrils nature has denied, neglecting all the while the peculiarly decorative character of the twining stem. Designers have seldom taken much account of the essentially ornamental way in which plants like the nasturtium and the clematis attach themselves to whatever they can lay hold on by their leaf-stalks ; nor have they rendered in design the suckers by which the ivy and the Virginia creeper adhere to the wall. It is so much simpler to provide convenient tendrils than to study nature.

And what tendrils they have provided! All of one pattern; whereas in nature they 
are delightfully diverse. How vigorously the mature and woody tendril contrasts with the silky growth of the young shoots groping for something to support them! How different the branched tendril of the pea from the simple bryony tendril, and both from that of the vine! Certain poets of a past generation thought fit to compare the tresses of their lady-loves to this last; and there was, perhaps, a certain suggestion of the corkscrew in both to warrant the comparison; but what a lively corkscrew the tendril is, how friskily it twists and twirls about, and how gaily it starts off, as it were, on a fresh lease of life!

It is too exclusively in the leaf, the flower, and the fruit, that the ornamentist seems to have sought his model. The leaf-bud, for example, whether as giving character to the bare twigs (Plates 3 and 8) or conveniently softening the angle between the leaf-stalk and the stem, has been comparatively neglected: one type of bud at all events has usually done duty for all. The thickening of the leaf-stalk, again, at the joint with the stem, has rarely been made use of ; nor yet the quite young shoot, which not only fills the empty space about the stalk, but gives an opportunity, most invaluable in design, of contrasting smaller detail with the larger forms of the general design. 
Plate 3

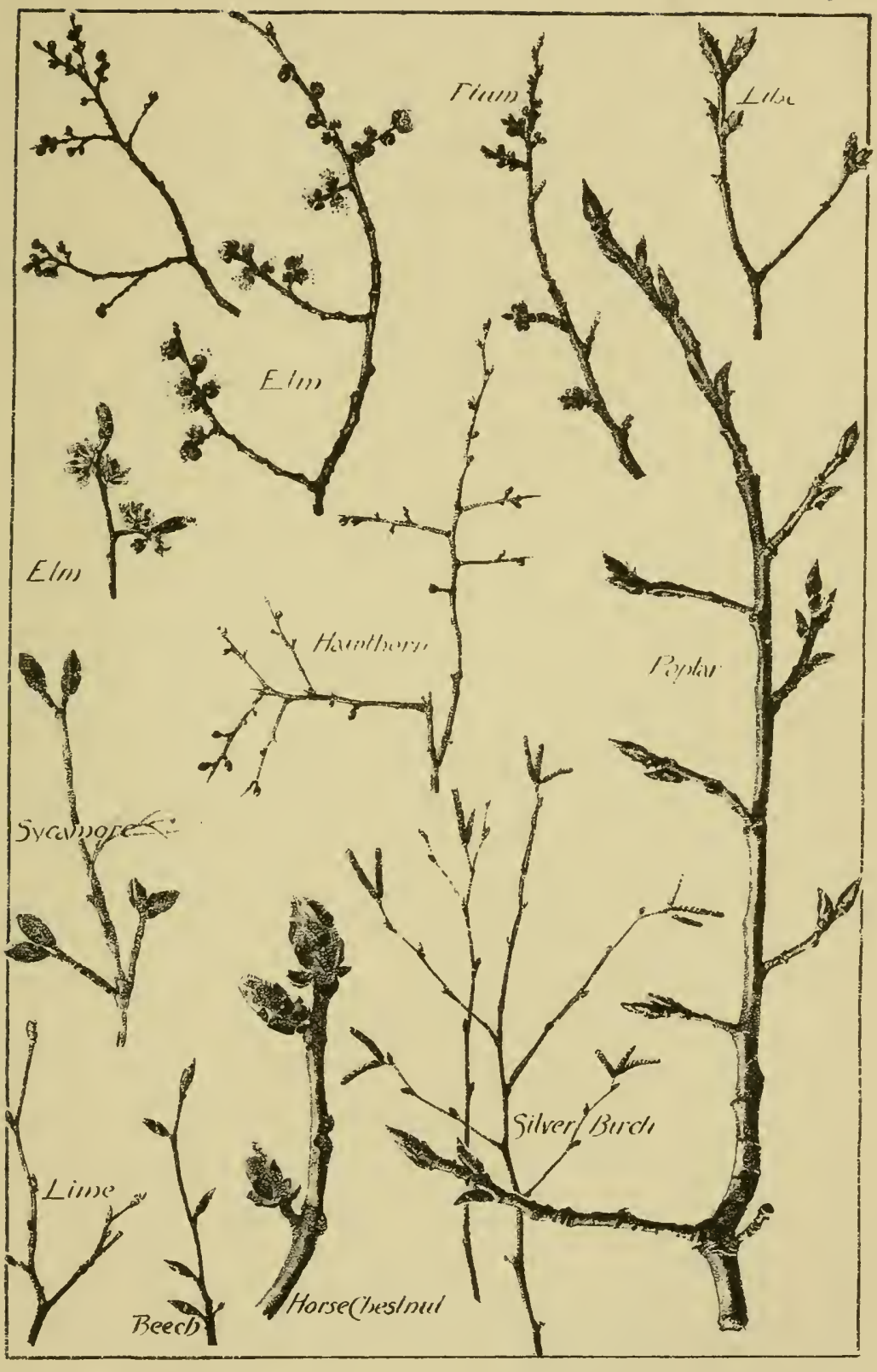

"Pното-TINT", oy dames Akermon.London W C

Budding branches, from Nature 

The stipules of the leaves, which also enrich the meagre joint, have been equally left out of ornament, characteristically ornamental as they are in the pea, for example, the sow thistle, and the passion flower. But even in the less marked form in which they appear in the hop, the medlar, the common nettle, and numberless wayside plants, they are worth an attention which they have not often received.

Nature seems to neglect no opportunity; the very scars left on the stems of certain trees, such as the horse-chestnut, form a kind of decoration. Even in the scarred stalk of an old cabbage you may see pattern. In the case of the palm, the remains of the leaves of years past resolve themselves still more plainly into ornament; and for once the Roman sculptors, who saw palm-trees growing about them, adopted the idea in the decoration of their columns. The Indian rendering of the same notion, on Plate 77 , is yet more conventional; but there is no doubt as to the origin of that zigzag. Was it so, perhaps, that the idea of decorating columns in zigzag, common enough in Norman architecture, originated?

In Greek ornament and its derivatives (Plates I I, I2, \&c.), use is made of the sheath to clothe the branching of the spiral stems, but 

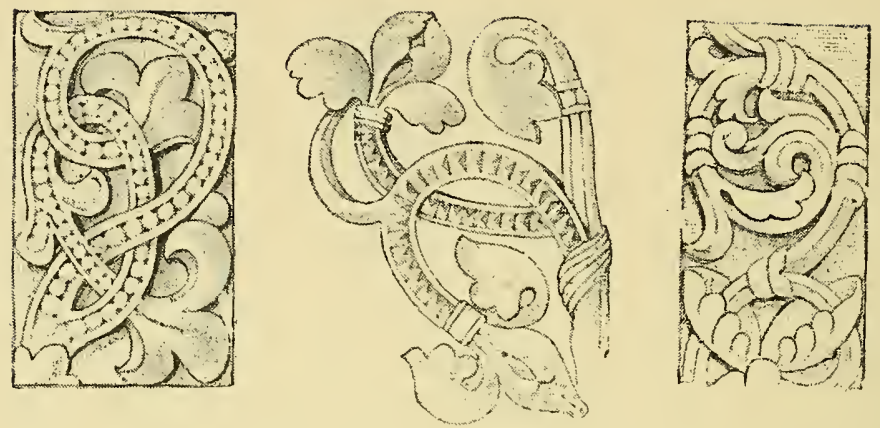

3. Romanesque ornamentation of the stem.

there is still much to be learnt from the way in which nature wraps round a stalk with leaves, sheaths it, hides it, discreetly discloses it (Plate 4). The leaf seems sometimes to close round the stem so that that has almost the appearance of growing through ; so much so that the "thorough-wax" (same plate), owes its name to that appearance. Still more plainly does the stem seem to grow through where the leaves are opposite and grow together round it, as in the teasel and the honeysuckle.

The arbitrary ornamentation of the stem in the Romanesque details above, indicates a feeling on the part of the artist that something is needed to relieve the baldness of a stem. That something Nature is very ready to suggest, as the Pompeian bronze-worker 
Plate 4

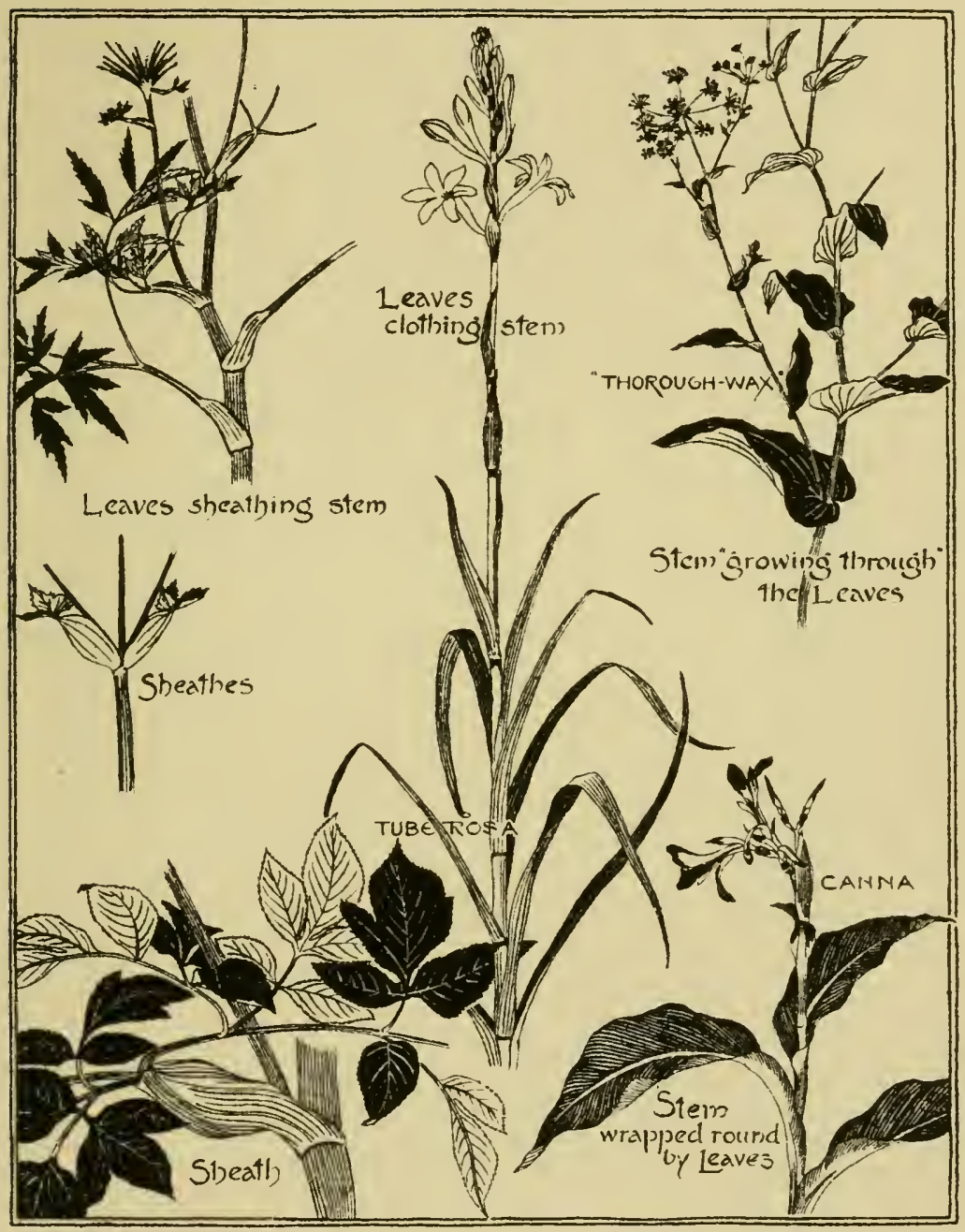

J Alkerman, Pboto-lith London

Natural leaf sheaths. 

realised when he went to the riverside for a reed as "motif" for the ornamentation of his candelabrum.

Certain fruits have, as I said, been made use of in design, either as affording convenient masses in the composition or, like the grape and the pomegranate, for reasons of symbolism. The smaller fruits have seldom had justice done to them. Bunches of berries are common enough in ornament, but they are just berries, without as a rule the character of any particular plant. Yet how various they are in nature, and how differently they grow! This is indicated, however inadequately, on Plate 5. Space fails in which to illustrate this part of our subject at all fully; but only compare the bryony with the spindle-berry, the snowberry with the privet, the solanum with the laurel, the aucuba-berry with the barberry, and you will see that neither are berries all of one shape, nor do they grow always in one way-in nature, that is to say.

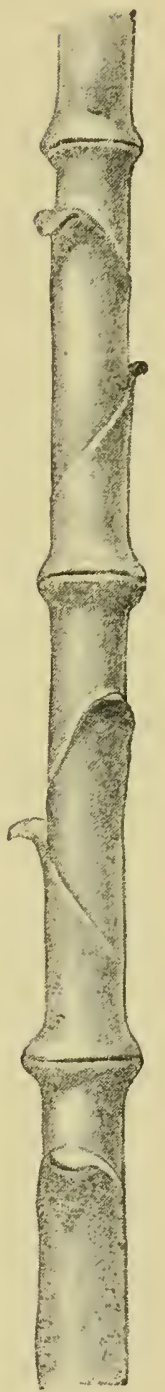

4. Part of a Pompeian candelabrum. 
In the seed-vessel there is yet greater variety of natural design, in many cases most ornamental. The pea-pod has been slightly used in Renaissance ornament, in the anthemion for example below, and on Plates 45 and 46 , where it is most effectively and characteristically treated.

On Plate 6 are a variety of cressworts in seed, indicating how in a single and unpretending family of plants there may yet be considerable variety and character in the seed-vessels.

Again, on Plate 7 are some studies of the open pods of the common broom curling up as they dry in the sun, strictly copied from nature,

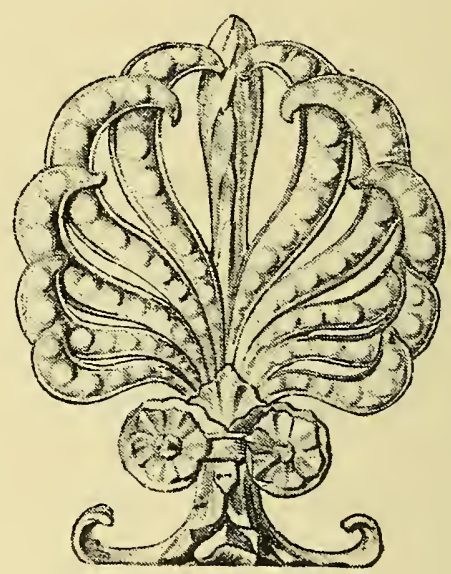

5. Renaissance use of pea-pods in ornament. but almost ready-made, as it seems, to the hand of the ornamentist.

The dried husks out of which flowers and seeds alike have fallen are often delightfully ornamental, as for example in the salvias, where they form at intervals a sort of crown round the stalk just above the starting point 
Plate 5.
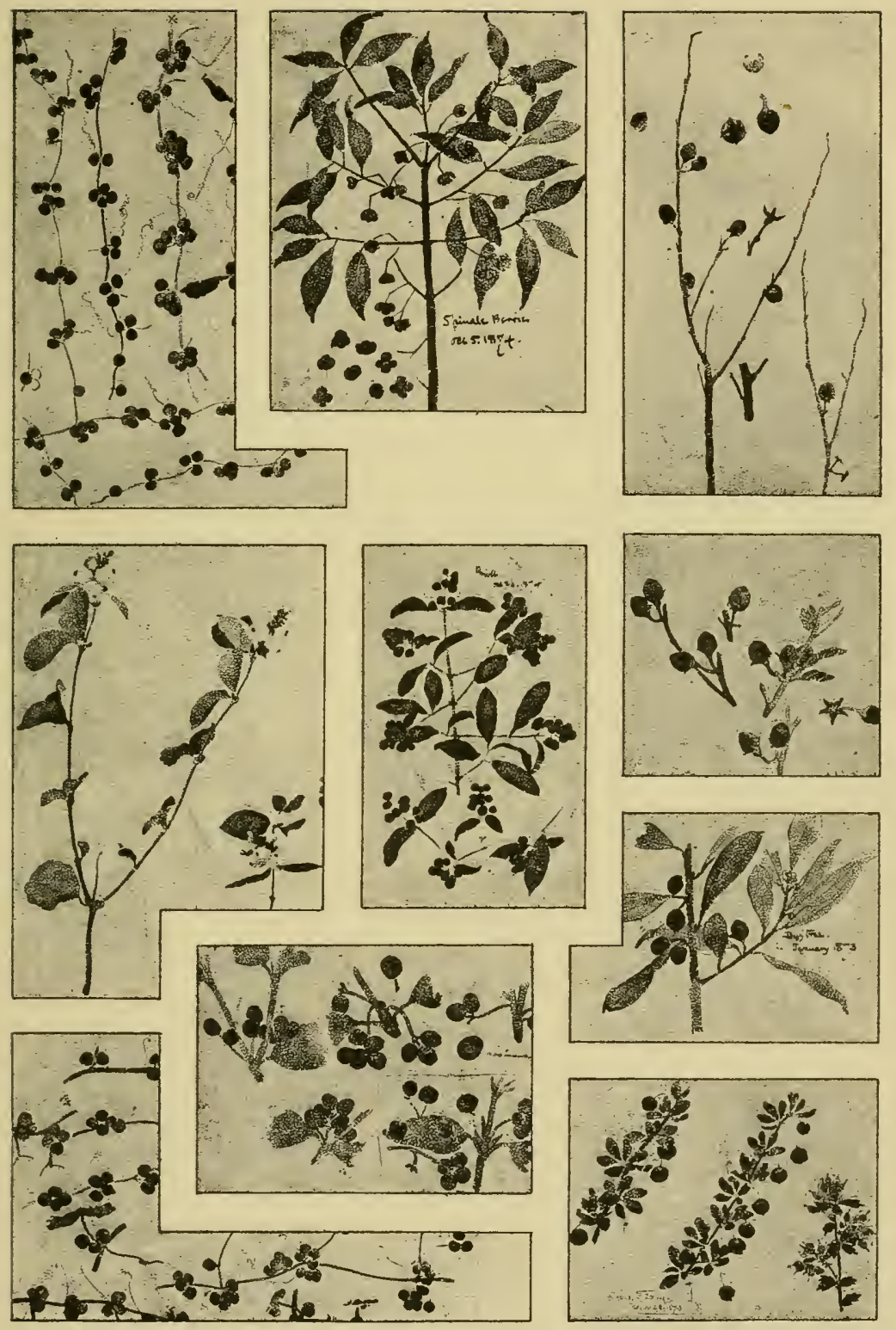

"F ното. TINT", by James Akermar. London.W.C.

Various berries from Nature. 

of the leaves. In certain thistles and kindred plants, the balls of seed-down are scarcely more beautiful than the silver-lined calices, from which the feathery seed has flown; they shine in the sun like stars.

Very considerable ornamental use has been made of the bursting of the full pomegranate fruit (Plates 73 and 87 and pp. 74, 75, 76, 77, I39, I40). It is strange that the effective treatment of this symbol has not suggested the availability of other opening seed-vessels, the horse-chestnut for example and other nuts, the pod of the iris, and so on.

In the representation of fruits it is usually the ripe fruit that is given; but there is often quite as much if not more character in the unripe ; and some variety of form and size is very desirable.

The leaf in ornament is usually attached in a rather arbitrary way to the stalk, without sufficient heed to the twist and turn of the natural leaf, or to the angle at which it leaves the stem, to the length and thickness of its stalk, and to the way alternate leaves, say those of the lime, pull the stem out of the straight and give a zigzag line-in all of which there is character, and possibly a hint in design.

Look at the poppies in the corn. Scarce 
one of them ever gets over the crick in the neck, which comes of hanging down its heavy head so long when it is a bud (see p. I72). There is always a tell-tale nick in the stalk of the full-blown flower, hidden it may be by drooping petals, but plain enough when they have dropped off and the seed-urn is left naked. It does not stand up straight and

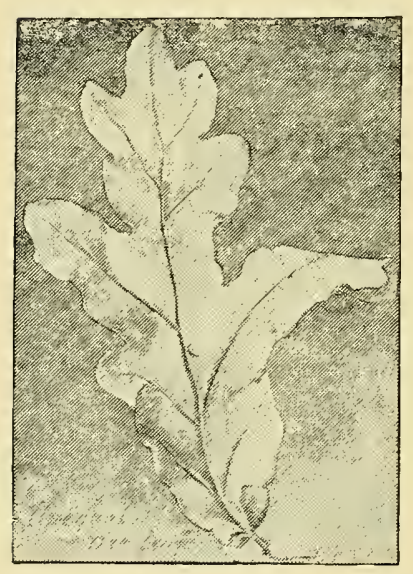

6. Unequally divided oak-leaf, from nature. stiff like a barrel on a pole, but is poised with a subtlety characteristic always of the natural line as distinguished from the mechanical.

Notice how the apple-tree blossoms (Plate 8). In each bunch a single topmost flower always opens first, so that it is quite a common thing to see a white flower nestling among its five pink buds. Then in the case of the oak, the empty cup (see Plates 9 and 74) is a characteristic variation on the acorn shape, and there is usually at the end of the fruit-stalk a withered button or two, never to arrive at due development, which may be turned to account in design (Plate 9). 
Plate 6.

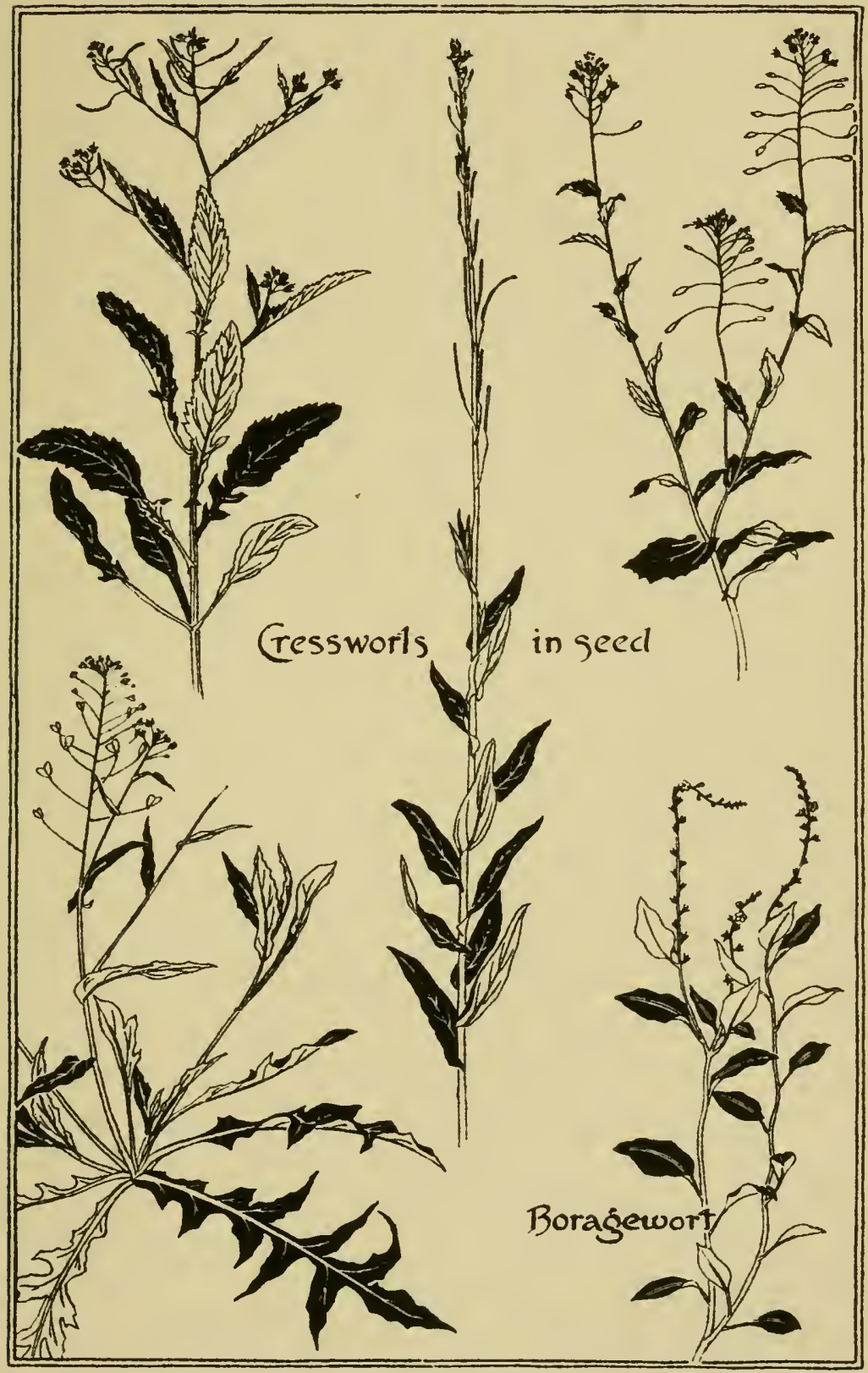

J. Akerman Photolitb London

Some seed vessels from Nature. 

The gall-fly, again (same plates), comes to the help of the artist, and furnishes him with a further variety of forms more or less fruitlike in appearance, growing often in places where fruits would never be, on the unequal leaf for example. I have counted rosy clusters of a dozen and more on a single leaf. Besides the soft oak-apple, associated in our boyish minds with King Charles, and the hard inkgall which decorates the bare boughs in winter, there is a canker which attacks the leaf-bud and results in something rather like a small fir-cone.

Every one is familiar with the beautiful feathery burr of the rose: there are other rose-galls, peculiar to the leaves, looking like little beads of coral on their surface.

In the poplar too, the prominent gall-knob at the base of the leaf-stalk is distinctly characteristic. Almost every plant, in short, is attacked by its hereditary enemy, that seldom fails to leave his mark behind him, suggestive, it may very likely be, of ornament. And so with great part of the vicissitudes to which vegetation of all kinds is subject-the ceasing of the sap to flow, the drying of the leaves, the spread of some parasitic growth, and so on.

Historian and poet find in the misfortunes 
and death of their characters a pathetic interest: the ornamentist may discover in the very decay of vegetation, apart from any sentimental interest, at least incident, character, and colour.

The vicissitudes of plant life, it may be said, are accidental, and what has accident to do with design? The very word implies, no doubt, the total absence of design. For all that, it is in some measure owing to the elimination of whatever is accidental in nature, that conventional ornament is apt to be so tame, and that the orthodox seems doomed to be dreary.

There is nothing, strictly speaking, accidental in design; but the designer is bound, nevertheless, to take every possible advantage of accident, not of course in order to incorporate into his work, after the manner of the realist, as he calls himself, the awkward or ugly traits of nature which others have for obvious reasons left out of account, but that he may seize upon every freak of nature suggestive of characteristic and beautiful design.

Strict attention to botanic accuracy has resulted too frequently in ornament much more mechanically exact than anything in nature. If natural leaves grow at ordered intervals, they do grow, vigorously and vari- 
Plate 7

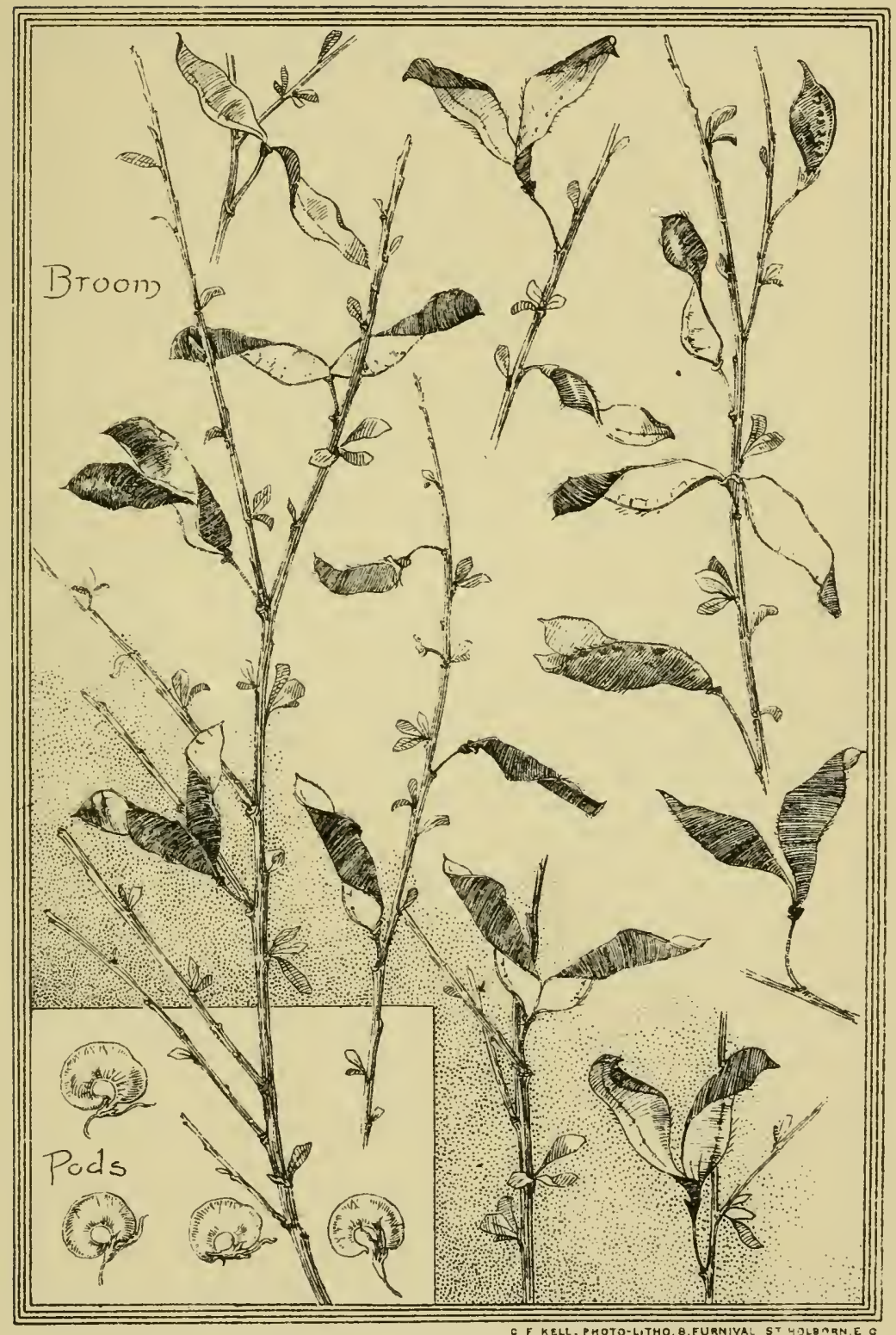

Pods from Nature. 

ously, as if they had something like a will of their own.

The ideal of the horticulturist is a flowerhead as even as if it had been "struck" geometrically, a spike of blossoms as trim as a clipped yew-tree or a French poodle. That is not Nature's way. Regularly as a natural flower-spike may be planned, the actual blossoms have a way of shooting out in the most casual manner. You see this very plainly in the salvias, for all the gardener's pains with them; and everywhere, in the woods and in the meadows, by the wayside and the river bank, Nature never wearies of playing variations upon the symmetric plan of plant growth. Certain plants, says the gardener, have a bad habit of "sporting." Truly there is nothing at all sportive in his reduction of all nature to one dead level of sameness.

Ornament might fairly be compared to the growth of a garden, not of a wilderness. But if, on the one hand, nature cannot be allowed to run wild over this garden, neither, on the other, should it be clipped and trimmed and formalised until there is no character of its own left in it.

The method of the florist affords a perfect example of what not to do in the way of modifying natural form. His plan is to eliminate 
whatever is wayward, occasional, uncommon, characteristic. Look at his hyacinth, as regular as the curls of a wig, and compare it with the wild bluebells. Look at his double dahlia: the flower was prim enough in the simple single form, with its obviously evennumbered petals insisting upon your counting them; but what a bunch of ribbons it has become in his hands! To reduce a flower to the likeness of a rosette is not to make it the more ornamental ; and every accident indicative of a return to nature is a welcome relief from such unmeaning evenness of form.

Those who would limit us to a hard and fast rule of growth, betray perhaps their own ignorance of the latitude Nature allows herself. We have to acquaint ourselves with the anatomy of plants, and especially with their growth; and where it comes to anything like natural treatment, we have further to take into account the habits of a plant, its manners and customs, so to speak-for which there is, of course, if we enquire into the matter, good structural reason always. It is, however, with the outward form of things that the art of the ornamentist has to do, and for the most part it will be sufficient for him to confine his studies to the visible side of nature. Very slight observation will show 
Plate 8.

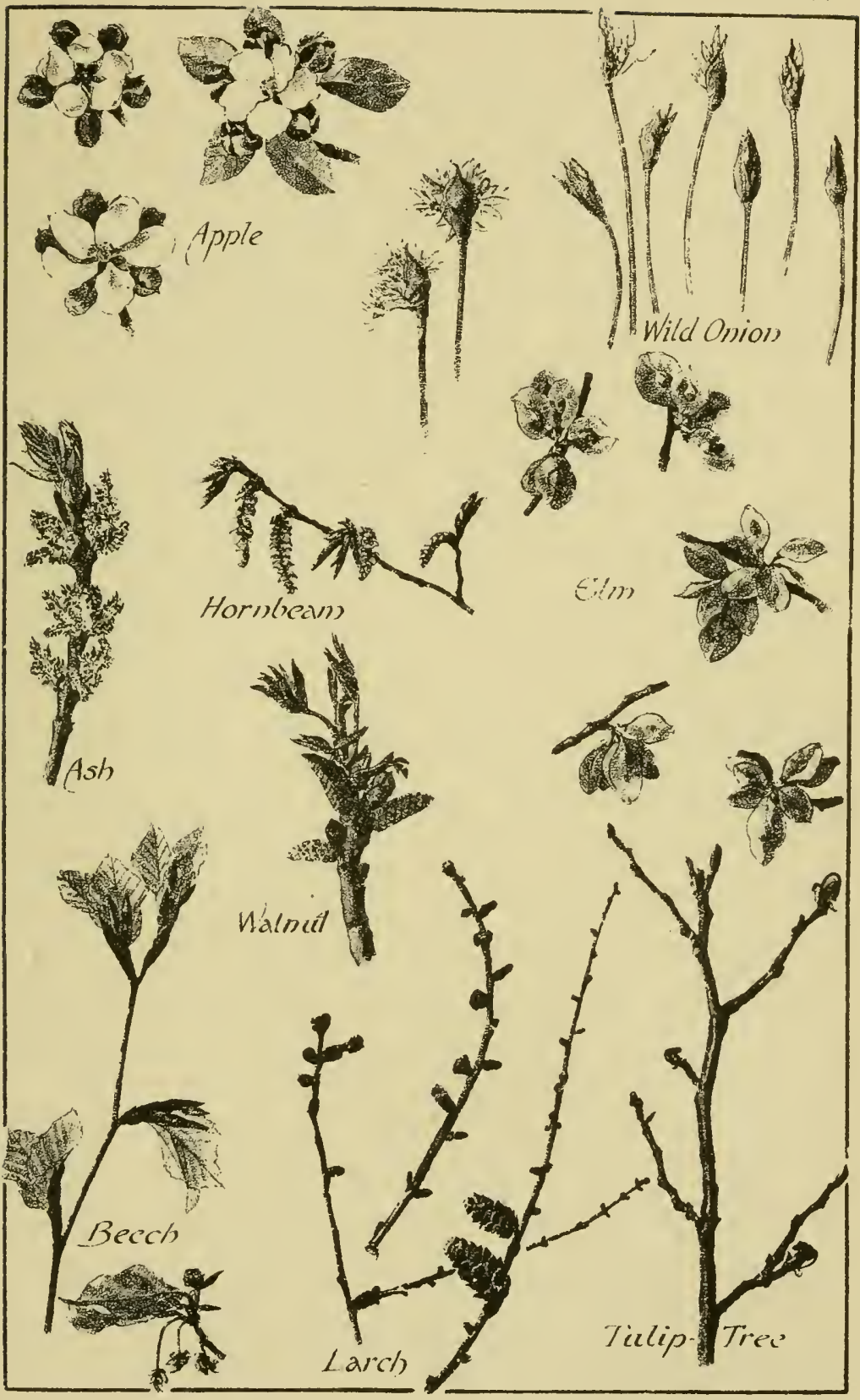

"Рното-TIMT, by James Akerman London W.C

Flower \& leaf buds 

him that Nature is not so careful always to emphasise botanical points as are some of us, and that she appears often to break her own laws: or perhaps it would be more accurate to say, she breaks the laws we have been bold to make for her.

At all events plants very often seem to grow differently from what science has taught us to expect. Against a wall, for example, where leaves cannot grow in the normal spiral fashion, they will arrange themselves quite contentedly on two sides of the stem or on one side of it. If that may be so in nature, why not also in art? There is only one caution necessary against it: that the designer must not let it seem as though he were ignorant of the way in which a thing naturally grows.

To do full justice to a plant it is not enough for the designer to make a drawing of it. One has to watch it through the year, perhaps through several years, in order to seize the moment when it reveals all the possibilities that are in it. Certain seasons are peculiarly favourable to the development of certain plants in the direction of ornament, In a wet summer, for example, when things grow quickly, the apparently confused way some plants have of growing is made clear. 
The stalks are so much longer than usual, and the leaves so much further apart, that they disclose for once the way the plant grows; and this opening-out of natural growth goes some way towards fitting it for the purposes of ornament.

Again, it depends in some cases very much upon the season whether the sepals of the withered flower remain intact on the ripened fruit, and whether the stipules at the base of the leaf-stalk and the bracts at the axes of the flower-stalks adhere or not. In exceptional seasons, also, fruit-trees begin to bloom again whilst the ripe fruit is on the tree. And what a vast difference all that makes to the designer who would found himself always upon nature!

Many a happy inspiration of design is no more than the turning to account some fortunate accident in nature. You notice, as you walk through a clearing in the woods, where an oak-tree has been cut down close to the root; and it has sent out a ring of young shoots all round it, so as to form a perfect garland of oak-leaves on the ground. A few days later and you would seek in vain a living, growing model for your oak wreath.

The conventions of artists are not so far removed from nature as we are apt to think. 
Plate 9

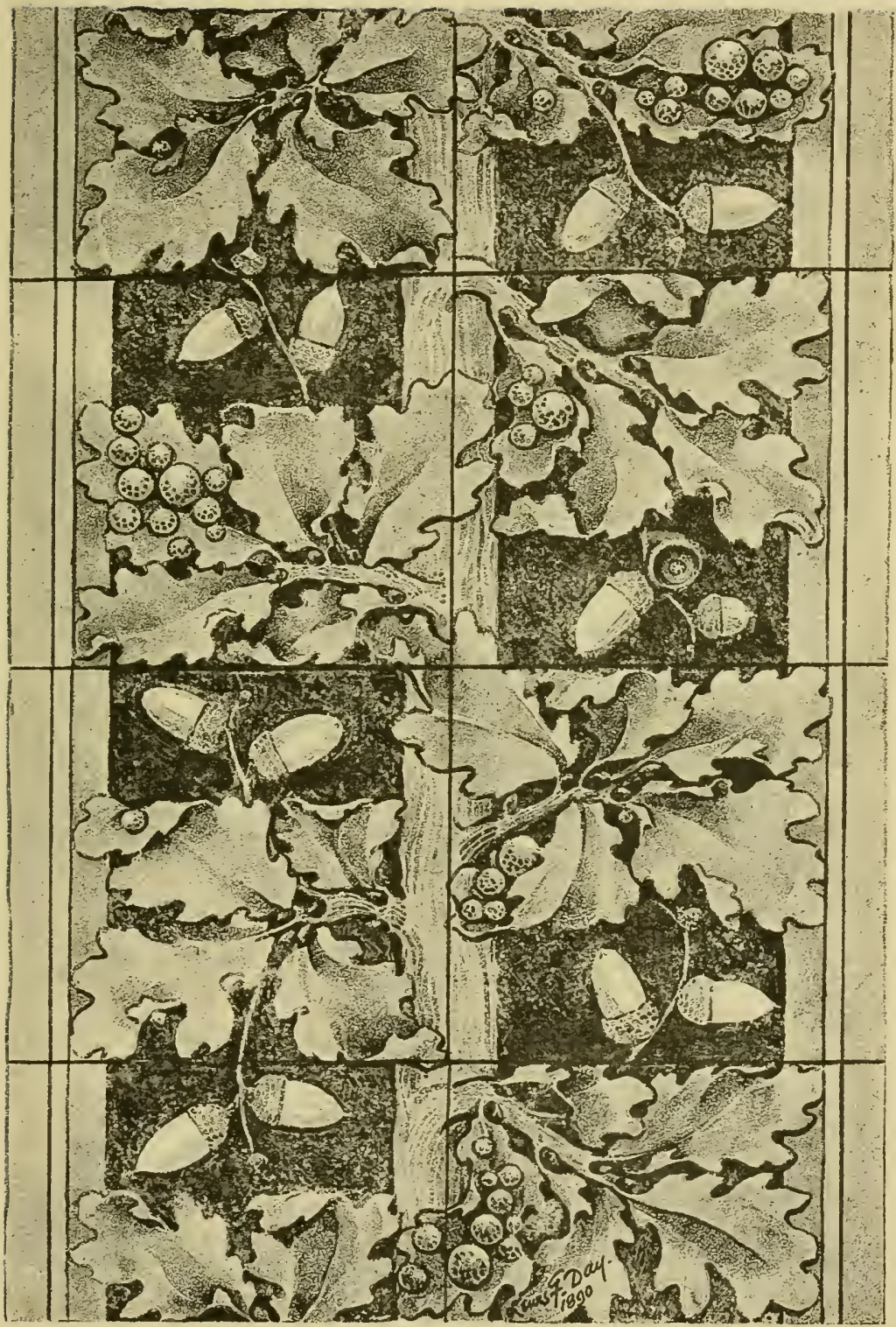

'Pното-Tint', by dames Akerman. London W $\mathrm{C}$

Tile panel, Oak Galls 

Trees do grow in Umbria as Perugino, and Raffaelle after him, painted them. The artist did not altogether imagine those graceful sprays of leafage, any more than $\mathrm{Ve}$ ronese evolved his lovely greenblue skies from his imagination. You see just such skies in Italy; as you see also in Titian's country the purple hills and quasi-conventional landscapes he put into his pictures.

Apropos of colour, we are too much disposed to take it for granted that red, blue, purple, and yellow are colours nature

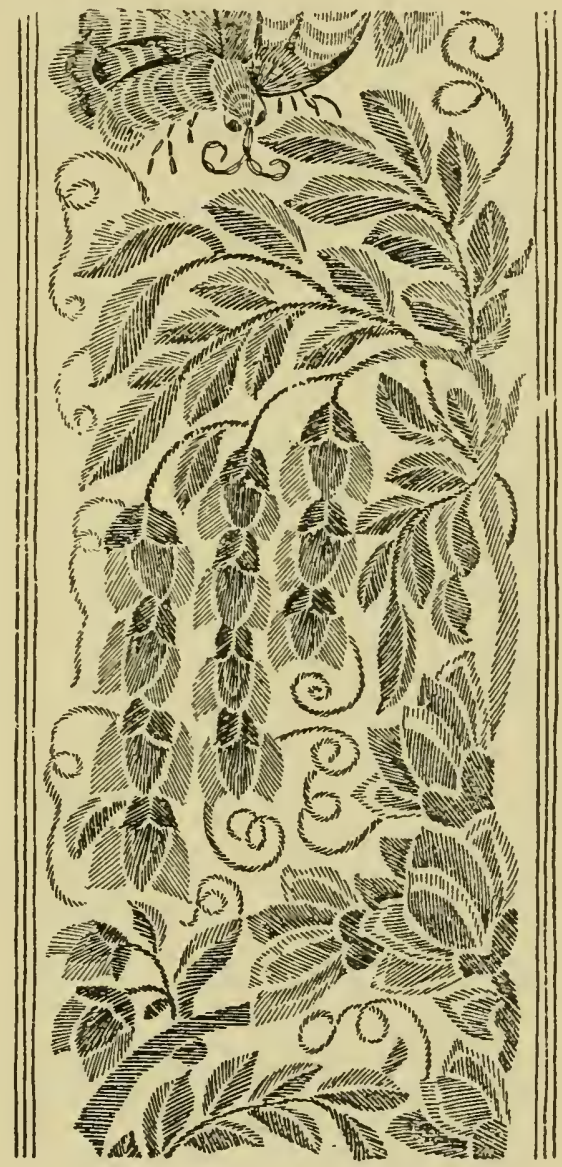

.7 Chinese rendering of wistariaold embroidery.

has reserved for flowers, and that leaves, stalks, and so on are only green. But as a 
matter of fact, the flower-stalk is often more in harmony with the flowers than with the leaves, as in the begonia, salvia, sea holly, and other plants. The leaf-stalk, also, is sometimes bright crimson, as in the little wild cranesbill and in the sycamore; or vivid yellow, as in the case of some poplarleaves.

Leaves themselves, again, are sometimes anything but green. I do not mean that they are merely greyish, as they often are, or olive, which they seldom are, or that they merely change colour in the autumn, but that the foliage is of a delicate brown, as in the young growth of the wistaria (which the Chinese embroiderer (see p. 29) has metamorphosed into something more like tendrils), or madder-coloured, as in the late shoots of the oak, briar, hornbeam, and other trees. And then what variety of tint there is in the backs of leaves: purple as in the wild lettuce, rich red-brown as in some magnolias and rhododendrons, silver grey as in the alder, the poplar, the willow, and some garden plants.

The Japanese have made admirable use of the contrast in colour between the back and front of leaves. They will make the leaf solid black with white veins, and sketch its reverse in outline only with black veins, 
Plate 10

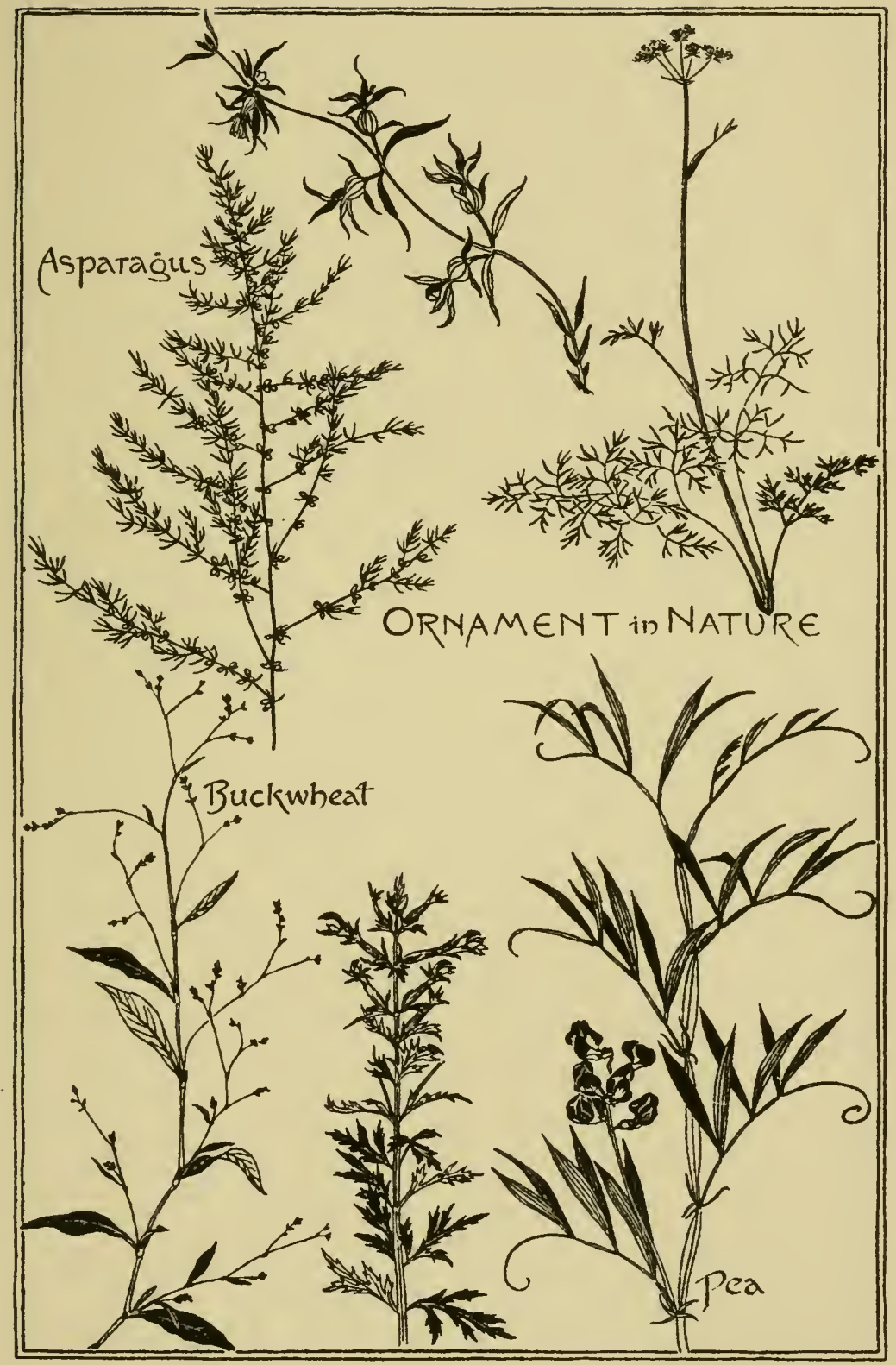

T. Arerman. Photo-litt London

Natural Growth. 

counter-changing the colour as frankly as a mediæval herald did in his treatment of the mantling about a shield.

Whether, then, it is form that we seek or colour, everywhere in nature there is material for the ornamentist, often, as it seems, almost ready made to his hand (Plate IO); but, promising as it may be, it is not yet ornament-it lacks always adaptation to our especial purpose. It is by our treatment of nature that we justify our use of its forms. 


\section{III.}

NATURE IN ORNAMENT.

IT is not at first sight obvious how much all ornament owes to nature. There is even a still surviving superstition that it is designed by the aid of the kaleidoscope.

True it is that the "itch to make patterns" was one of the very earliest symptoms of that artistic fever to which the human race has from the first been liable. Man may or may not have begun by scratching animals on bones of other animals, he very soon began to scratch ornamental devices. The English race scarcely suffers from the malady nowadays. When it does break out in us it may be traced probably to some Welsh or other Celtic ancestor. But to certain of us, however few, it is every bit as natural to trace patterns as to draw animals-or to kill them.

For all that, even the born pattern-designer is necessarily, as man, and more especially as artist, so intimately acquainted with nature that his work is inevitably imbued with it. 
Plate 11

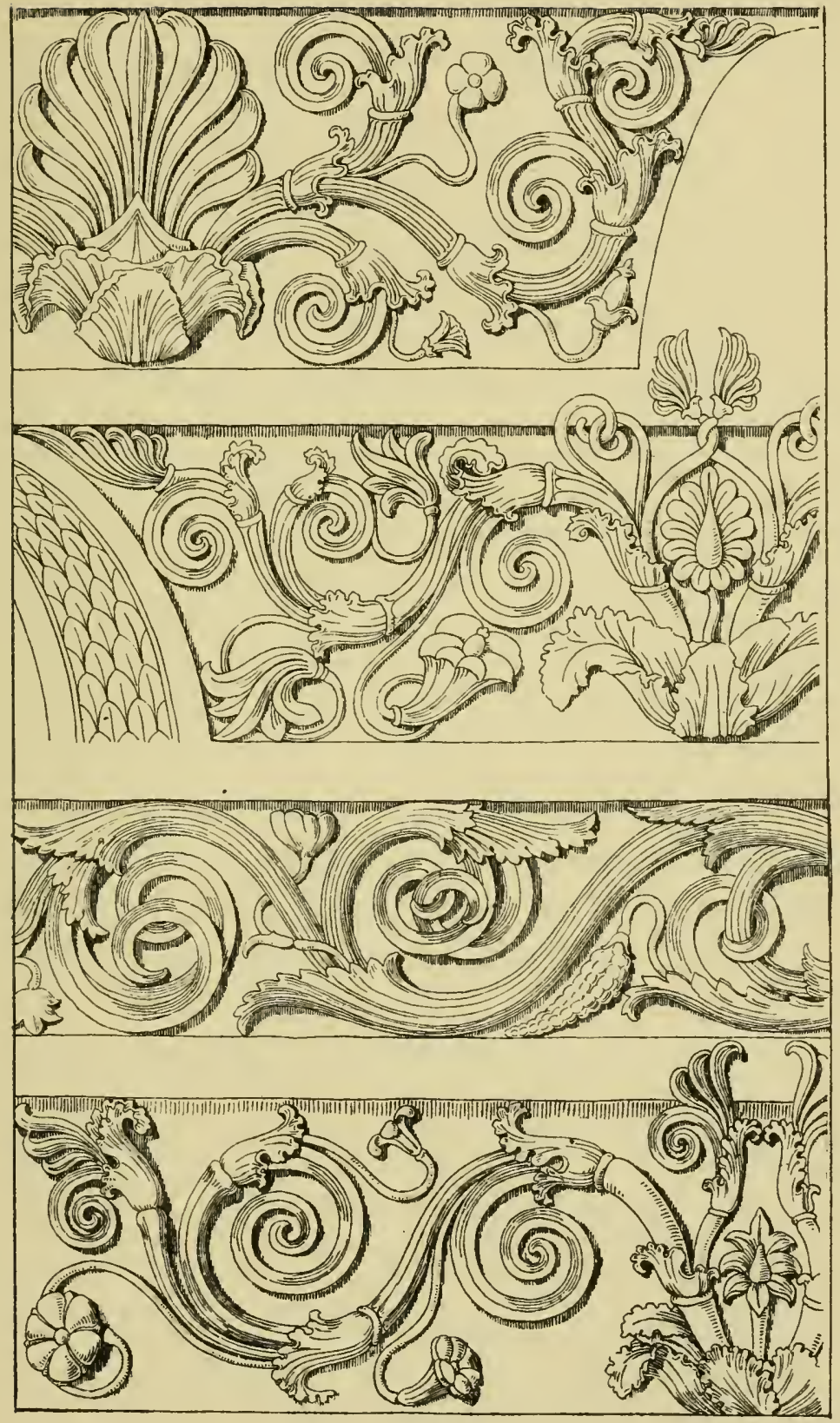

C F KELL. MOTO-LITHO. B.FURNIVAL ST HOIBOAN,E.C.

Greek Scrolls. 

In almost every detail of design there is, whether he be conscious of it or no, a reminiscence of nature. In the most abstract design he is accustomed to obey instinctively the natural laws of construction and growth, so much so that we resent his departure from them, and take exception, for example, to the scroll, even the most arbitrary, which violates the rule and presumes to grow, so to speak, both ways at once.

I have explained at length elsewhere * how the Greek honeysuckle ornament, as it is called, originated in no attempt to imitate natural bud forms, but grew, as one may say, out of the use of the brush. The fact remains, notwithstanding, that the brush-strokes came to range themselves very much on the lines of natural growth-all the more readily, of course, because of the memories or impressions of plant form stored away in men's brains. The fact is those memories, vague as they may be, prompt the ornamentist at every turn in design.

What we call the acanthus scroll seems to have grown simply out of the desire to clothe with some sort of leafage the mere spiral lines with which archaic ornament, whether in Greece, or Northern Europe, or the Fiji

* 'Some principles of Every-day Art,' p. $\mathrm{IO}_{4}$ et seq. 
Islands, instinctively set out; which spiral line not only occurs in many shells and in the horns of animals, but results inevitably from a certain natural action of the draughtsman's wrist.

The Greek scrolls on Plate I I consist practically of little more than branching spirals, with just a husk of something like foliage to mask the dividing of the stem : the lilies and the like are minor features obviously put in to fill up; they form no integral part of the main purpose.

The Roman scroll (Plate I2) is plainly more full of sap; it seems to be bursting out into leafage; but it remains only a development of the Greek idea : it is simply a spiral clothed in conventional leafage, devised primarily to disguise its lines, and especially the branching of the lines. That is the root and origin of the acanthus scroll-not any attempt to reduce the acanthus to ornament, but a desire to clothe

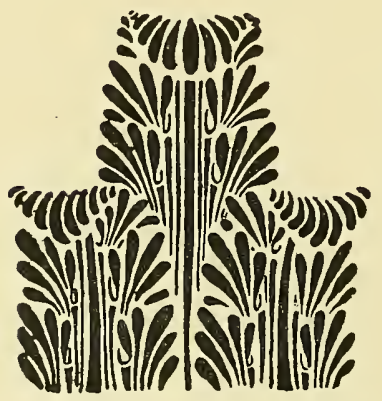

8. Acanthus leaves reduced to brushwork. the lines of the scroll.

Archaic Greek ornament is made up mainly of spiral lines and groups of brush-strokes. On Plate i3 I have reduced two typical acanthus leaves to brushwork, in order to show 
Plate 12

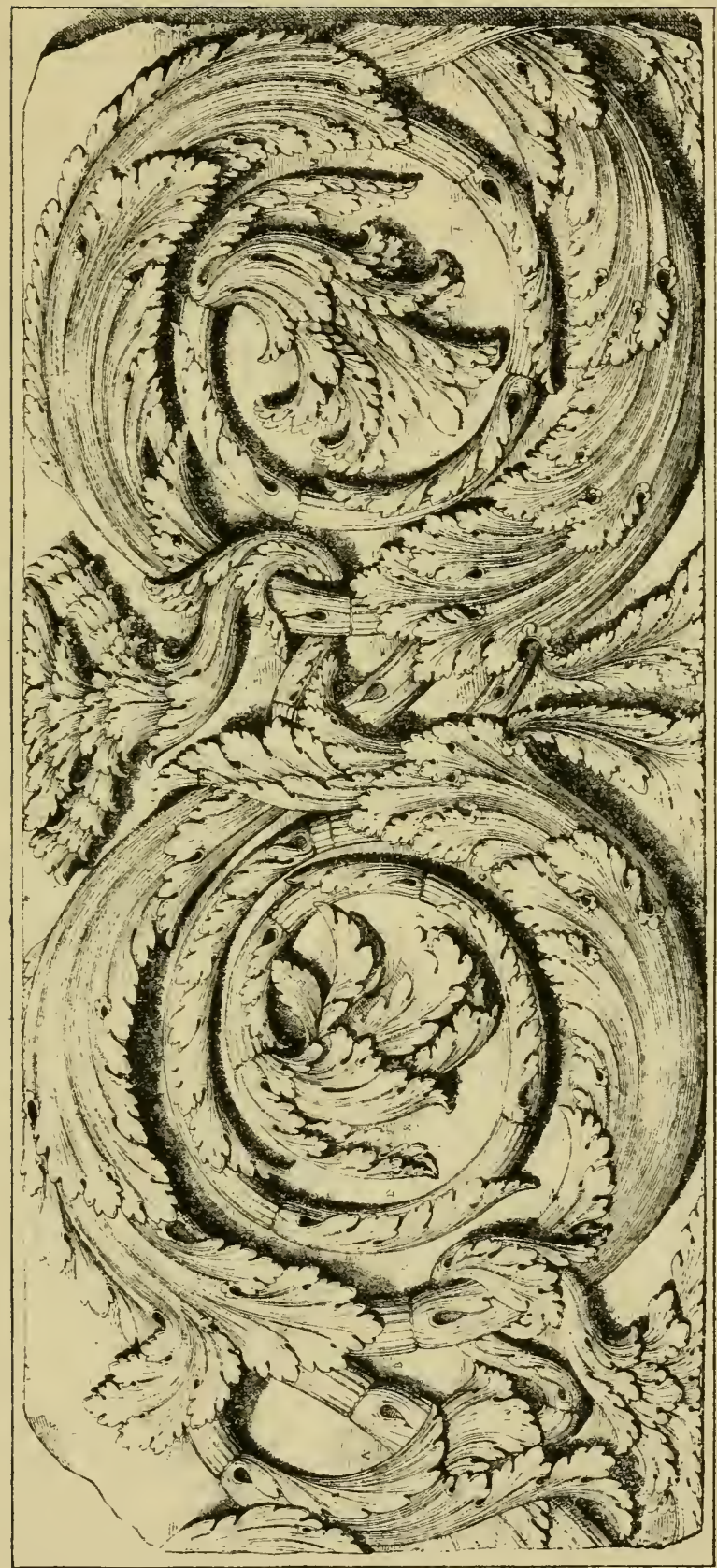

5
0
0
0
0
0
0
0 



\section{Plate 13}
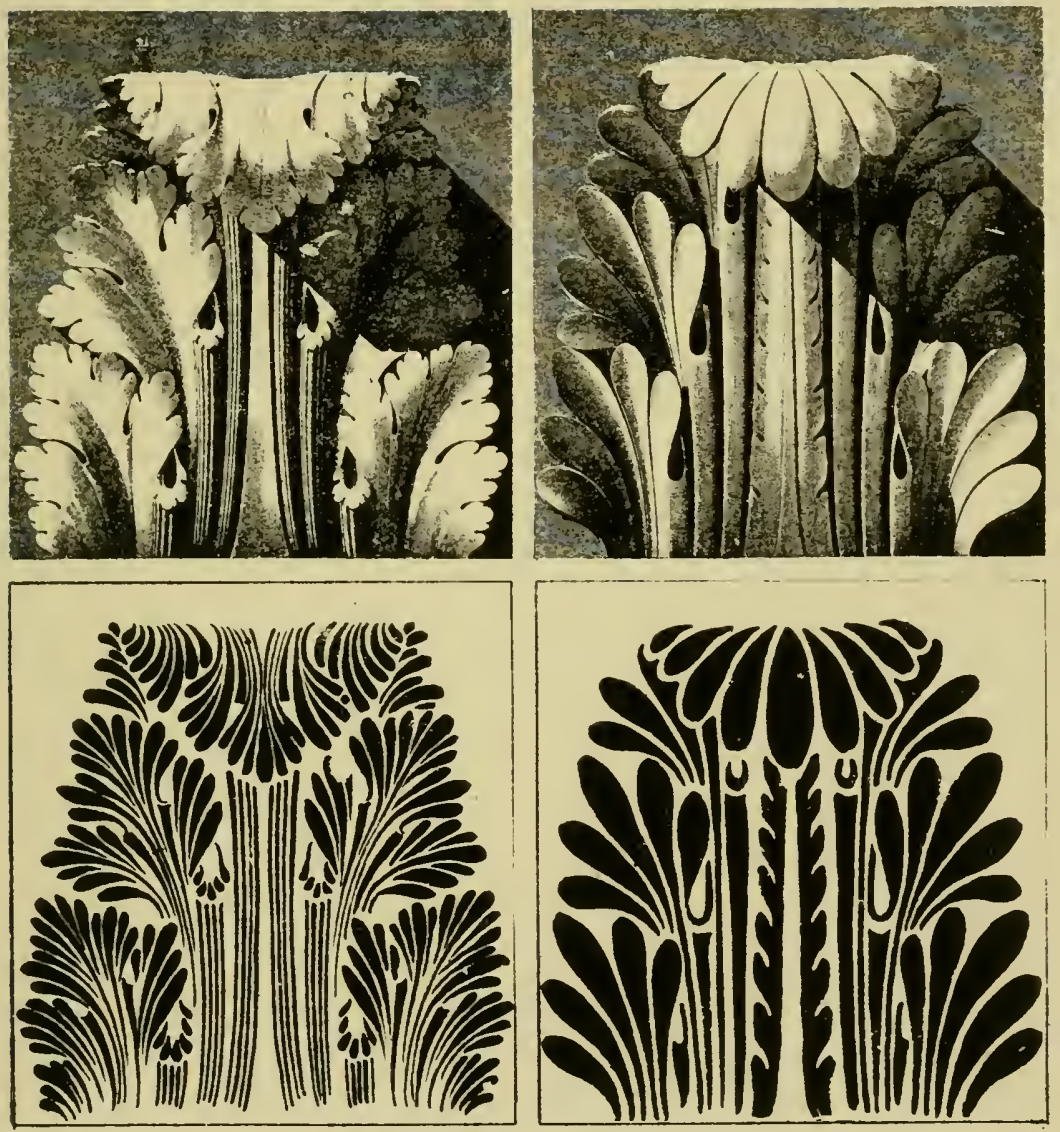

C F KELL POTO-LITHO, B.FURNIVAL ST HOLOORM,E.C.

Acanthus Sculpture \& brushwork. 

P1ate 14

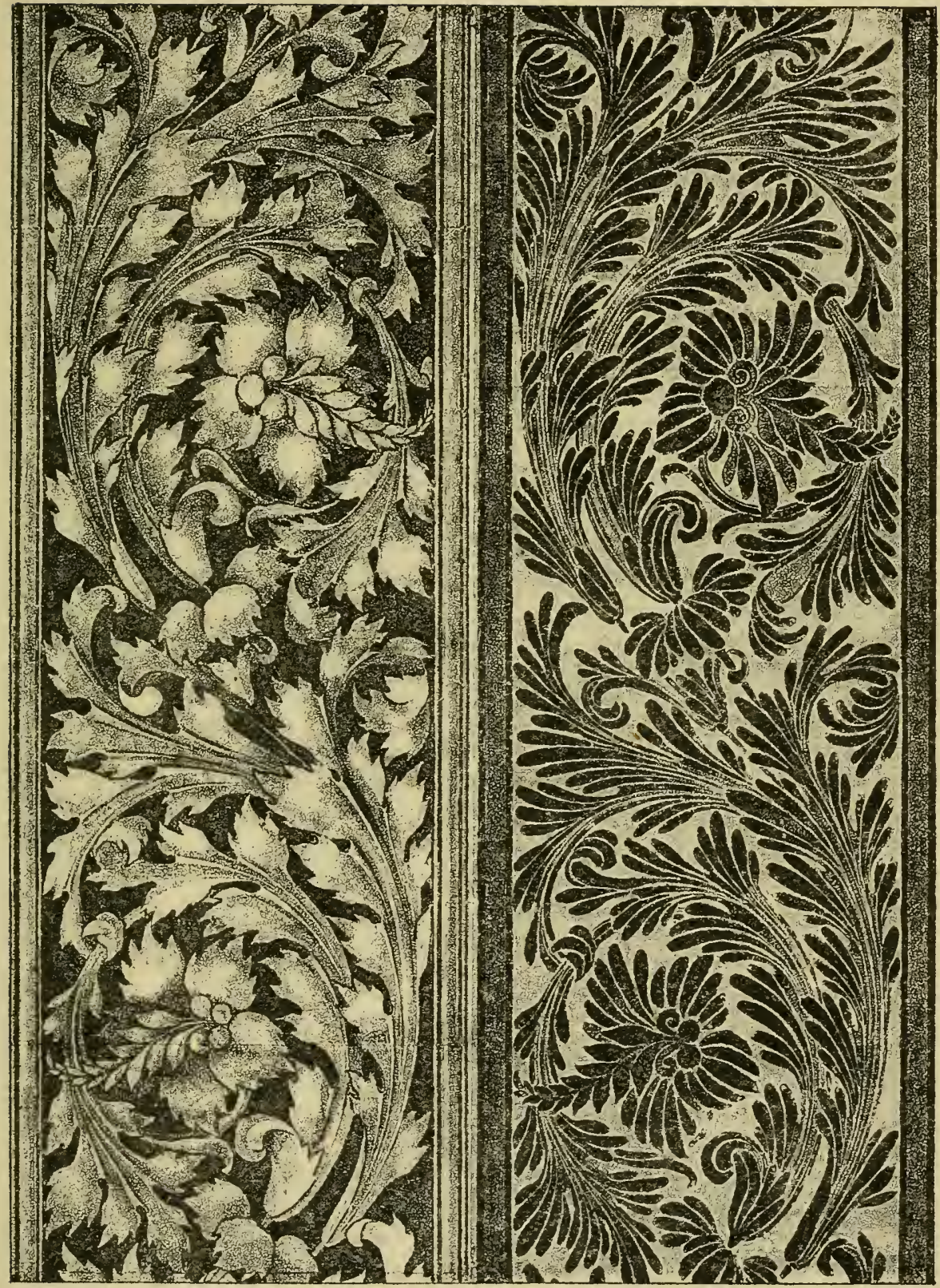

Photo-TINT", by Jomes Akerman Jondon W. C 



\section{Nature in Ornament.}

how, starting with the idea of decorating bald lines with brushwork, a painter, haunted as we all must be by the ghosts of natural growth, might have arrived at something uncommonly like the conventional Classic leafage. And again, on Plate I4, I have translated a scroll more or less of my own into the same language of the brush. It is not, of course, meant to imply that that is, as a matter of fact, how the acanthus scroll came about, but that it might have been developed in that way. That fable about Callimachus and the Corinthian

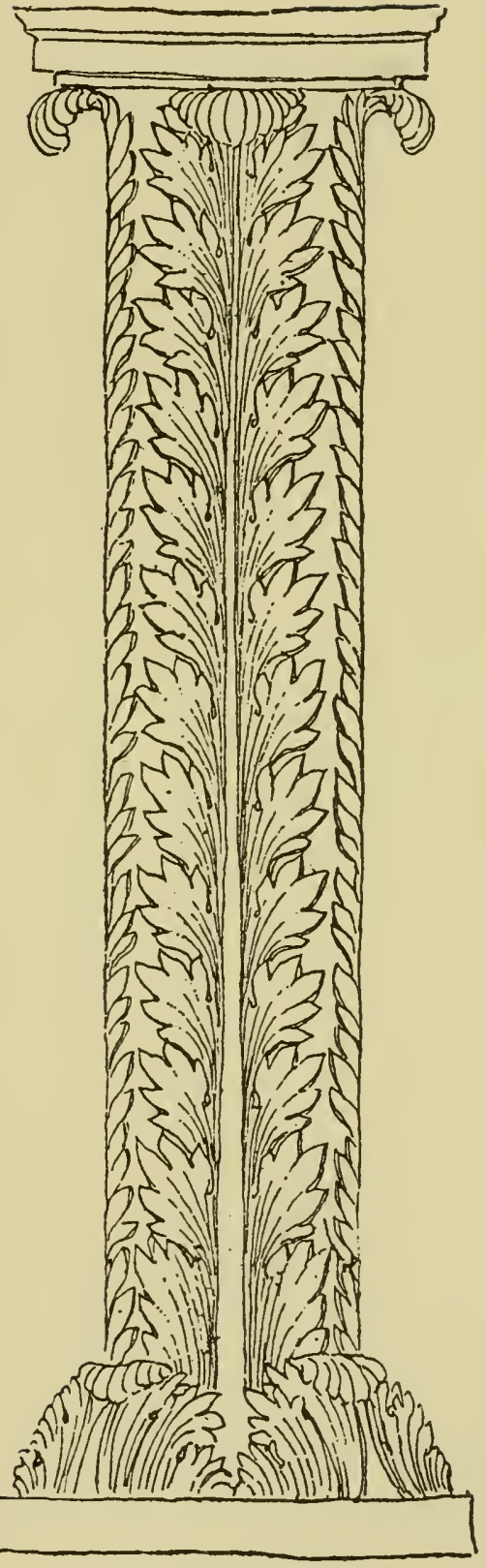

9. Simple acanthus leafage.

D 2 


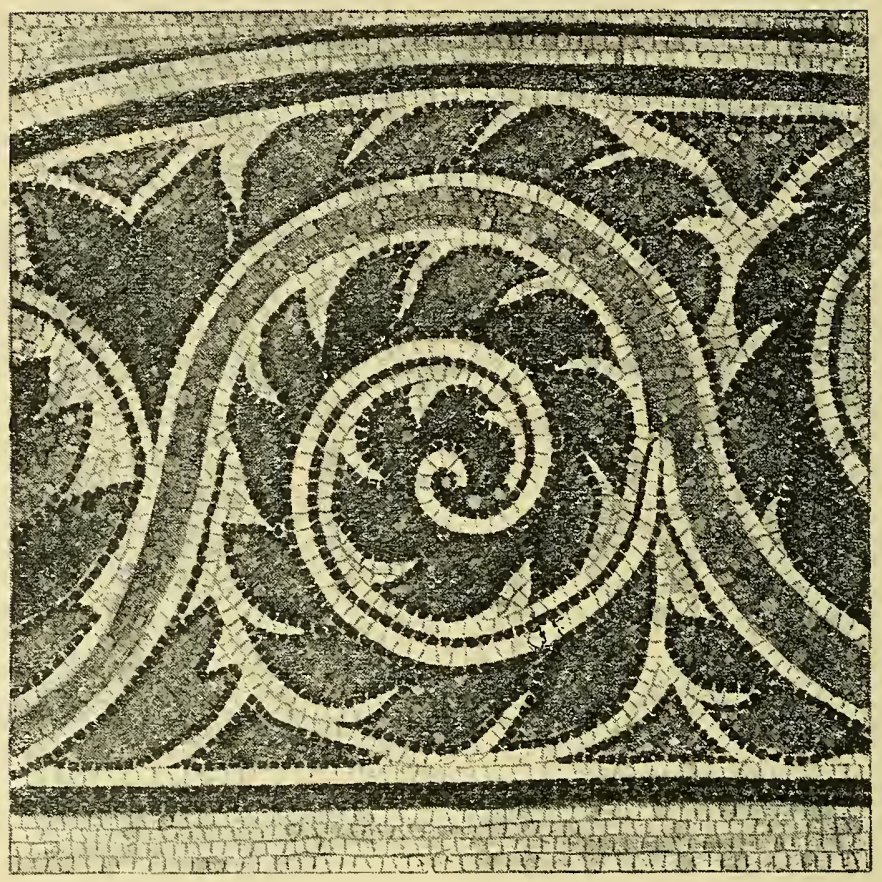

Io. Step between wave and acanthus scroll-Roman mosaic.

capital is the invention of a poet, not of a practical ornamentist.

Again, on the Roman pedestal on p. 35, where there is no scroll and no branching and no great variety of foliation, one may see very plainly indeed how the familiar type of foliation may have grown out of the very simplest idea of clothing a straight line. It is one step, just one step, beyond the Greek bay-leaf pattern (Plate $8 \mathrm{I}$ ) : instead of simple bay-leaves in pairs we have opposite groups 
Plate 15

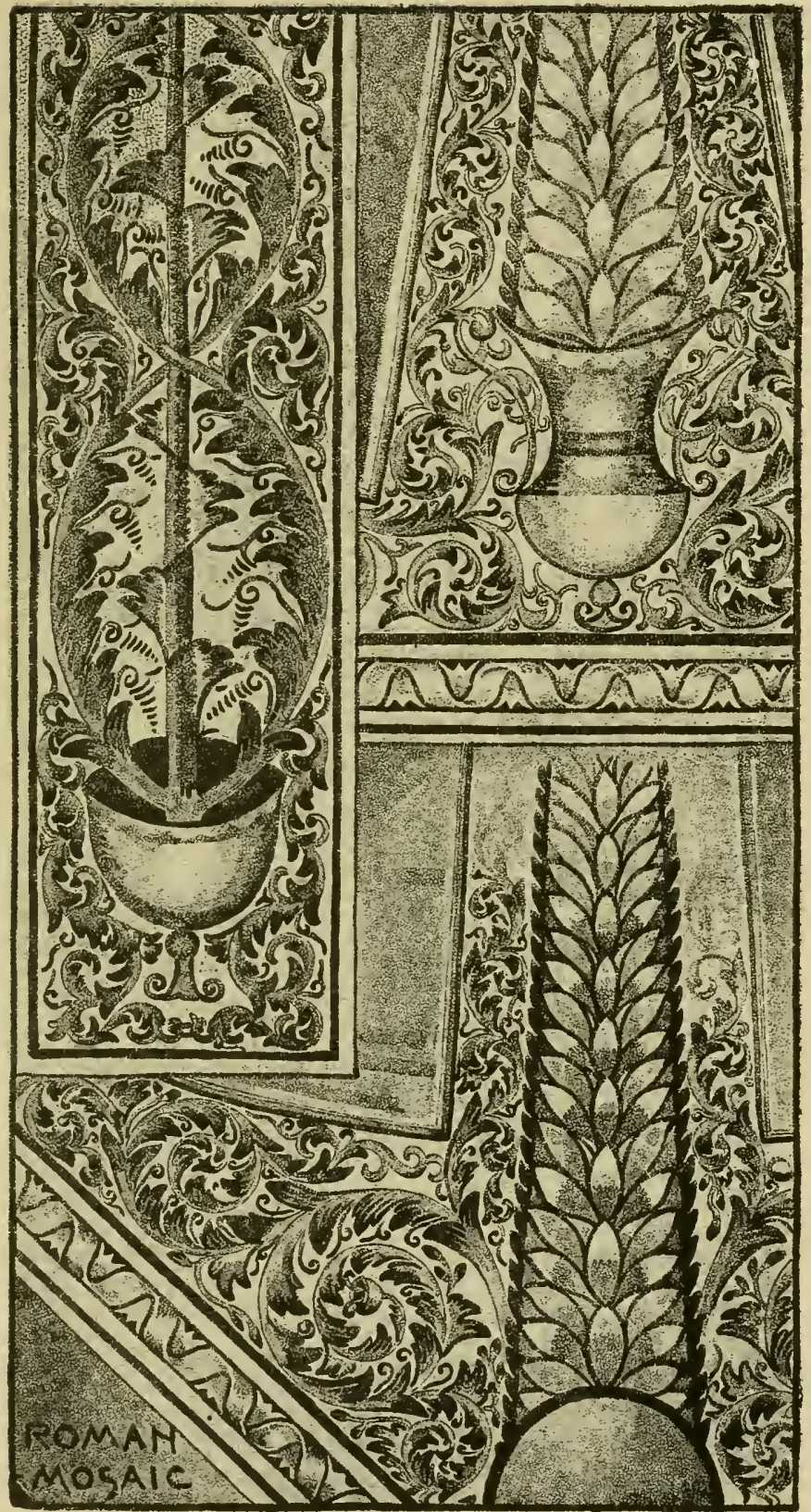

"Рното -Tint", by James Aǩerman. London. W. C

Deta1ls of Mosaic from Carthage. 

of five, not separate leaves, but massed together sculpturesquely, forming at the junction of the groups the "pipes" so conspicuous in the full-grown Classic scroll.

In the Roman mosaic border on p. 36 is an indication of the growth of a very similar idea; a simple wave stem is supplied with a spiral offshoot, and both are clothed with leaflets of the very simplest description. Serrate or subdivide such leaflets, and we

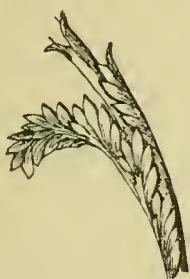

זr. Olive-like leafage.

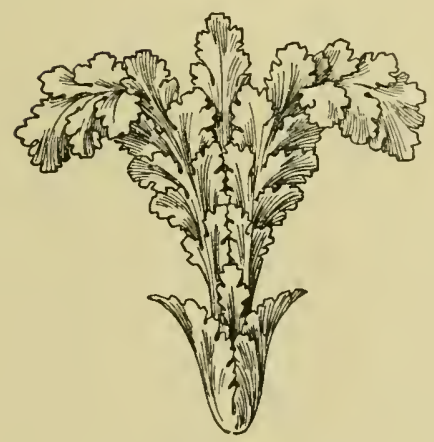

12. Oak-like leafage. should not be far from the familiar arabesque. Something of the kind does in fact occur in the mosaic detail from Carthage on Plate I 5, which looks almost like the next step forward in the development of the scroll.

Such a system of foliation once invented, it was easy and natural enough to make the detail more or less like some natural leaf. It has been made to resemble the acanthus and the olive ; and it is clear, by the acorns accom- 


\section{$38 \quad$ Nature in Ornament.}

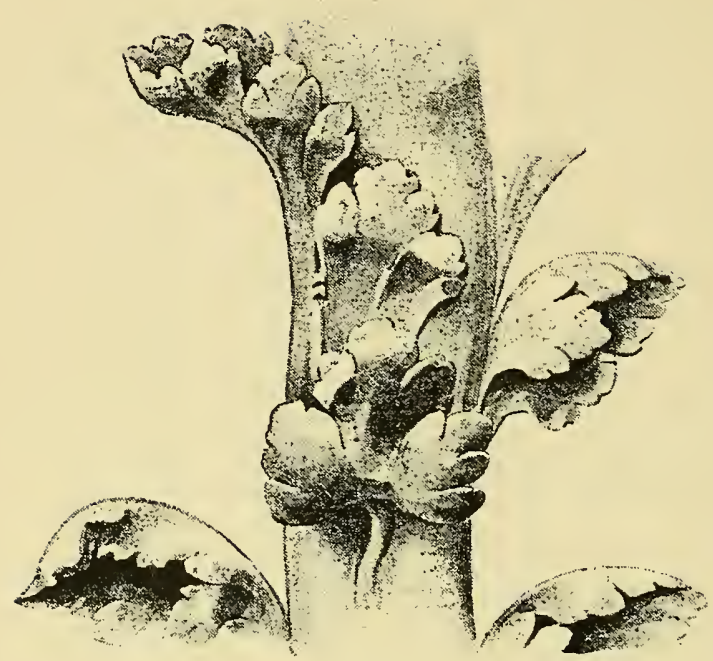

13. Vine-like acanthus leafage, from the Jubé at Limoges.

panying it, that it was used also to represent the oak. The quasi-Classic scroll of the Renaissance assumes at times also a distinct resemblance to the vine. This is very plainly seen in the leafage from the famous Jubé at Limoges (above). Judging by this particular instance, one might pretend that the stock pattern of conventional foliage was suggested by the vine. The vine-leaf is here as unmistakable as the relation of the ornament to the Antique. The detail in question belongs of course to a transition period. It halts between two opinions.

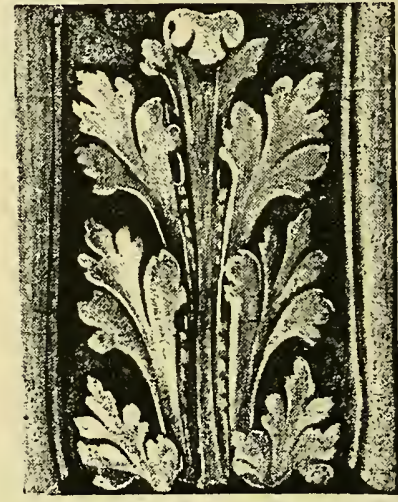

I4. Crocket-like foliage, from Limoges. 
Plate 16

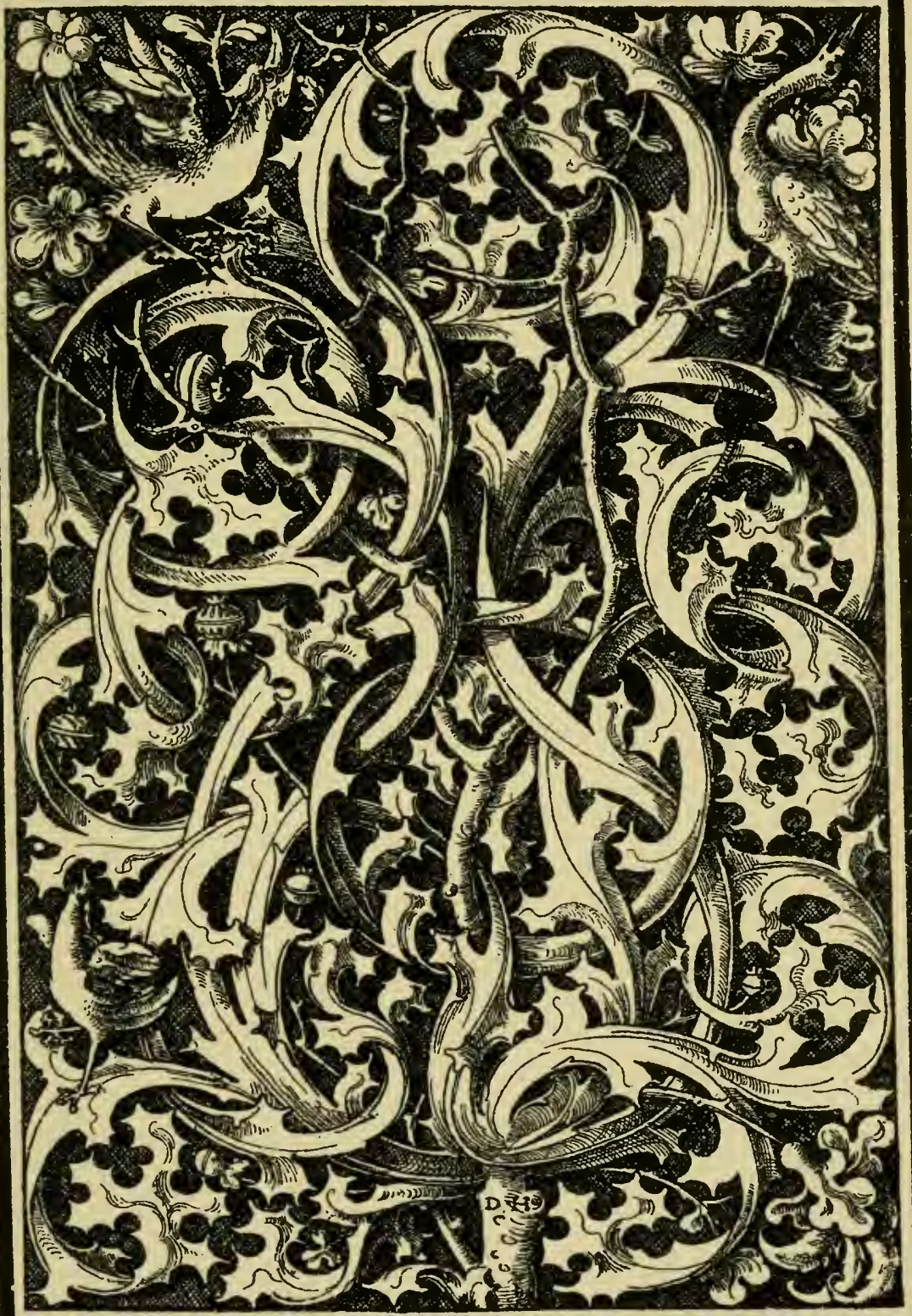

Transitional Scroll, D. Hopfer. 



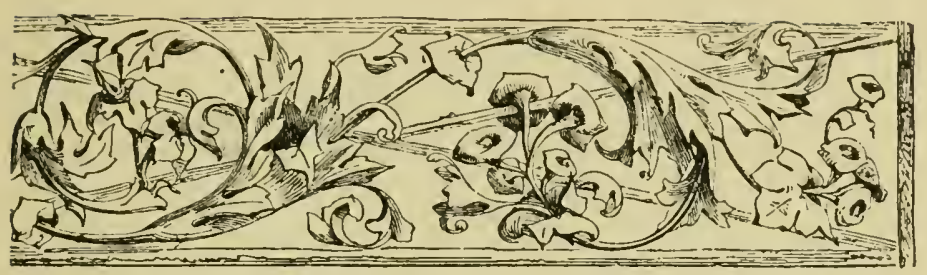

15. Modern modification of Classic leafage.

You see the hesitation, perhaps, more plainly still in the bracket from the same source (No. I4). That was plainly inspired by Classic art; but the sculptor was more accustomed to carve Gothic crockets than Roman scrolls. The result is ornament which, but for association of ideas, would never suggest the notion of the acanthus. A very characteristic and individual modern rendering of the old theme is given above, the design, apparently, of the late Godfrey Sykes.

Had the Classic scroll really been only a conventional treatment of the acanthus, it would have been difficult to understand how the sculptors stopped short at that one type, and did not attempt to manipulate other forms of leafage in the same way. That merely abstract leafage should, on the other hand, eventually remind us of olive, oak, or acanthus leaves, is readily understood.

The Gothic scrollery of Hopfer (Plate I6) is very remote indeed from the acanthus. The spirit of the Renaissance was already in 
the air in the time of Hopfer, and probably influenced his work. If it did so to any extent, it shows how differently men could interpret the same notion. If it did not, it shows how from different directions they arrived at something of the same kind. There is nothing of the acanthus here-the foliation is more suggestive of the thistle-but yet there is in the design a family likeness to Classic and Renaissance types. The more naturalistic flowers introduced to fill up remind one distantly of the lily-like additions to the Greek scroll (Plate II), and even the birds, too natural for the foliage they inhabit, have their counterparts in Roman and Renaissance arabesque.

In the typical Renaissance arabesque the idea is still to clothe lines in themselves merely ornamental; and in the best work these lines remain always apparent through the clothing (Plates 96 and 105). But that the Italians of the Cinque Cento did not allow themselves to be hampered by any consideration of natural possibility, still less of probability, is shown by their indulgence in the absurdities which deface many of their most graceful compositions-such for example as da Udine's in the Loggie of the Vatican, and those of Giulio Romano at the Palazzo del $\mathrm{T}$ at Mantua, one of which is given on Plate $\mathrm{I}$. 
Plate 17.

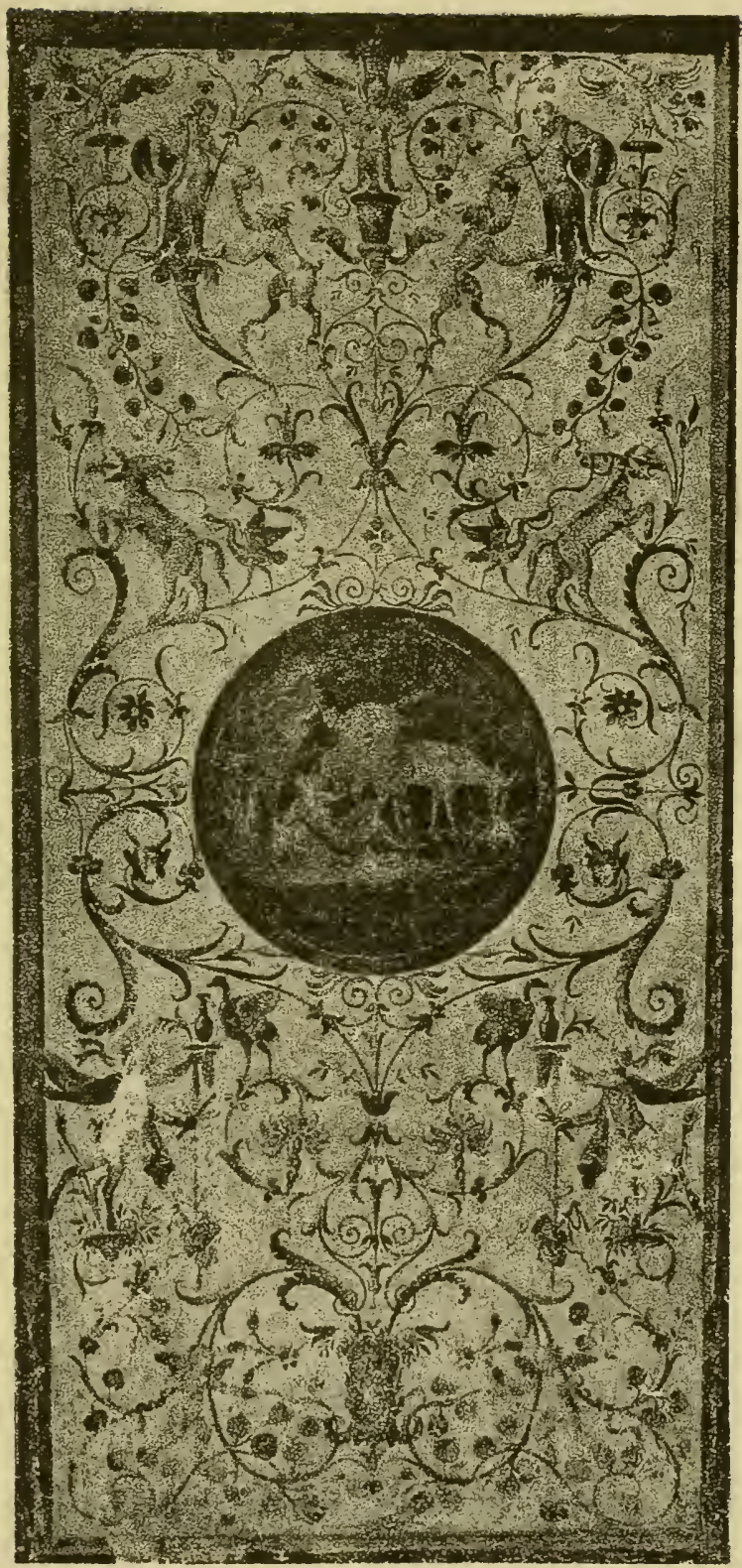

"Рното-TIнT", by James A.kermon. London W.C.

Painted Wal1 Panel, by Giulio Romano. 

The Italian of the sixteenth century was seldom very particular how he arrived at his effect, so he arrived at it - the end justified the means with him; but, little as he cared

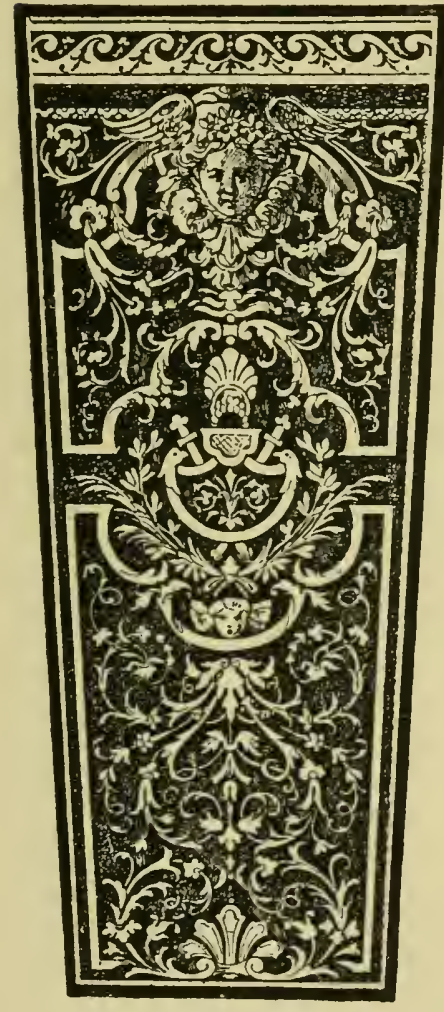

x6. Seventeenth century scrollBoulle. for natural growth, he could not do without it, and his most unnatural ornament bristles with natural details.

The ornament round the faïence dishes on Plate is (a class of ornament commonly distinguished as Raffaellesque) begins plainly with the idea of purely ornamental lines. It is another development of the foliated line. Both lines and masses are here obviously quite arbitrary, suggested by ornamental considerations; but, almost in spite of the artist, they take the form of winged head, dolphin, leaf, flower. That fault already referred to of growing two ways at once, which 


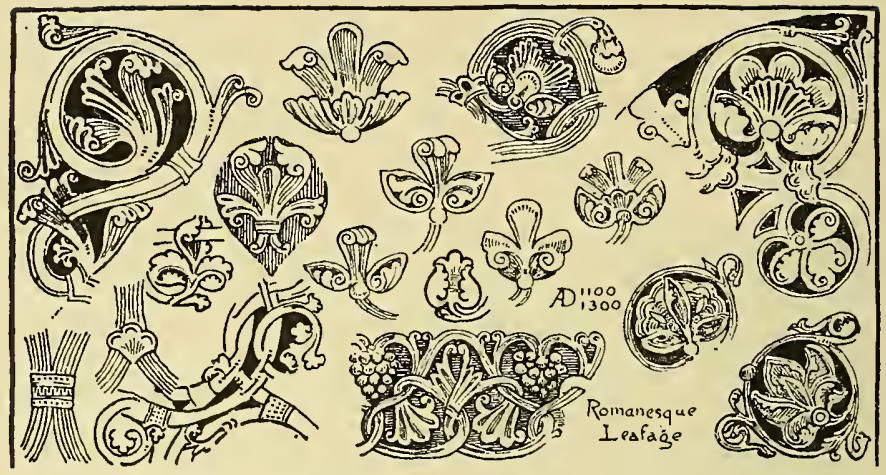

I7. Details of Romanesque ornament.

may be here observed, is a very common defect of Italian arabesque-as of Arab art also, although in it the detail is so very far removed from life that the defect is less apparent. Even in its degradation, however, the Renaissance arabesque never quite let go the thread of nature; and in the hands of Boulle (p. 4I) it blossomed out during the seventeenth century into something more distinctly floral than the purer scroll of the Cinque Cento.

In Romanesque ornament, which is in the first instance only a rude rendering of Roman detail, there is, towards the twelfth century, some return to nature. The details above, for example, are not to be traced to any natural type, but they are alive with reminiscences of nature. It is plain, nevertheless, always, from the freedom of the rendering, that the primitive idea was not to reproduce 
Plate 18

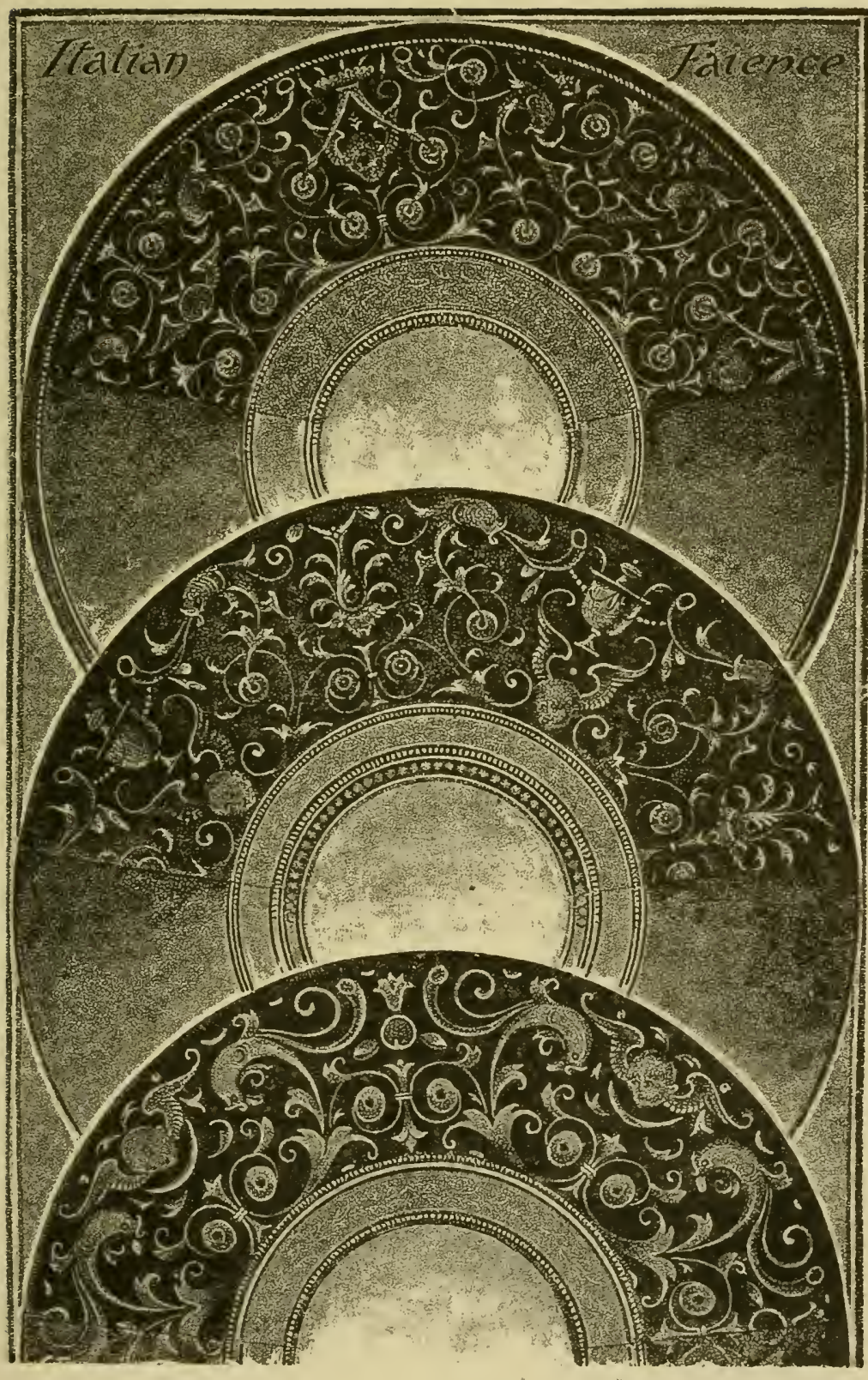

Lustre Dishes 16 th Century 



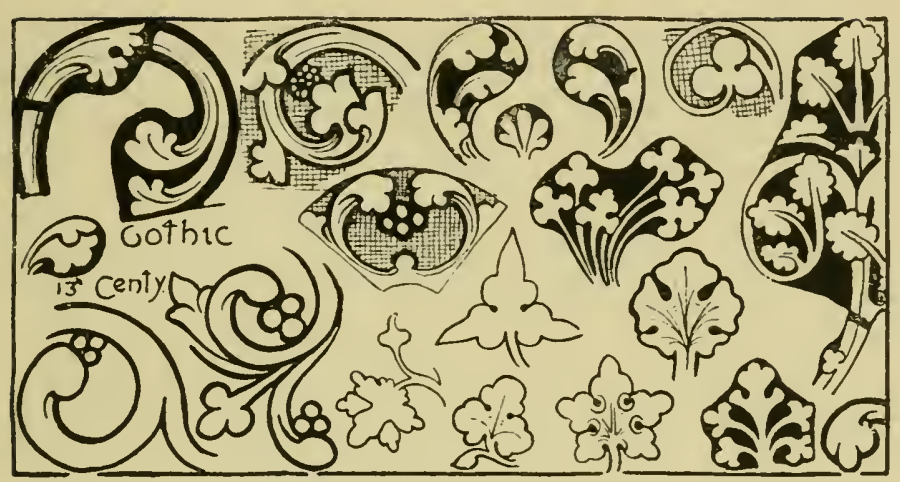

I8. Details of Early Gothic ornament.

nature, still less to represent it naturally, but only to find a starting-point for design.

The same may be said with regard to Early Gothic ornament, originally little more than a carrying on of the Romanesque idea, and reminding us at times, even in the thirteenth century, unmistakably of Classic detail.

In some of the details at the head of the page may be seen how, eventually, the artist went more directly to nature; but though you might trace these home, they are as yet very arbitrary renderings. And for my part I think the earlier and more arbitrary Gothic forms by far the more ornamental: the stone budding into crockets or other sculpturesque foliation, is to me far more beautiful than the would-be natural leaves and flowers spread over the architecture of the fourteenth century. In other words, the more strict 


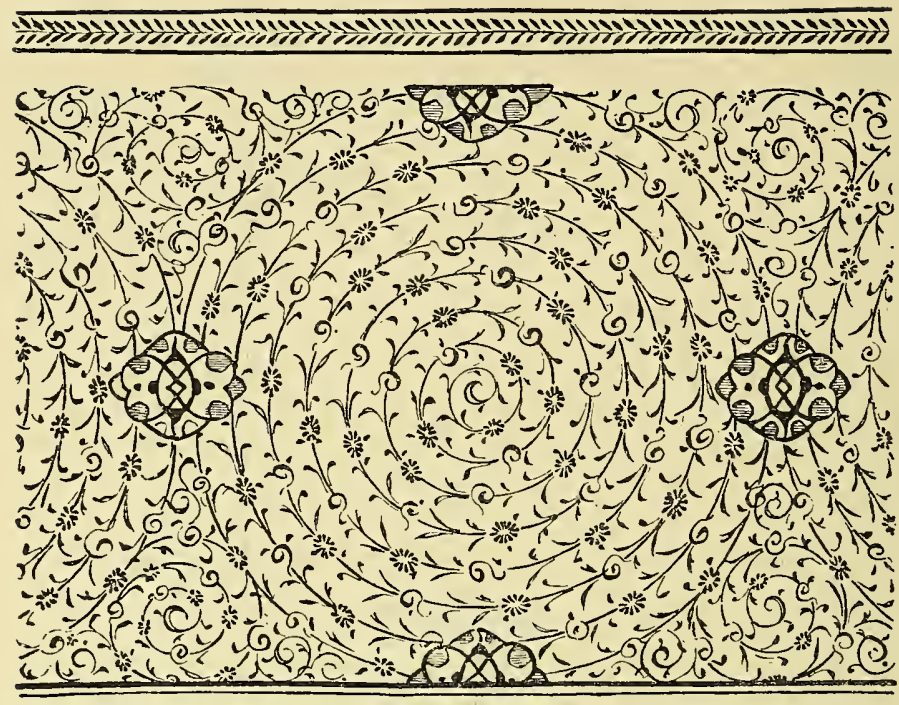

I9. Spiral Persian scroll.

adherence to the natural type has resulted in the less satisfactory ornament.

The artists of the latest Gothic period seem to have realised that themselves. In the German tapestry on Plate I9 there is, properly speaking, neither leaf nor flower, but only ornamental detail corresponding to both. The lines are in a way ornamental; but the growth is of more account with the designer than the line of his ornament. In this respect it is interesting to compare it with more deliberately ornamental arabesque. In its vigorous Gothic way it too is a model of the use that may be made of nature in ornament. 


\section{Plate 19}

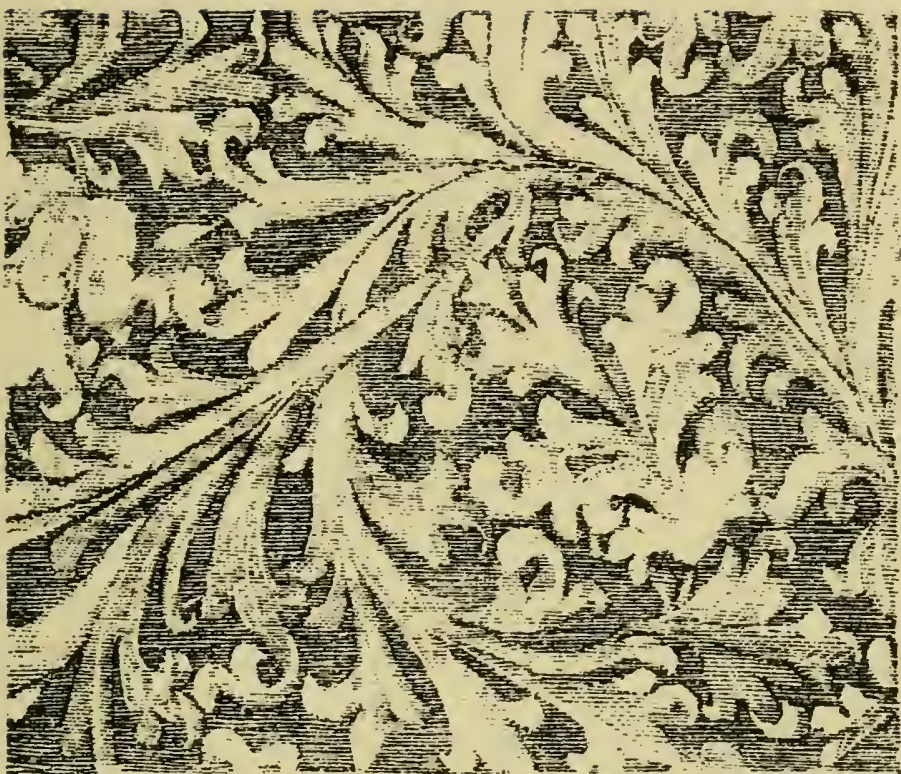

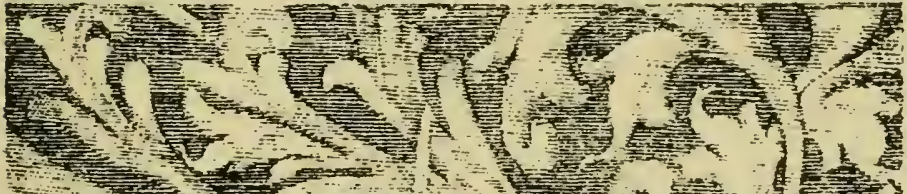

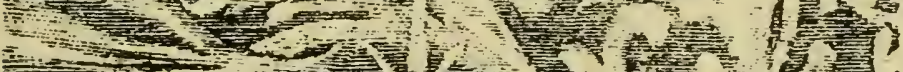

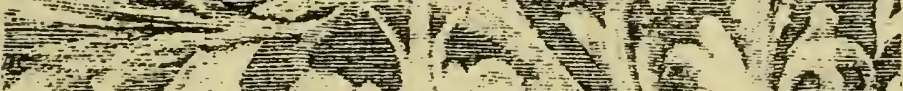
等 n 年,

Gotbic Scrnil 



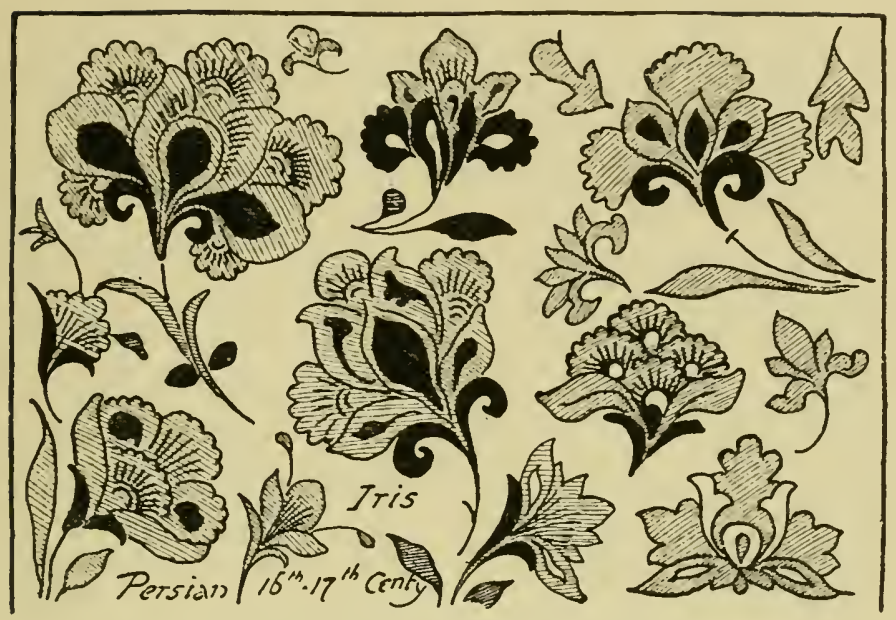

20. Iris-like details of Persian ornament.

In the Persian pattern on p. 44 , the spiral line is decorated in a quite different manner from the Classical: it is not so much clothed in leafage as relieved by leaf-like touches and broken by daisy-like rosettes. It is quite certain that no natural type ever suggested the design; it was in seeking ornamental forms that the painter happened upon something which suggests, but only suggests, nature. On the other hand, there are forms above, which, though scarcely recognisable at first, are distinctly formed upon the flower of the iris.

Still more remote from actuality are the details of Arab and older Persian ornament. And yet the most frequent feature in it is 


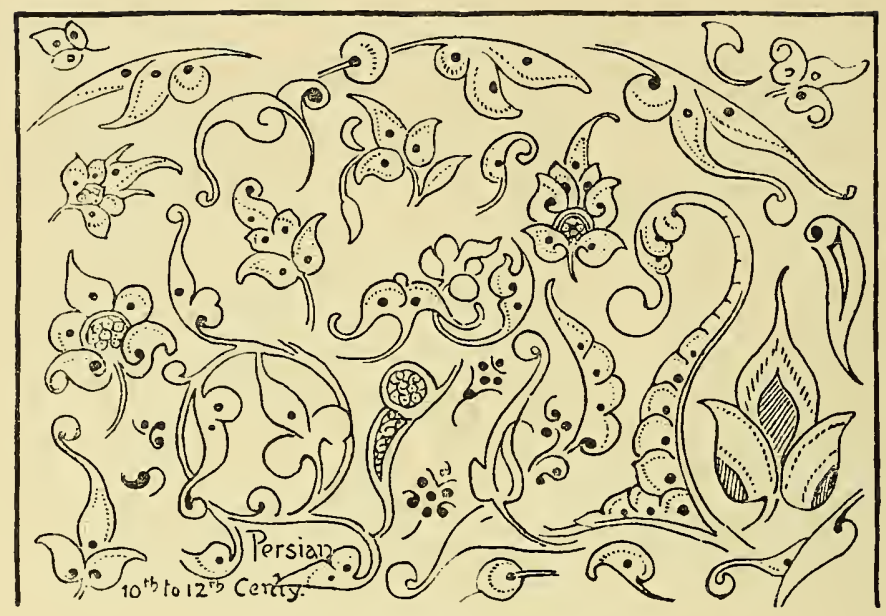

21. Details of early Persian ornament.

not altogether unlike a folded leaf in profile ; and in other shapes (above) a likeness has been traced to the unfolding fronds of the young fern. If these forms are indeed founded upon nature, it only goes to show how far one may, perhaps unconsciously, stray from one's starting-point. If they are not, it indicates how impossible it is to invent forms which shall not in some degree recall the life and growth about us.

Mohammedan design, we know, purposed deliberately to avoid the natural; but, for all that, the forms it borrowed from nature are perpetually betraying themselves, reminding us, if not of leaf or stalk, then of flower and bud. It looks as though, try as they might to 
Plate 20

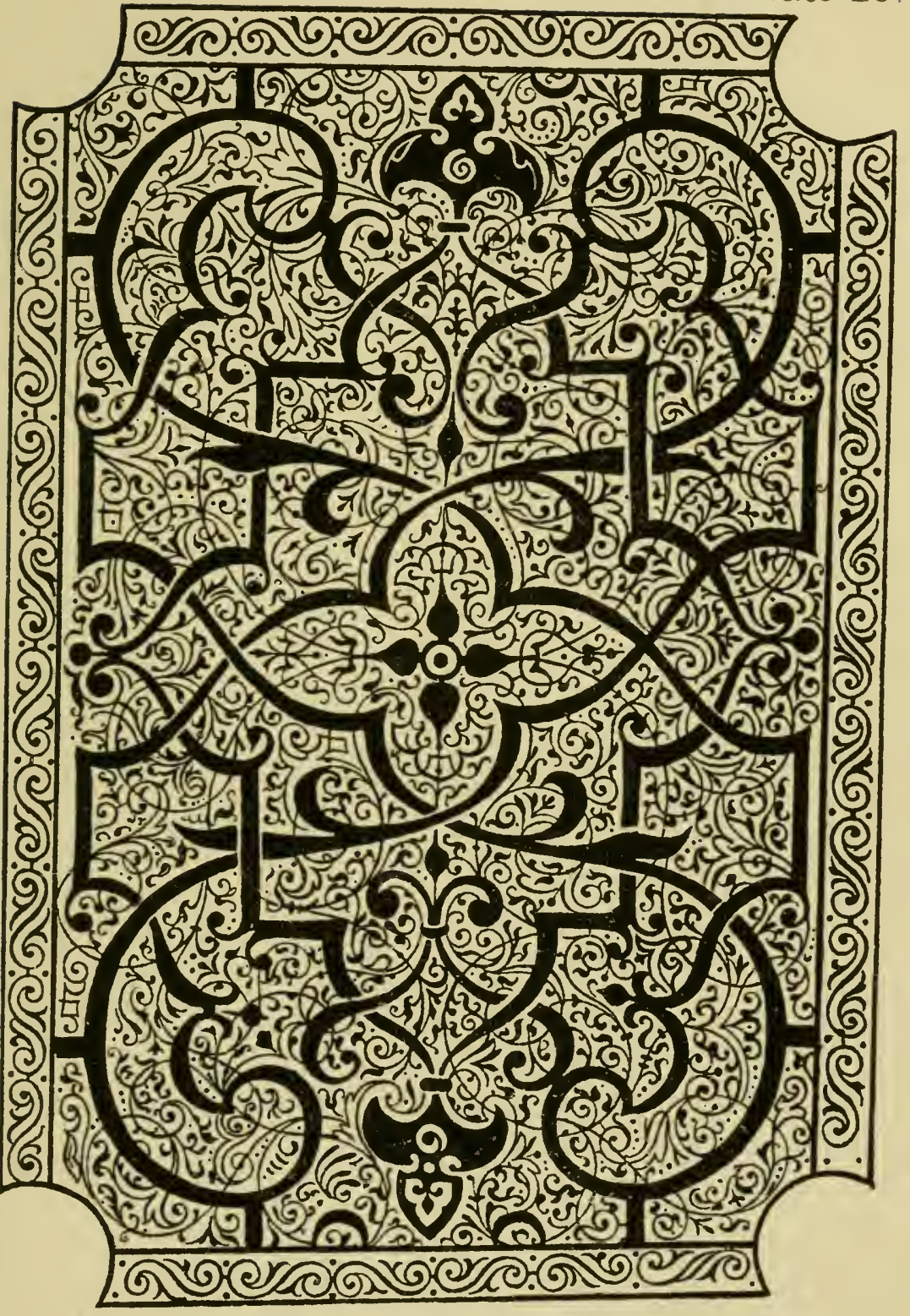

Arab-esque Renarssance moment 



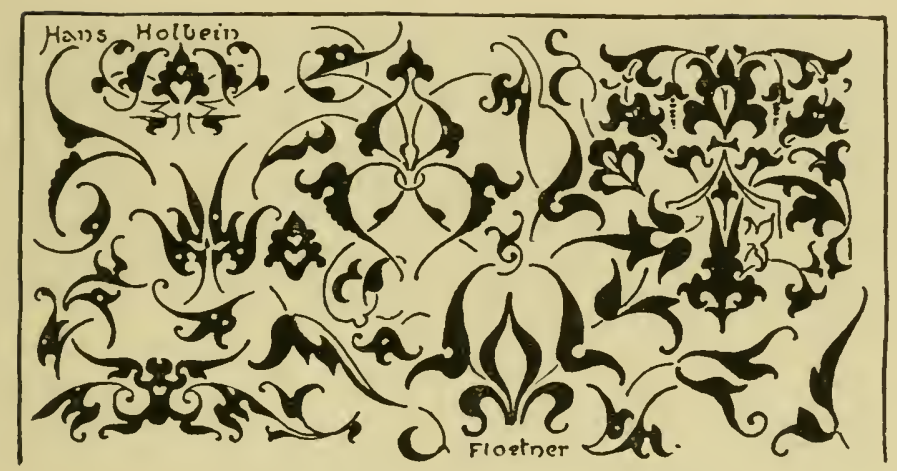

22. Sixteenth century arabesque details.

evolve ornament out of their inner consciousness, the Arabs could not altogether silence their memories, even though conscience forbade them to represent anything " on the earth beneath." Doubtless they sinned often unconsciously; but they were foredoomed to sin.

And so with their Renaissance imitators, German or Italian. Whenever they strayed

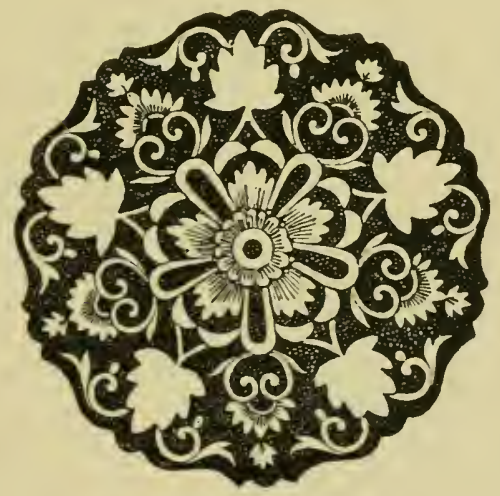

23. Rosette in Rouen faïet.ce. from the source of Eastern inspiration, it was invariably in the direction of nature. There is sometimes growth enough in the abstract Orientalism of Flötner and Holbein to make 


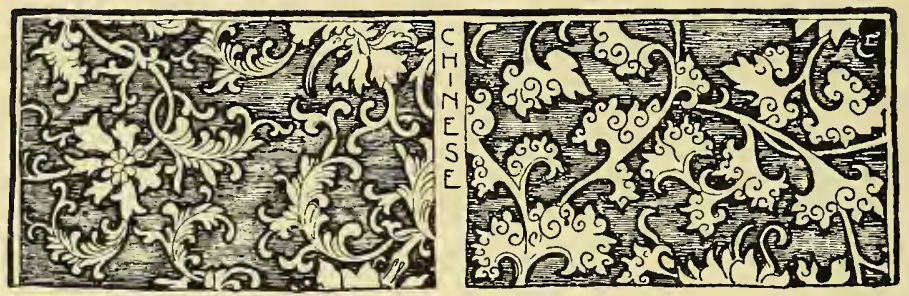

24. Chinese foliage, not easy to identify.

us wish it were more thoroughly consistent. One feels the lack of some controlling conscience in the growth.

It is curious to note how, on Plate 20, the deliberately ornamental lines of strapwork break out into something like foliation-as

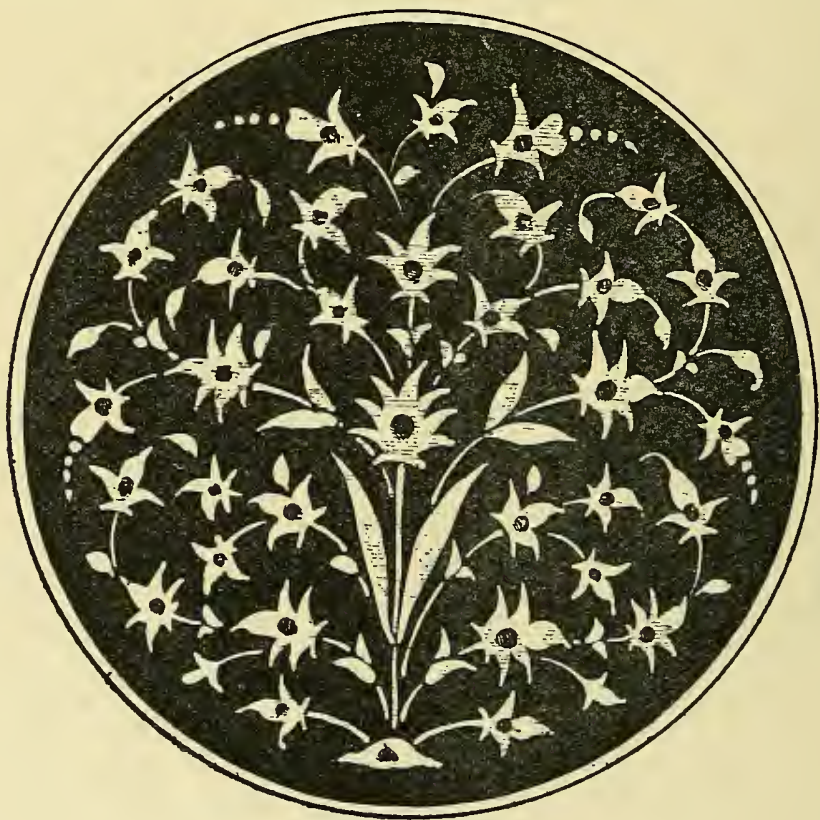

25. Bouquet of conventional ornament. 
Plate 21.

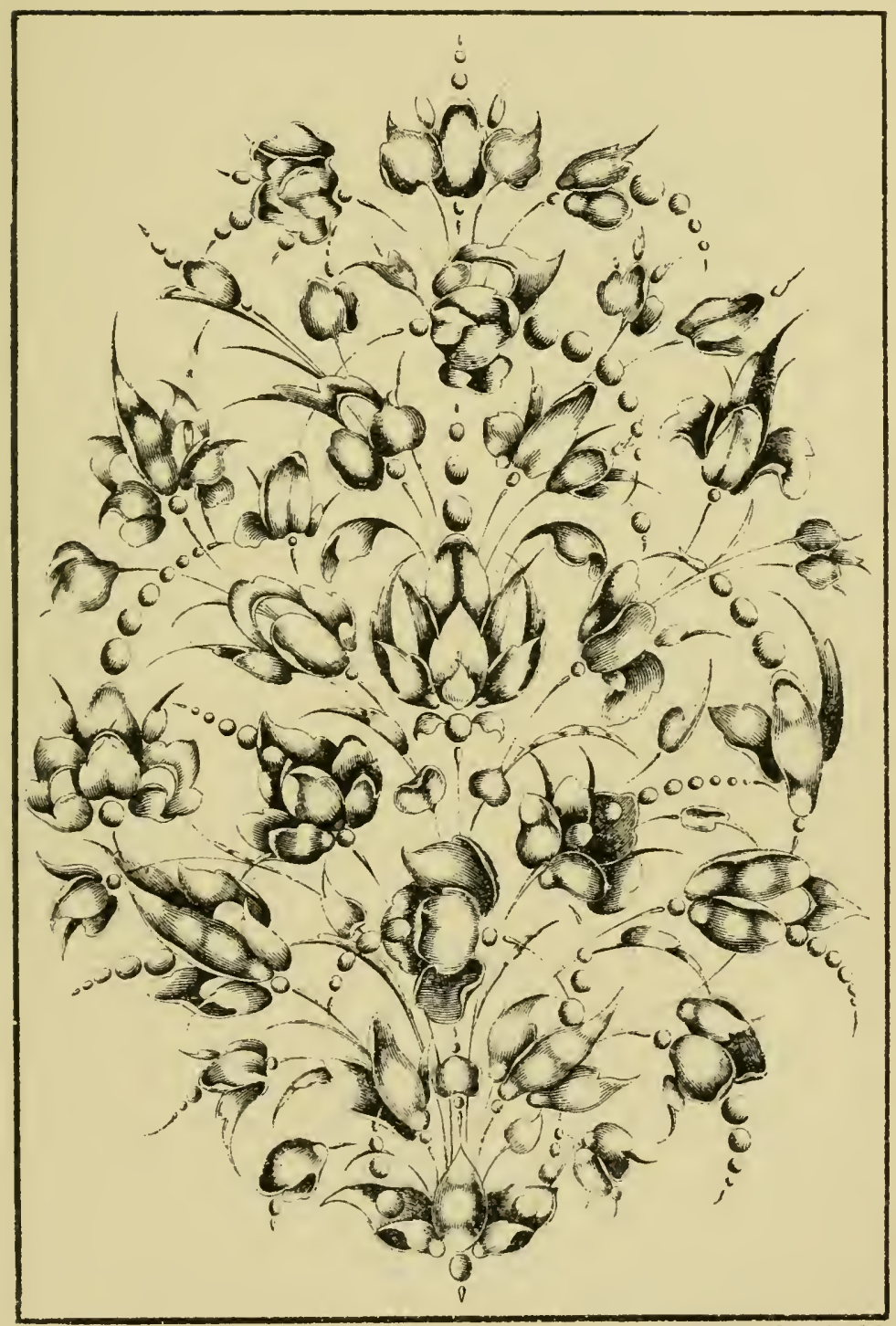

Ornamental bouquet $17^{\text {th }}$ Century 



\section{Nature in Ornament.}

for the undergrowth of filigree it does grow. Even Nicholaus Drusse (Plate I 17 ) does not manage to get clear of natural influence, though it must be admitted that he treated nature with very scant respect. So in the arbitrary

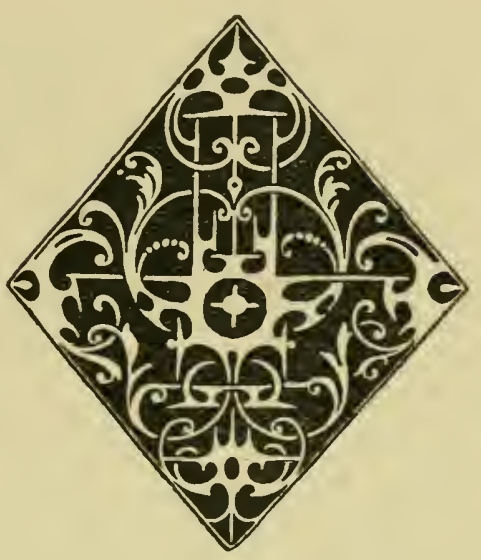

26. Abstract ornament, not free from foliation. inlay pattern above, the abstract lines of ornament must needs break out incontinently into something like foliation.

And again, in the faïence pattern on p. 47 , the painter, working on radiating lines indicated by the shape of his dish, seems to have arrived as a matter of course at a rosette suggesting a flower, and calling for something like a leaf in connection with it.

It is not by any means in the scroll alone that we trace the influence of nature in ornament. It is quite a common thing in Oriental art to find bouquets of quite conventional flower forms. There is an ingenious example of this in the Persian plaque on p. 48 , in which the ornament consists almost entirely 


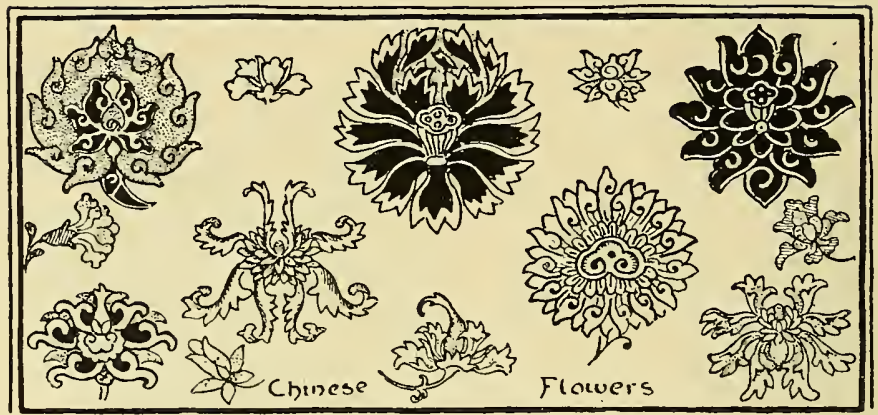

2.7. Conventional Chinese flower forms.

of flower forms, evenly diapered over the dish, and yet conforming to the idea of growth. The Oriental influence is seen again in Plate 2I, where the ornament, far removed as it is from nature, conveys quite clearly the idea of a nosegay. Forms only remotely resembling flowers are arranged, with due regard to balance, I will not say in imitation, but in recollection, of a bunch of flowers, and lines are found to connect and support them, and give them a sort of artistic coherence. The artificiality of the design is obvious, but it is the artifice of an artist, and a very accomplished one too. It represents a type of ornament suggested by a wealth of flowers, where the stalks and especially the leaves go for very little.

There is a considerable amount of traditional ornament which was founded, no doubt, 
Plate 22.

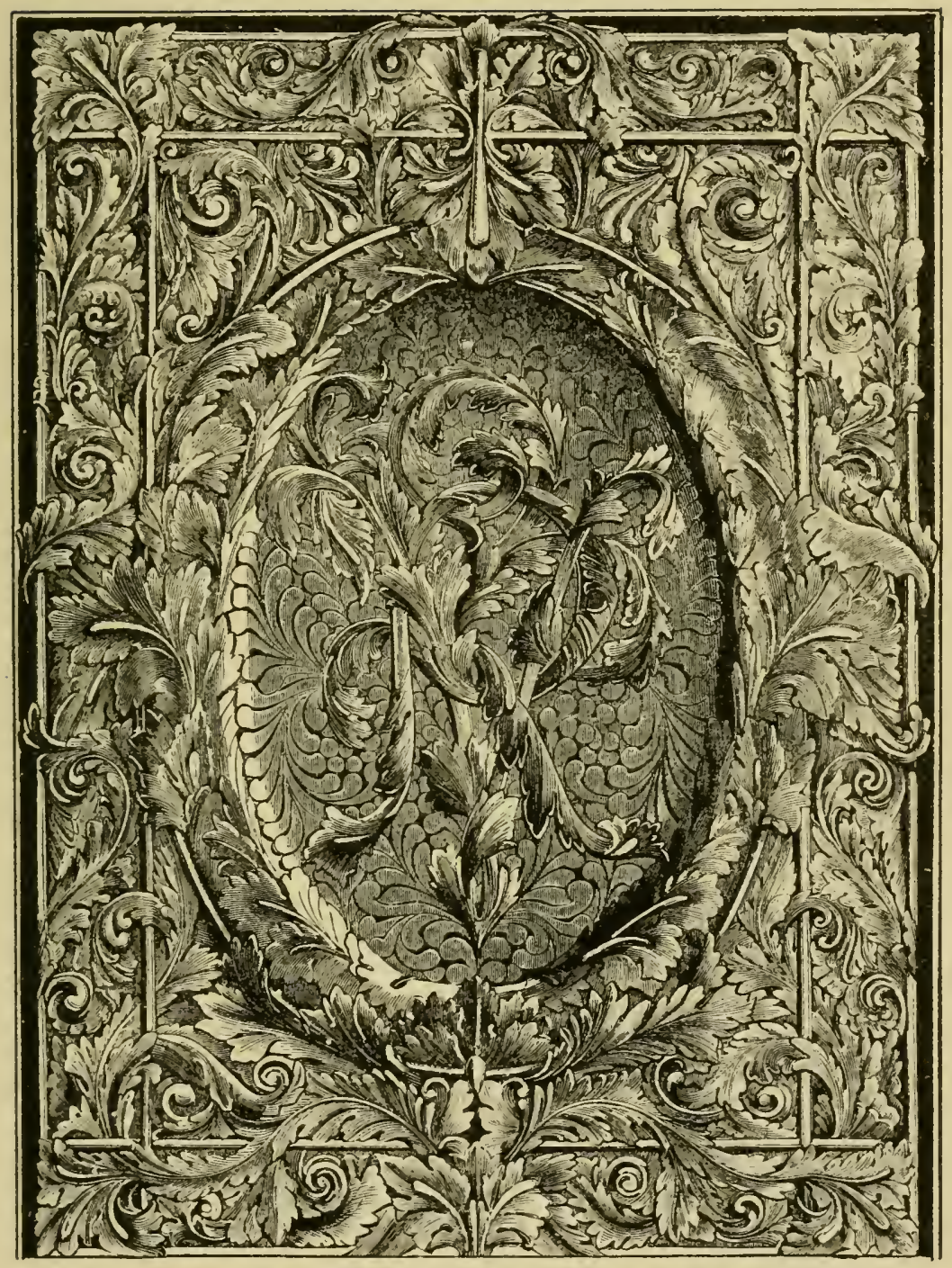

J. Alerman Photo-lith London.

Book Cover by Owen Jones. 



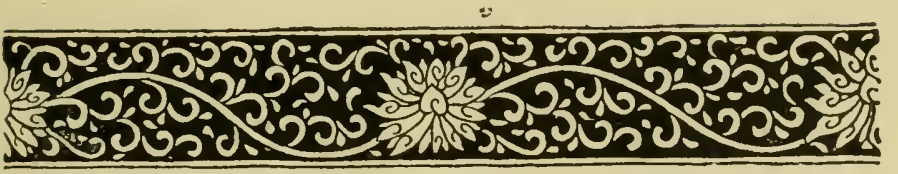

28. Conventional Chinese foliage.

originally upon natural types lost in the mists of long ago; artists have repeated the form so often, and at last so perfunctorily, that in the end it is as difficult to decipher as a man's signature. One has almost to take it on faith that the flowers on p. 50 are asters, peonies, and so on. So with the border above, the flower is, I suppose, an aster, but what goes for leafage belongs to no flower that ever grew.

Even Owen Jones, who laid it down as an axiom that the recurrence to a natural type was by so much a degradation of design, could not do without foliation and growth, more or less according to nature. This is very plainly shown in the typical example of his work on Plate 22. He had the strictest views as to the lines on which ornament should grow, but he insisted that it should grow; and his theory led him in practice to something always more or less suggestive of nature-because the logical way in which he went to work was indeed the way of nature. 


\section{IV.}

THE SIMPLIFICATION OF NATURAL FORMS.

To conventionalise is in some cases scarcely more than to simplify. So plainly is this so that the frequent occurrence of certain floral forms in decorative design is in part at least accounted for by the fact that they could be very considerably simplified without losing their clear identity. The sunflower, for example (Plate 23) came into fashion not entirely because of the whimsical folly of a few so-called æsthetes, but because its handsome and massive head was such an unmistakably ornamental feature. Foliage and flower alike lent themselves to, and indeed almost compelled, a broad and simple treatment; whilst the character of the plant was so well defined, that it was difficult by any kind of rendering or any degree of conventionality of expression to eliminate it. It was never in danger of being reduced to the mere abstraction of a flower, that might have been suggested equally by any one of a dozen different natural types. 
Plate 23. 要,

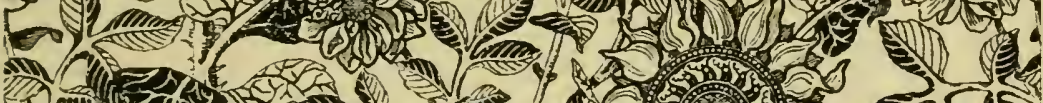

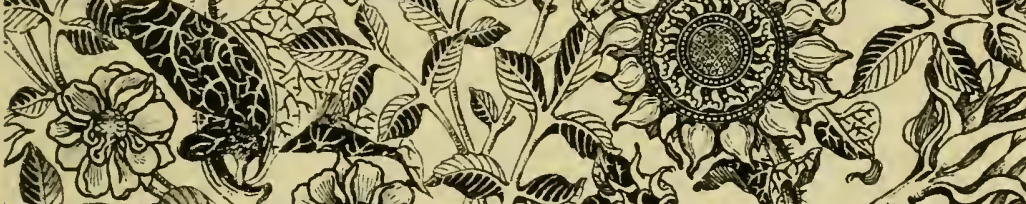
- 105 .

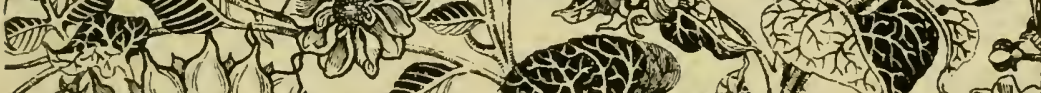

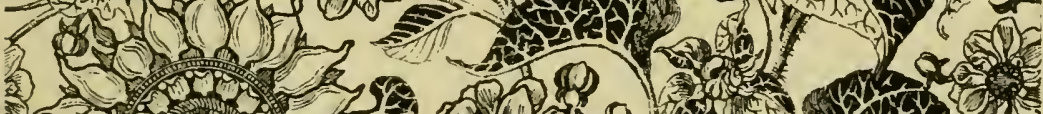

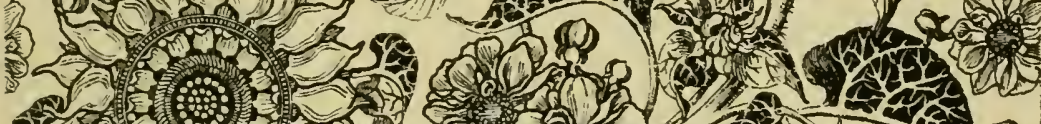
art

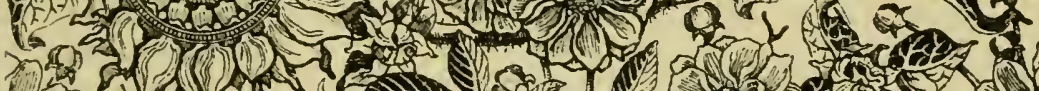
2 2. 140 con (-) Fon N(u Sin

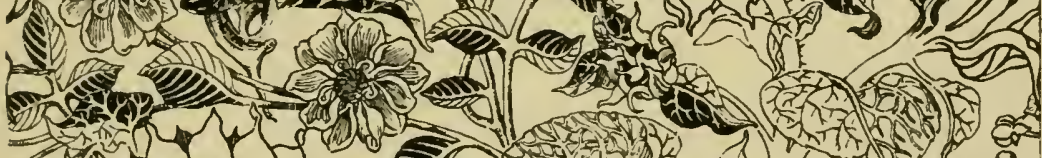

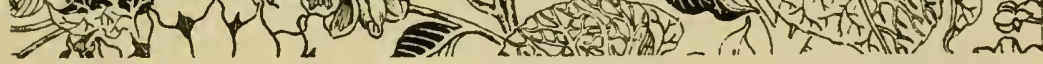

Sunflowers \&e Roses by B. J. Talbert. 

Simplification of Natural Forms. 53
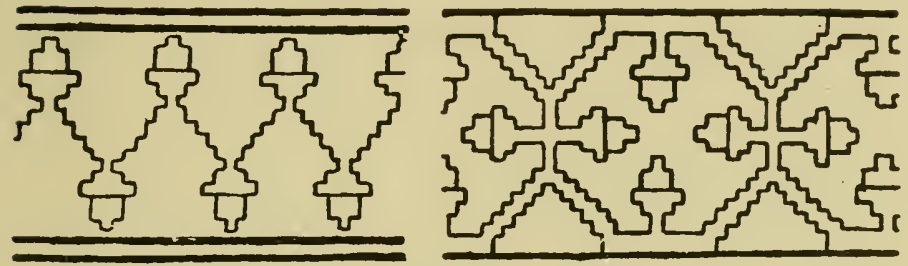

29. Rectangular acorn patterns.

So also the acorn asserts its identity even in the rudimentary form in which it occurs in the old German stitching above.

You may see again in the late George Edmund Street's cleverly contrived panel overleaf how a really characteristic and energetic shape will hold its own. Shorn as it is altogether of its leaves, its prickles, the very featheriness of its flower-heads, there rests not the least doubt that it is a thistle.

Less emphatic forms lose, when simplified, all individual character; and indeed you have only to carry such simplification far enough, to reduce the greater part of natural forms to one level-I might say perhaps one dead level-of convention.

It is remarkable how slight a modification will remove a flower from recognition. An alteration of scale is sometimes enough to puzzle us. To magnify a flower is in most cases to disguise its identity. Draw the pimpernel the size of a flax blossom, or the flax blossom the size of a mallow, and who 
is to recognise it, especially when the subtler characteristics of texture and the individual turn of the petals are conventionalised away? One can never be quite certain that any conventional five-petalled flower, such as the German Gothic rosette on p. 55 for example, is not meant for a rose.

Even in the case of more characteristic blossoms, like the speedwell, with its petals three and one, we are put off the scent at first by unaccustomed proportions in the flower.

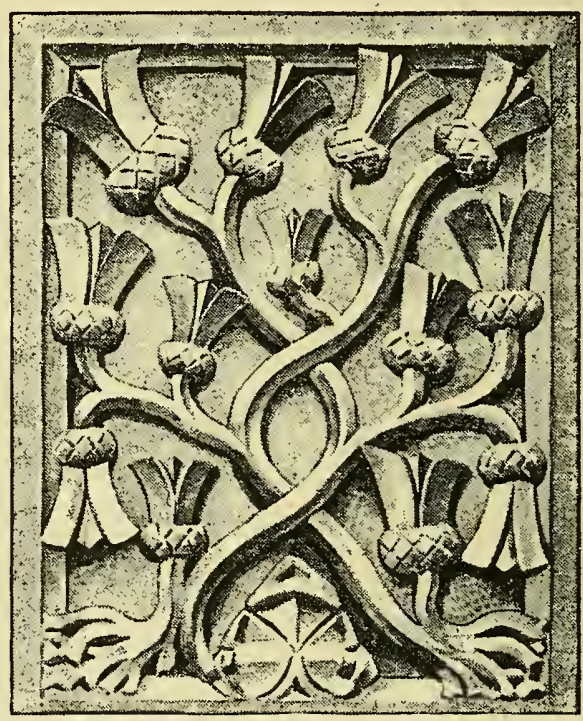

3o. Simplified thistle. G. E. Street, R.A.

And so with leaves. Failing anything like strict accuracy as to their growth-very rarely indeed observed in ornament-it is more than difficult to distinguish between one lanceolate leaf and another: the same shape may stand just as well for willow as for bay or olive. The heart-shaped leaves in the 


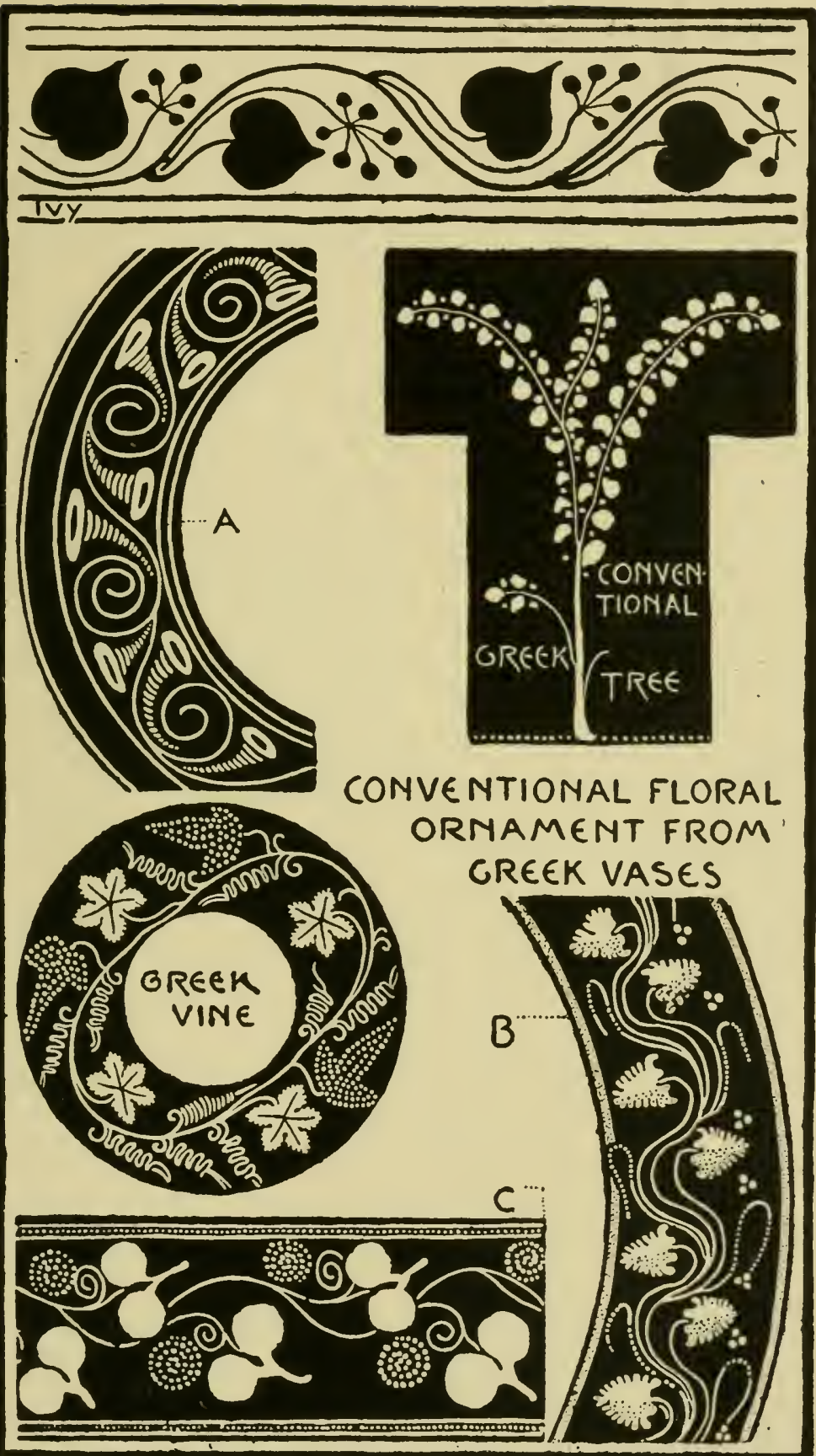

Detarls of Greek Terra Coita painting 

Simplification of Natural Forms. 55

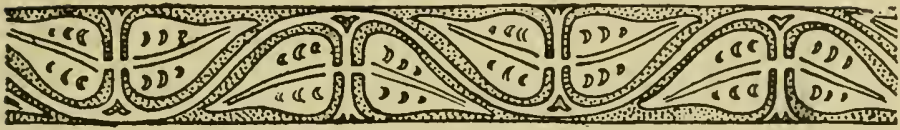

3x. Gothic leaf border-wood carving.

border above may indicate the poplar or the lilac: possibly the carver had in his mind no leaf in particular.

It cannot be said that the danger of mis-

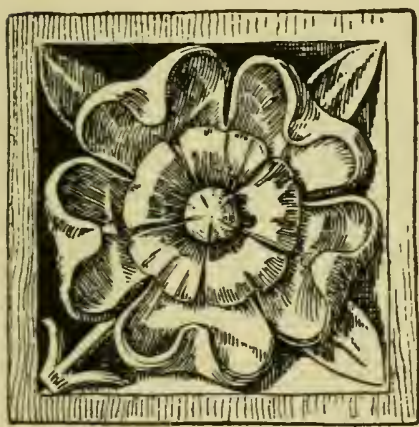

32. Rosette or rose? take in the identity of natural forms has deterred the designer from simplifying them. We find in every period of art floral or foliated forms which may be meant for this or that, but which it is quite impossible to identify with any degree of certainty. The Gothic border below may stand for a rose, for all we know ; the Greek border A on Plate 24 may stand for a convolvulus; and B, I feel pretty certain, consists of birch-leaves and catkins. The strange leaf in border $\mathrm{C}$ on the same plate used to puzzle me until I discovered

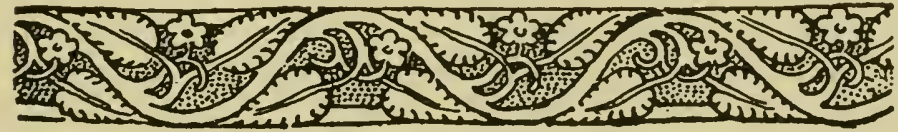

33. Gothic leaf and flower border-wood carving. 


\section{${ }_{5} 6 \quad$ Nature in Ornament.}

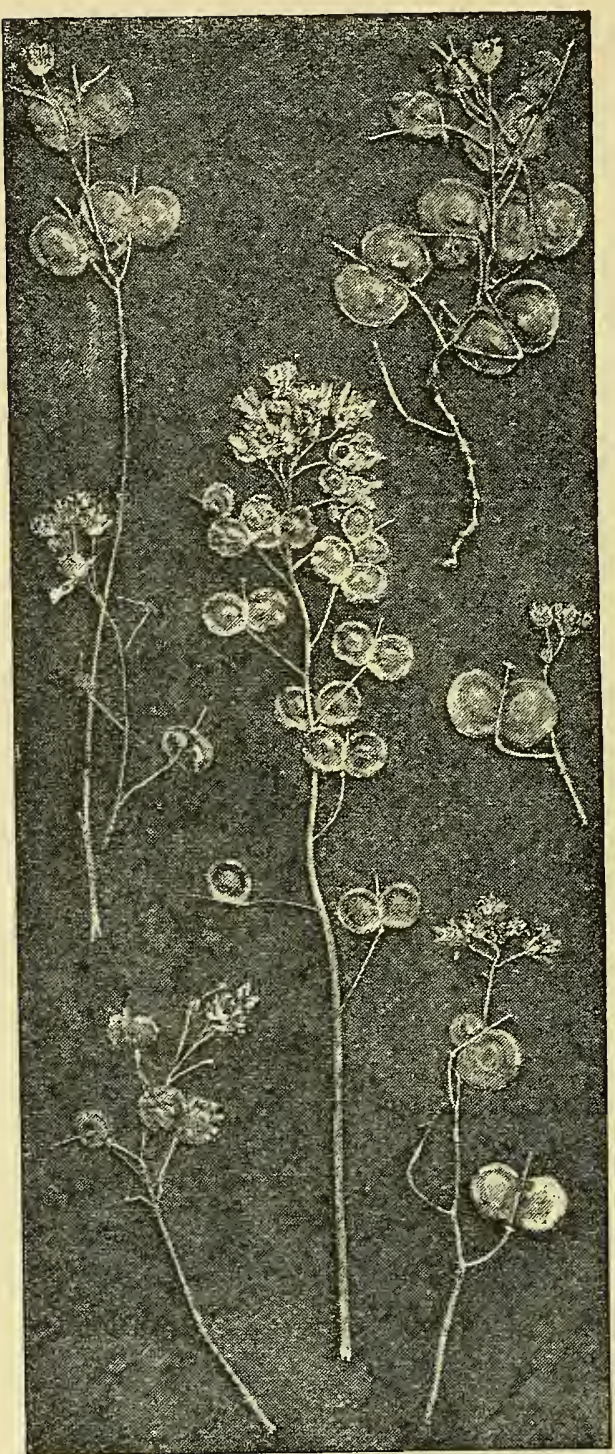

34. Seed-vessels from nature.

its source in nature. It proves, as you will see at a glance on this page, to be no leaf, but a seedvessel : soften the angularity of the stem, pulled out of the straight by the pods, and you have the startingpoint of the Greek design. There is sometimes in this Greek pattern an indication of the way the seed - vessels split asunder and shed the seeds. The identification of this peculiar two-lobed feature 


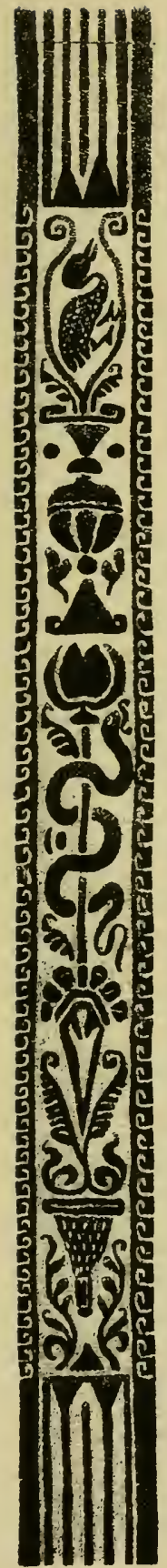

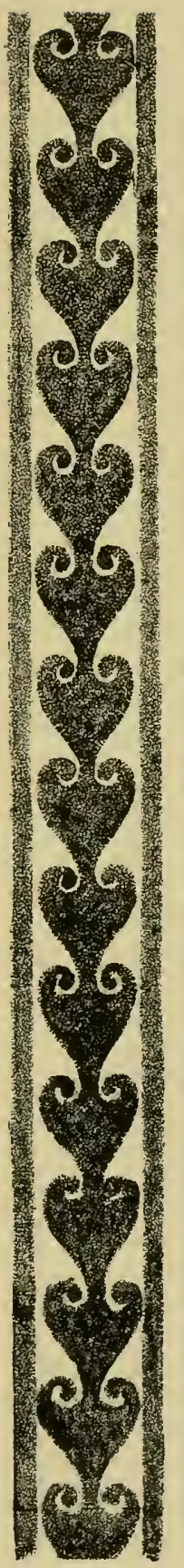

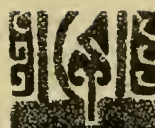
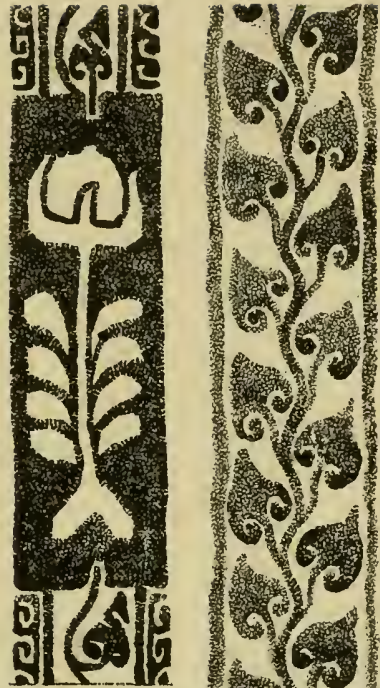

筑
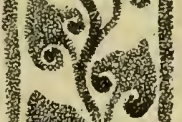

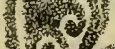

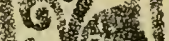
装
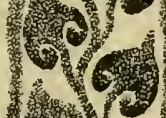

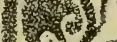

倠

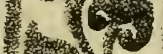

단.
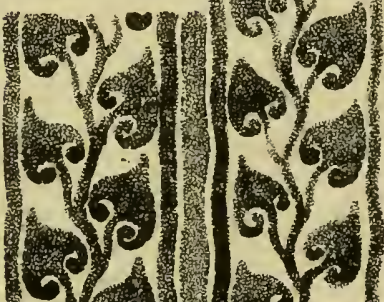

16)
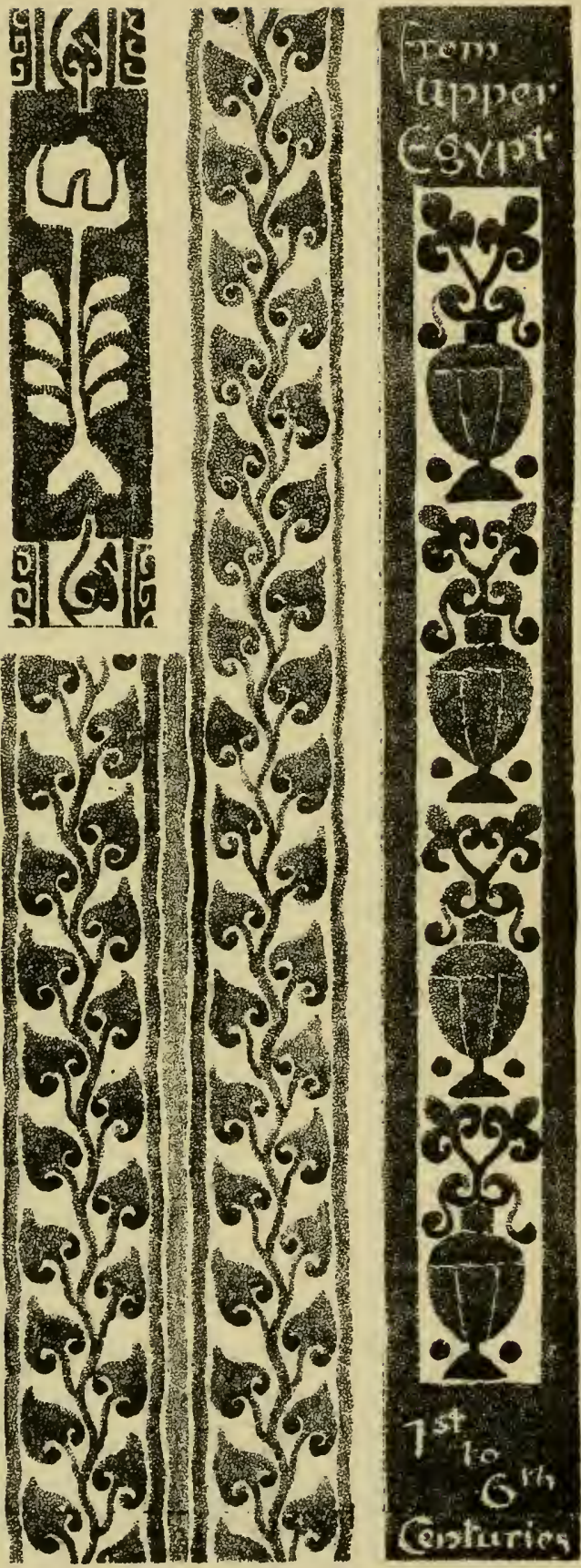

"Pнате-Tint", by Jumcs Akermen landon Wi C

Details of Ancrent Coptic Eimuroideries 

Simplification of Natural Forms. 57

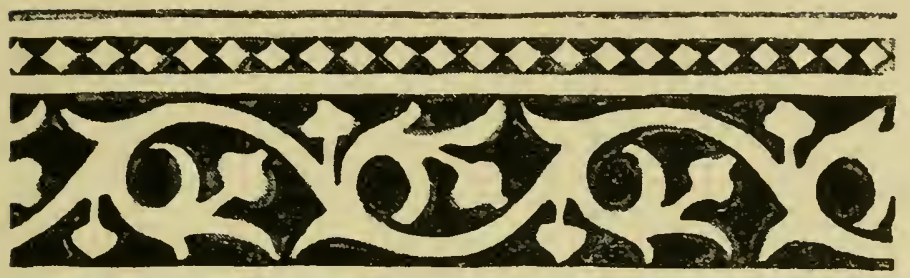

35. Conventional buds, or seed-vessels ?-marble inlay.

was all the more difficult, because you see in other Greek vases something like the same shape doing obvious duty for a leaf.

The conventional tree, on the same plate, is quite impossible to name; the ivy in the border above it, on the other hand, is for once very clearly indicated; the berries, in particular, are very characteristically given. Compare them with the more usual Greek ivy-berries below.

Again, in the Coptic embroideries on

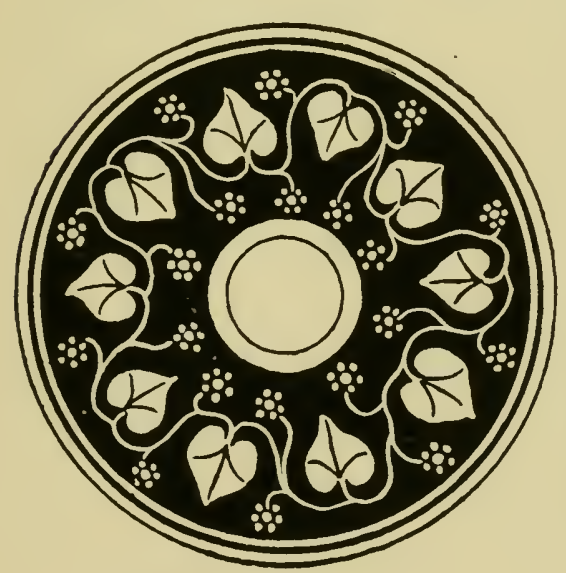

Plate 25, we have heart - shaped leaves and trefoils and fruit and flower, all alike symbolic no doubt, but without any meaning in particular to us.

In the Floren36. Conventional Greek ivyleaves and berries. tinc border above, 
as in the Japanese border here given, we can please ourselves as to whether they are buds or seed-vessels that are represented.

Again, the Sicilian tree, below, may stand for anything with a serrated leaf. Simplicity could not much further go than in the Roman version of a tree on p. 59. In the Indian

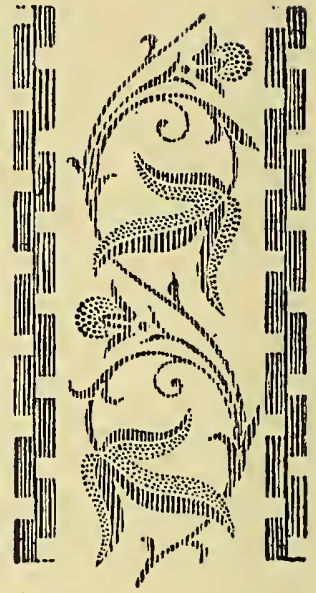

37. Japanese borderbuds or fruits? kinkaub pattern, on Plate 26 , the character of the flowers and leaves, no less than the growth of the plant, are part and parcel

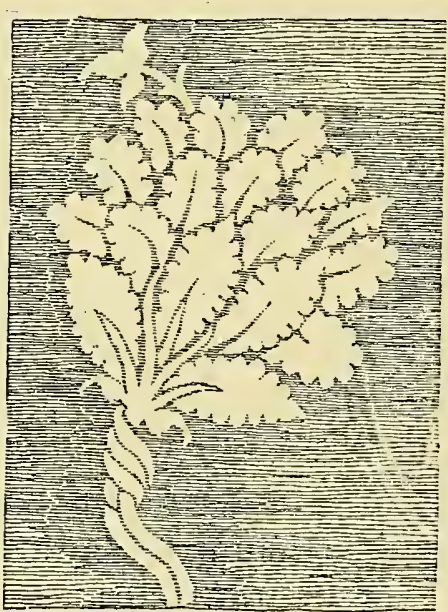

38. Conventional tree, frum a Sicilian silk. of the process of weaving employed; there is a distinct reminiscence of some plant with large foot-leaves and small stalkleaves, but it would be rash to say more than that.

The Pompeian details on Plate 27 betray more or 
Plate 26.

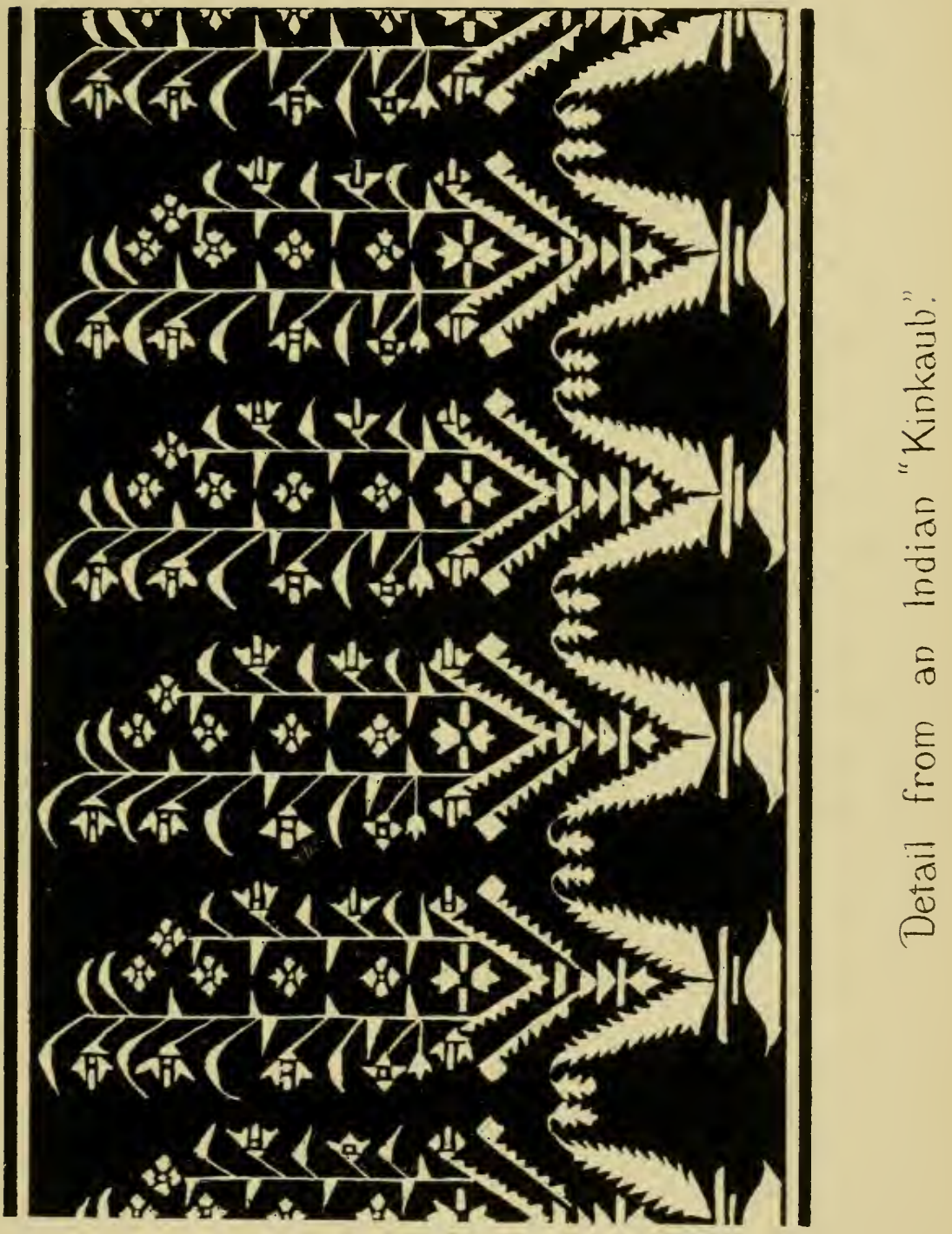



Simplification of Natural Forms. 59

less a natural source of inspiration, but with the exception of a tendril and something like a passion flower, there is not much in the mosaic that one can identify; whilst in the painted panel the various details are so remote from lily or campanula, or whatever may have been their starting points, that one accepts even the arbitrary way in which they are put together. Compare this Pompeian panel

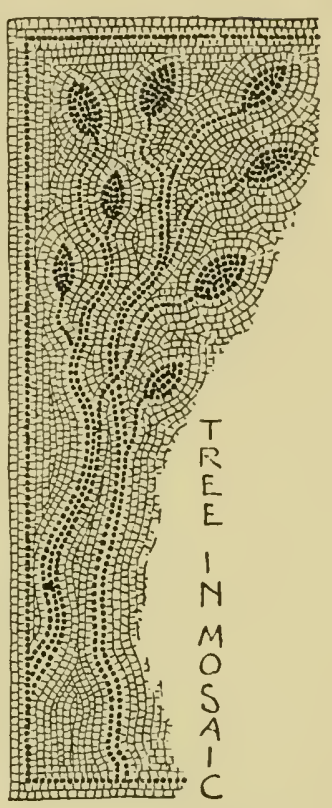

39. Simple Roman tree. with the Roman candelabrum on p. I33.

Again, in the carved door from Cairo, Plate 28, the details of the flowers are reduced to something 40. Hawthorn crocket. very nearly approaching to chipcarving; the details consist not so much of leaves and flowers as of cuts of the chisel, an effect all the more satisfactory inasmuch as the types, as far as one can make 4r. Vine crocket. them out, are rather mixed. Even 
so, by the way, they are exceptionally natural for Arab work.

In Gothic art, as elsewhere, we identify a plant in many instances only because we expect to find it there. Whatever can by any stretch of imagination pass for a vine-leaf (Plate 29) we accept as such-any bunch of berries we take for grapes.

In very many cases it is only by the flower

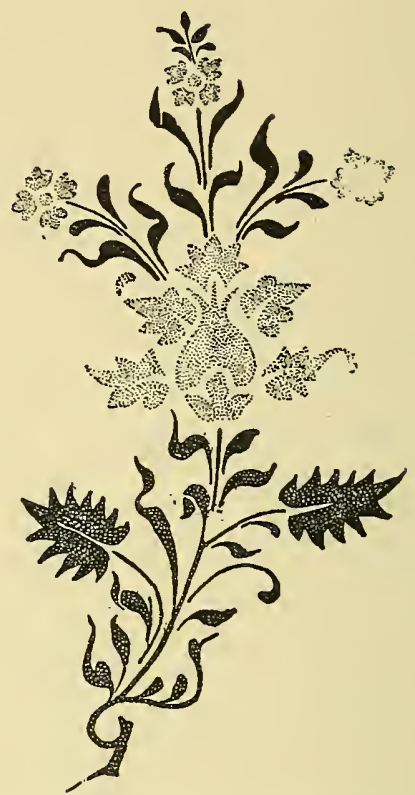

42. Late Gothic pomegranate.

or fruit that the definite relation of the leaf to nature is recognised. The crockets on the plate referred to are more like crockets than leaves; it is only by the berries and the winged seeds that one knows them to do duty for hawthorn and maple. One guesses that one of the crockets on p. 59 may also be a hawthorn leaf. It is only the tendril which gives us to suppose that the other is a vine. And so with the foliage from Henry the VII.'s Chapel on Plate 29. But for the acorn cups, no one would ever have suspected the carver of having 
Plate 27.

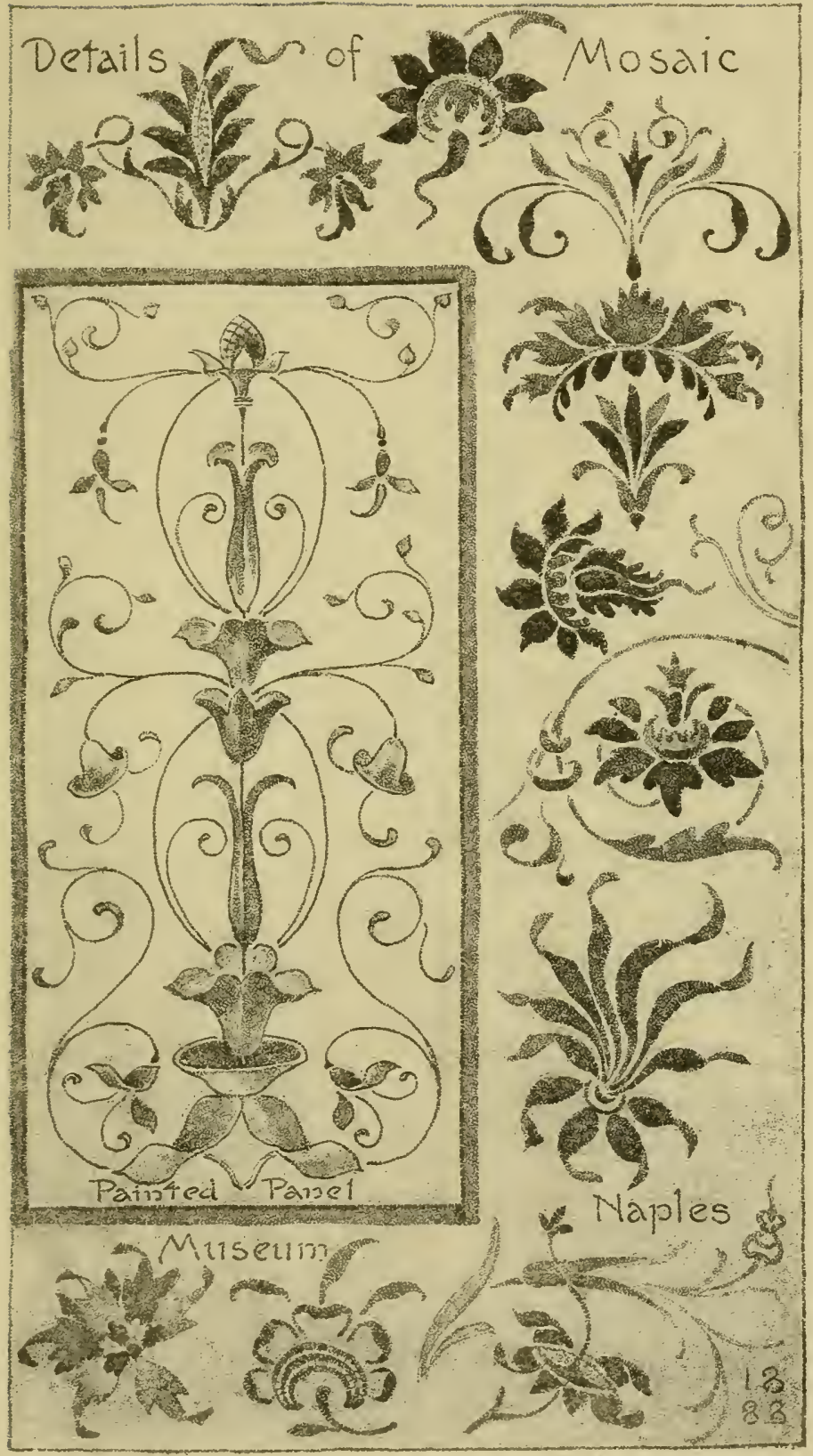

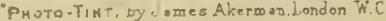

Details from Pompeii. 

Simplification of Natural Forms. 6I

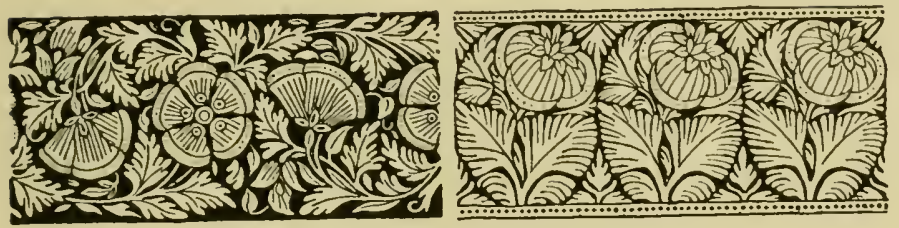

43, 44. Indian renderings of the poppy.

had any thought of oak-leaves; and with regard to the sprig of painted decoration on p. 60 , we make up our minds that it stands for the pomegranate only because it comes nearer to that than to any other symbolic fruit.

It is all the more difficult, sometimes, to identify the plant which is meant, because one can never be sure of the knowledge, or of the conscientiousness, of the artist. The two damascened patterns above presumably represent the poppy, but, in the one case at least, the artist has supplied the flower with five petals and a calyx-details which, if one had perfect faith in the artist, would completely put one off the scent.

One is puzzled also by the wiry shoots between the lily-

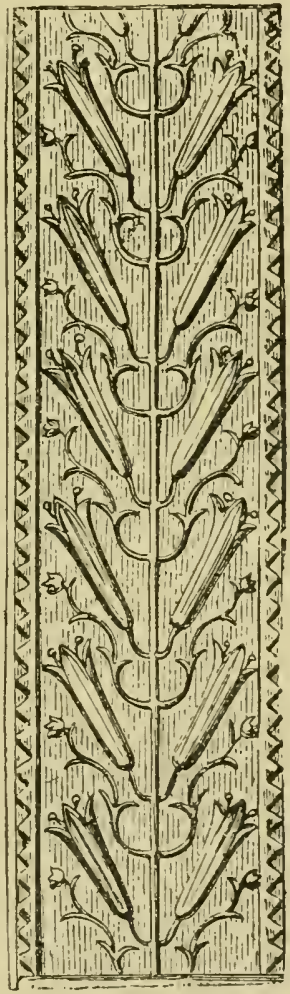

45. Greek border, with lily-buds. 


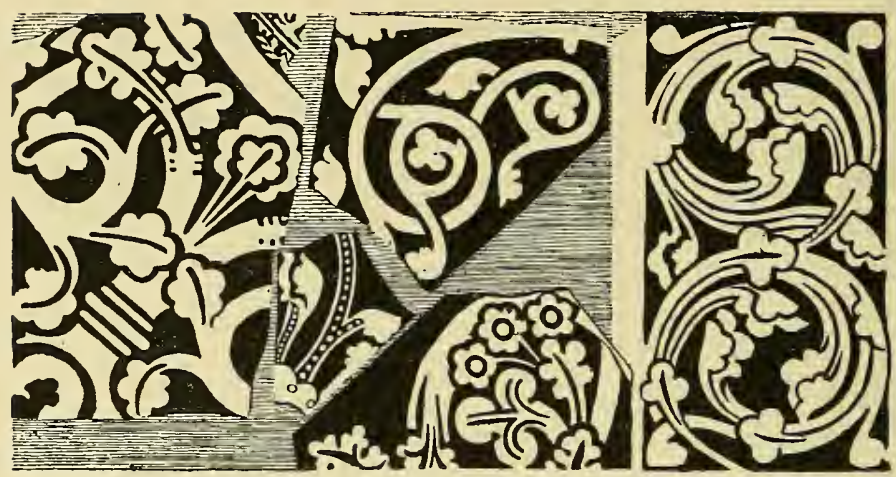

46. Early Gothic foliated ornament.

like flowers in the admirably severe Greek border on p. 6I, and wonders as to the source of its inspiration-the Solomon's seal perhaps?

Any trefoil or cinquefoil may have influenced, in its turn, the shape of early Gothic foliage, such as that above, which is founded, as we know, directly upon no natural type at all, but is a recollection of a recollection of a recollection going centuries back. It grew out of Byzantine or Romanesque forms, themselves derived from Classic foliage; and it was only when the sculptor had arrived, through symbolism, at something reminding him of clover, or wood sorrel, or hepatica, that he began to think of making it more nearly like nature.

It is clear that the carver of the detail on p. 63 , had in his mind some natural leaf; what that leaf is, is not so certain. One of 


\section{Plate 28}

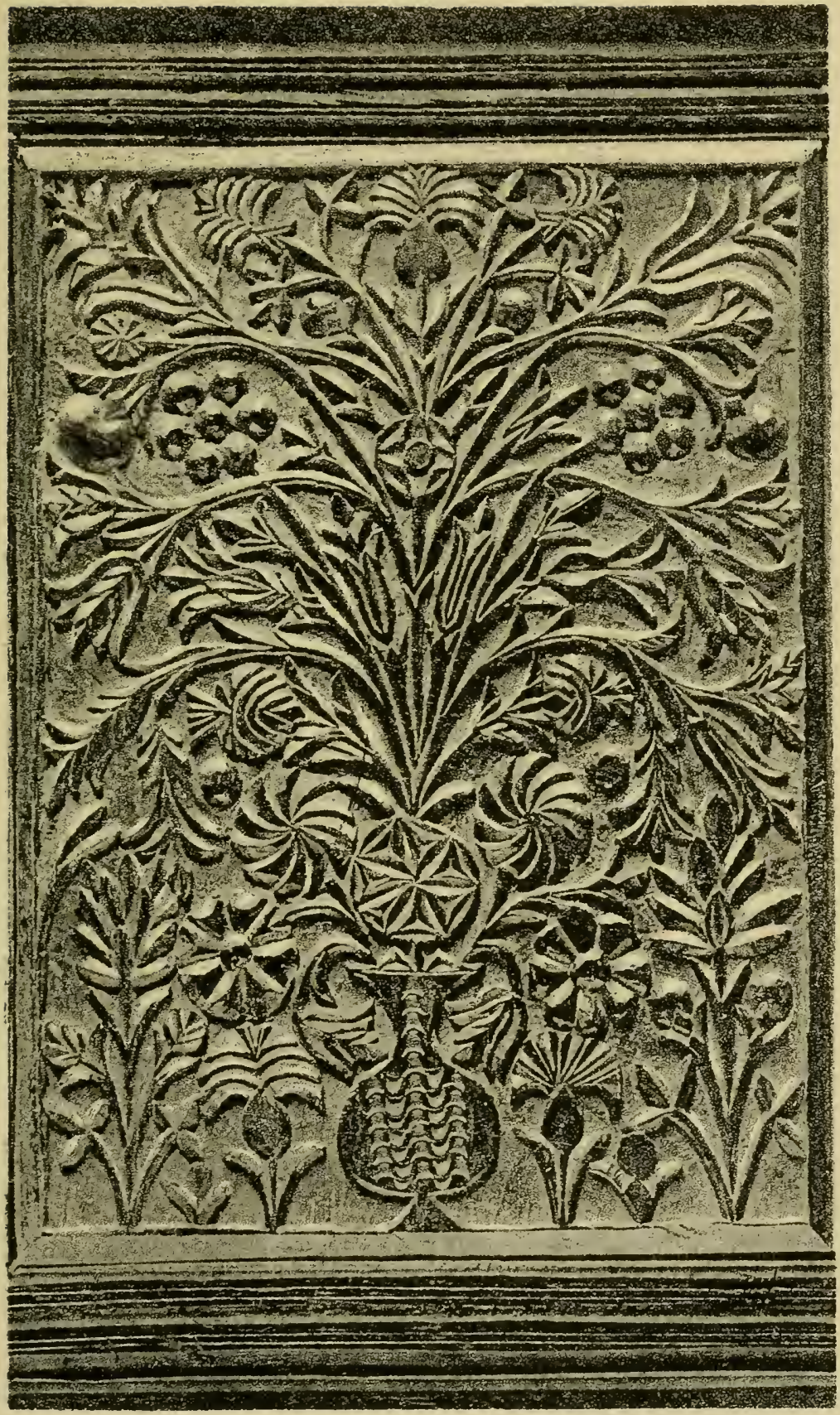



Simplification of Natural Forms. 63

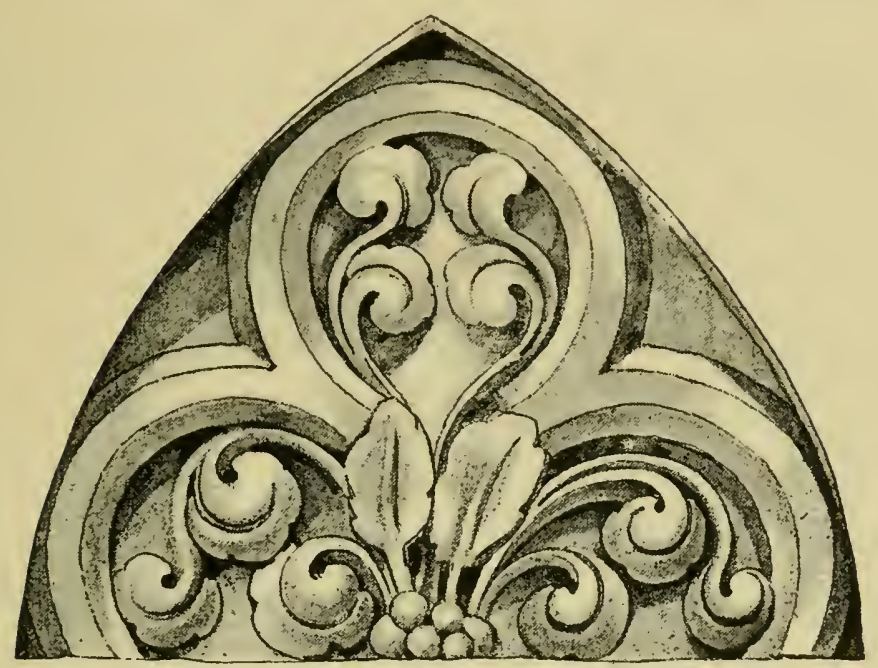

47. Natural and ornamental foliage-Early French.

the charms of Early Gothic is that, conventional as it is, and in the main of one type, there is always a chance of our coming upon some touch of nature which brings the workman nearer to us. You can see sometimes, in Early French Gothic, how the detail was

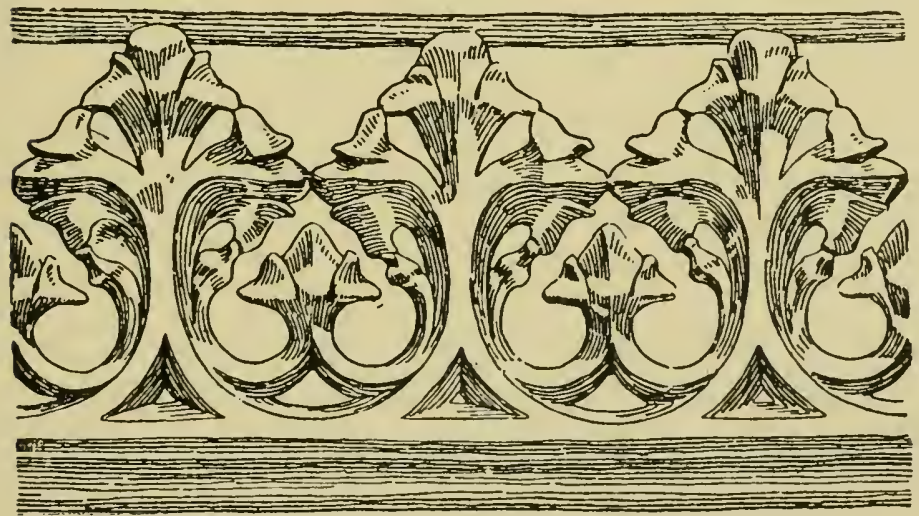

48. Bud-like ornamental forms. 


\section{$64 \quad$ Nature in Ornament.}

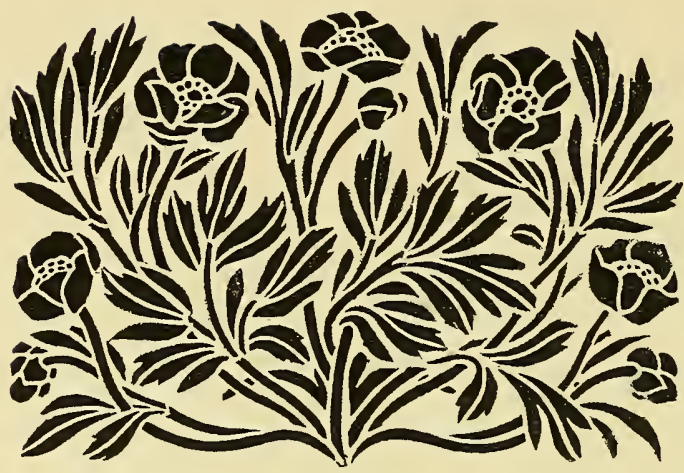

:49. Peony simplified to form a stencil-H. Sumner.

inspired, as Viollet le Duc points out, by the fronds of the bracken and other plants; but the sculptor leaves out so much, that it is not always easy, even with the assistance of Viollet le Duc, to detect the natural type. Whether of set purpose or by instinct, too, the sculptor chose persistently the simplest floral forms, which lent themselves to breadth and dignity of treatment. It is not surprising that, magnified in stone, they should appear to us abstractions.

In many instances, it is tolerably clear that no leaf was intended, but only foliation, no particular plant, but growth. And it is marvellous how the early Mediæval sculptor contrived to convey that idea of vitality in the stone. In the crockets so peculiarly characteristic of early French Gothic, for example, he imitated no particular bud, but the stone itself seems budding into life. A later Gothic instance of that bud-like ornament in wood is given on p. 63 . 


\section{Plate 29}

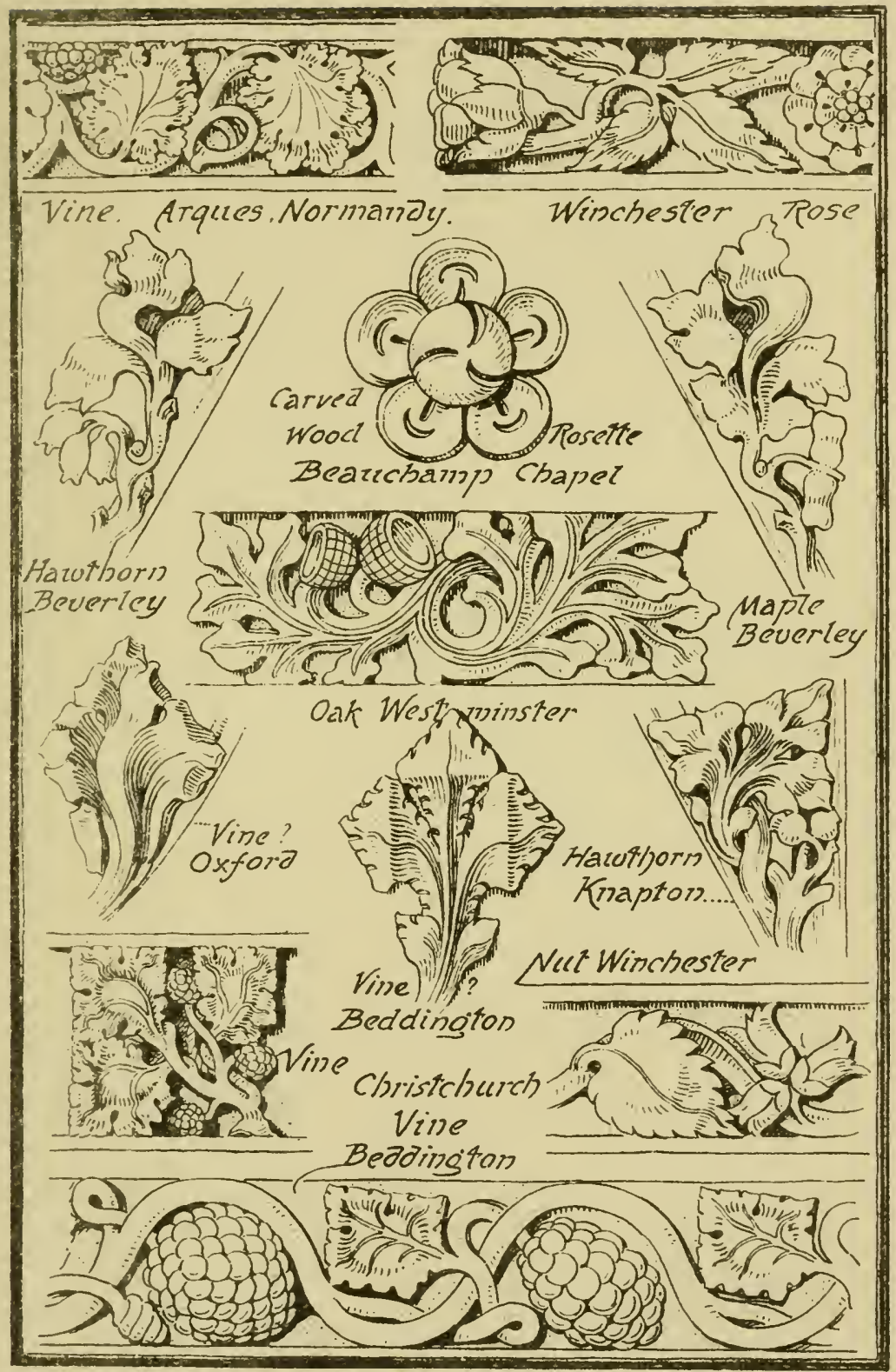

J Akerman, Floo:o-lith Londoc

Enolish Gothic Details 

Simplification of Natural Forms. 65

How far the primitive Gothic sculptor could, if he had been so minded, have rendered nature in the coarse stone in which he worked, is doubtful ; happily he seized that in nature which he could express, and expressed it like an artist. It is of the very quality of an ornamentist, that he should be

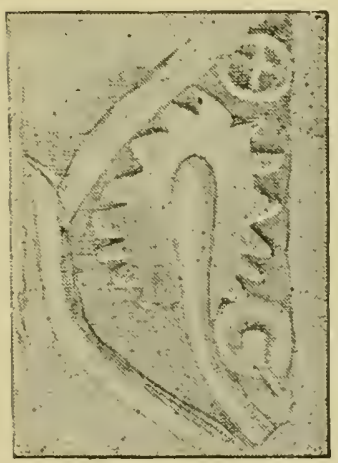

willing to omit much that he could have put into his work had it been to the purpose. In the peony pattern on p. 64 Mr. Sumner has had the courage to leave out whatever could not conveniently be rendered in stencilling.

It is curious how dif52. Greek that might be Gothic. 
S.

ferent artists, working at different times in different countries, have arrived sometimes at results not so very different. There seems to me a curious correspondence between the detail of the Indian scroll and the late Gothic rosette on p. 65, the result, presumably, in each 53. Persian that might be Gothic. case, of a sympathetic use of the tools the carver had.

So, again, the fragment of archaic-Greek sculpture on the same page is so like certain rude stone carving of the Gothic period that one would have taken it almost for Mediæval work. That bulging midrib is characteristic of a certain form of Perpendicular carving, derived no doubt from beaten metalwork. Did Greek and Gothic workman alike refer for inspiration to goldsmiths' work, and so arrive at something like the same form?

Once more in the Persian details above,

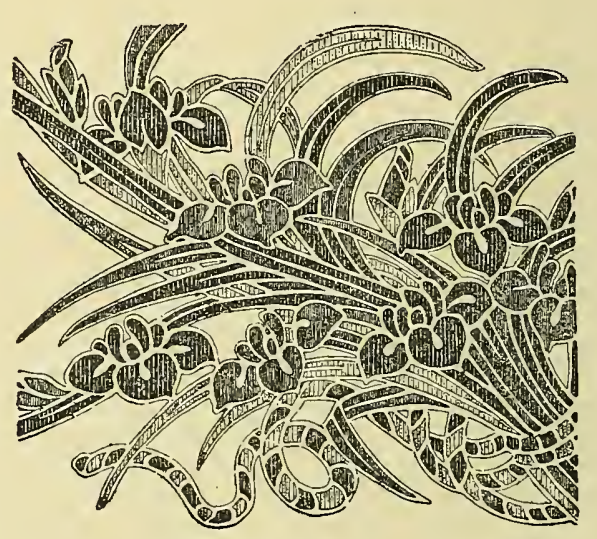

54. Japanese treatment of the iris. 


\section{(1)ate 30}

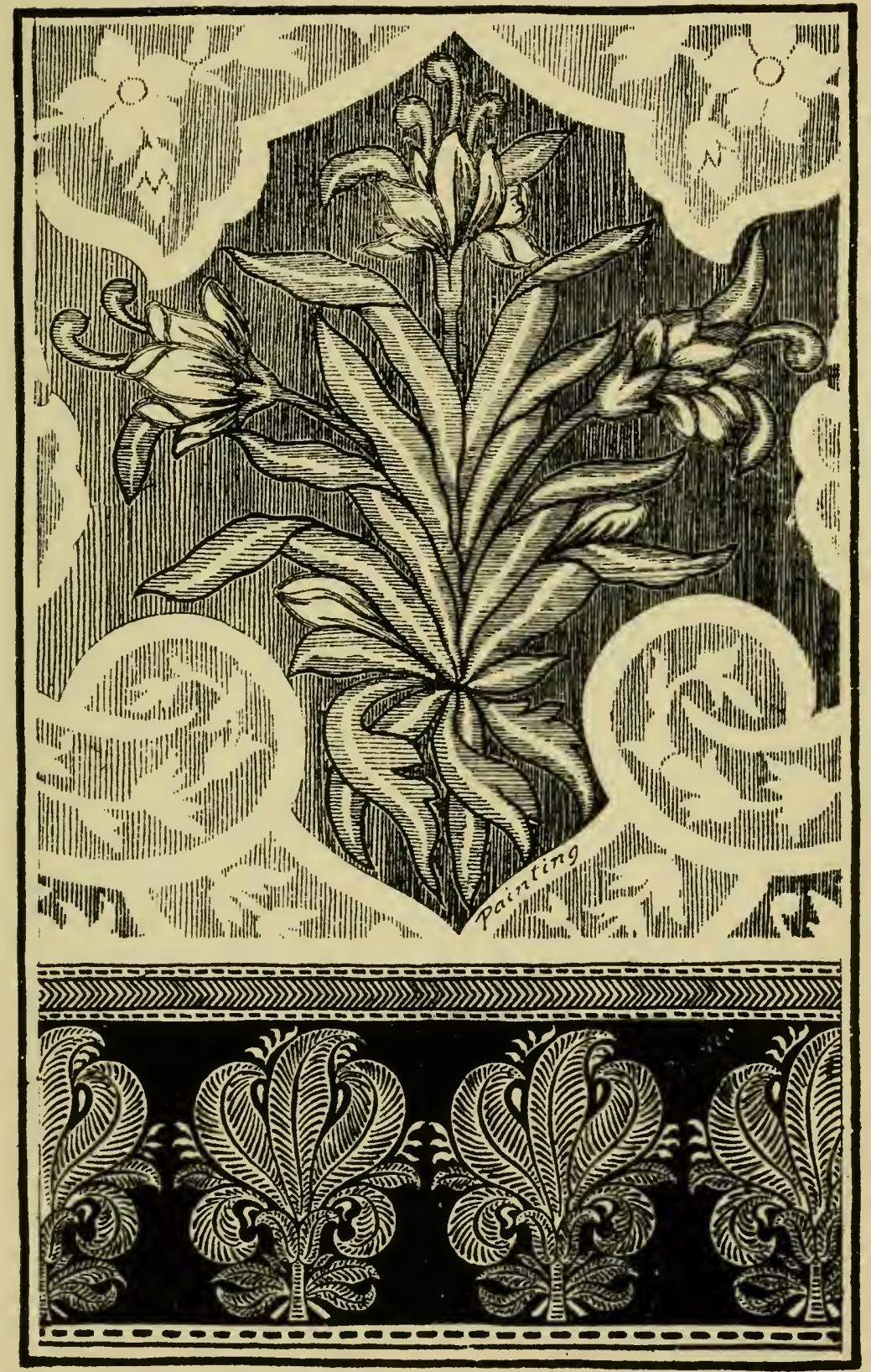

Indian renderings of the Iris. 

Simplification of Natural Forms. 67

there is a most marked resemblance to certain Decorated Gothic crocket forms-especially as they are rendered in stained glass-the play of the brush accounting no doubt partly for the likeness.

At other times one is struck by the variety in the sundry simplified versions of the same plant. There is a wide difference between the painted iris and that in niello, on Plate 30 ; and between these Indian renderings, again, and the characteristic adaptation of the plant in the Japanese embroidery on p. 66, in which nature is reduced to extreme simplicity without any loss of character.

Again, in the panels on Plate 3I, modification consists mainly in simplifying the natural forms. The leaves, indeed, are elongated and refined, and, like the flowers, arranged to suit the ornamental scheme. But the liberties taken with the growth of crownimperial, fritillary, bluebell, and Lent lily, are such as would not greatly shock the botanist. The lines on which they grow are (organically) not altogether impossible.

At times the simplification resolves itself into something very different indeed from the actual thing, as in the Italian silk overleaf, in which the ears of corn take the form of a distinct pattern; from which we may 
68

apprehend how easily, from the simplification of natural form, the ornamentist glided imperceptibly into its elaboration. But that will form the subject of a separate chapter.

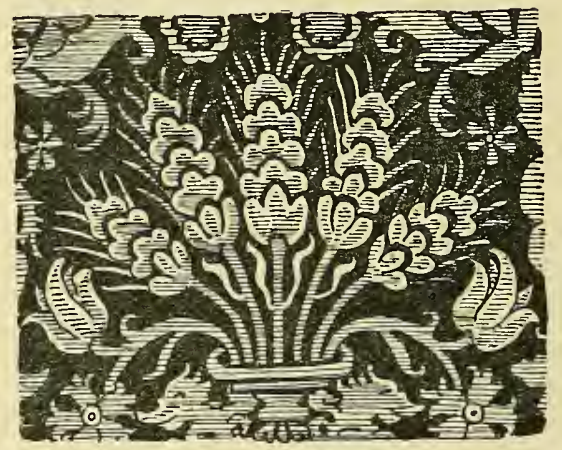

55. Wheat-ears, simplified or elaborated ? 
Tlate 31.
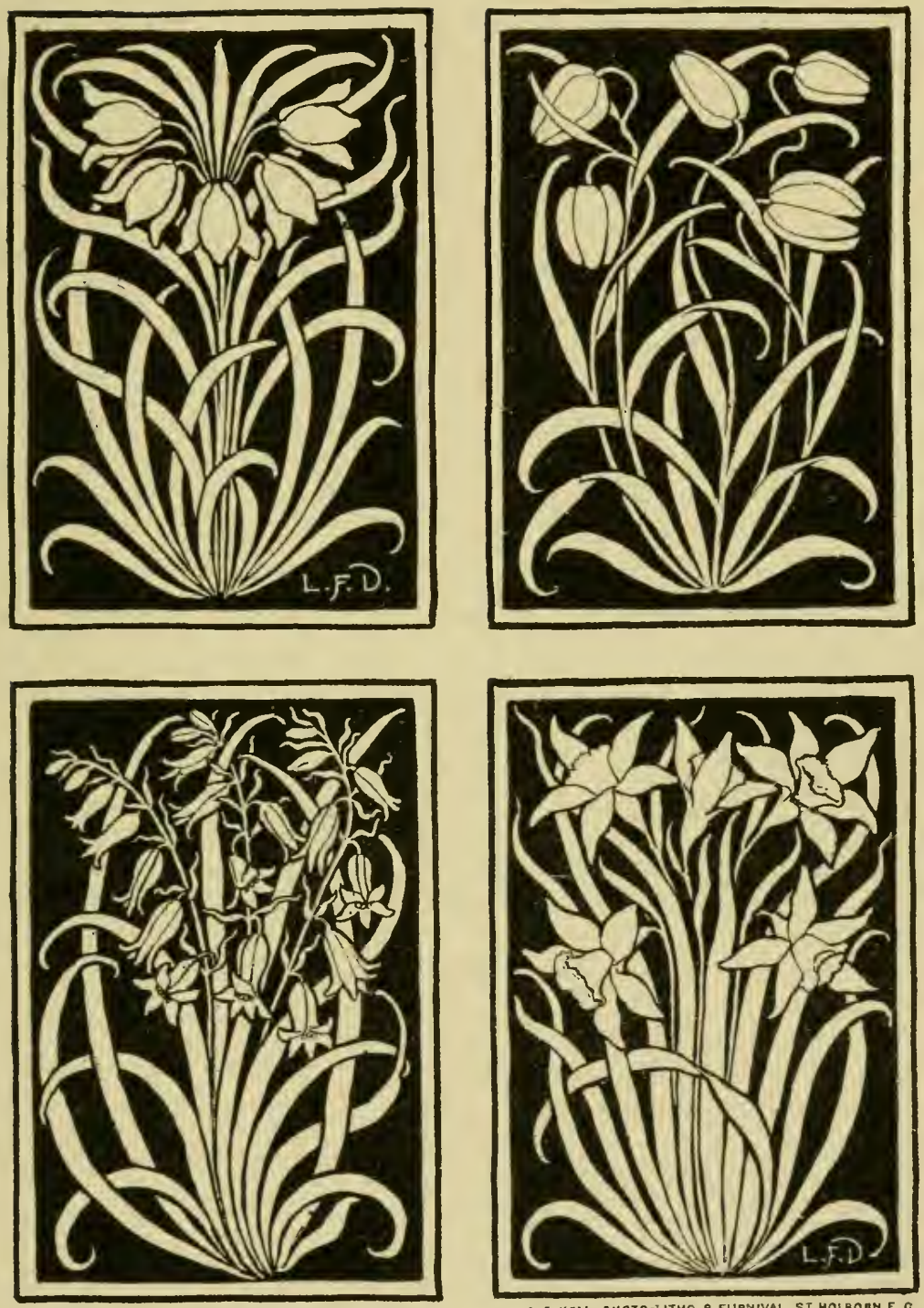

Inlaid flower Panels. 

THE ELABORATION OF NATURAL FORMS.

IT has been shown in a preceding chapter, how the necessity of simplifying natural forms led as a matter of course to conventional treatment. It will be seen presently, that there is sometimes sufficient technical reason for the elaboration of the type before us.

The omission of the superfluous in ornament is indisputably right. How far it may be desirable or permissible to elaborate the simple forms of nature, is more open to question. It rather suggests to us painting the lily or gilding gold. There is a strong flavour of artificiality about it.

As a matter of fact, the practice flourished, though indeed it existed long before, in artificial times, that is to say during the seventeenth and eighteenth centuries. It would be scarcely fair, however, to take everything of the kind as an indication of decadence. We are bound in justice, no less than in reason, to inquire if such elaboration may not have 
led to some satisfactory results, and what those results were.

It may possibly prove that what was best in the later French styles, for example, was more or less of the artificially elaborate type. The rockwork and the broken scrolls, the garlands and the trellises, the bows and ribbons, and all such frivolities of the later French monarchy, have much less to recommend them than the patterns of the silks of the period. Restraint was out of the question. Licence was the order of the day, and kings' mistresses reigned over art. Granting, however, the absence of restraint in design, more objectionable to us than in French eyes, there is in the Lyons silks of the seventeenth and eighteenth centuries not only considerable beauty of colour, but quite exceptional ingenuity of design, especially in its relation to the technique of weaving; and it will be time well spent to seek out the method, artificial though it may be, by which results so beautiful are arrived at.

The effect may be so far from nature as to be quite characteristically artificial, and yet it may turn out that almost every detail in the design is directly borrowed from reality. One might say, for instance, that in Plate 32 natural forms are removed from nature mainly 


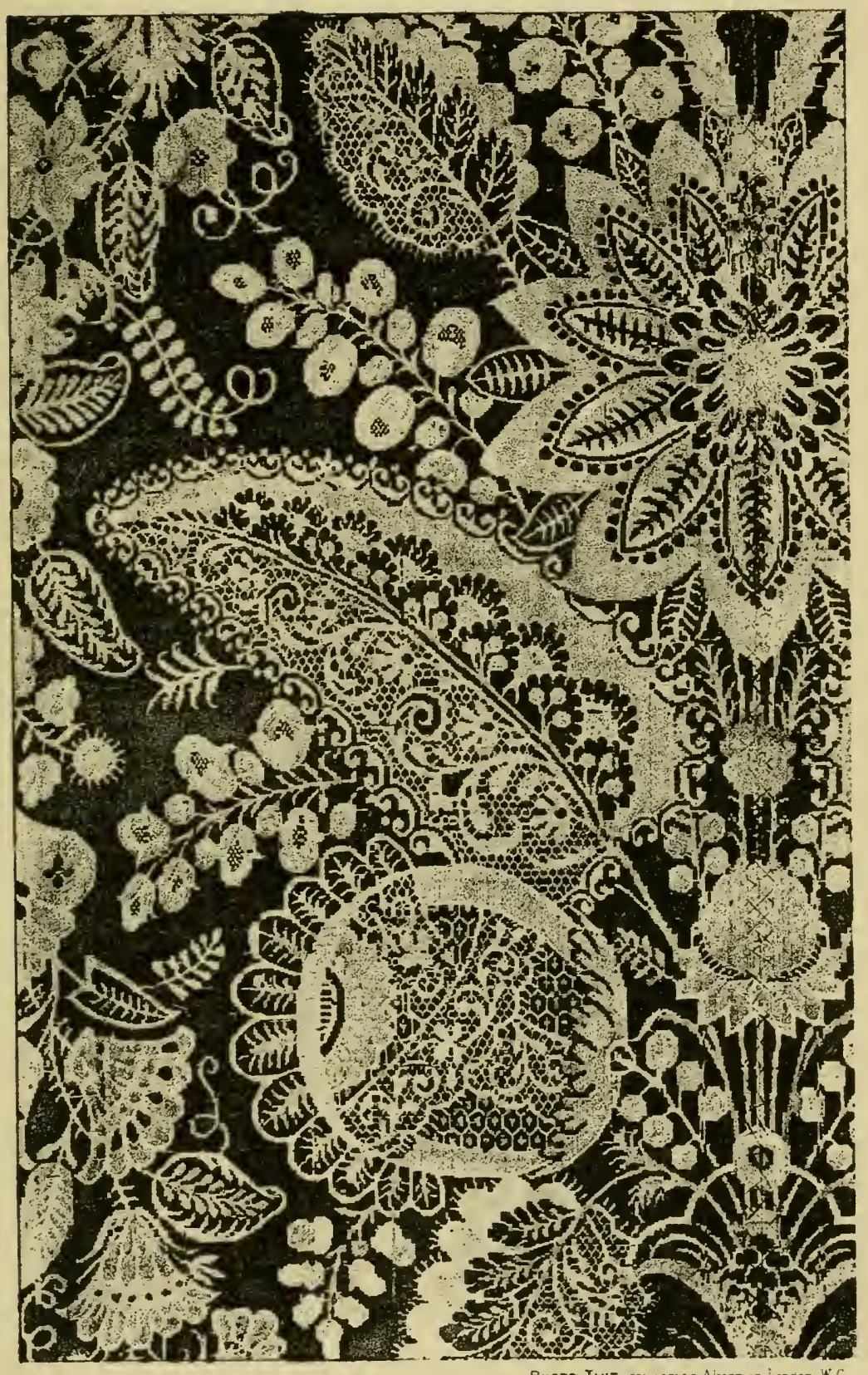

Lyons Silk of the $17^{\text {th }}$. or $18^{\text {th }}$. Cen ${ }^{\text {ty }}$. 



\section{The Elaboration of Natural Forms. 7 I}

by diapering them over with other details borrowed from the same source. And this was quite the current way of design. Men adopted forms more or less natural, probably because such forms occurred most readily to them. But the natural veining of leaves and petals did not present sufficient variety and interest of surface for their purpose; and so they supplied its place by a subsidiary growth of smaller foliage. By the judicious alternation of light on dark and dark on light, they even went so far as to produce an effect equivalent to-not at all resembling, but equivalent to-that of shading. Something of the same kind is seen again on Plate 33, where a sort of shading resolves itself into fresh forms of ornament. Those leaves are characteristically of the eighteenth century.

This is a device at all events much more appropriate to silk weaving than the futile attempts at natural shading which have also had their vogue. Besides, in the rendering of the details themselves-observe the ornamental serration of the large leaf on Plate 32, the cresting of the fruit, its calyx, the diapering of the forms generally, and the rendering of the smaller foliage-there is such consistent artificiality throughout as to give a distinctly ornamental character to the design. 
If the artists of the artificial periods were not always tasteful or intelligent, all the more opportunity for us to show how, by the exercise of intelligence and taste, it may be possible to turn their expedients to new and better account.

It was not they, however, who first hit upon the expedient. A simpler, bolder, and altogether nobler example of the same kind of thing is shown on Plate 34, an Italian damask of distinctly earlier date. Such a design loses very much by reduction to the scale of the illustration, and it depends also very much for its effect on its fitness to the simpler kind of weaving; but on the scale of the original, in single-colour damask, it is simply perfect for breadth and richness-a model of appropriate treatment. That is at all events one way of proceeding, namely, to design big, bold masses of foliage, and to break these again with smaller foliated detail.

That this should be done consistently would hardly need to be pointed out, were it not that in old work consistency has so frequently been lost sight of. There is no defending flowers and fruits which agree neither with one another nor with the leaves in association with them; but if the pattern be but 
Plate 33

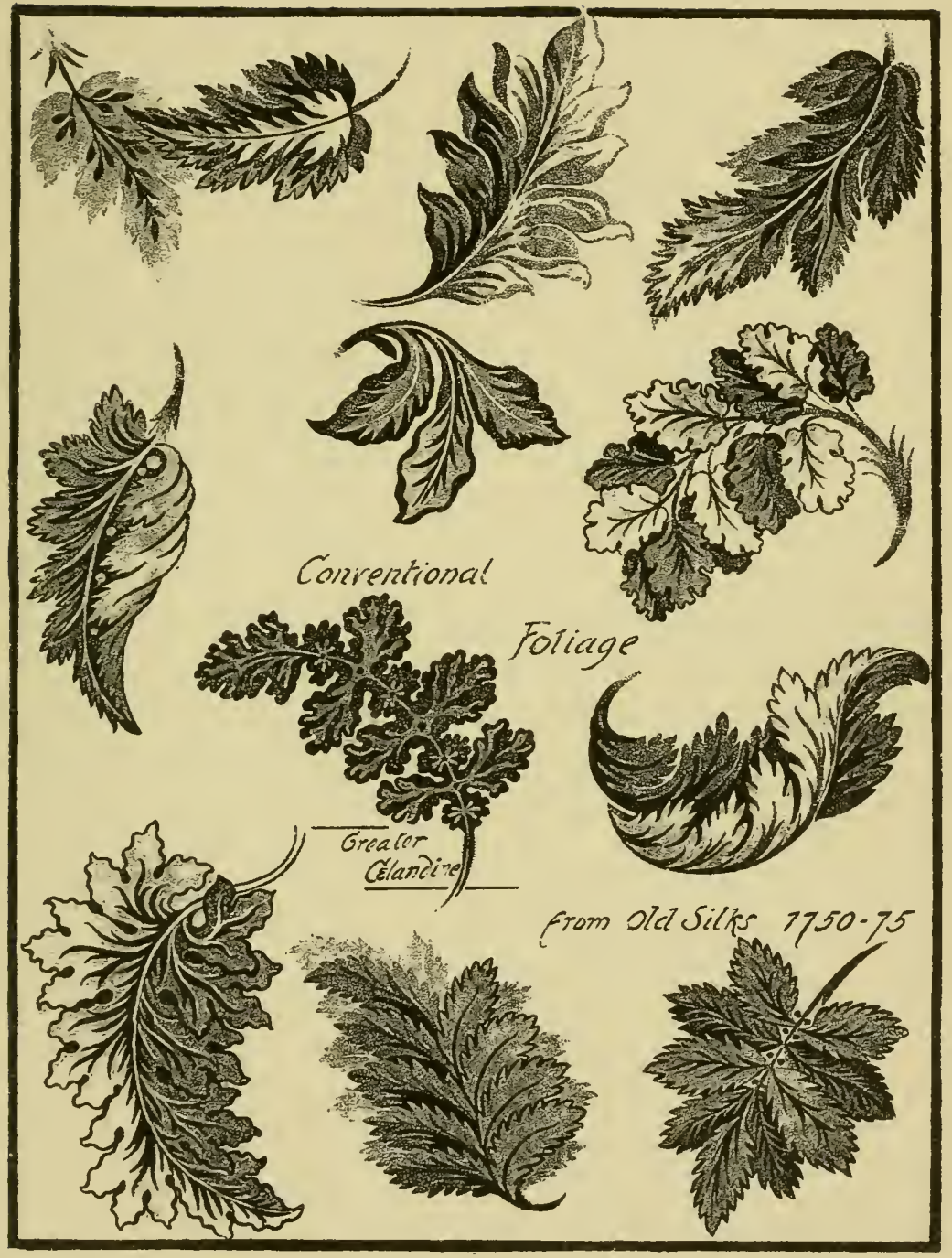

Details of $18^{\text {th }}$ Century Foliage 

The Elaboration of Natural Forms. 73

homogeneous, it would be absurd to say that it should not be constructed on the principle exemplified in Plate 34.

That principle, indeed, dates farther back than the Renaissance. The Italians borrowed it from the Persians, as the French borrowed

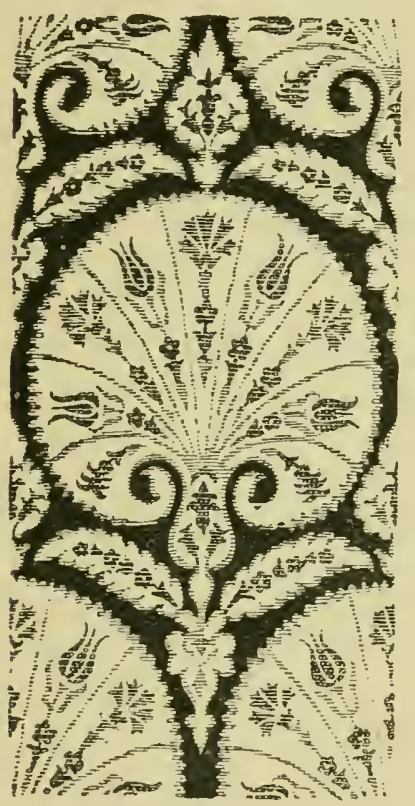

56. Floral forms within floral forms.

it from them. The brocade here illustrated $(56)$ is of old Italian manufacture, but the design is pretty literally taken from a Persian source. The way in which the broad surface of the main design, itself floral, is broken up with smaller floral detail, is distinctively Eastern. Precisely the same principle is involved in the design of the Persian silk on Plate 78. You see it, too, on the pottery of Damascus, and in all manner of Oriental ornament.

A characteristic Persian treatment of the pomegranate is shown overleaf, where the bursting of the fruit takes a peculiarly ornamental bud shape. Other elaborately 


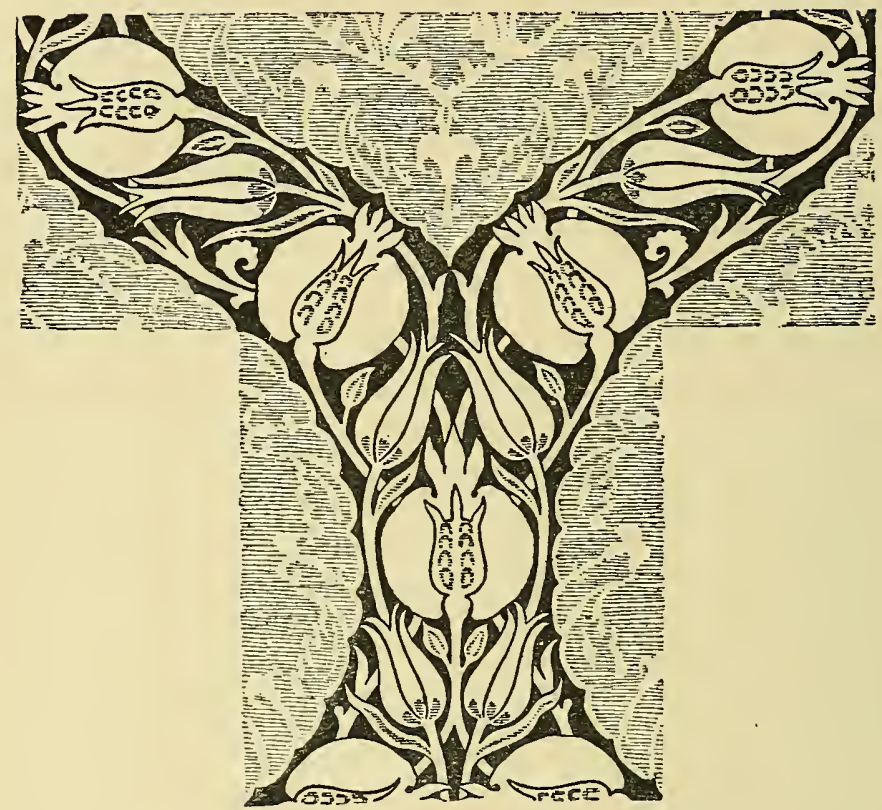

57. Pomegranate-berries arranged in bud-form.

ornamental variations are shown on pp. 75 , $76,77, \mathrm{I} 39, \mathrm{I} 40$, and on Plates 73 and 87.

The Italian version (58) is ornamental enough, but the artist has not realised that the crown of the pomegranate represents the sepals of the flower, and has added a sort of calyx beneath the fruit. In the eighteenth century version, the seeds are more fantastically rendered than ever-they are represented not merely by diaper as on p. 77 , but by diapers as on p. 76 . Observe also the ornamental scalloping of the rents in the fruit. Natural 
Plate 34

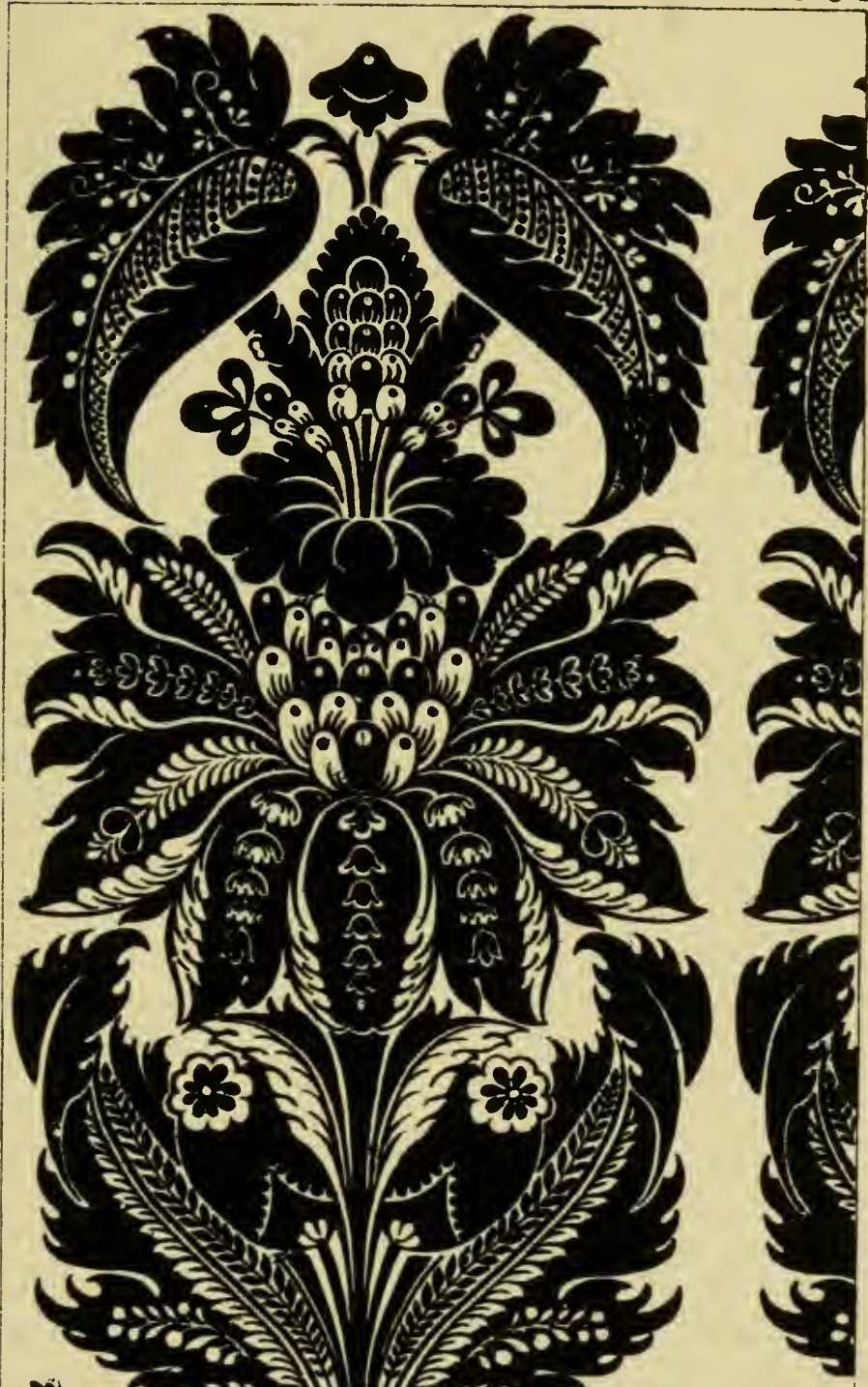

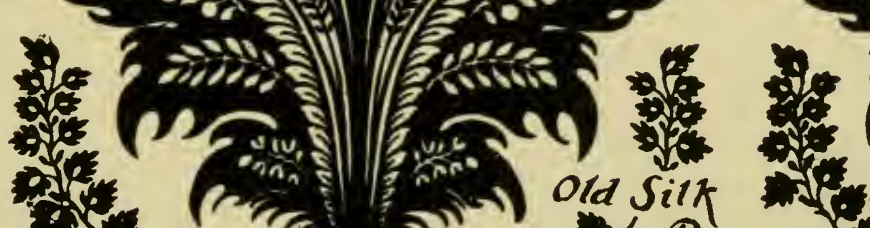
- 1 ( n

Silk Damask of the $16^{\text {th }}$ Century 


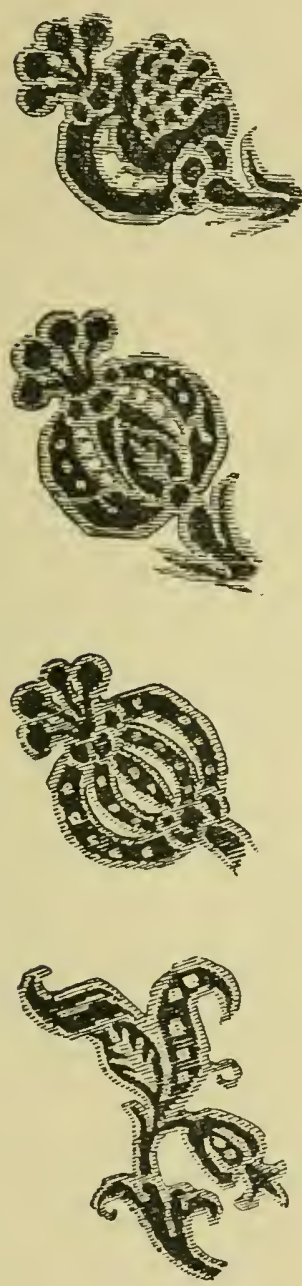

58. Ornamental pomegranates.

form is used, indeed, only as a means of getting variety of texture in the silk.

One great advantage in the method of thus breaking up broad surfaces is, that the introduction of the smaller detail does away with any possible appearance of baldness in the design; whilst yet, at a sufficient distance from the eye, the broad masses alone assert themselves. You get, in short, breadth at a distance, and detail on close inspection, each without interfering with the other. Leaves and fruits are very naively diapered in the Japanese pattern on page 78 , designed presumably for weaving.

With the larger floral forms in French silks are usually associated (see once more Plate 32) subordinate floral details, more on the scale of the detail within 


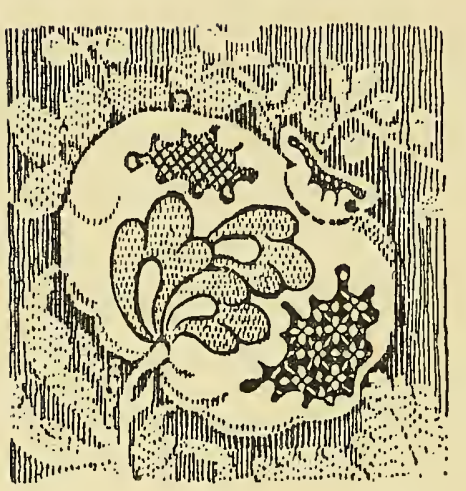

59. Ornamental pomegranater8th century silk.

the larger detail, introduced mainly for the purpose of breaking the background. It is obvious that such undergrowth must be ornamentalised accordingly.

By this means you get a further advantage in the opportunity it affords of mingling in the same design effects of light on dark and dark on light. If, for example, the ground is dark and the larger details light, and the smaller details breaking these dark again, any smaller details in light on the dark ground will contrast with the dark details on the same scale, and create a certain mystery in the design, which is of very distinct artistic value.

The substitution of geometric diaper in place of subordinate foliation, which occurs, for example, in the Japanese pattern on p. 78, is less absolutely satisfactory-least of all so when, as is often the case in silk (Plate 32), it takes the form of imitation lace. In actual lace there is perhaps more excuse than anywhere for elaborately orna- 


\section{Plate 35}

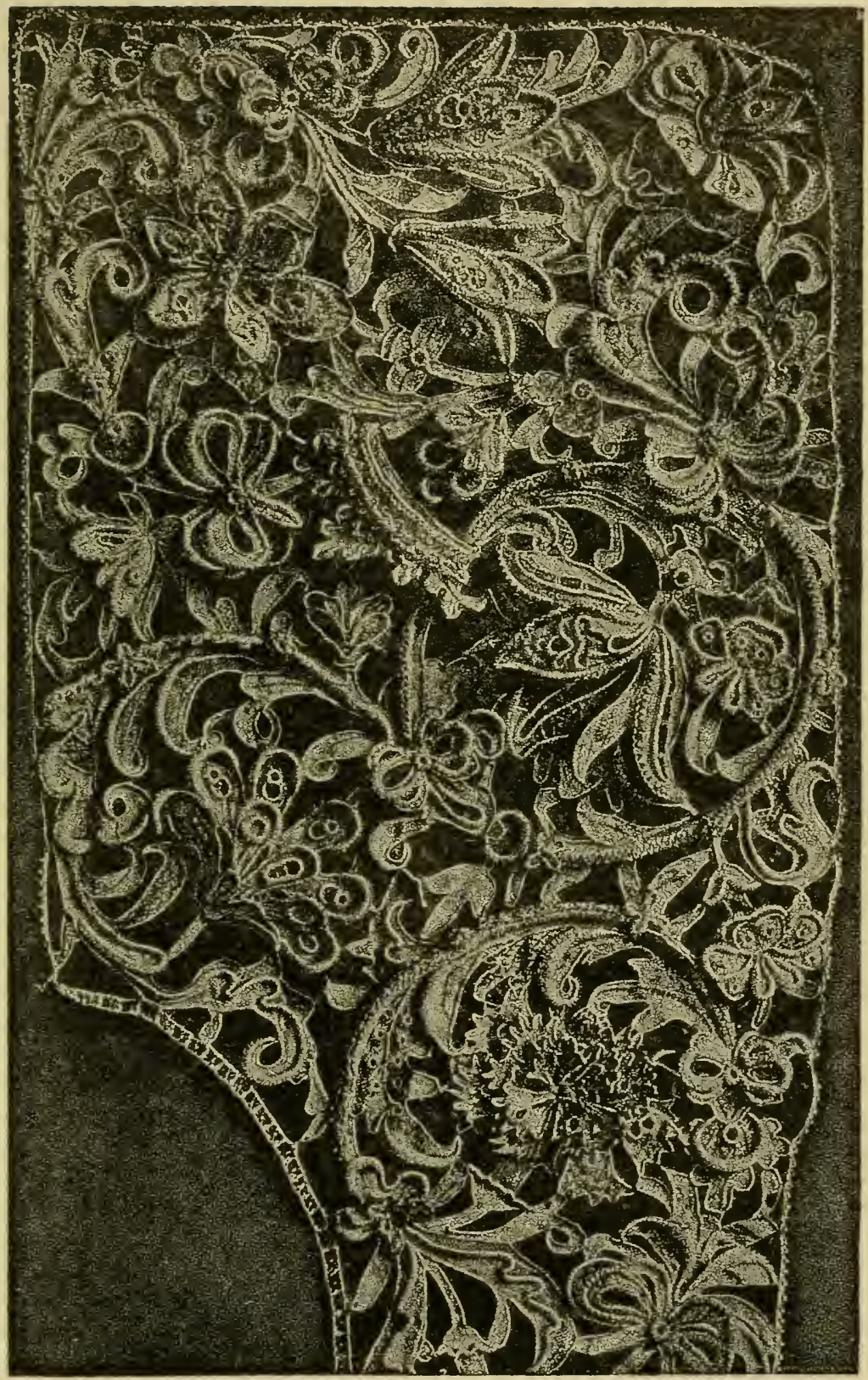

Pното-Tіnт, by wames Akerman.tondon WC

Old Lace, "IVory Point. 

mental treatment, and there geometry seems not to come so much amiss. A certain artificiality in the material seems to justify something very much like frivolity in the design. This refers more especially to the fanci-

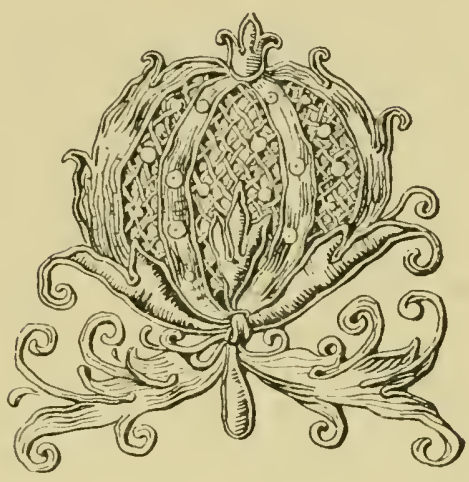

60. Ornamental pomegranate-old German embroidery.

ful patterns of the lighter and flimsier lace of eighteenth-century frills and flounces.

A more dignified example of lacework, also elaborately artificial in its way, is given on Plate 35. It is open to the objection of combining in one growth flowers of various families, but in the general richness this effect of discrepancy is to some extent lost. The lily, the heartsease, and the picotee do not assert their individuality.

In lace and in certain kinds of embroidery ultra elaboration of detail is accounted for by the process of work. In stitching there seems some reason in making much of the stitches; and this is what lace-workers and embroiderers have continually done.

An equally characteristic, but very different kind of elaboration grew out of the conditions 
of smiths' work. Given the idea of foliated ironwork, and the facilities of cutting, hammering, and twisting, it was only natural it should take something like the late Gothic forms on Plate 36. Some such excuse for elaboration makes a confessedly dangerous practice more tolerable if no safer.

Another good excuse for elaboration is when, in what may be called fictitious detail, the fiction is founded upon fact, when it is the development of some natural form or effect, when the hint has been given by nature, and the ornamental

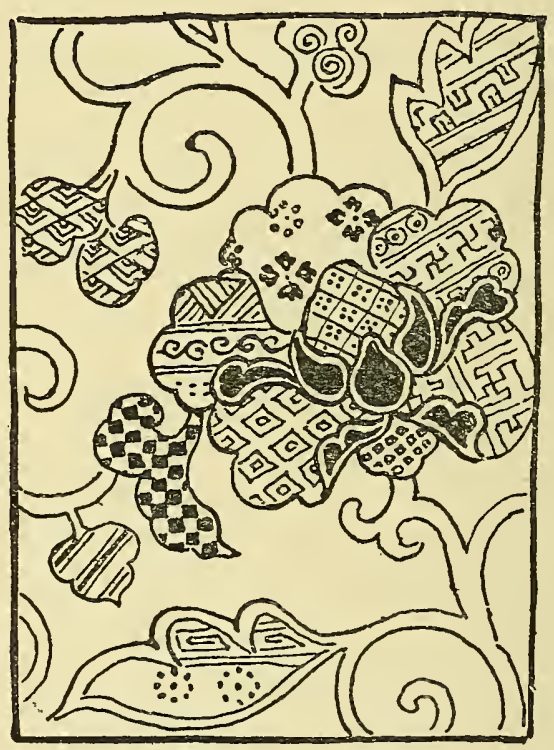

6r. Fuliated forms geometrically diapered.

character is only an exaggeration of natural characteristics.

The seeds of the pomegranate already referred to are a case in point. In the embroidered fruit on Plate 73 they are represented by a diaper of chequers. In the 


\section{(P1ate 36}

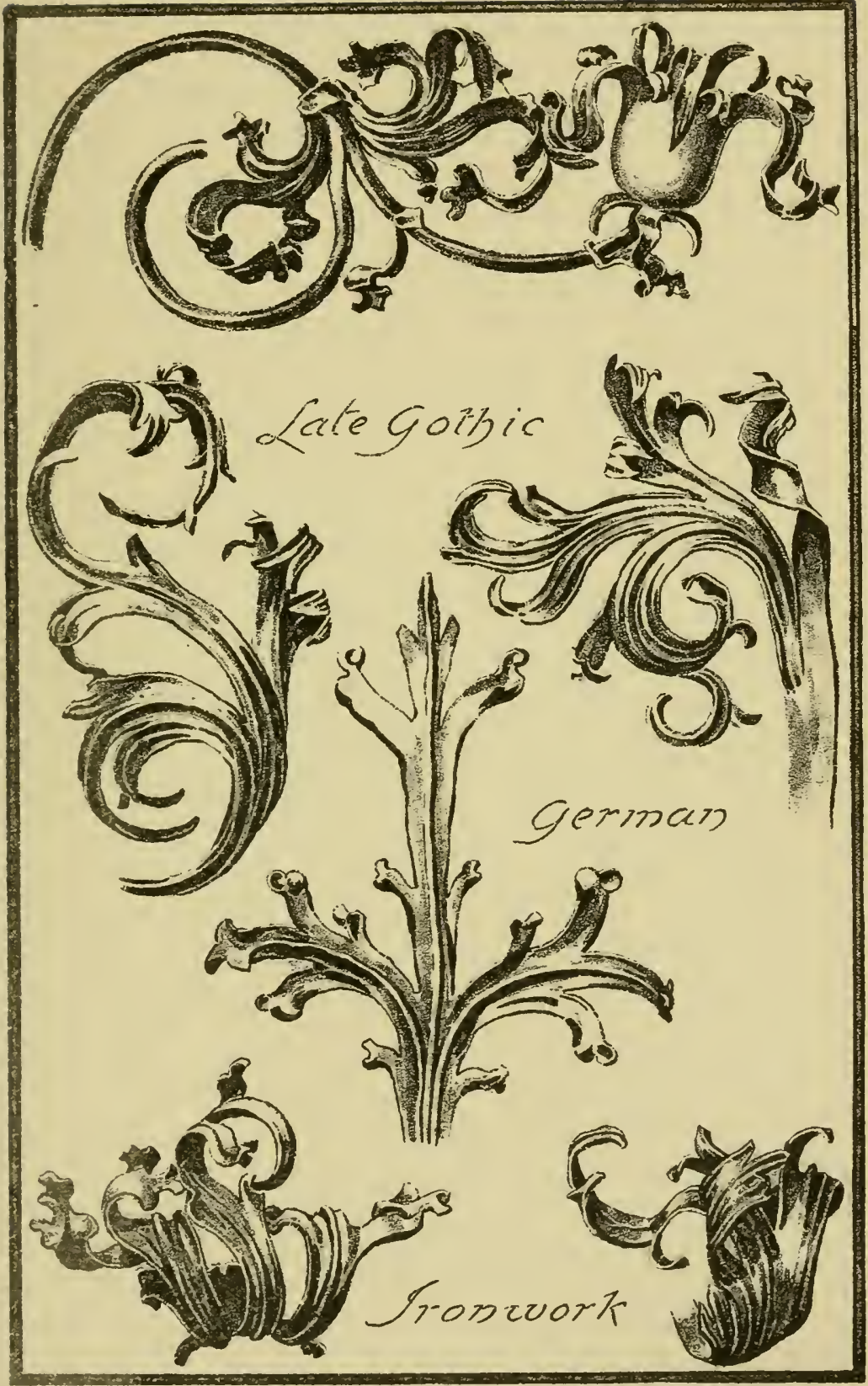

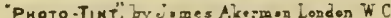

\section{Details of Hammered Work}



The Elaboration of Natural Forms. 79

German embroidery on p. 77 they are indicated by a lattice of silk cord, with here and there a spangle.

The most impossible development of the Gothic ornaments below and overleaf is par-

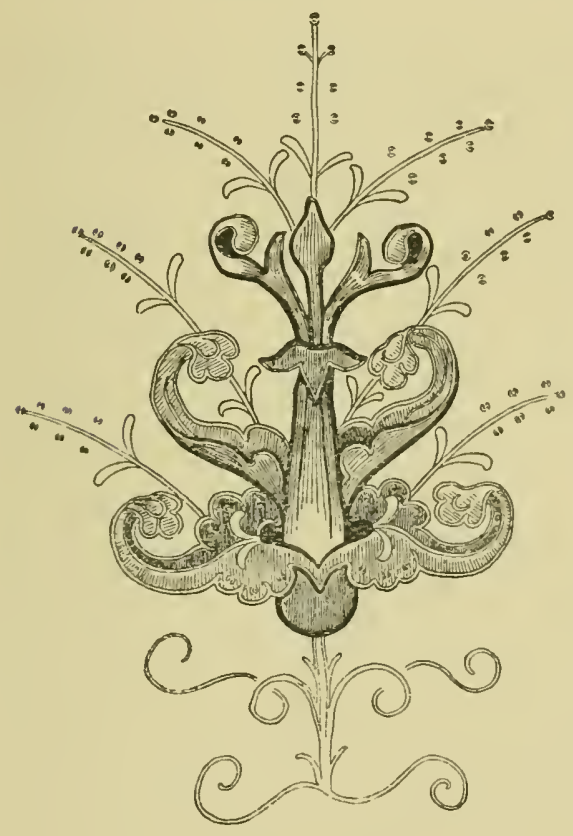

62. Elaborated flower.

tially accounted for as a reminiscence of some flower in which the pistil was very strongly pronounced.

No excuse of the kind can be urged for the treatment of the leaves in the design for wall paper on Plate 37. The more or less naturally drawn leaves are just enriched with pattern, which takes the place of natural veining, and gives variety of surface. That personally I think such a proceeding not altogether unjustifiable, is shown by my adopting it.

Another form of elaboration very common 
80

in fifteenth and sixteenth century ornament, consists in the turning over and curling up of the ends and edges of foliation of all kinds. Something of the kind occurs indeed in Greek and Roman scrollwork; but it is not until late Gothic times that it becomes a marked and characteristic feature in design,partly, perhaps, owing to the influence of the worker in iron, just as a certain bossy characterin Perpendicular carving is derived from

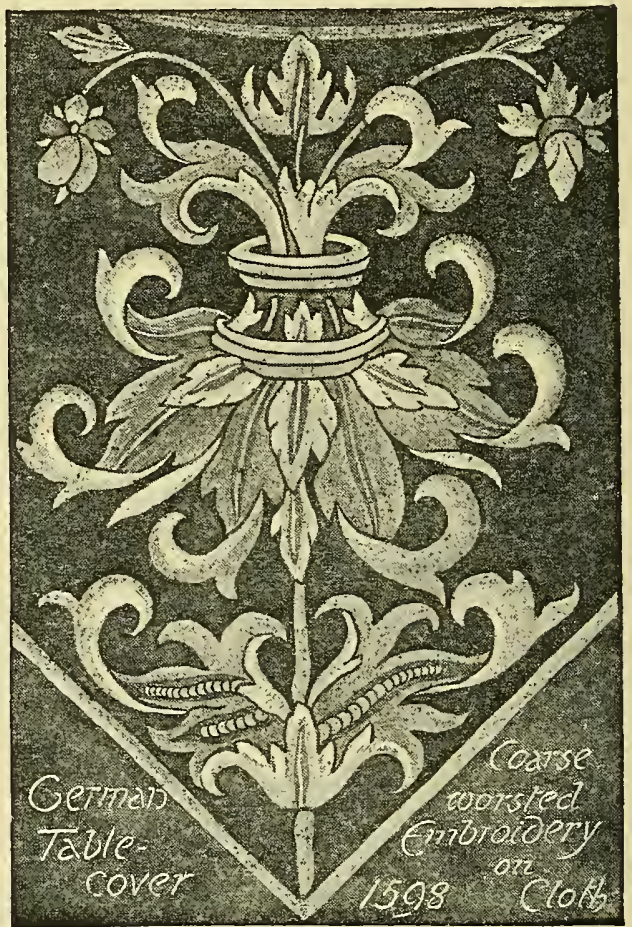

63. Elaborated flower. goldsmiths' work. 'You see that bossy character in the rendering of the hop on p. 8I, and in the leaves on pp. III, II 2, I I 8, I I 9. The limits within which the character of 


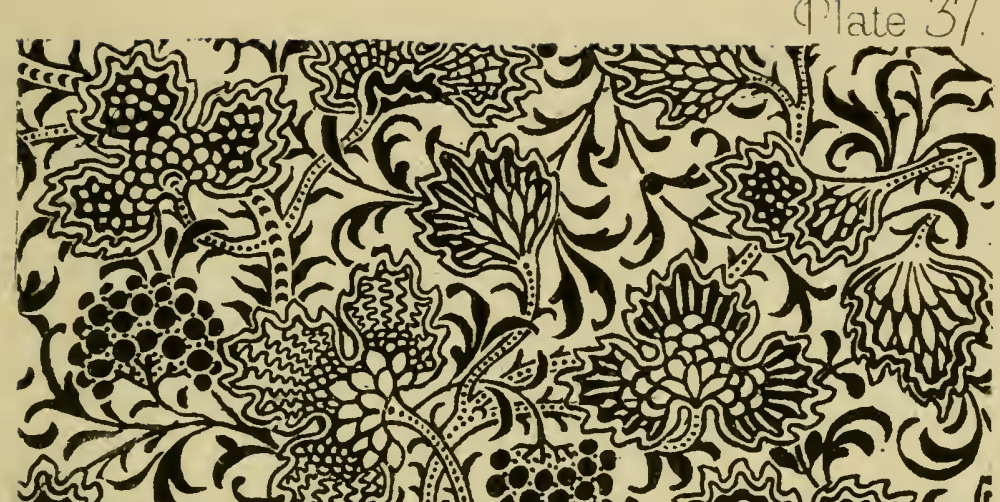
4.25 I 3250

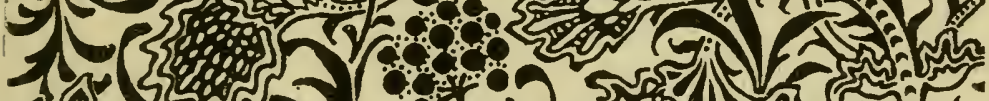

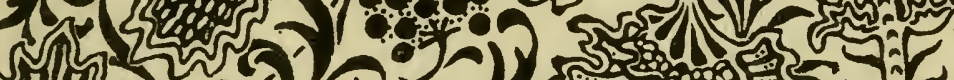

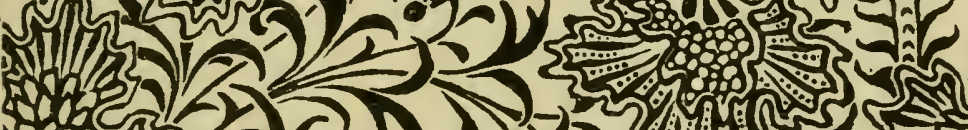

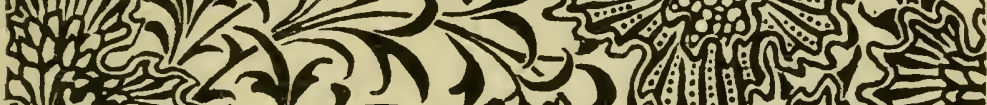
年

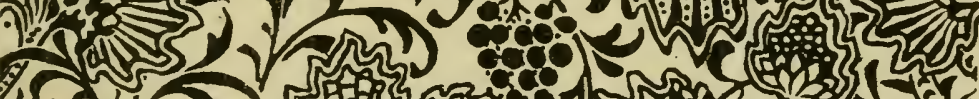
$175-7)$ s

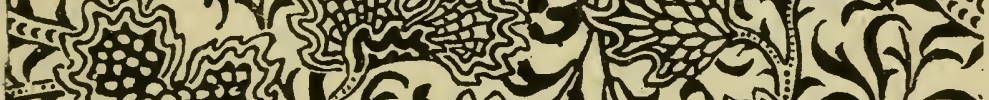

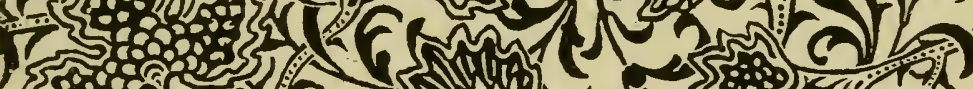
( (.3. (3) ( (cox - 127 . ح.

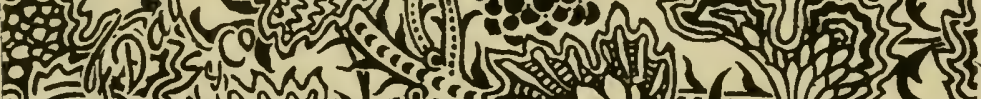
For H Lusis 

The Elaboration of Natural Forms. 8I

one material may fairly be given to another are soon reached. It is clearly a mistake in taste to give, as Gothic carvers did, to leaves in wood or stone the bulbous look of beaten metal, or to give to an embroidered scroll the character of forging. But one would be loth to give up that very valuable and practical device in design, the "turn-over," whatever its origin. What indeed would Perpendicular and Flamboyant ornament be without it? The Gothic scroll would be robbed of half its energy, the Tudor rose would be resolved into a flat rosette, the

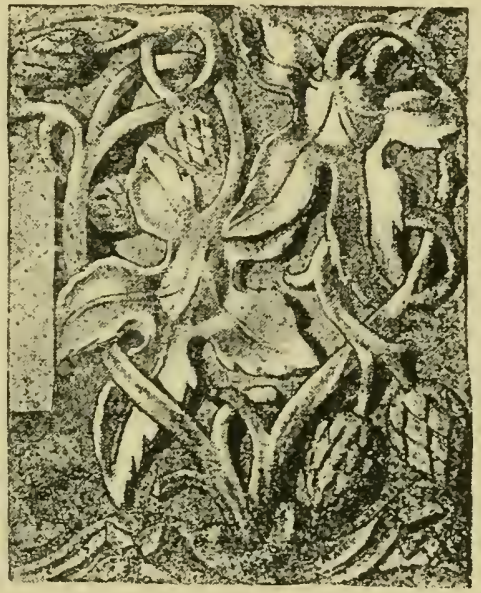

64. Bulbous hop leaves-German Gothic. leafage of Aldegrever (p. I 24) would lose al its crispness. I have resorted freely to the use of overlapping in Plate 38 , a wall pattern founded upon the artichoke. If you take a plant only as a motif of ornament, and attach no further significance to it, you are comparatively free to be-decorate nature.

There would seem to be in nature some 
sort of precedent even for the be-frilling of floral growth. Certain ferns grow with every appearance of artificiality. There is a particular kind of cabbage, much in favour with Mediæval illuminators, which grows very much as though the milliner had taken it in hand; and there is a wild flower, not uncommon in marshy places, which looks for all the world as if it must have been designed somewhere about A.D. I 500 .

The excellent rendering of the gooseberryleaf on Plate 98 is a further application of the manner of the sixteenth century to new forms. It reminds one of the vine-leaves of Aldegrever, and of certain leaves of the clematis and other plants "treated in the same way in some Renaissance carving at Brescia. Professor Anton Seder has worked out the problem of treating vegetable form $\grave{a} l a$ Eenaissance very thoroughly in that sumptuous work "Die Pflanze." It might be suggested that the growth of the gooseberry in the example given is rather too rustic for the extremely ornamental turn of the leaves. The danger of such discrepancy is inherent in such treatment, and is seldom completely overcome. As it is, this is a most competent and indeed accomplished piece of work.

Once more, to presume to elaborate natural 
Plate 38

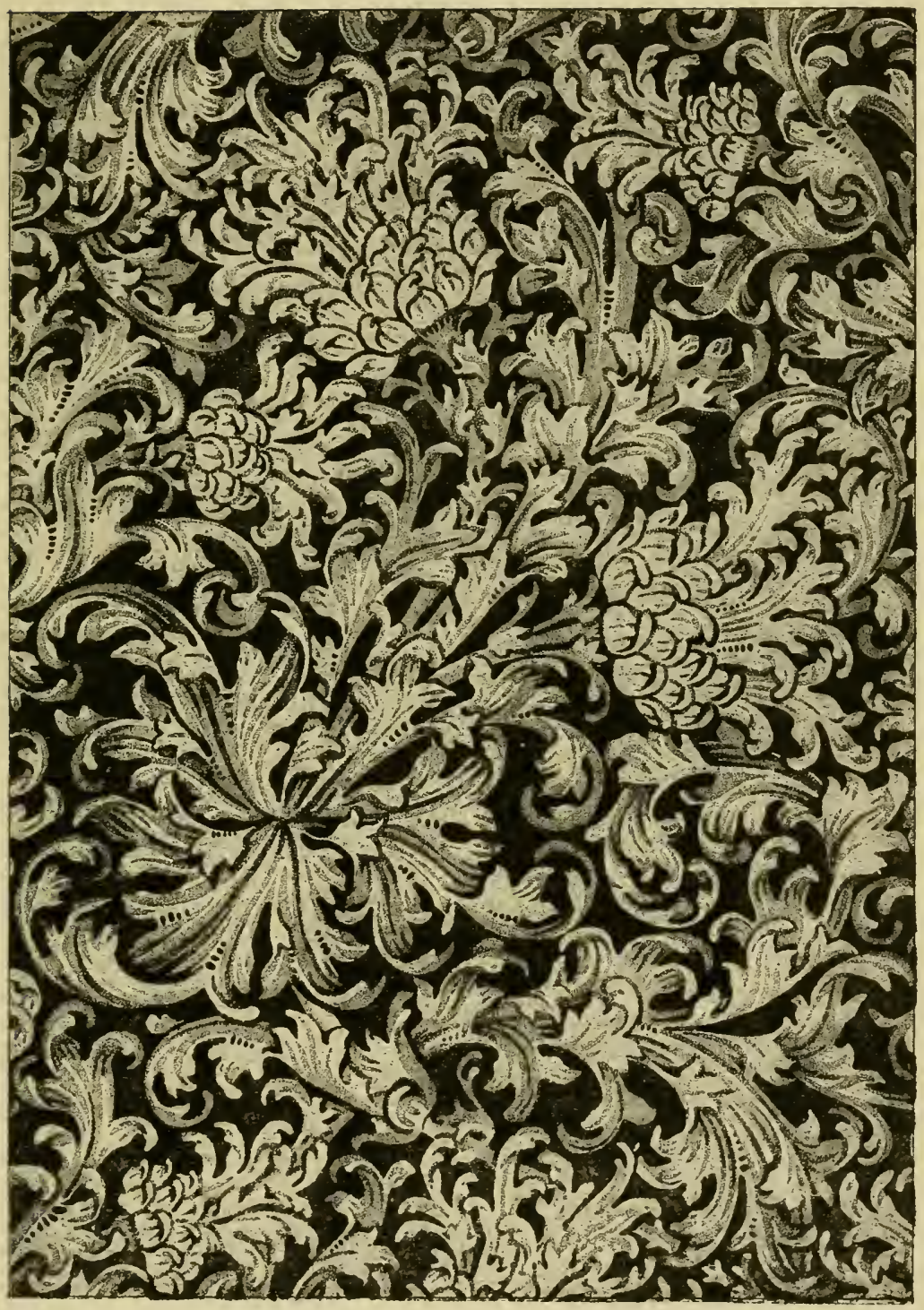

Wall paper founded upon Nature 



\section{The Elaboration of Natural Forms. 83}

form is to trench upon very difficult ground; but we cannot afford to shut ourselves off from any opportunity in design. It is easy enough to dismiss whole schools of thought and treatment with a word of contempt. We have most of us done so in our time. As we grow older we become, let us hope, more just, and confess to ourselves that there are more things in art and ornament than were dreamt of in our philosophy of a while ago. 
CONSISTENCY IN THE MODIFICATION OF* NATURE.

ACCORDING to the use we make of natural form, it helps or hinders us in design. The flow of line, the grace, the growth, the tenderness of colour, the subtlety of suggestion, which so delight us in ornament, would never have been evolved from man's imagination apart from natural influences; but nature does not provide for us ornament ready made; were that so, our occupation would be gone. Nature is the starting-point, by no means the end, of ornament.

When Owen Jones went so far as to say that in proportion as ornament approached natural form it had less claim on us as ornament, he overstated his case quite as much as they who contend, on the contrary, that only in so far as it approaches nature has it any claim on our sympathy at all. The two opposite contentions may be taken to balance one another. The truth lies midway between. 


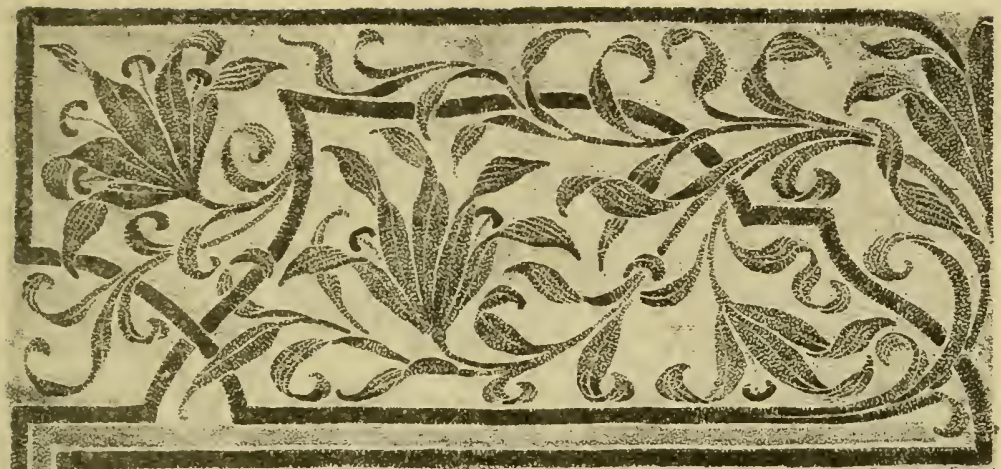

\section{OBLONG PANEL FOR FIGVRE SVBJECT}

10. (1)

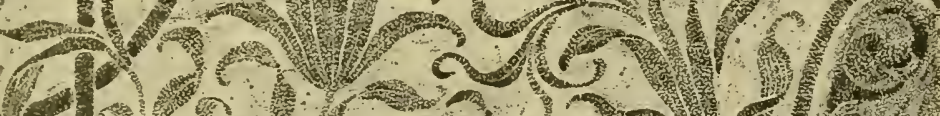

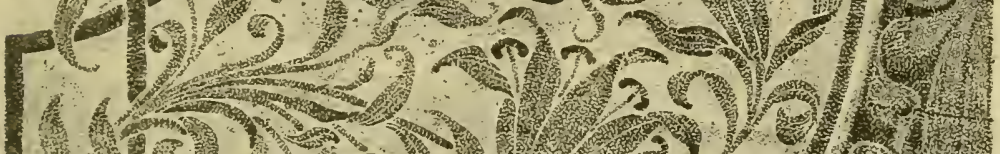

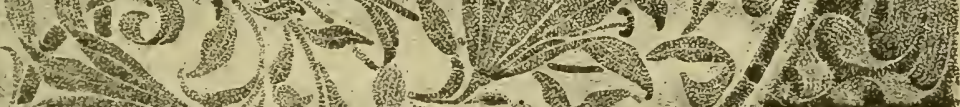
(4) 4
4 Fin

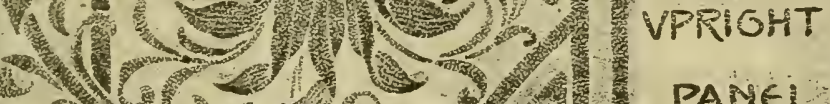

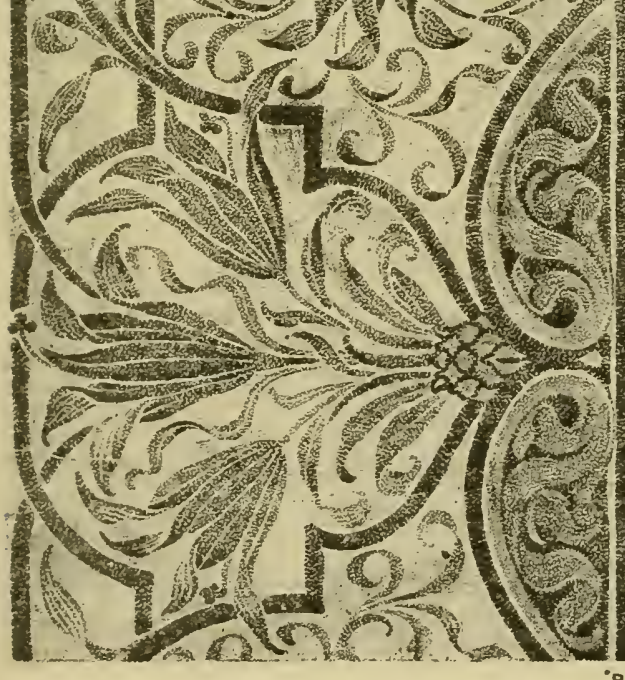

PANE FOF

FIGVRE SVB ECT 



\section{Consistency in Modification of Nature. 85}

To reconcile the rival claims of nature and art it needs only the artist.

But how, it may be asked, can nature be, in any case, a hindrance to design?

Whatever diverts for a moment the attention of the artist from his artistic purpose, is distinctly a hindrance. The purpose of the ornamentist is ornament. Nature has a way of claiming too much attention to herself; and the artist, in his frailty, is only too likely to yield to the seductions of a mistress, worthier, it may be, than all others, but not the one he has, so to speak, sworn to love and cherish, if not to obey.

The designer can hardly make too many studies from nature, but he can easily make bad use of those he has made, and easily encumber himself with them. A man can design quite freely only when the burden of natural fact is so familiar that to him it ceases to be a burden. Refreshing as it may be to refer to his studies, or to Nature herself, he cannot design with either in front of him. The actual thing is not malleable enough for his purpose, whereas an impression or a memory of it accommodates itself in the most surprising manner to the conditions of the case, and the necessary modification occurs as though it were a matter of course. 
In our happiest moments that is so. At other times the question as to the necessary modification has to be deliberately decided.

It is not possible to lay down any limit as to the degree of naturalism permissible in ornament, or to say that the most natural rendering may not sometimes be the best. The conditions of the case may determine the elimination of the natural element in design altogether, or permit it to rule paramount: they determine the degree of modification necessary, or the degree of naturalness allowable.

And even where they leave the artist free, as soon as ever he begins to design he sets himself his own limits. He pledges himself by what he has done, and is bound in consistency to carry his idea logically through. A formal arrangement of lines involves an equally formal kind of foliation, and free growth pledges him to equally natural foliage. So also natural detail prescribes free lines of growth, and conventional detail implies lines proportionately conventional.

If, that is to say, it is proposed to clothe a geometric skeleton with foliage, it is quite easy to make the turn of the leaves too natural; the danger in the case of a more natural skeleton would be in making them 
Plate 40.
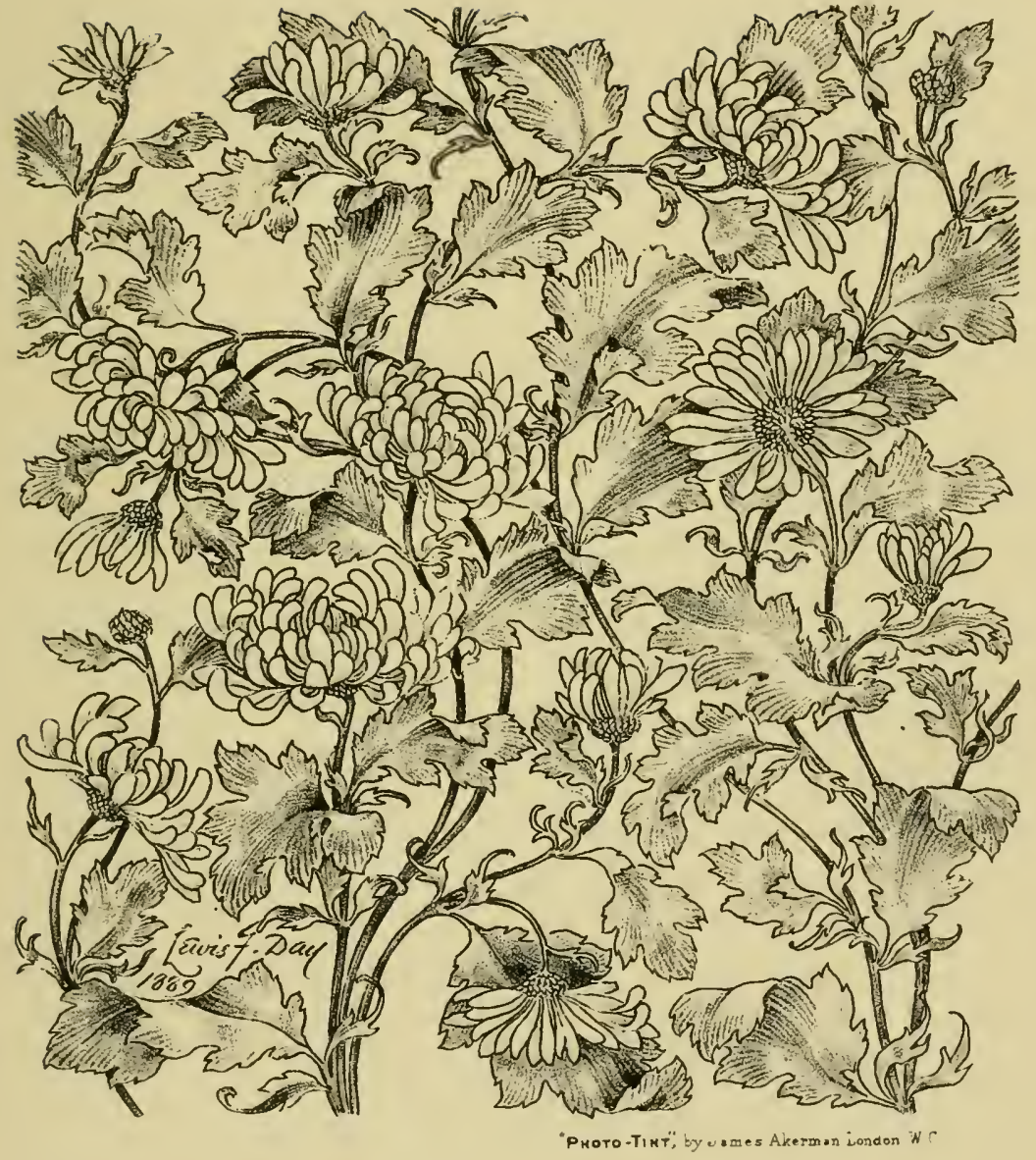

Chrysanthernum Pattern. 



\section{Consistency in Modification of Nature. 87}

too hard and formal. On Plate 39 the symmetric lines on which the design is set out logically determined a certain restraint in the rendering of the lily, and it is reduced accordingly to what might be called mere ornament.

On the other hand, the free growth of the chrysanthemum, on Plate 40, not only permitted, but demanded detail more in accordance with nature. It was possible, therefore, to proceed altogether on the lines of nature, only modifying natural form in the direction of symmetry and ornament.

One of the most irritating things in design is to see flowers like catherine-wheels, or other such prim rosettes, on stems suggesting growth, or to find naturalistic flowers springing from quite arbitrary and mechanical lines.

In the otherwise masterly design on Plate 23 , by the late B. J. Talbert (an artist who deserved better than to be so soon forgotten), there is just that flaw, that the eyes of the sunflowers, in comparison with the freer growth of the leaves and petals, are so formal as to stare out of the pattern at you. This effect is to a great extent obviated in the wall-paper by judiciously soft colouring, but the fault in design is still there.

This point of consistency needs the more to be insisted upon, because it has at no 


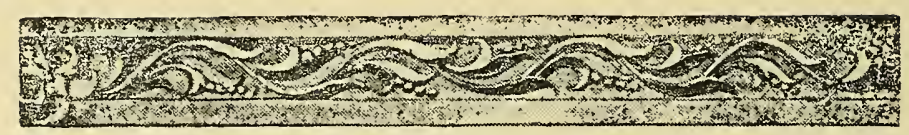

65. Indian corn, adapted to ornament.

time been strictly enough observed. Everywhere, in Greek no less than in Gothic art, we find the artist (weak creatures that we are) lapsing into inconsistency. The border, in particular, is a pitfall in his path. In it arbitrary arrangement is, one may say, a necessity; and it is only with difficulty, often, that he brings himself to reduce leaves and flowers to consistency with the waves or spirals or other symmetrical lines on which they grow.

In the border at the top of the page the adaptation of the Indian corn to its place is perfect: that is ornament. On Plate $8 \mathrm{I}$ there are sundry instances of much less successful treatment, where the ivy-leaf is natural enough in shape to make us want it to grow more naturally; which is the case also in the borders on Plate 83 . On Plate $4 \mathrm{I}$ the leaves and their arrangement are equally remote from nature, and the result is correspondingly satisfactory. The happy mean of conventionality is found also in the borders on pp. 55, 57, 58, 6r, \&c.

The arrangement of wave or other scroll 
Plate 41

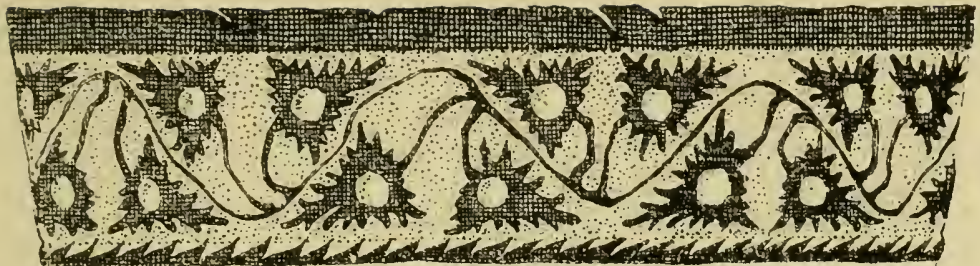

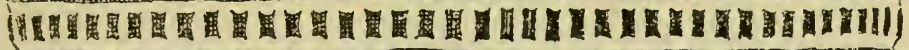

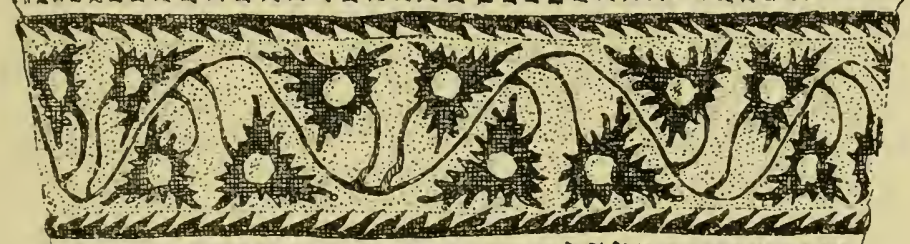

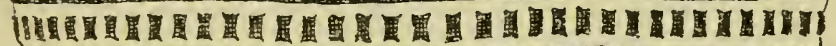

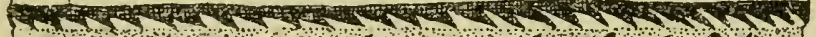

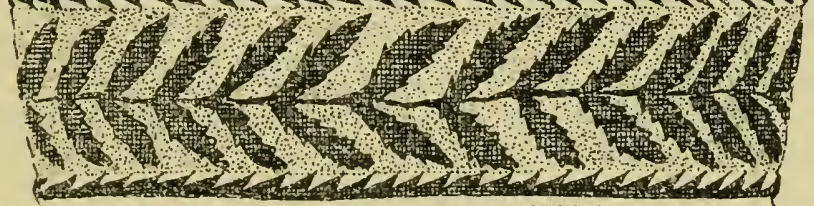

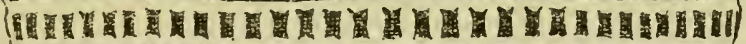

सि

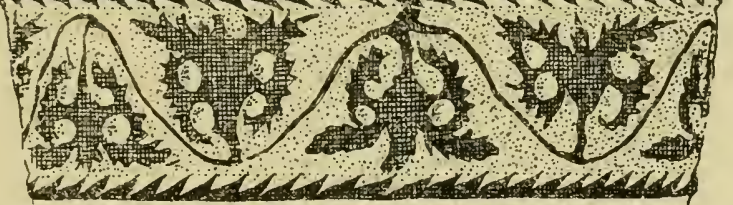

(

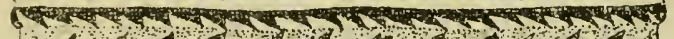

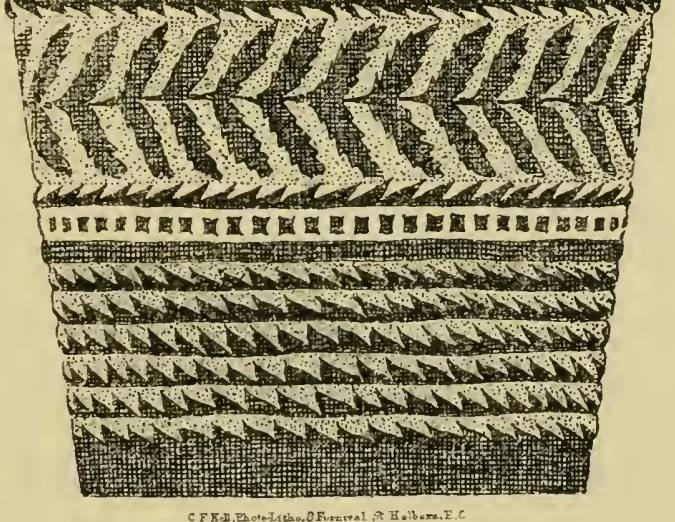

Archaic Foliage. 

Consistency in Modification of Nature. 89 with leaves alternately on either side of it (or leaves and flowers, or leaves and berries) is objectionable (Plates 24, 25, 4I, 68, 8I) just in proportion to the naturalistic rendering of leaf, flower, berry, or whatever it may be.

There are two separate starting-points in ornamental design. Natural form, once modified, may resolve itself into ornament pure and simple; and, on the other hand, ornament has always a tendency to assume familiar natural shapes.

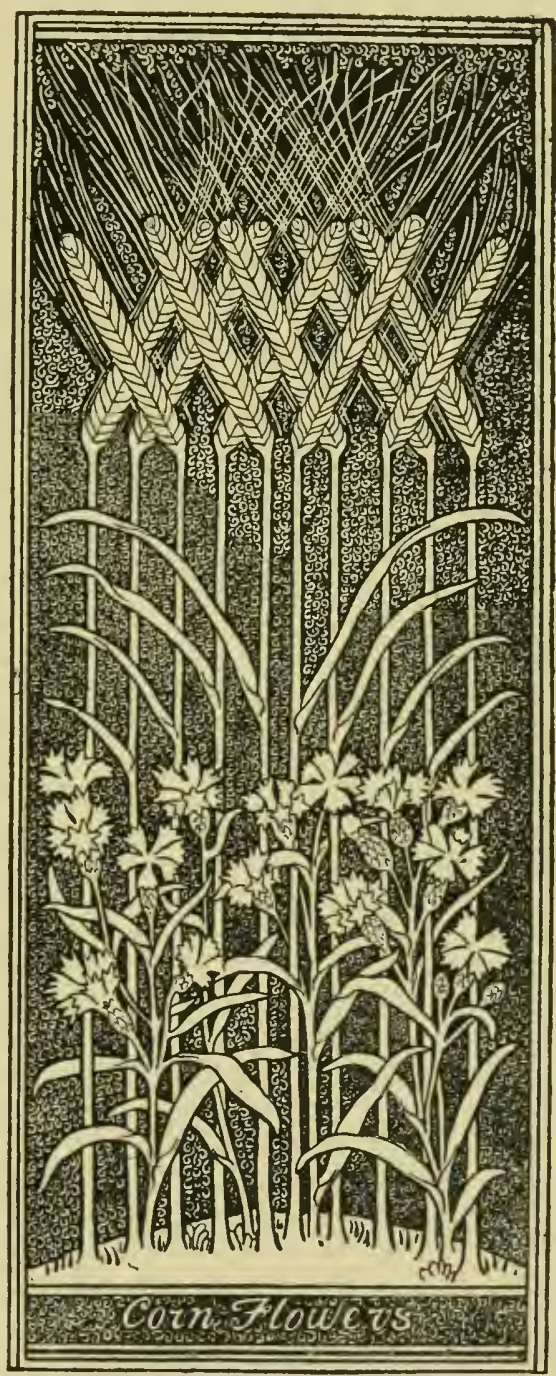

66. Rigid lines of growth turned to ornamental account. 
But, though somewhat similar results may be arrived at from such different directions, nature modified by considerations of ornamental propriety is one thing, ornament modified by memories of nature is quite another.

If you start with nature, the difficulty is in making natural forms subserve decoration without eliminating too entirely the natural element.

When the lines of growth peculiar to a plant are not in the direction of ornament, what is to be done?

The better plan is not, if you can help it, to go against nature, but to persuade, if possible, the natural and charac-

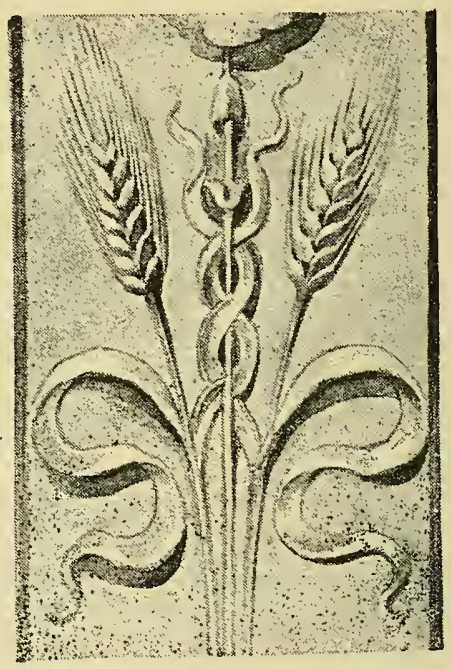

67. Artificial grace of line. teristic growth into lines more in accordance with the purpose of ornament. Even the Greeks, as I have said, when they resorted to arbitrary lines in connection with natural forms, did not succeed.

It must not too readily be taken for granted that a certain rigidity of growth may 
Plate 42

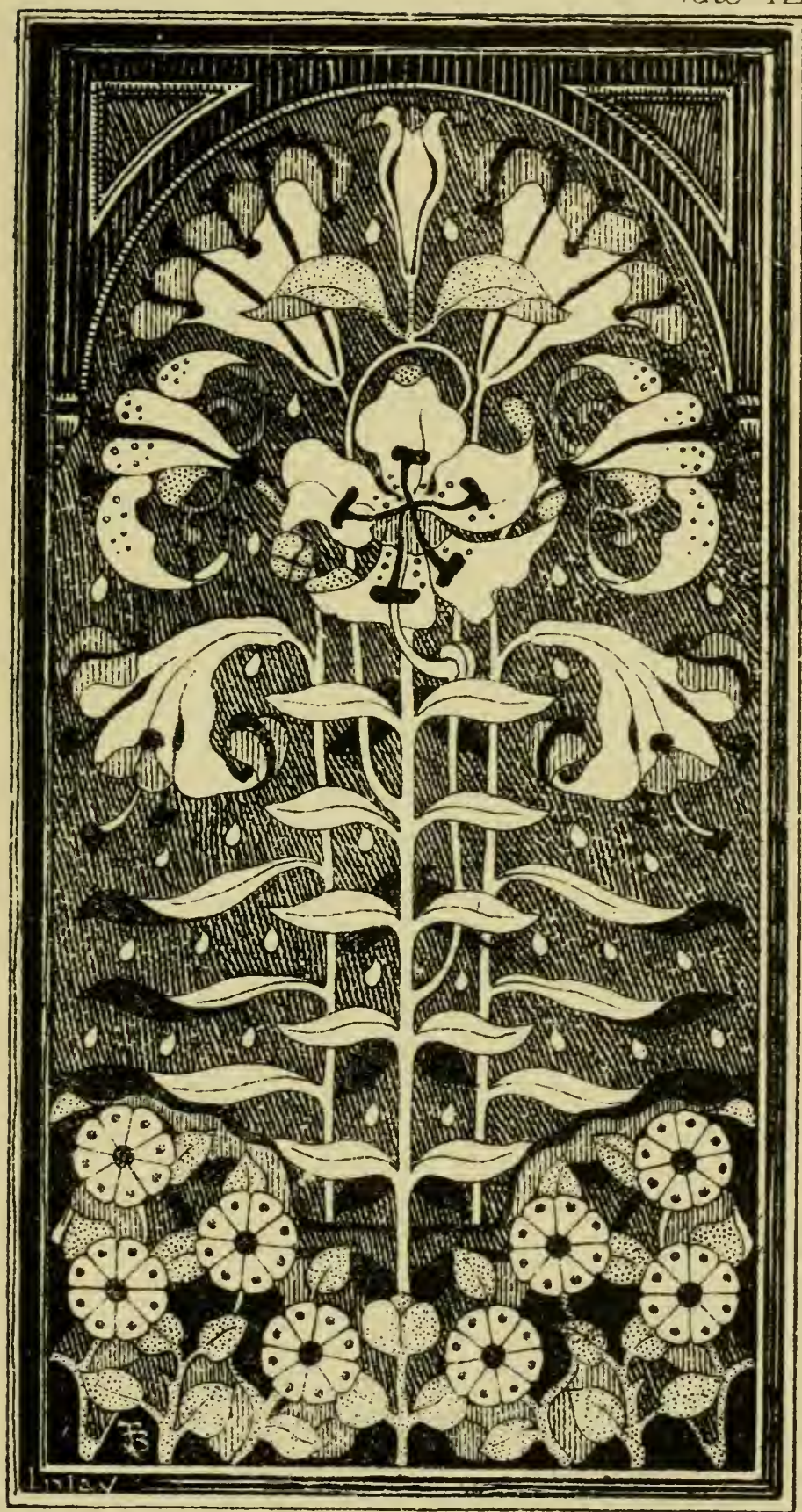

Modern Gotbrc Lily panel 

Consistency in Modification of Nature. 91 not possibly be turned to account in ornament. There is evidence of the availability

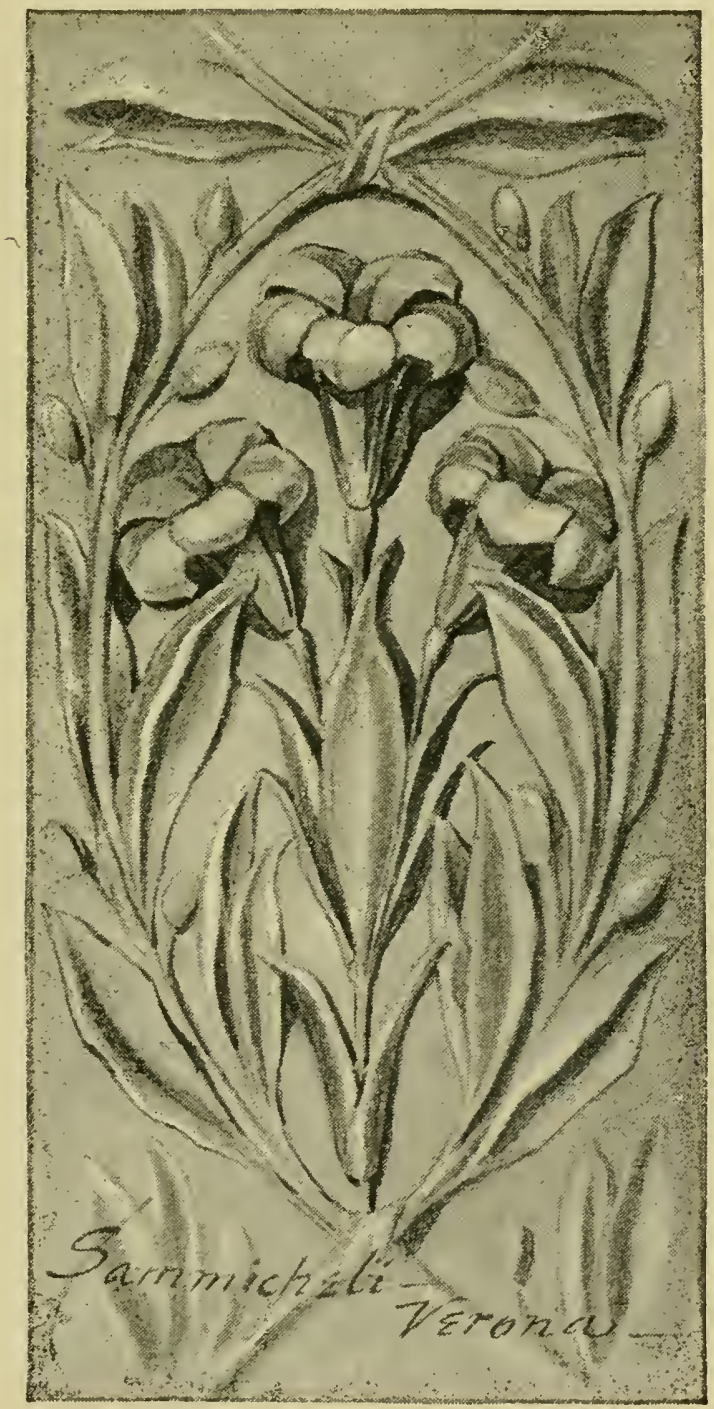

68. Quasi-natural rendering of lily. 
of rigid lines of growth in the ingenious composition of the late Clement Heaton on p. 89, compared with which the admittedly more graceful Italian version of the bearded wheat on p. 90 is not without a suggestion of sickliness. What is fanciful in this last design makes for ornament, no doubt; but there is something almost discordant in the association of lines so sweet with the growth of corn.

Sanmicheli's quasi-natural lily (p. 9I), with its five impossible

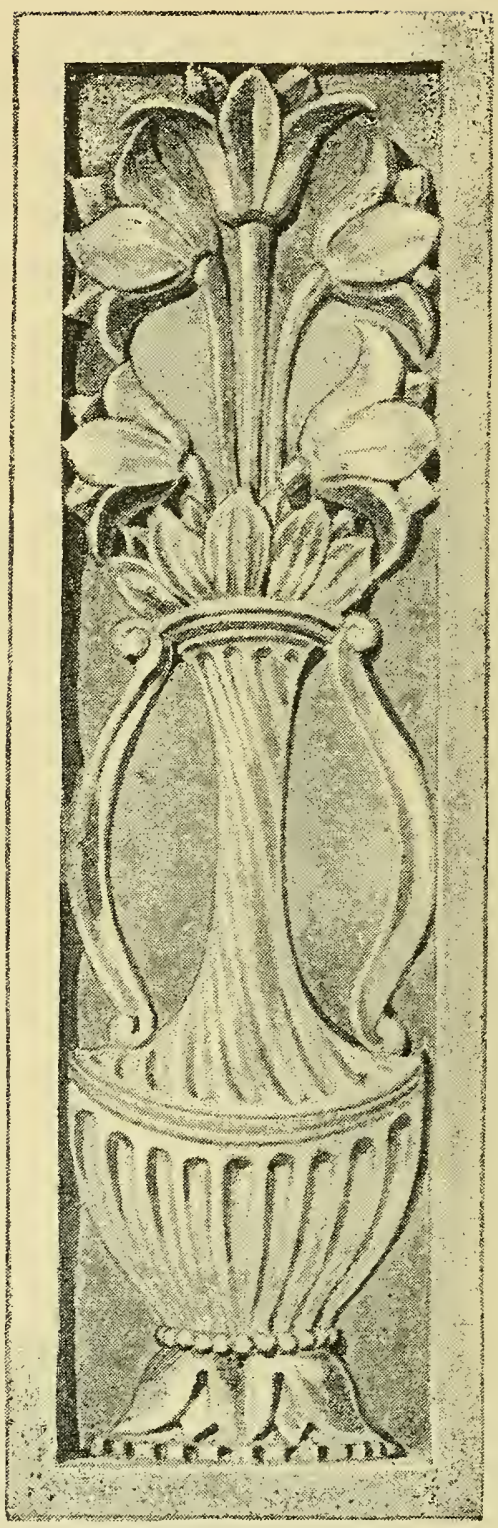

69. Quattro-cento Iily. 
Plate 43.

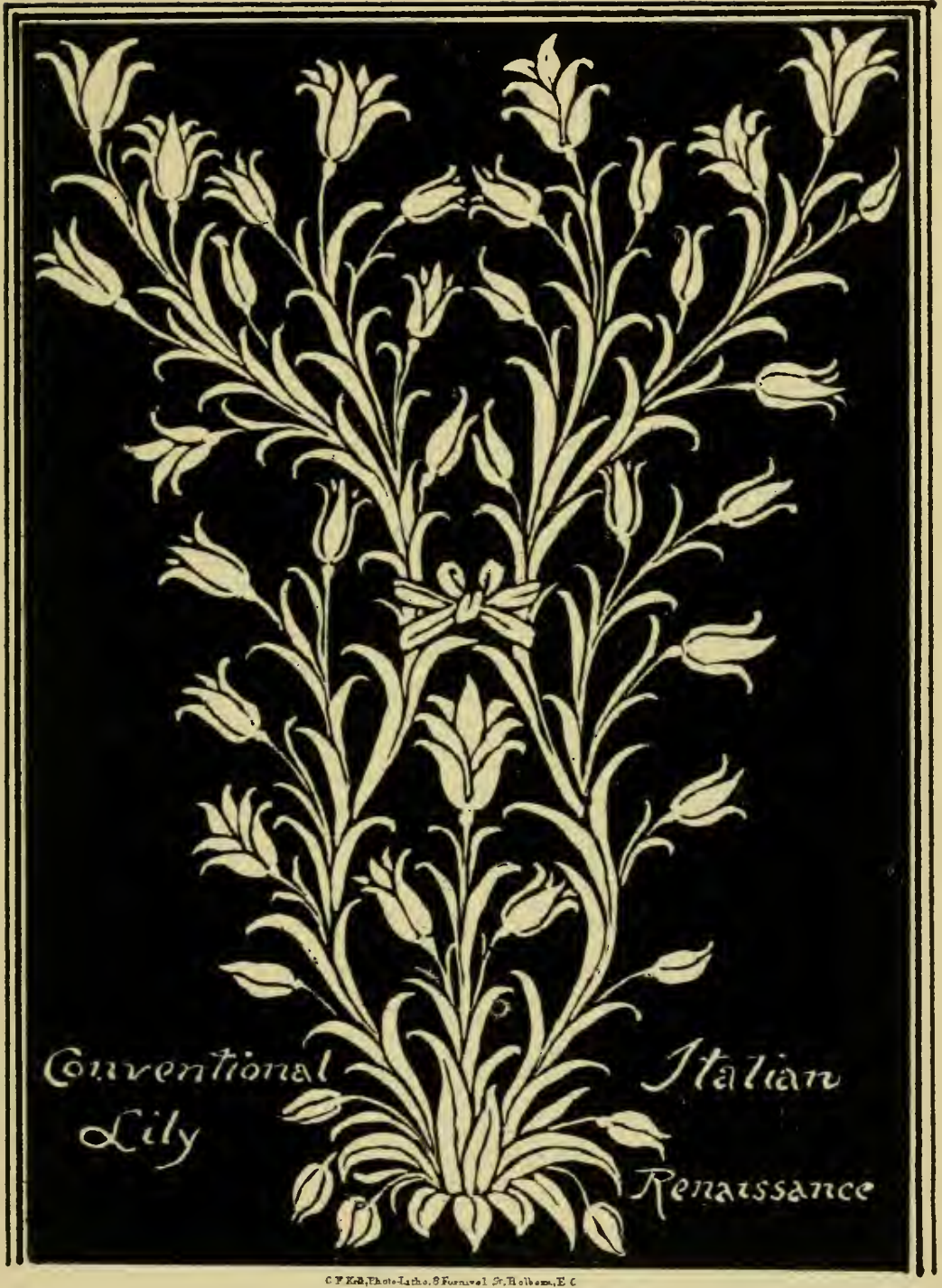

Inlaid Lily Ornament. 

Consistency in Modification of Nature.93

petals, has not half the character of Talbert's manlier lily on Plate 42. The earlier Quattrocento example on p. 92 is equally guilty of five petals; although in the very rigidity and dignified simplicity of the composition there is something that recalls the natural flower.

One may admit, however, a certain character and beauty in the stiff growth of the lily, and even allow that it may be made use of in design, without denying for a moment that it is stiff. The ornamentist may quite fairly

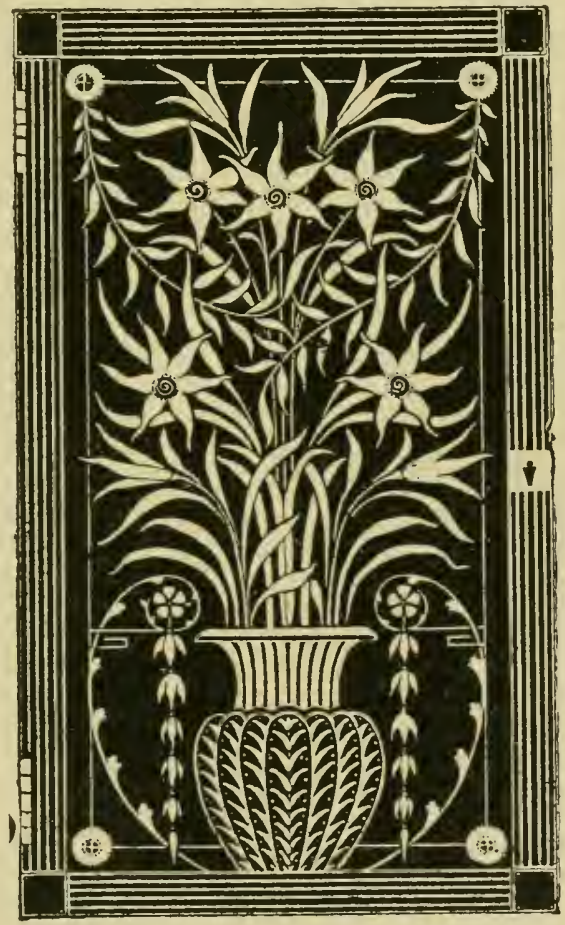

70. Narcissus compelled into the way of ornament.

seek lines more graceful. Still, unless he looks upon the lily merely as a motif of ornament (as shown on Plate 39) he is hardly at liberty to make it branch like a 


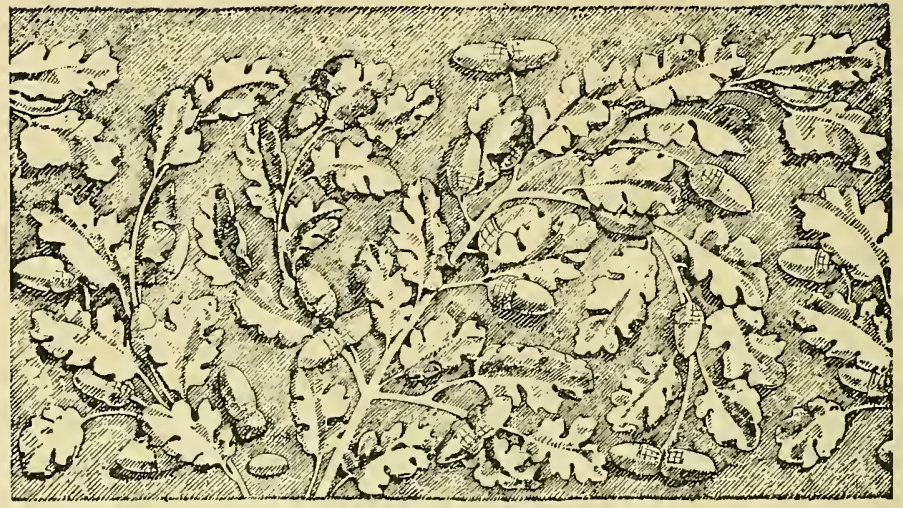

7 I Incorgruous trea'ment of the oak.

bush or twine like a creeper; nor need he wish it. It is quite possible, to one sufficiently at home in nature and in design, to indue any such refractory plant with a grace of line and a general suavity of form which, though by no means characteristic of the natural growth, do not, at all events, bluntly contradict it.

The graceful character of the growth on Plate 43 is not precisely that of the lily; but one is hardly disposed to quarrel with a composition in itself so satisfactory. The detail is not so natural that you miss the natural growth. As a rendering of the lily, the design may not be all that one could wish; as ornament there is not much fault to find with it: the deviation from nature is all in the direction of design. It is evident, too, 
Plate 4.4

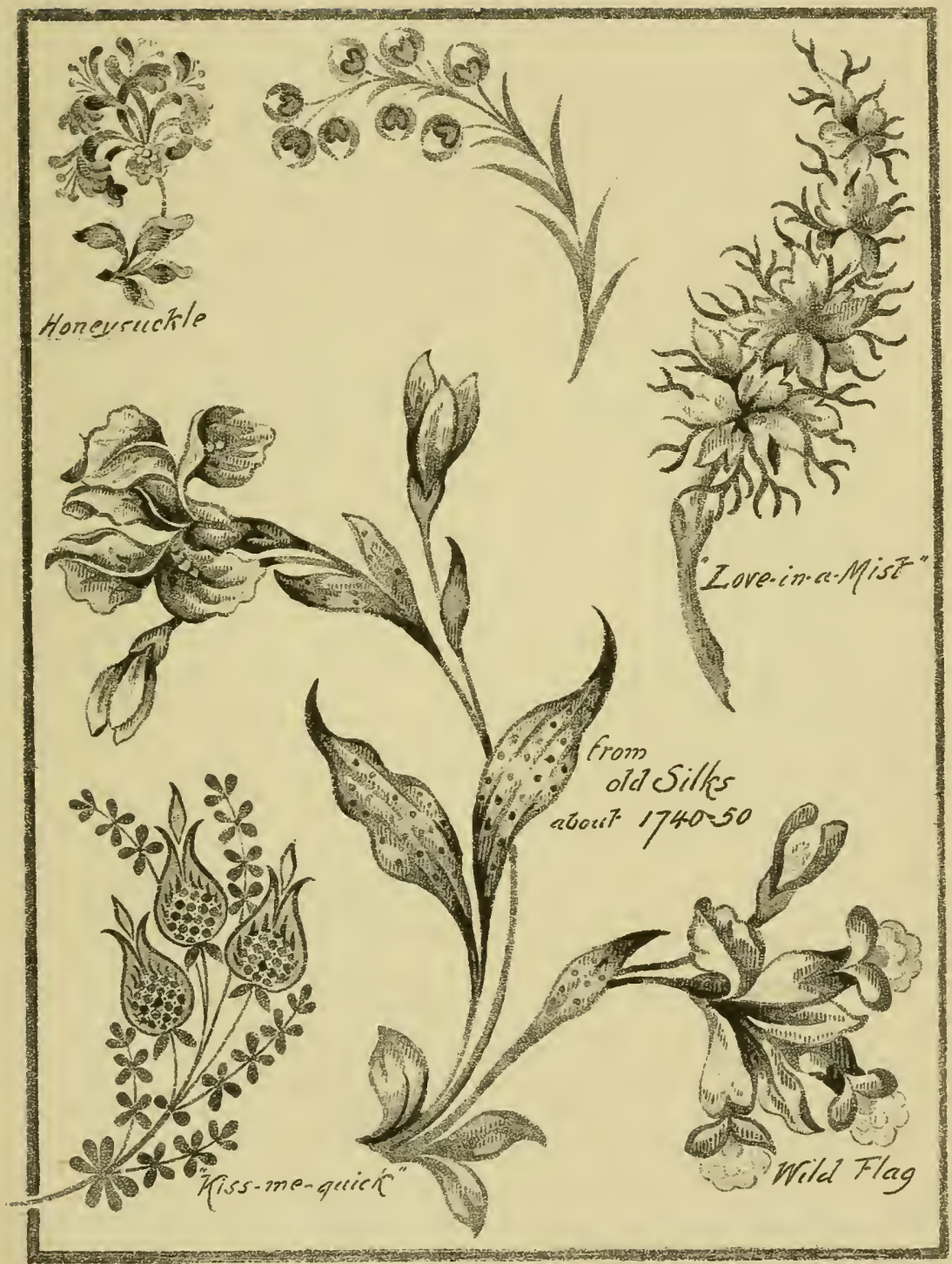

"Pното-TInt", by J. Akermen.6, Peeen Squere,W.C

$18^{\text {th }}$ Century flower rendering. 

that the artist looked at the lily for himself, and conventionalised it according to his needs. It almost seems as though the plant might have been trained to grow so.

This is the natural cvolution of ornament, and not the mere distortion of nature which is sometimes mistaken for ornamental treatment. In the panel on p. 93 it has been attempted to subject the narcissus to somewhat similar ornamental treatment.

In the eighteenth century version of the wild flag on Plate 44 there is a certain appearance of naturalness, or, more properly speaking, of picturesqueness; but it grows with a grace and elegance absolutely artificial. That same affectation belonged indeed to the period (see Plates 32, 33, 62, 70); but

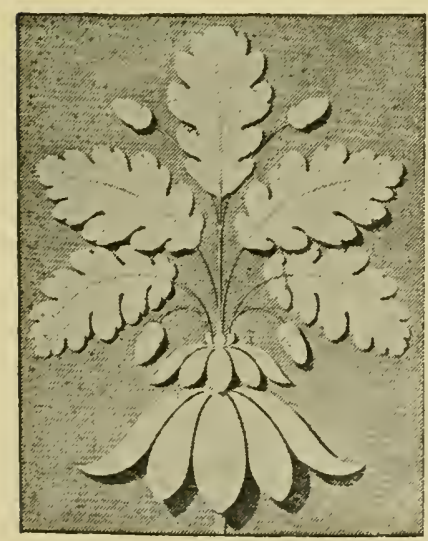

72. Characterless design.

it is at least a graceful affectation, and consistent with itself.

That can hardly be said for the rendering of the oak on p. 94, which has the unfortunate appearance of being either too natural or not natural enough. And even were the lines more 


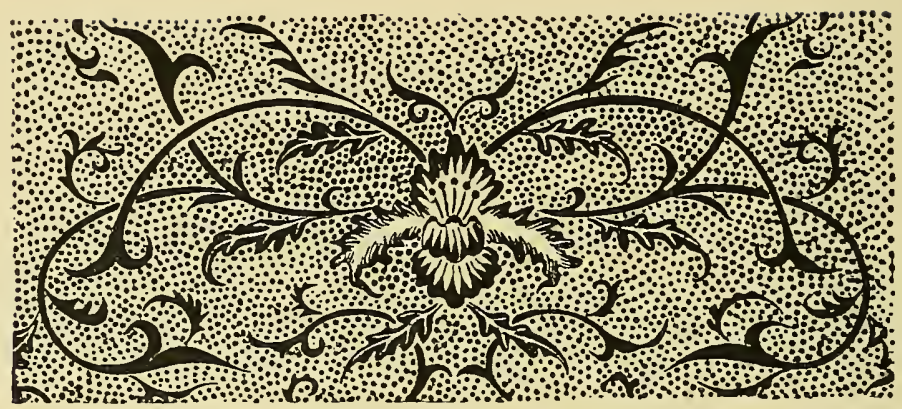

73. Inconsistency between flower and leaf.

satisfactory than they are, one would still feel that there was something incongruous in the combination of lines so suave and slender with the oak. And so again in the case of the still more timid treatment of the leaves by Albertolli on p. 95. This particular tree is, more than all others, associated always in our minds with the idea of sturdy angularity.

The rendering of a plant may be by no means very natural, and yet by far too much so. In the ornament above, the flower is too distinctly an orchid to go with foliage distinctly belonging to another family. This is a fault rather exceptional in Japanese design, where the rendering of nature is usually either frankly natural or deliberately and uncompromisingly conventional.

In the art of the Renaissance the fault of inconsistency is of the commonest occur- 
Plate 45.

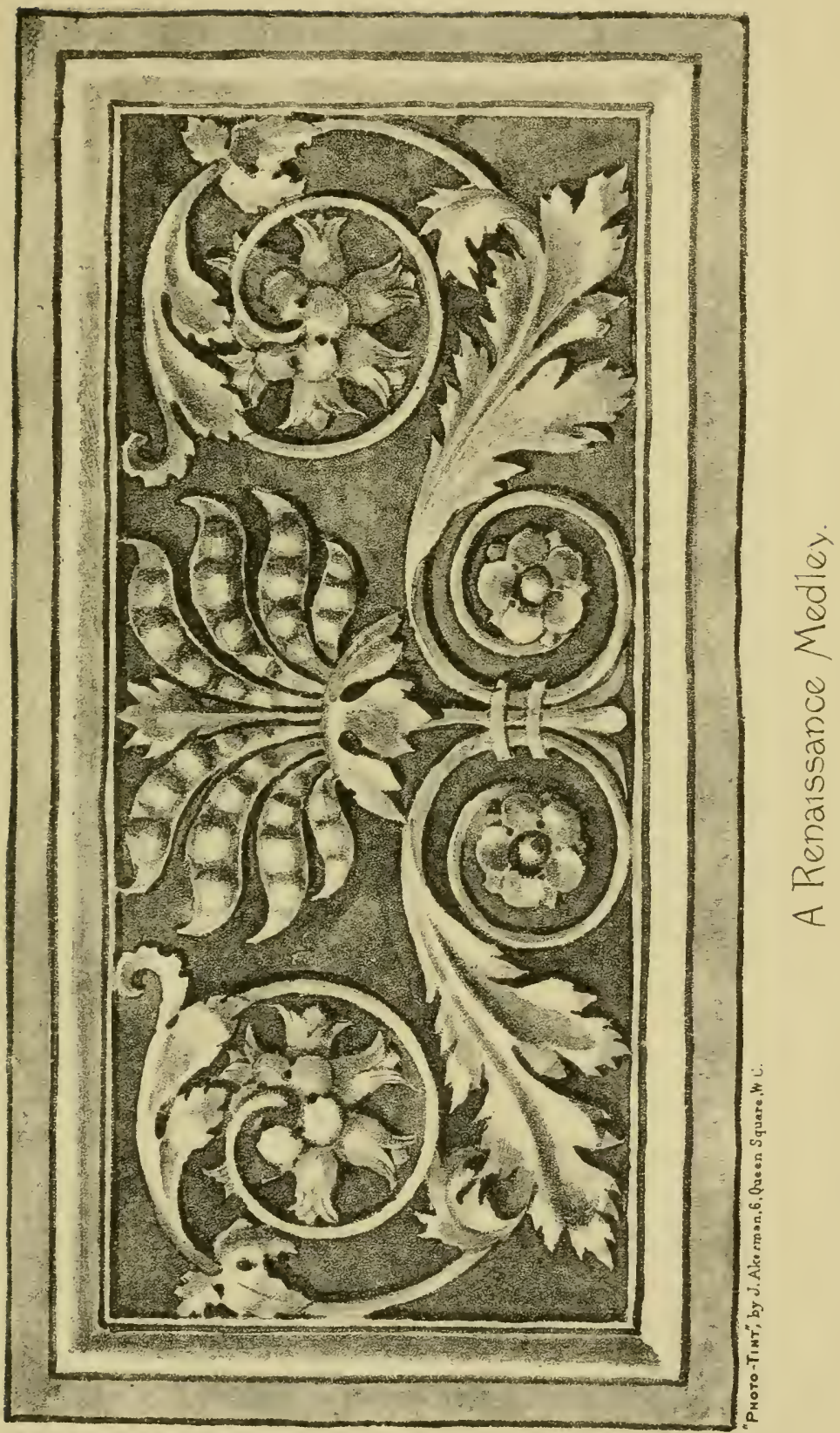



Consistency in Modification of Nature. 97

rence : the nuts, the pods, and the five-petalled flowers on Plate

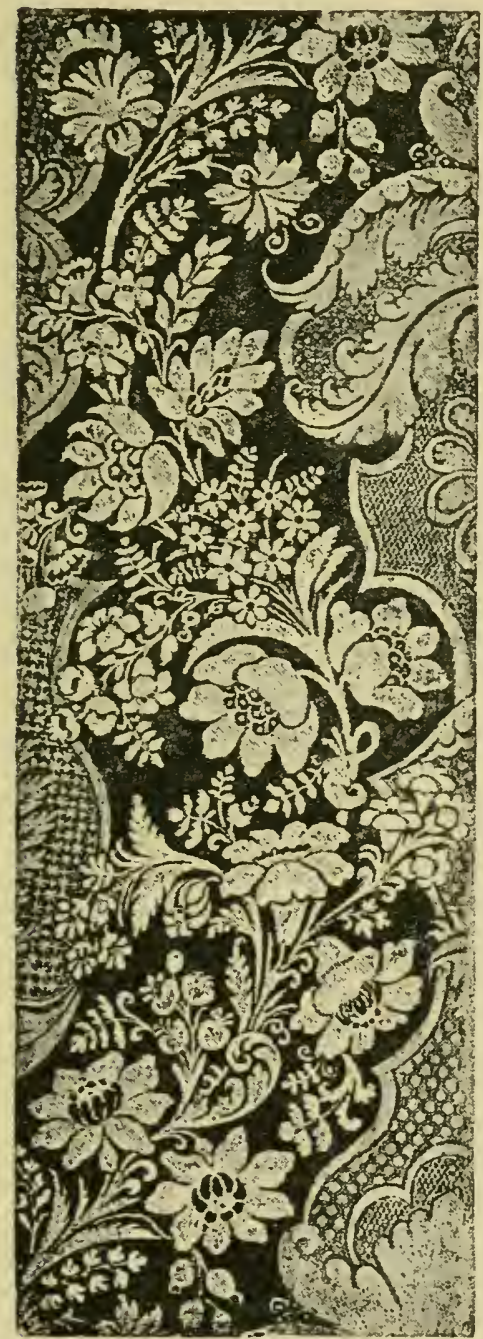

.74. Graceful artificiality

45 , are not especially life-like; but that forms so immediately recognisable as nuts and pea - pods should grow from the same stalk as a flower of five petals, to say nothing of their conjunction with absolutely artificial lines, and with foliage of the usual Renaissance type, is enough very considerably to discount the charm of an exceptionally graceful and wellbalanced composition. A rather more coherent, and in some ways admirable, version of the pea-pod is given on Plate 46 . 
In the example on p. 97 the offence of ncoherence is somewhat mitigated, inasmuch as the detail is not very real. All sorts of different flowers grow from a single stem indeed, but the stem is not very obvious. There is a kind of natural confusion in the foliage, and the types are not strongly pronounced. Everything is uniformly graceful

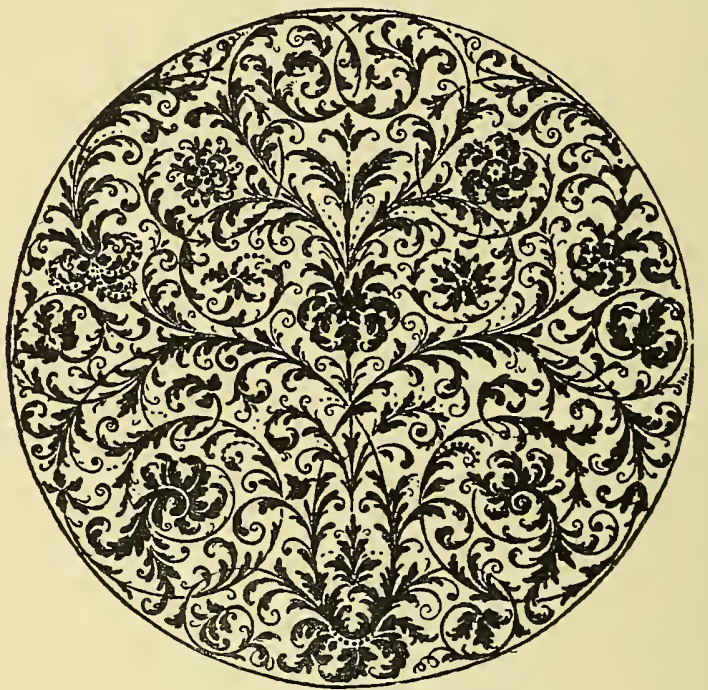

75. De-naturalised floral details.

and artificial, and the unreality of the detail prepares one for the violation of natural growth. Even then it is hard to forgive it.

Much the same criticism might be passed on the less graceful panel in the centre of Plate 47. The manner in which flowers of various kinds grow from a common stem is 
Plate 46

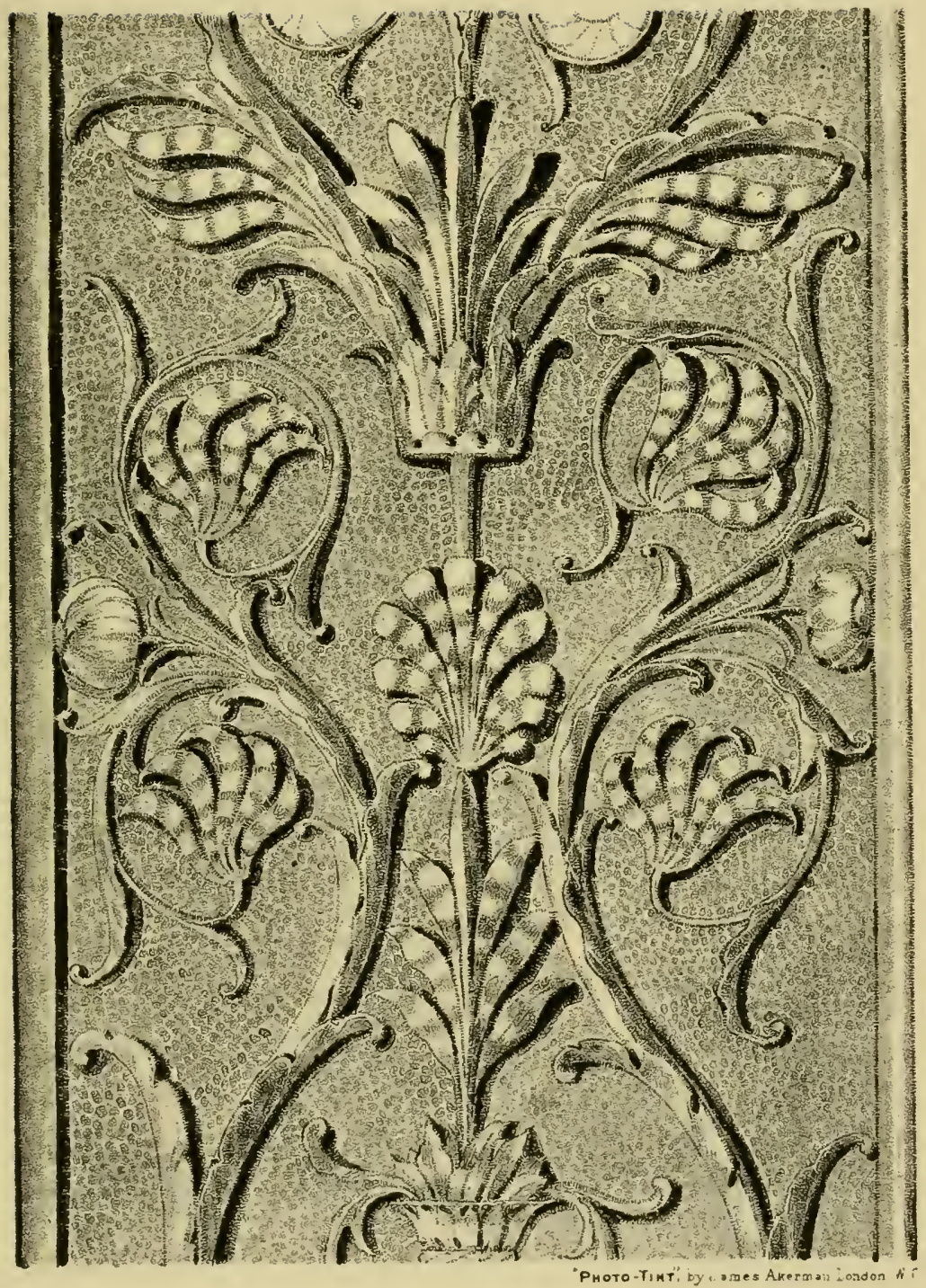

Pea-pud (Ornamerit, Renaissance. 

Consistency in Modification of Nature. 99

of the eighteenth century, not of nature. In the panel at the top of the plate there is less shock to us, inasmuch as the details are more distinctly ornamental: the danger in design of this kind is in proportion as the details assert their natural identity. Better denaturalise them altogether, as in the ornament on p. 98, than jumble up all manner of detail into a quite heterogeneous whole.

It is easily understood why eighteenth century designers mixed their types so recklessly. They aimed at effect, at any price; and consistency was, in their eyes, a very small price to pay for it. By making lilies and roses and daisies and pomegranates all branch from one stem, it was easy to get variety and contrast. The more consistent way would have been, of course, to intertwine one stem with another, and so account logically for the variety in detail.

It would be comparatively easy for us to get the qualities of eighteenth century ornament, if we were willing to pay the same price for it. Art and puritanism have not much in common, but even the artist may well be puritan enough to sacrifice something of effect for the sake, I will not say of honesty, but of consistency. $\mathrm{He}$ is quite free to efface, if he like, the natural type; 
but, once it asserts itself, it binds him to a certain adherence to natural growth and detail. $\mathrm{He}$ is not justified in pocketing his conscience. His details may bear, if it so please him, but the vaguest resemblance to leaves and flowers and fruits; but if they are recognisable as such, they must grow as such : a stem, for example, has no business to grow two ways at once.

Moreover, the artist will instinctively select his types: he will not associate compound leaves with lily flowers, or simple leaves with pea blossoms. If the growth of his ornament suggest a forest tree he will not fill-up with tendrils. If the fruit suggest an acorn he will not decorate the stalk with thorns. Where the flowers occur singly he will not make berries in clusters; or if the flowers form a spike he will not make the fruits droop. He will not make apple blossoms develop into acacia pods or daisies into gooseberries.

According to his acquaintance with nature, and to his artistic sense of fitness, he will abstain instinctively from incongruity, and conform at least so far to the law of order, that there shall be in his design no suggestion of conglomeration; it shall be one growth, reminding you of nature or not, but in any case consistent with itself.

If several flowers are used in combination 


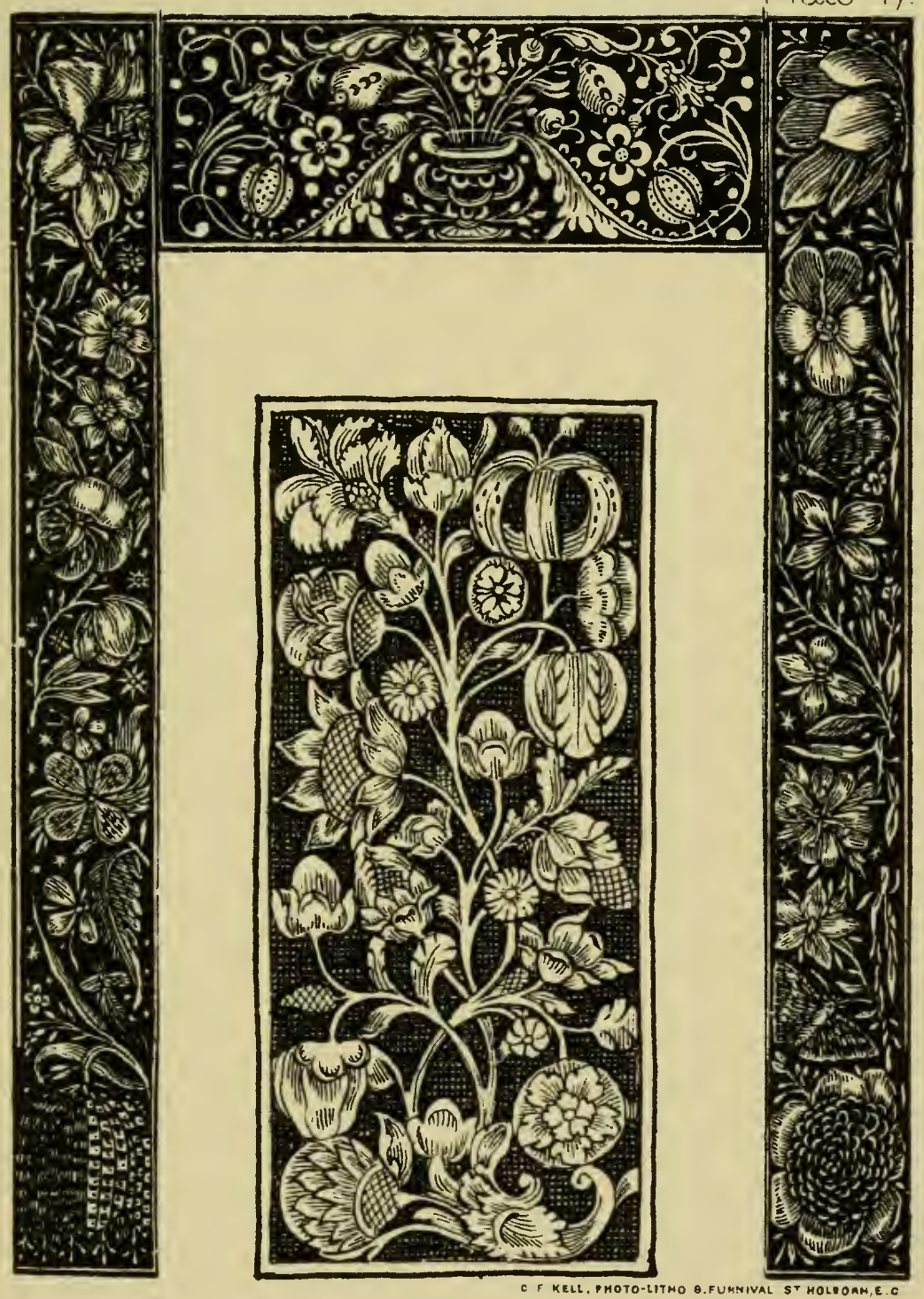

Dutch \& Cerman Comentions of the 17. Century. 

Consistency un Modification of Nature. I I I

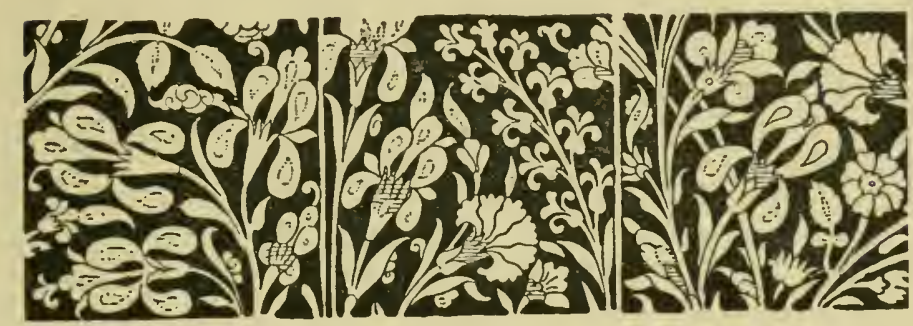

76. Confusion of effect without confusion of growth.

each should have its identity. The ornamentist chooses naturally, where he can, the types in nature most amenable to ornament. But, apart from the fact that many of the most accommodating have been long since, as one may say, appropriated, there are cases in which he is bound to use such or such a plant, which may possibly be very awkward to deal with in the way of ornament; and one very obvious and convenient way out of the difficulty is, to associate with it some other plant or plants complementary to it, by help of which the qualities lacking in the original plant are supplied.

Yet there is no necessity that the various flowers, fruits, and what not, should all grow from one stem. In the side borders on Plate 47, mere disjointed sprays of flowers are fitted together, without producing any very unpleasant effect of disjointedness, which of two evils would certainly be the lesser.

In the detail of Damascus tilework above, 
the separate flowers have separate stalks. It may not be easy always to get rid of so many stalks in the composition, but in the intertwining of them there arise fresh possibilities in design-if you are man enough to seize the opportunity.

Another way out of the difficulty of combining various floral forms is to introduce the one only as the undergrowth to the other, as shown on Plate 48 . By this means it is possible to contrast bold with delicate detail, broad masses with broken surface, without doing violence to natural laws.

How far one is bound to adhere strictly to the lines on which a plant grows, and to the character of its detail, depends to some extent always upon the purpose of the artist; only in strict fidelity to that purpose lie the possibilities of perfect art.

What if even great artists have been guilty of all manner of inconsequence in design? They are so much the less to be trusted as safe guides in the matter of taste. One may find authority for any kind of ill-doing. The accepted precedents are not all of them sound by any means. Every precedent should be stripped of its prestige, and scrutinised as carefully as the newest of recruits, and the ricketty ones dismissed from the service of art, relentlessly. 
Plate 48

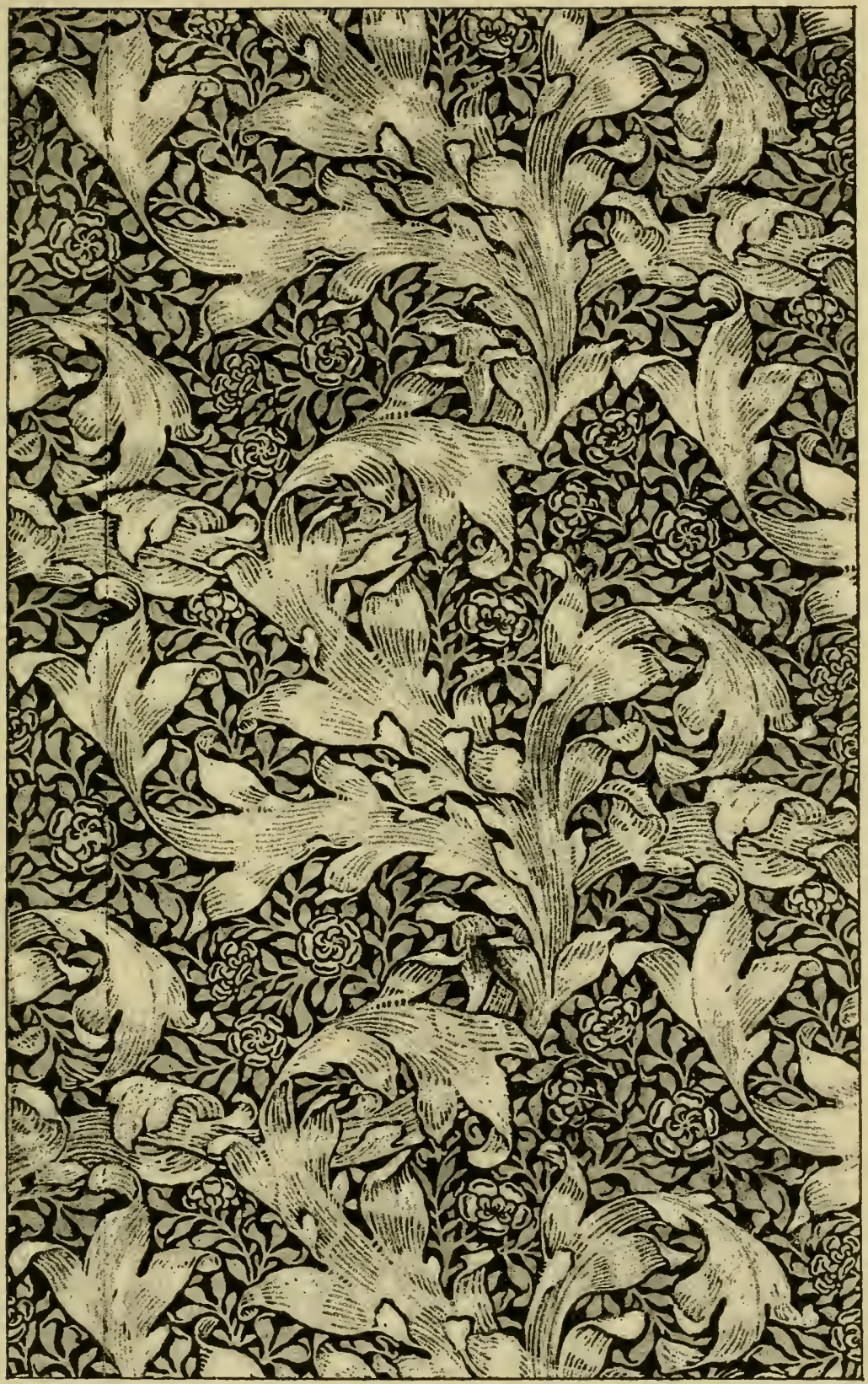





\section{IO3}

\section{VII.}

PARALLEL RENDERINGS.

THE study of ornament should proceed pari passu with the study of vegetable forms-not botany necessarily.

The scientific study of botany is quite a thing apart. The ornamentist has no more occasion for exact scientific knowledge than the painter has need to know surgically about anatomy, no more occasion and no less. We want, in either case, just science enough to enable us to see the surface of things, and no more. The classification of a plant according to its hidden organs is as nothing to us compared with its character, its beauty, the hint in it of ornament. Its order and its family concern us only as they affect its outward development and growth. We need not greatly concern ourselves in pulling flowers to pieces. An artist can do with comparatively little science, if only he make full use of his eyes.

Suppose the student in ornamental design 


\section{4}

to have begun by being thoroughly well grounded in practical geometry; soon he might proceed to put together, somewhat on the kinder-garten system, geometric patterns, simpler or more complex according to the degree of his ingenuity. Then, as he grew beyond this elementary stage, he might exercise himself in drawing freer and more flowing forms-say, until he acquired facility in sketching off (with the brush) ornament of the kind the Greek pot-painters drew with such freedom (p. I 52).

Simultaneously with this he should be making intelligent studies of leaves, flowers, fruits, and all manner of details of plant-form and plant-growth. With equal diligence he should be studying the masterpieces of applied design, especially noting the way the masters treated those same natural forms, and always choosing his model, whether of plant form or of ornament, for the definite reason that it meant something to him.

His studies should be carried just so far as their purpose warranted: there should be no attempt to make pictures of them, or showdrawings, or to make them even presentable. What the student has to do is to make notes serviceable to himself, sufficient in every case to impress upon his memory what the original 
Plate 49.

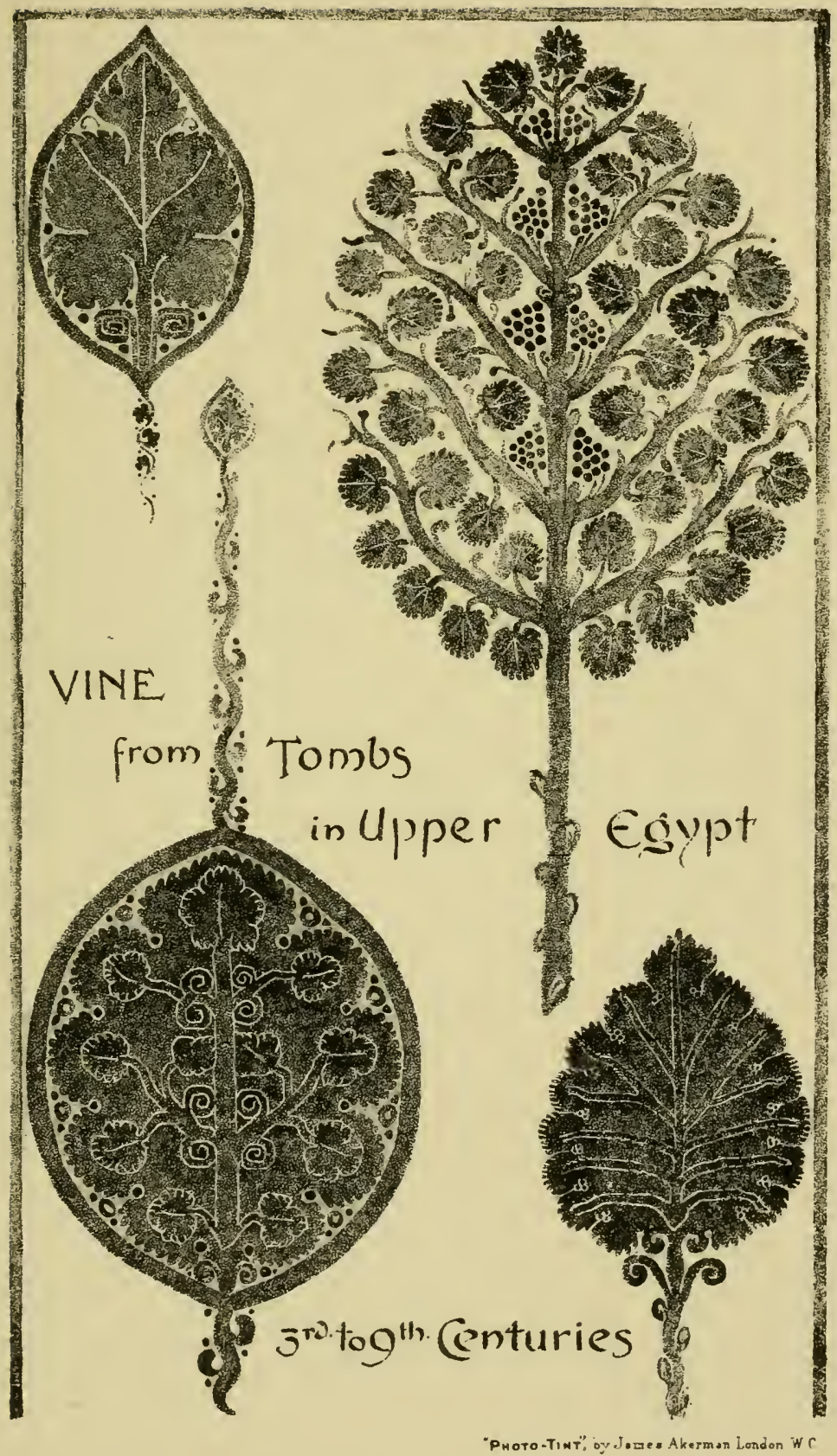

Ancient Coptic Embroidery. 



\section{Parallel Renderings.}

conveyed to him, records of what he wanted to record, that is all.

The urgent need of choosing each example needs the more to be insisted upon, because the designer cannot too early begin to cultivate the selective faculty. Judgment is onehalf the battle in decoration.

The closer the relation between a man's studies from nature and his studies from old work the better. Take, for instance, any flower you like and study it from nature carefully -its form, its structure, its growth, its colour, its character; then see how it is rendered in Classic art, in Gothic, in Renaissance, in Japanese, in Persian, and so on. Observe again its treatment in sculpture, in inlay, in metalwork, in textile fabrics, and what not. A series of such exercises conscientiously and thoroughly done, would be an education in itself, and would in some degree fit one to conventionalise on his own account - all "without the aid of a master."

The already mentioned partiality of each particular period and country for a certain few, usually symbolic, types (p. I2), makes it impossible to trace any one single natural form through all history; but you can trace most forms through a great variety of historical developments. 


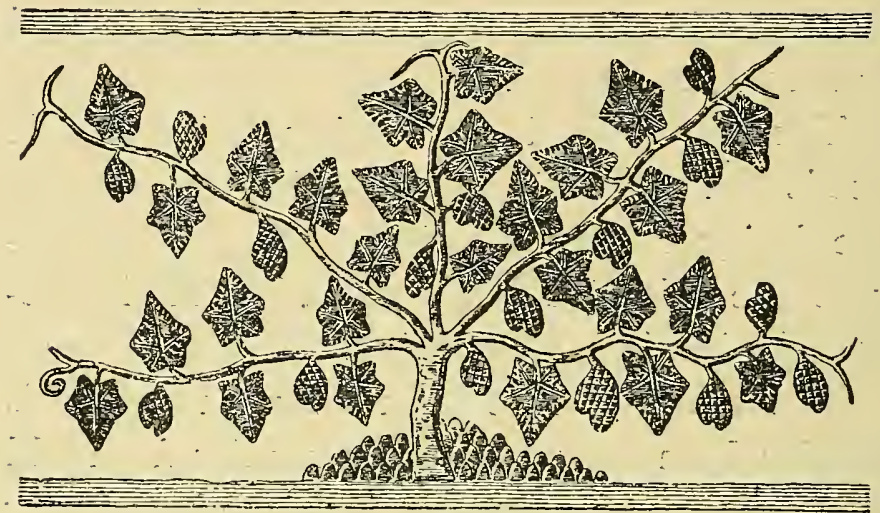

77. The vine in Assyrian sculpture-r.c. 705-626.

The type of most universal occurrence in ornament is probably the vine, symbol of philosophies as wide apart as the poles. We find it in the bas-reliefs of Nineveh, and the painted decoration of Egypt; on Etruscan vases, and Greek and Roman altars; on Byzantine sarcophagi, in Coptic embroideries, and in early Sicilian silks; it recurs in every form of Gothic art, and throughout all phases of the Renaissance.

In the Assyrian treatment of the vine above one finds, of course, the archaic formality of the age of Sennacherib, but at the same time a certain adherence to the natural type which has not varied from that day to this. If the leaves are all spread flat against the wall, they are quite unmistakable in shape. If the branches are symmetrically displayed 
Plate 50.

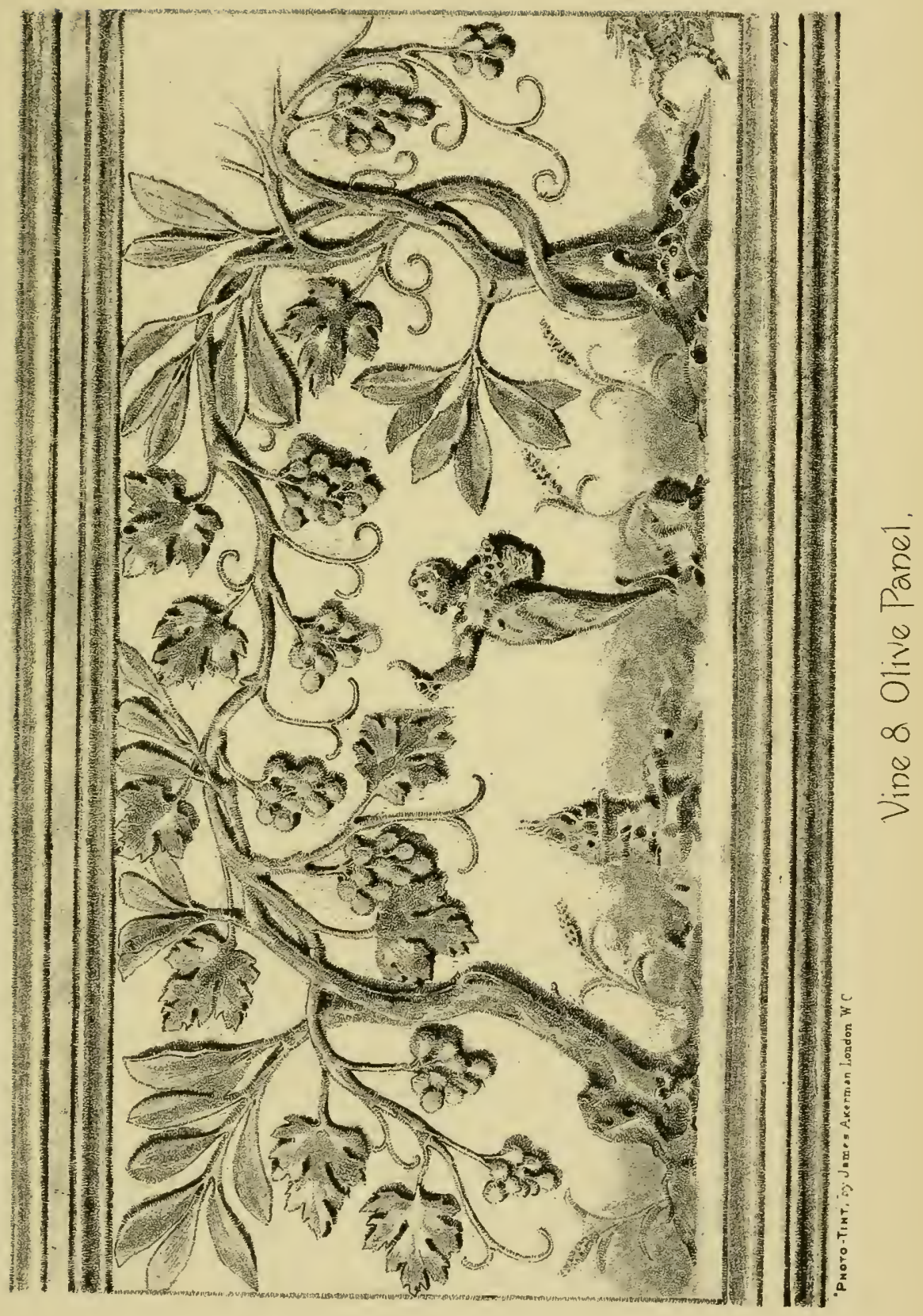



there is a suggestion in that of the way fruittrees are still trained in modern orchard houses. Again, there is a sort of natural spring in the lines themselves; and in the arrangement of the five branches (which is not according to nature) one seems to see a reference to the veining of the vine-leaf. At all events, this arbitrary grouping is so characteristic of the Ninevite sculptures that it can scarcely be accidental, and must almost certainly have some symbolic meaning. The irregular shape of the Assyrian grape bunches is a curious concession to nature, seeing that some of them stand up on end, and that the grapes are just square. It will be noticed that leaves and fruits do not occur in the order in which a botanist would place them, and that the tendrils are made use of only as a convenient means of ending off the branches.

On Plate 49 is a Coptic rendering from a tomb in Upper Egypt, which is equally archaic, but infinitely more ornamental. Observe the reticent use of grapes, their systematic arrangement, and the fact that they also stand on end. The vine-leaf on the same plate, veined, as it were, with a growth of vine, is also extremely curious. The way in which the tendrils ornament the stem is worth noticing. 


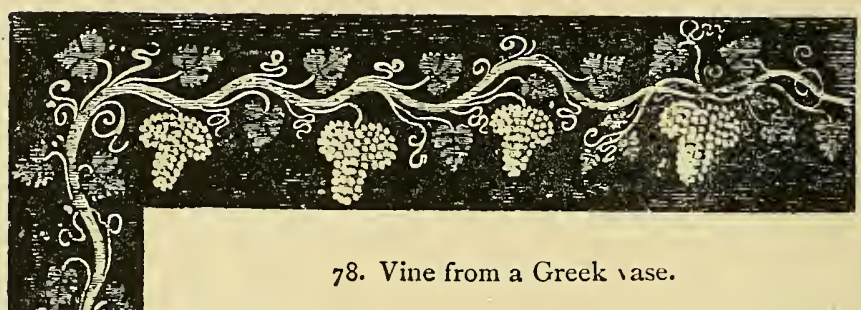

The Greek treatment above is, if not more natural, at least more florid. The stem indeed diminishes in thickness towards its extremity, and is clothed at the same time with smaller leaves; but the stem itself is a mere wave-line, and the leaves, though founded on a more graceful natural variety than the Assyrian, are less unmistakably vineleaves.

It is a rather curious thing in the decorative treatment of the vine in early art, that although there is no plant growing which varies more as to the shape of its leaves-heart-shaped, round, angular in outline, divided into three or five, the divisions deeply cut or scarcely noticeable, sometimes not seen at all-it is yet the rarest thing in the world to find in any ornamental version of the plant more than a single type of leaf. That is one point at least in which there is opportunity for a new departure in design, and to considerably ornamental purpose. 
Plate 51

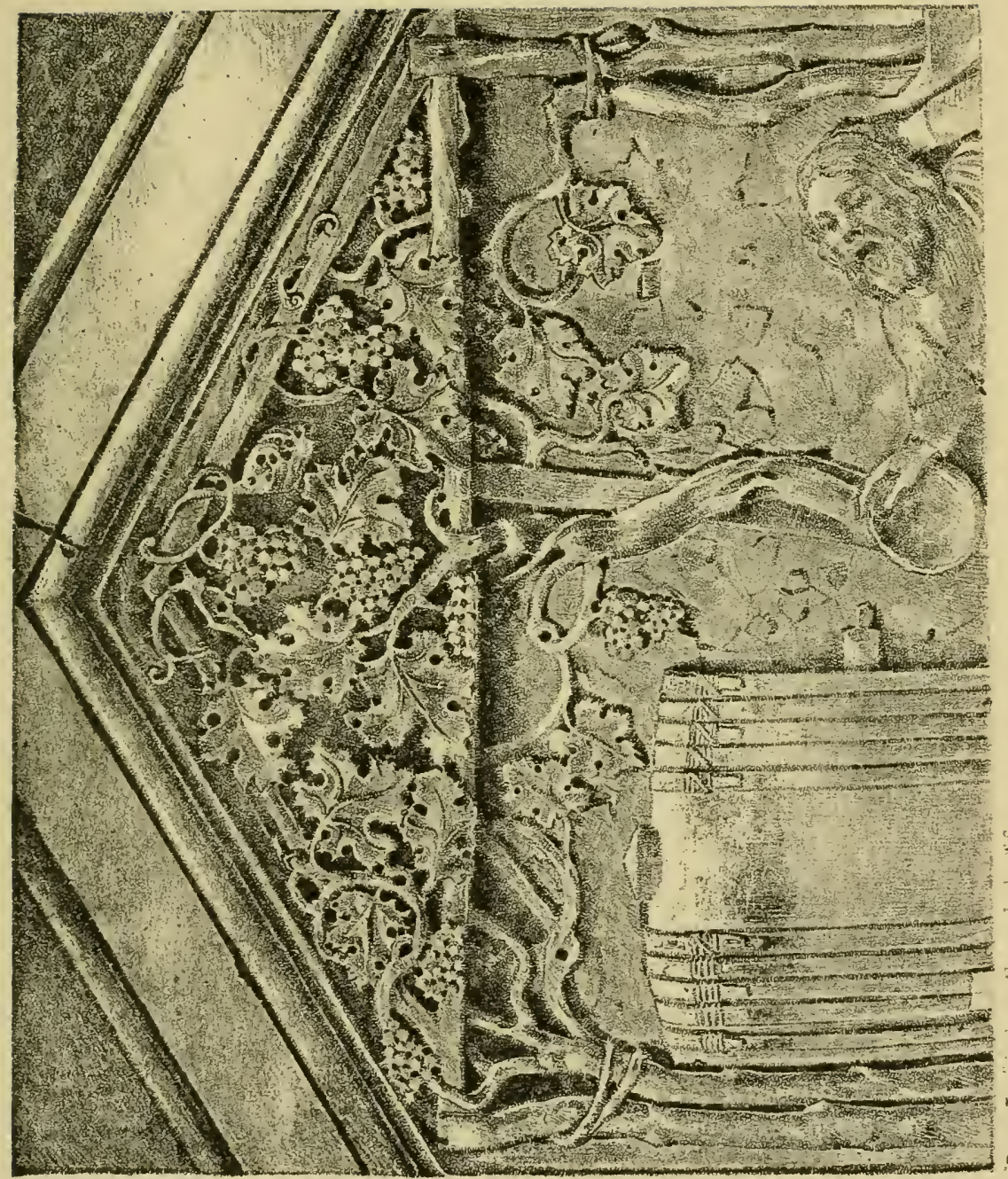

5
5
$\frac{5}{5}$
$\frac{5}{0}$
$\frac{5}{6}$
$\frac{6}{5}$ 



\section{Parallel Renderings.}

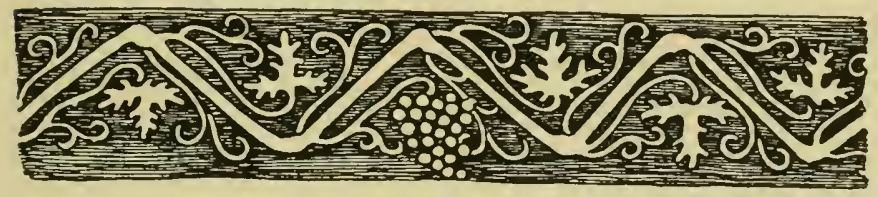

79. Pompeian vine border.

The tendrils in the Greek vase painting are, for the most part, more obviously twirls of the brush than transcripts from nature; even when they are branched they take the lines of our old friend the spiral scroll, and are graceful where in nature they would be vigorous; there is never anything like clutch in them. The artist seems sometimes just to have realised that leaf and tendril grew from somewhere about the same point on the stem, but no more. If he had any definite idea at all of the relation between leaf and tendril, it would appear to have been the erroneous notion that the leaf grew from a point of junction between the tendril and the stalk.

Perhaps the most natural thing in the design is the way in which it is composed, very much in the way of the trellis-another method of training that has survived without change from the beginning of vine culture. The bunches, besides, do hang down, obedient to the law of gravity.

A more formal Greek rendering occurs in the disc on l'late 24 , but in both cases the 


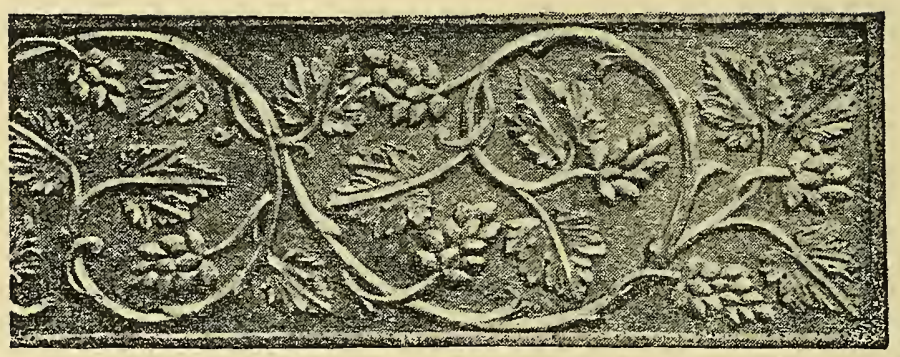

80. Italian wood-carving-hop or vine?

grape bunches are much the same in outline.

In later Classic sculpture, especially in Roman work, the vine-leaf is often represented naturally, only again without the variety of nature, one shape doing duty throughout. And here also we find the tendrils always deliberately made softer than in the living plant. They have no inclination to twine themselves round anything; they are not much more than graceful scroll lines. What growth there may be in them is certainly not studied from the particular plant. Leaves, tendrils, fruits, occur wherever the artist has occasion for them. There is a touch of nature in the thickening of the leaf-stalk at its base, but this feature also is softened down to gracefulness; it is rather suggested than expressed. The very grapes are frequently reduced to bunches of five or seven.

They are rather fuller on Plate 50. The 
Plate 52

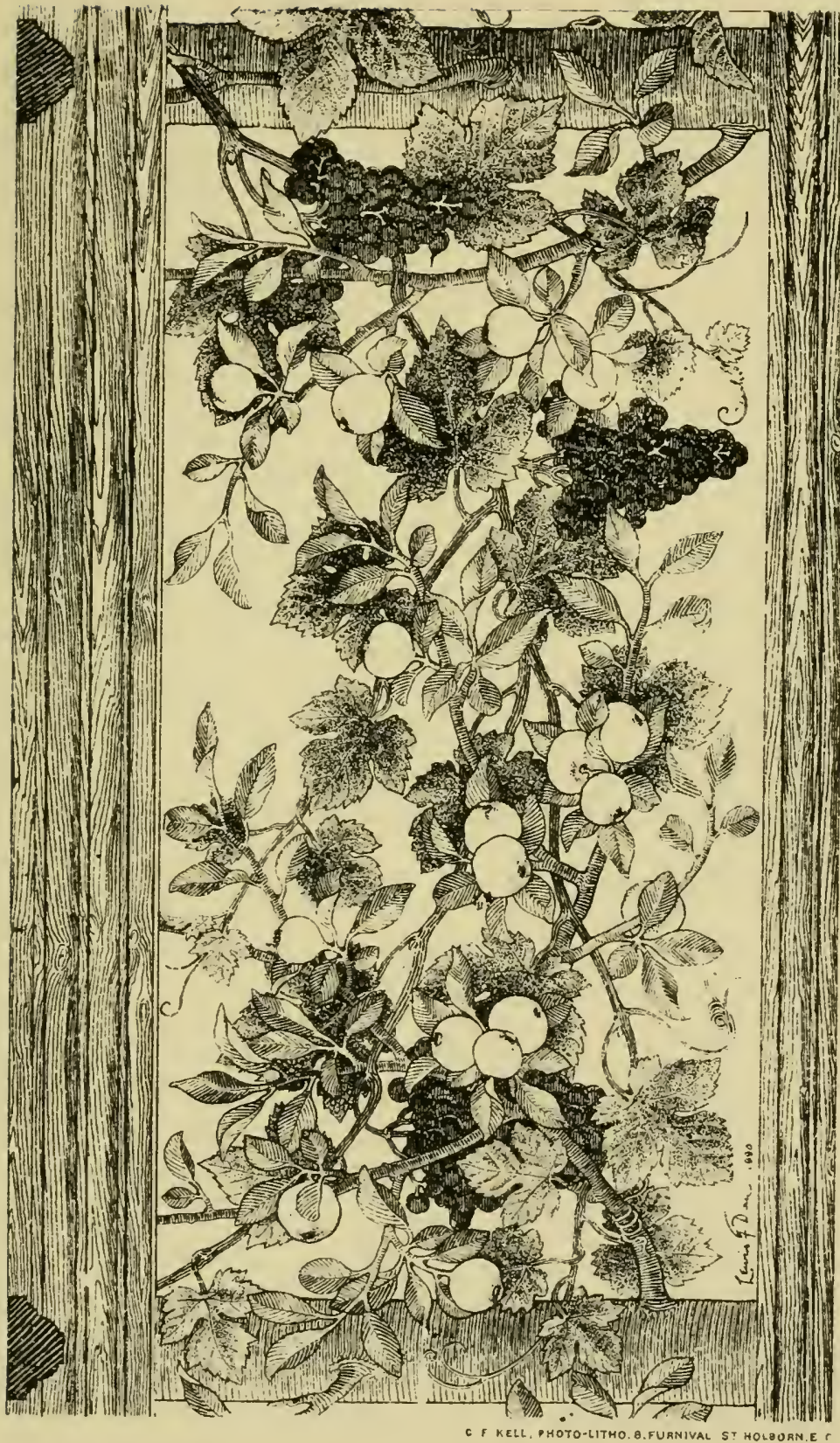





\section{Parallel Renderings.}

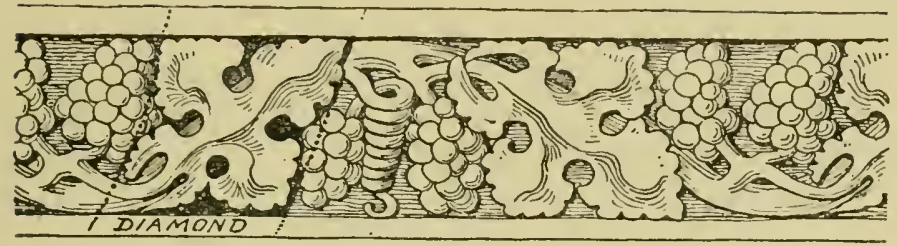

8r. Conventional Gothic vine and grapes.

disregard of natural scale in this design is as frank as in the Assyrian treatment. It is strange to find, in connection with such an arbitrary rendering, anything so realistic as the knobby bowls of the olive trunks, which are as cavernous as you see them in nature.

Again, in the vine from Giotto's Tower, at Florence (Plate $5 \mathrm{I}$ ), the artist, contrary to the usual Gothic practice, has thought fit to support the vine, perhaps because the leafage, distinctly ornamental as it is, is intended to represent a vineyard. It forms a sort of canopy over the subject of Noah's drunkenness.

In the more natural frieze of my own, on Plate 52, the vine is supported by appleboughs: the upright trunks of the trees, corresponding in position to the beams in the ceiling, form a marked feature in the design.

Among the Græco-Roman details on Plate 53, the grapes are rather more natural than the leaves, which are in one case just the reverse of natural. The leaf cut in cameo 


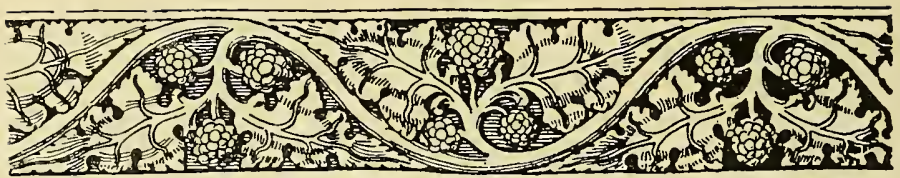

82. Gothic vine, with mulberry-like grape-bunches.

is, however, at once natural and ornamental. In the embossed silverwork a distinctly ornamental character results from the employment of the stems, tendrils, and fruits only: the same thing occurs in later Classic sculpture.

In the border from a Pompeian bronze in the museum at Naples, on p. I09, the thickening of the leaf-stalk is indicated; but the growth is again absolutely arbitrary. The leaf, though like enough to nature, could not be identified with any degree of certainty, were it not for the accompanying grapes and tendrils : but for that evidence it might just as well pass for maple, or cranesbill, or hibiscus leaf.

Such corroborative evidence of identity is often needed. In the process of adaptation to ornamental conditions the unmistakable character of a plant is not uncommonly eliminated. One is perplexed, for example, by the Italian wood-carving on p. I IO. According to its tendrils it should be a vine, but its fruits are more like hops. In Gothic ornament one has, once more, frequently to take the vine-leaf on 
Plate 53.

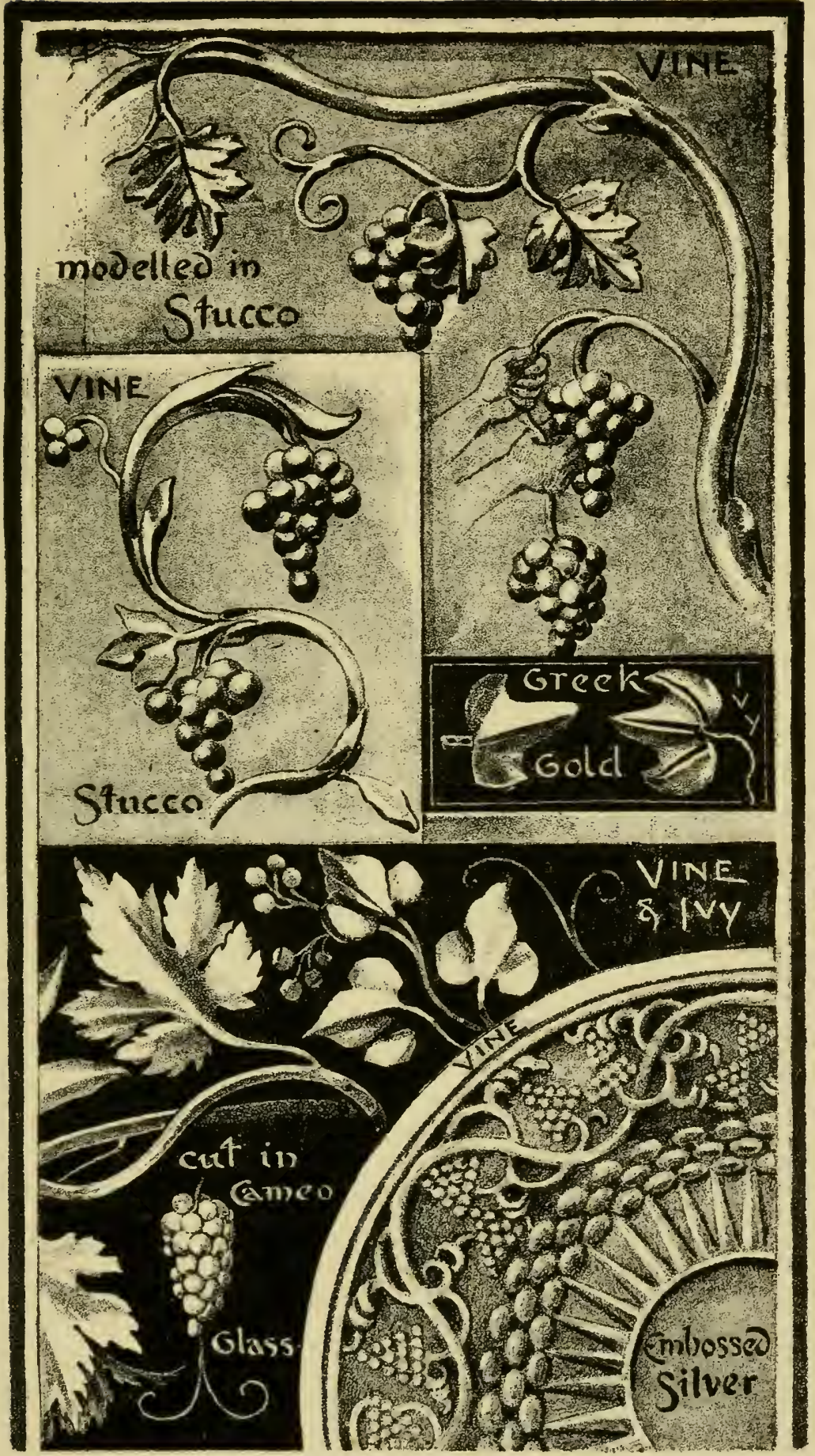

"Pnoro-TInt", by Jemes Akormon Losdon W C.

Clasical rendering of the Vine. 



\section{Parallel Renderings.}

faith, failing grapes, and more particularly tendrils (p. 59 and Plate 29).

The grapes are sometimes as remote from nature as the leaves, and the scale to which the bunches are reduced often removes them

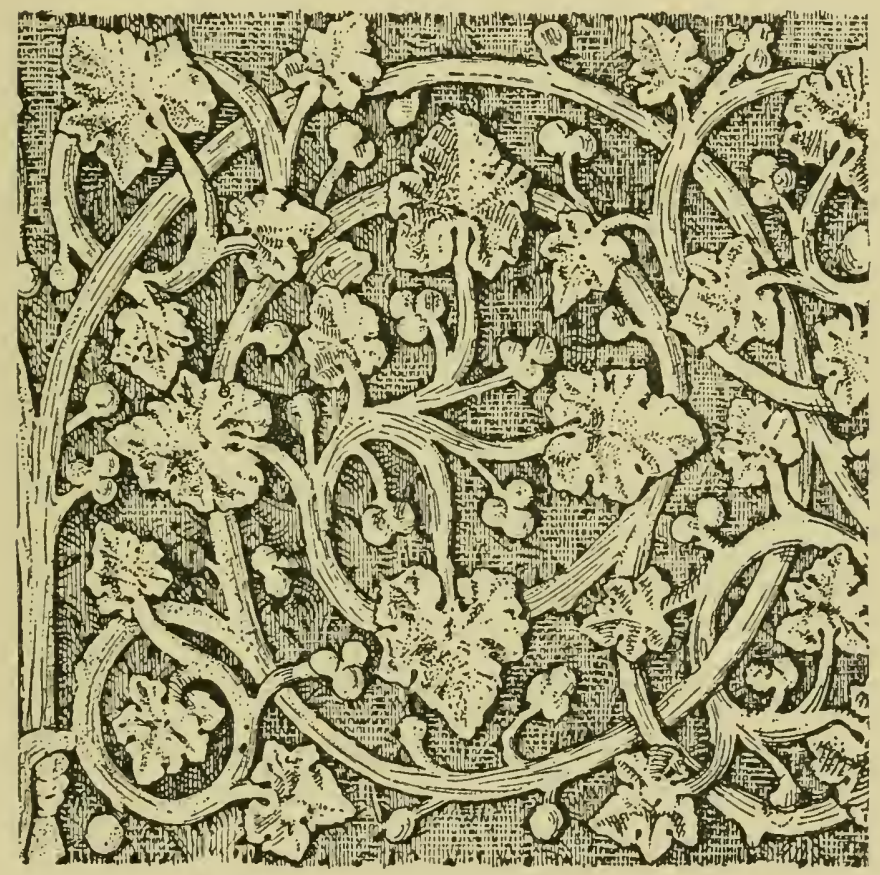

83. Conventional vine, from Toledo.

still further from recognition. It is possible that the mulberry is sometimes mistaken for the vine. Many a conventional vine leaf (as for example on P. II I) is much more like the leaf of the white mulberry of Lombardy 
than it is like a vine-leaf; whilst the compact little bunches of diminutive berries look occasionally much more like mulberries than any grapes one has seen. In the border on p. II 2 they might almost be blackberries. It is possible also in Gothic w ork to confound them with the berryspike of the wild arum.

It is only our familiarity with similar conventions which enables us to understand that the GothicoMoresque foliage on $\mathrm{p}$. I 3 stands

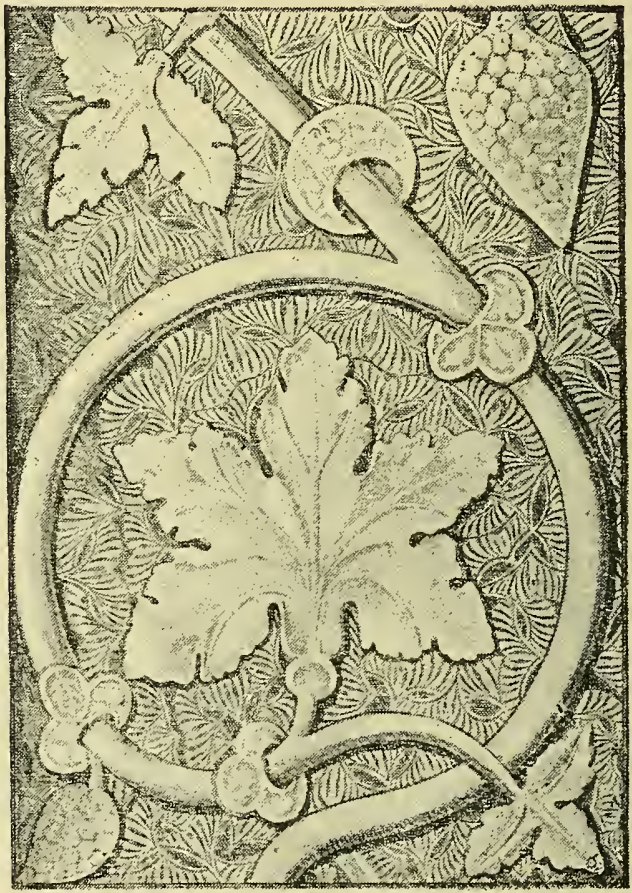

84. Moorish vine. for the vine. For growth the Moorish sculptor has simply branched a spiral line. His vineleaves would answer at least as well for bryony leaves, and his berries would do as well for bryony berries. His reason for bunches of 
Plate 54

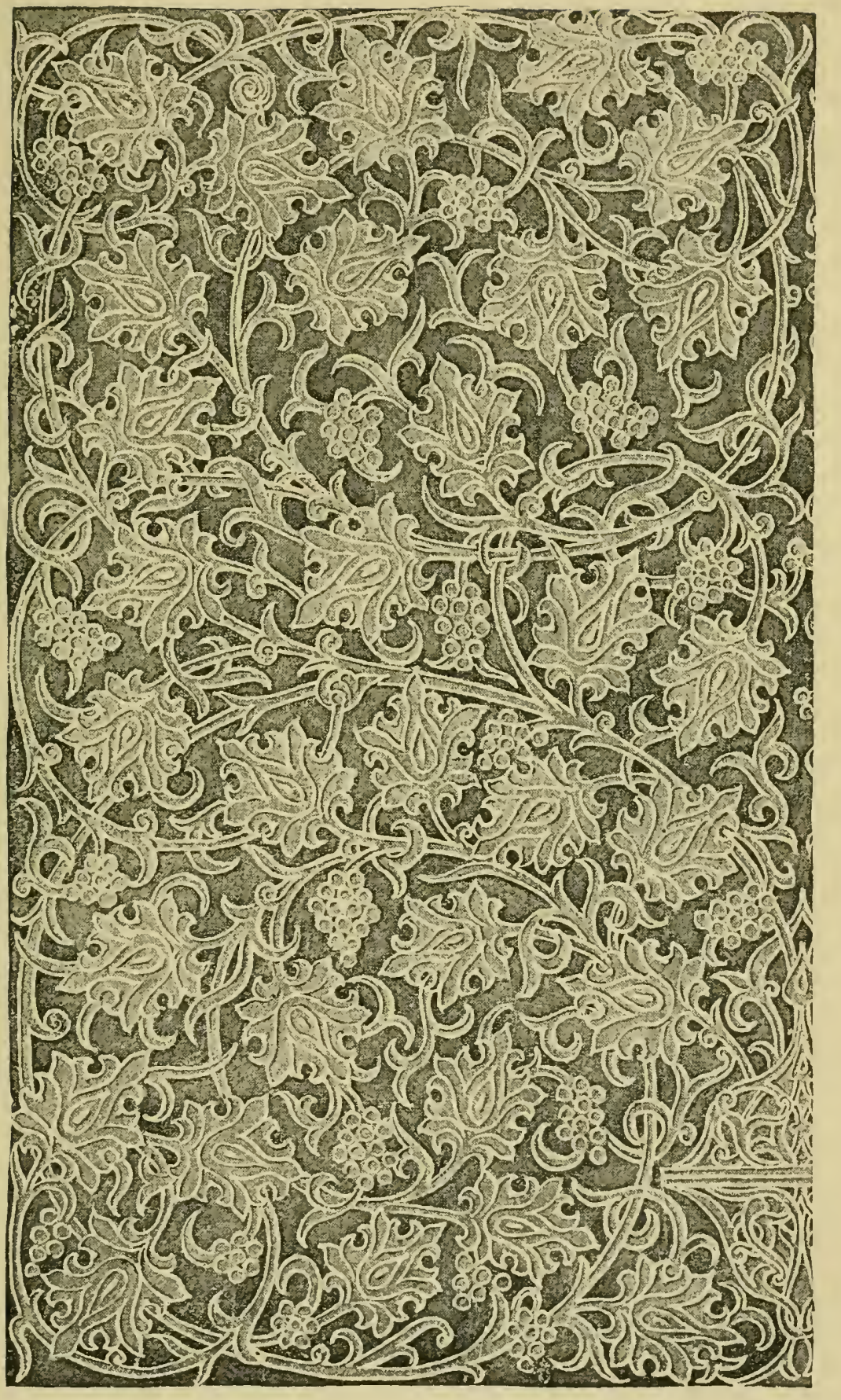

Arab Vine panel 



\section{Parallel Renderings.}

three was doubtless symbolic. He has not bothered himself about tendrils at all. Probably he was happiest over his diaper behind the foliage, which [though the illustration does not show it] is Moorish ornament pure and simple.

An equally arbitrary Moorish rendering is given on p. II4. It is clear the sculptor was more at home in Saracenic ornament than in nature.

The more resolutely ornamental vine, of pure Arab carving, on Plate 54, is, curiously enough, far more suggestive of
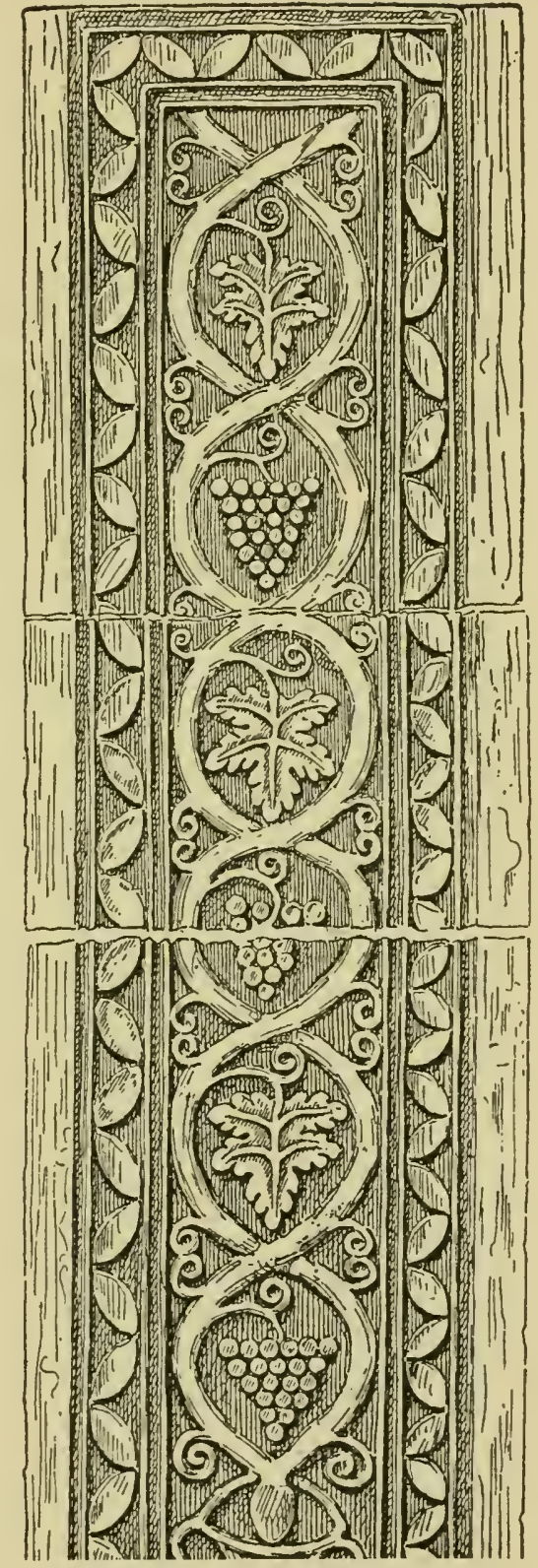

85. Naľve Byzantine vine. 
nature, whilst professedly avoiding it. The

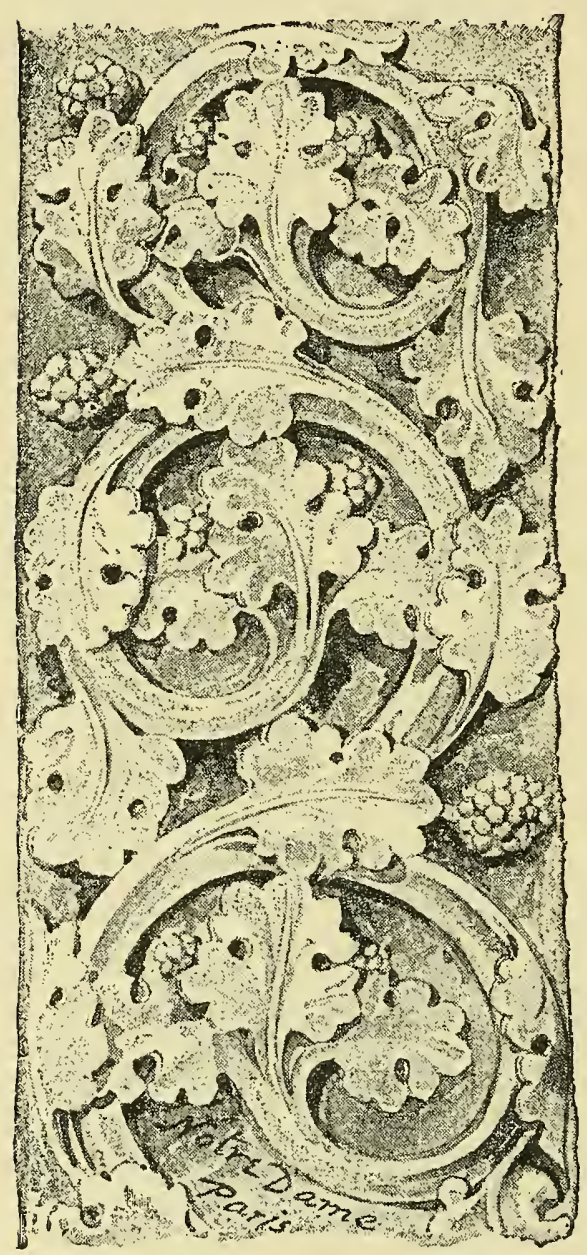

86. Early French Gothic. treatment of the tendrils is a peculiarly happy feature in a most satisfactory design. As a representation of the vine it may not be altogether adequate-it pretends to nothing of the kind--but as a piece of surface ornament suggested by a natural type, it is in its way about perfect.

The Byzantine vine from Ravenna, on p. I I 5, is not without a certain grace, rudely as it is carved. Its growth is distinctly ornamental; and the way in 
Plate 55.

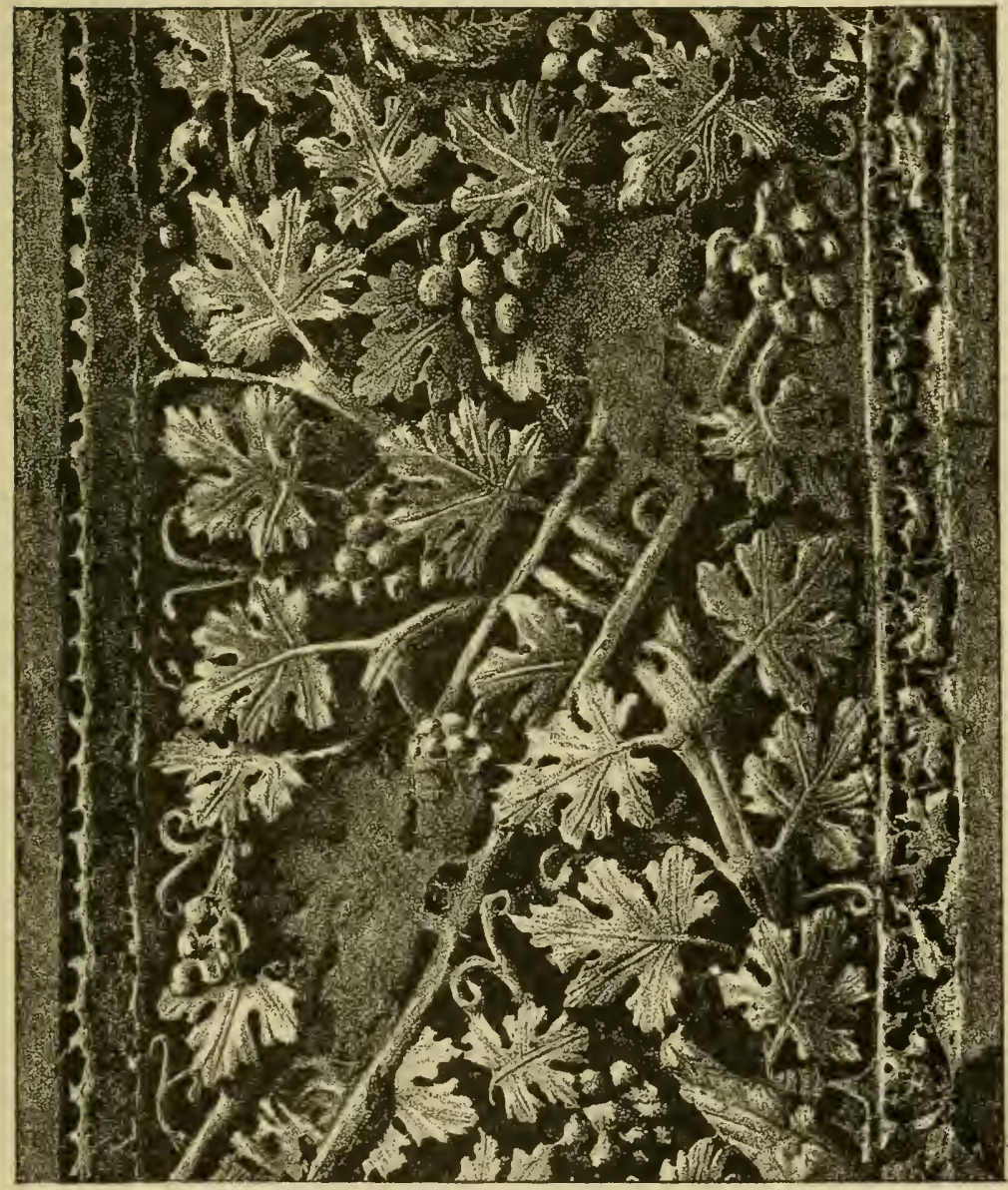

"Рното-Tint", by James Akerman.London.W C

Vine Sculpture. 

which the tendrils are used to fill the side spaces is a most ingenious adaptation of familiar Classic lines to a quite new purpose; the objection to it is that it suggests the growth of the tendrils in two contrary direc-

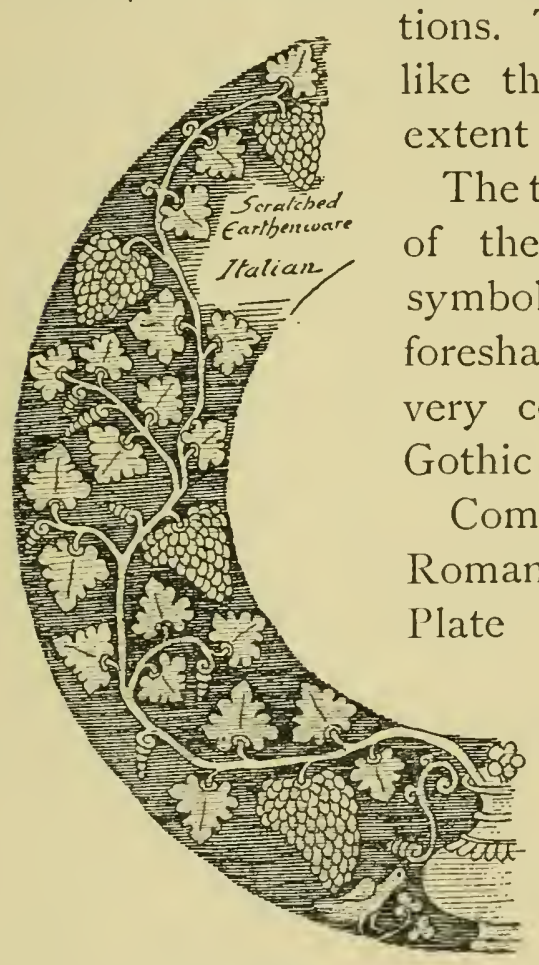

87. Square-shaped vine-leaves.

tions. The charm of work like this lies to a great Tht in its naïvety.

The triangular grouping grapes, at once symbolic and ornamental, foreshadows a treatment very common indeed in

Compared to this the Romanesque vine, on Plate 55, is natural. Conventional as the leaves may be in form, they grow from the stem, which has some of the character of the vinestock. You see even just a hint of that twist in its growth of which Mr. Heywood Sumner has made such admirable use in his stencilled decoration on Plate 56. The way in which the lines 


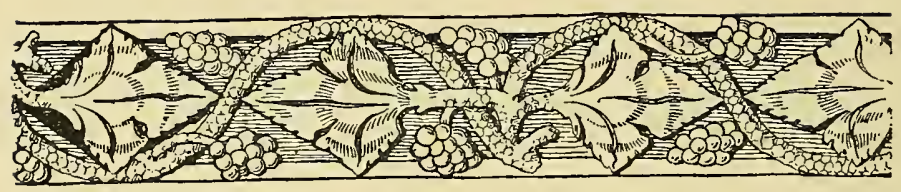

88. Diamond-shaped vine-leaves-Gothic.

of the twisted stems form the necessary ties in his stencil-plate is most artful.

The berries may be taken as evidence that the thirteenth century Gothic scroll from Notre Dame at Paris, on p. I 6 , is meant for the vine; and there is some likeness in the leaves, when one looks for it.

We may take it also, probably, that the still more conventional scrollwork of the early Gothic period did symbolic duty for the vine. In the pre-Gothic circular design on Plate 57, one sees the five-pointed vine-leaf dwindling away to quite a conventional trefoil. It is only in the comparatively uninteresting middle period of Gothic art that we have leaves as much as possible in imitation of nature.

In later Gothic we get design again. The Mediæval sculptors deliberately designed their leaves, as it were, into set spaces-taking a square, a diamond, a circle, a vesica, and so on, as its general outline. The Assyrians did so before them (p. I06), and the Italians after them, as may be seen in the 
Plate 56

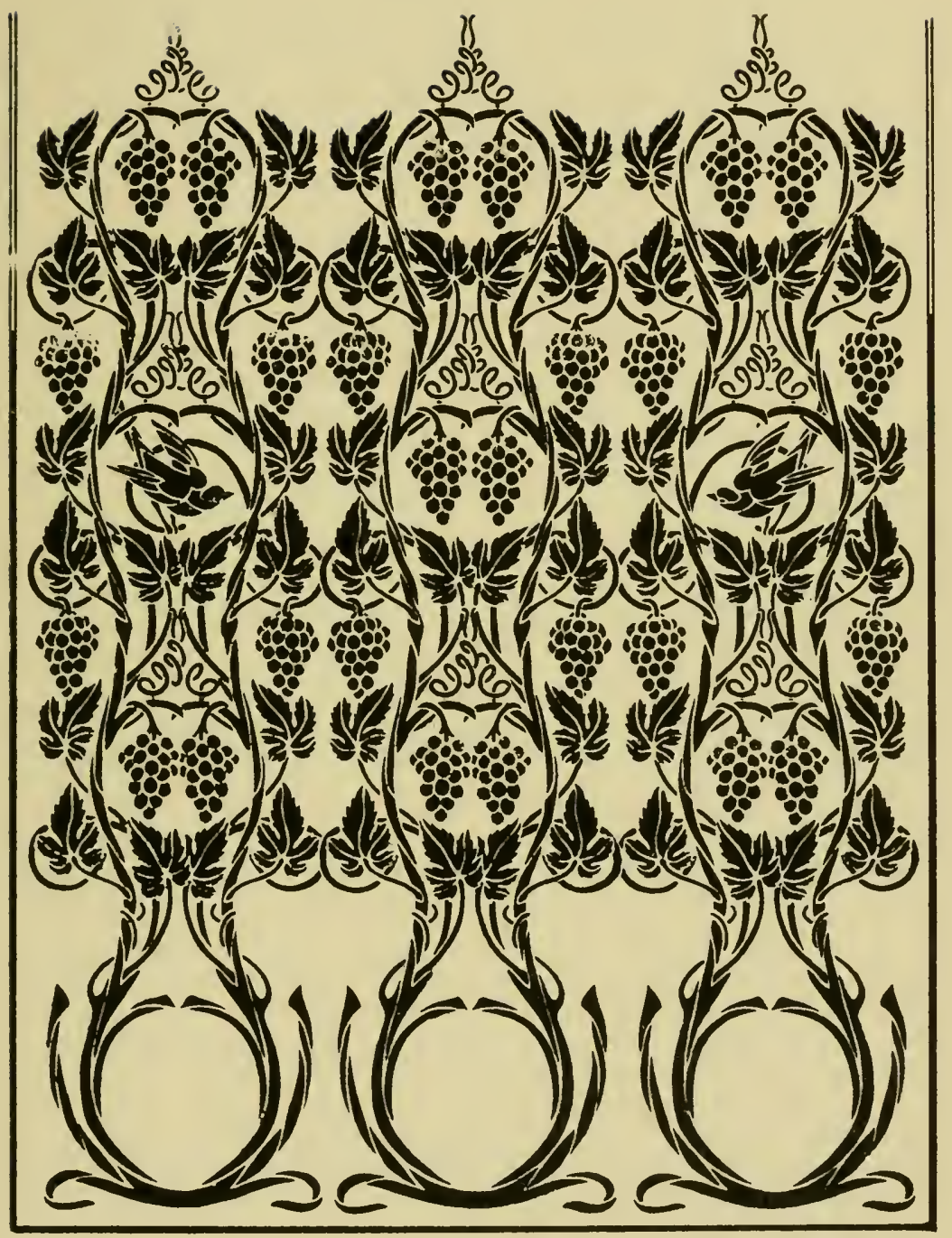

J Akerman. Photo Lith London

Stencilled Vine Decoration, H.Sumner. 



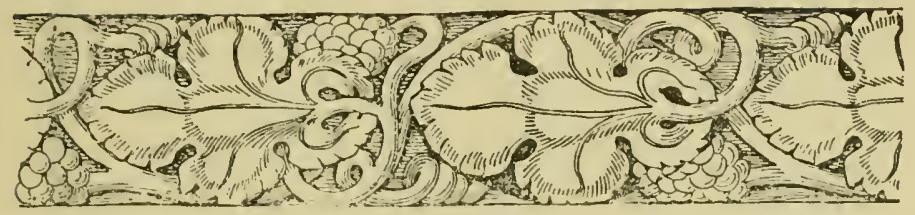

89. Vesica-shaped vine-leaves, York.

vine border on p. II 7 , with the odd shell-like tendrils.

This would come about in a very simple way. They would begin by blocking out the leaf mass, then they would hollow out the main divisions, and finally they would notch the edges. In roughing out the design it would occasionally happen that some other mass-square, diamond-shaped, or what notcame more happily; they would accordingly adopt it, and the leaf needs must follow suit.

Hence such treatment of the leaf as we find on pp. III, II 2, II 8 , and above, where it is designed to conform to an outline of diamond or vesica shape, or made, together with the berries, to fit the spaces formed by the waved stem and the margins of the border. In Plate 58 also it is plain how the leaves are designed, so to speak, into the corners of the panel. It is curious to see just such a system of composition in the Coptic borders of centuries before (Plate 57).

The Gothic sculptor sometimes went so far as to rough out the foliations of his scroll in 


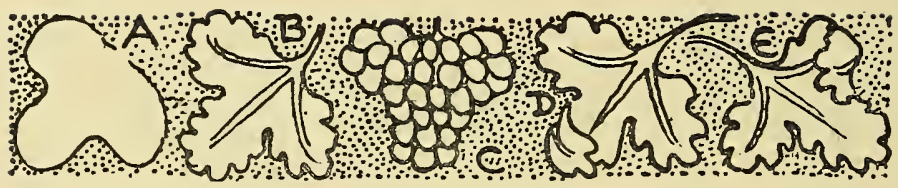

90. Diagram of Italian Gothic treatment.

the form of trefoils ( $\mathrm{A}$, above), leaving it apparently to the inspiration of the moment to determine afterwards which of these should be finished as leaves (B), and which as grapebunches ( $\mathrm{C})$. In a certain case at Padua he went much farther than that, and even turned over here and there a part of the leaf (D and E), without in any way altering its general outline. It came more naturally to him to do obvious violence to possibility than to modify his predetermined outline. This is not mentioned as a thing worthy of imitation, but as an instance of simple-mindedness not without its charm in old work.

In Plate 59, part of the design for a Gothic window, I have endeavoured to follow, more strictly than I have ever seen it followed in old Gothic work, the actual growth of the vine, whilst at the same time very scrupulously fulfilling the conditions of stained glass.

Much as there is to be learnt from the breadth and simplicity of the Gothic treatment of the vine (as of other foliage), it by no means solves for us the problem of treatment. 
Plate 57.

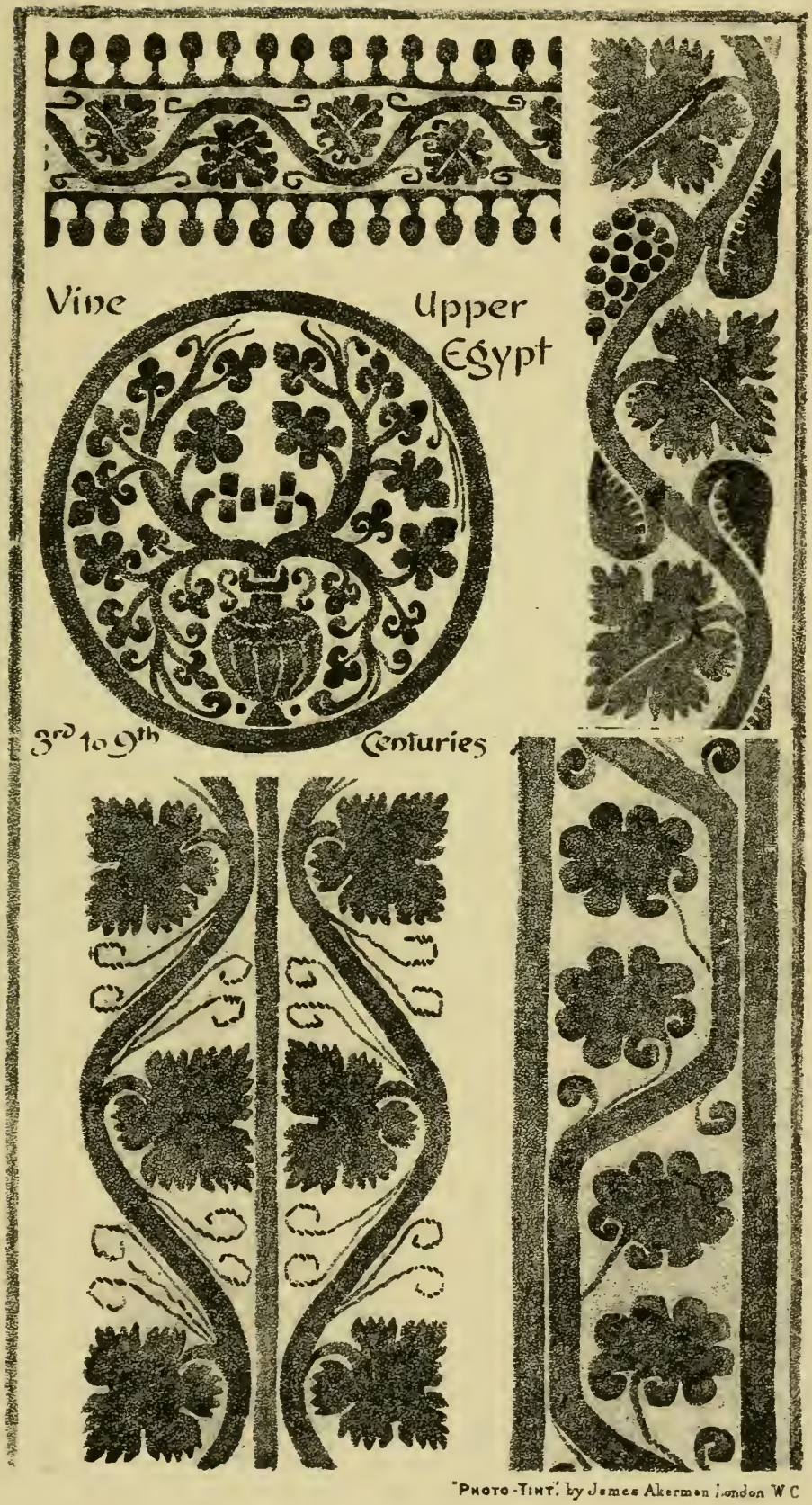

Coptic Vine Ornament. 



\section{Parallel Renderings.}

It is seldom that it shows much appreciation of the essentially characteristic vine forms. One wearies of the regularity of the "ecclesiastical " grape-clusters, and resents their standing up like bunches of privet-berries. Why should we be content with the continual recur-

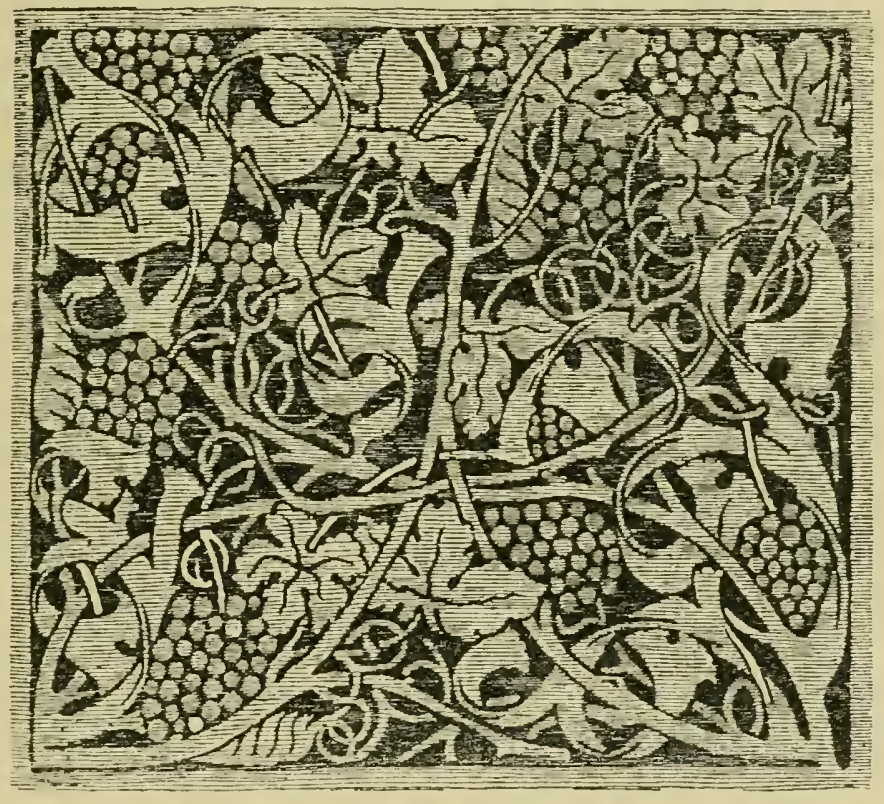

9r. Transitional vine scroll.

rence of one stereotyped pattern, when nature is so varied and that variety is so ornamental?

In later Gothic ornament, and especially as it began to be influenced by the spirit of the Renaissance, it is no uncommon thing to see a scroll that halts between two opinions, 
clearly showing that the artist did not quite see how to reconcile the one with the other. In the instance of this given on P. I $2 \mathrm{I}$, the rather loosely drawn leaves contrast curiously with the purely conventional foliation proceeding from the same stem; and yet, for all the hesitation of the artist, the general effect is that of direct and accomplished workmanship. Here the main lines of the stem remind one more of fifteenth century Gothic window tracery than of growth. The ornamental arrangement of the tendrils is ingenious, and so is the way the grapes form a sort of diaper on the background. This is a device not uncommon in late Gothic work, especially German work-that, for example, of Albrecht Dürer.

Dürer, to tell the truth, had but a poor invention in ornament-his facile pen is continually running away with him; his flourishes remind one too much of the writing-master of a more recent generation. The vine scroll on Plate 60 is an exceptionally good specimen of the great draughtsman's ornament, but it misses at once the grace of nature and the dignity of ornament. Only in respect to the variety in the size of the grapes, and the looseness of the bunches, does it approach more nearly to nature than the earlier 
P1ate 58

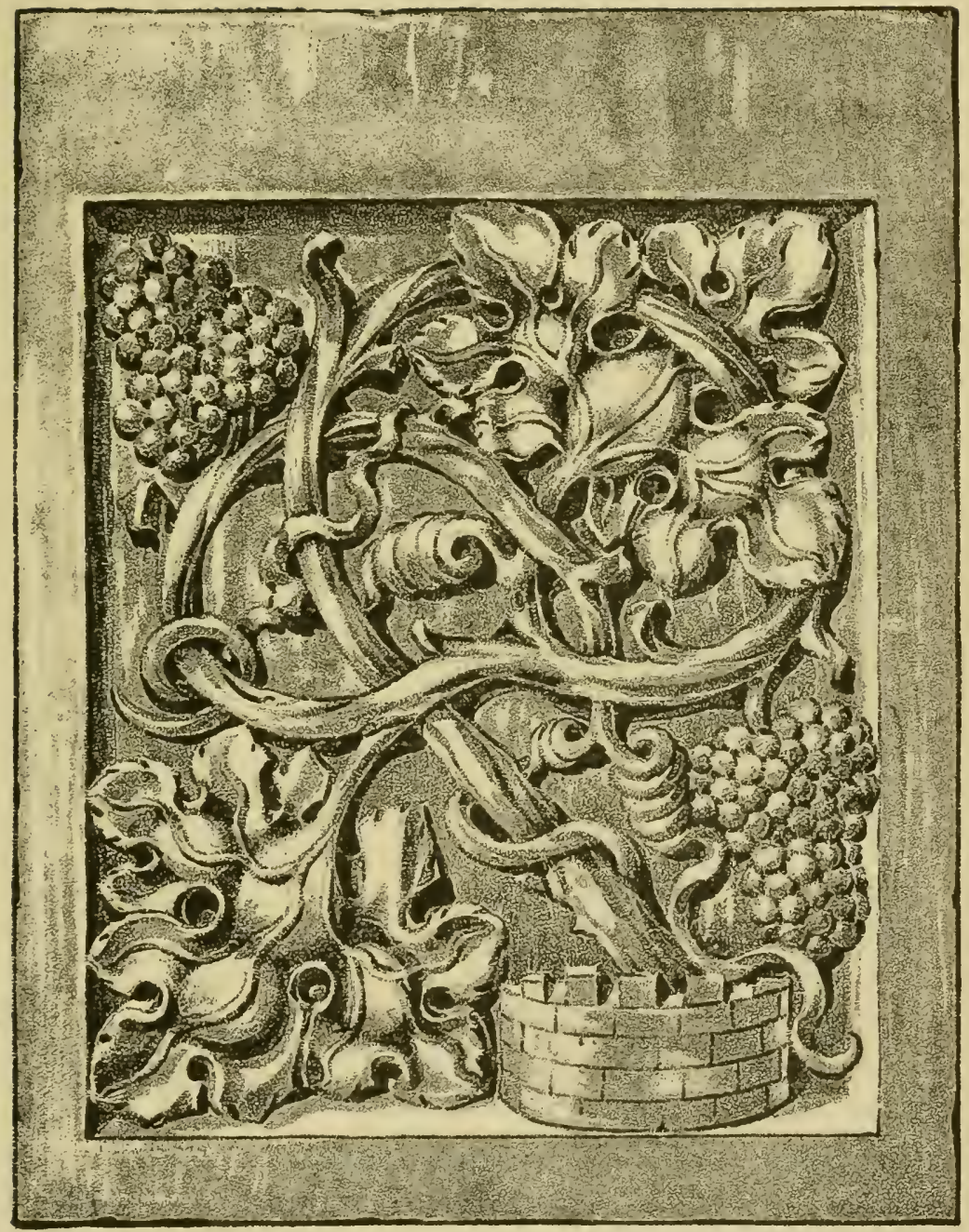

"Рното-Tint", by James Akerman London W C

English Gothic Vine. 



\section{Parallel Renderings.}

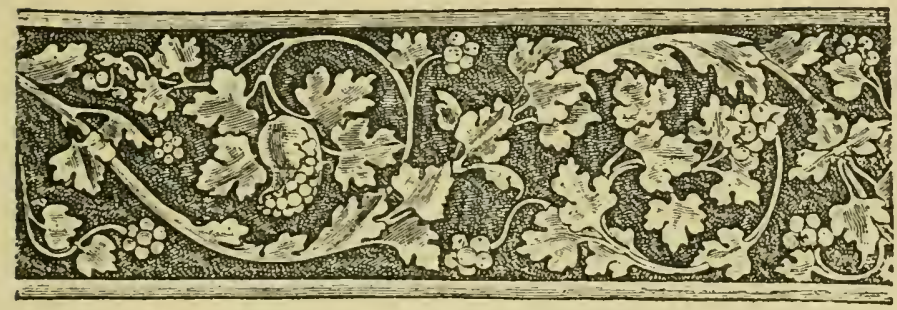

92. Italian Quattro-cento vine scrolI.

work. It is, indeed, picturesque rather than decorative; and the picturesqueness seems almost like a foreshadowing of the then still distant Rococo.

The artists of the Renaissance followed pretty closely in the footsteps of ancient precedent, and when they departed from the scroll and branched out into something more like natural growth, adopted by preference a form of leaf plainly recalling the vine. It was less a rendering of nature than an ornamental leaf more or less in its likeness.

Italian, French, or German rendering was modified always in some degree by national character. In the François premier foliage (p. 38 ), there is always a certain severity, showing that the carver had not quite thrown off the Gothic yoke, under which Italian ornament (above) never passed. The German version was still more determinedly national -indeed it was always more clearly Teutonic than Renaissance-witness the ornament of 


\section{I24 Nature in Ornament.}

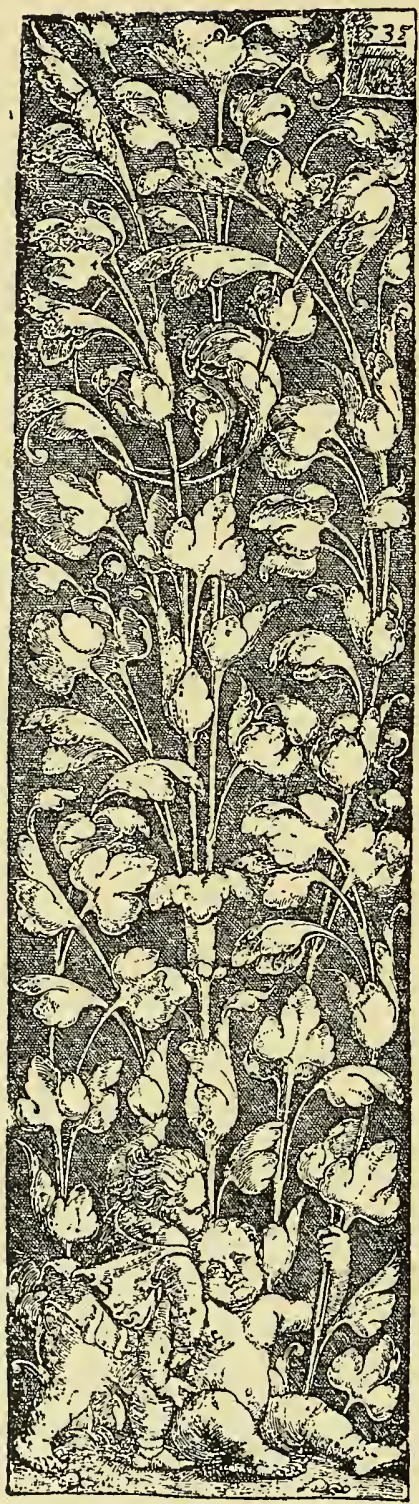

93. German Renaissançe.
Aldegrever on this page. Before our days of archæological pretence, there was in all ornament an undertone of national feeling, telling of the country to which it belonged. There was no need then of a Trade-marks Act to identify it as carved in France or Germany.

At the risk of trenching upon a subject discussed at length in a previous text-book ('The Application of Ornament') it is necessary to allude briefly to the influence exercised by material and manner of .workmanship on the modification of natural form. This is really half the secret of convention- 


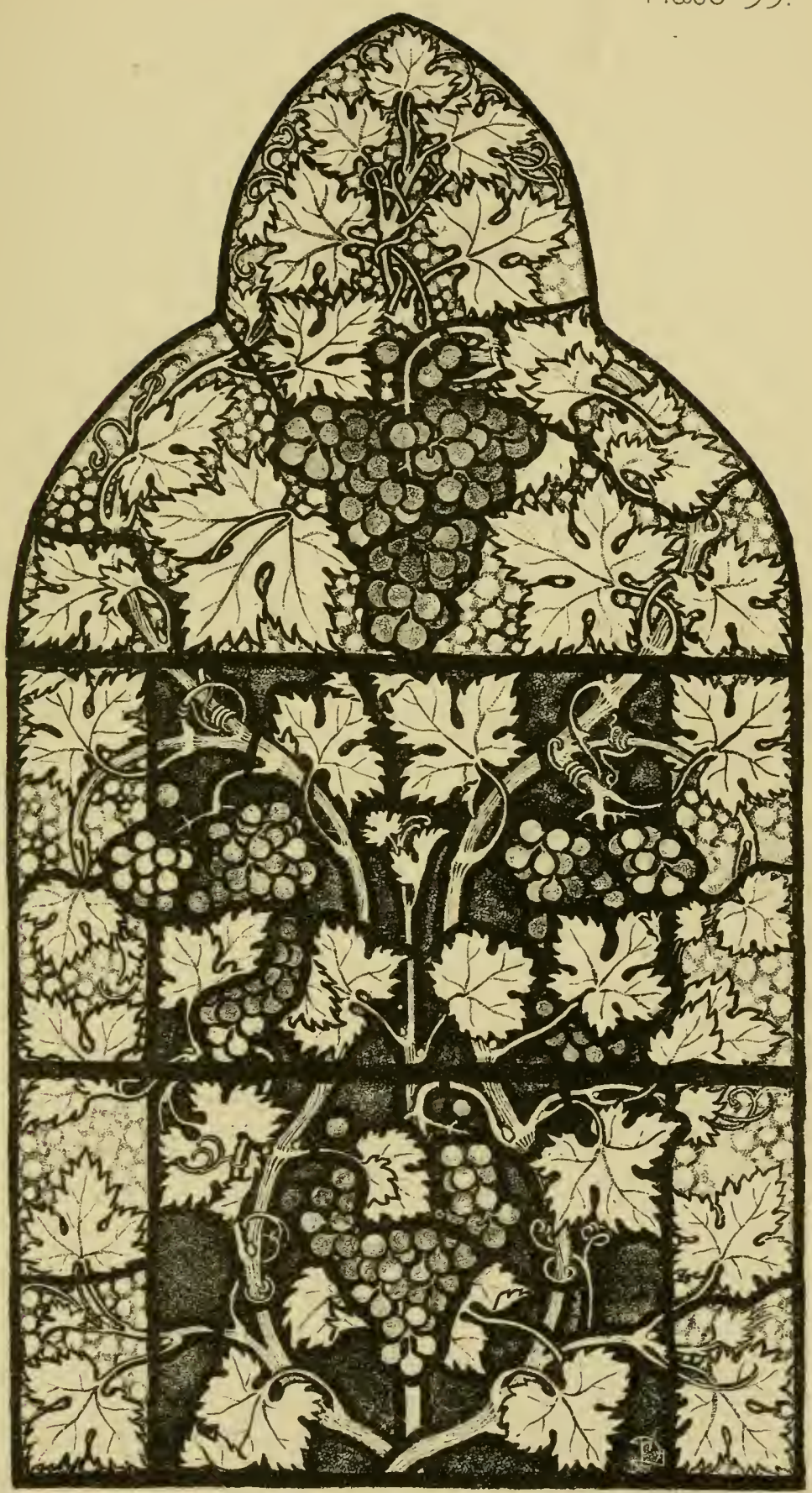

"Pното-Tixt", by dames Akerman. London, W. C

Vine, Stained Glass. 



\section{Parallel Renderings.}

alism, the other half being in the fitness of the form to its place and purpose.

The sculptor has thus been a powerful factor in the development of the ornamental vine.

You can see quite clearly in the Assyrian example (p. Io6) how he blocked out his fivepointed shapes, scooped out the main divisions, and notched the serrations round the edges, much as the Gothic carvers did, and how he just chiselled two series of lines across his bunches to suggest the grapes.

In the Greek vine (p. I08) the leaves are this time serrated by brush touches: in designing his tendrils the painter just played with the brush; whilst in the case of the grapes, he first washed in the mass of his cluster in two shades of colour, and then, with little blots of white, indicated the grapes upon it.

The Greco-Roman border (p. Iog) is inlaid in silver on bronze, and the serrations of the leaves are produced by so many digs of the graver. The stiffness of the zigzag stem, it should be mentioned, is modified, in the actual bronze, by the fact that it is on the curved member of a moulding.

The severe simplicity of the Byzantine design (p. I I 5 ) fits it for its intended purpose of a pilaster. 
The breadth of the leaves in the example from Toledo (p. I I 3 ) is calculated to contrast well with the broken background. On a smooth ground it would have been desirable

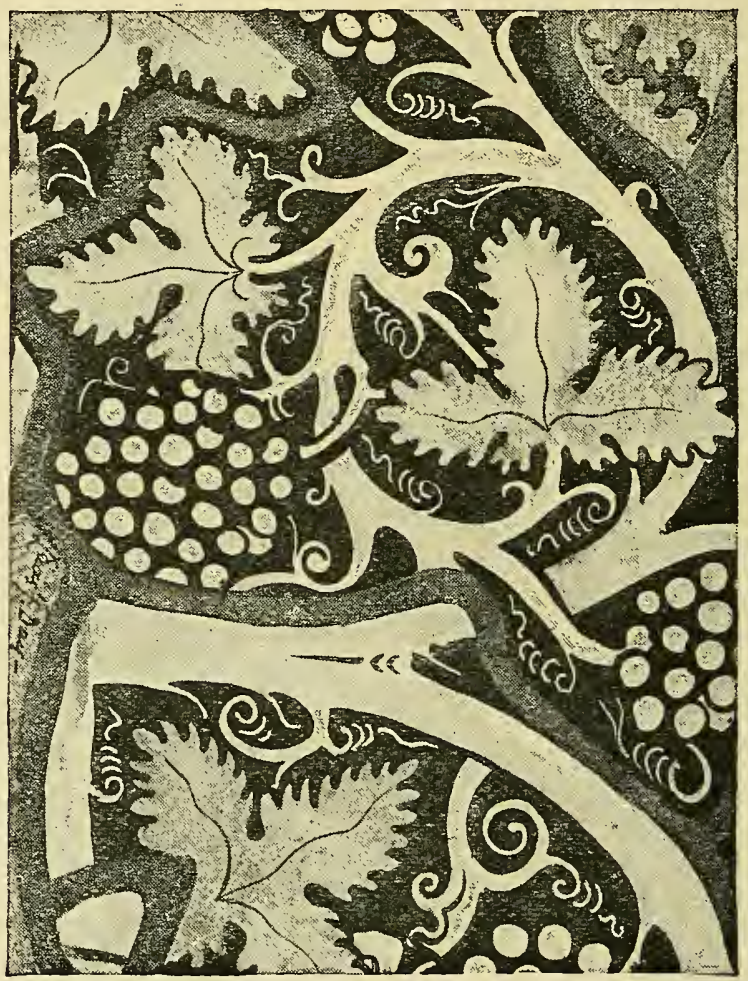

94. Vine in Gothic glass-painting.

to mark the subdivisions of the leaves more emphatically.

In the Arab leaf (Plate 54) the need of something like veins was felt by the sculptor; 


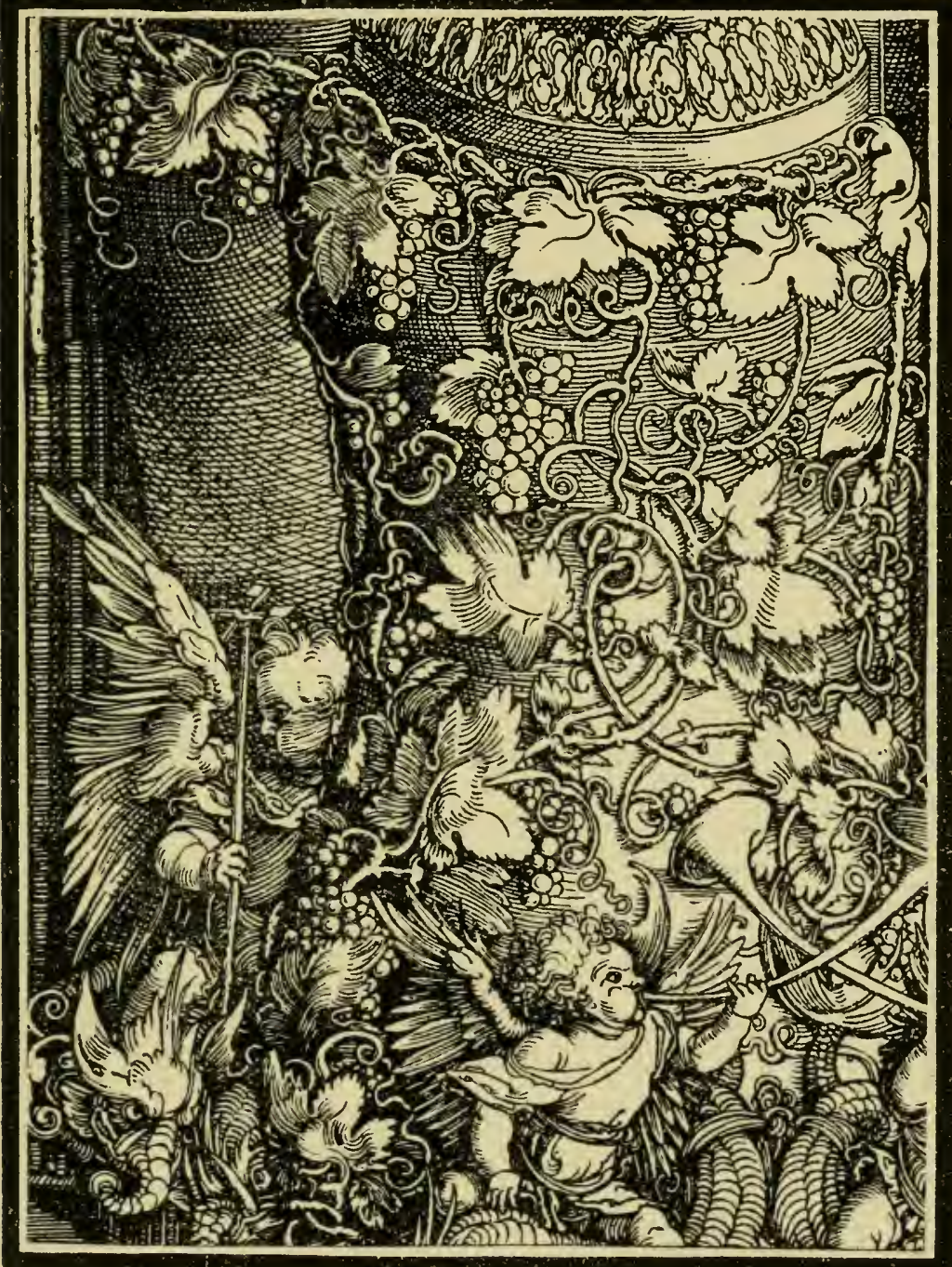

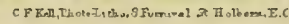

Vine by Alurecht Dürer. 

and the ingeniously ornamental tracery by which he supplied their place is a lesson in design.

In Plate 6I I have taken a hint from some sixteenth century damascening, and diapered the leaves with arabesque in the place of veining. The idea was to break the surface of the leaf whilst preserving an effect of flatness.

Dürer's leaves (p. 60) are pen-ivork, and had they been drawn with any other implement they would never have been just so.

The resolute avoidance of modelling in the German damask napkin (p. I2I) is in order to show off the quality of the linen.

In the various Gothic renderings of the leaf the tool is plainly to be traced. There is considerable difference between the convention of the wood-carver and that of the carver in stone. In the wood-carving on p. IIO, the veining is indicated and a certain effect of modelling obtained by leaving the gouge marks-but then the gouging was done to that end, and with intelligence.

The greater delicacy of the Quattro-cento leaves (p. 123) shows how the finer marble led to altogether more delicate workmanship. The coarser stone employed in English Gothic buildings made it absolutely necessary to mass the tendrils together if only for the sake 
of strength. The tendrils in the fragment of old glass on p. I26 owe their scratchy appearance to the circumstance that they were actually scratched out of the solid pigment with the stick end of the brush; the serrations of the leaves are as the brush made them -and so on. In short, conventional form proves to be the net result of comparing the supply of natural shapes with the demands of ornament, and choosing the line of least resistance between them. 
6) ()) (2) (2) (ิ2) (5) - (1) 40 (0) 1 (2)

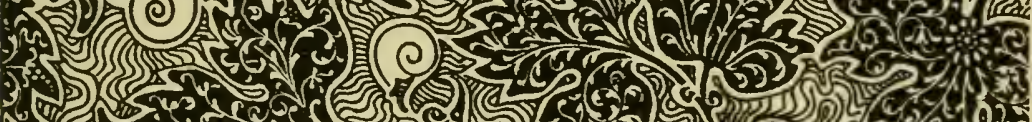

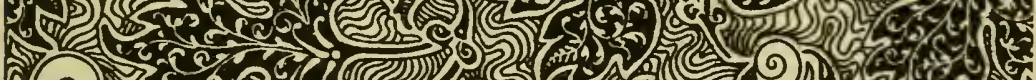

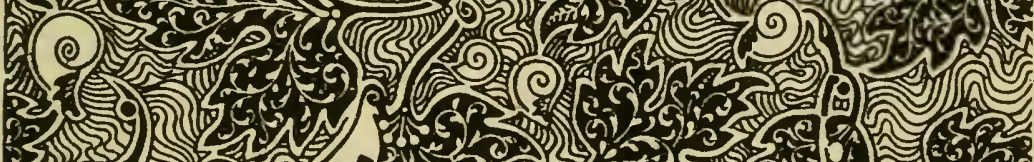

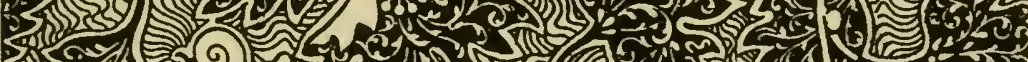

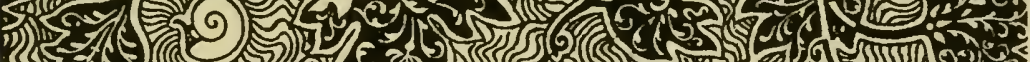

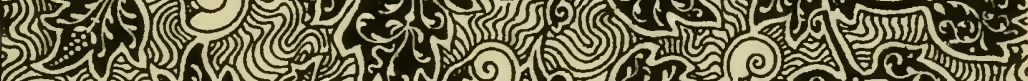
(9) 1 (1) - int 5 .

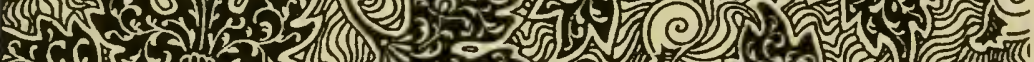
S.T.

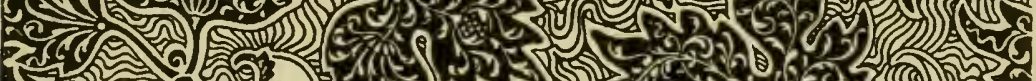
R2 5) 5 (c) (0)

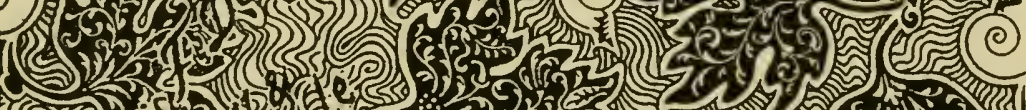
(2) (av)

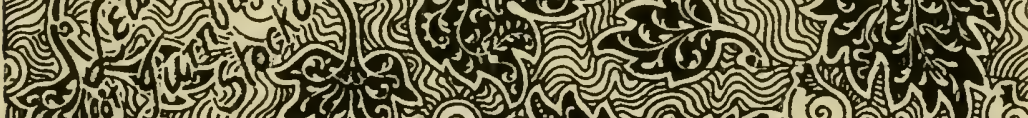
Co 90 - (2)

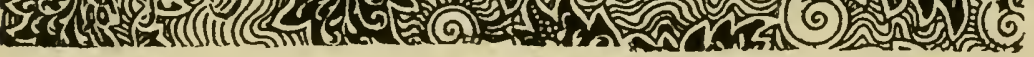

Conventional Vine leaf pattern. 



\section{VIII.}

MORE PARALLELS.

IT may be as well, lest the argument seem to rest upon a specially selected type, to compare, as briefly as possible, the various renderings of certain other plants which occur by way of illustration throughout this volume, and which have been chosen partly with a view to such comparison.

The Japanese treatment of the rose, on Plate 2, is only in so far decorative as the detail and the point of view are carefully chosen, and as the execution is simple and direct. Compare the energy of its growth with the sweeter lines on Plate 62 . This last expression of the decadent Renaissance is not nearly so accurate as it somehow pretends to be. The stipules of the leaves, for example, are very inadequately acknowledged; and what at first sight looks like picturesque shading of the leaves, turns out to be quite arbitrary. Indeed, it is only as ornament that 


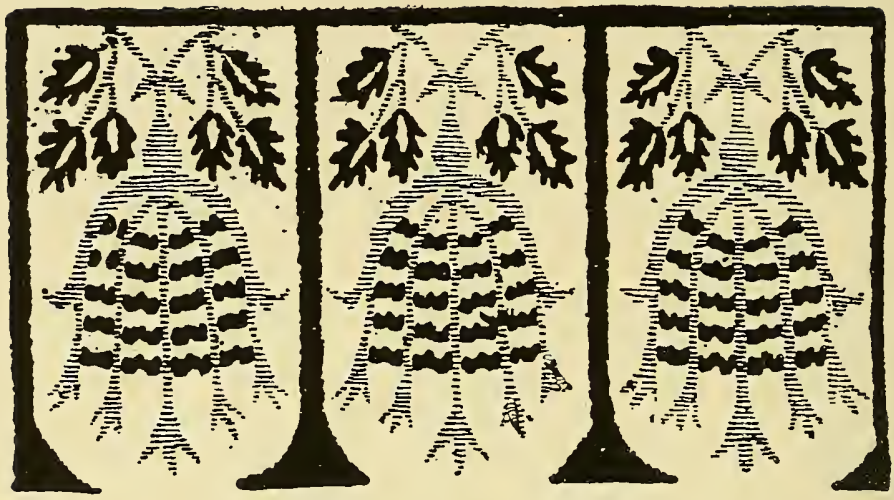

95. Quasi-Persian rose-Italian velvet.

this quasi-natural treatment has claim at all to our respect: as nature it has none.

As a model of conventional treatment, the Tudor rose must always hold a very high place. What could be better in its way than the dignified simplicity of the Gothic rose and crown on Plate 63? How good the lines are, and how well the panel is occupied! A certain breadth is gained by the reduction of the compound leaf to the simple form, and a certain character is given by the exaggeration of the stipules, unlike as they are in form to the natural type.

In the other Tudor rose from the stalls of Henry VII.'s chapel (Plate 64), the treatment is at once traditional and distinctly individual. It was something of an inspiration to twist the leaves and stalks encircling 
Plate 62.

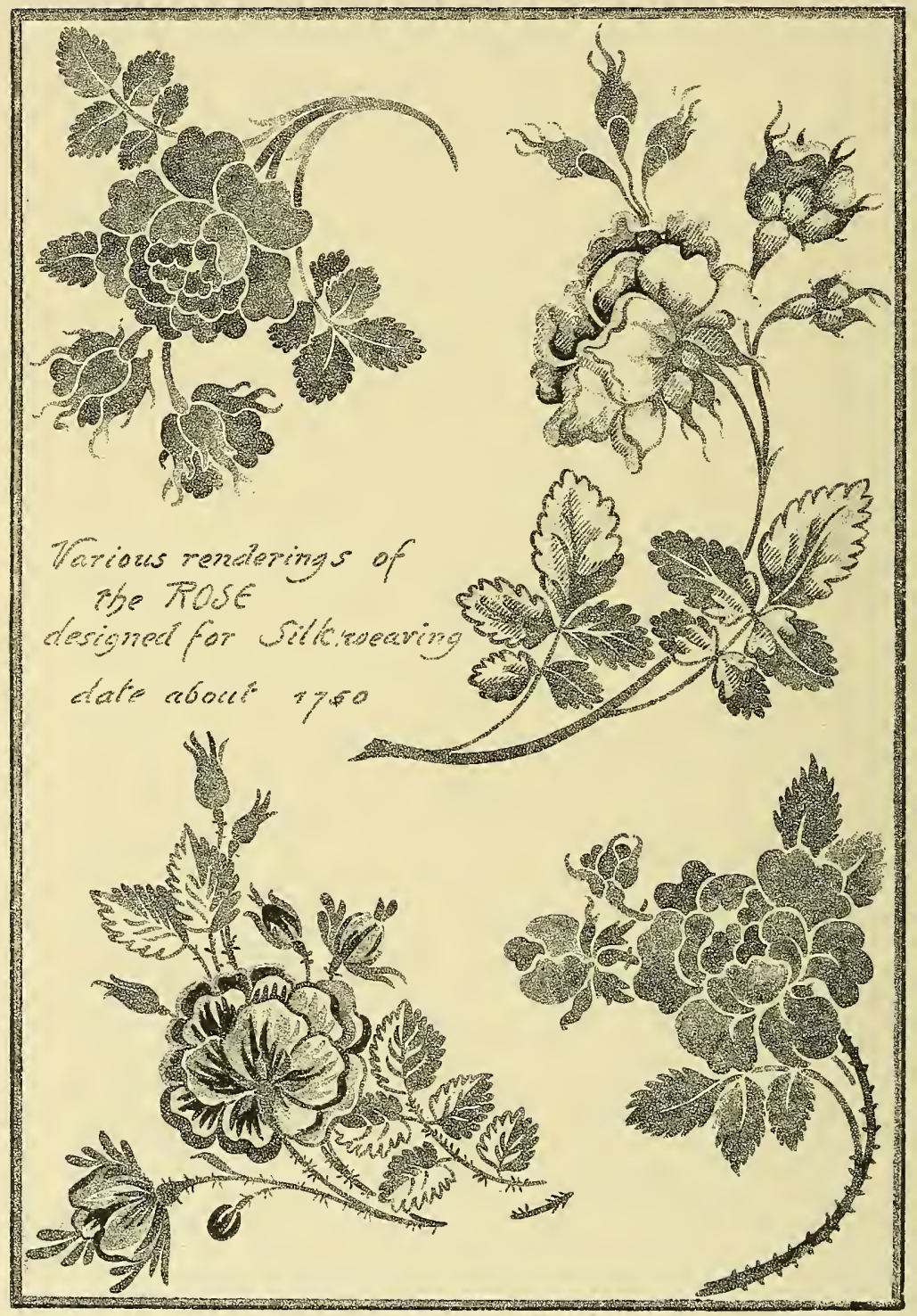

"Pнoto-Tint", by J. Akerman,6, Dueen Square,W.C. Artificial rendering of the Rose. 
P1ate 63.

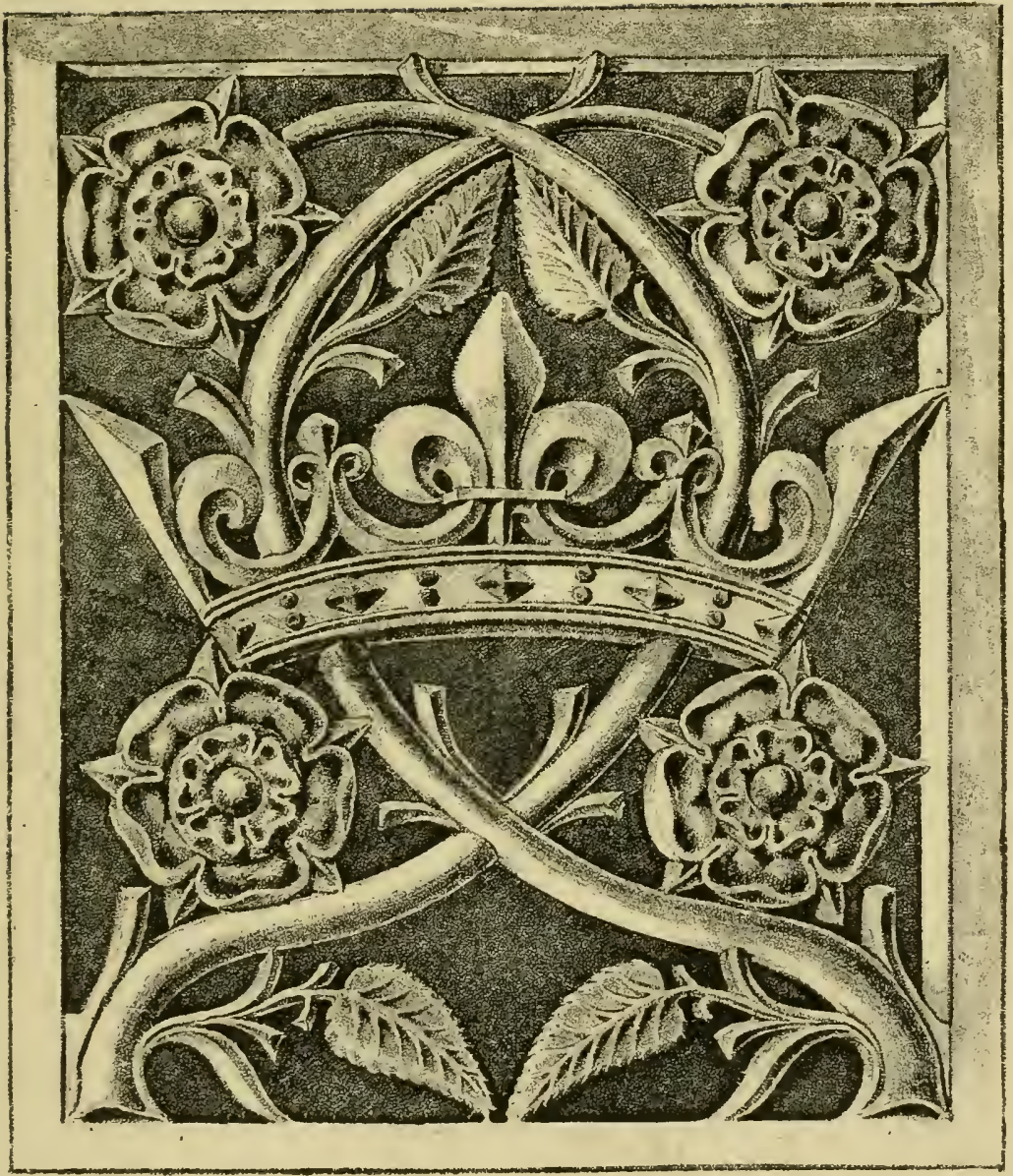

"Pното-TInT", by inmes Akerman London 'W

Tudor. Rose Bronze. 



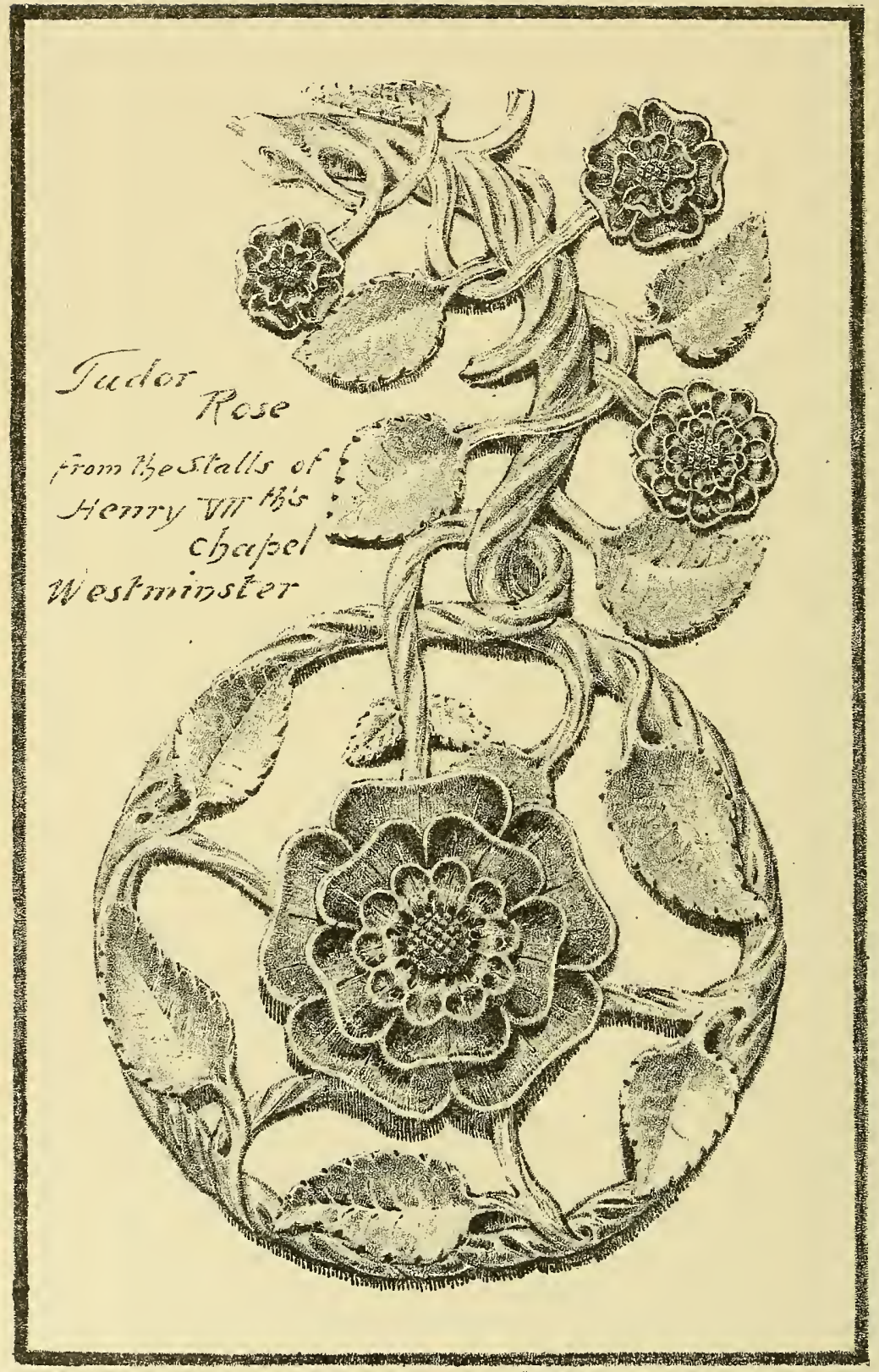

"Photo-TinT", by J.Akerman, 6, Queen Square W.C

Tudor Rose, Wood Carving 
Plate 65

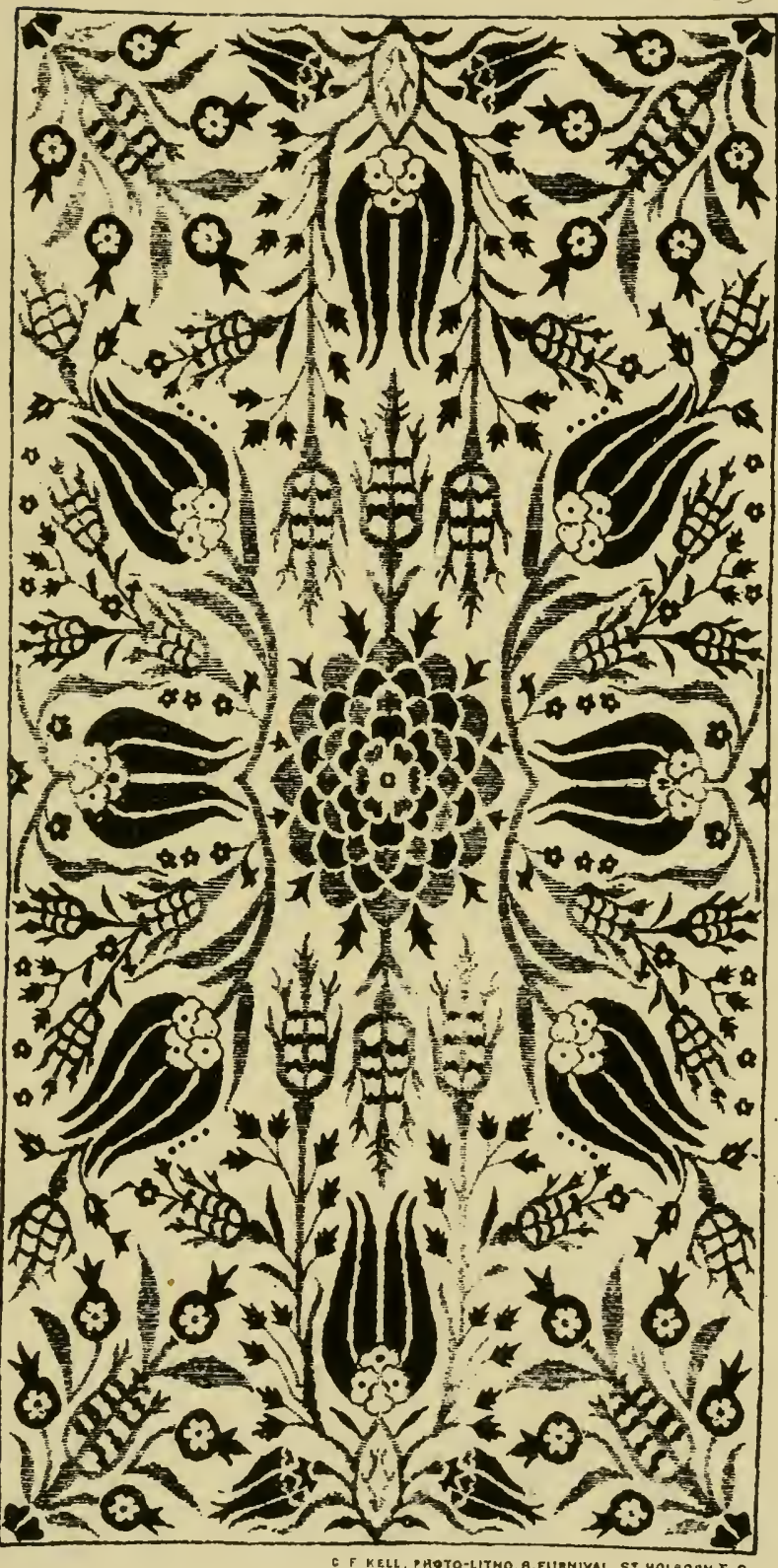

Italian version of a Persian Carpet. 


Plate 66.

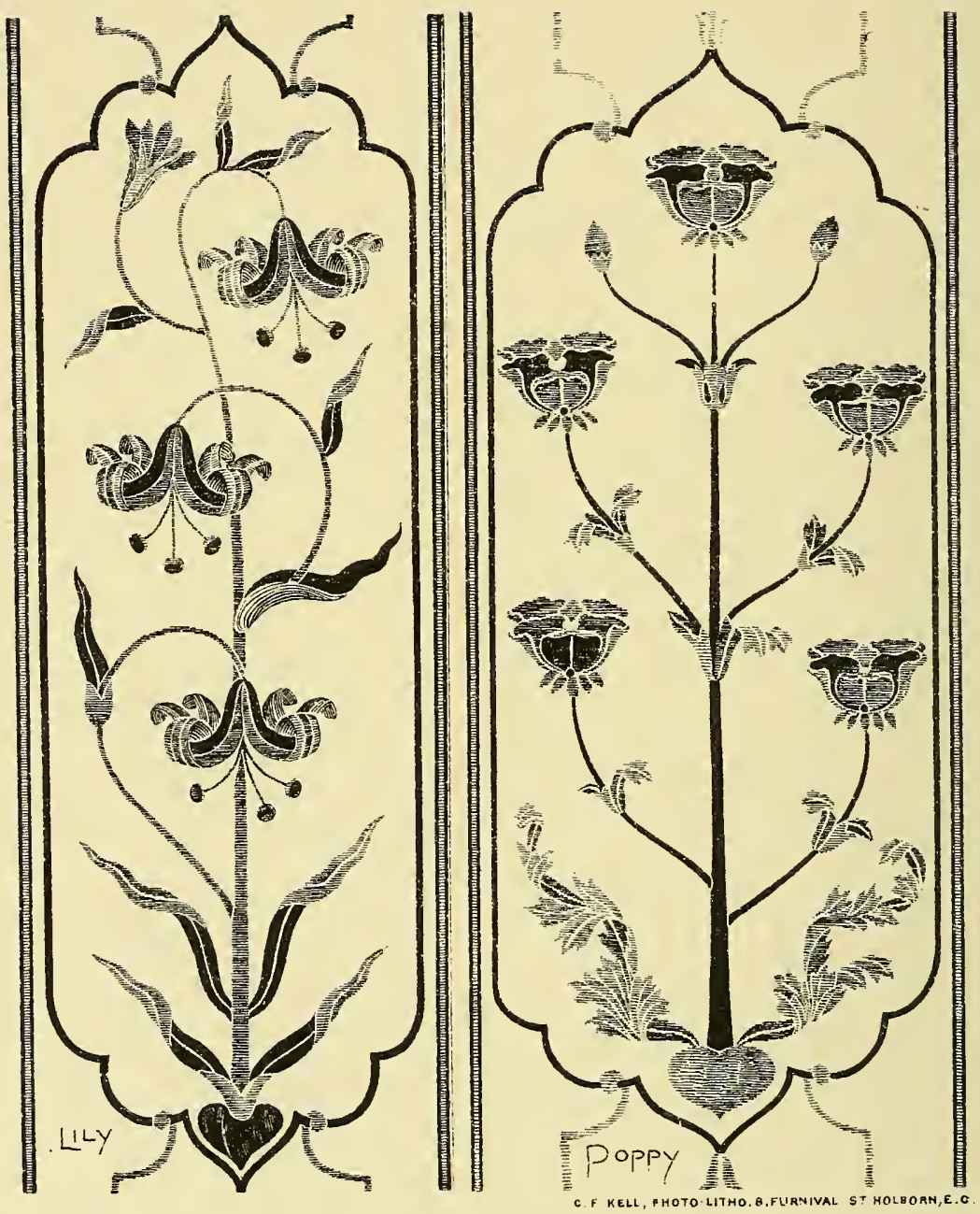

Marble inlay from the Taj Mahal. 

Plate 67.

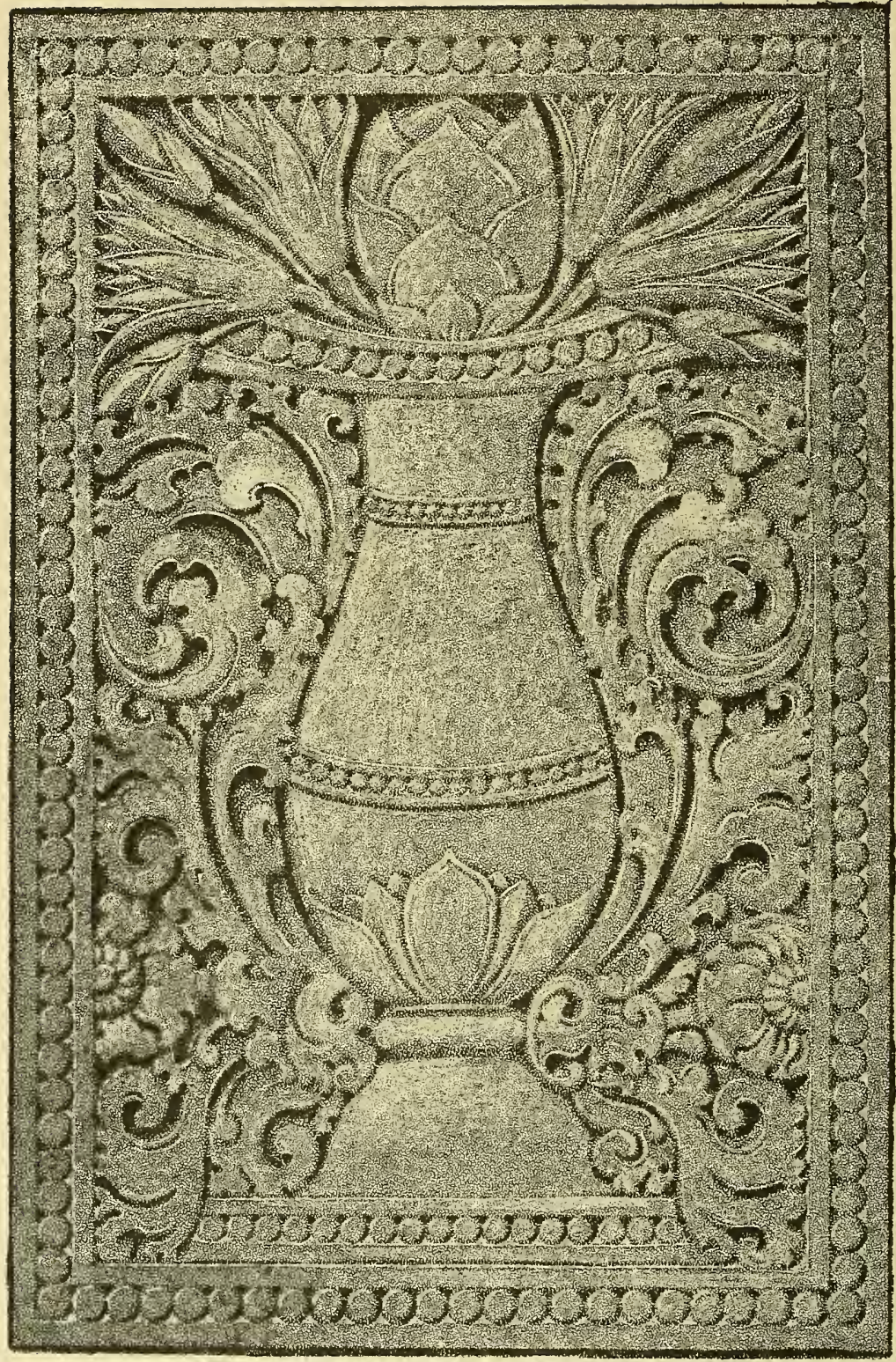

"Proto-Tint", by James Akermen, London.W.C.

Indian Lotus Panel. 
Plate 68

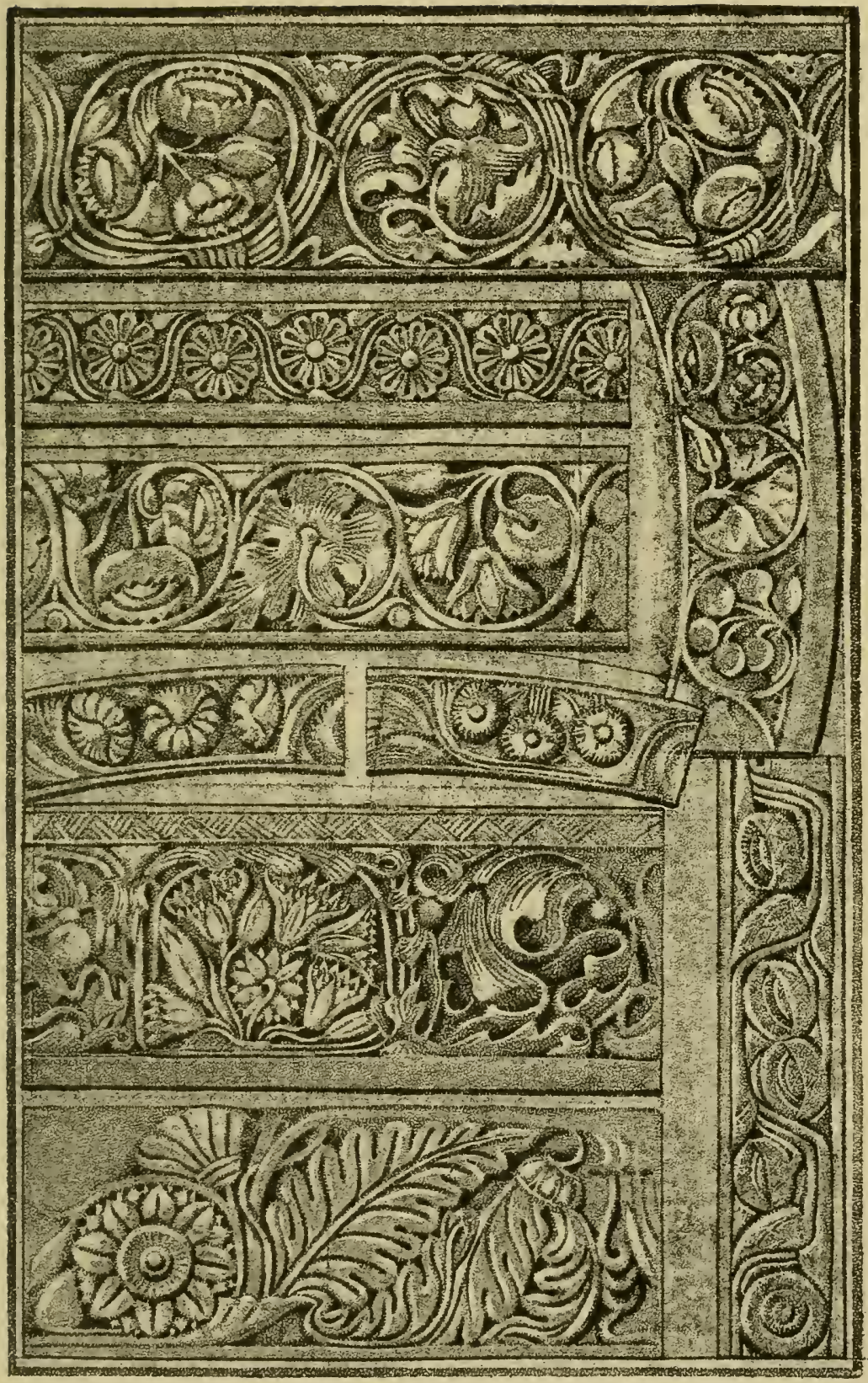

"Pното-Tint", bj ímes Akermon London W.C

Details of Stone Carvind, (Buddhist.) 

the rose into a further suggestion of the fivepetalled flower.

The monster roses at King's College, Cambridge, are other splendid examples of Gothic treatment. B. J. Talbert's modern rose on Plate 23 owes something, but by no means everything, to Gothic influence.

The rose-buds on p. I 30 are from a velvet of Italian manufacture, but so distinctly Persian in design that it may be presumed to have. been copied almost literally from an Oriental original. The eye or jewel of light colour in the centre of the leaf, in place of veining, is essentially Persian. In Plate 65, from the same source, the rose-buds are at once more elegant and more typical. The exaggerated sepals in particular are ornamentally of extreme value.

In the ruder Oriental embroidery on this page, the buds and sepals are again very characteristically emphasised. The angularity of the stalks comes of follow-

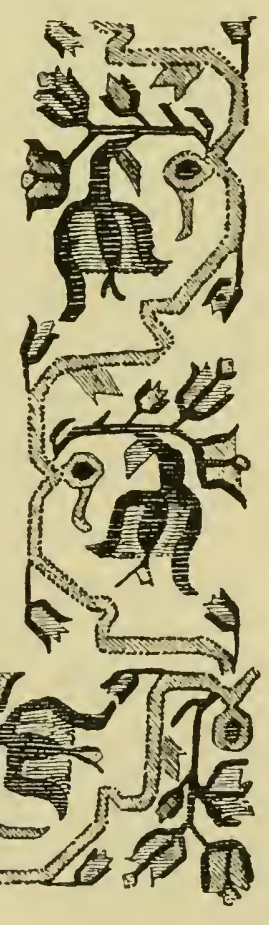

6. Oriental rose border.

K 2 
ing the square web of the linen on which it is worked.

The Rhodian example below would hardly be taken for a rose, but for the unmistakable bud once more: the open flower is more like a marigold. The broken stem is

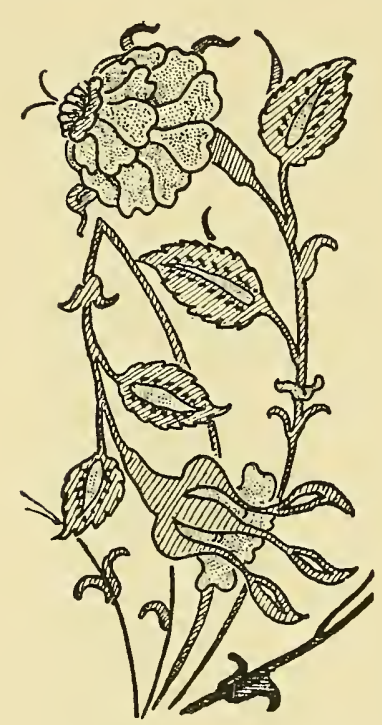

97. Rhodian rose. a convenient, and in Rhodian pottery not an uncommon, means of bending the lines in the way it is desirable they should go. Once in a way that may pass, but it is not a device upon which it would be well to rely in design.

Comparison has already been drawn (p. 93) between the Quattro-cento lily on p. 92, the Cinquecento lilies on p. $9 \mathrm{I}$ and Plate 43, my own lily ornament on Plate 39, Talbert's Gothic lily panel on Plate 42 (something like, and yet unlike, the panel from the Taj Mahal at Agra, on Plate 66), and the more natural growth on Plate 75. These may further be compared with the more or less lilyshaped flowers occurring in Greek scroll-work 


\section{More Parallels.}

(Plate I I and p. I60), with the Greek pattern on p. 6I, and with the Roman candelabrum opposite, a characteristically clumsy way not so much of designing as of compiling ornament.

In the Greek lilies already referred to, and still more in those on p. 158 , the relation to the anthemion is obvious, and to the lotus, that other form of lily so conspicuous in Egyptian and Assyrian art (Plates 79 and 80 and pp. I 5O, I 5 I, I 55, 240). The Hindoo rendering of the waterlily on Plate 67 is very much like the

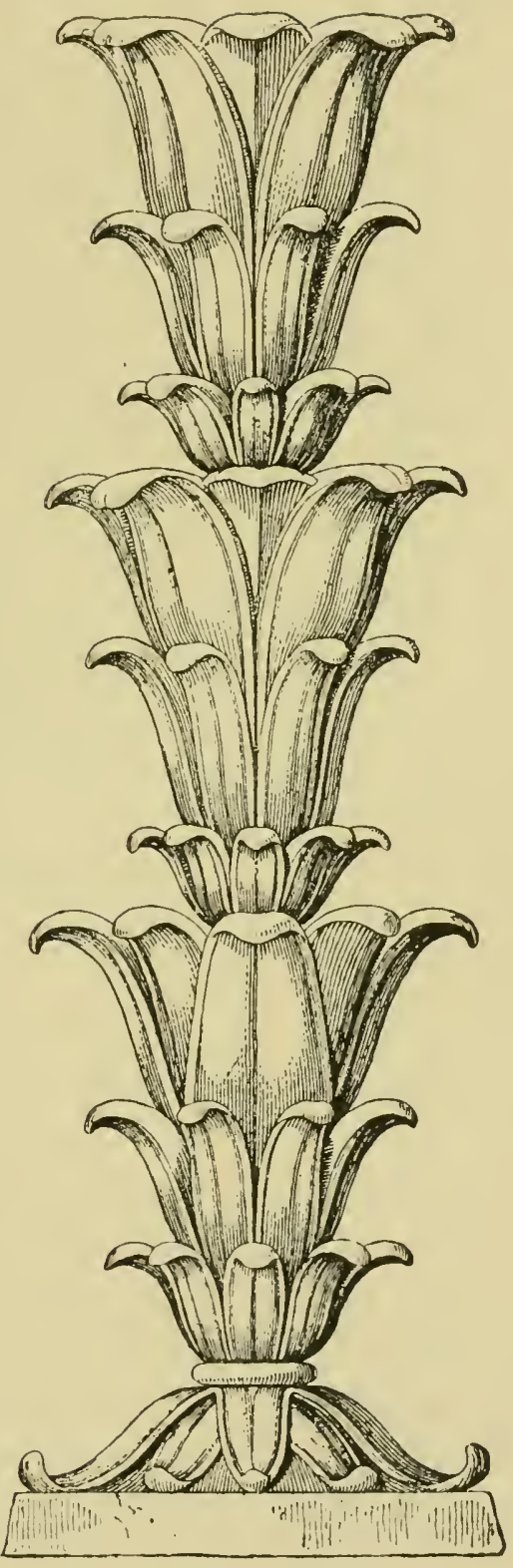

98. Roman lily forms, 


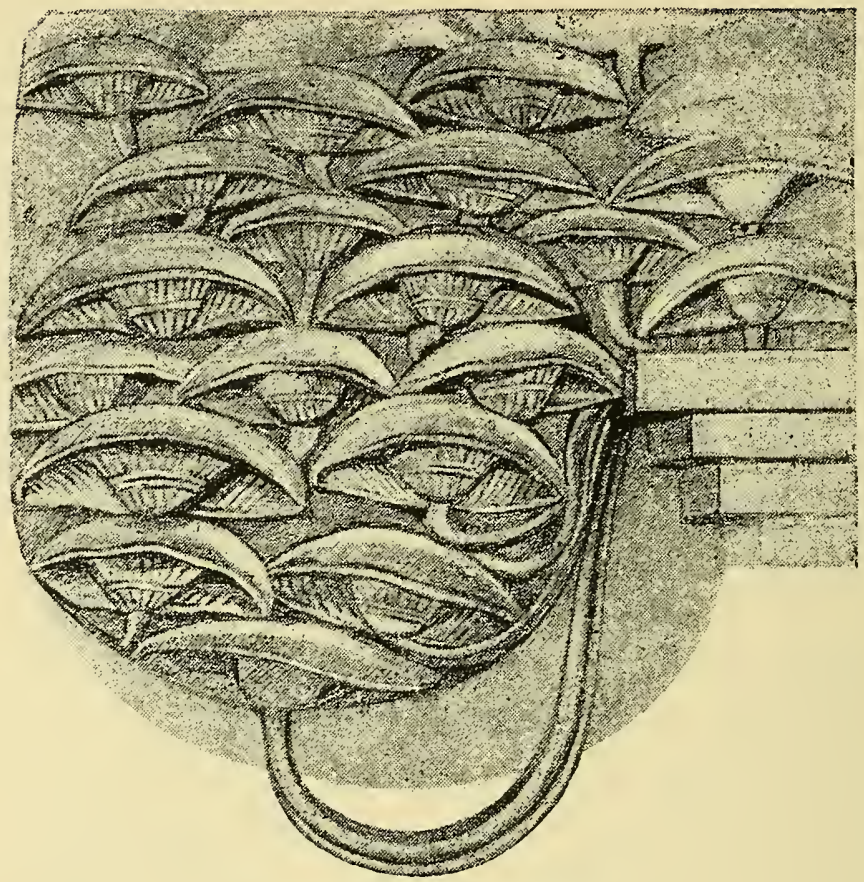

99. Indian lotus-Buddhist.

Egyptian, but it is sometimes looser, as on Plate 68. A very characteristic treatment is shown above.

The Chinese rendering on Plate 88 is yet freer, but still essentially ornamental.

Referring once more to the Greek shapes on p. 158, one may see in some of them a resemblance to the young growth of the lily as it bursts from the ground in spring. That is seen still more plainly in the Assyrian ornament on the lower part of Plate 80. 
There is something most natural in that very stiff conventional upright growth-reminding one rather of the young iris shoots.

The iris flower is, it has been already said, the origin of the fleur-de-lis. Compare the flamboyant fleurs-de-lis on Plate I2I with the earlier Gothic renderings on pp. 238 and 24I, with the renderings on $\mathrm{p}$. 160 , and with the Romanesque ornament on p. 18. The flowers

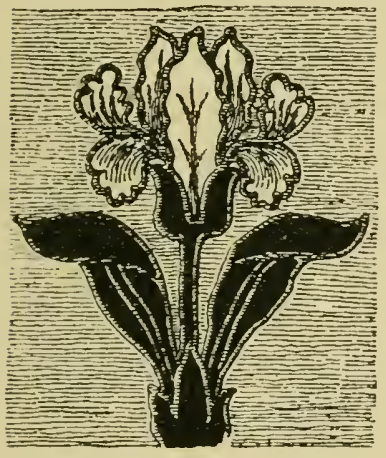

100. Seventeenth century iris. in the central ornament (p. I8) are remarkably like the iris. In the Renaissance ornament on p. 240 , the characteristics of the iris are reconciled somewhat to the shape of the fleur-de-lis.

In the Indian damascened pattern on Plate 30 , there is distinct resemblance to the fleur-de-lis. The painted version above it, whilst pretending to be more pictorial, is altogether less characteristic of nature.

In the Persian examples on p. 45 , the flower is reduced to ornament, as it is also in the ingenious border of the frontispiece which Mr. Crane has designed for me. The figure of Iris in the centre is designed in a vein 


\section{I36 Nature in Ornament.}

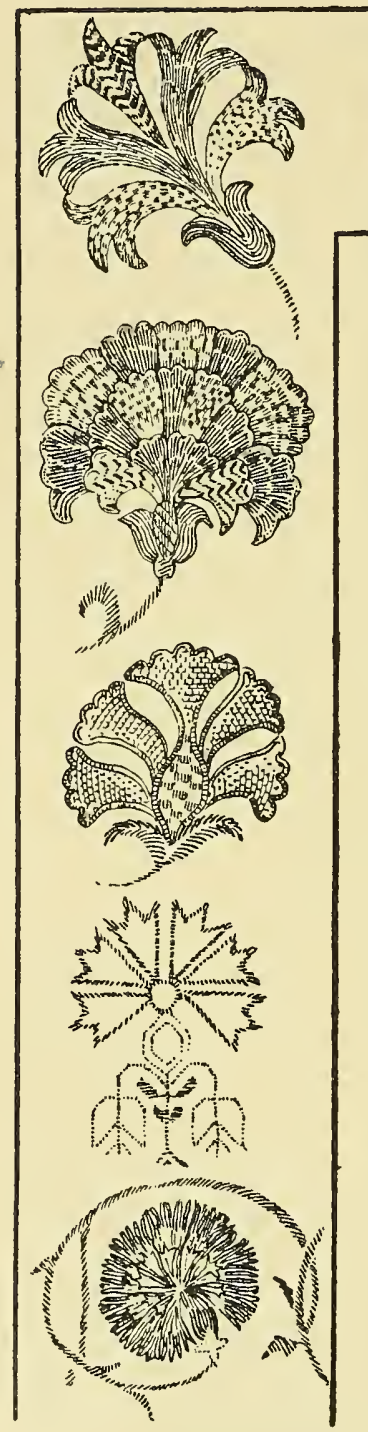

roI. Renaissance pinks.

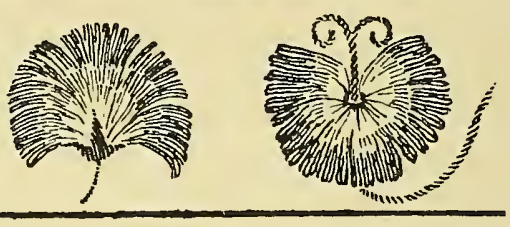

peculiarly the artist's own. His "Flora's Feast" is a very feast of ingenious and fanciful and altogether delightful design of the same kind.

Ornamentally as the flowers are treated in the Damascus tiles on p. IOI, they are still most characteristic - as are the equally abstract forms in the Japanese embroidery on p. 66. These are quite unmistakably flags.

The sixteenth century Italian embroidery, on $\mathrm{p}$. I 35 , is scarcely far enough removed from nature to be effectively ornamental.

In the eighteenth century silk weaving (Plate 44), there is a certain suavity of line which goes towards ornament 

Plate 69.

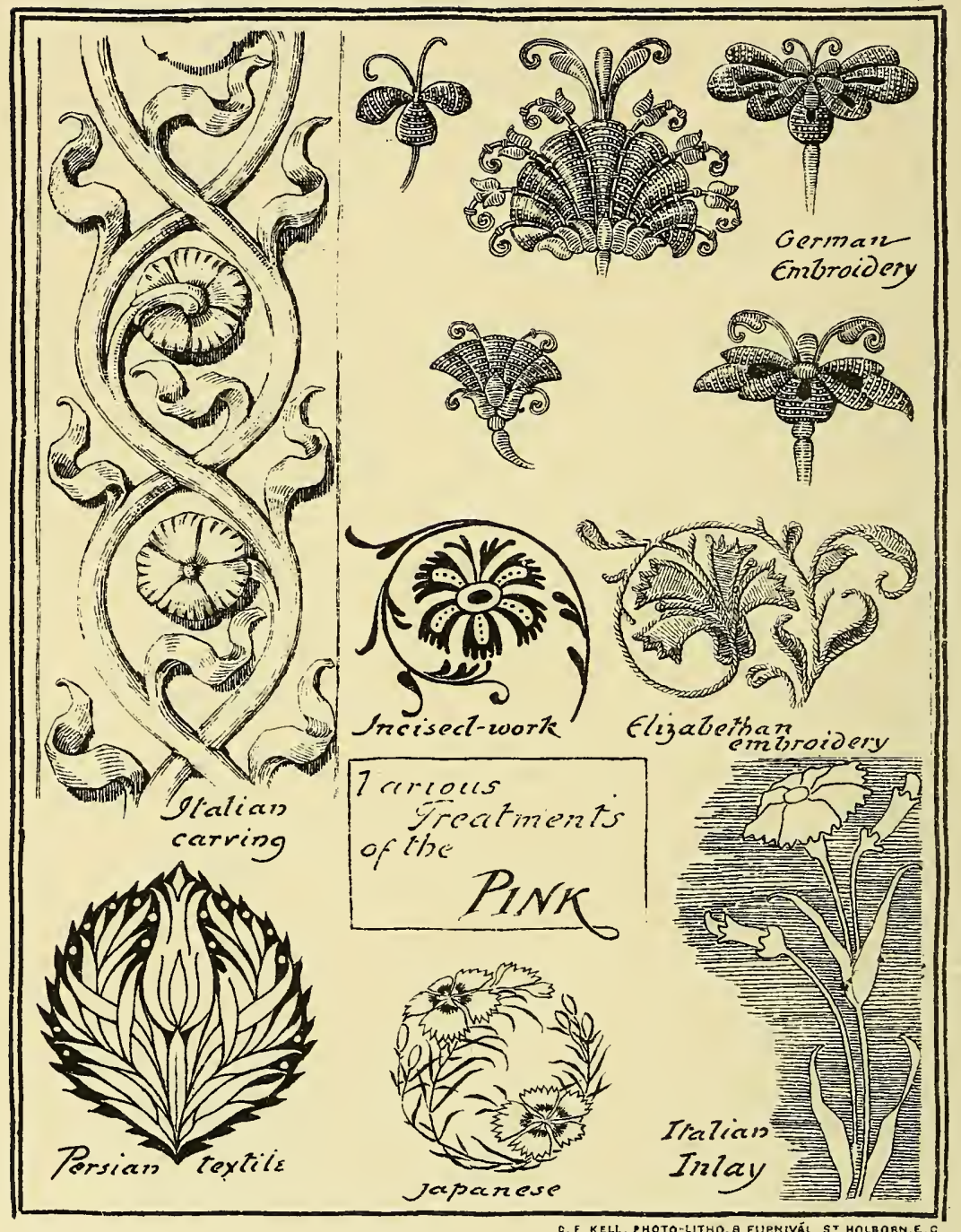

The Pink. 
P1ate 70

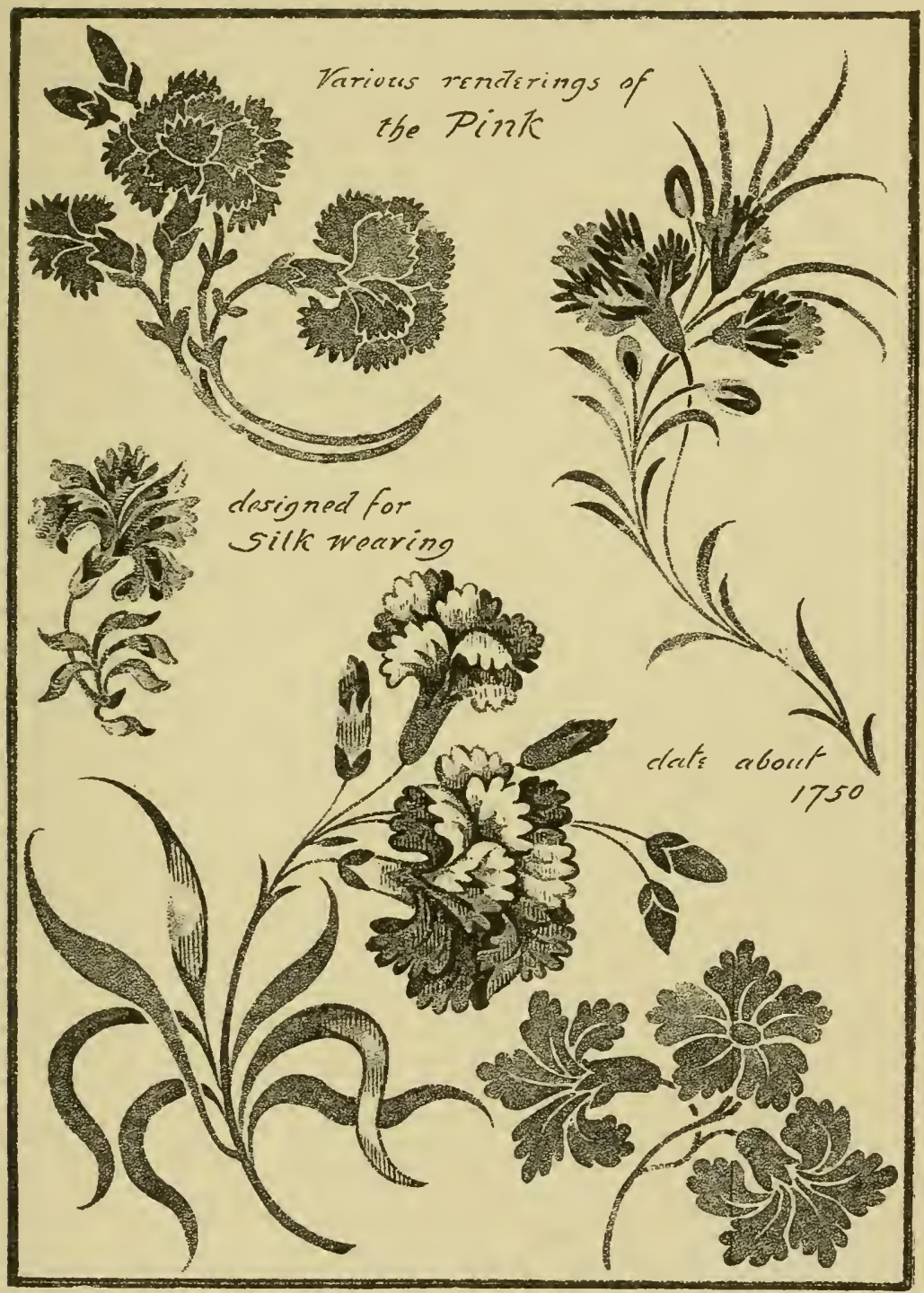

"Pnoto-Tint, by caraes Anermon iondon in C

$18^{\text {th }}$ Century, Versions of the P1nk 

but such affectedly graceful growth is not quite in keeping with the quasi-natural rendering of the flowers.

Further parallels between the iris and the fleur-de-lis are drawn in the chapter on Tradition, pp. I6I, \&c., and in that on Symbolism, p. $24 \mathrm{I}$.

The pink or picotee occurs frequently in Oriental ornament, whence probably the Italians of the sixteenth and seventeenth centuries borrowed it. In the Italo-Persian brocade on p. I49 the indebtedness of the weaver is obvious.

Among the comparatively late Renaissance flowers on p. 136, interesting as showing a variety of modifications all more or less according to the scheme of the embroiderer, only one instance occurs in which the curled horns of the pistil are made use of. In some examples on Plate 69 the horns, more or less modified, are a prominent feature. The modification of nature in the various renderings there given is according to the material and mode of work, embroidery, incised work, inlay, carving, and so on.

As in the case of other plants alluded to, the late Renaissance renderings on Plate 70 are ultra-elegant and graceful.

In the very excellent panel from the Taj 


\section{I38 Nature in Ornamen.}

Mahal (Plate 66) the poppy is trained deliberately in the way it should go-a delicate and graceful way, for all its formality; and, for all its symmetry, varied.

The damascened patterns on p. 6I are more distinctly Indian. In one of these, the occurrence of sepals, which the bud naturally sheds as it bursts, has already been pointed out; in the other the severe lines within which the growth is compactly grouped, result in distinct dignity of design.

Ghiberti's poppy on Plate 7I is one of the most satisfactory of the flower-groups bordering the celebrated doors at Florence. The leaves are just conventional enough, and the seed-vessel or poppy-head tells for what it is, at once a characteristic and an admirably ornamental feature.

In my own poppy-pattern on Plate 72 , the brush touches are such as could most conveniently be reproduced in block printing. It is meant for pattern first and poppy afterwards.

In the border on p. I72, the growth is comparatively natural. The flowers are arranged in the order indicated by the necessities of composition, and the growth is made to accommodate itself, with as little violation of nature as possible, to them. 

Plate 71

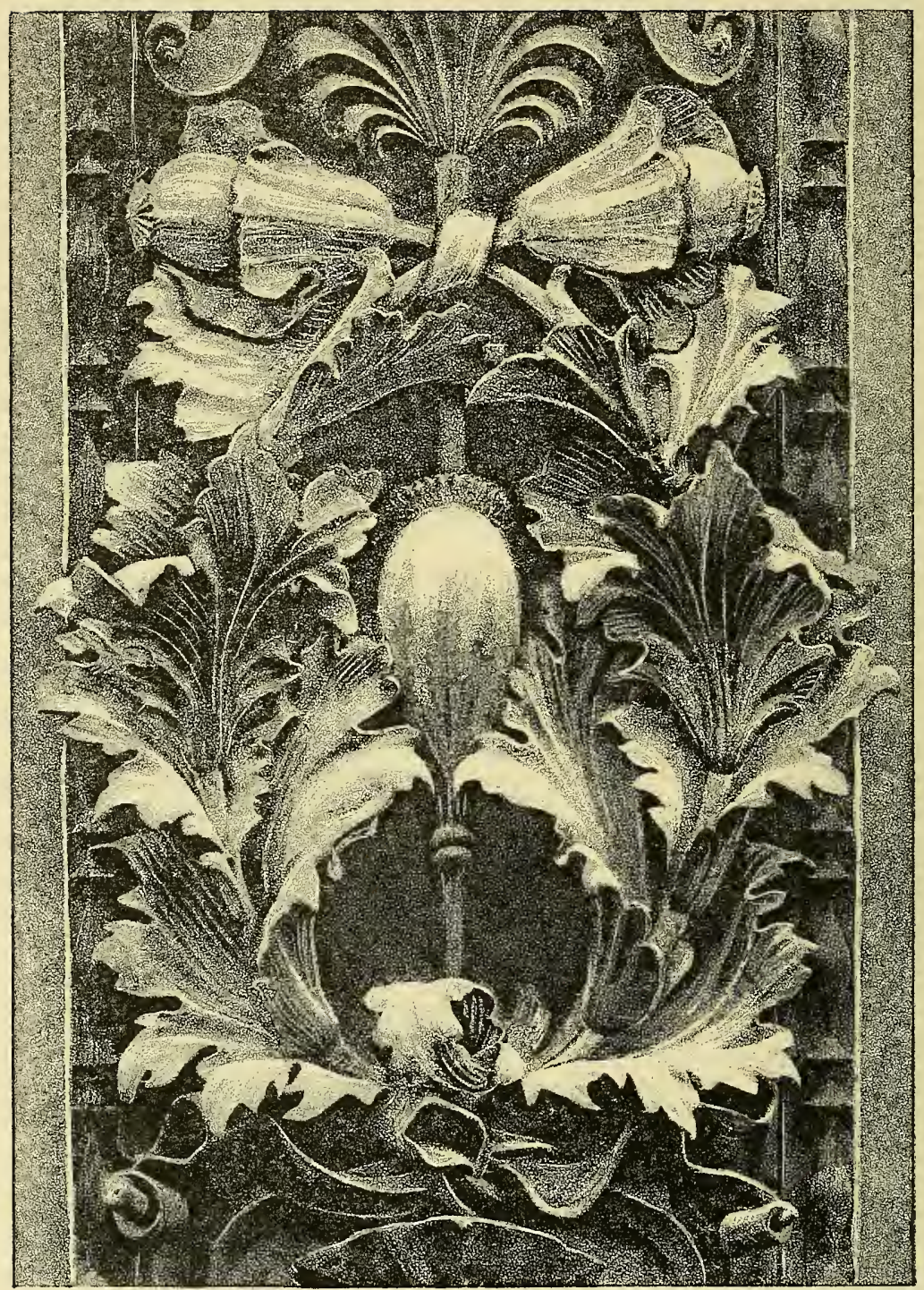

Pното-TINT, dy Uames Akerman London. W. C

Popples by Ghiberti, Bronze 
Plate 72

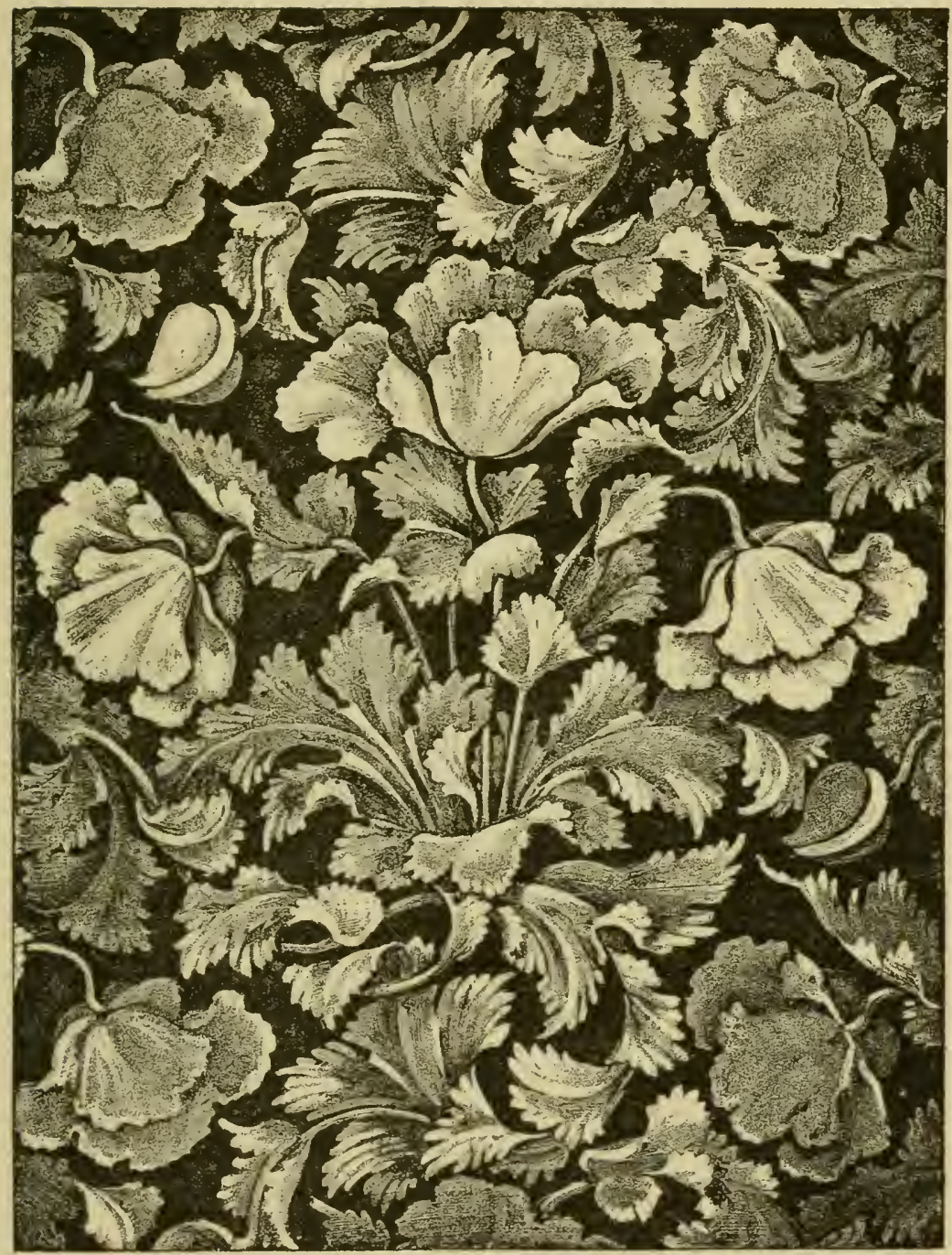

"Рното-Tint", by james Akerman. London W

Poppy pattern. 

Wheat ears are a favourite symbol in Gothic work, but the rather intractable growth of corn seems to be against any great variety in its treatment. The stiffness of the design

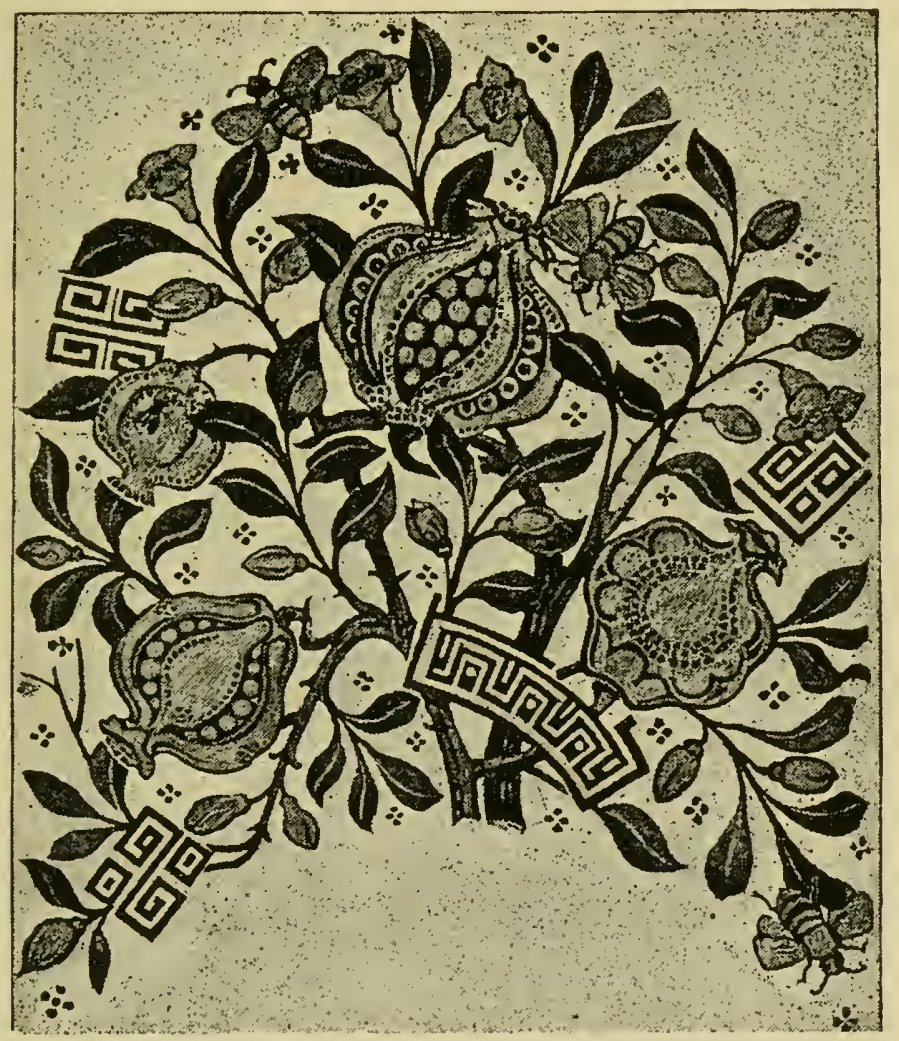

I02. Modern Gothic pomegranate. B. J. Talbert.

on p. 89, which belongs to the period of the Gothic revival, is likely to be more noticed than its ingenuity, which is all the artist's own. In the Italian silk on p. 68, the wheat ear 
is reduced to a pattern; in the carving on p. 90 , it is the leaf-blades that are manipulated. To adapt the rather rank growth of the Indian corn to the purpose of a simple and satisfactory border, as on p. 88, is something like a triumph of ornamental modification.

It is mainly in Gothic art that the thistle has been taken as a motif; but there is a wide difference between Hopfer's scroll on Plate i6, and that on Plates 83 and $9 \mathrm{I}$, and between any of these and the late G. E. Street's bold experiment in modern Gothic on p. 54. My own pattern on Plate 38 is thistle-like (it was in fact suggested by the artichoke, the king of thistles), but the natural characteristics of the plant are deliberately sacrificed to the purposes of pattern.

In the representation of the pomegranate, the bursting of the fruit (as

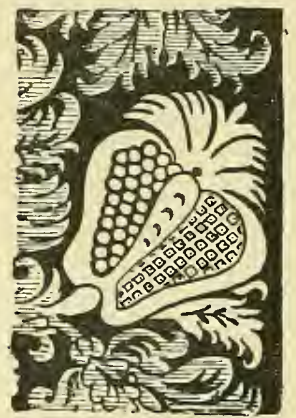

I03. Pomegranate. already mentioned on p. 74), has been very variously rendered. The late $\mathrm{B}$. J. Talbert, too (p. I 39), turned the seeds to ornamental account. Mr. Morris's fruits on Plate 87 burst naturally. In the Chinese pattern on Plate 73 the bursting 
Plate 73.

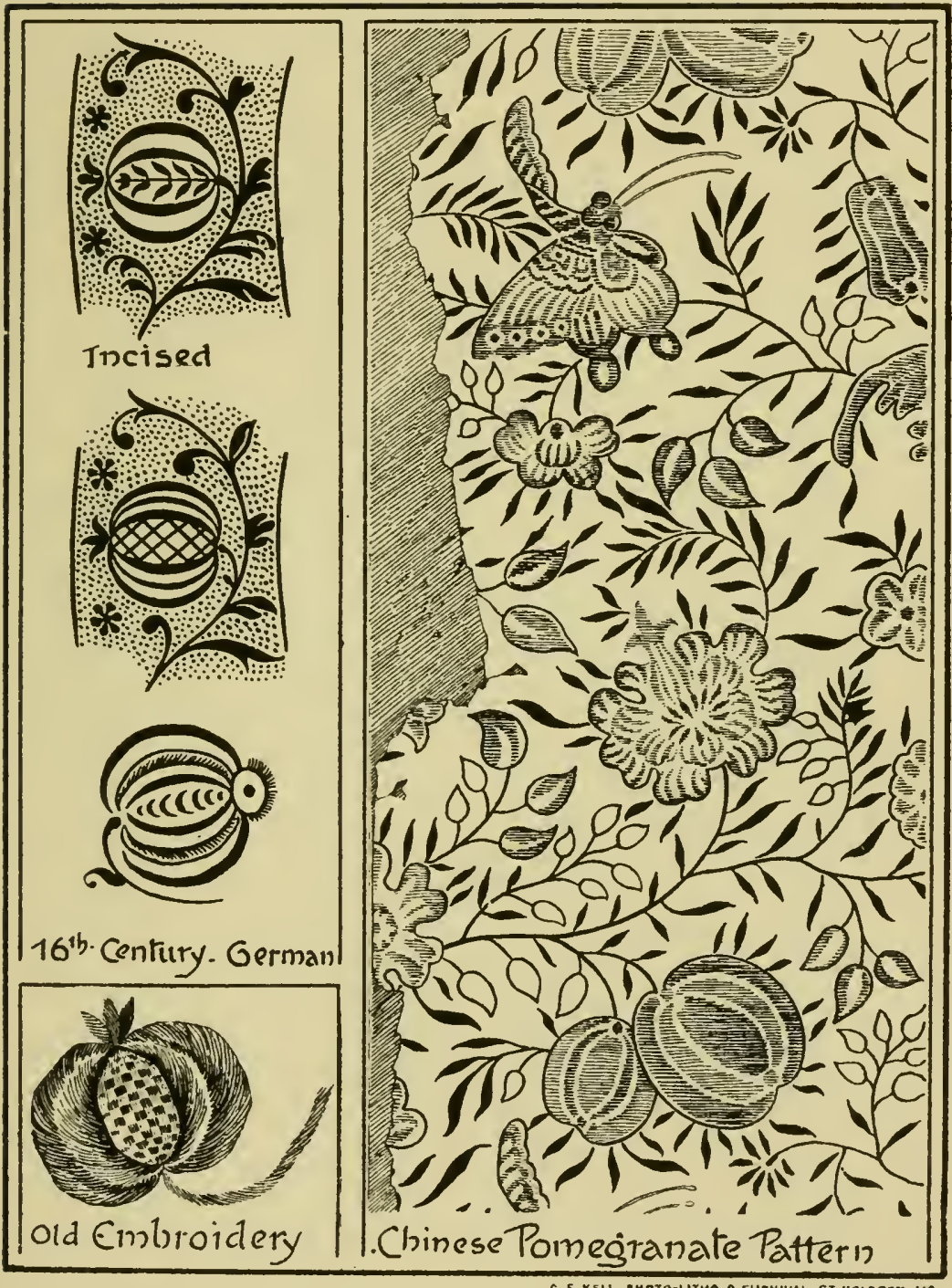

Pomegranates. 

of the fruit is indicated only by a change of colour: no seeds are revealed. The sixteenth century German treatment (same plate) is equally arbitrary.

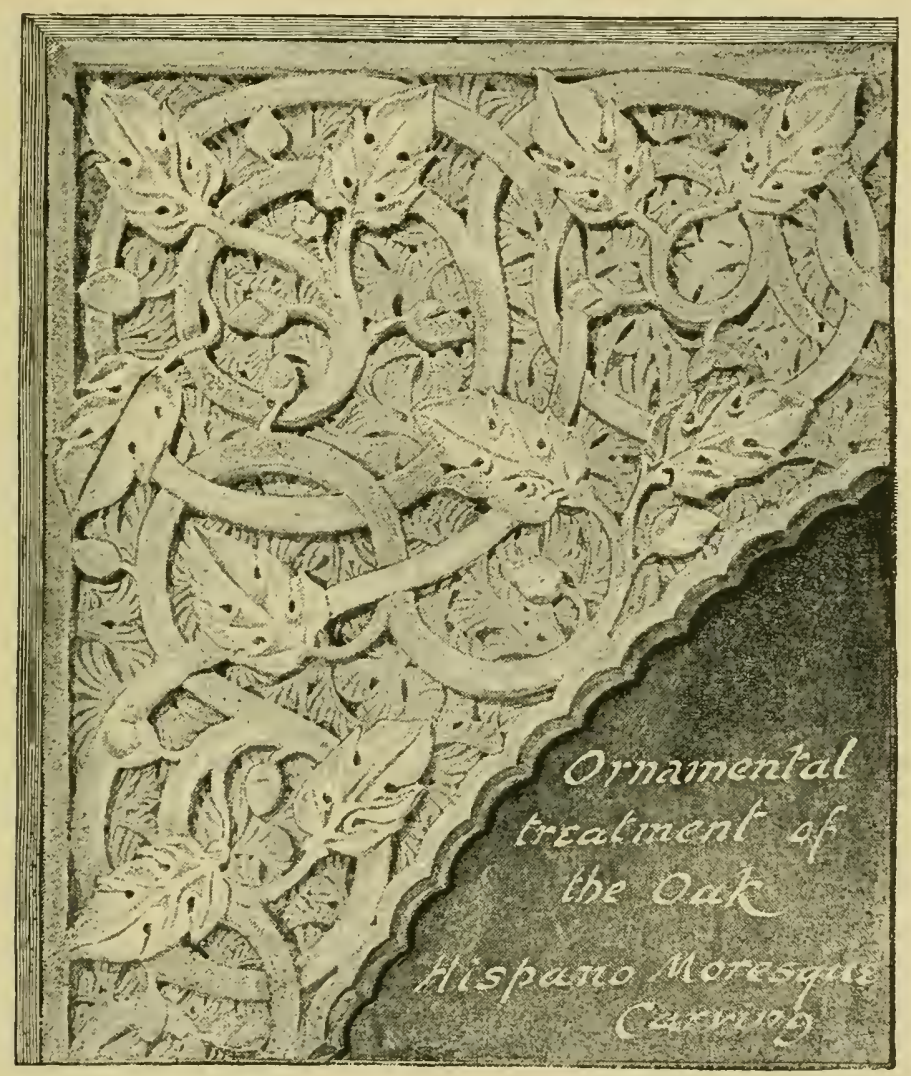

104. Oak from the cathedral of Toledo.

Persian influence is seen again in the Italian rendering on p. I49. One assumes that the pear-shaped fruit on p. I4O is meant for a pomegranate. The Gothic ornament on p. 60 


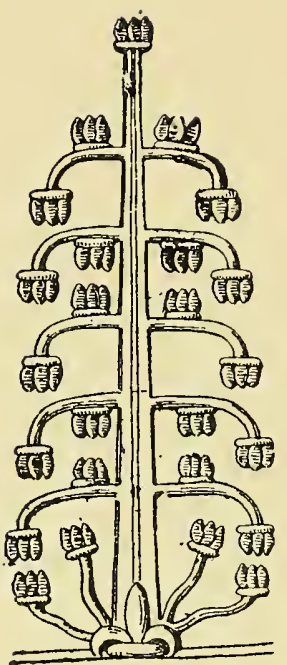

105. Assyrian Tree of Life.

stands also, no doubt, for the pomegranate; but it is quite a traditional rendering, by a man who probably never saw the fruit. Compare this also with the pine patterns on Plate 84 and on p. 157.

The various renderings of the oak, Classic on p. 94, Gothic on Plates 29 and 74, Italian on p. 247 , Sicilian below, and other examples on p. 53 and on Plates 9 and 83 , have none of them

any resemblance to the characteristic Hispano - Moresque oak scroll on p. I4I, which is akin rather to the vines on $\mathrm{pp}$. I 3 and II 4 .

Reference is made elsewhere (p. 246) to the daisies on Plates 122 and I23, and (p. 88) to the examples of the ivy occurring on Plates

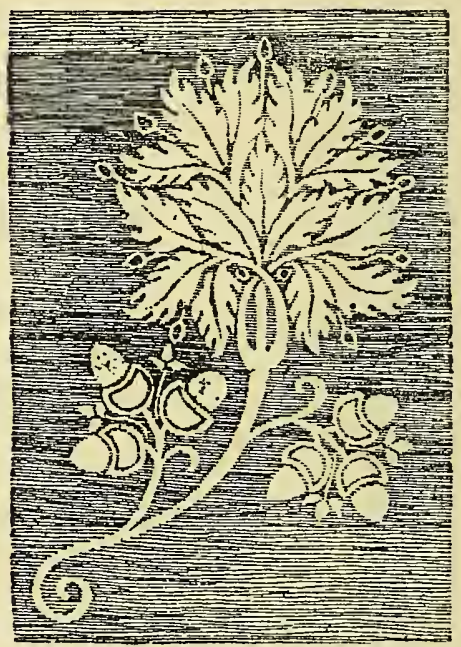

106. Oak-from a Siçilian silk. 
P1ate 74
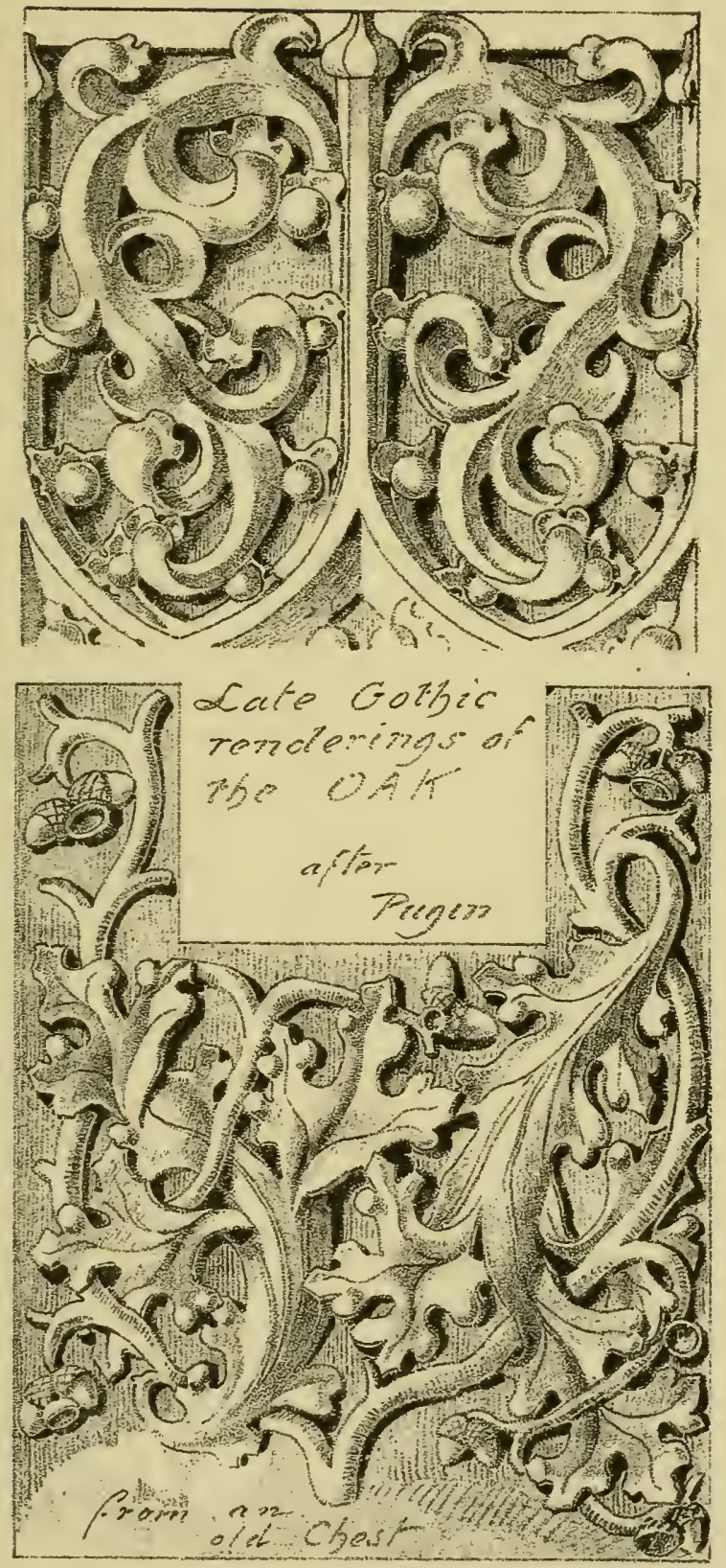

"Pмото-TInT", by James Alcermen. London T. T.

Gothic Oak Ornament. 



\section{More Parallels.}

24 and $8 \mathrm{I}$ and on p. 57. The versions of the olive on Plates 50 and 8 I need only just be alluded to.

There is something to be learnt from a comparison of the various conventional trees, Assyrian on pp. $\mathrm{I}_{42}$ and 239 and Plate 8o, Greek on Plates 24 and $8 \mathrm{I}$, Roman on p. 59, Indian on Plate 77 , Coptic on Plates 49 and 57, Sicilian and Italian on Plate I 20 and p. 58, Romanesque opposite.

It is wonderful with what unanimity ornamentists have everywhere, and from the be-

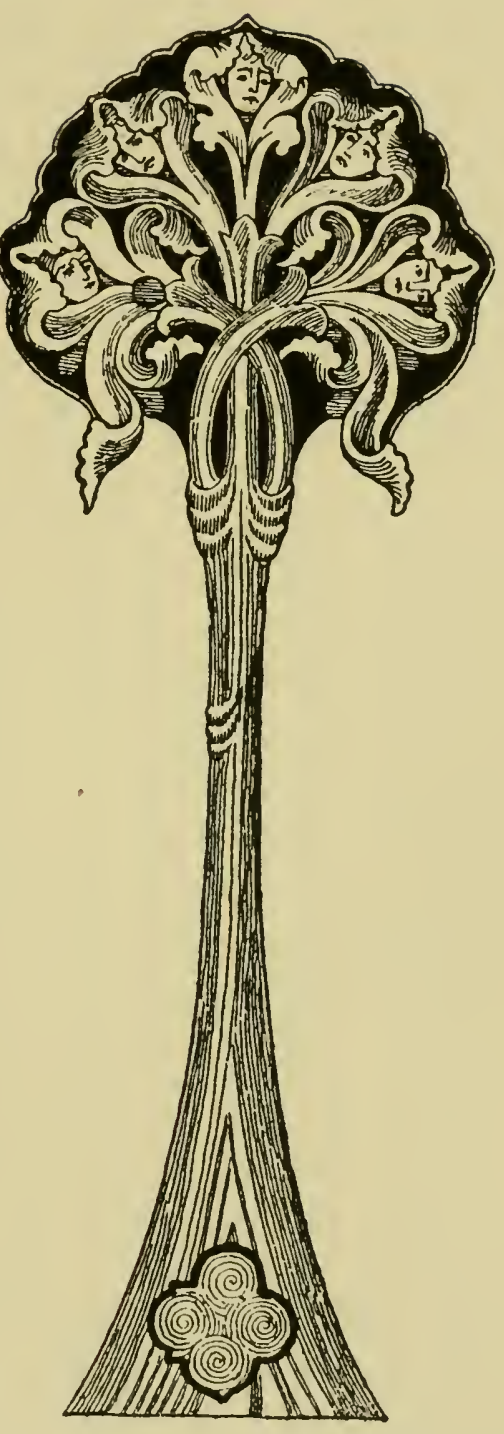

107. Romanesque Tree of Life. ginning of time, resolved the growth of the 
tree into its elements and made it into ornament, reducing its outline in many cases to the shape of a single leaf, and its branches to something like smaller leaves. Those to whom such rendering of natural form does not come easily, by instinct as it were, were not born for ornamentists; let them turn their attention to work for which nature has fitted them.

Comparison may further be made between the works of modern men (Plates I, 22, 23, $42,56,86,87$, and 98 , and pp. 39, 54, 64, 89, I 39, I 80, I 85, and 226); and, lastly, reference to my own design (Plates 9, I4, 31, 38, 39, 40, $48,52,59,6$ I, 72, 75, 85, 89, 90, IO2, IO6, I I I, II 2 , and I23, and pp. 93, I72, I73, I74, 223, and 245) will help to explain more clearly than words, not what I think necessarily good, but the degree of naturalism on the one hand, and of convention on the other, which seem to me personally permissible in ornament.

To any one in the least susceptible to natural beauty, it is not difficult to understand the resentment which some persons feel towards any interference with nature. To disturb it is to deform it, no doubt; but in the interest of cultivation it has to be done. Brier, and bracken, and yellow gorse must give place to rose gardens, apple orchards, 
Plate 75.

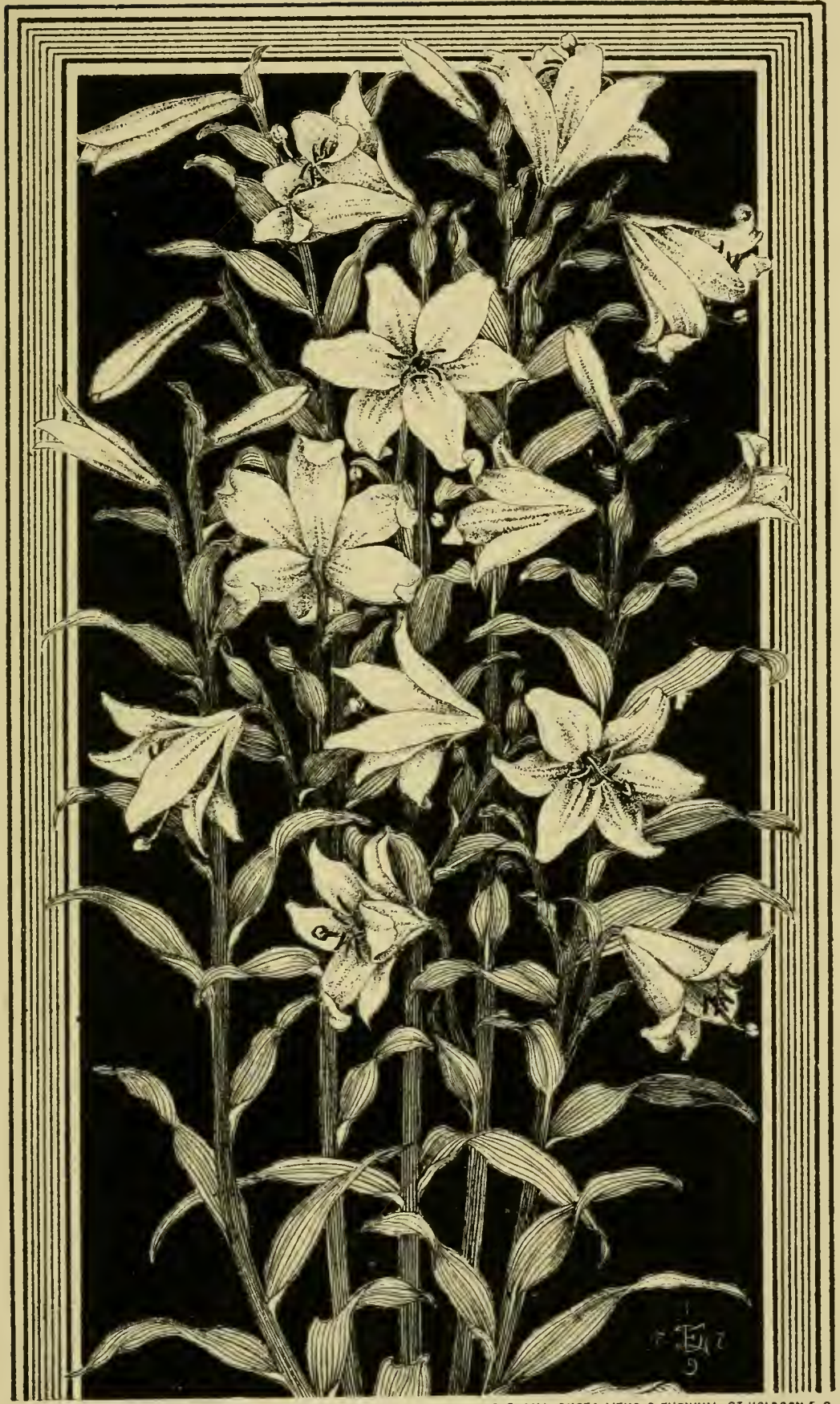

Comparatively natural Lily Panel. 

and fields of corn. They too are beautiful; not the less so that they owe something to the hand of man. It is, after all, a false and rather a cowardly sentiment which makes us afraid of disturbing what is beautiful, when the end is a beauty better worth having.

Those who profess to follow nature seem sometimes rather to be dragging her in the dust. There is a wider view of nature, which includes human nature and that selective and idealising instinct which is natural to man. It is a long way from being yet proved that the naturalistic designer is more "true to nature" than another. It is one thing to study nature, and another to pretend that studies are works of art. In no branch of design has it ever been held by the masters (least of all could it be held by the masters of ornament) that nature was enough. It is only the very callow student who opens his mouth to swallow all nature whole; the older bird knows better. "Lor, how natural!" bursts out the admiring rustic: the artist in like case thinks to himself "What perfect art!" 


\section{IX.}

TRADITION IN DESIGN.

THERE have been times, perhaps, when art ran too much in the ruts of tradition: there is no danger of that just now-more likelihood of our wandering so far from any beaten track as to lose our bearings altogether.

Whatever the danger of merely traditional treatment in design. (a danger less imminent than once it was), it is time we bethought ourselves that traditions are not inherently pernicious. They represent, when all is said, the sum of past experience. Past masters of their crafts must be presumed to have known something. The course of art ran, at all events, more evenly along the broad smooth ruts aforesaid.

Whatever the traditions of his art, and whether he mean to follow them or not, the student must acquaint himself with them. It is not until he is acquainted with the traditional ways of doing a thing that he is in a position to form an opinion as to the relative merits 
Plate 76

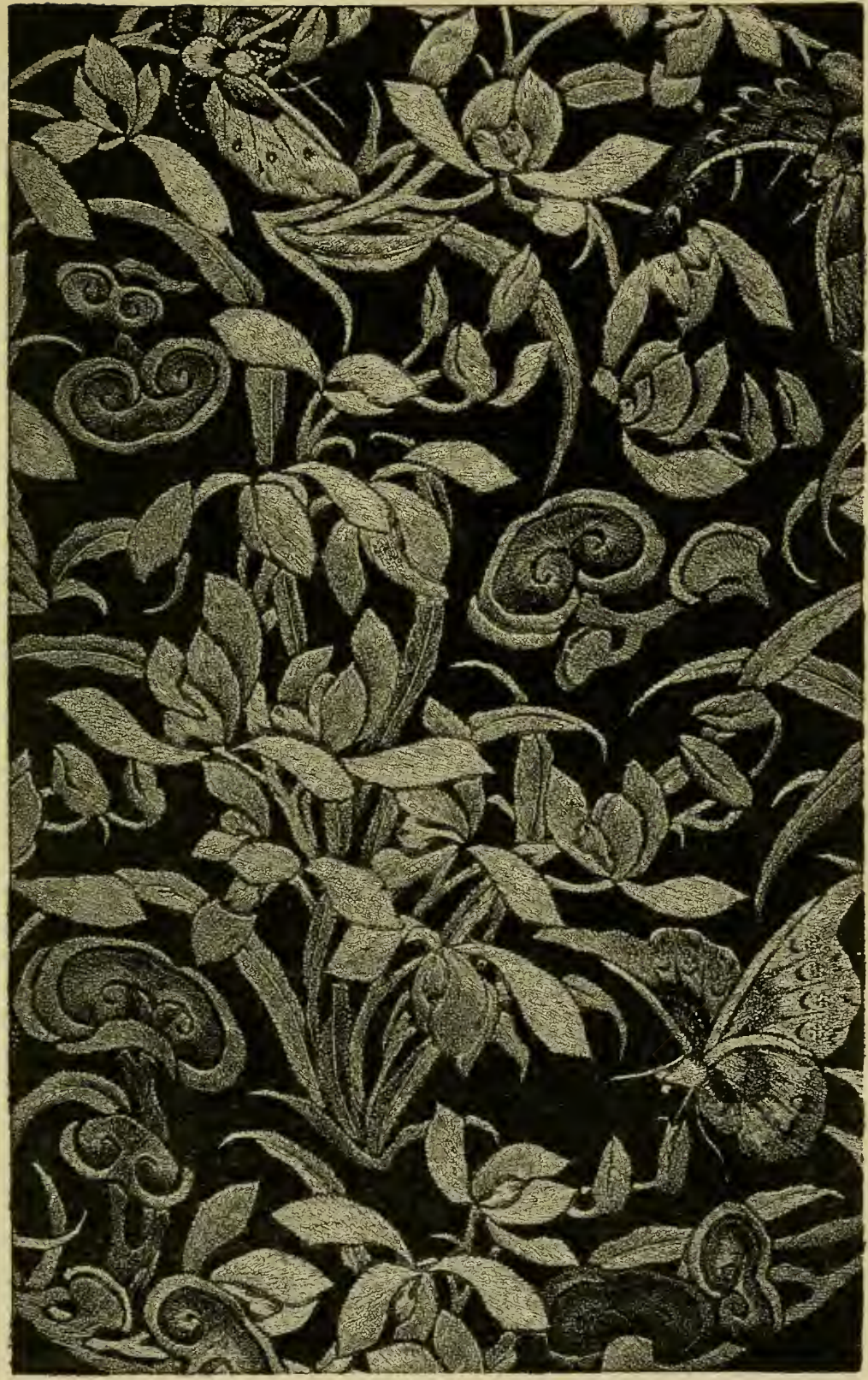

Рното-Tint DV ames Akerm n. London. W C

Orchid \& Fungus pa4tern - Chinese 

of the divers ways of doing it : to presume to rely upon his unaided insight is sheer selfsatisfied conceit-worse than the pedantry of the typical purist (mock-mediævalist, or whatever he may be) who is always so terribly afraid of doing anything for which there is no precedent in old work, that he is invariably and inevitably dull.

Whether for his guidance or his warning, then, the student needs to know the various ways in which natural forms have so far been manipulated by the ornamentist. There is the graceful Greek manner and the energetic Japanese, the rigid Gothic way and the much more strict Egyptian, the fanciful Chinese and the suave Persian, and again the manners of the Renaissance from the fifteenth century to the eighteenth.

The most naturalistic type is afforded by the Japanese. They start quite frankly from nature, and indeed seem to copy natural forms as nearly as their tools and the conditions under which they are working allow; but they seldom lose sight of the fact that they are decorating something; and so careful are they of the conditions of design (as they understand it) that one is frequently at a loss to determine which is uppermost in their minds-nature or ornament. 
It is not meant to suggest for a moment that Japanese ornament is in every way perfect: it lacks qualities indispensable to any really dignified and noble style of design; but in the mere treatment of natural form as naturally as possible and yet ornamentally, there is probably more to be learnt from Japan than from any other source.

Although the traditions of the Japanese are inherited directly from the Chinese, the work of the younger race is characterised by a vigour and spontaneity of design, with which we are not accustomed to credit the elder. But the floral element of design is characteristic of Mongolian art from the first, so much so that its prevalence in Persian and Indian art betrays, one may say, the Mongolian conqueror.

If at its best Chinese ornament is less characteristically natural than Japanese, it is more characteristically ornamental. Whatever modification there may be of natural form is all in the direction of design. Orchis, fungus, and butterfly (Plate 76), each is designed into its place, and is, moreover, made to conform to the necessity of ornament. Musicians have no very high opinion of what they call "tuney" music. Perhaps Chinese ornament may be "tuney," but at least it is in tune. 
Plate 77

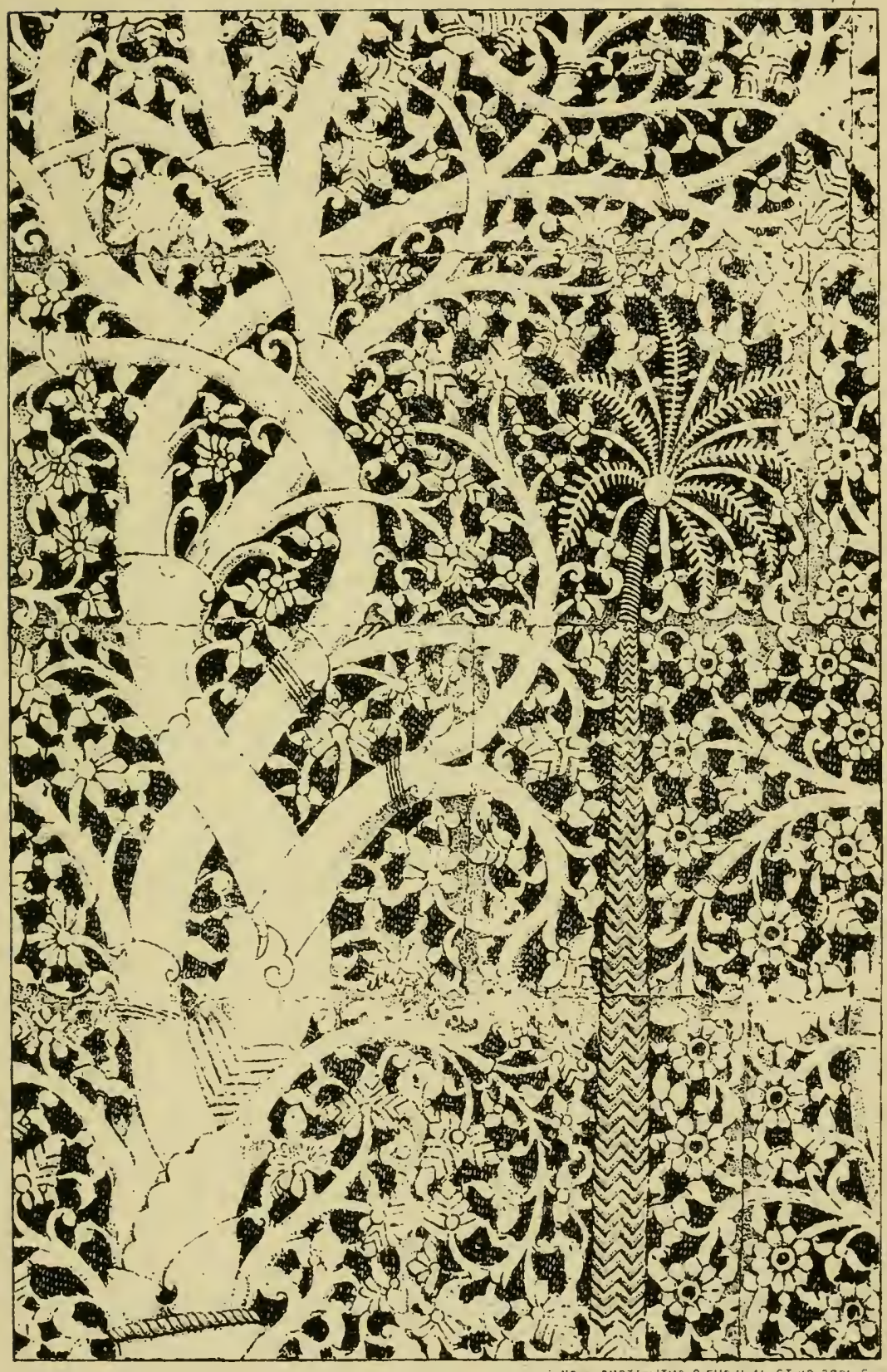

Conventional Tree work 



\section{Tradition in Design.}

That is even more true of the kindred art of India (Plate 77). There also everything is doubtless inspired by nature, but everything is compelled into ornament. The very luxuriance of the design is suggestive of tropical vegetation, but the ornament never runs wild. The date-palm is there with its

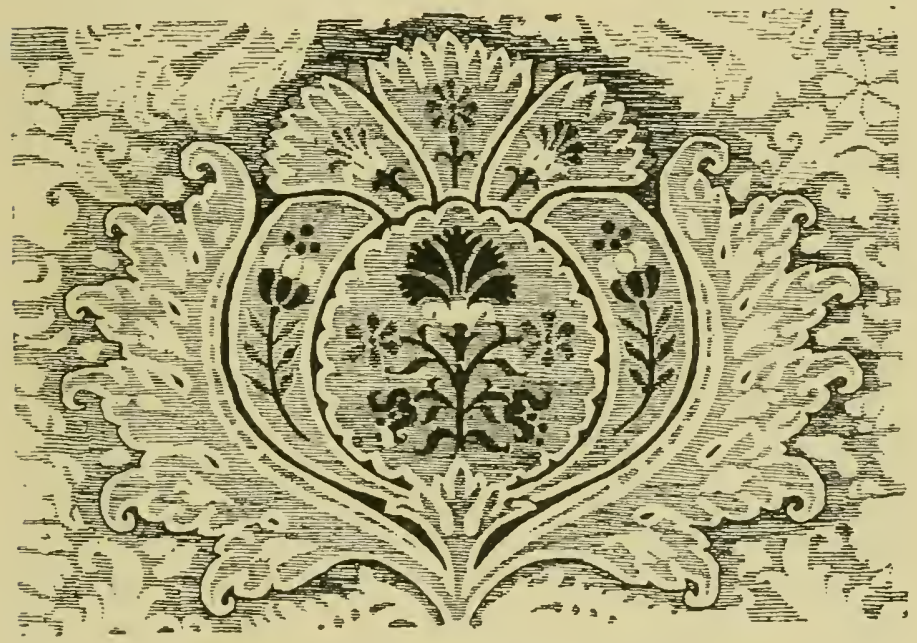

ro8. Renaissance silk showing Persian influence.

scarred trunk, but the scars are made into a pattern. So with the branched stem contrasting with it, it branches into distinctly ornamental lines, and breaks out into equally ornamental foliation.

The man who carved the lattice of which a portion is given on Plate 77 loved nature, no doubt, but he was an ornamentist to the tips 
of his fingers; and the superiority of Oriental art in respect to rhythm, harmony, sweetness, is the immediate result of working on the lines of tradition, of devoting trained faculties to the perfection of an accepted method, of refining upon refinement until the acme of easy grace is reached.

The Persian rendering of natural forms is more free: there is more of the variety of nature in it; but its starting point is always nature, whatever liberties the artist may take with it: it must be confessed he does not stand upon ceremony. One favourite freak of his (Plate 78) was to break the surface of a leaf by diapering it over with other foliated or floral detail. $\mathrm{He}$ was enabled thus to introduce amidst the smaller forms bolder shapes, contrasting most usefully with them, and yet not forming unbroken patches in the design.

The artists of the Renaissance borrowed this idea and made considerable use of it. The way in which the big pomegranate shape on the piece of sixteenth century silk,

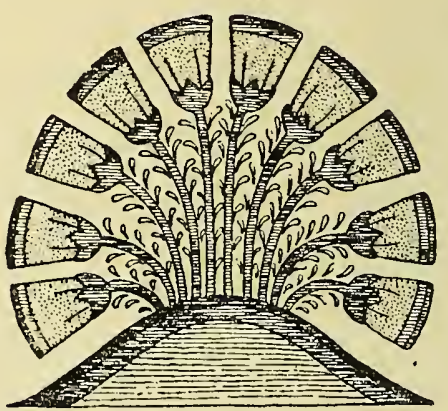

rc9. Egyptian symbolic papyrus. 
Plate 78.

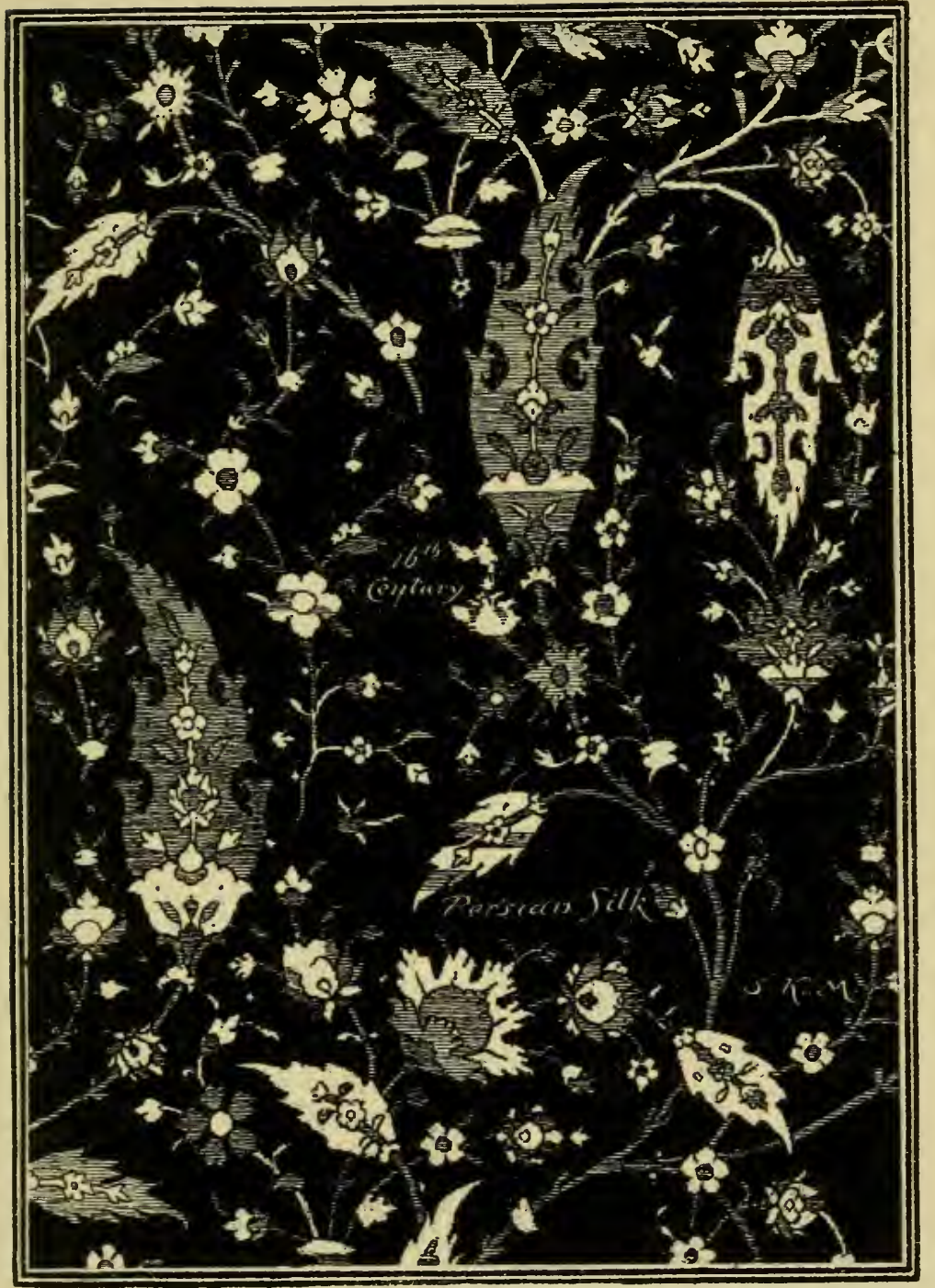

OF

Persian foliage 



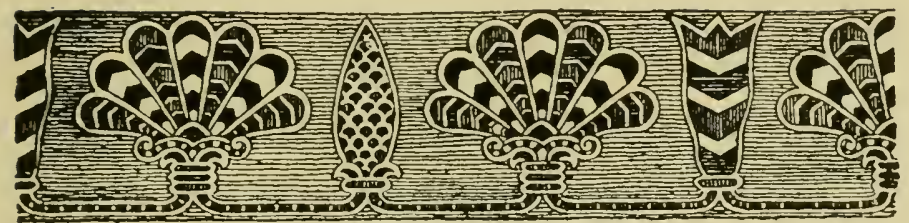

I ro. Assyrian symbolic ornament.

shown on p. I49, is enlivened by the introduction of smaller floral details, betrays distinctly the influence of stuffs imported from Persia (compare it with the velvet on p. 73); the design is Renaissance, but with a difference.

A similar influence is apparent in the damask design on Plate 34 ; indeed, there was a period when European silk designers worked habitually on those lines.

Tracing tradition back to its beginnings, we find that the art of ancient Egypt was confined within very narrow lines; but within those lines it fulfilled admirably what it purposed to do. It is worth study, if only to see how the symbolism which was at the root of it was made to subserve to ornament, how orderly arrangement and restraint in treatment went far towards decoration, and how the most severe simplicity resulted in invariable dignity (p. I 50 and Plate 79).

Much the same may be said of Assyrian design. It does not afford, it need scarcely be said, any more than Egyptian, a fit model for 
nineteenth century ornament; and the restraint which we observe in either (p. I 5 I and Plate 8o) was, perhaps, if we inquire into it, not so much a matter of restraint as of necessity; but none the less it shows us what may be done by self-control; and, working as we do under conditions which make it almost necessary for us to assert oursclves, it is as well that we should be reminded from time to time that, if the world went on the whole no better then, at least it

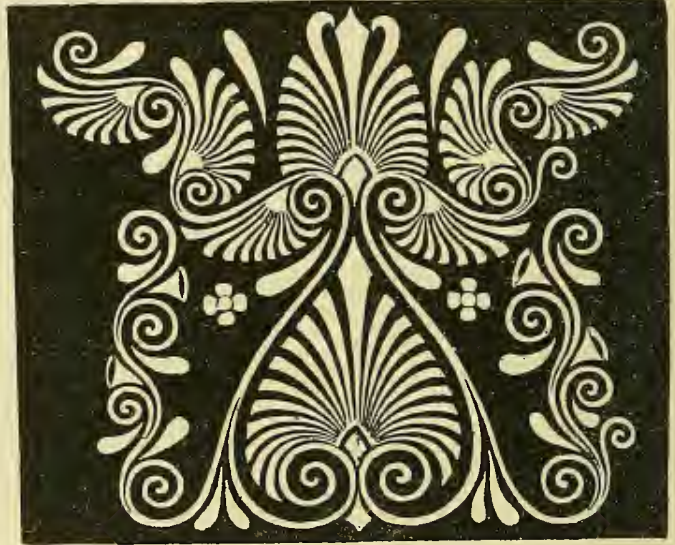

IIr. Abstract Greek ornament.

permitted a naïve and simple-hearted kind of art, from which the most advanced of us have much to learn.

Greek ornament is in the first instance quite abstract in character (above), consisting of curling lines and touches of the brush ; but, such abstract forms assuming by chance (or, as I should say, of necessity) some resemblance to floral forms, it occurred to the artist 
Plate 79

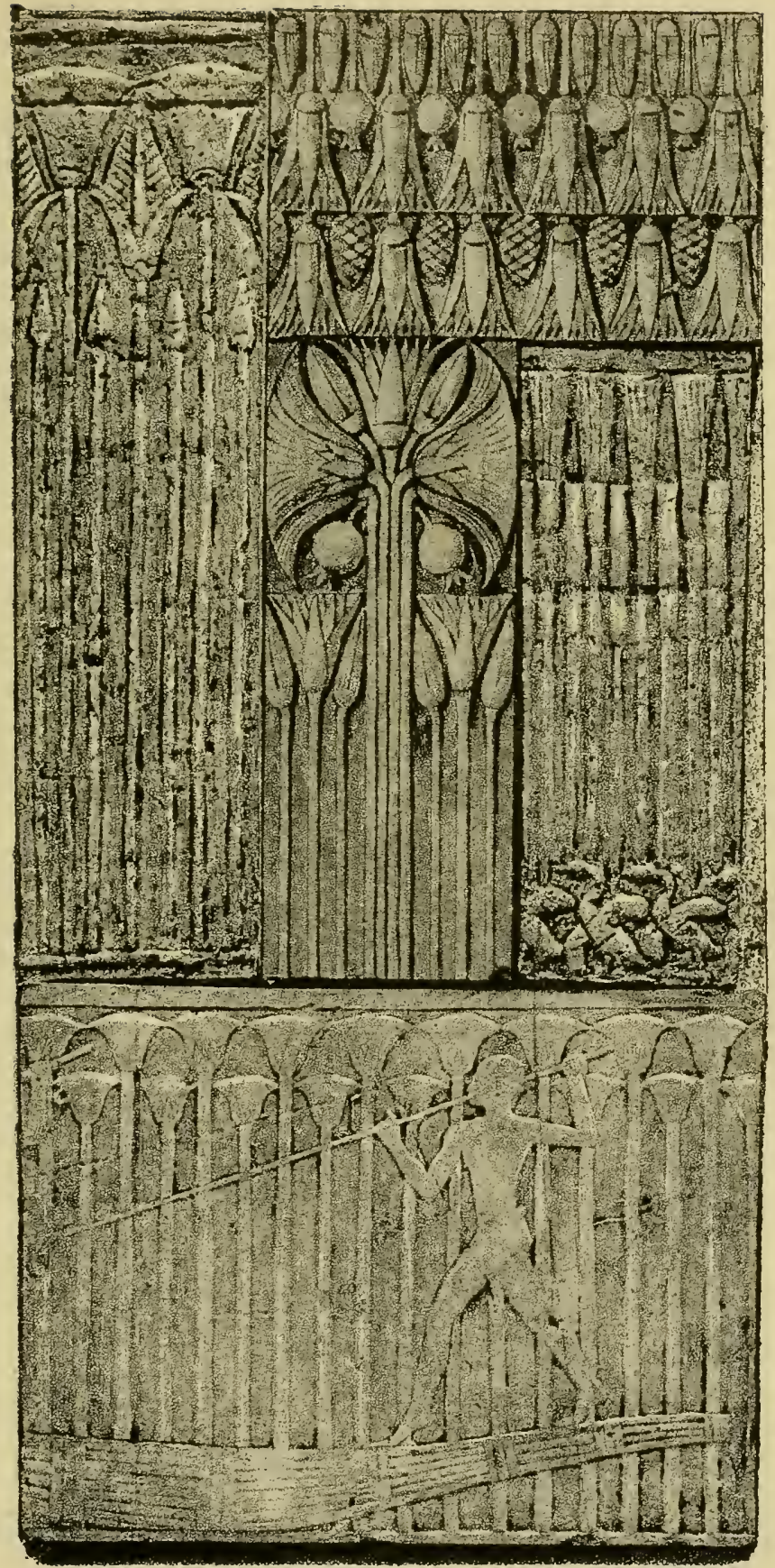

"Pното-Tınт, by dames Axerman.London. W.C.

Details of Egyptian Sculpture 



\section{Tradition in Design.}

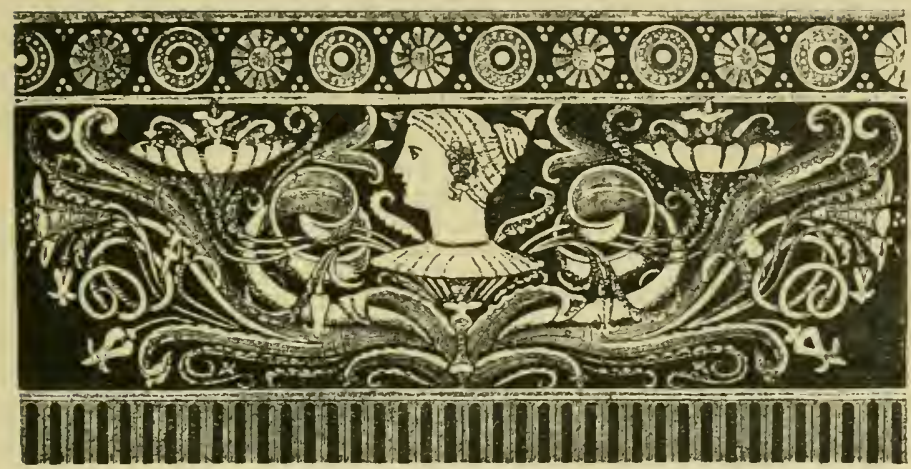

112. Later Greek ornament.

to develop the naturalistic idea-much, as it proved, at the expense of beauty and design. This is plainly to be seen in the ornament of the later period (above), in which the spirals in perspective and the scrolls which look like wood-shavings, mark a very distinct step downwards in design.

When it came to the rendering of the natural shapes of leaves, berries, and so on, the Greek continued to arrange such details arbitrarily, with a view to composition and without regard to natural growth. There is no objection to that so long as the leaves are not so natural as to call for something like natural connection; but in Greek ornament the growth was not always consistent with the detail.

In the lower border of ivy on Plate $8 \mathrm{I}$, leaves, berries, and growth are alike conven- 
tional; in the upper border the three-pointed leaves are more natural than the berries, and the stalks are too natural for the arbitrary order in which these are arranged.

Again, in the borders of olive, there is a sort of naturalism about the fruits inconsistent with their arrangement two and two along the stem. Moreover, the flower introduced into the lower example is a quite incongruous feature.

The altogether abstract rendering of the bay at the bottom of the plate-so abstract that one cannot be quite certain it is meant for the bay-is more absolutely satisfactory. The earlier Greek traditions were the best.

Eventually, in Classic sculpture, bay, olive, ivy, and other plants were rendered almost naturally.

In the fragment of Roman carving on Plate 82 we have quite a different kind of thing: natural growth, that is to say, is twisted into ornamental lines, the tree is made to grow as the ornamentist would have it. There is a certain decorative treatment in that (as there was almost invariably in ancient art), but it is not ornament, and it is ornamental only to the extent that all sculpture was, until in recent times it broke loose altogether from tradition. 
Plate 80

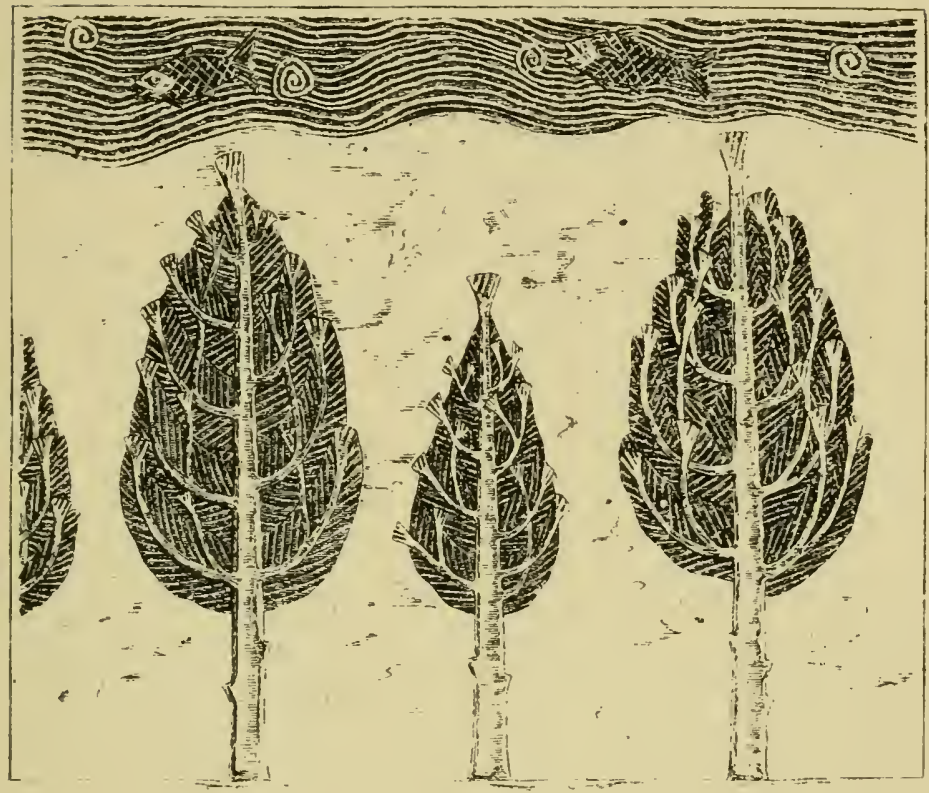

is.

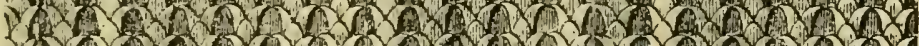

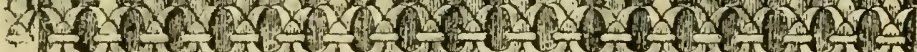

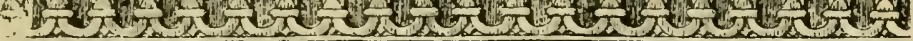

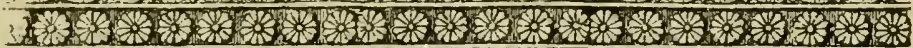

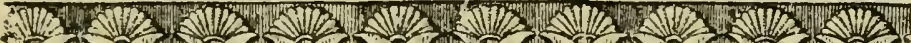

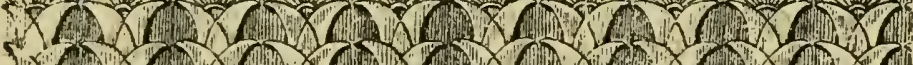

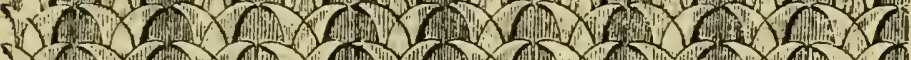
Q f

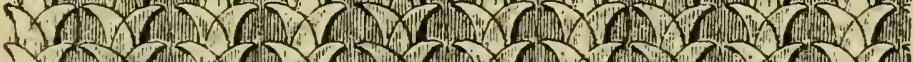

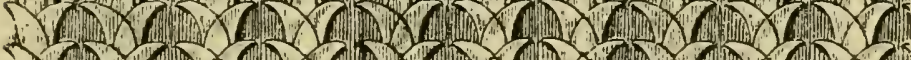

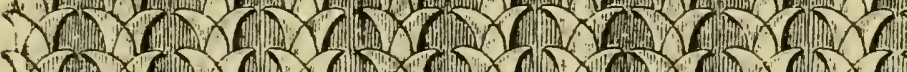

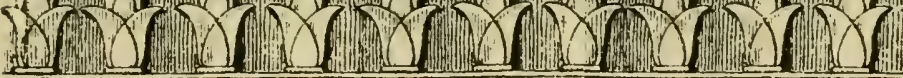

Details of Ninevite Sculpture. 

That idea of making natural things grow unnaturally is continually cropping up in ornament. It is illustrated again in Plate 83 . There is no mistaking Master Peter Quentel's types. The nightshade, the columbine, the pea, the oak, the thistle, are natural enoughtoo natural almost for the impossible lines on which they grow: the oak branches, for

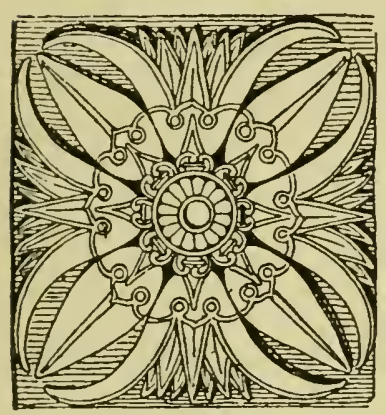

113. Assyrian rosette. example, are shown to have each two separate starting-points.

However much we may prefer the vigour of the Gothic workman to the somewhat effeminate grace of the Oriental, in that one respect Eastern art is more consistent by far: detail and its distribution go together, and are one growth, however artificial it may be. The difficulty in adapting comparatively natural forms to artificial growth is very great; only a master ever quite gets over it.

I have already explained (p. 33) the development of the Classic scroll. The tradition was taken up again by the Italians of the Renaissance. The arabesques of the fifteenth and sixteenth centuries are Classic 
with a difference; and down to the period of the French Revolution, if not indeed of the Exhibition of $185 \mathrm{I}$, through all the changes which it underwent, we can trace in the scroll the development, or it may be the degradation, of Classic tradition.

Examples in point occur in Plates 96, 99, 105; and whether the deviation from the original idea be in the direction of nature (Plates I7, 45 , and 46), or of abstract ornament (Pls. I 8 , i 6 , and I 7 ), the

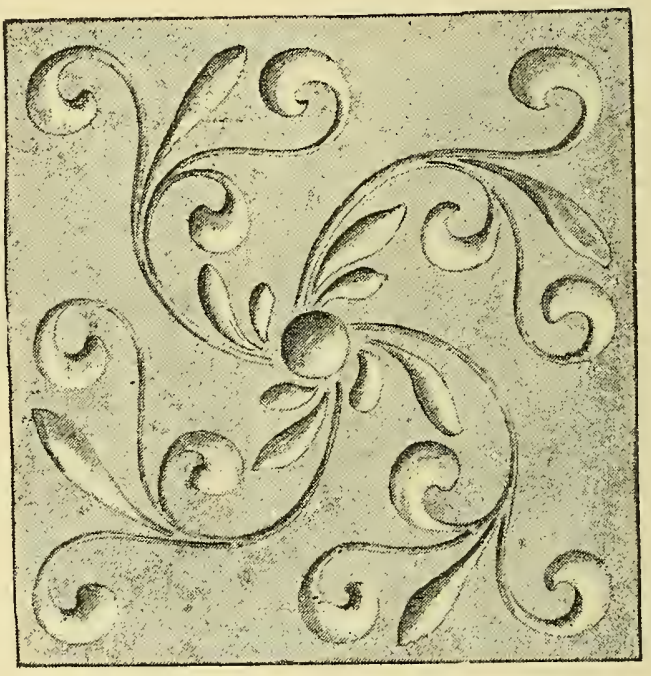

Ir4. Gothic ornament rrom Notre Dame, Paris.

descent of the design is always easily to be traced. For better or for worse, one style grew, that is to say, out of the other. As certainly as the Assyrian rosette on p. I 55 was influenced by Egyptian tradition, so certainly did the tradition of such work influence the Greeks. 
Plate 81

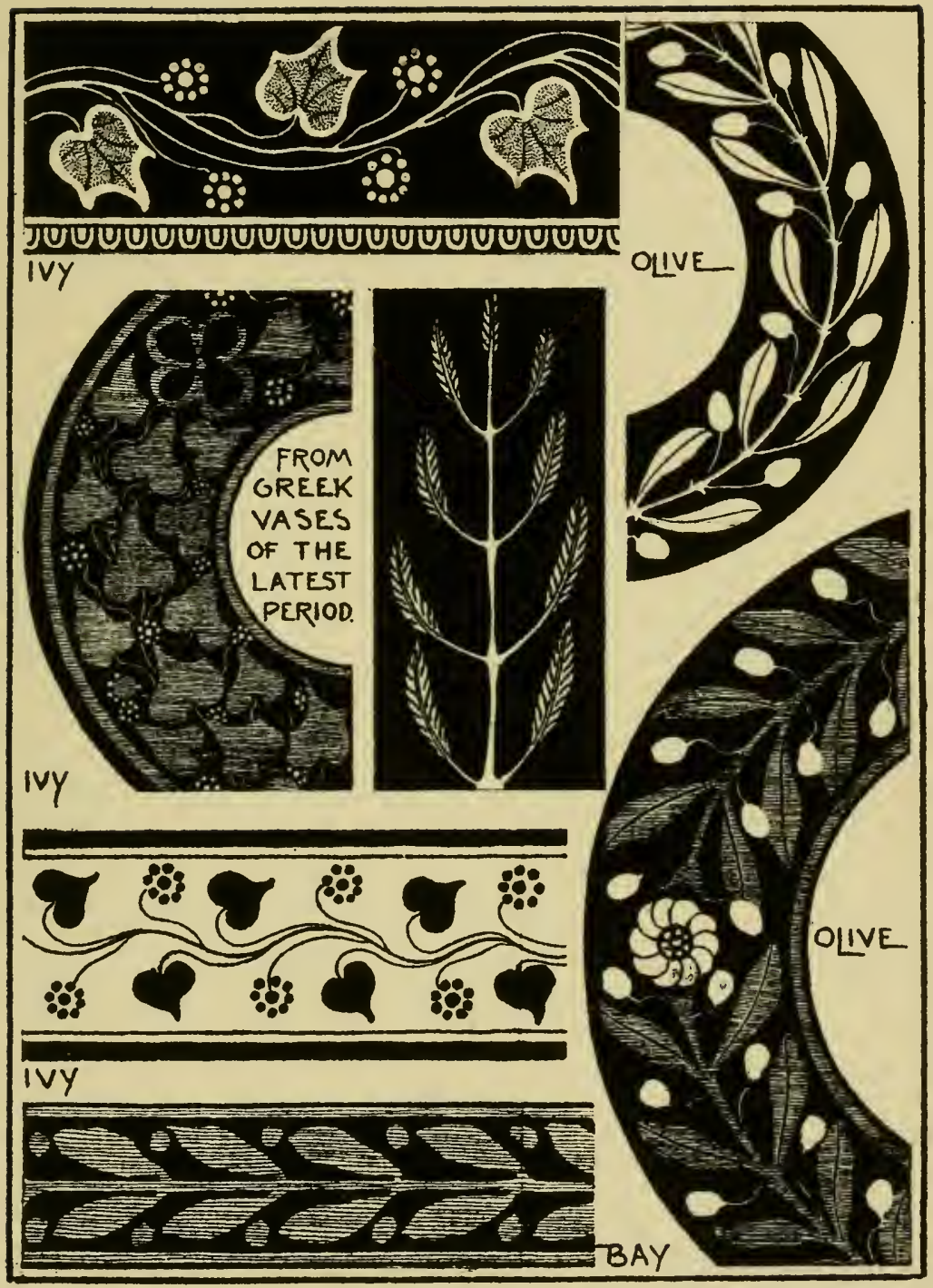

J Alierman. Pboto lith London

Details of Greek Vase painting. 



\section{Tradition in Design.}

And so it was with Gothic art. We can trace it through its various phases back to the Romanesque, and so find a connection with the Classic. Indeed, in some details of early

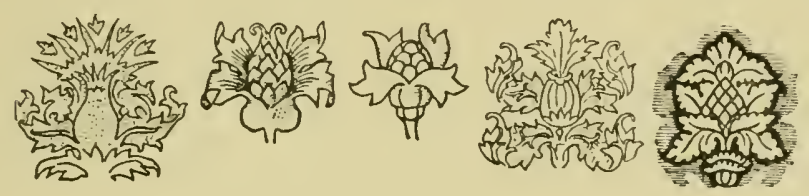

I15. Fifteenth century fir-cone or pine-apple ornaments.

Gothic ornament one can trace a distinct resemblance to Greek art, from which in important particulars it is most remote.

In the detail from Notre Dame at Paris, on $\mathrm{p} . \mathrm{I} 56$, there is a distinct relationship to the painted ornament on Greek vases, and the typical "Early English" detail assumes at times in the hands of the glass painter something of the same character.

Not only may one historic style of ornament be traced from another, but the very details of ornament are in many instances traditional, and survive long after they have lost any significance they may originally have had ; so much so, that what is strange and unaccountable

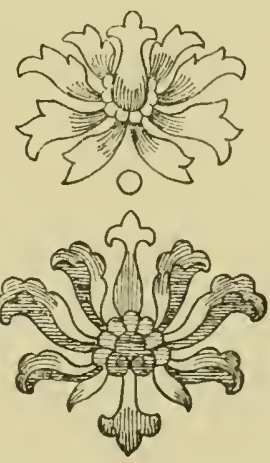

I16. Chinese flower forms. 


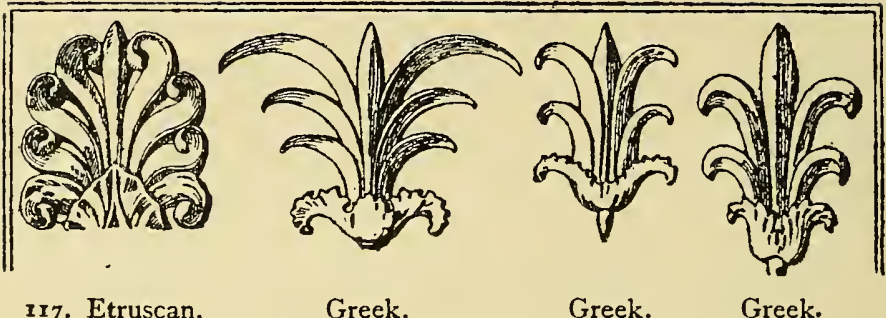

in ornamental design, proves often to be only the survival of some long lost tradition.

The fir-cone, or, as the French call it, the pine-apple, which figures in nearly all fifteenth century pattern-work (see Plate 84 and p. 157 ), figures not only on the thyrsus of the Greek god, but in Assyrian ornament (p. I5I), and in still earlier Egyptian sculpture (Plate 79). On Plate 80 the Assyrian fir-trees are regularly cone-shaped.

It is possible, no doubt, to work oneself into a state of mind in which it seems plausible enough, if not quite proven, that all ornament is derived from a single source, the "hom" or date-palm, to wit. But without going quite so far as Sir George Birdwood in his ingenious theory as to the development of the knop-and-flower pattern, one cannot but admit that the unanimity with which, from the days of the Pharaohs to the days of Elizabeth, ornamentists have put together similar forms on similar lines, leaves no possible 
Plate 82

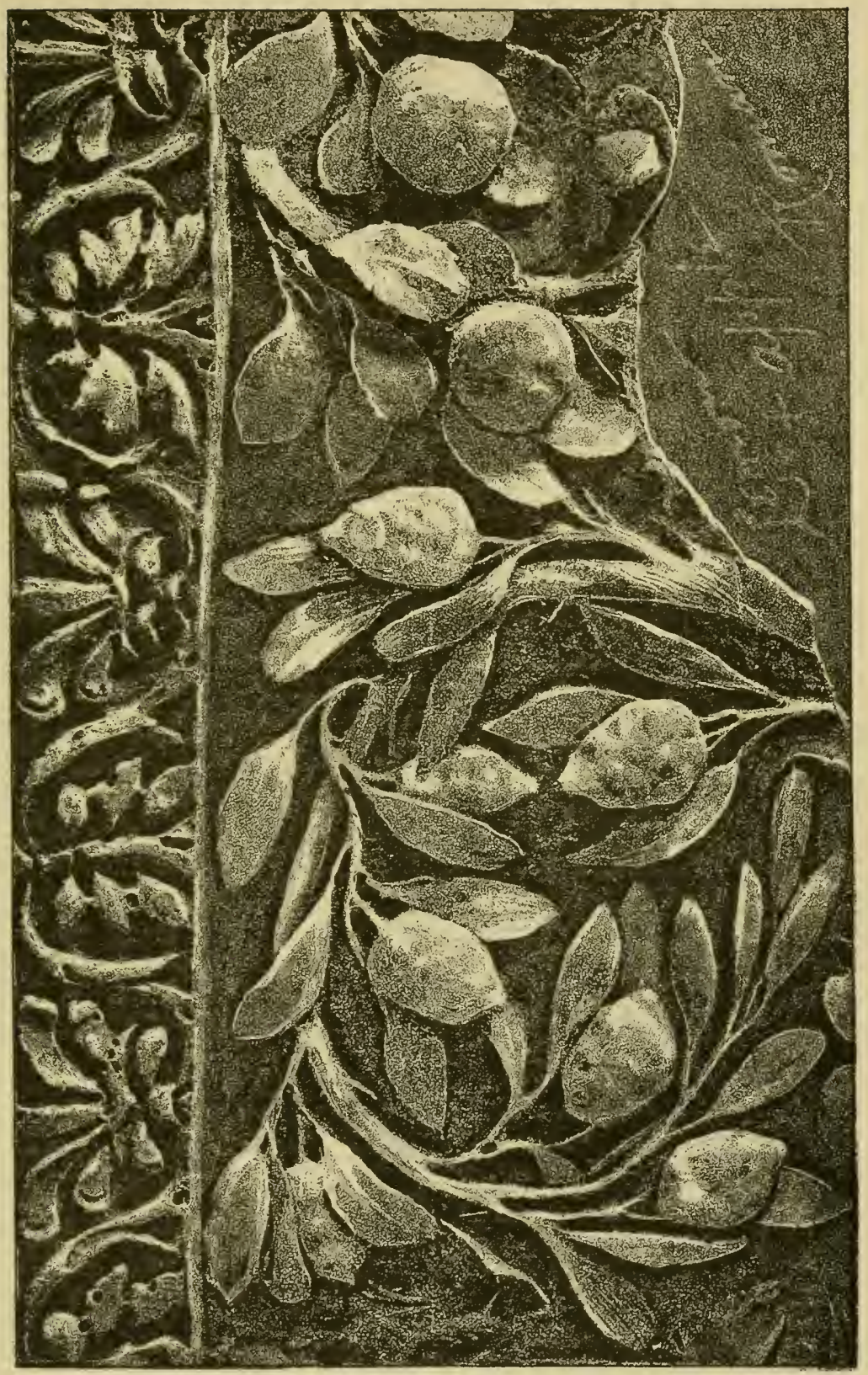

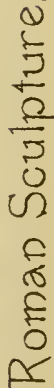





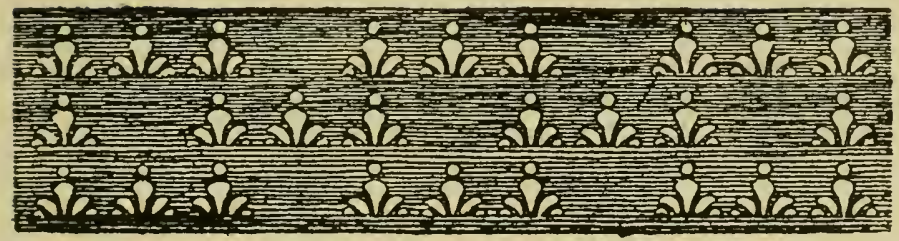

x 8 . Japanese diaper.

doubt as to the lingering influence of tradition upon design through all that time.

It is especially curious, also, to notice how on very similar lines very different and yet clearly related forms are developed.

Whatever may have been the origin of the characteristic form popularly known as the honeysuckle ornament of the Greeks, * there is no mistaking its relation to the Egyptian lotus and papyrus ornaments, pp. I 50 and 240 , and to the Assyrian palm ornament, p. I $5 \mathrm{I}$. See also Plate I Io.

In Chinese flower forms, also (p. 157 ), one seems to see very much the same lines;

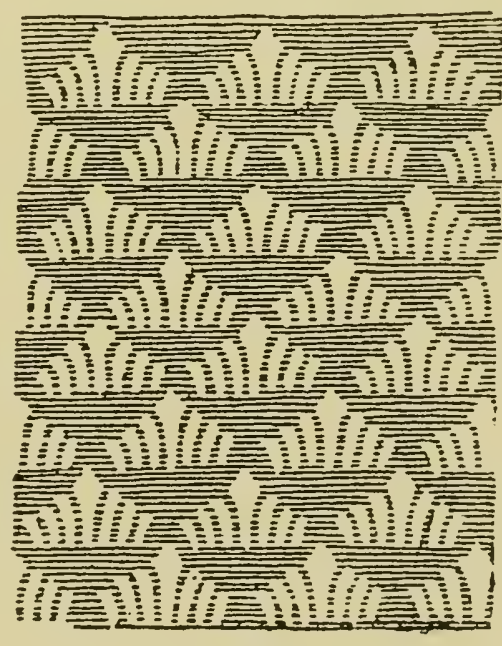

Ixg. Japanese diaper.

- 'Some Principles of Every-day Art,' pp. 104-107. 


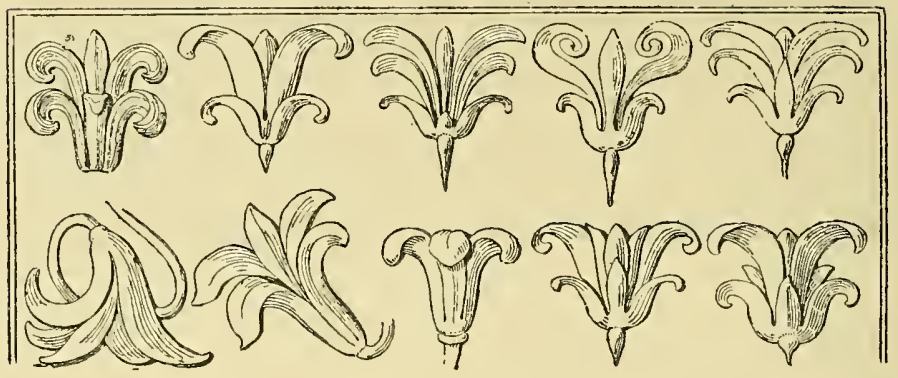

I20. Lily-like Greek details.

and in the Indian naya, or many-headed snake, the resemblance is so striking as to suggest that serpent-worship may possibly have been after all the starting-point of the idea.

The Etruscan anthemion on p. I 58 is very like the Indian naya (Plate I I9); the Greek details on the same page might have been suggested by the young leaves of the iris, which seem to me clearly to have suggested the Assyrian pattern on Plate 80.

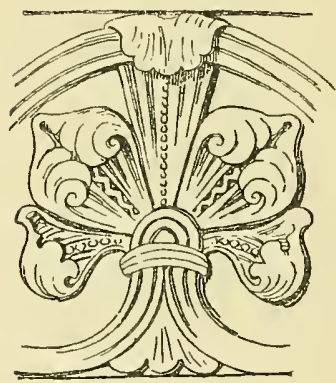

I2r. Romanesque detail.

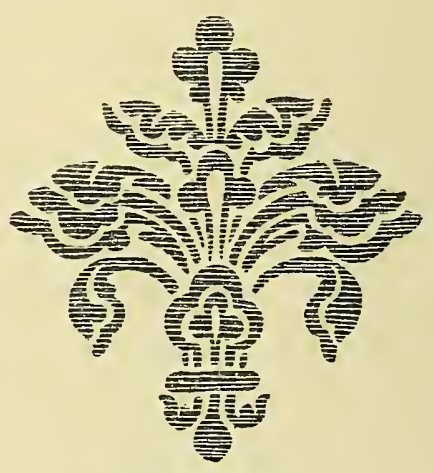

I22. Gothic pattern. 

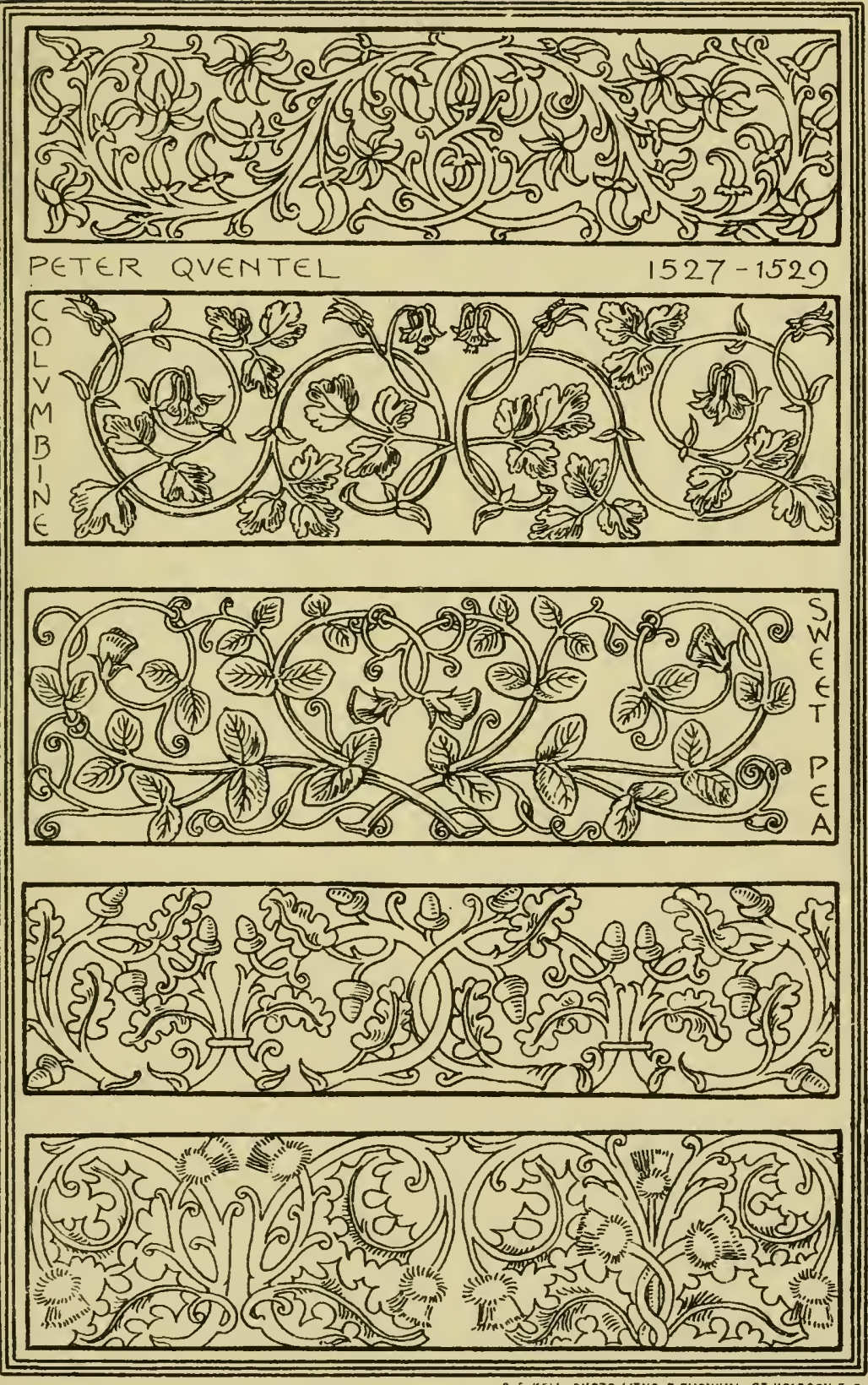

16." Century German design. 



\section{Tradition in Design.}

The resemblance of the Japanese diapers on p. I 59 to Greek brushwork is explained somewhat by the fact that they also are brushwork.

Other Greek details, especially some of those on p. I60, take, as before said, distinctly the form of lilies.

In the Romanesque development of the anthemion (p. I60) we have, indeed, leaves of the most conventional, but there is no mistake about its source; and, strangely enough, the leaves spring from a semicircular feature resembling that from which the separate serpents' heads issue in Plate II9.

Here, too, as in the Early Gothic tile pattern on p. 160, is foreshadowed the fleur-de-lis, which assumes a more distinctive shape in the Gothic cross on p. 238. Fully developed instances of the fleur-de-lis occur on p. 24I.

The fleur-de-lis, says Voltaire, was obviously derived from the top of a halberd; but whence, then, the form of the halberd? There is not much room for doubt that the actual form of the fleur-de-lis was suggested by the iris; but for all that the ornamental shape is only a development of the old idea in a somewhat new direction.

It seems as though, whether because of the perpetual recurrence in nature of radiating and 


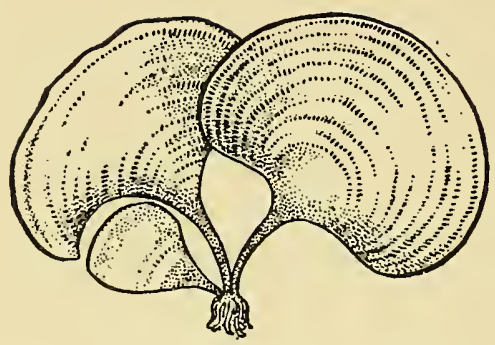

I23. Concentric forms, seaweed.

concentric forms, or whether because of the inherently ornamental disposition of the old lines, the ornamentist could never get quite away from them

for long at a time; their influence appears even in the comparatively natural design on Plate 85 . Certainly the glass painter in designing a cruciform nimbus, the detail of which is given (124), had no idea that he was following Classic precedent at all; nor he who stencilled the diaper

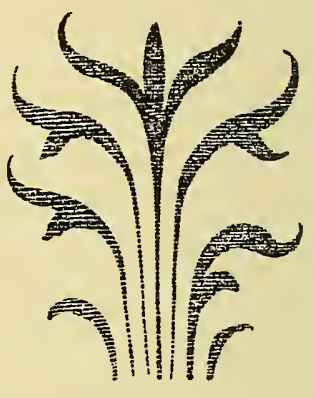

124. Gothic. of rays on the screen of a Norfolk church

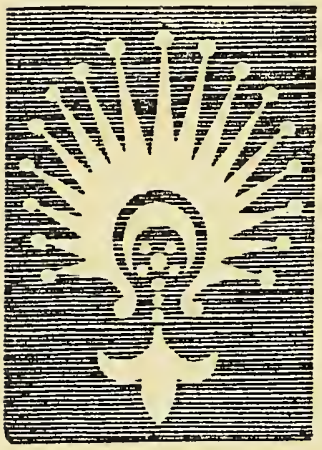

125. Gothic diaper. (below). The rays of light arrange themselves more or less in the familiar order; as do the lines of a cockleshell (p. 222), - so much so that it has been contended that the Renaissance shell ornament is only a variation of the anthemion.

In the Renaissance or- 
P1ate 84
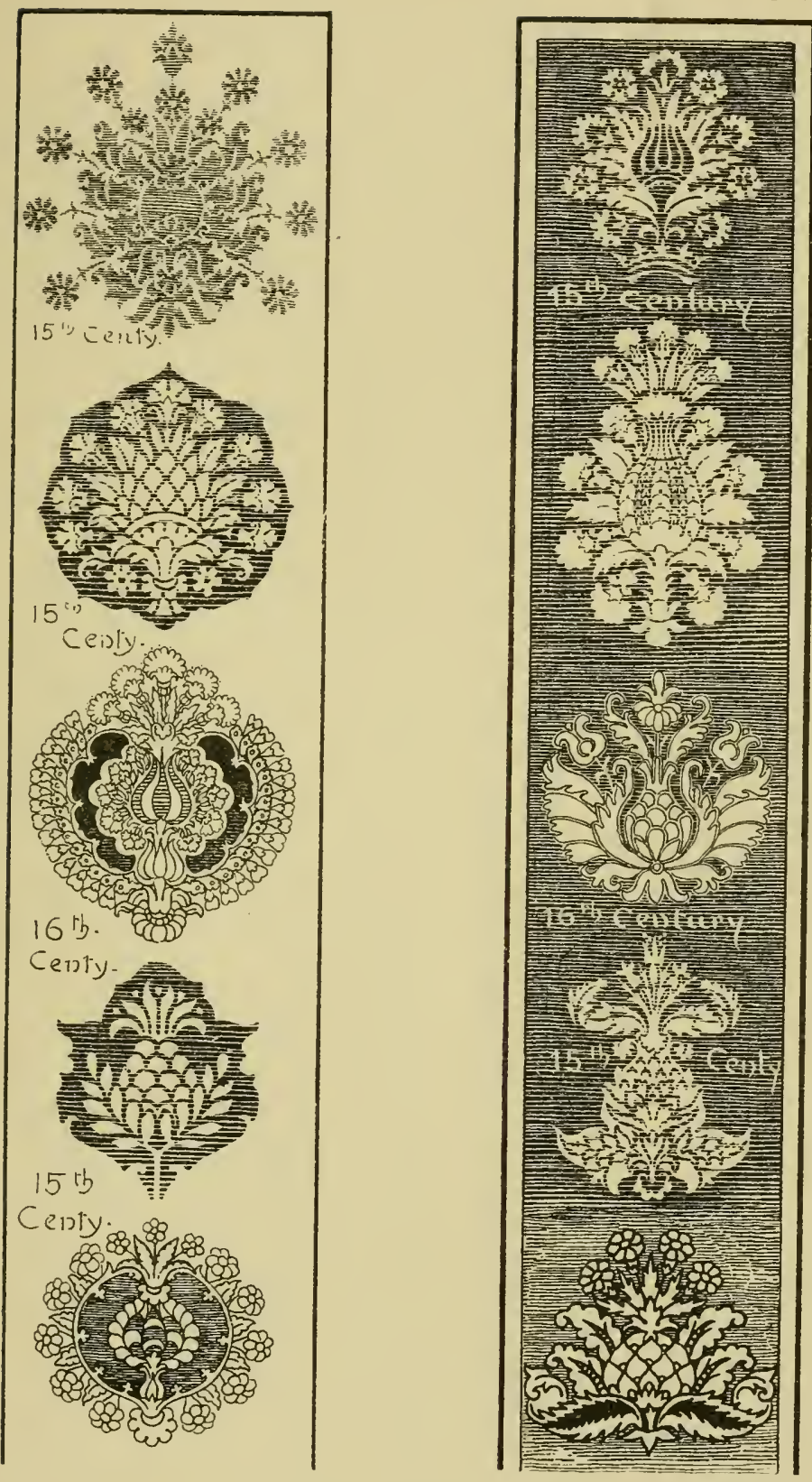

3 Aiverzan Photo ditb London

Late Gothic" Pine Ornaments. 

naments below, distinctly founded upon the ancient lines, the introduction of the oak-leaf and of the pods is not altogether happy; the designs are too plainly made up; on the other hand, the serrating of the leaves (p. I64), and the substitution of pods (p. 20) in their stead, are new departures, quite justified by

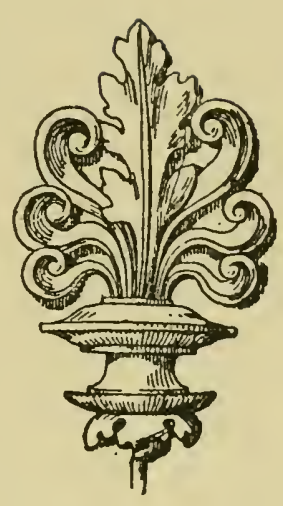

126. Renaissance ornament. success.

It is only by such departure that success is possible. What has been done is done with, so far as design is concerned. Its teaching is what is valuable,-if only we would learn from it the way it was done. We waste our

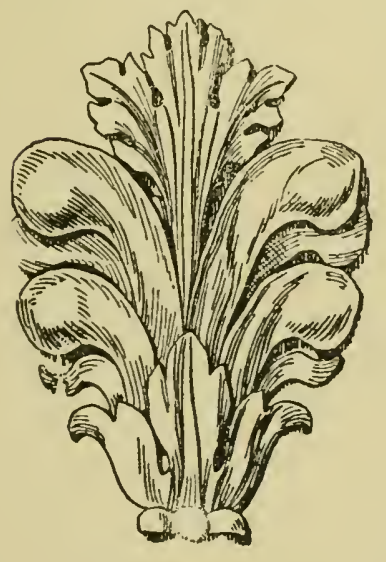

127. Renaissance ornament. time in copying the forms of ancient art instead of trying to penetrate its secret.

It is by virtue of its eclecticism, not of its archæological accuracy, that the work of such a man as the late William Burges has any hold upon us. He founded himself, indeed, upon 
Early French Gothic, and he was inclined to like anything answering to that title, but he did not scruple to borrow from Oriental or Classic art what suited his purpose. And although his manner was archaic, his ideas were his own. He found room in his decoration even for a joke now and then, the very surest sign that he was quite at his ease in the habit of mediævalism he chose to assume.

Such assumption may not be altogether affectation in some men. Yet our art must be ours, whatever else it may be.

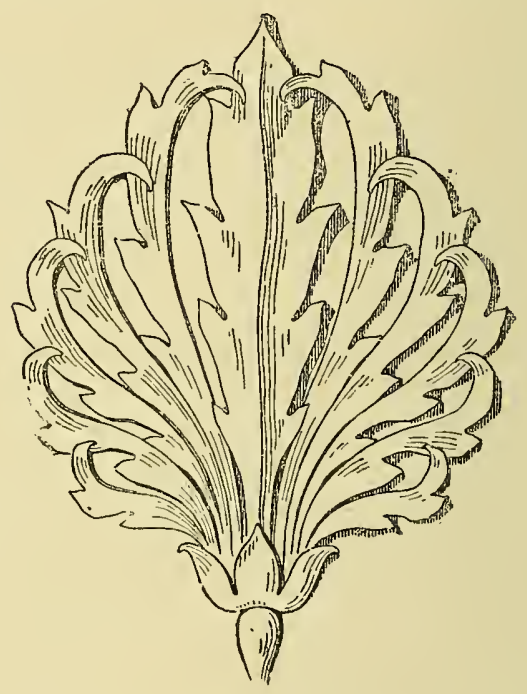

r28. Renaissance anthemion.

A man may confine himself to the lines of tradition and follow them, if he will, or if he must; but why follow traditional forms? there is no good tradition for that. 
Plate 85

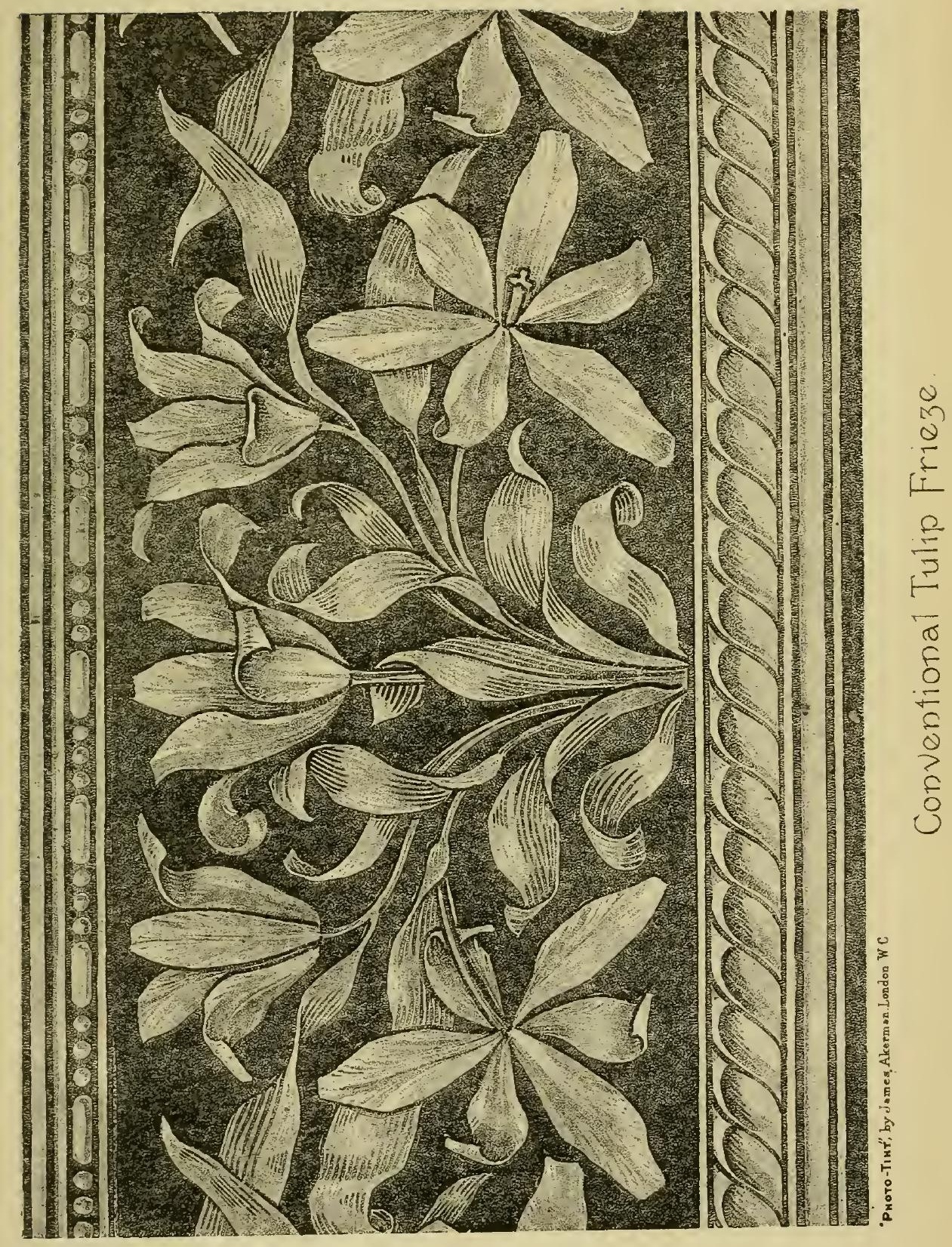





\section{5}

\section{$\mathrm{X}$.}

TREATMENT.

THE obvious fitness of certain natural forms to certain purposes of ornament, and to certain processes of work, needs no pointing out.

Some simple leaves suggest of themselves how easily they could be rendered in painting. One stroke of the brush is enough to indicate a blade of grass or a willow-leaf; a series of touches will express at once the compound leaves of the acacia, tare, or other pod-bearing plants. On Plate II 8 such leaves are used indefinitely to suggest indeterminate foliage. Again, the petals of many flowers may be painted with so many dabs of the brush. With the finger-tip one can indicate a bunch of berries, a berry at each touch. And not only in painting is this so ; each particular craftsman sees in nature the chance for his particular craft, and, if he is worth his salt, seizes it.

It is clearly the business of the ornamentist to select the natural types which lend them- 
selves to his purpose; not to take things as they come, but to choose for painting, forms which are paintable; for carving, what is carvable; for metal, malleable shapes; and so on.

It would be absurd to adopt for any process of conventionalism a model of which the character is inevitably lost in such a process. You would not choose for rendering in coarse material a type characteristically delicate, for a colourless substance one depending altogether on its tint, for a dull material forms characteristically crisp, or for one diffcult to manipulate forms full of intricate and subtle detail. That would be at best only bravado. Ordinarily it comes of sheer ignorance. In design, as elsewhere, brains count for something.

We have, then, to seek in nature, not only beautiful types, but types amenable to our artistic purpose and the means by which we intend to carry it out. The very mention of a material is often enough to suggest available types in nature.

Indeed, it would be time well spent by the student if he were to ask himself from time to time a question or two of this kind :-To what decorative purpose are such and such plants fit? or, what plants are adapted to such and 


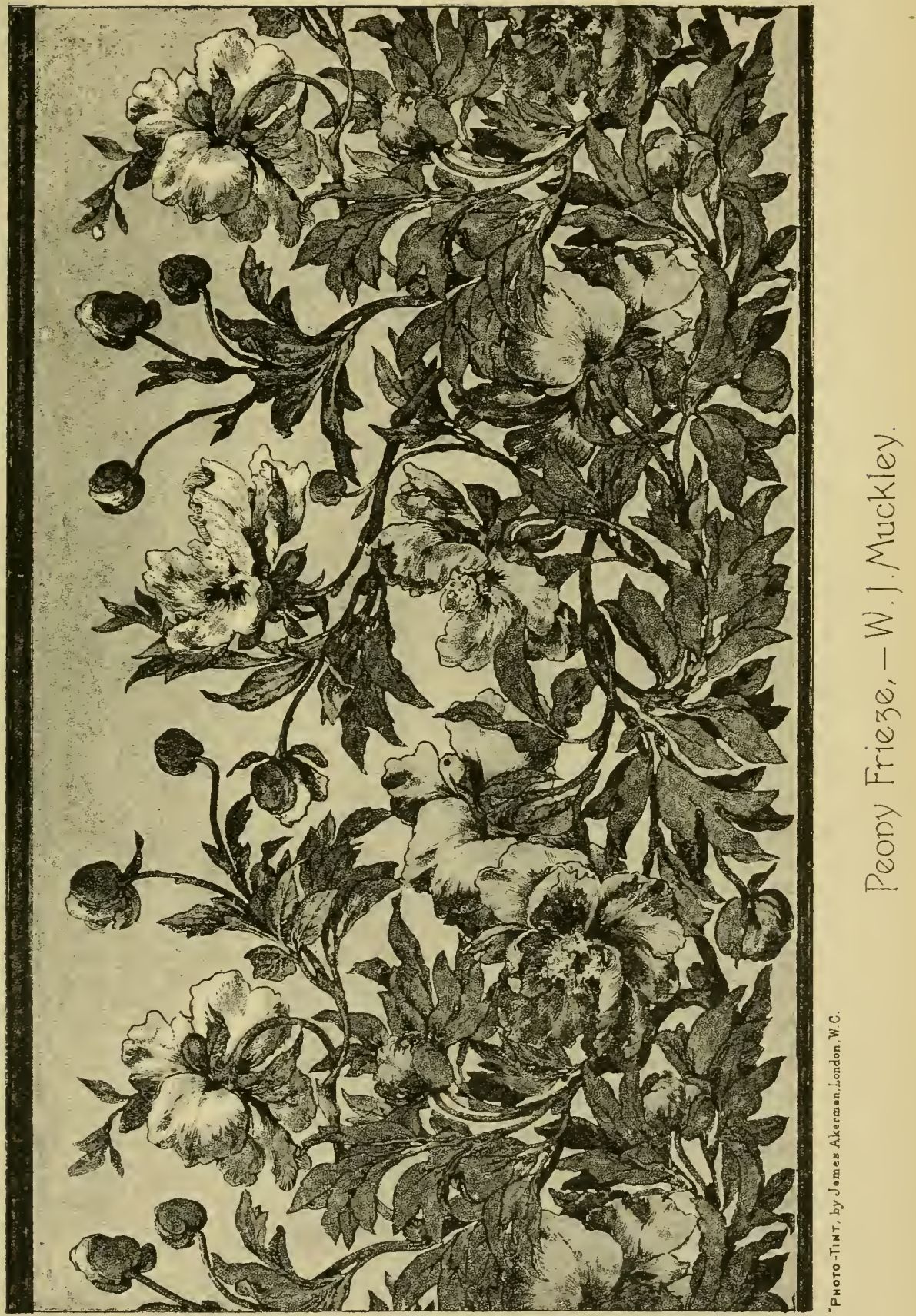



such materials, to such and such treatment?and so on.

And it should be noted that, just as it is not in the most romantic, or what is called picturesque, scenery that the landscape painter finds subject-matter for his pictures, so it is not in the most obviously elegant and graceful forms of growth that the designer seeks his inspiration. The convolvulus, the passionflower, and the birch tree, do not lend themselves especially to ornament.

The experienced designer gets to know how useful some forms are, and how hopeless others. He knows, too, that nature, kind as she is to those who approach her in the spirit of conciliation, never does his work for him. Natural form is resolved into ornament, that is to say, only by treatment.

This is a point on which dogmatism is peculiarly dangerous, and advice of practically no value. An artist must settle for himself what he shall render, and how he shall render it. No one but himself can determine for the individual what he can do. He may take by assault the position we pronounced impregnable. The conditions of success are that he should form a just estimate of his own powers, and regulate his ambition accordingly. His treatment of a natural type is his 
justification for choosing it. Having selected a type, he should have no great difficulty in treating it. Technical difficulties suggest to him fresh expedients in design. And if he really belongs to the "natural order" of designers, he works with perfect ease under all manner of limitations as to space, line, colour, and so on. The weight of conditions only steadies him.

Between the treatment which consists in merely composing natural forms with such regard to decorative needs as may constitute what by a stretch of terms is called ornamental arrangement, and the reduction of such forms to ornament pure and simple, there is the widest possible range, the whole range of design in fact. The merely pictorial treatment, on the one hand, seems as remote from ornament as the absolutely abstract invention, on the other, is removed from nature. And yet it is impossible to deny that a painter, for example, may combine with a very natural rendering such regard to the conditions of design as will constitute a decidedly decorative, if not precisely ornamental treatment.

Such a treatment is exemplified in Plate 86, part of a frieze by Mr. Muckley. This is flower-painting, if you like, and not orna- 


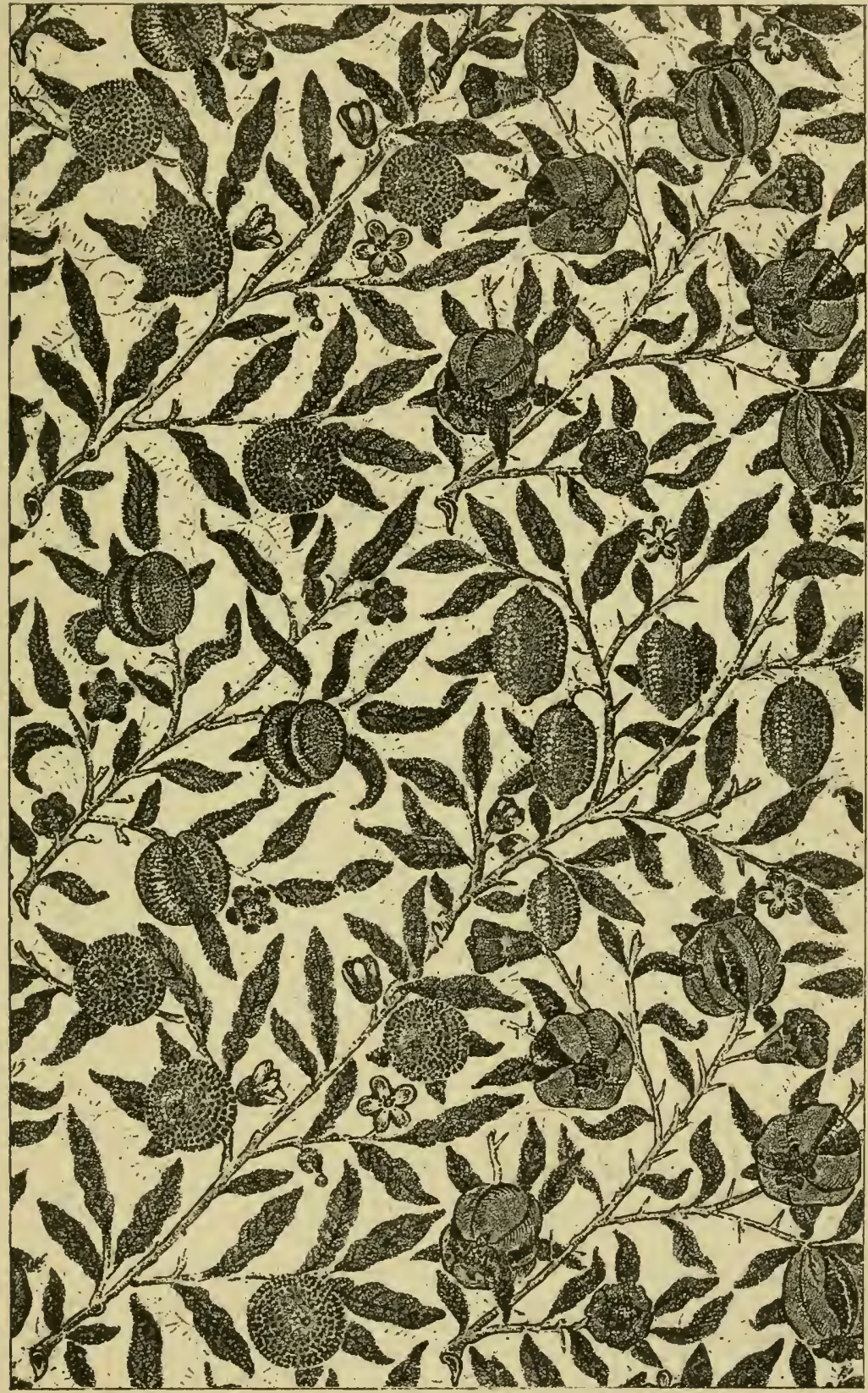

"Рното-TINT", by Ismes Akermon,London, W C

Fruit pattern, William Morris 

ment; but it is something more than mere flower-painting: there is design in it. As a printed fabric in which the same flowers must perforce recur at regular and very short intervals, the artist himself and the producer of the wall paper would probably be the first to admit that it was open to reproach; but

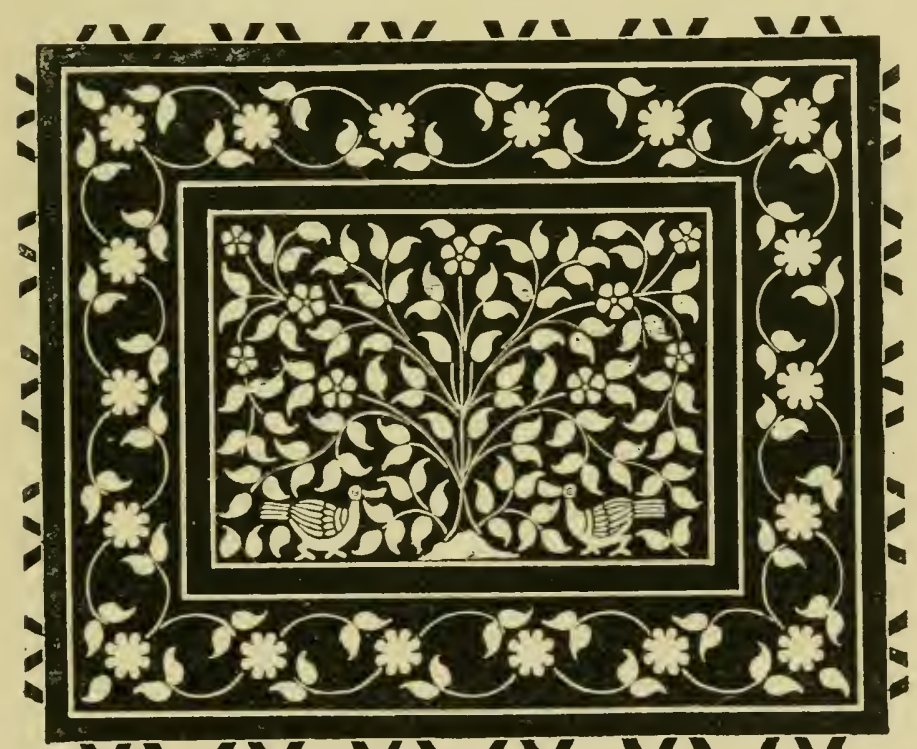

129. Abstract foliage-Persian inlay.

as a painted frieze, such a rendering has its raison dêtre. There is no need to say that my own sympathies lean towards something more severe in design.

The delightfully restrained foliage above, so absolutely ornamental that it might have 
been derived from any one of a hundred different plants, designed by a man who probably could not have painted a natural flower to save his life, fulfils almost perfectly the conditions of ornament. Albertolli's feeble celandine opposite fails, on the other hand, precisely for lack of treat-

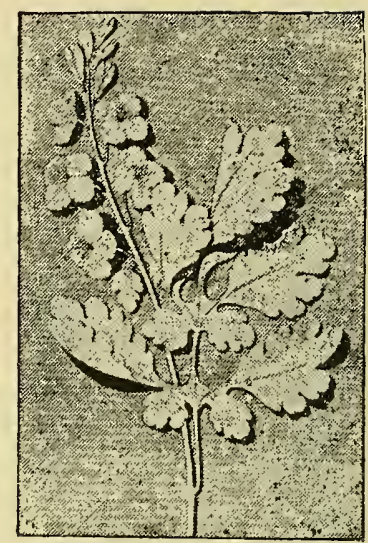

I30. Wo:ild-be ornamental celandine. ment.

One great charm in more conventional treatment is that it reveals the individuality of the artist. Mr. William Morris is very plainly recognised in the design of the wall-paper on Plate 87. It is not often that one sees in design the claims at once of nature and of ornament so evenly balanced as they are here. The straight lines of the stems, for instance, are characteristically natural ; but by the direction they are made to take in the design they give diagonal bands, which fulfil a distinct decorative purpose, preventing the eye from wandering away in the direction of other lines which would be less pleasing. The rendering of the fruits again, whilst it is unmistakably like nature, is emphatically ornamental. 
Plate 88

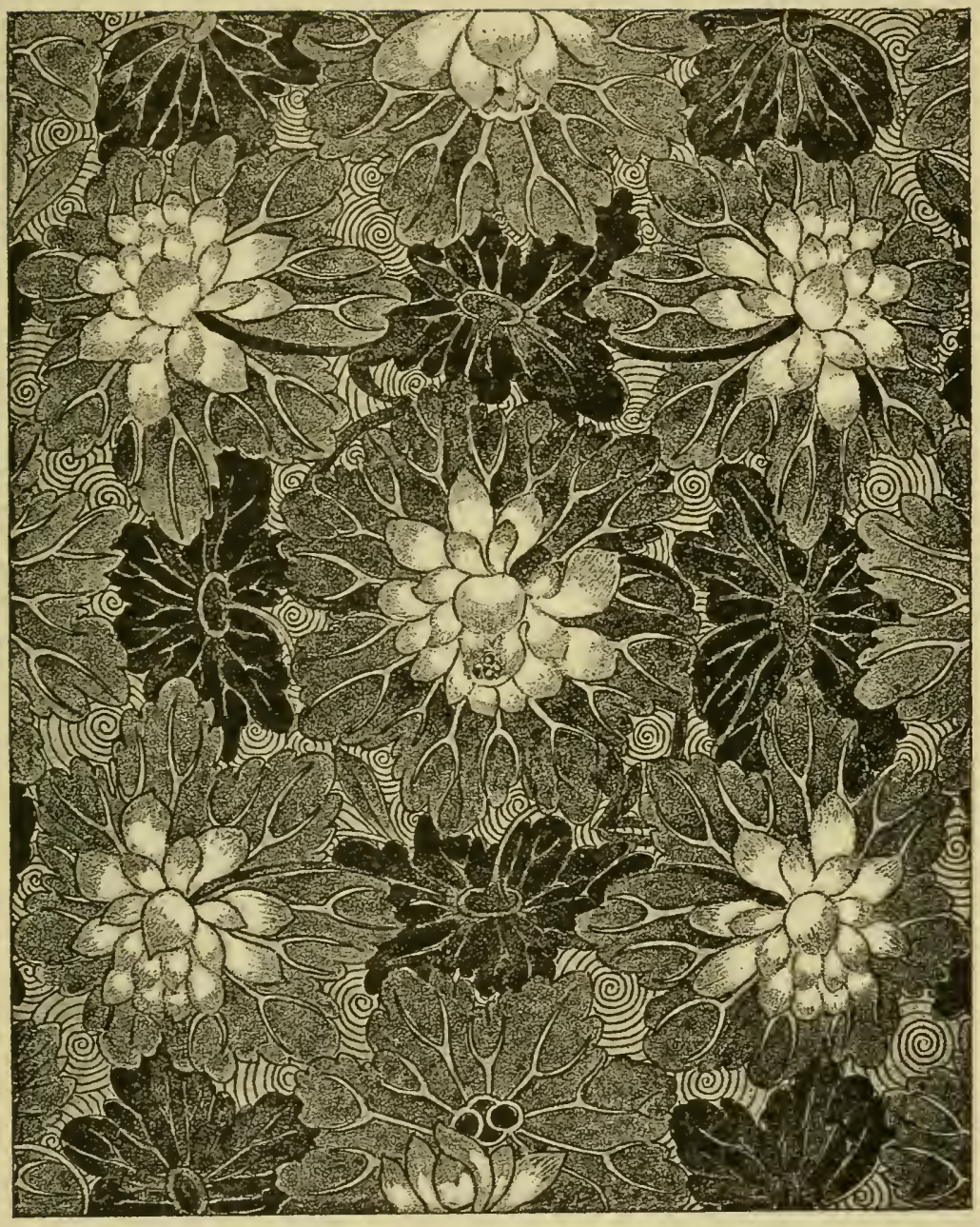

"Pнoto-Tint, by James Akerman London.W C

Chinese Lotus Porcelain Paintind 

The balance between natural form and ornamental design is sometimes very evenly adjusted in Chinese art. In Plate 88, for example, forms of leaf and flower are given with considerable fidelity to nature. The art has consisted mainly in their systematic distribution. Light-coloured water-lilies occur at regular intervals, backed each by a leaf in middle tint, with leaves in reverse of still darker tint connecting them, the light ground being diapered over with wave lines (appropriate enough to the water-lily), so as to give value to the whiteness of the flowers. The scheme is here very simple, but it results

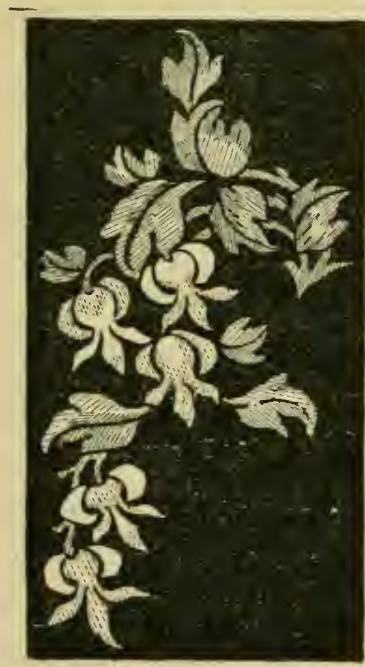

131. Chinese rendering of "hiss-me-quick." in extremely beautiful colour, and nature is not outraged.

There is a wonderful look of nature, too, in the quite ornamental rendering of the "kiss-mequick" below. Compare it with the more artificial flower on Plate 44.

Other instances of Chinese treatment occur on Plate 76 , and on p. 29.

The ornamentist arrives 


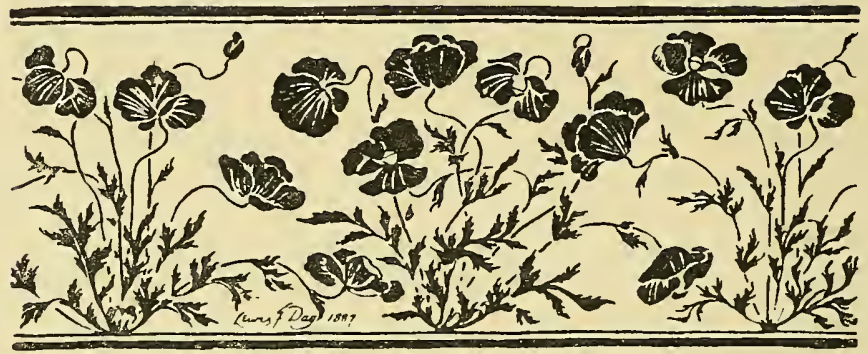

132. Comparatively natural treatment of poppy.

very soon at the conviction that it is of no use entering into any kind of competition with nature. $\mathrm{He}$ is not impressed by the antiquity of the old, old theory that what is fittest in nature is without more ado most fit for ornament.

In the design on Plate 89, the form goes about as far in the direction of nature as it was advisable there to go. The growth is strictly according to nature. A cobea scandens might grow so. All that has been done is to make it take lines which conform to the very arbitrary demands of the Jacquard loom, and to choose details which were not merely graceful and characteristic, but capable of being rendered in two flat tints-or, more strictly speaking, textures-upon the ground.

The border of field poppies above, conforms in an equal degree to nature. The flowers are not only chosen and composed, they are made to grow as they were wanted. 


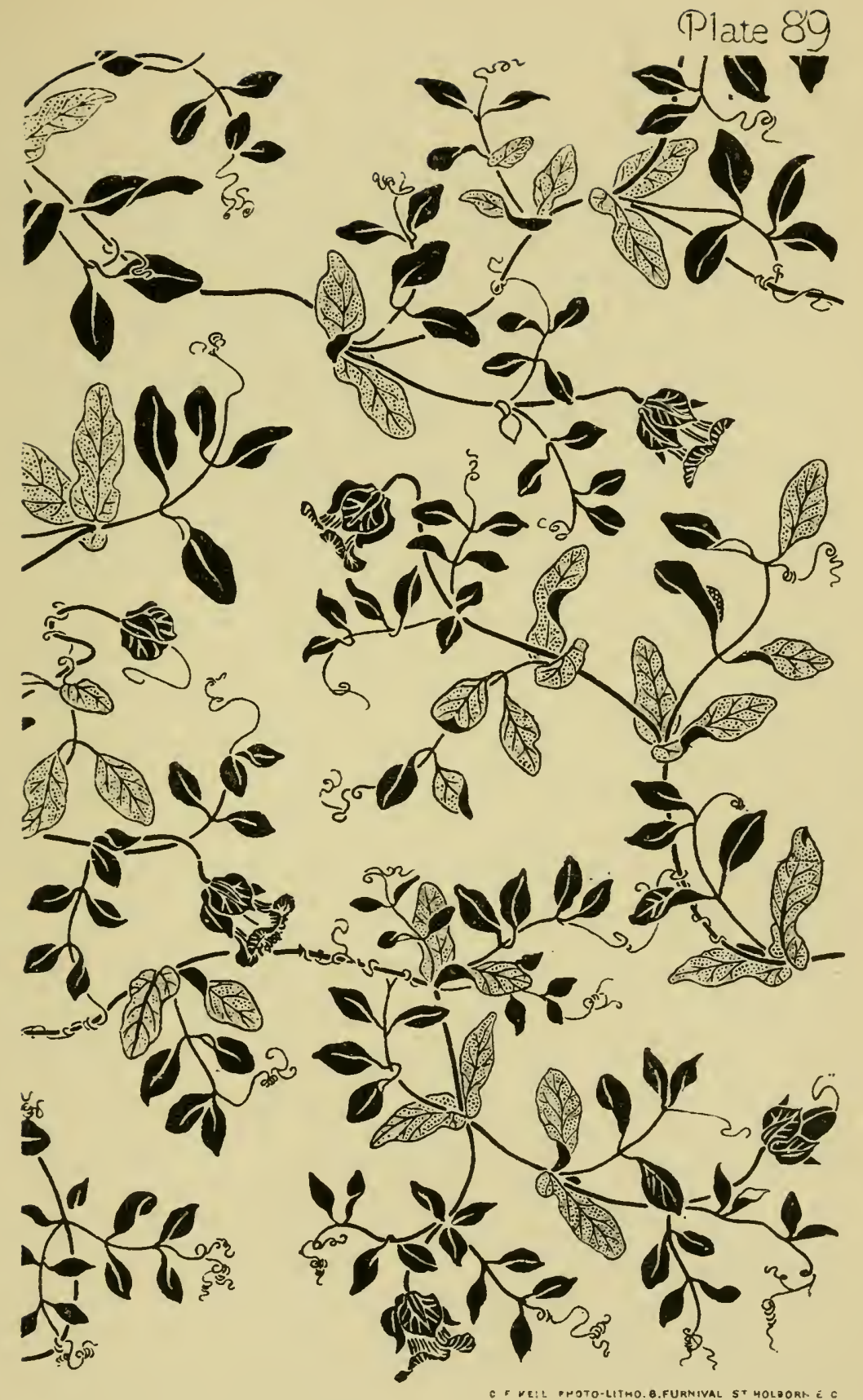

Coboca Scandens - Linen Damask. 



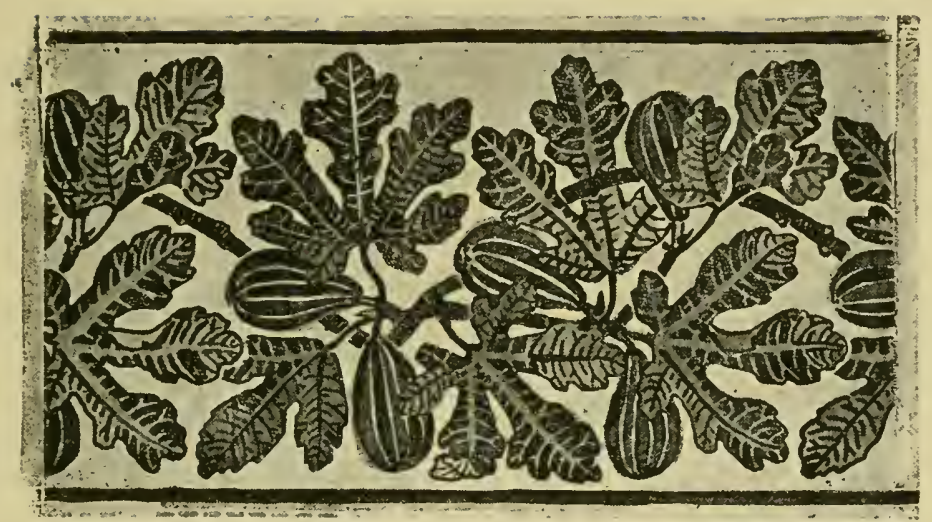

133. Comparatively natural treatment of fig.

And again, in the fig border, above, the growth is as natural as it could well be, considering the purpose for which it was designed.

The next plate illustrates, on the other hand, how far one may safely go in departing from nature when it is desired to retain something of the character of the plant. The dandelion on Plate 90 is systematically reduced to ornament. The lines it takes are if not actually systematical, very carefully balanced. The jagged edge of the leaf assumes almost the form of a Greek waveline. The bracts develop into radiating lines of ornament. But though the growth is thus made formal, the serration of the leaves thus simplified, the bracts thus exaggerated-the idea is yet to suggest the dandelion, and no other thing in nature. 


\section{I $74 \quad$ Nature in Ornament.}

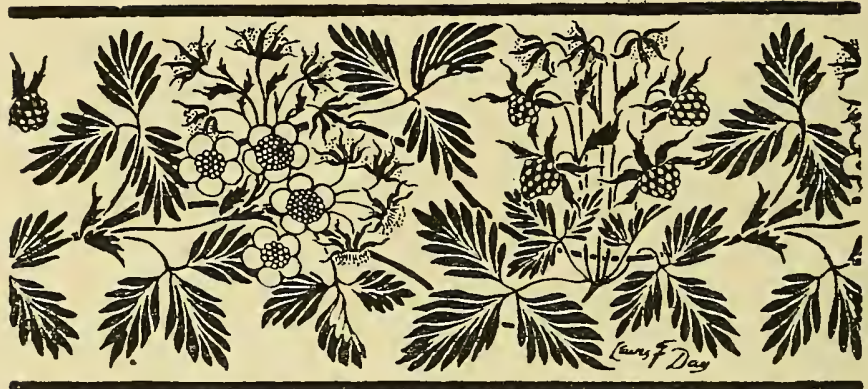

134. Ornamental treatment of strawberry.

Ornamental treatment consists largely in the deliberate disregard of pictorial consideration. There is nature still in the strawberry border above, although nature is not very strictly followed. The leaves in particular have been subjected to a process of ornamental treatment, similar to that employed on Plates I 3 and I4, and suggested by the forms of Greek brushwork.

The treatment of the thistle in the German wood-carving shown on Plate 9I, is so essentially ornamental that one scarcely knows whether to describe it as a rendering of the thistle or a development of the scroll. It shows in either case the strong influence of tradition.

Ghiberti's poppy on Plate 7I, although the influence of the Classic scroll is very apparent in it, is not so much a departure from the acanthus scroll as a treatment of the poppy somewhat in the manner of the scroll. 


\section{Plate 90}

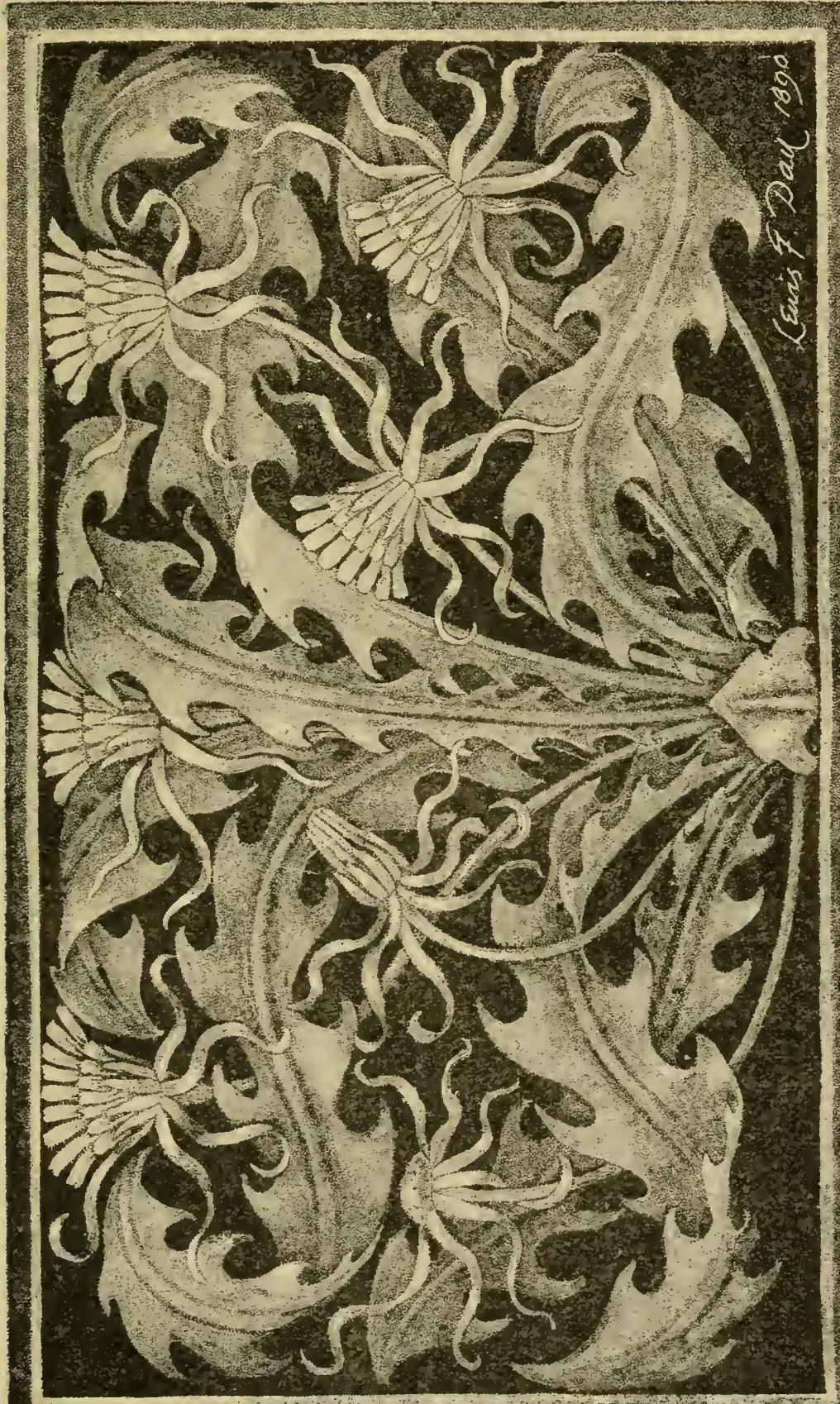

$\frac{5}{0}$
$\frac{1}{0}$
$\frac{0}{0}$
$\frac{6}{0}$
$\frac{5}{0}$
$\frac{1}{5}$
$\frac{5}{0}$
0 



\section{Treatment.}

That is really the spirit in which to accept tradition. It is not something to be religiously preserved, but handed on.

We are too much in the habit of adopting traditional forms, as though all necessary modification had been done for us. That is not how the good old work was done. It was the result of constant reference, if not to nature, at least to the conditions of the case ; and our modern essays in what is called "style" prove us often more Gothic than the Goth, more Classic than ever Greek was.

The result of adopting any ready-made selection of types and details, the very significance of which is nowadays a thing of the past, is inevitable common-place and dreariness. Our treatment should be not only modern but individual.

The adoption of the old lines is pardonable only on the assumption that the perfect rendering has been found and cannot be bettered. That may be so occasionally. And one readily admits there are renderings so perfect in their way that they must always influence us; but even though the old rendering were perfect, what was perfect then is rarely quite what is wanted now; and so it cannot fairly be contended that tradition, powerful as it is, has any right 
to say "thus far" to our invention. If we halt it is of our own innate weakness.

Whoever is not quite without initiative will believe always in the possibility, if not of some new and better tunes than the old, at least of some happy variation upon them. Only in that belief, in the consciousness of the vitality of art, can he put himself into his work. Designer, he must believe that there is yet possible such a thing as design; artist, he must recognise that art is not such an artless thing as, on the one hand the devotees of nature, and on the other the slaves of the past, would have him suppose. 
Plate 91

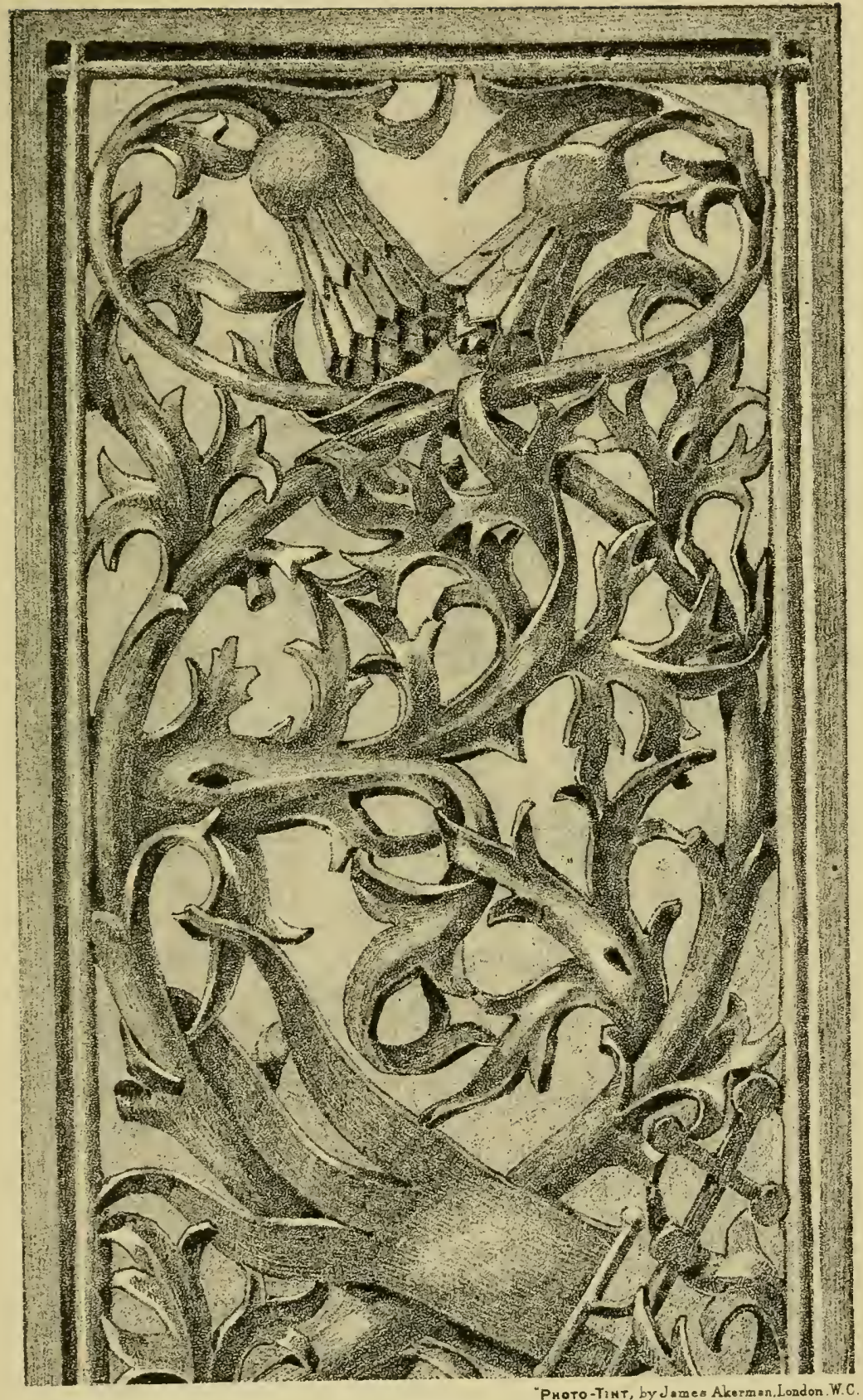

German Gothic Thistle Scroll. Wood Carving 



\section{XI.}

ANIMALS IN ORNAMENT.

No doubt the most amenable model for ornament is to be found in vegetable growth. This is not because it is without order-the anatomy of plants needs, indeed, as careful study as that of bones and muscles-but because in vegetation the proportions of the parts are naturally subject to such infinite variety, that, so long as one obeys the general law of growth, there is no great fear of overstepping the bounds of verisimilitude; and verisimilitude, not "truth to nature," is the law to which ornament owes obedience.

The forms of birds and beasts lend themselves less kindly, but still more kindly than the human form, to ornamental manipulation. The less, that is to say, one is likely to resent a liberty with the normal proportions of a thing, the more readily it can be turned to account.

It is not surprising, then, that the ornamentist has sought his inspiration mainly in 
vegetable growth; but it would have been amazing if he had found it nowhere else ; since the summer noon-day landscape is buzzing with insect life, and the flowers themselves are ornamented more or less with living creatures which the artist would be blind to ignore in his design.

Bird, butterfly, and moth are inceed so obviously useful in any scheme of composition that they have very frequently been made use of merely to stop gaps in the designer's ornament-or in his invention.

One danger in the use of living creatures in ornament is lest they should start out of the picture, a danger not altogether avoided in Plate 16, where the birds, though not precisely natural, are too picturesquely treated to harmonise with the scroll.

Indeed, in Græco-Roman, or what we commonly call Pompeian, decoration the beasts are for the most part mere blots on otherwise very likely graceful ornament. And it was just so in the Renaissance ornament immediately founded upon it -in much of Da Udine's design, for example, and in that of Giulio Romano. To have taken the trouble to set out his design in delicate and graceful lines, as on Plate 17 , and then to perch upon them ostriches, donkeys, and the like, seems 
Plate 92

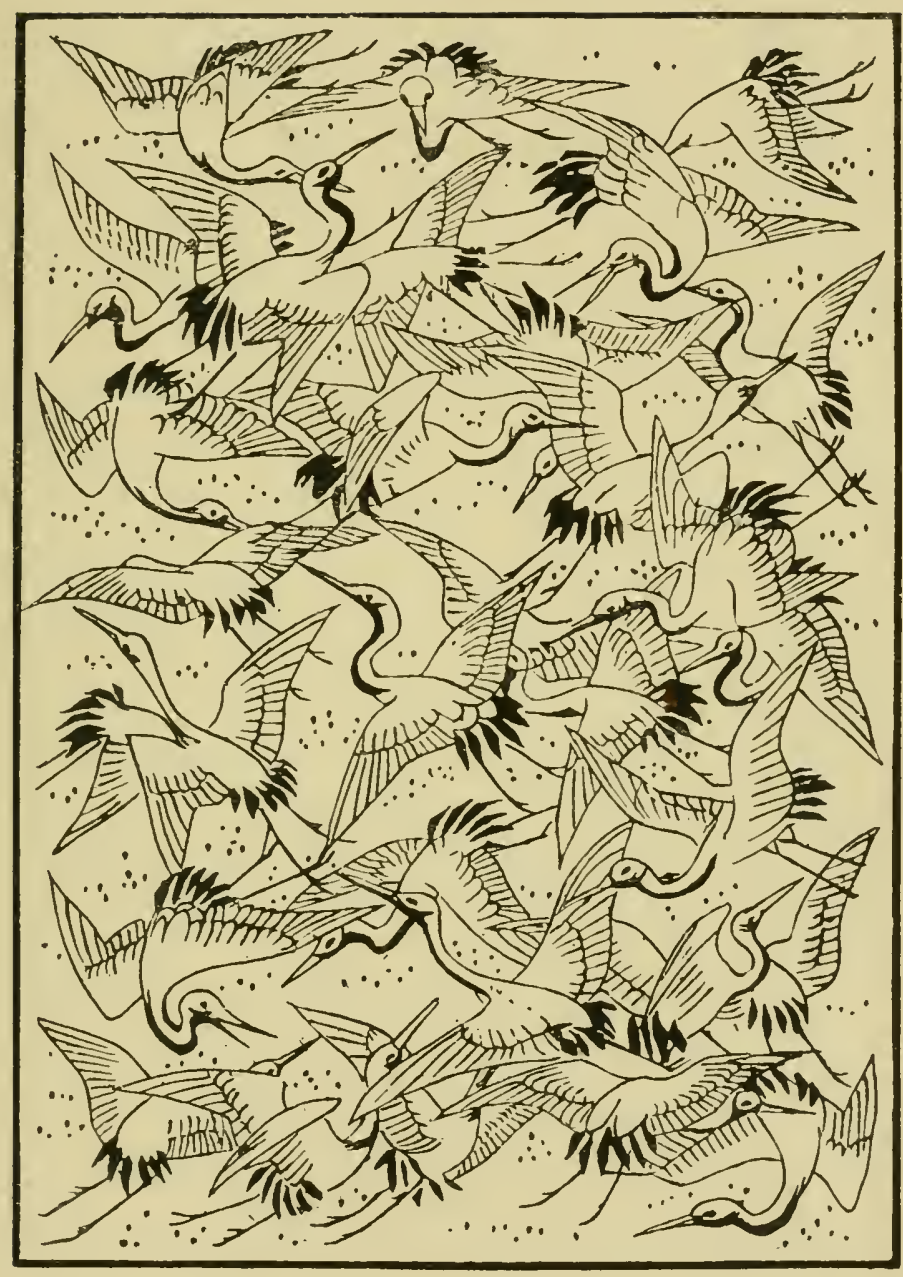

Japanese Cranes. 

something like sheer perversity on the part of the artist.

Whatever may be the temptation to introduce into a design anything which will occupy an empty space and complete the composition, without regard to natural fitness at all, it is really as absurd, when you think of it, to put together night moths and daisies, or butterflies and evening primroses, as it would be to paint peacocks strutting about on arctic shores, or polar bears prowling in the jungle.

It is not meant to say, of course, that in ornament only the particular creature which preys upon a plant should ever be associated with it. But it is an additional source of interest when such creatures have some excuse over and above that of filling a vacant space. Here, as everywhere, nature herself will often furnish the designer with a valuable hint. Notice the bronze-green beetles foraging in the full-blown rose. See the bees on the sunflower: they may be found diapering its plain disc in the most interesting manner but the incident has never been made much use of in ornament, not even when the sunflower reigned, for a brief moment of fashion, over all English ornament.

You may have noticed also how the common 


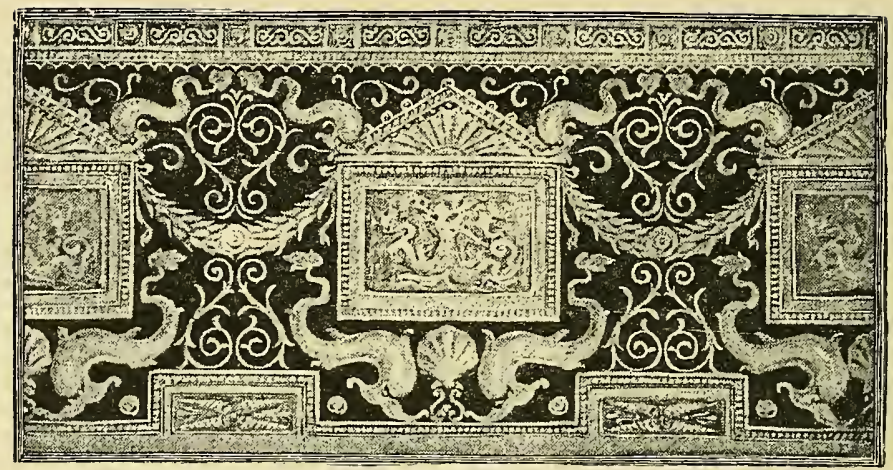

135. Dolphins used as ornament. George Fox.

broom, of which the foliage is so insignificant as to go for little, is sometimes dotted over after a shower of rain with the daintiest little snails, whose delicately-marked shells form quite a feature in the pattern of the shrub.

It is a very common fault in modern ornament to introduce into it animals or human figures for the sake of bringing them inas though merely by their introduction the design gained an additional artistic value. It is only when such figure or animal serves some distinctly ornamental purpose that it does so, only then that it ceases to detract from the value of the design. Figures or animals in ornament should themselves be part of the ornament-as they are in the designs of Signorelli and Holbein (p. 202 and Plate I03), and as they are in the frieze above. The dolphins there are not mere porpoises but 
Plate 93.

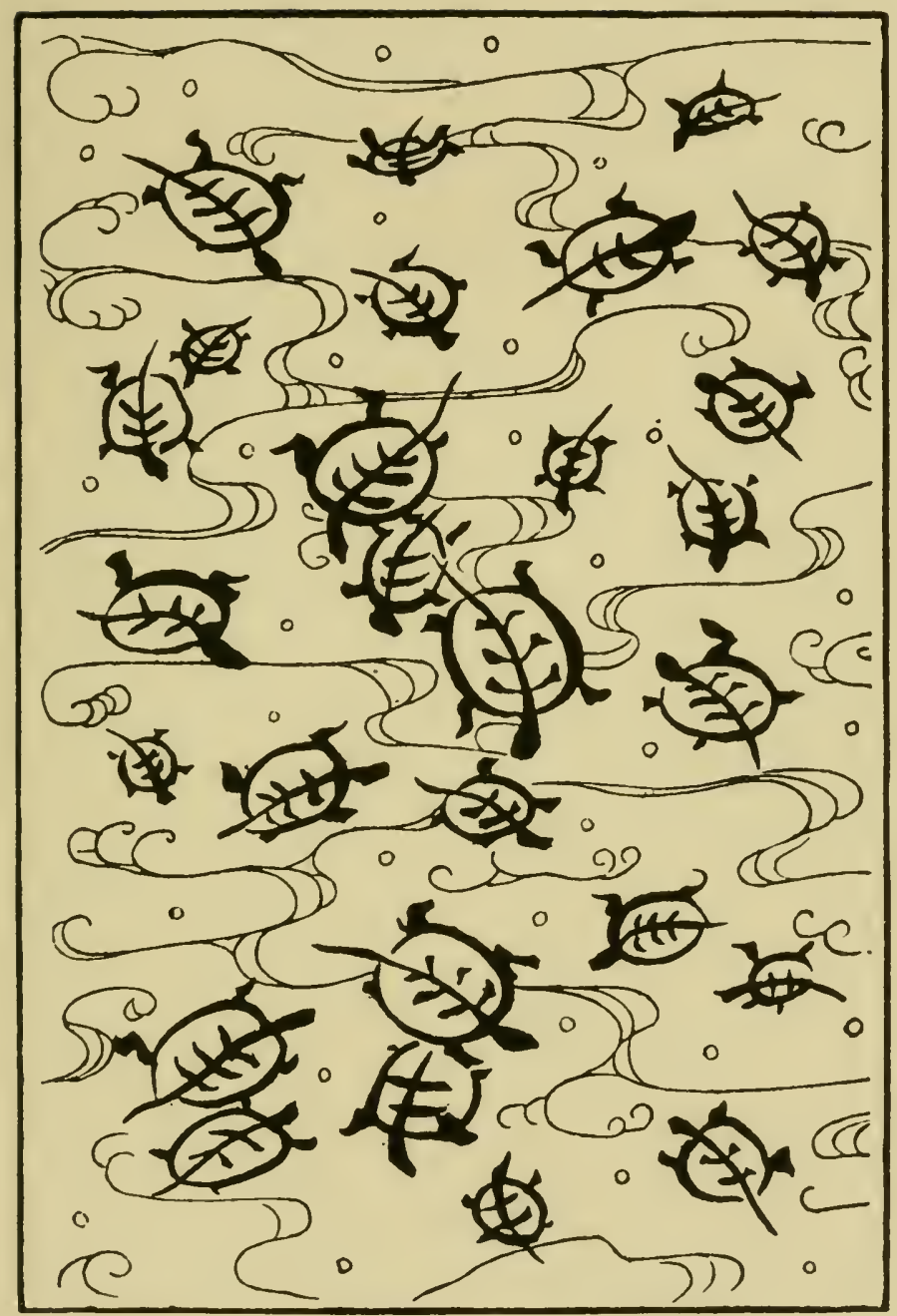

Japanese Tortorses 

ornament, as much so as the scrolls themselves. The dolphin is, of course, a familiar feature in Classic and Renaissance design, but it is not often, even in Greek art, that it is so gracefully treated as in Mr. George

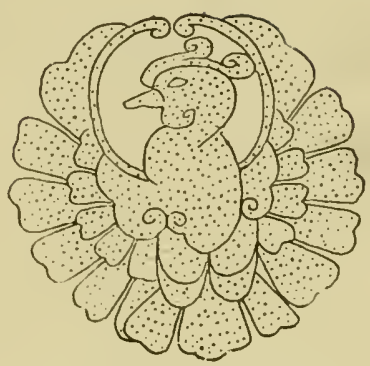

136. Circular bird and flower crest.

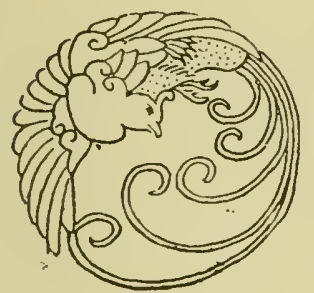

137. Circular bird crest.

Fox's design. He has studied the antique to some purpose.

The Japanese have a most ingenious way of disposing creatures over a given surface in a manner which, unsymmetric though it be, is distinctly decorative; and though the action of the creaturesbirds, as on Plate 92, tortoises, as on Plate 93, or whatever they beis characteristic to a very remarkable degree, the simplicity and directness with which the natural form and

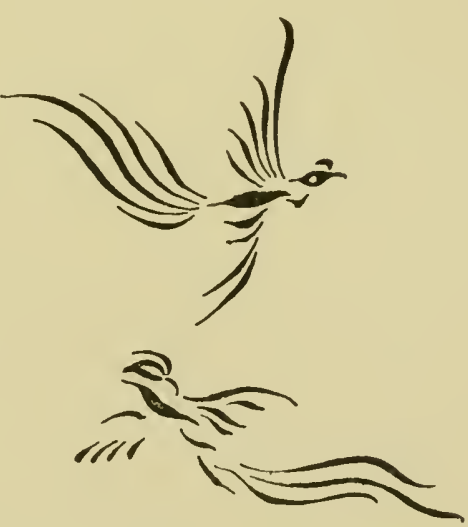

I 3 8. Ornamental indication of birds in flight. 


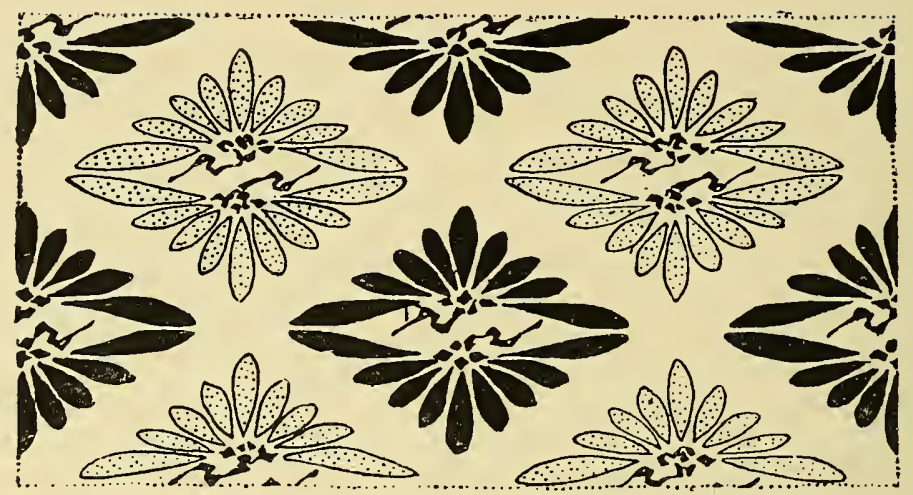

I39. Diaper of storks and chrysanthemum flowers combined.

natural action are rendered, is such as to make us feel that the graphic power of the artist was well under the control of his decorative sense or instinct.

Their remarkable appreciation of what is characteristic in natural form enabled the Japanese the more effectively to reduce such natural form to absolute ornament.

To adapt a bird shape to the circular shape, as on p. $18 \mathrm{r}$, or to express the action of flight in a few strokes of the brush, as on the same page, appears to be as easy to a Japanese as it would be difficult to us. His ornamental faculty is still more plainly shown in a diaper such as that above. Are they storks or chrysanthemums of which it is made up? $\mathrm{He}$ has so successfully combined the characteristics alike of bird and flower that you are left in wonder as to which it was he adapted to 
Plate 94

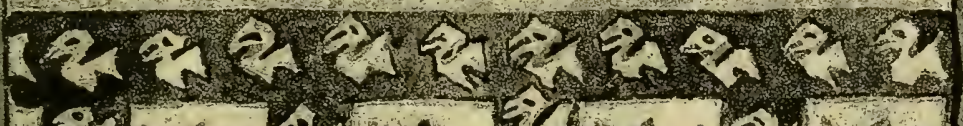

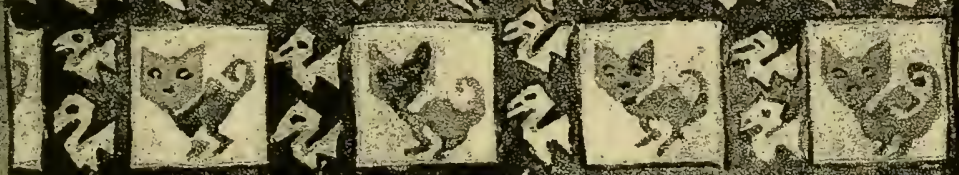

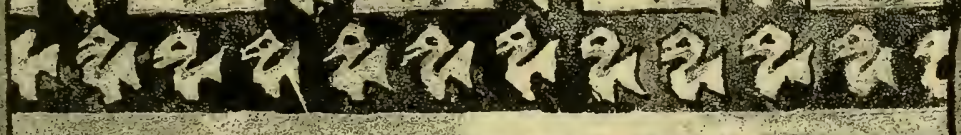

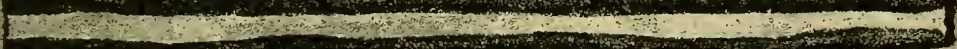

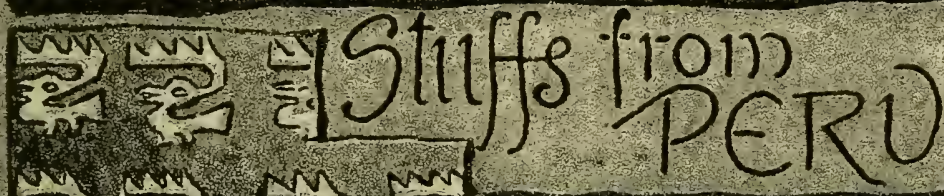

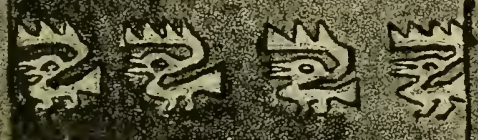
$\rightarrow \longrightarrow$ 2 래 (2) $\Rightarrow$, सहक्ष सक्ष

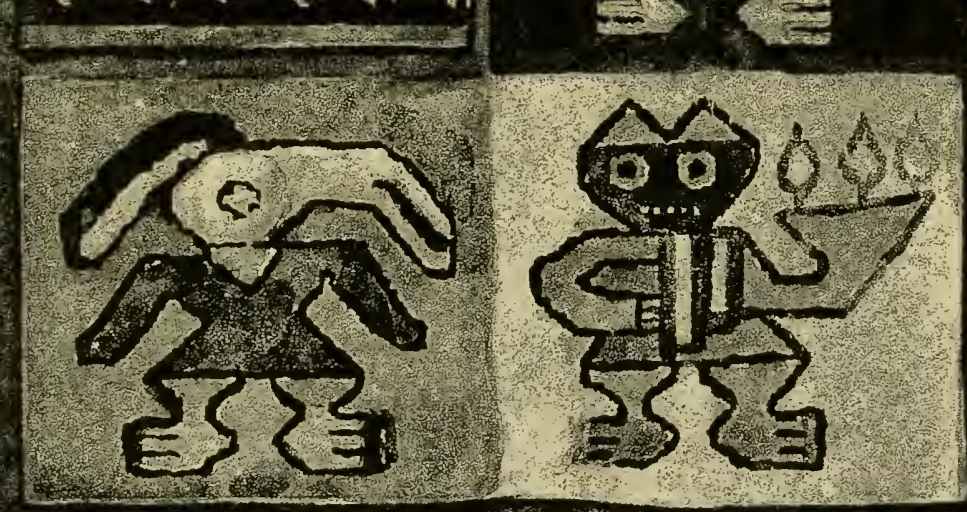

"Pното-Tint", by smes Akermen, London. W C

Peruvian Excentricities 



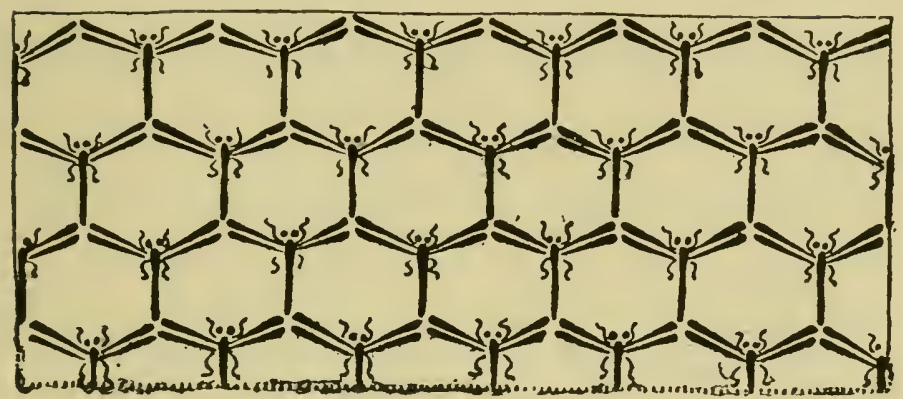

I40. Uragon-Hy diaper-Japanese.

the likeness of the other. It is so essentially and so simply a diaper, that it seems not so much to have been designed, as to have grown out of a natural likeness between the flower in profile and the bird in flight-which likeness would, however, never have occurred to us but for the designer. The explanation of this combination of bird and flower, as also of that on p. I8I, is to be found in its heraldic significance. The diaper of insects, above, is so obvious, when we see it done, that we scarcely appreciate the ingenuity with which the dragonflies range themselves in hexagonal order.

Absolutely archaic or non-natural creatures lend themselves very readily to diaper work. This is illustrated in the diaper of bats overleaf, and in the primitive patterns from Peru on Plate 94. The Peruvian attempts at human or semi-human form strike us only by their comicality; but the nondescript creatures in 


\section{Nature in Ornament.}

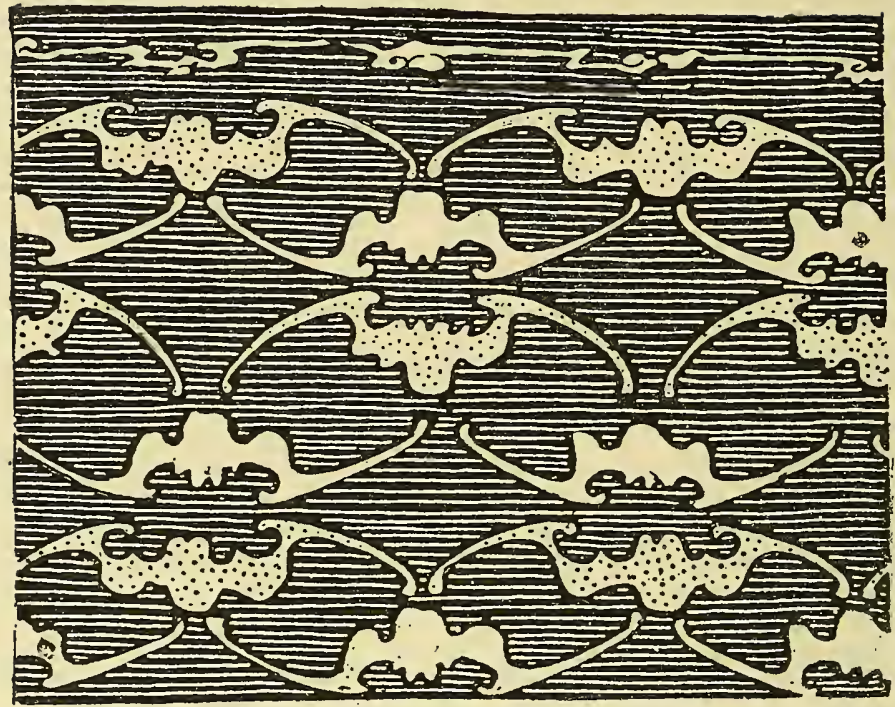

I4I. Diaper of conventional bats.

the border at the top of the plate, and particularly the fledgelings and the cocks, are not only comical but essentially ornamental in treatment. The exaggeration of the cock's comb is delightfully imagined.

The late William Burges, in the pattern on p. I85, has cleverly adapted his birds to the severe strap-work associated with them. One is a little disappointed to find that the interlacings do not actually form (as they seem at first sight to do) the tails of the birds; but the design is ingenious and effective; it is built obviously upon Byzantine lines.

The Sicilian silk designers and their 


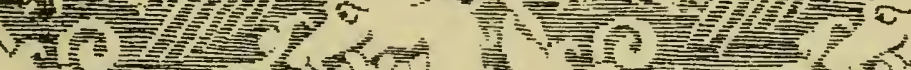
3.

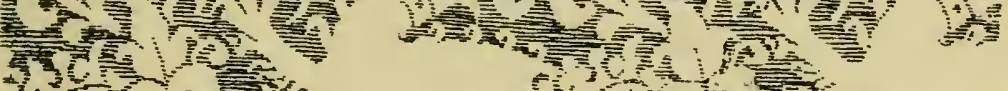
and

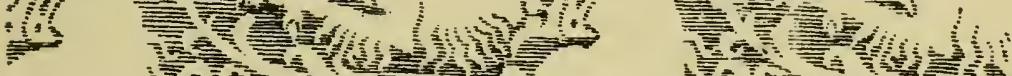

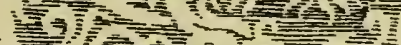

我

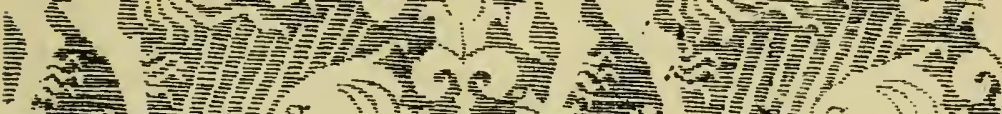

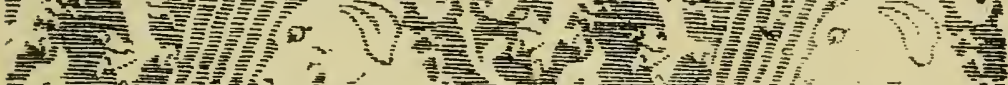

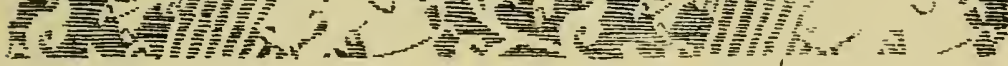

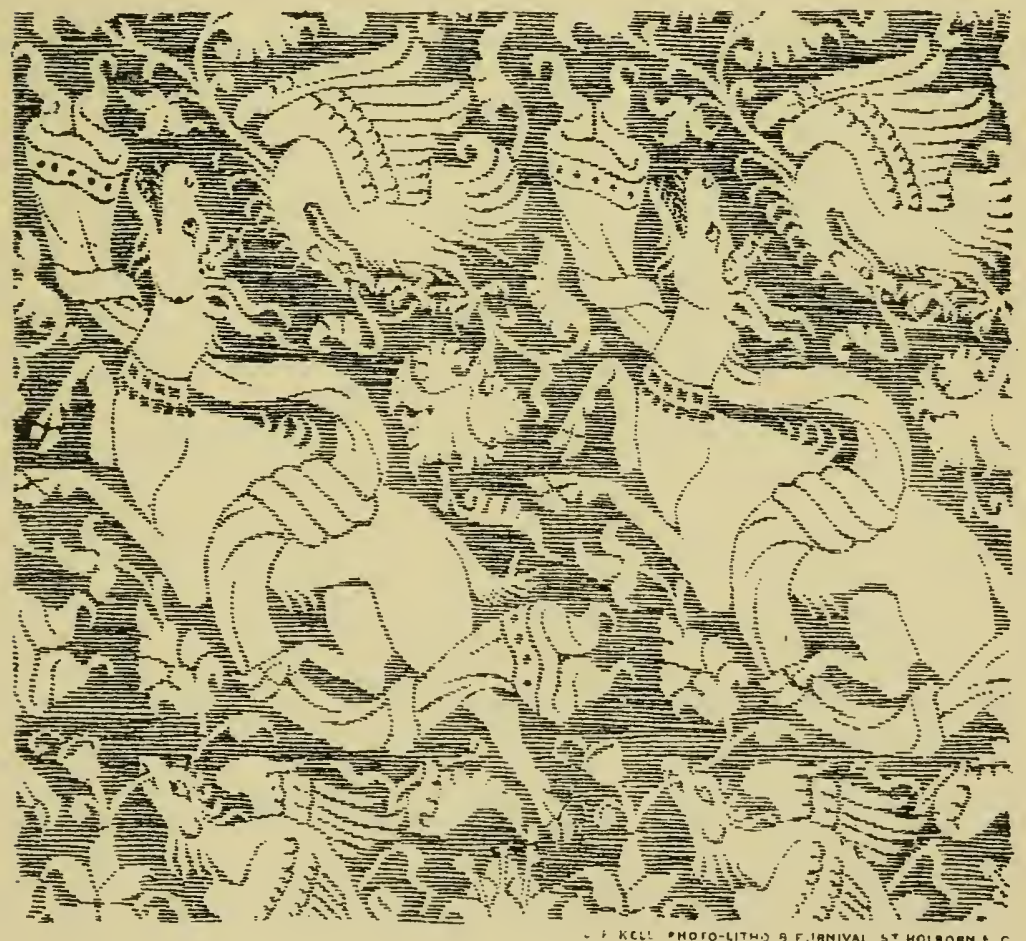

Sicrian Silk paitems 



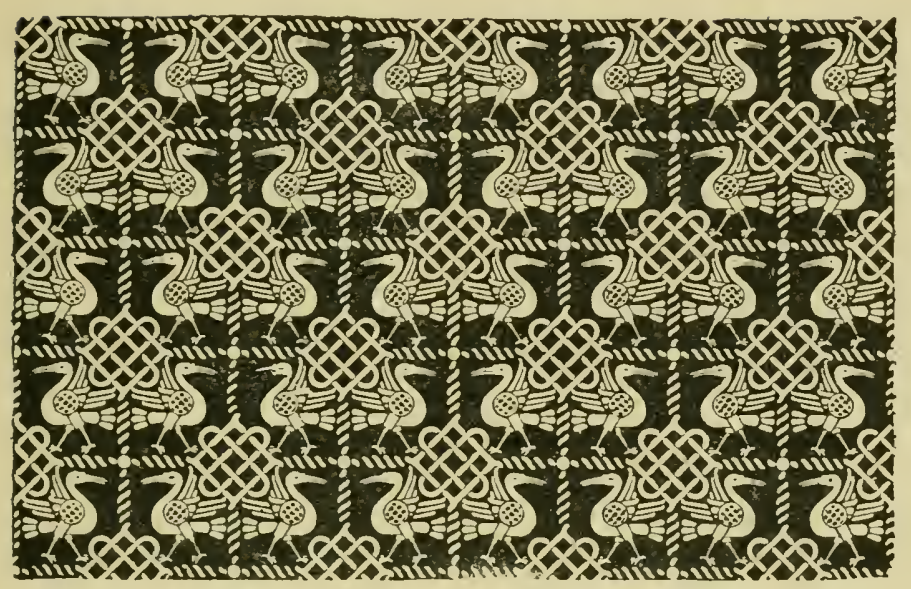

I42. Bird diaper by Wm. Burges.

imitators of Lucca and elsewhere in Italy, made considerable use of animal form in their weaving-carrying it, indeed, to the extremest limit in actual pattern-work. There was usually, one may presume, some heraldic significance in the creatures they represented (Plate 95); but there is a lesson in the way they are introduced, and in their treatment, especially in the way their broad masses contrast with the smaller foliage and other such detail associated with them. Fantastic they often are, but still they are quite natural enough. The continual recurrence of creatures more like life would be intolerable. The fault in the otherwise amusing pattern overleaf is that one cannot put up with the same little twins ad infinitum. 
Birds are very frequently to be found amidst the arabesques of the Renaissance, with which they are not, it must be confessed, always in keeping. The introduction of a bird is rather a cheap solution of the difficulty there may be in occupying any awkward interval in the scroll itself without in any way interfering with the grace of its lines or the ease of its curves. It was quite a common practice to terminate a pilaster or other tall panel with an eagle taken bodily from the Imperial Roman standard, its feet planted firmly on the rim of a vase, its wings amply and very conveniently filling those topmost angles of the panel so difficult in many instances satisfactorily to occupy. This is well enough, once in a way, if only the eagle be not too much of an eagle for its place. Ordinarily the birds pecking

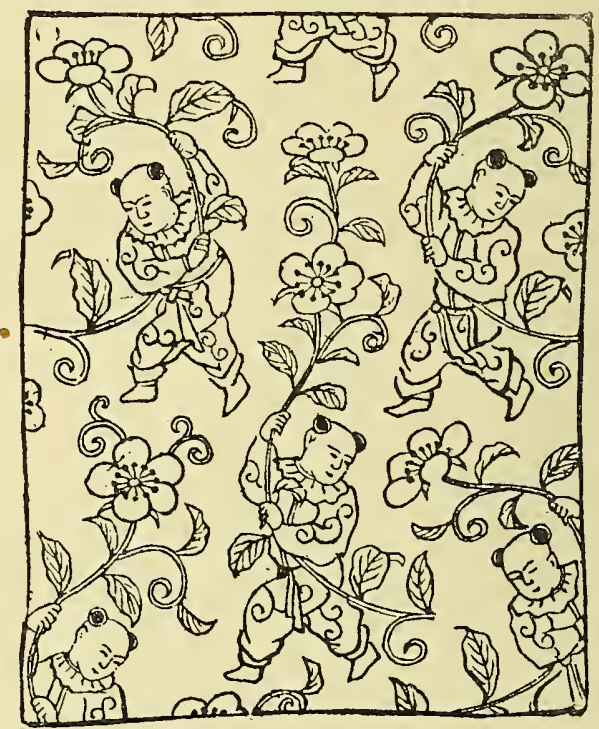

143. Repeating figure pattern. 


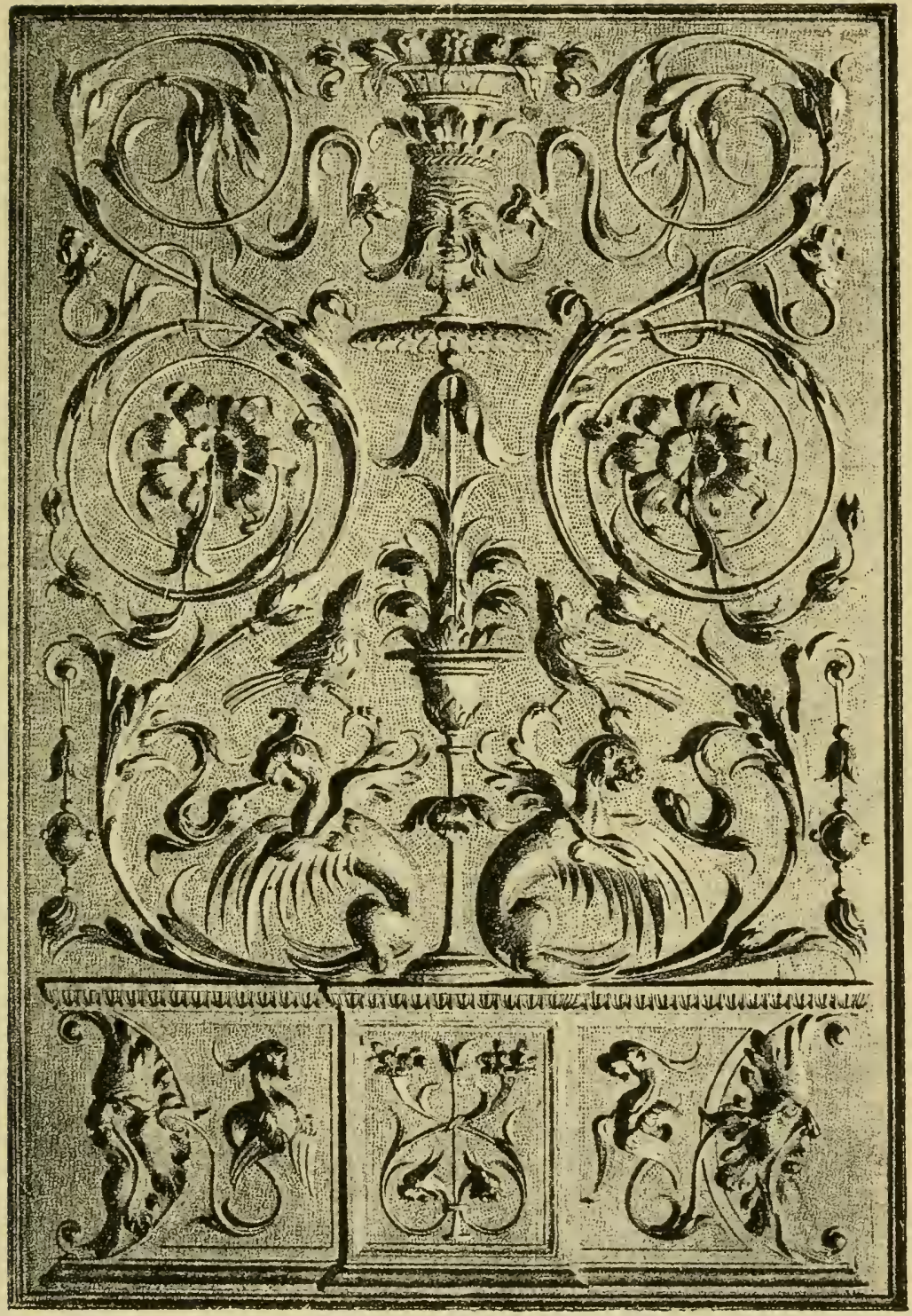

Pкото-TINT, oycames Axermat wondon iN

16. Century Wood Carvind 



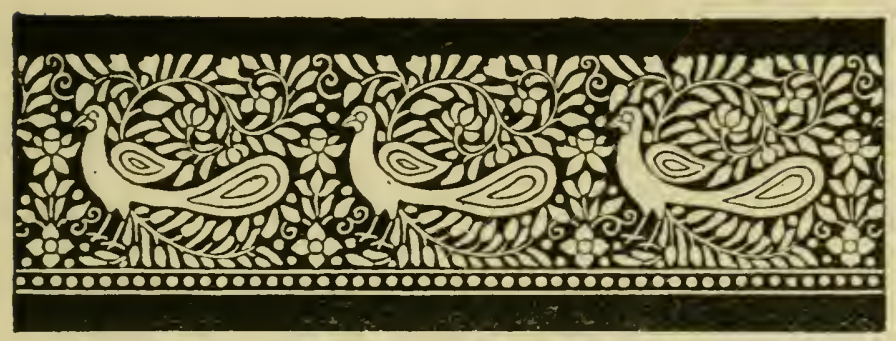

I44. Conventional peacock border-Indian.

at berries or what not in Renaissance arabesque, as on Plate 96 (and in the Roman work from which they are borrowed), are comparatively too real. They would be more in place had they been modified in conformity with the ornament about them.

The Oriental ornamentists were invariably more careful in this respect. The peacocks, for example, at the head of the page, whilst like enough to nature to be recognised at a glance, are quite conventional enough to correspond with the foliage; and their value as masses of solid colour amidst the smaller and more broken detail is none the less on that account.

As a rendering of the bird, and especially of the bird's wing, the Indian example leaves much to be desired-how much will be seen if you compare it with the ancient Egyptian renderings. The vultures overleaf, and the hawk on p. 189, afford types of 


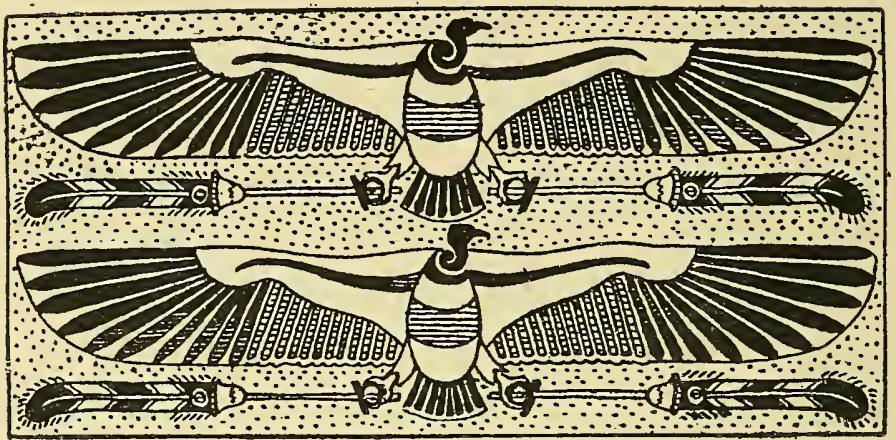

145. Egyptian'wing treatment-vultures. ${ }_{i}{ }^{1}$

simple, dignified, and decorative wing-treatment.

But it is not only in birds that wings occur in ornament. They are appended (more especially in Renaissance art) to every conceivable thing, to sphinxes and chimeras, men and animals, griffins and all manner of grotesques, cherubs' heads, globes, hour-glasses, and symbols of every sort.

In adapting wings to the human form the great danger is that of disproportion. To make them of sufficient size to support the body is out of the question; the design would appear all wings. All that is to be done is to proportion them decoratively to the figure, without any attempt to make them mechanically adequate. One may suppose them to be features which through disuse have dwindled to proportions artistically adequate. The 
tiny cupid's wing, for example, just budding from his chubby shoulders, the mere germ of a wing, seems to belong more intimately to his body than any other form of wing yet invented.

Still more difficult is it satisfactorily to arrange the wings about a cherub's head. One remembers in certain old windows a glory of colour resolving itself, as you look, into a mystery of mingled wings and angel faces; but the attachment of the wings is best not too closely inquired into. Neither is it well to consider too accurately the mechanique of the wings in which Della Robbia embeds his sweetest of child faces. One is too thankful for their beauty to blame him for not having accomplished what is after all impossible.

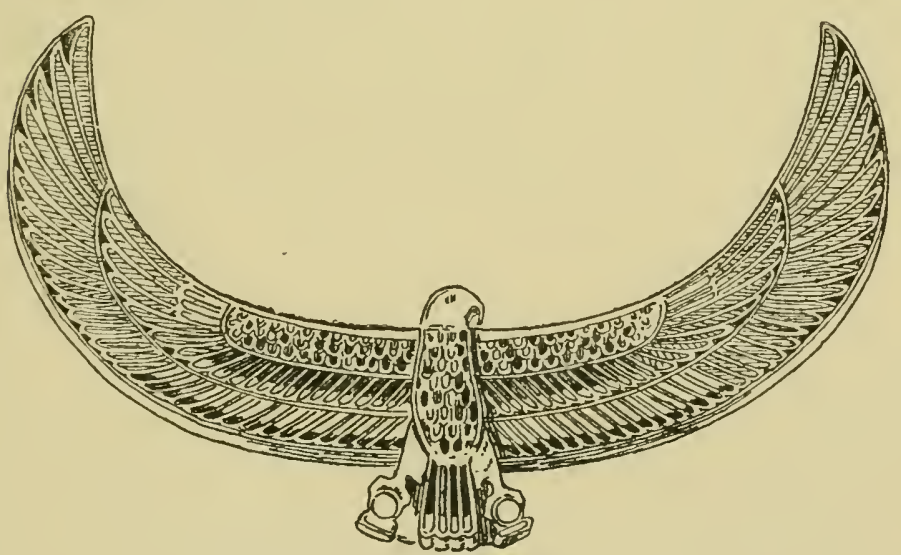

146. Egyptian wing treatment-hawk. 
The idea, common enough, of wings in the place of arms or in the place of ears (it is beautifully carried out in the bronze head of Hypnos, in the British Museum), seems more anatomically possible, and may be most ornamentally rendered.

In dealing with quadrupeds a single device has for the most part sufficed: alike in the winged bull of Assyria, in the Greek gryphon, and in the Evangelistic symbols of early Christian art, the wing is made usually to grow from the shoulder so as to form, as it were, one member with the fore leg-removing the creature, indeed, by so much from nature, but not bringing it anywhere near to the ideal winged creature. The mechanism of the trick is too apparent. There is none of that mystery by which alone we might possibly be impressed. In Sansovino's griffins, on Plate IO4, one misses the fore legs no doubt, but the wings which take their place seem on that very account to be anatomically more possible.

The outspread bird's wing has always been considered a most valuable "property" in ornament; but although it is usually the bird's wing that one meets with in design, the bat's wing occurs also, more or less in association with devils and dragons, as the bird's 
Plate 97.

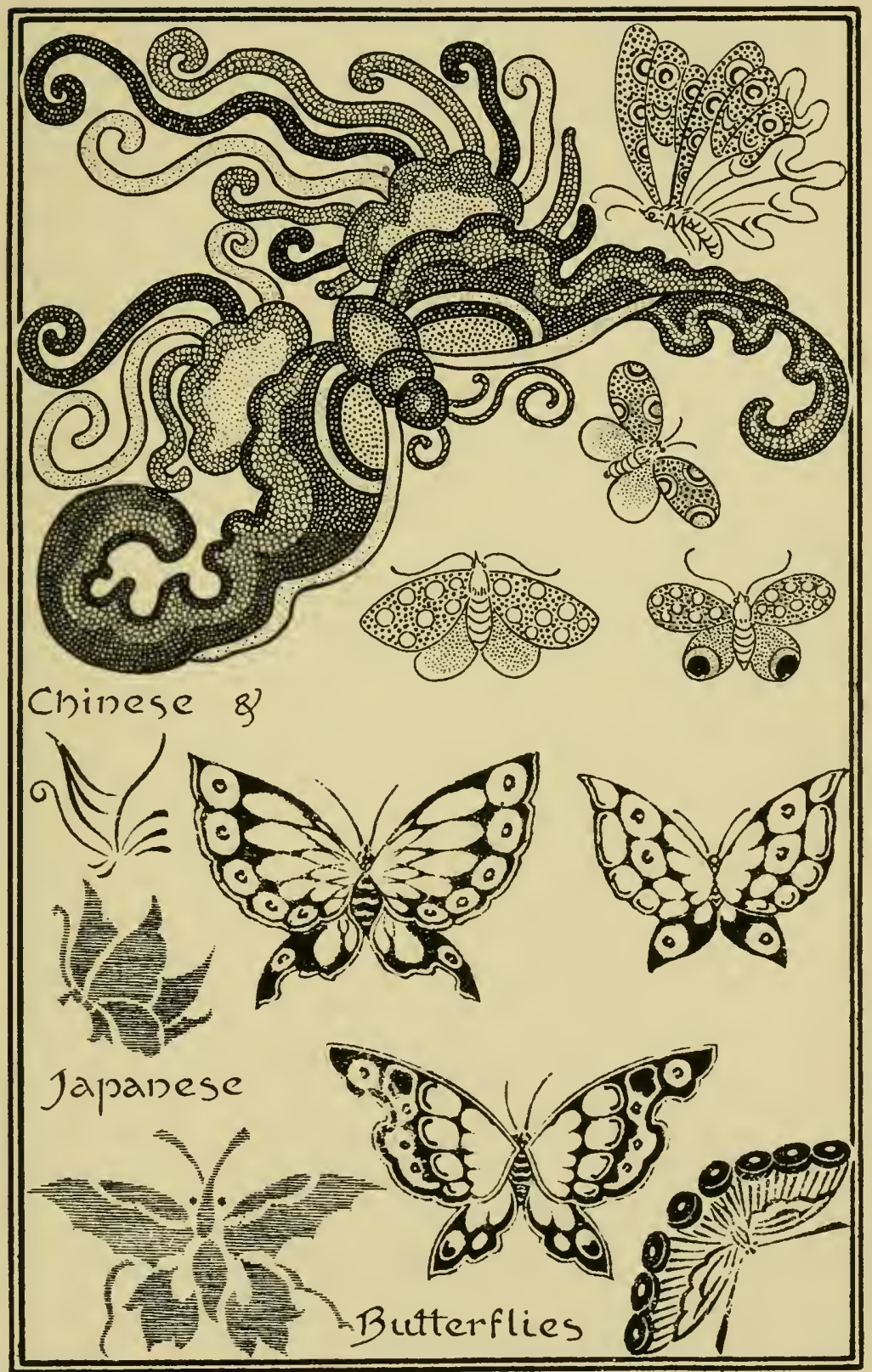

F KELL, PHOTO-LITHO. B.FURNIVAL ST HOLIORN,E.C. 



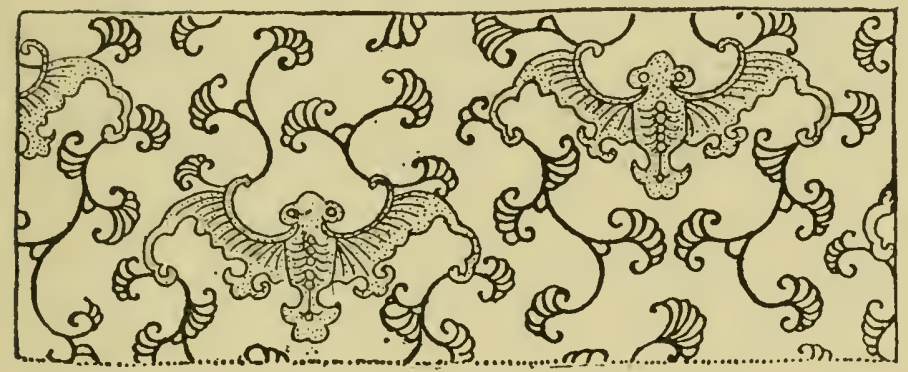

147. Bat diaper.

wing with angels and cherubim. The bat itself is a symbol very frequent in Chinese art and its derivative Japanese (pp. I84, I94, and above). It is represented, however, in the gayest of gay colours, and in shape so turned to ornament that it is difficult at first to identify it. Were either form or colour more naturally rendered the effect would certainly be less distinctly decorative.

The wing of the butterfly is so obviously ornamental that one wonders how it is that only the Celestials have turned it to any good account. In their embroideries especially the Chinese have made admirable use of it (Plate 76)-ornamentalising it sometimes in the most extravagant manner, as, for example, in the most important instance on Plate 97, where the under-wings are fringed somewhat in the manner of the tail of their sacred bird, which itself is a sight to see.

That the anatomy of the creatures found in 
ornament is so seldom all that a naturalist might desire (the creatures on Plate 98 are more realistic than an ornamentist could wish), is sometimes, and to some extent, owing to the exigences of ornamental design; but it is more often the fault of insufficient acquaintance on the part of the designer with the facts of zoology.

Few men have even nowadays the chance of studying nature from end to end; and in the middle-ages the "Zoo" was not within a shilling cab-fare of the church. The Mediæval sculptor, however, was, according to his possibilities, more studious of nature than we are accustomed to suppose : there is abundant evidence of that in his work. His comparative ignorance saved him as a rule from too directly recalling this or that zoological type in the demon or dragon of his invention -and presumably of his belief.

Of the decorative, as distinguished from the ornamental rendering of animal form, this is not the occasion to speak at length. The Egyptian lion statues and the Assyrian basreliefs show what may be done in adapting it to decoration; and these abstract renderings come very near to perfection-nearer, at all events, than any modern has come with his zoological realism. 
P1ale 98

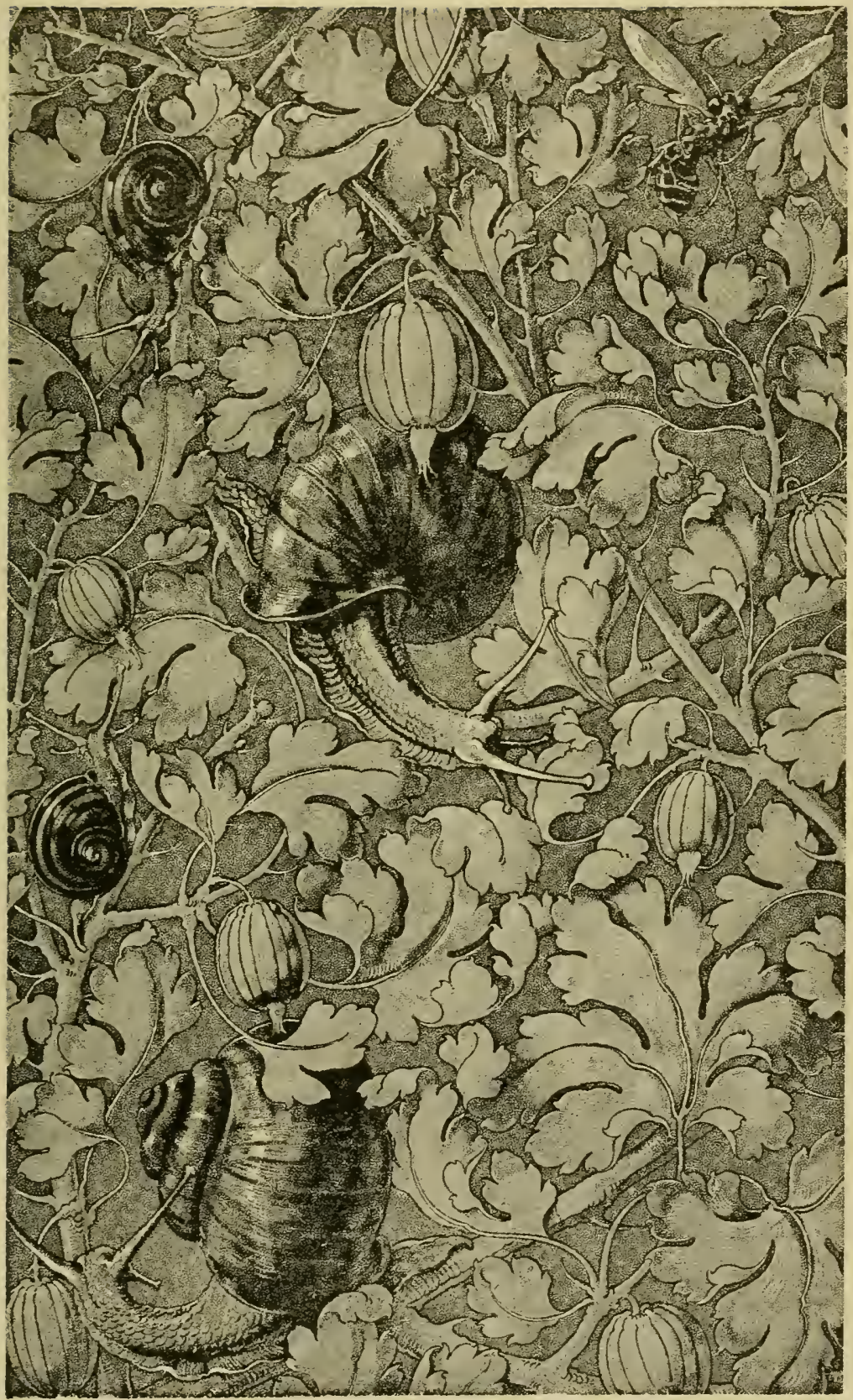

'Photo-Tinf', by James Akermon, London. H C

Modern Gerinan Renaisance,- A Seder. 

The sculptors of these master-works had no occasion very likely-happy mortals !-to concern themselves about treatment; their manner was traditional, and art had not yet "emancipated" itself from the control of fitness. Possibly the sculptor exercised no sort of conscious restraint over himself. $\mathrm{He}$ was a slave, perhaps, and did as he was bid, or belonged to a caste content to work patiently on in the accustomed way. It matters little to us why he did thus and thus so long as he did it. The moral of his work is the same. It is a plea (even though the artist thought of no such thing) for self-restraint on our part Where he stopped short instinctively, never dreaming of realism, we may stay our hands deliberately, knowing the value of restraint.

This we should do in decoration. In ornament, the modification of all natural form being inherently essential to it, even the human form divine must step down from its pedestal and submit itself to the lowly use to which it is put. Mention has been made of two old masters who could, without offence to nature, bend the human shape to ornamental purposes. In our own day the late Alfred Stevens and Walter Crane have shown themselves equal to the task. If others cannot modify the human figure without degrading 
it, that may be an argument for omitting it from their scheme of ornament, it is no excuse for the introduction of raw nature in the place of art. It is one of the ill effects of compelling every student of design to acquire a certain acquaintance with the figure, that he is tempted to introduce it in season and out of season into his compositions, at the cost very often of consistency and ornamental effect. One is inclined to ask what the little Love on Plate 99 is doing amongst the scrollery. It would be at least as satisfactory without him.

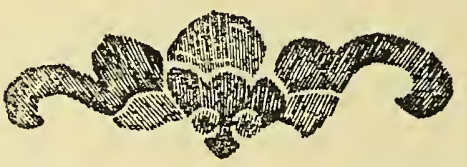

148. Embroidered bat-Chinese. 


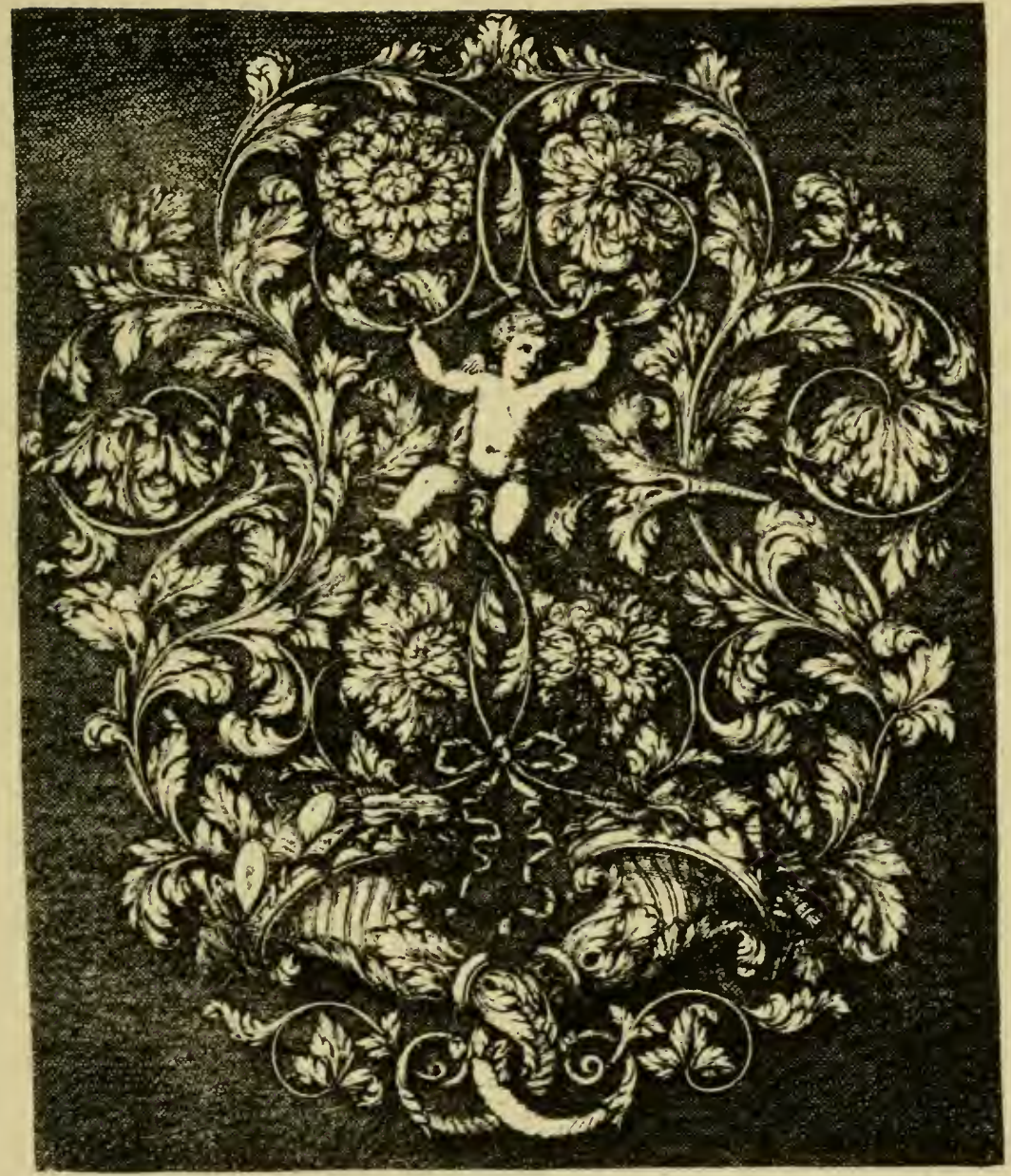

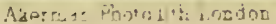

$17^{\text {th }}$ Century Scroll Work, S. Uribelin 



\section{XII.}

THE ELEMENT OF THE GROTESQUE.

THAT the element of the grotesque has been abundantly abused in ornamental design is no argument against the discreet use of it in design. But if we would reconcile reasonable persons to its use we must ourselves keep within the bounds of reason-not of fact indeed, but of sober fancy.

One has a right to expect of creatures, however remote from natural possibility, a greater degree of consistency than the artists of the Renaissance appear to have thought necessary. We are not satisfied, for example, that a substantial beast should suddenly taper off into wiry lines obviously and absurdly out of relation to it, or that its neck should be so inordinately lengthened that when one comes upon the head at last it is with something of a surprise: our dissatisfaction is aggravated if that head should not after all tally with the body, as when a human head is joined to the trunk of a quadruped. 
It is a peculiarly unpleasant shock to us to find that a creature has not only two heads, but one at each extremity of its body: even of a myth we expect a beginning and an end. A scroll may, so to speak, blossom into creatures, just as a creature may develop into foliage; but it should be that-development ; it is not enough that the tail of a beast break out into vegetation. We don't expect a creature so far developed as to have what can be called a tail, to make quite a new departure in the direction of foliage or scrollery; and we resent such freaks, as evincing a want of taste in the artist.

It would be mere pedantry to pretend to define in so many words the precise limits within which one may take liberties with animal form; but one may safely say that the more familiar the form is to us, and the more realistically rendered, the more dangerous it is to take them. The grotesqu which reminds us obviously of some particular animal, is apt to strike one as if it changed into ornament instead of developing into it; and wherever a creature has the appearance of having been put together the limits of discretion have been passed.

Those creations are happiest which seem to belong entirely to the imagination of the artist, 
Plate 100.

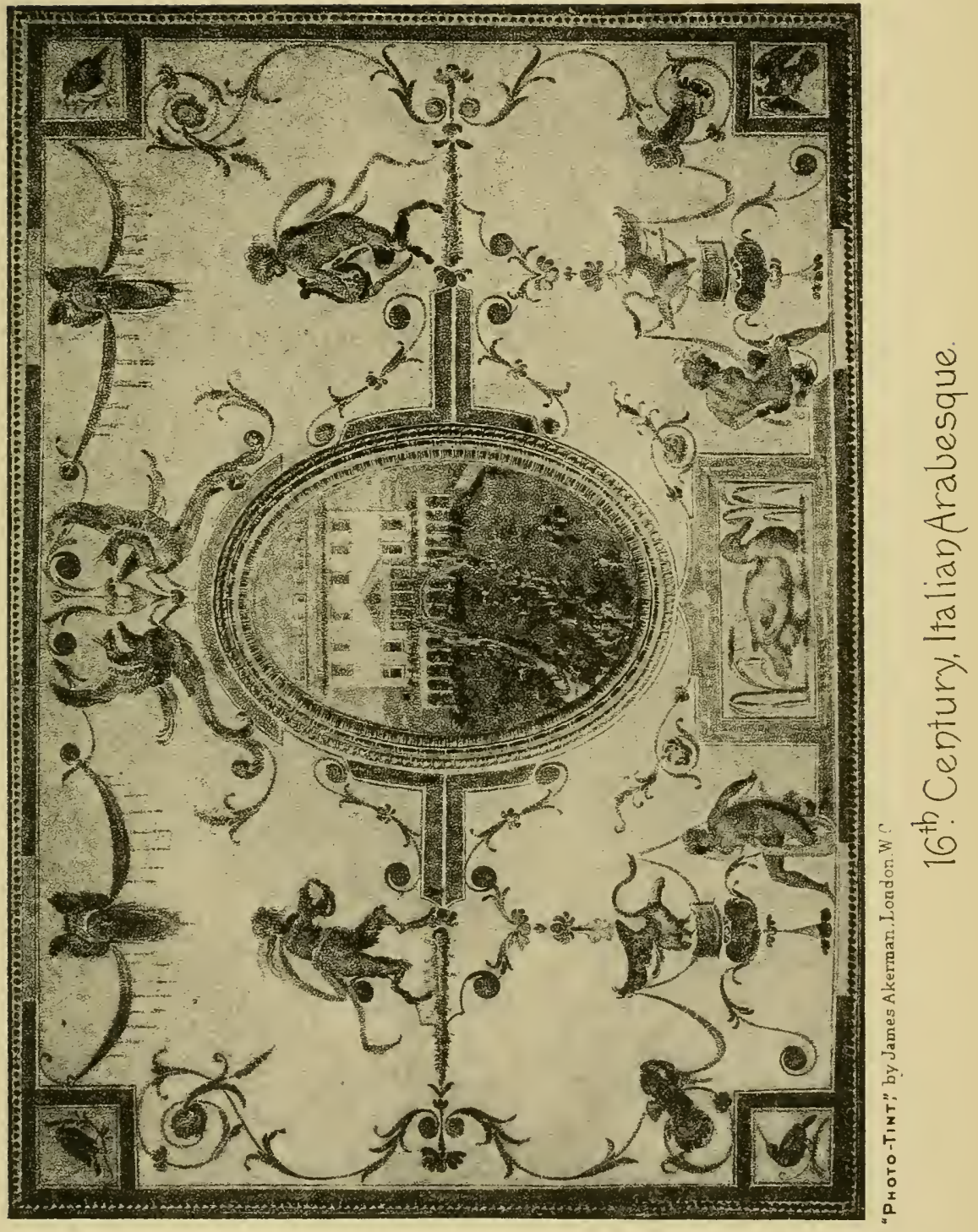



to have been conceived in the spirit of grace. We cease to judge them then by any standard but that of fit design and beauty.

There is a peculiar difficulty in harmoniously combining in one creature the characteristics of various animals. The acceptable grotesque must be less a combination of creatures than their hybrid offspring in the artist's brain -a dream, a remembrance, a fancy-anything but a patchwork. There exist, no doubt, in nature, impossible-looking animals like the giraffe, with its preposterous neck and absurd little misfit in the way of a head at the end of it ; but that is no excuse for disproportion in design.

It is not as with plant form, where we are at perfect liberty to shorten or elongate the stalks and branches, seeing that under certain conditions nature will do much the same, modifying them, indeed, almost out of our knowing. She seldom takes such liberties with the limbs of animals, and when she does we take exception to it, and find deformity in the abnormal proportion.

The artist may, in short, only do what he can make seem right. The romancer who can imagine, like Dumas, impossible persons involved in impossible adventures, and yet interest you in them, make you for the 
moment believe while you read-or at least forget to doubt-has, so far as you are concerned, created them. The ornamentist may equally be permitted to invent what never was or could be, if he can but persuade you, while you look, I will not say to believe in the impossible, but to accept it.

The taste of the artist and the prejudices of the critic will not always go together. There will always be risk of offending susceptibilities in introducing the grotesque element into design. On the other hand, to repudiate the grotesque is to give up a valuable element in design, one difficult to secure by means of pure ornament-and worth having, even at some risk of offence.

One may recognise the temptation to its abuse, and the remarkable unanimity with which artists of the Renaissance succumbed to temptation, and yet make bold to assert the possibility, and the existence too, of such tasteful and artistic use of the grotesque as only a purist could find it in his uncomfortable conscience to reject.

To persons of a somewhat rigid way of thinking, and they are not a few, the impossibility of grotesque creatures is quite enough to condemn them; they see only, as they would say, the absurdity of it all ; they would 


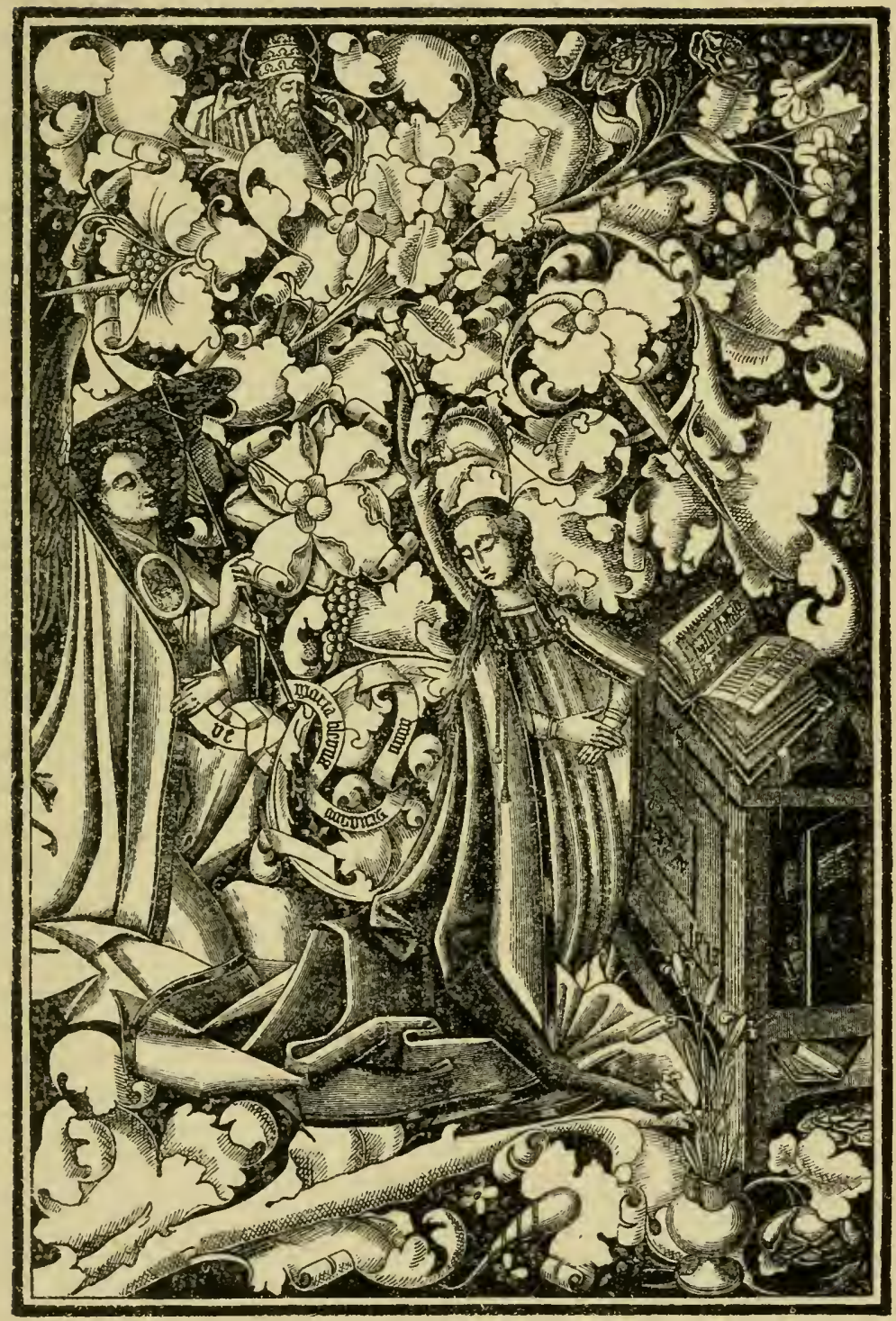

Late Gothic lllumination. 

pass over the grotesque as a mere blot upon Italian arabesque, of which it is so essential a characteristic. I would maintain on the contrary, that something at least of the variety and pregnancy of Quattro- and Cinque-cento design is due to it, and accept it for what it is, a most convenient and effective means of counteracting the dangerous tendency of mere ornament to lapse into monotony and all-overishness.

Moreover, whatever we may think of it individually, it would seem as though not only the Cinque-centists, but artists before and after them, came to the unanimous conclusion that they could not well get on without something of the sort-and he would be a marvellously clever fellow who could do without it all that the craftsmen of the Renaissance did with its help.

An artist must obey his conscience. It treats him harshly when it cuts him off from a resource so helpful in design, so near at hand, so needful.

The fact is, a mere scrollwork of something like vegetable form does not always suffice. The designer wants here and there certain masses, or weight, which it is difficult to get in the form of flowers and such like. The difficulty has been solved sometimes, or rather 
shirked, by the introduction of actual figures, human or animal, among the foliage, excusable only when they are reduced, by their treatment, to strict conformity with the surrounding foliage.

The nearer such creatures approach to reality, the more incongruous they appear in the midst of non-natural foliage. You feel that in the Italian decoration on Plate Ioo, the masks and griffins belong, in a way, fairly well there; and the goat-legged figures are not so much amiss; but the life-studies below are entirely out of place. So are the little birds in the corners. As for the disproportionate duck, it beats the record of absurdity. Disproportion of this kind is a very common failing in design. For, to tell the truth, the difficulty of keeping figures, human or animal, at all in scale with the surrounding ornament is very considerable. In the Persian panel on p. I69, the ducks are disproportionately small. And again, in Plate IOI, the figures are for once overpowered by the ornament. The artist was no doubt naïvely pious : to us such an "Annunciation" is simply grotesque.

In the case of creatures frankly ornamental, with no claim to possibility, the danger of disproportion is in great part avoided. You are enabled by means of them not only to get 

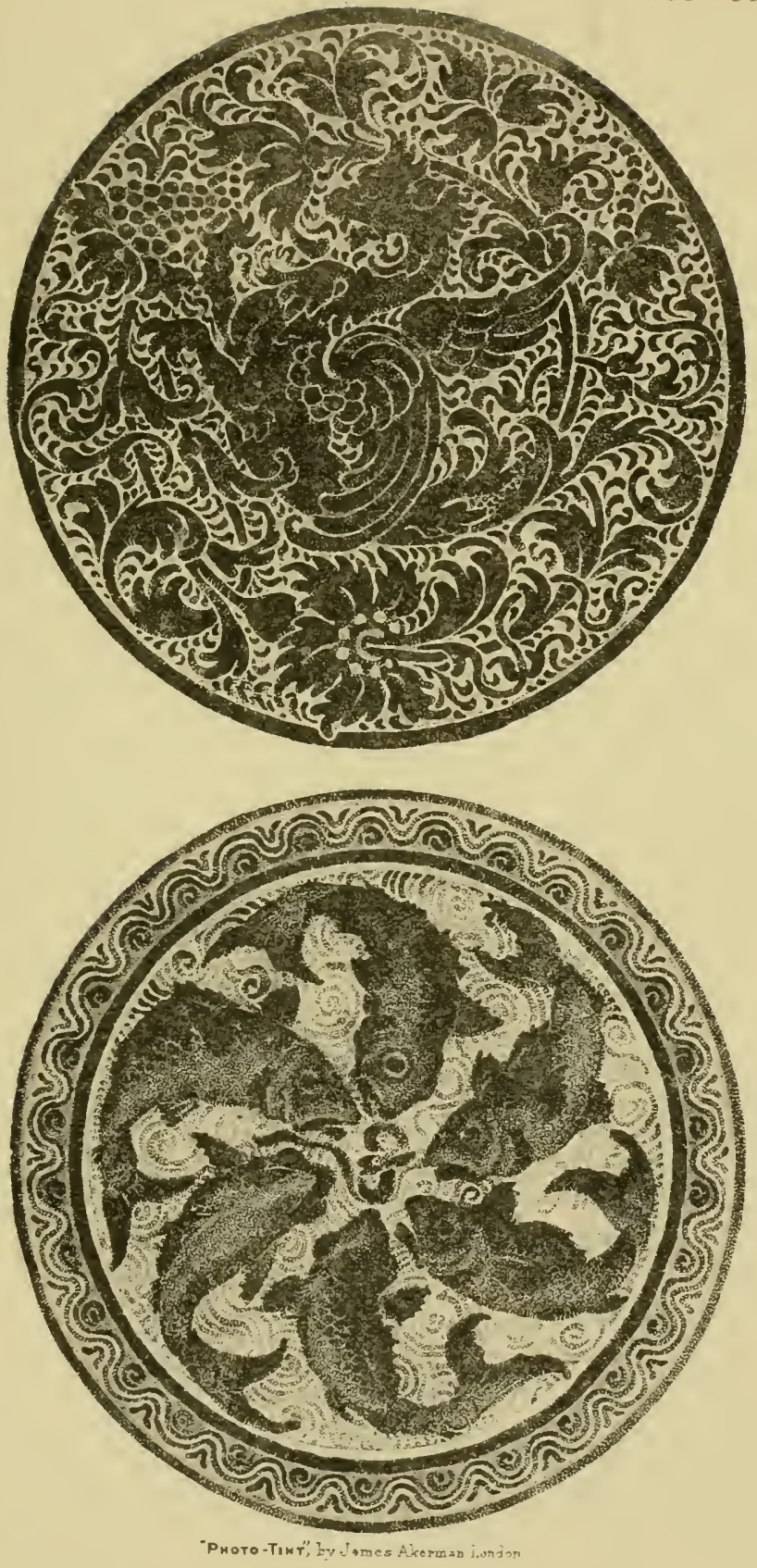

Lustre Plaques. 

just the weight and mass you require, but to get it just where you want it; whereas, in the case of natural objects, there should be some sort of dramatic reason for their occupying this or that position. The creature in the centre of the upper plaque on Plate 102 gave weight just where it was wanted. In the case of the less absolutely ornamental fishes in the lower design, the worm supplied the necessary centre of attraction.

The mere grouping together of creatures, human, animal, or monstrous, though it may form a kind of grotesque enrichment, seldom results in anything which can properly be called ornament. It is the resource of the figure draughtsman, who relies naturally upon forms with which he is familiar, and which come more easily to his hand than any severer type of ornament. He seldom succeeds in producing ornament: when he does, he justifies himself by success.

One may have a personal opinion as to the straight and narrow path in design, without insisting that all the world should be driven along it. And in the presence of masterly work one recognises the master, and allows that one's theorising does not apply to him.

In the work of Holbein and Luca Signorelli one sees that the artist has digested his 


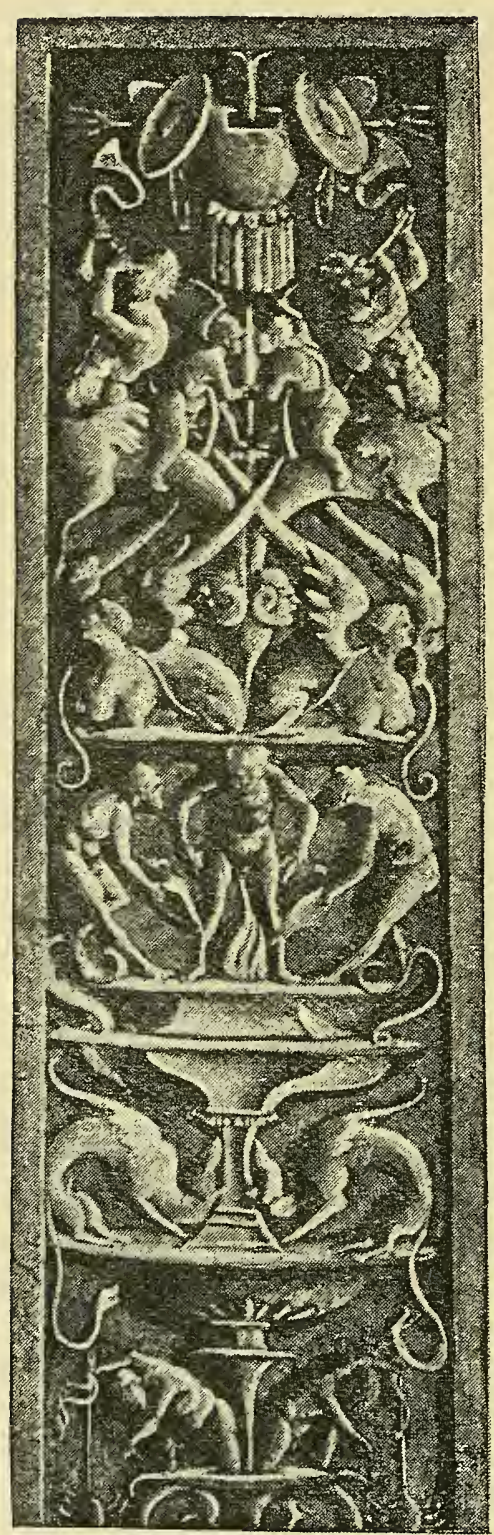

149. P'ilaster by Signorelli. knowledge of the human figure. In seeking ornamental lines, those of the human figure came naturally to him, and he was so familiar with every turn of it that it was easy for him to bend it absolutely to bis purpose - which purpose was ornament. It is seldom indeed that a master of the figure cares enough about ornament to submit himself to its conditions. When he does, it is probable that he was well grounded in it before ever he took to the figure. That was certainly so in Holbein's case. 
Plate 103

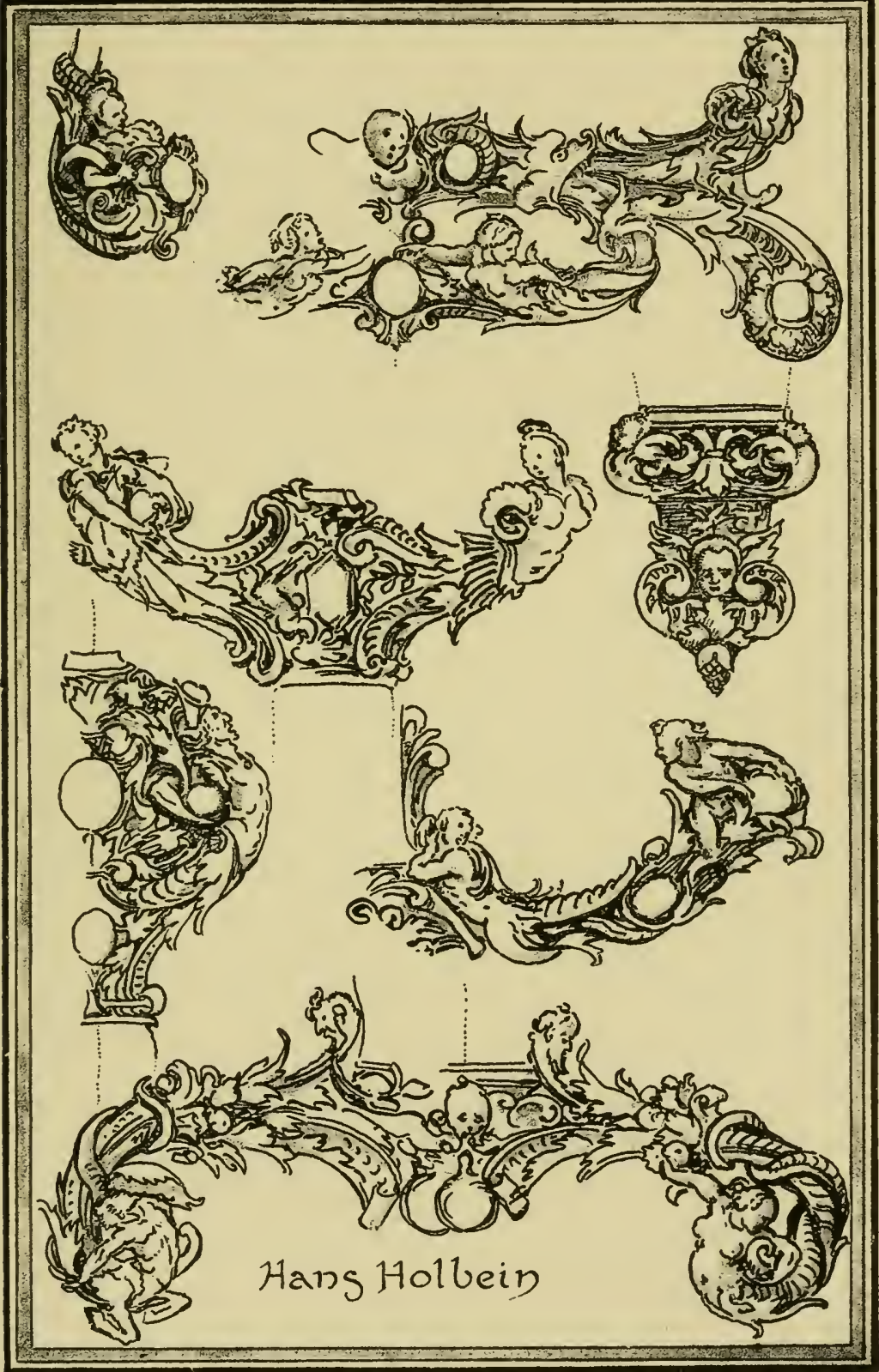

Studies in Urnamental Figure Work. 



\section{The Element of the Grotesque. 203}

You can see in Holbein's work (Plate IO3), how every line and every pose was dictated by considerations of ornament, for all the dramatic intention he managed often to combine with it. It is pretty plain to the designer that such dramatic quality grew out of the lines of his ornament, and did not suggest it. It is that extra something which the consummate artist always throws in-it was not bargained for in the ornament.

Signorelli's pilaster (p. 202), is more entirely made up of the figure-and the upper portion of it illustrates to some extent the dangers which beset the painter. The lower half illustrates how much can be done in figurework almost alone. Only a designer, perhaps, can realise how studiously the lines of the figures, actively engaged as these may be, have been not merely controlled by decorative requirements but suggested by them. The figures were designed, not worked into ornament; they are conceived or remembered, not taken from his sketch-book. Like Holbein, Signorelli too delights to find a reason for the form dictated by ornament.

The work of these men does not go to show that the figure is peculiarly amenable to ornamental use ; but it shows at least to what good ornamental purpose it may be put by those 


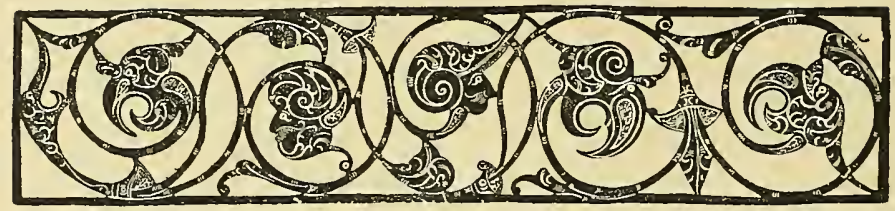

150. Grotesque iron grille-German.

who have thoroughly mastered both the figure and ornament. They are not manyand never were.

Sansovino's monsters on Plate 104 are extravagant, but still ornamental. The lines are so cleverly schemed, and the effect is so undeniably decorative, that the strongest objection to such detail as that of the two-legged quadrupeds at the top of the panel is swallowed up in admiration of the composition as a whole. But Sansovino's design is by no means a model of what arabesque ornament should be. It is an instance, rather, of what a consummate artist may be excused for doing.

The artist begins by blotting in his design, intent at first mainly upon the lines of his composition and the distribution of its masses. We may take it that it was in order to get the requisite weight of form that he roughed out certain bolder masses, half accidental perhaps, which suggested animals, much as one sees faces in the fire. Once he has resolved upon such masses in his composition, the designer 
Plate 104

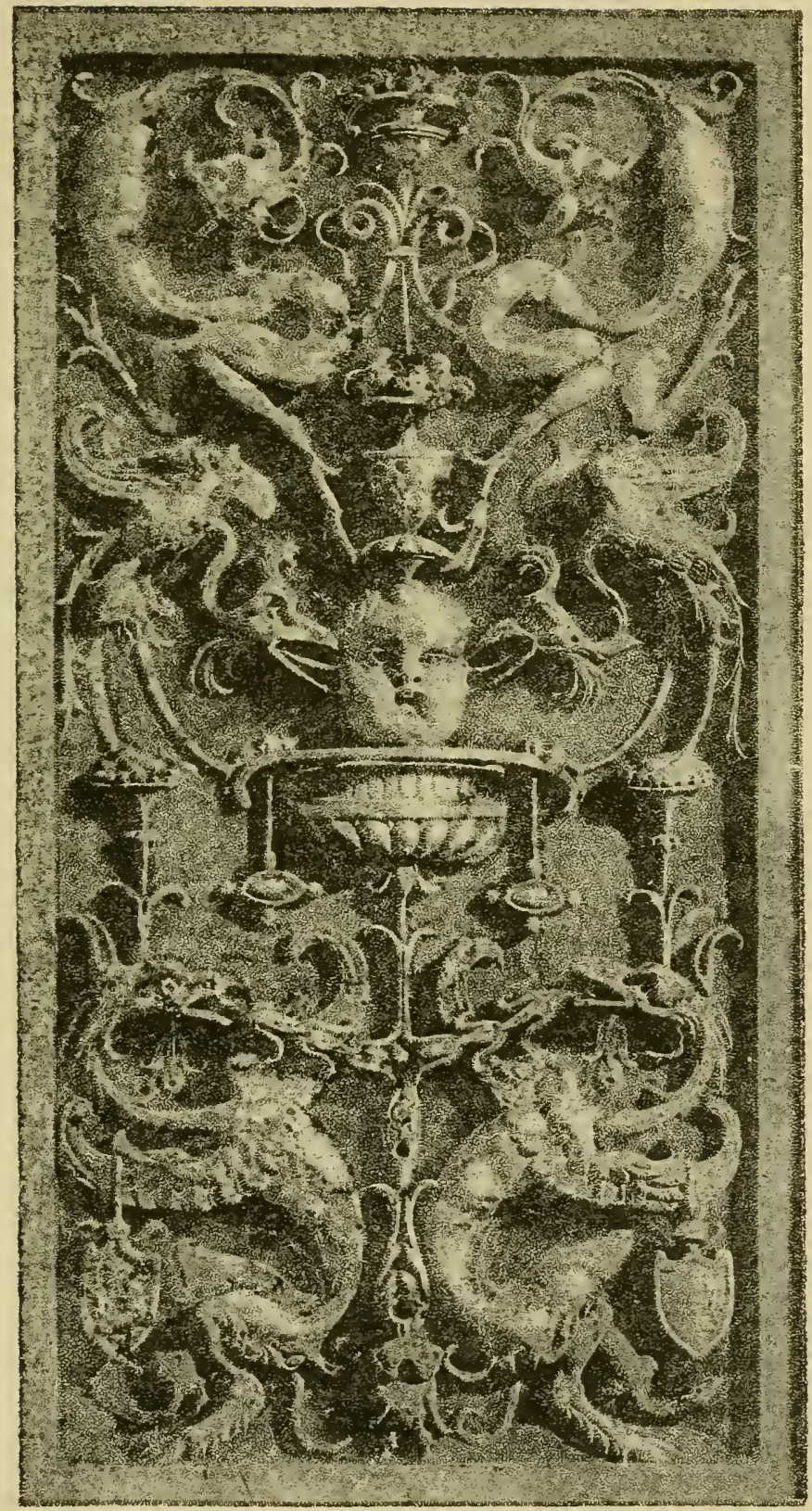

"Pното-TimY', by James Akermm. London. W C.

Grotesque Panel, by Sansovino. 



\section{The Element of the Grotesque. 205}

is bound to give them an interest worthy of their prominence. It is so, no doubt, that the German ironworker came to design the helmeted and parrot-shaped heads in the grille opposite; it was his desire to avoid that monotony of line which is the vice inherent in wrought-iron work.

The lines of imagined creatures are in the best examples so essentially graceful, so obviously inspired by considerations of ornament, all is so entirely one, that it is selfevident, to any one who has himself designed, that it was the ornamental consideration which suggested the animal element. Certainly it was so in Plates 96, 103, I04. Only in that way does it seem possible to arrive at a combination of grotesque and arabesque so essentially harmonious that one has a difficulty in saying where the one ends and the other begins.

The grotesque lends itself delightfully to ornamental requirements, but only on one condition-that it follow the lines suggested by ornamental design. It is especially amenable, because no thought of nature need enter the mind of the designer, to hinder the free play of his fancy. The lines may be the lines of animal form more or less; they must be the lines of grace and beauty. Whether the animal form be the root from which the orna- 
ment springs, as in Plate 105, or the outcome of the scroll, as in the design on Plate 106, the one essential thing is that it should be, not merely in harmony with it, but part of it ; grotesque and arabesque must be one growth: the least shock to our sense of congruity is disenchantment.

Scandinavian and Celtic ornament (Plate 107) never jar upon one. The strange and impossible birds, beasts, and dragons discovered in the interlacings whether of carving or illumination, had doubtless a symbolic origin; but, so far as carver or penman was concerned, he never conceived them first as independent and then twisted them into knot-work; it is perfectly plain that the designer gladly accepted the symbol because he knew the value of emphatic masses in ornament, and found it most convenient to end his strapwork with a head, to broaden it out somewhere into a body, to make it branch into legs or wings, as best suited his composition. In short, he invented his interlacings, and then by the addition of legs, wings, head and so on, converted it into a sort of dragon.

Abuse of the grotesque, which goes far to account for the disfavour with which anything of the kind is by some regarded, comes partly at least from the fact of the work- 
Plate 105.

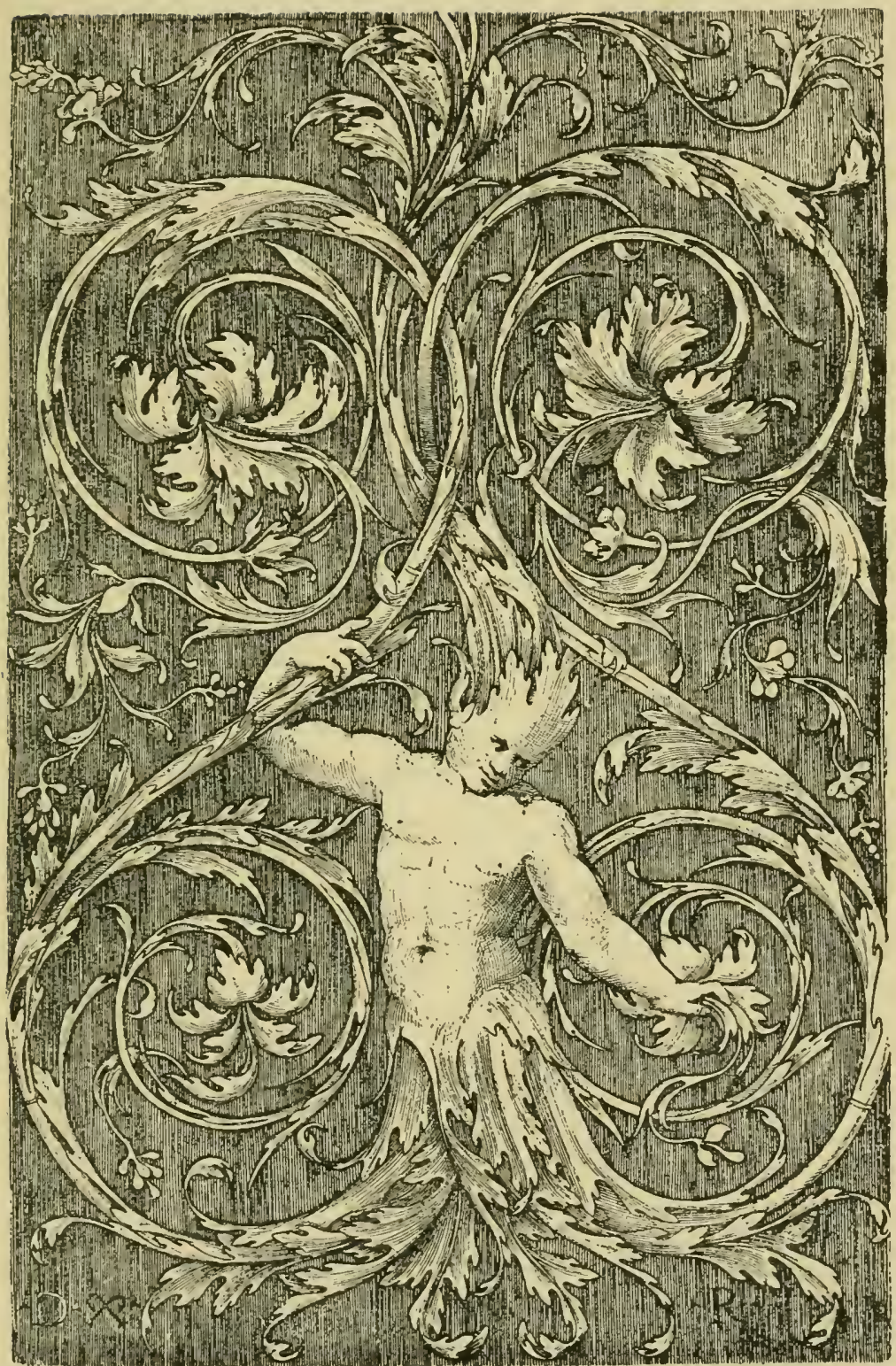

Grotesque fioure. Marco Dente da Ravenna. 



\section{The Element of the Grotesque. 207}

man being more adept in figure-work than in ornament. In the design, for example, of the School of Fontainebleau there is no rest from creatures, human or animal, starting out at you; it is bursting out into life all over.

The artist had usually, no doubt, some reason of construction or balance for the introduction of his perhaps ugly grotesque or demi-figure-sufficient it may be to justify the introduction of the figures, but certainly not to excuse their ugliness. Memory calls to mind certain human skulls in marble, bedecorated with foliation in itself more or less graceful, which are enough to make one loathe for the time being the very thought of the grotesque.

This is just one of those cases in which the absurdity of imitating old work becomes most apparent. Here, at all events, one cannot safely follow precedent; it would be a warrant for every imaginable extravagance. In old work it is easy to forgive such things ; one finds a certain compensating quaintness about it; but our pretence of quaintness is intolerable affectation.

The problem of the modern designer is how, without the ugliness or incongruity marring the beauty of old work, to get that breadth of mass, that variety of detail, that richness of effect, which we see and admire in it. And he 
will find the simplest solution of the difficulty in removing his imagined creatures considerably from nature. They should be fancies, not misshapen or distorted facts. The foliation of animal form, fantastic as it may be, should seem to us almost a matter of course-what, under certain impossible conditions, nature might possibly have done. It is so in the land of dreams.

The objection to the animals, grotesque or natural, which figure among the scrollwork with which the Loggie of the Vatican are decorated, as also in the panel from Mantua by Giulio Romano (Plate $\mathrm{I} 7$ ), is that they are inconsistent with the ornament; it is too thin to support them, too conventional to harmonise with them; they are not part of the ornament but patches in it.

This is a common fault, more apparent in painting than in sculpture. In colour other than monochrome one expects something in the direction of natural colour; and the sphinx, for example, which is half flesh colour and half fur colour, looks more than ever a compound and not a creation. So also with the texture which a painter is tempted to give. The vaguer a monster the more possible he appears. Realise him and he becomes ridiculous. When hair and scales and feathers are 


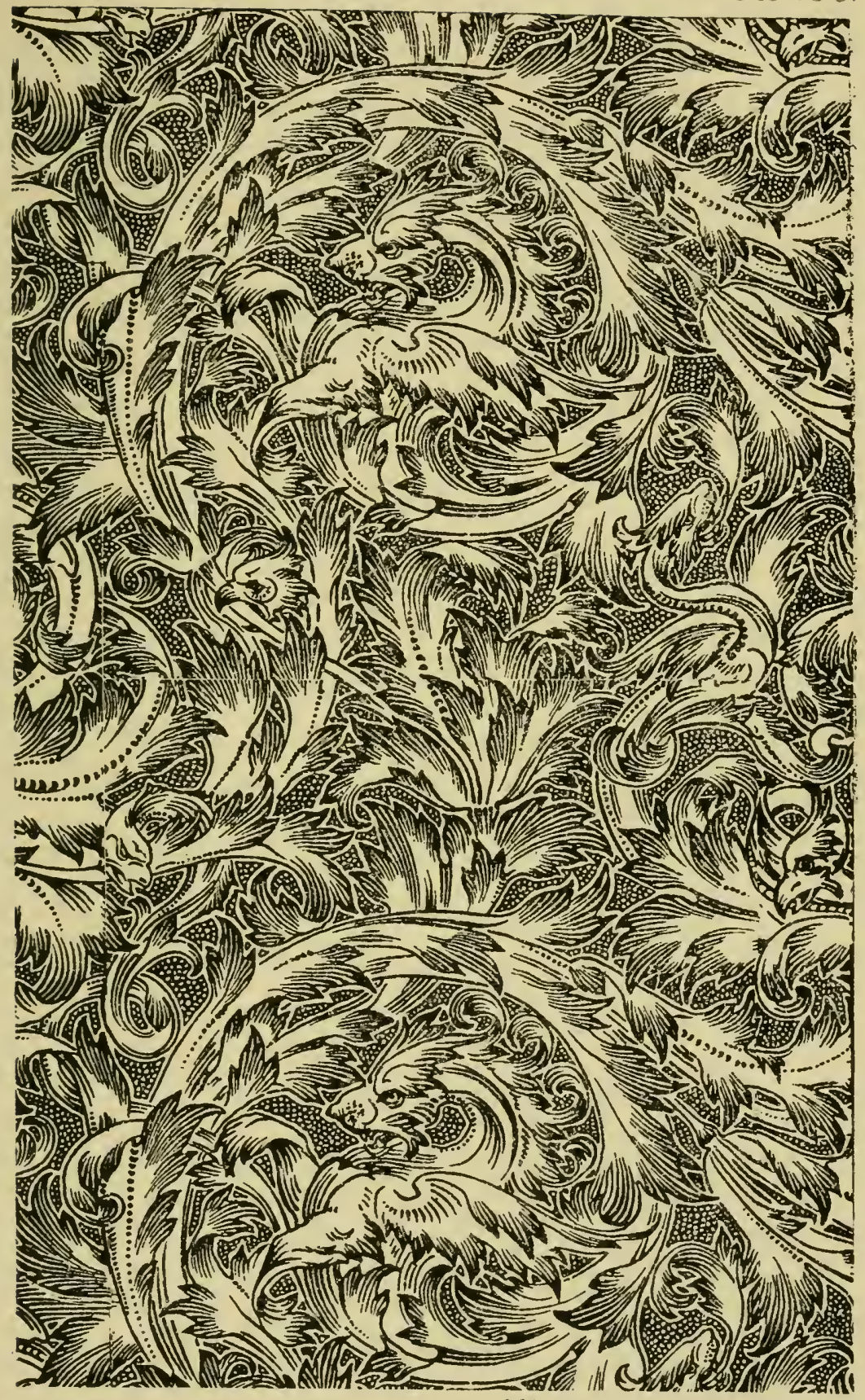

Grotesque Scroll 



\section{The Element of the Grotesque. 209}

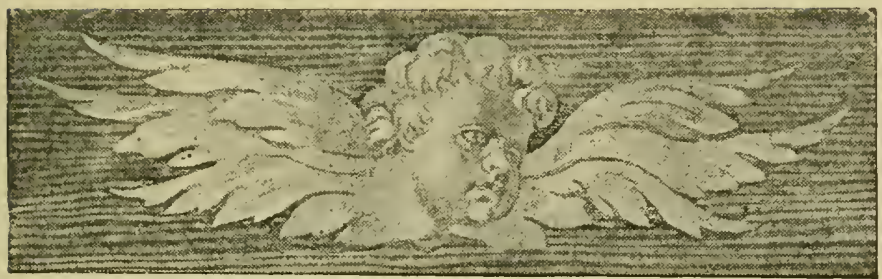

I5 $\mathrm{x}$. Wings reduced to ornament.

all naturally depicted you miss the naturalness in the creature to which they, it can't be said belong, but are appended.

If a figure such as that on Plate 105 may tail off into ornament (the doubt suggests itself whether, in that case, the figure should be quite so real) there is not only no reason why his ears should not be foliated and his hair flow off into scrollery too, but every reason why they should: it is better somore logical certainly.

Again, in the case of the winged head above, it is surely permissible to remove such an impossibility still further from the possible. And from the point of view of naturalism, the absolutely ornamental appendages strike one, in such a connection, as less absurd than obvious goose-wings would appear. A fantastic rendering of the wing is plainly compatible with the grotesque (Plate I08). There at least no one can quarrel with a departure from naturalism, though the detail be so absolutely 


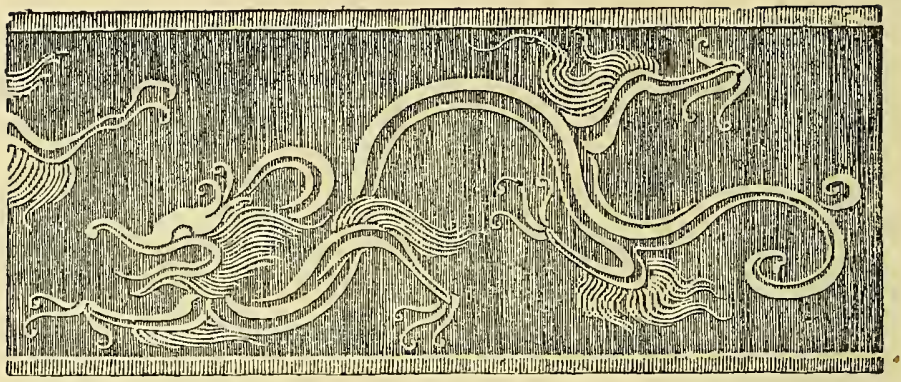

I52. Ornamental dragon-Japanese.

ornamental as to partake, as it often does, more of the nature of foliage than of feathers. Over and over again the sculptors of the Renaissance have shown that it is possible to endow a monster with members which are neither arms nor wings, and yet something more alive than mere scroll-work. The one essential thing, of course, is that such members should belong to the creature.

The Japanese dragon above conforms admirably to the conditions of ornament. $\mathrm{He}$ does not even break out into scrollery-he is the scroll. His construction is anatomically impossible: from the curl of his mane to the turn of his claws he is unlike any imaginable creature. Yet he is full of life and go, graceful without any loss of energy, and altogether one with himself-a fantastically ornamental creation.

I have confined my remarks on grotesques 
Plate 107

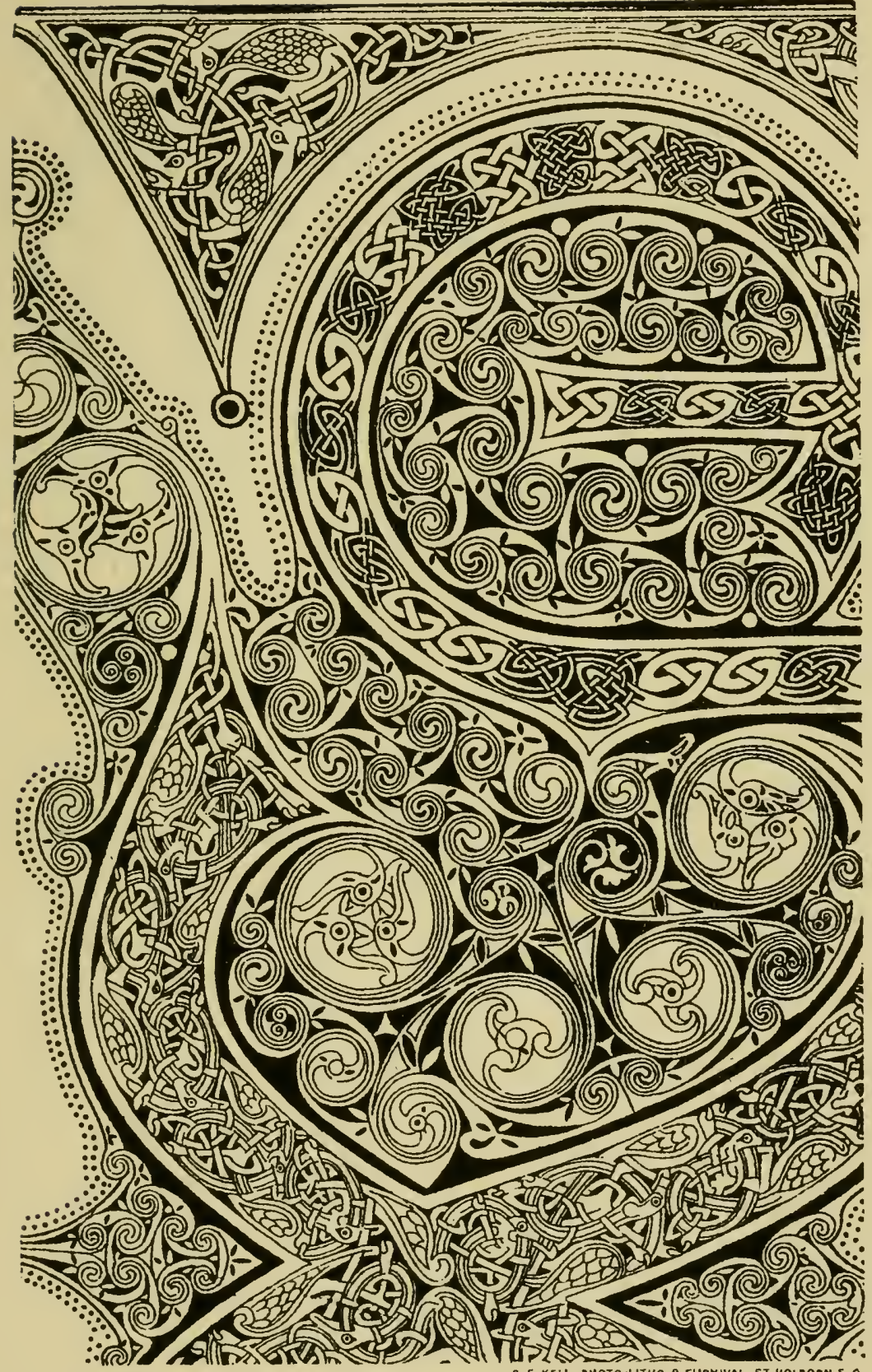

Keltic interlaced orrament. 



\section{The Element of the Grotesque. 2 I 1}

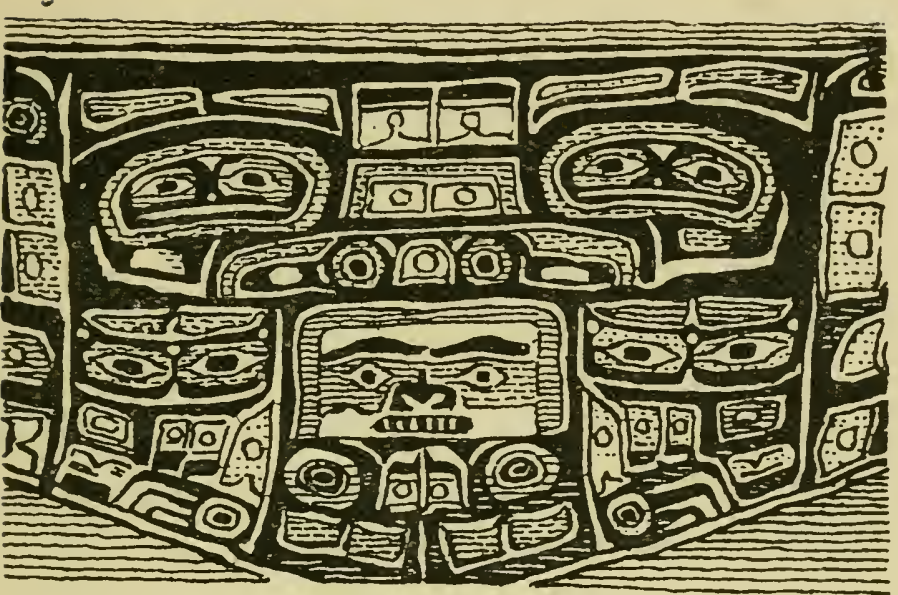

153. Arctic American grotesquerie.

mainly to the Renaissance, because in it and its Classic precedent, but especially in it, the ornamental capacities of grotesquerie have been most fully developed. The grotesque gave character to Gothic art, but did not greatly enrich its store of ornament. The monk or freemason or whoever he may have been, found vent in it for his humour, his satire, his humanity in short. It is because they show us something of the man behind his work that we like his grinning gurgoyles and exuberantly humorous miserere seats, ugly though they may be.

There is a certain naivety in all archaic art which is likely to strike us as grotesque. Of such unconscious grotesquerie it is not here necessary to speak, further than to say that the 
conscious aim at anything of the kind on our part argues us wanting in that first essential towards practical design, common-sense-if, indeed, it might not justify a certificate of insanity. As the work of Arctic American Indians one recognises in the design on p. 2 I I qualities decidedly ornamental; as to founding ourselves upon it in any way, we might as well throw off at once the clothes of civilisation and tattoo ourselves forthwith. 
Plate 108

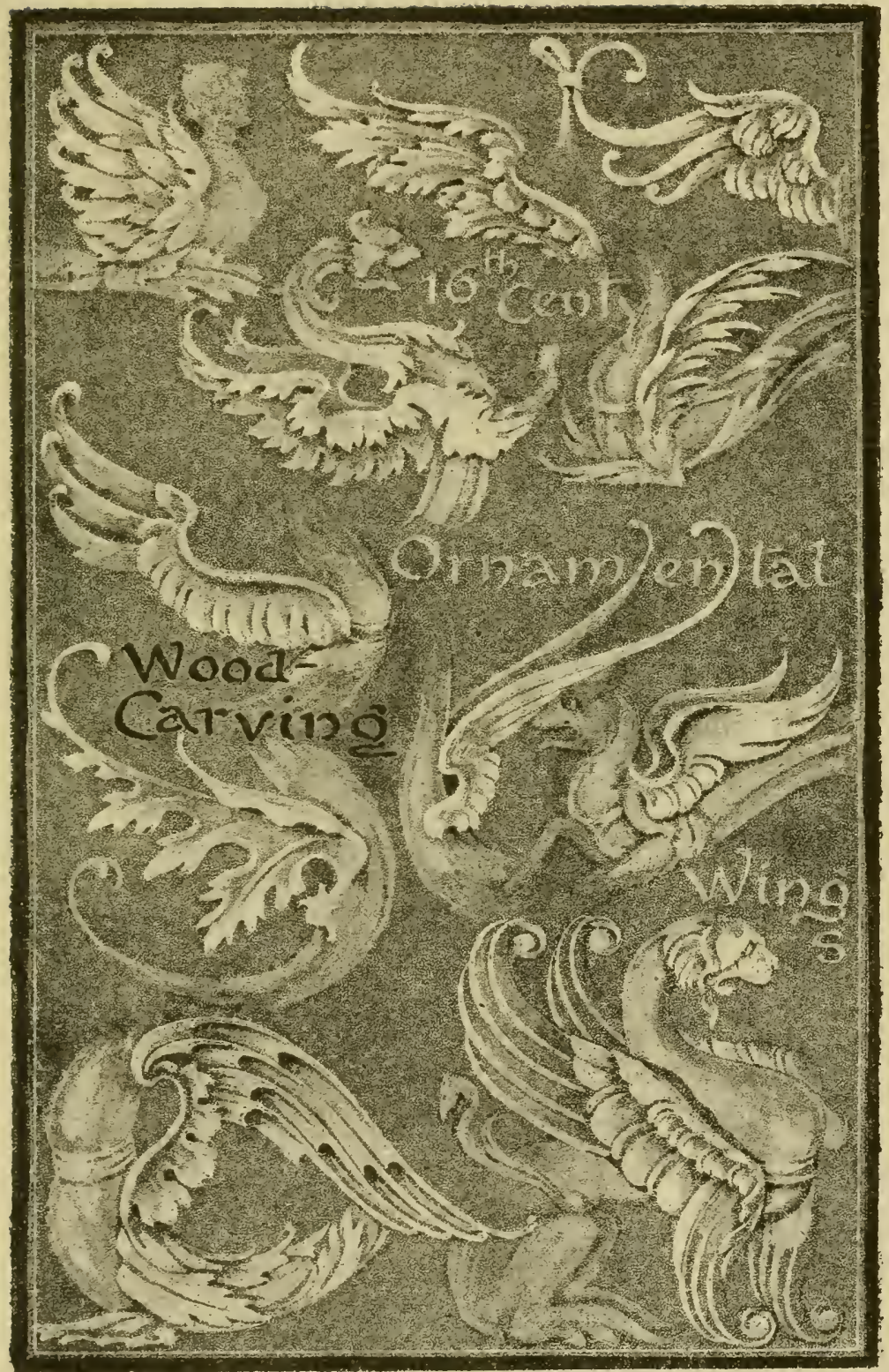

"Pното-Tint", by Jumes Akermen. London. W.C.

Conventional Wing Forrns. 



\section{XIII.}

STILL LIFE IN ORNAMENT.

Considering the popular and insatiable desire for novelty, it is remarkable how little variety there is in motifs of decorative design.

Our very familiarity with certain obviously available and consequently well-worn types, to say nothing of the cheap travesties of

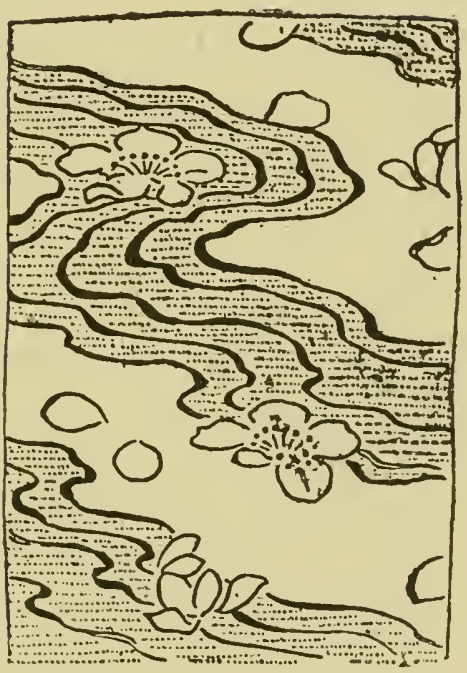

154. Spring blossoms on the stream. them, should be in itself an inducement to us to go further afield in search of something less hackneyed.

The historic styles of ornament were, we may be sure, much more alive than they appear to us in the specimens surviving in the collections and museums of to-day. To judge 


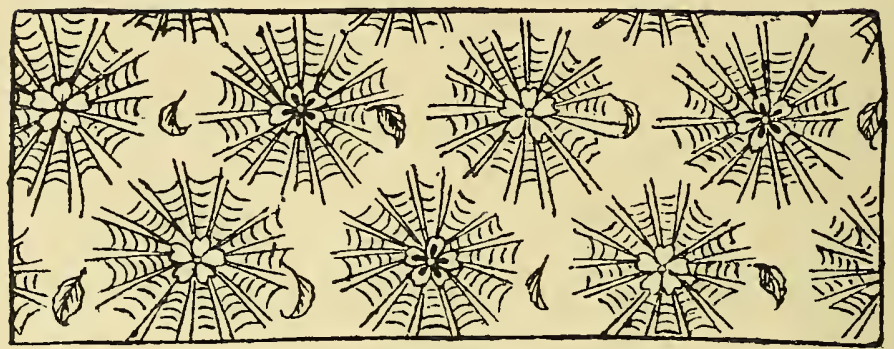

155. Diaper of spiders' webs.

by them alone would be much as if we estimated tropical scenery by the botanical specimens at Kew. The impression one gets from a casual glance round any museum is that Greek ornament is all very much alike; so is Roman, and so is Renaissance ; and still more so is Gothic, Byzantine, Assyrian, or Egyptian ornament.

Undoubtedly there is always a certain distinguishing character about the work of any ancient period, which is the first thing that strikes us about it. The family likeness asserts itself before everything to our unaccustomed eyes. But as the shepherd knows his flock, though to us they are just sheep, so the artist detects, even in ancient art (which was not to our ideas particularly individual) the individuality of the craftsman; and the more familiar he becomes with it the more he sees in it a variety of which at first he had no suspicion. 


\section{Plate 109}
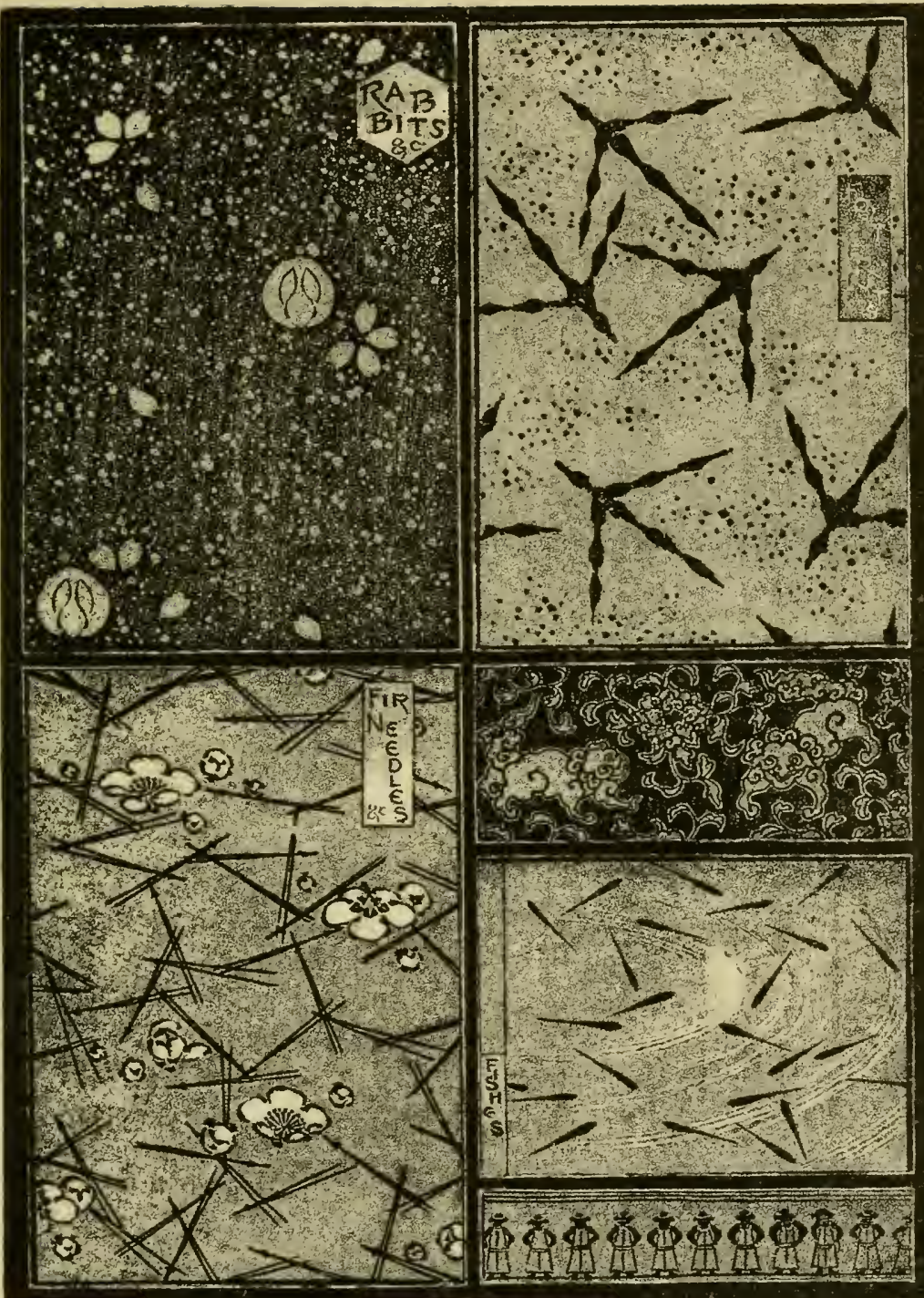

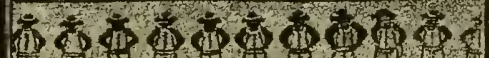

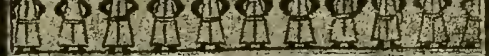

"Pното -TimT", by Jumea Akera an London 'W" $\mathrm{C}$

Japanese Diapers $8^{\circ}$. . With a meaning. 



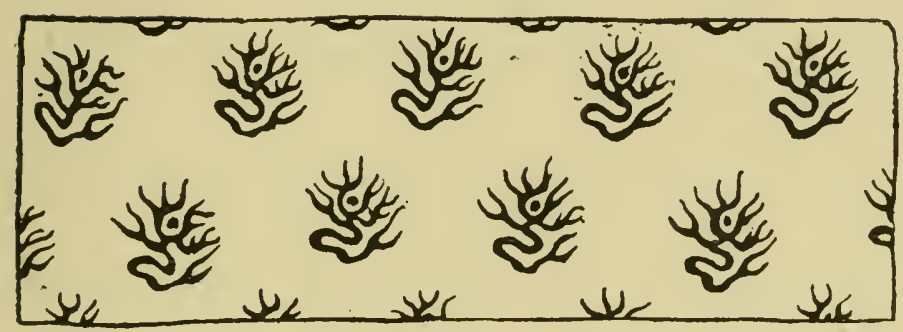

156. Diaper of flames.

On an ancient Roman tripod in the Louvre is carved a crown-imperial, quite conventional and yet quite unmistakable. The top-knot of leaves is very like the Greek anthemion; at the top is a bee; two more bees attack the flowers, and fill the gap where naturally no leaves occur; and again there are two others between the foot-leaves and the leaves of the stem, where there would be in nature an empty length of stalk. If an artist of our day had introduced such a composition into Greek work he would have been accused of seeking inspiration rather from a Japanese than from any Classic source.

The truth is that all ancient art was once alive, difficult as it seems to be to us to realise that obvious fact.

Nevertheless it would appear that Japanese art is not only more directly and spontaneously natural than, for example, Classic art, but that its range is wider and more varied. Japanese 


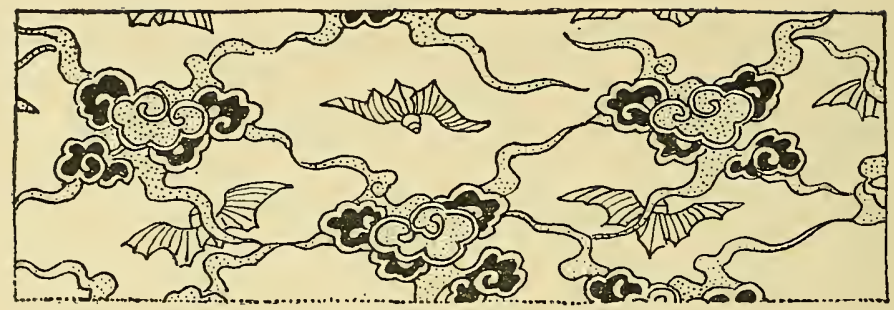

157. Cloud and bat pattern.

art has been fashionable, and is now for the moment under a cloud of disfavour, the inevitable consequence of reaction. When that is dispersed we shall still perhaps continue to over-estimate or to undervalue it, according to our idiosyncrasy. But, whatever its shortcomings in the way of grace and purity and dignity of form, there is no denying its distinctive charm of spontaneity, variety, and freshness.

No one was ever more alert to everything in the shape of ornament about him, more ready to seize a suggestion from nature, than the Japanese craftsman. The snow falls, the

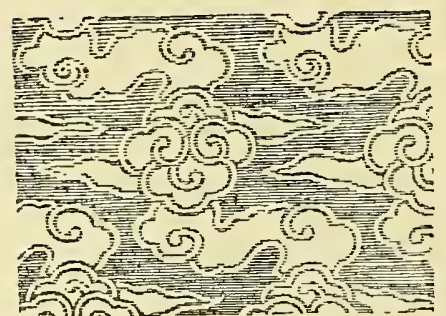

I58. Cloud pattern.

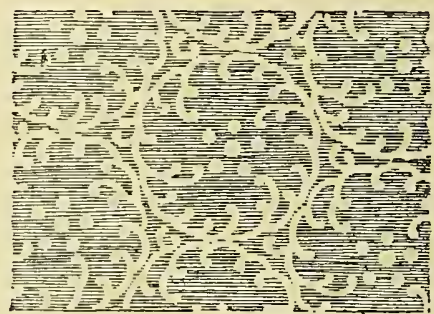

159. Wave pattern. 


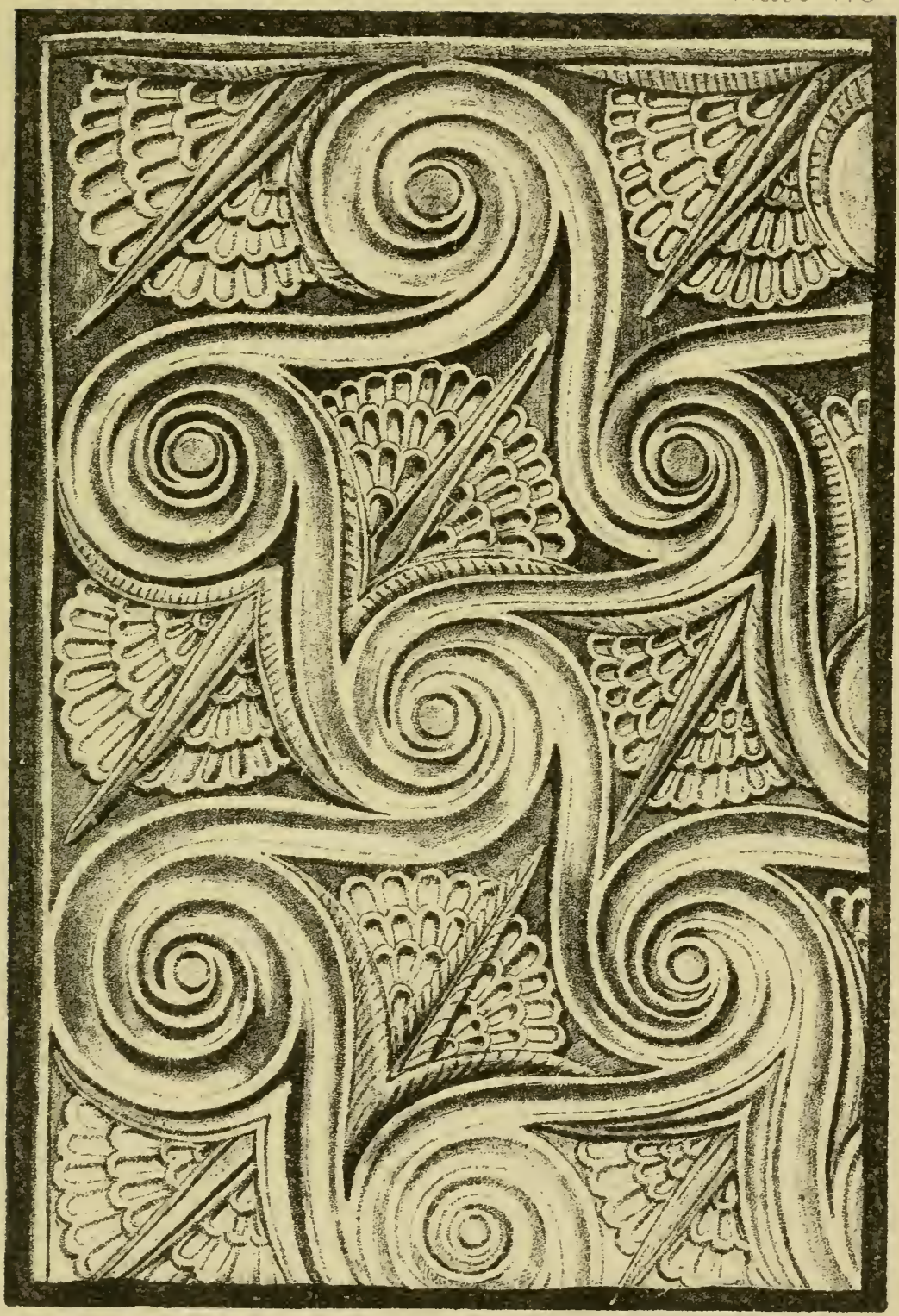

"Pното-TIMT", by Jumes Akerman London W $C$

Garly Greek Wave \& Lotus Diaper. 

almond blossoms drop, the rabbit huddles itself together (Plate I09), birds leave their footprints in the snow, fir needles and peach blossoms strew the ground or float upon the stream (p. 2I3), little fishes dart about in the pool-whatever happens furnishes him with an idea for decoration. The spider's web,

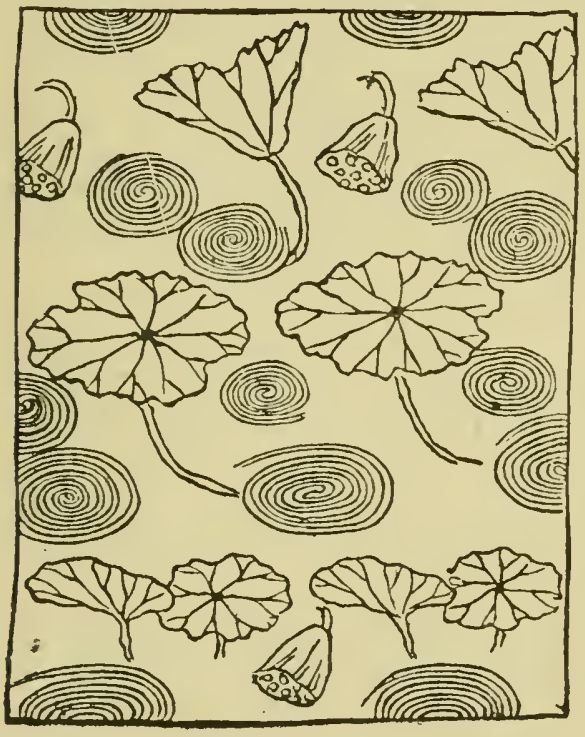

r6o. Water and water-lilies. with leaves and flowers caught in it (p. 2 I4), suggests to him a diaper.

$\mathrm{He}$ is far indeed from conforming to our ideas of symmetry. He does little more in some cases than dispose natural shapes, rendered in the simplest possible manner, in an order which, if not precisely ornamental, answers to some extent the purposes of ornament (Plates 2, 91, 93, and I09).

It would be pedantic to say that decoration such as this may not on occasion serve all the 


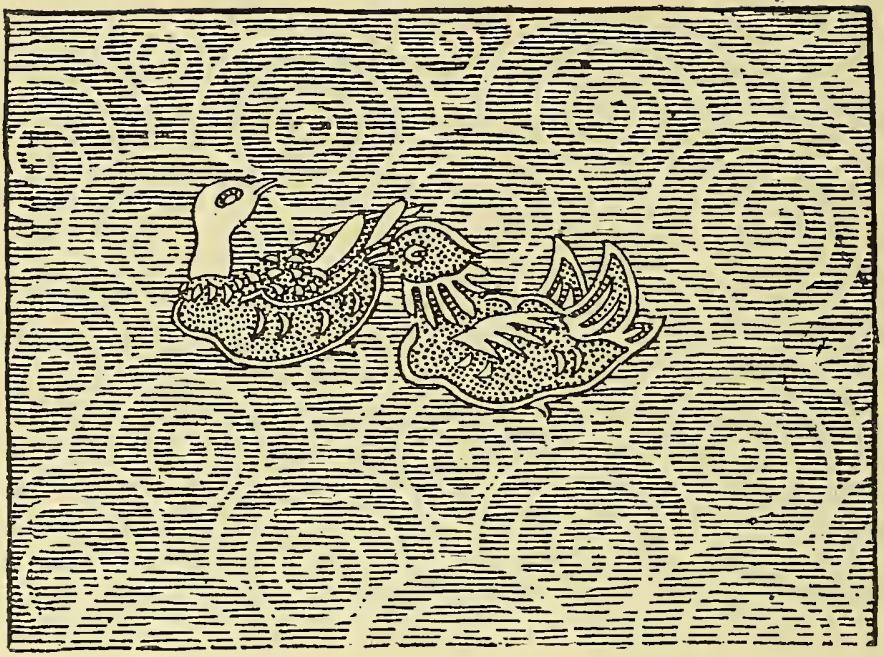

r6r. Wave pattern, and water-fowl.

purposes of art pretending to no serious aim, such, for example, as that of the cotton printer. It is not essential that ladies' dresses or peasants' petticoats should be designed strictly on architectural lines.

If, on the whole, inanimate nature has not been turned to full account in ornamental design, historic ornament exemplifies pretty well its fitness to our purpose. The flames of fire-to go beyond still life-were only very occasionally made use of by the Japanese (p. 215),

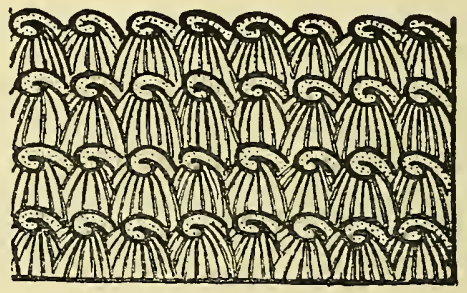

r62. Wave pattern. 


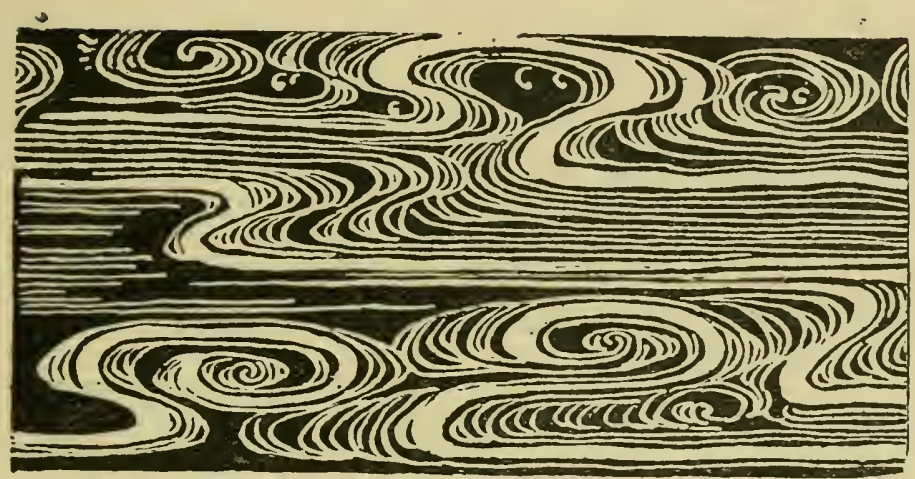

163. Wave pattern.

but they were a very common motif of ornament in Gothic art, so common indeed as to give its character and its very name to the style we call Flamboyant.

In later times, William Blake founded his wild style of ornament almost entirely upon flames, and there has been even a later sect, founding themselves upon him, whose ornament is still more alive with tongues of fire, still more restlessly flamboyant.

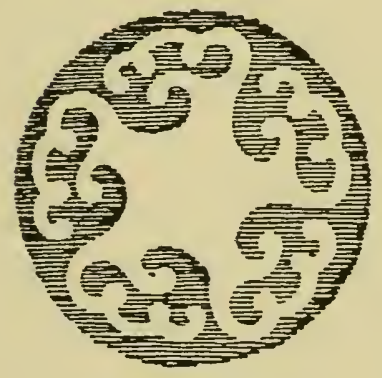

164. Wave ornament.

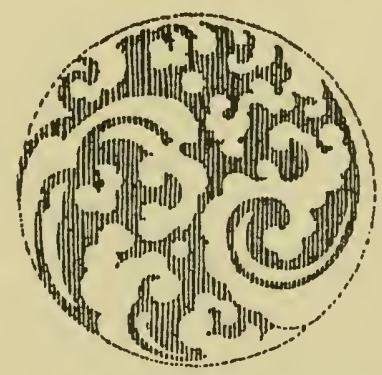

165. Wave ornament. 
In Gothic art, again, cloud patterns are of quite common occurrence, although so remote from anything aerial that it is only by the use to which they are put (as borders round a halo, for example) that one knows them to have any reference to clouds. That may be said also of Chinese and Japanese cloud patterns (p. 216). The bats certainly help to reassure one that these odd forms do stand for clouds. The birds on $\mathrm{p}$. 238 are of similar service. At all events, there is some variety in the various Japanese renderings.

The lines of waves have from

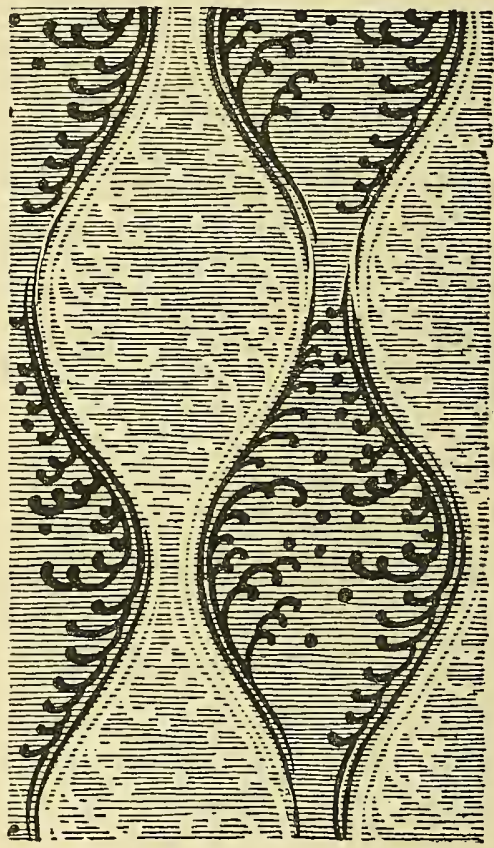

I66. Wave and spray pattern.

the first been used as ornament. The Egyptian zigzag, the Assyrian water-diaper, and the Greek wave, are among the earliest border patterns. There is a late Renaissance rendering of the Classic wave_on p. 4I. 
Plate 111
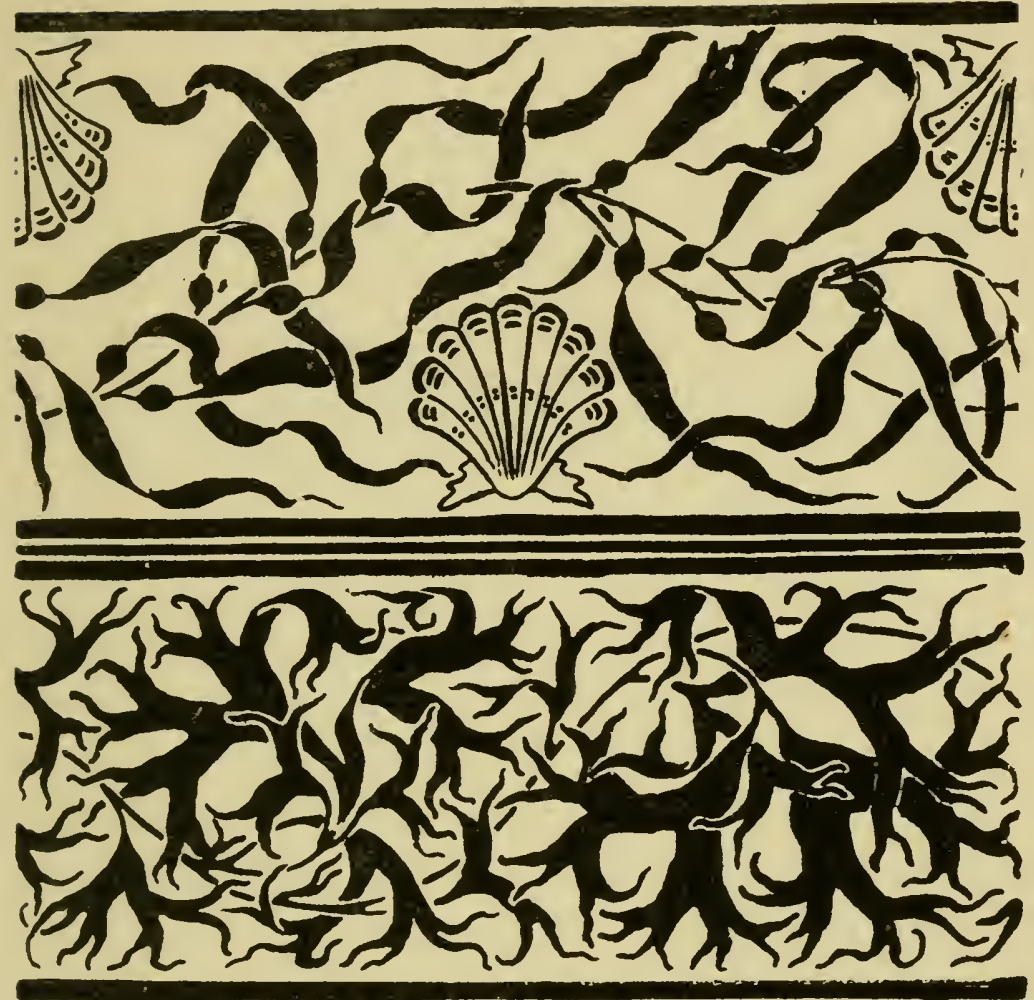
DU. 52 a 145

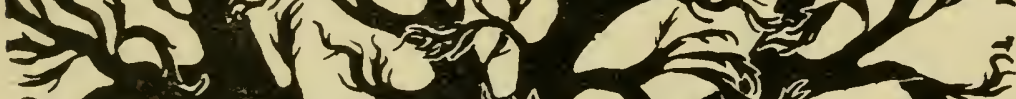
or a - 34 S 7. 1 \%

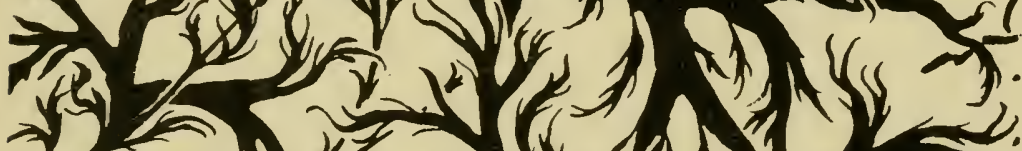

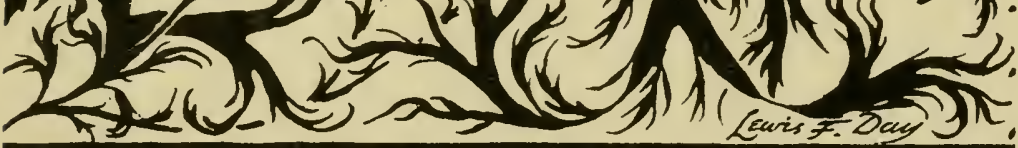

J Akerman Photo-lith London

Seaweed Borders. 



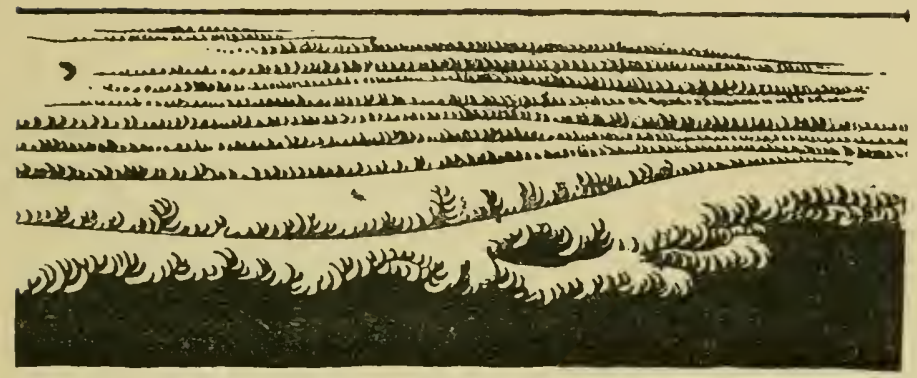

167. Decorative rendering of incoming wave.

In Celtic ornament one sees something of the same kind. It is certain that the spiral patterns on Plate IO7 are suggested by water; as are also some of the carved ornaments of the South Sea islanders. In the archaic Greek diaper on Plate I Io (in which, by the way, there is a strong family likeness to familiar Egyptian diapers), the lotus is put there as if to prove that it is not only taken from, but meant to represent, water. Compare it with the wave and lotus pattern on p. 2 I 7.

There are certain arrangements of waved and zigzag lines which are so universally employed in ornament that one can scarcely describe them as Egyptian, Greek, Gothic, or what not; they are simply ornamental symbols of water, as, for example, in the zodiacal sign of Aquarius.

The Japanese patterns on p. 2 I 8 might almost pass for Gothic; but the distinctive 


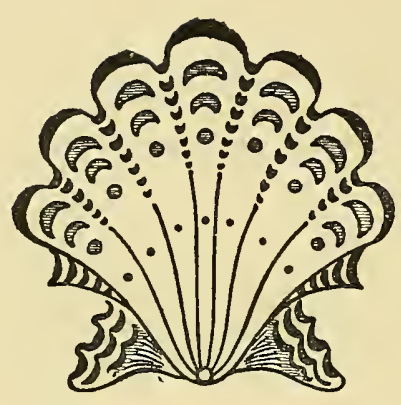

I68. Shell ornament.

thing about the Japanese renderings, and they are very various, is that there is more movement in the water (p. 219); and that the artist turned to account the crest of the wave and the spray (pp. 219 and 220). Take away from the circular wave ornament (164) on p. 219 , the outer frilling of conventional froth, and you have a familiar Greek form. On pp. 2 I9 and 220 the spray is represented by round dots. The rendering of the in-coming waves on p. $22 \mathrm{I}$ is more pictorial in intention, but in effect is ornamental too.

It is only one more sign of the way in which we borrow, and have always borrowed, our ornament, that islanders like ourselves should not have gone more often to the sea shore for suggestions in design. Shells of all kinds are in them-

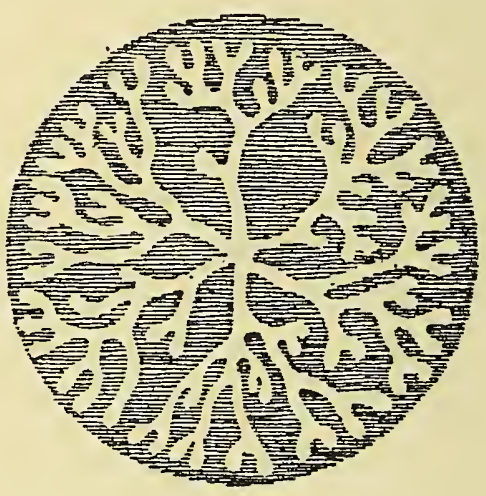

r69. Seaweed ornament. 
Plate 112. s-in

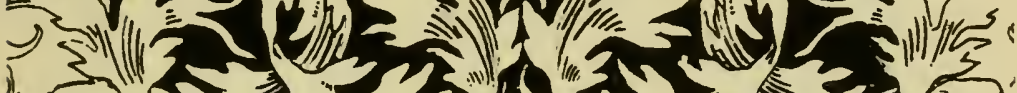
2 1 m

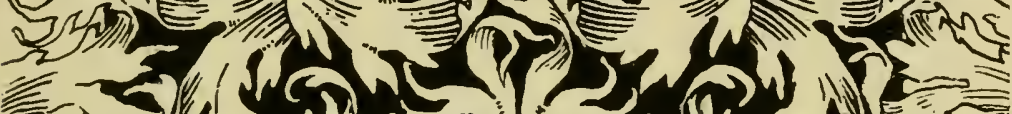

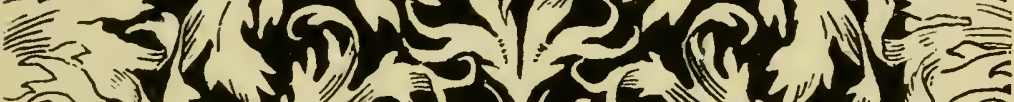
है $\rightarrow 20$ )

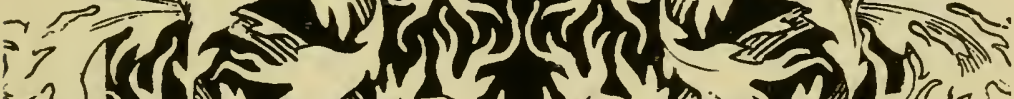

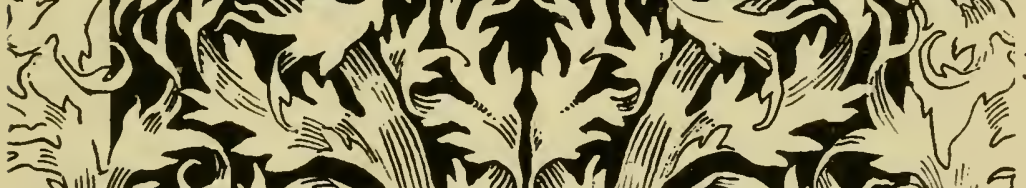

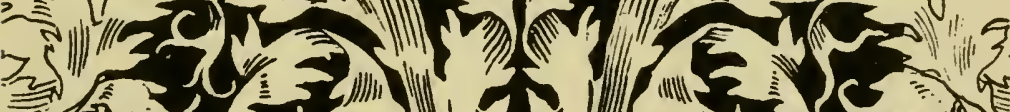

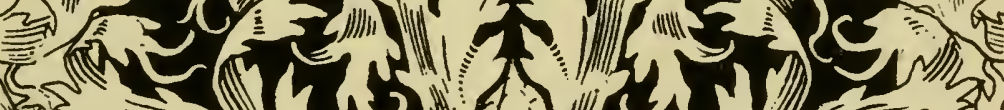
sin $=1(4)$ ins $a$,

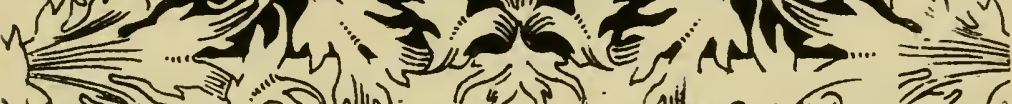
sin C F KELL. PHOTO-LITHO. B.FURMIVAL ST HOLBOAM,E C. 



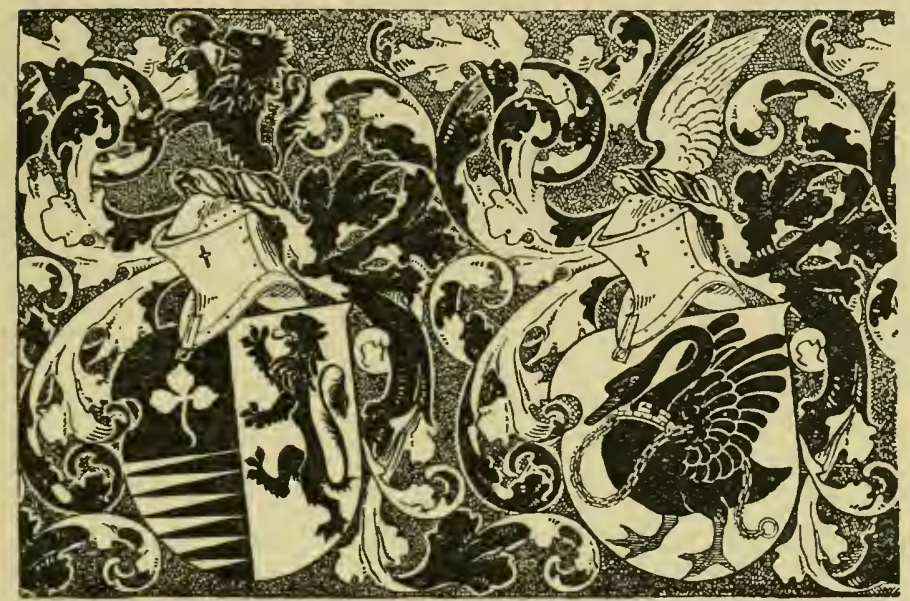

I70. Heraldic mantling.

selves so beautiful in line and colour, that they are quite sufficient to form the motif of ornamental design.

It is, however, mainly the scallop shell which has been turned to account in ornament-for symbolic reasons, originally, no doubt, but also because it is so obviously ornamental. It falls, indeed, very nearly into the lines of the anthemion, of which it has been contended the Renaissance shell ornament is only a variation. But, as in the days of the Renaissance, and of the Roman Empire before that, it was quite a common thing to supplement decoration in mosaic or stucco with actual cockle-shells embedded in the walls and pillars, it is natural to conclude that 


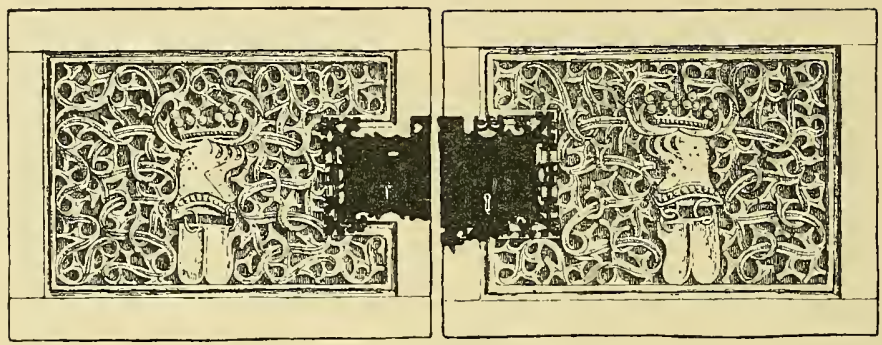

I7 r. Heraldic mantling-wood carving.

it was thence the sculptor and the painter derived their inspiration.

The shell is used in connection with a flowing seaweed pattern on Plate III, on which are also other varieties of seaweed borders. But it would have been better to have used some other form of shell. Toujours cockleshell palls upon one at last: one would prefer a limpet, or a mussel, anything for a change.

A more distinctly ornamental rendering of seaweed is given on Plate II2, in which the scroll, conventional as it is, does not branch either accidentally or after the manner of any flower, but is forked as seaweeds and lichens are. That form of growth is shown also in the Japanese ornament on p. 222.

It is strange how we are inclined to branch our scrolls always in the way suggested by vegetable growth. Even in the heraldic mantling of the Middle Ages, where the idea was to represent a scarf slashed about and cut into 
Plate 113

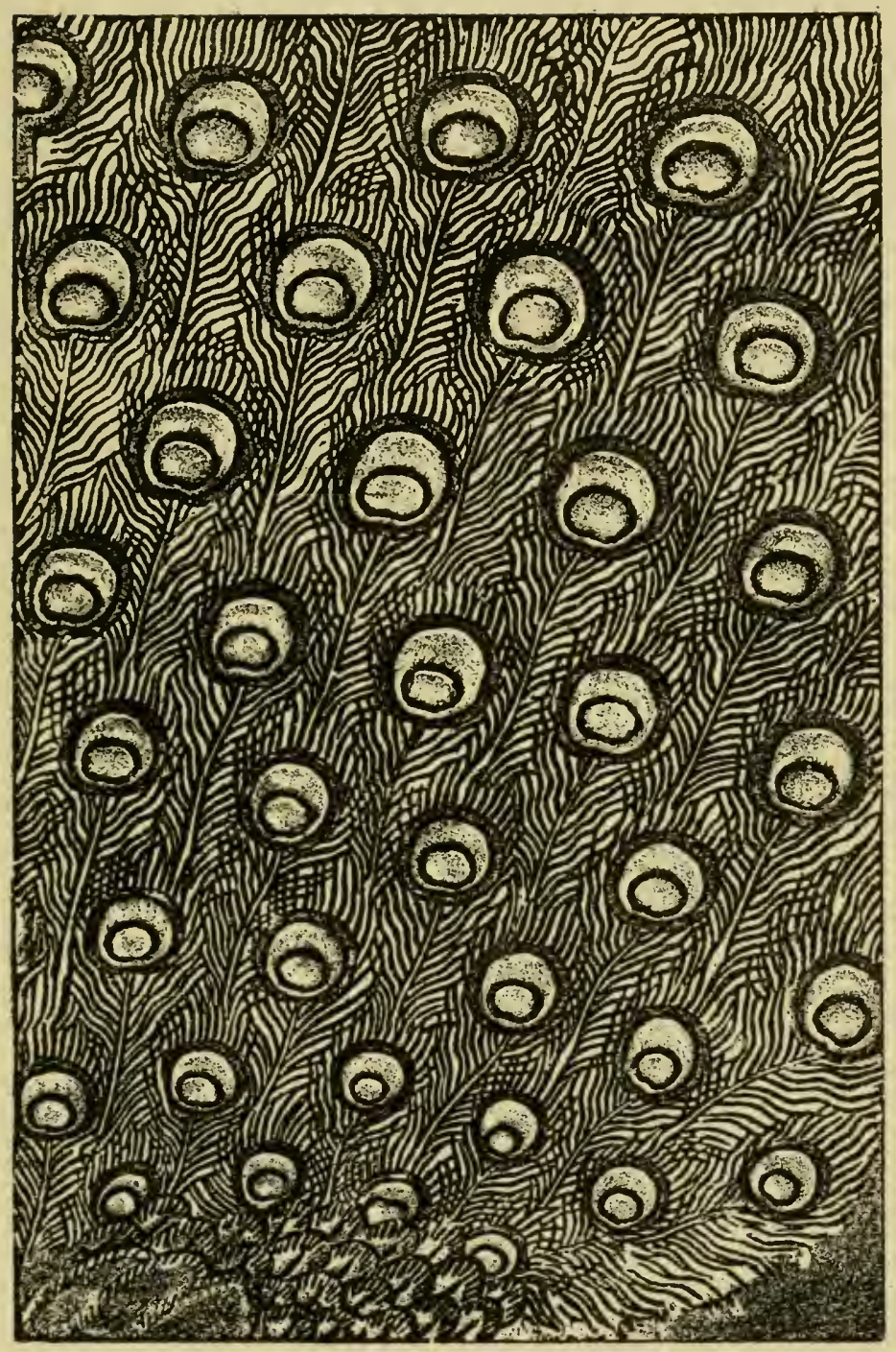

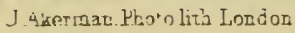

Peacock Feather Pattern,-Japanese. 

ribbons, the shreds develop into something so very much like conventional foliage, that the idea of drapery is often altogether lost. It is so in the frieze on p. 223 ; and in the old German work on p. 224, where it takes almost the form of strapwork, the strapwork is uncommonly like what in Mediæval work of the same period does duty for foliation.

Birds, natural and conventional, are of such common occurrence in ornament, that it seems strange their feathers have not been put to more use in design-more especially as feather ornaments were always largely used, not only among savage tribes, but in civilised countries from China to the British Isles-the very bedsteads of our ancestors were tricked out in plumes, in a way which speaks volumes as to their entire unconcern about hygiene and even cleanliness: there are rooms of state in many a noble mansion which can never have been kept wholesome for long, and are something to shudder at now.

Feathers, too, were used as emblems of sovereignty - those on which the vultures perch on p. I 88 have some such significance of course. For all that, with one exception, they have not been adequately adapted to design. That exception is the peacock's feather.

It is interesting to compare the not too 
naturalistic rendering of it on Plate I I3, with the more strictly ornamental modifications on Plate II4, and with Talbert's modern Gothic inlay pattern below.

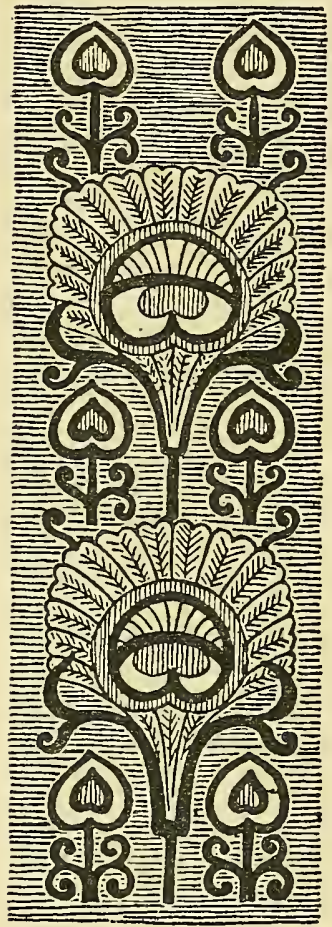

172.

Inlaid feather ornament. B. J. Talbert.

It is clear that the Italian versions owe something to Oriental inspiration. In the least natural of them there is always some character of the original. The majolica patterns, in particular, are in their unlikeness yet so like. The Coptic patterns (p. 227) and the Persian tile (p. 228) are further removed than ever from actuality, but still the peacock's feather is unmistakable.

In all of these cases the feather of itself suffices for its ornamental purpose. In Plate I I 5 a new principle comes in: there is a sort of connecting stalk with tendrils, an element of scroll-work not quite in keeping with the feathers. But the way they are rendered is interesting, and the effect is decorative enough. 
Plate 114.
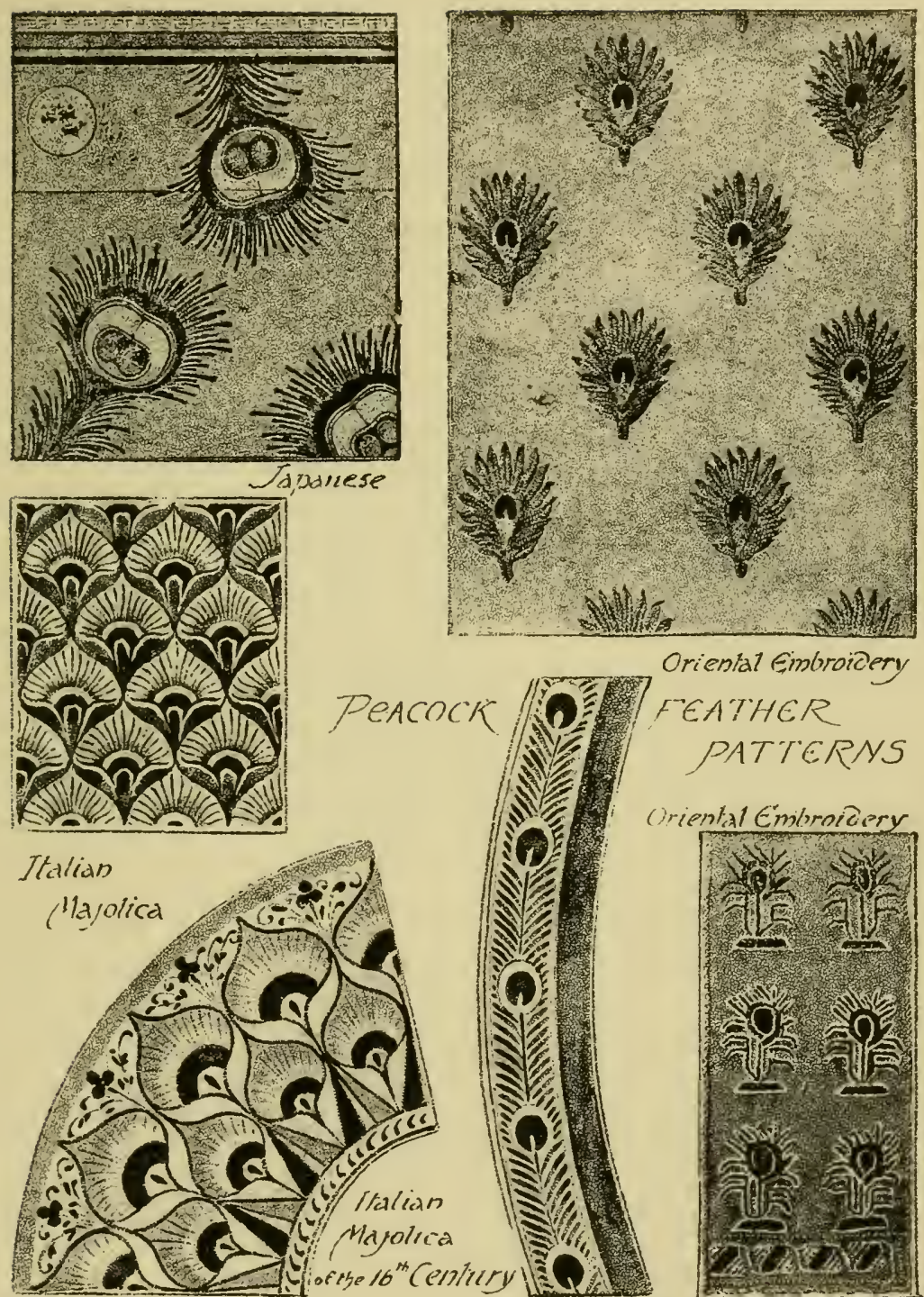

PEACOCK OEVI FEATHER

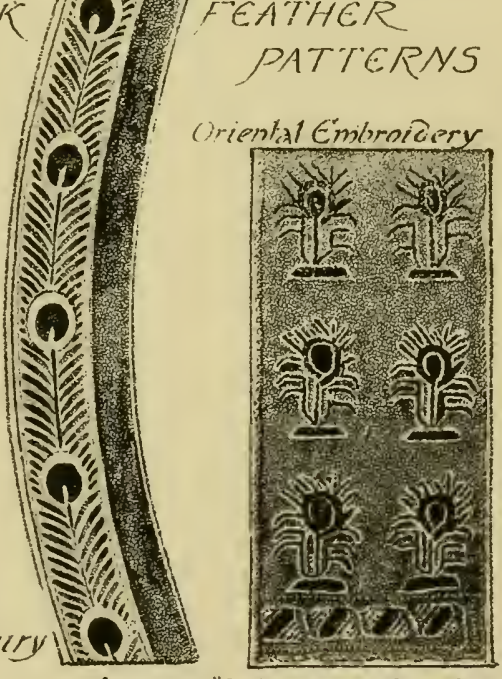

'Pnoto-TInt', by James Akermen London, W C.

Peacock Feather diapers. 

It is a far cry from work of this kind to the Rococo ; but one can hardly look at Plate I 6 without seeing in this more than usually graceful example of ultra-florid late Renaissance scrollery, a distinct resemblance to the ostrich feather. And, knowing how State carriages were bedecked with plumes (the
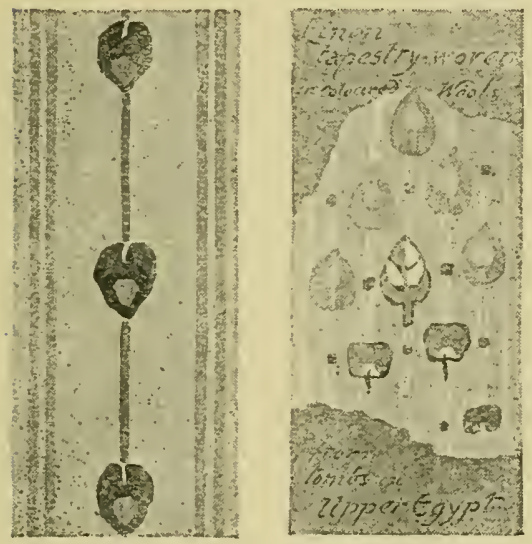

173-4. Coptic feather border and diaper.

custom comes down to us in the conventional hearse), one can easily imagine how it occurred to the coachbuilder to carve feathers somewhat less flimsy, which, moreover he could gild! The very notable thing is that this feathery scroll-work is not so unlike all other Rococo scrollery.

A not unusual form of ornament, or substitute for it, is the grouping together of inanimate things, trophies, \&c., as in the pilaster panel on p. 229.

In connection with certain commemorative monuments, there is a sort of reason for the introduction of emblems; and on occasion, as 


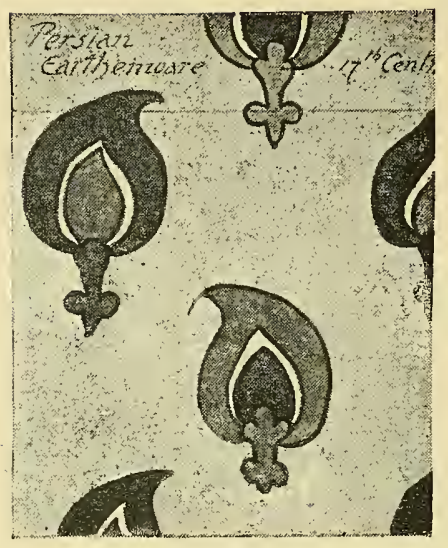

175. Persian peacock feather pattern.

for example in the Doria Chapel at Genoa, shields, helmets, breastplates, swords, and other insignia of war can scarcely be called out of place; but the conditions of ornament are not fulfilled by stringing such things together down the length of a pilaster. The composition on p. 229 may or may not be ornamental-but it is not ornament. Whatever excuse there may be in Ancient art for the sacrificial emblem which occurs at the top of the pilaster, it has no significance, and no excuse in work of the Renaissance.

In work of our own day, the bull's head reminds one too much of the butcher's shop, and the Classic ox-skull is still more unpleasantly suggestive. Artists of the Renaissance, however, seem to have seen no reason why they should not treat the skull ornamentally. To many of us the rather graceful detail on p. 230 loses all its charm when we realise that the cartouche is really a skull.

It is possible, of course, to dispose almost any series of objects, natural or artificial, in 
Plate 115

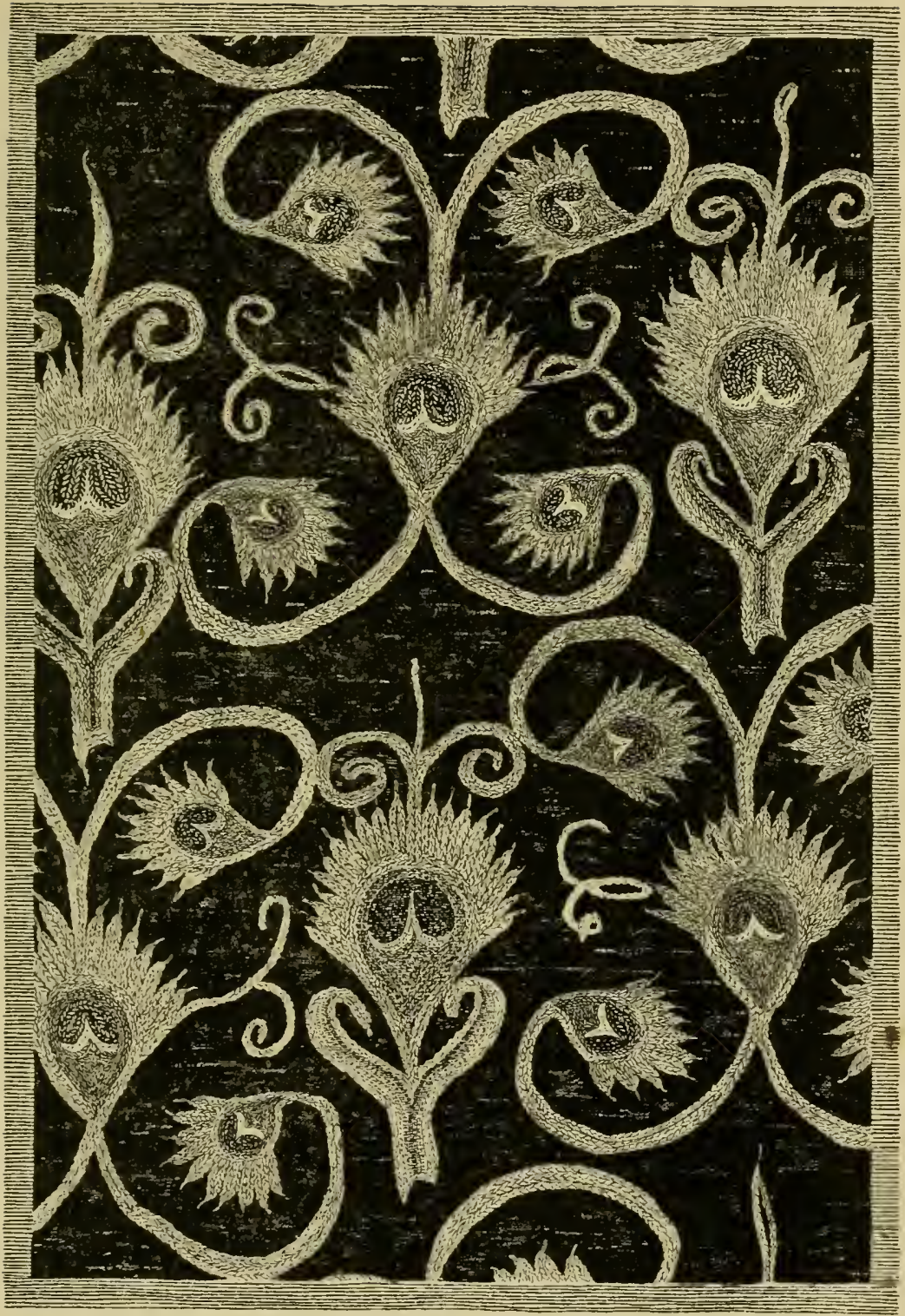

J Alerman, Photo.lith London

Peacock Feather pattern, Turkish. 

such order as to present what passes for an ornamental appearance; repeat a shape several times over, and it forms a sort of pattern; but that is not exactly ornamental design.

The occasional introduction of such a thing as a cornucopia (Plate 99), or a vase (Plates I 5, 57, 96, \&c.), is not only useful sometimes as affording a convenient starting point for growth, but it may be the means of introducing a mass which is very valuable in the composition. In that respect the recurring vases in the centre plaque on Plate 18 , and in the border on Plate 25, are useful, casually as they occur in the design.

The most satisfactory of such vases are the least realistic. In Persian art in particular we see the thing reduced to the mere outline of a vase filled in with ornament, which by its treat-

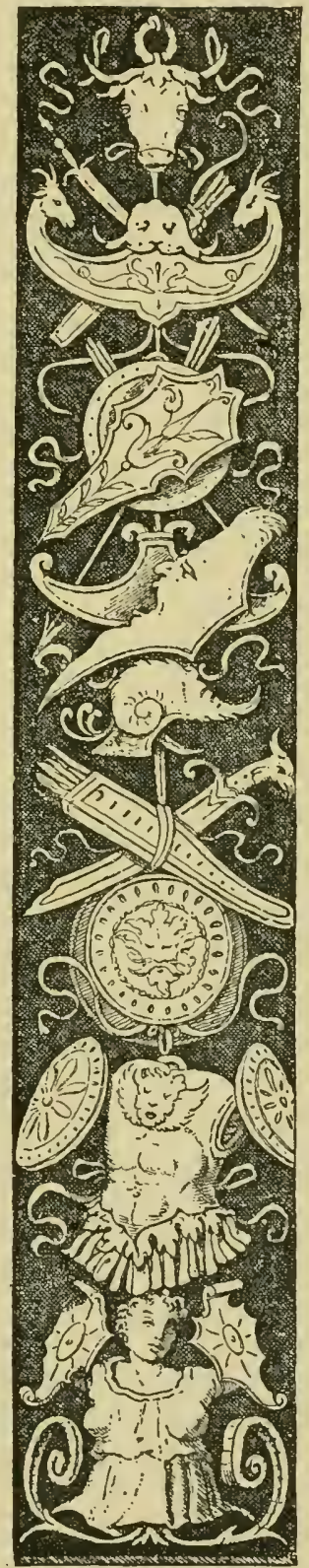

176. Trophy panel. 
ment contrasts with the floral ornament springing from it. An equally arbitrary rendering of the vase occurs on Plate 28 , the pattern on which must be taken to represent the water in it.

The shield, the tablet, and the cartouche are so conspicuously useful in ornamental composition, that at certain periods of design artists seem with one accord to have relied

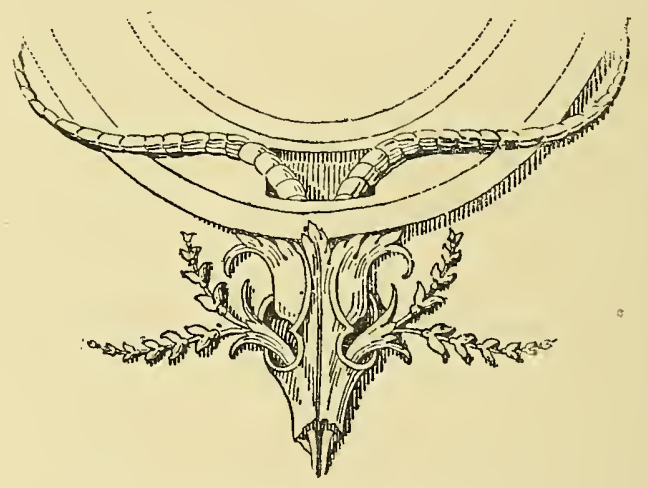

I77. Renaissance skull ornament.

upon them, to the exclusion of other and more fitting devices.

Used for its own sake, or merely for the convenience of composition, shield, tablet, or cartouche becomes a mere stock property, a shift or stop-gap in design. Its introduction is quite happy only when it is called for to bear a coat-of-arms, an inscription, a cypher, an emblem, or whatever may form 
Plate 116

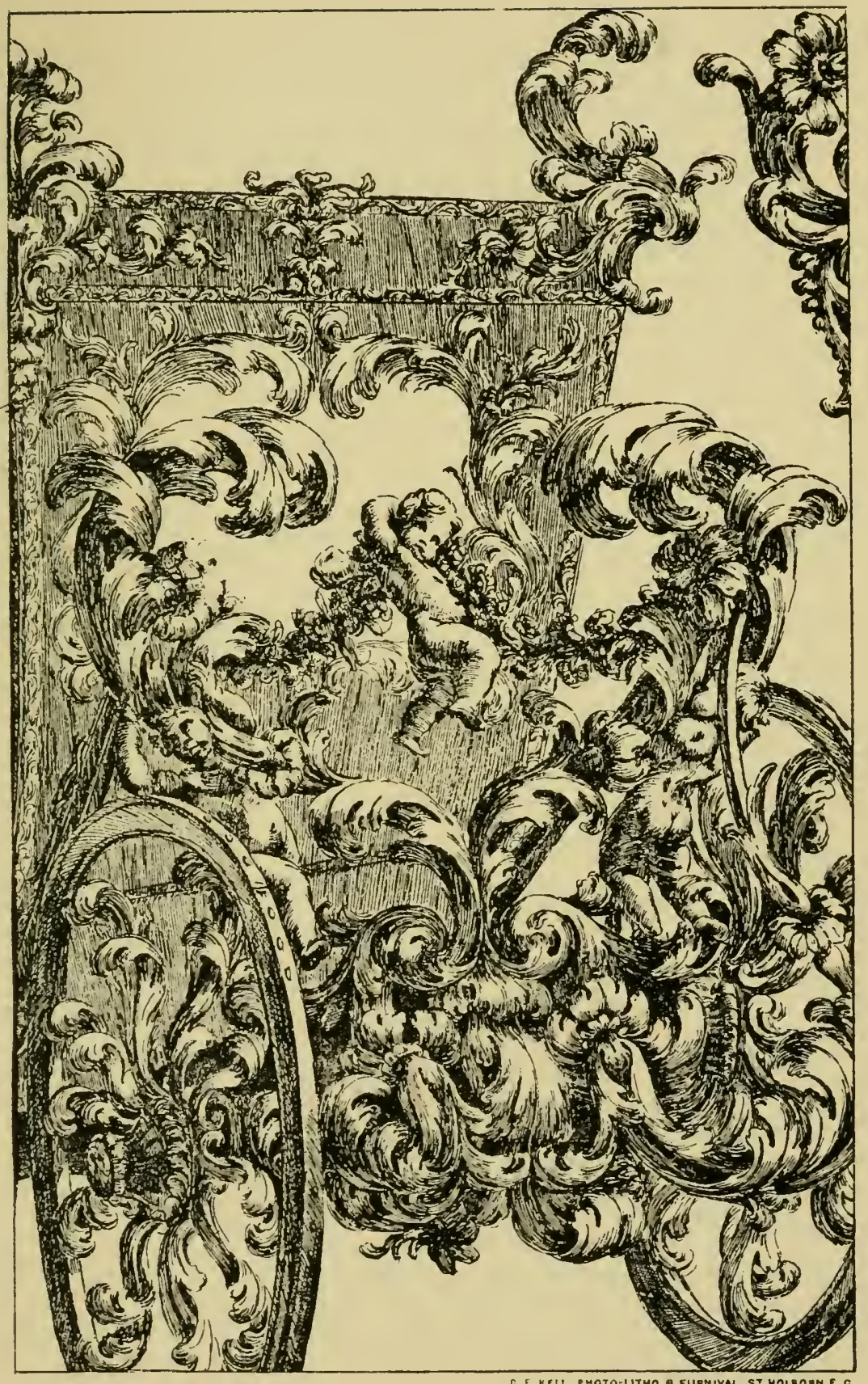

Rococo Scroli work, Passarim 



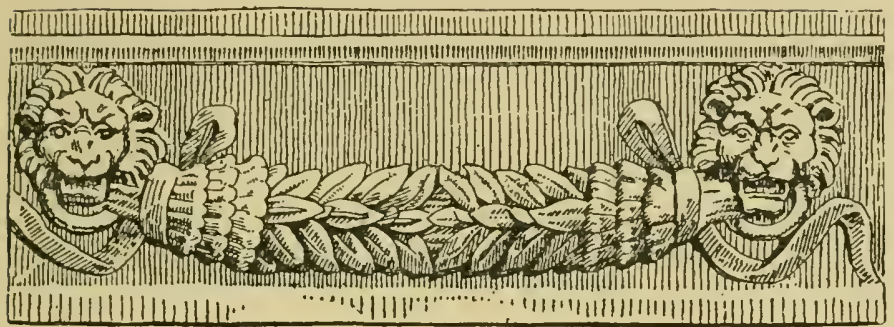

178. Early Phonician wreath.

part (and a prominent part) of the decorative scheme.

Lifeless things have thus their place in ornament; but they need to be used with great discretion. This applies also to what is more generally called still life. Bunches of cut flowers are not in themselves ornament, and the abundant use of them argues little faculty of design. The garlands of fruits and flowers which trail over late French Renaissance art, are at best a makeshift, fit only for a frivolous French boudoir. But that a wreath may be used in a manly way is shown in the early Phœnician ornament above, which is dignified enough in design even for the decoration of a sarcophagus. Nor is there any fault to find with Mr. Fox's swags on p. I 80.

There is nothing to wonder at, that in countries where vines and roses and all manner of flowers are trained to grow in 
garlands, and where it is the custom, as in Italy to this day, to hang strings of fruit and maize on the walls of the houses to dry in the sun (where they form a delightful decoration), the idea of something of the kind should have found its way into ornament.

It was not altogether a bad idea, and it had this to recommend it, that it afforded lines not otherwise to be got, and lines, too, very valuable in decoration.

That the device has been very much abused is only too obvious. We cannot afford lightly to give up the quality of vitality in ornament; and the festoon or swag is open to the objection that it is at best "still life," and as such inferior in interest to living, growing form.

The inherent sinfulness of the device is an invention of the purist. The offence is, once more, mainly in proportion to the realism. The more a swag looks like weight, the more it wants suspending ribbons to hold it up and nail-heads to attach it to, the less endurable it is. There is no occasion to waste one's wrath over wreaths so absolutely ornamental in intention as those of Nicolaus Drusse in Plate I 7 .

The mere suggestion of a garland, such as you see in quite early Renaissance work, can offend no evenly balanced mind. It is often 
Plate 117.
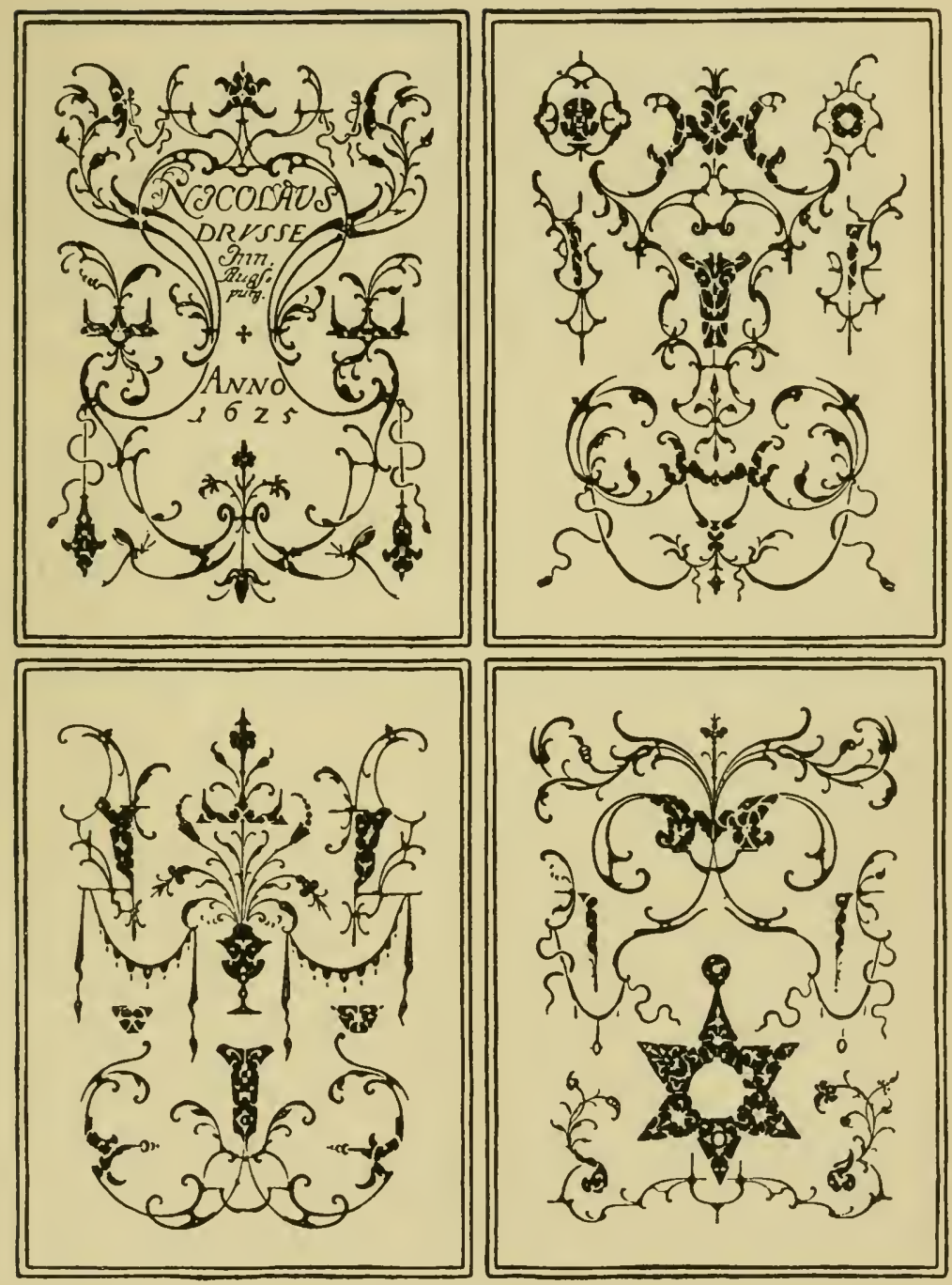

17. th Century Scrollwork. 



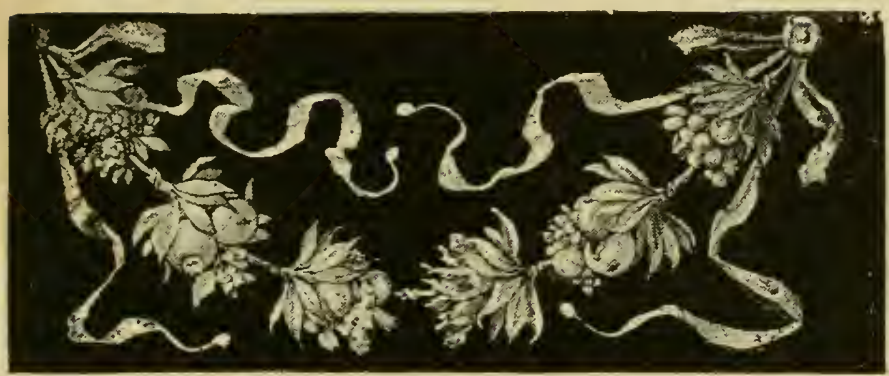

179. Swag of fruit bunches.

little more than a border of leaves and fruit, strictly confined, it may be, within the lines of parallel mouldings. It looks as though the sculptor had felt the need of a break in this border, and so had crossed it by a ribbon at intervals. Perhaps he felt there should be some beginning and some end to his border, and so he finished it with bows and loose ends. You cannot help seeing that his starting point was not so much the idea of a wreath as the idea of due enrichment. That his design resolved itself into a wreath was something in the nature of an accident. It happened so.

In later Renaissance swags you are often painfully aware how proud the artist was of his fruit bunches, and especially of the masterly way in which he could carve them. There is, it must be owned, a certain dandified selfsufficiency in the not ungraceful swag above, 
with its flying ribbons occupying the vacant space.

Admitting the trivial purpose to which they have been put during the last century or two, I would like to say a word even in favour of ribbons. Nothing could well be worse than millinery in stone, in wood, or in serious painted decoration; but the frippery of the later Renaissance is no reason why we should not avail ourselves, within limits, of the grace of line suggested by a strip of ribbon floating in the air: that too is nature. Only preserve us from actual millinery. The Gothic variation of the ribbon or label is dignified enough and admirably decorative.

It is pride of execution, and especially of realistic execution, which is the real pitfall in the path of ornament. Even what pretends to be no more than a memory of something done before, should appear to be always the outcome of the architectural or other conditions, designed to go just there, and introduced because just such enrichment was wanted.

It must not be understood, however, that the reproduction of merely architectural features by way of ornament, is here advocated. The Pompeian decoration on Plate II 8 is indeed graceful and delicate, more especially as com- 
Plate 118
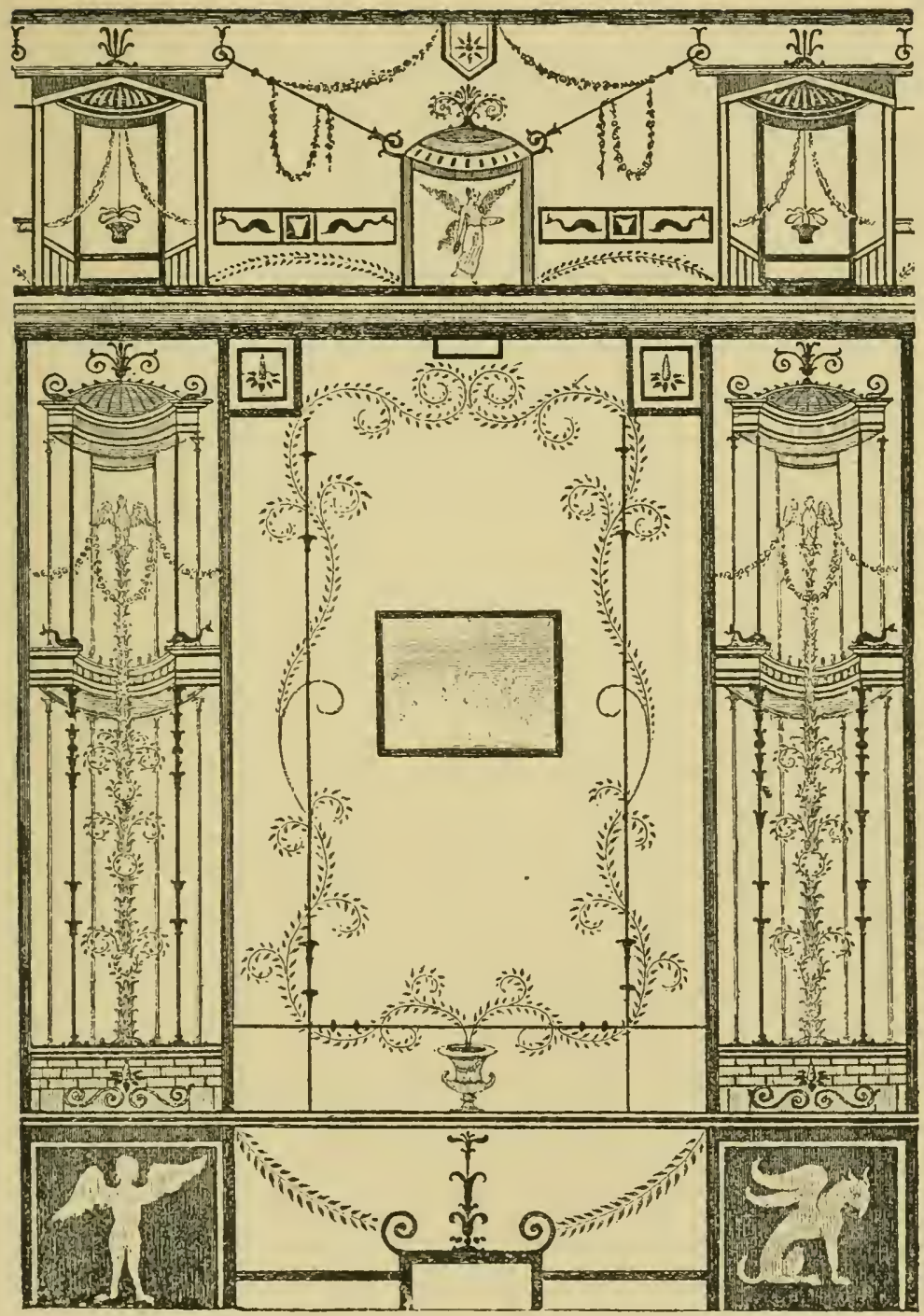

Pomperan Wall painting. 

pared with the "canopies," which were the stock in trade of so many Gothic craftsmen; but, whether in true or (what was more usual) false perspective, such constructions are a very poor substitute for design. They have been employed pretty freely, and will be so again no doubt. But the unprejudiced taste is so little likely to be led astray by their attractions, it is hardly necessary to point out that the device is really banal beyond endurance. 


\section{XIV.}

SYMBOLIC ORNAMENT.

ORNAMENT has primarily nothing to do with story, poetry, or other purpose than that which it sets itself-the purpose, that is to say, of ornamenting some given space or thing.

It may be quite true that ornament which does no more than this deserves no very high place in our esteem. The artist very naturally magnifies art; and to the craftsman craftsmanship is of the first importance; but to him only. To mankind in general it is the man behind the art that is interesting; and the Philistine is not such a fool, after all, in asking of the artist who claims his attention that he shall have something to say for himself. When the everlasting burden of his song is only, "See what an artist am I!" we soon weary of that monotonous brag, even though it be warranted by some degree of achievement.

The craftsman very rightly insists upon 
Plate 119

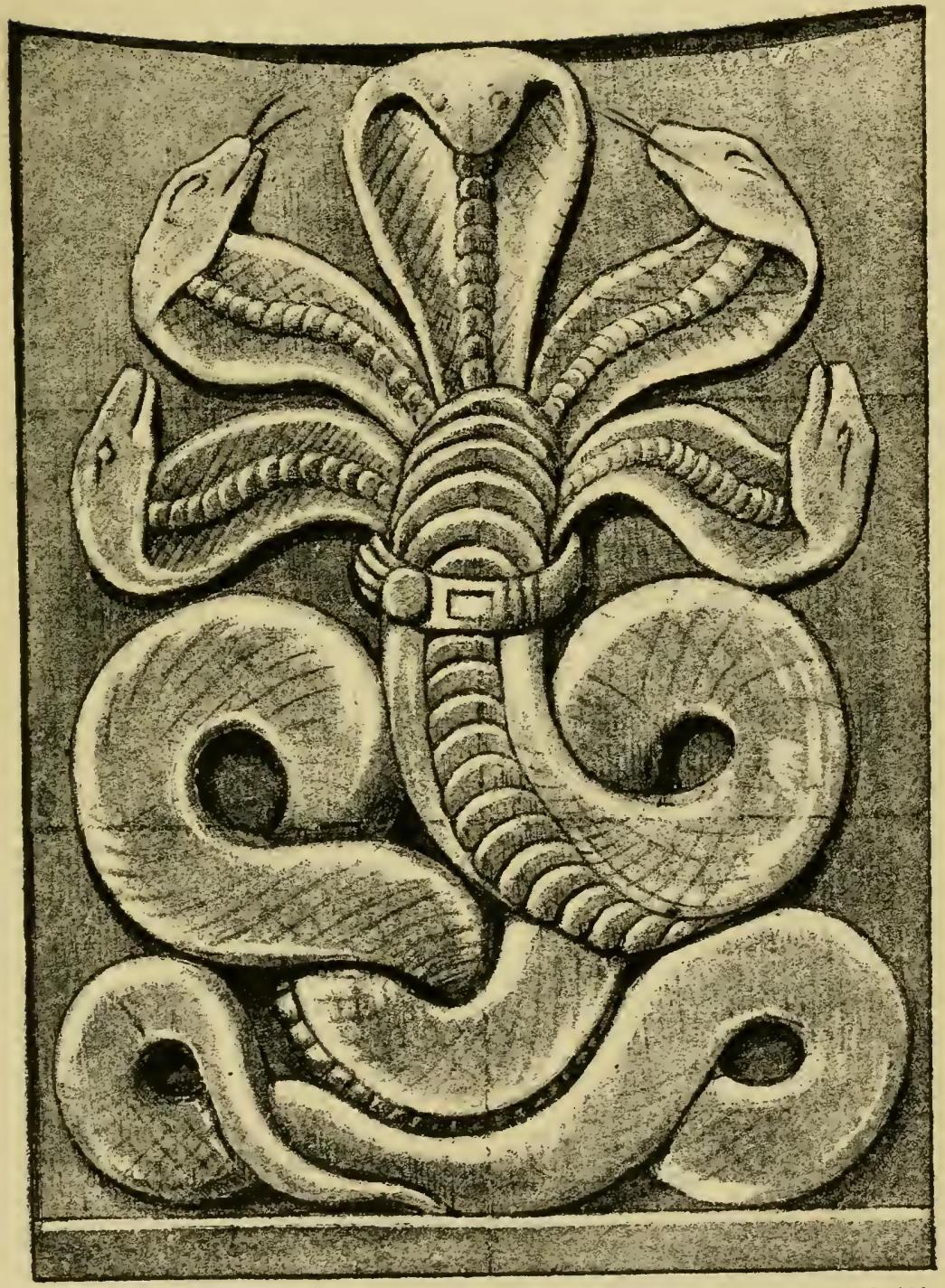

"Рното-TINT", by Jam... Akerman londen W C

Indian Naga, Stone carving. 



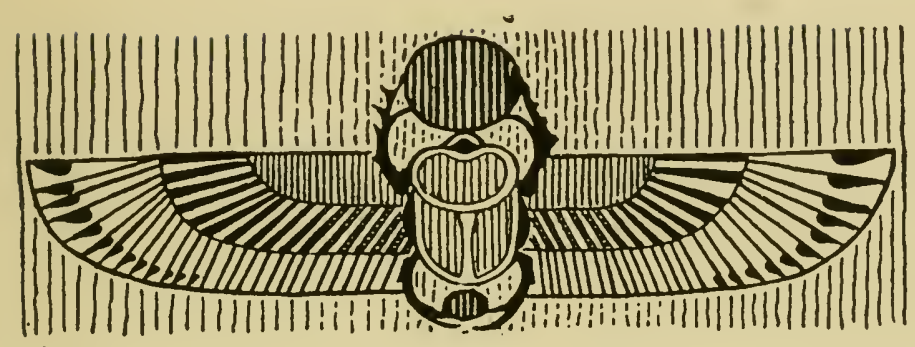

180. Egyptian sacred beetle.

adequate craftsmanship. The rest of the world finds craftsmanship inadequate, and asks for something more.

We find accordingly that in ancient and mediæval ornament there is usually an undercurrent of symbolism. Indeed, one might safely say it is always there, and that when we do not see it, it is only the distance that dims its meaning to us. There is probably no single detail of ancient ornament to which a symbolic origin could not plausibly be assigned by those who give themselves up to the interpretation of such mysteries.

Eastern ornament, in particular, is apt to embody some sentiment or meaning. Egyptian art was, practically speaking, hieroglyphic picture-writing (Plate 79) of the same kind (only much more nobly developed) as the totems of the North American Indians.

Persian ornament, again, is always inspired by some poetic notion-it is, in fact, a sort of 
language of flowers. The ornamentist has in his mind a bed of roses and tulips (Plate 65), a garden, and so on, and combines his flowers, we may reasonably suppose, so as to convey to Persian eyes a distinct sentiment.

In the ornament of other Eastern countries there is a kindred spirit of suggestion. The Indian lattice of which part is given on Plate 77 , is plainly intended to convey the notion of a forest.

In a very different way
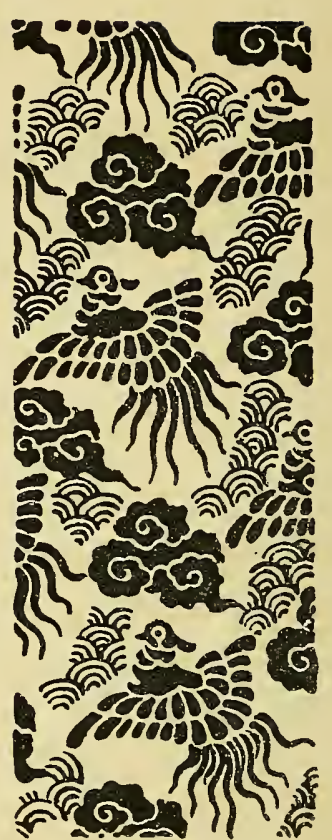

18r. Diaper of waves, clouds, and sacred birds.

of his own the Japanese, again, loves to put some meaning into his pattern (Plate 109), and in a mere diaper (as above) will manage to convey the suggestion of fire, air, and water.

Everywhere, moreover, the symituols of re. ligion have been turned to account, from the naja or many-headed serpent of Buddhistic worship

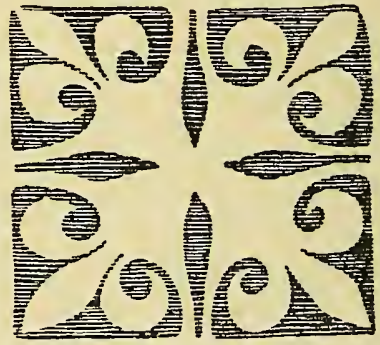

182. Cro-s of fleurs-de-lis. 
Plate 120

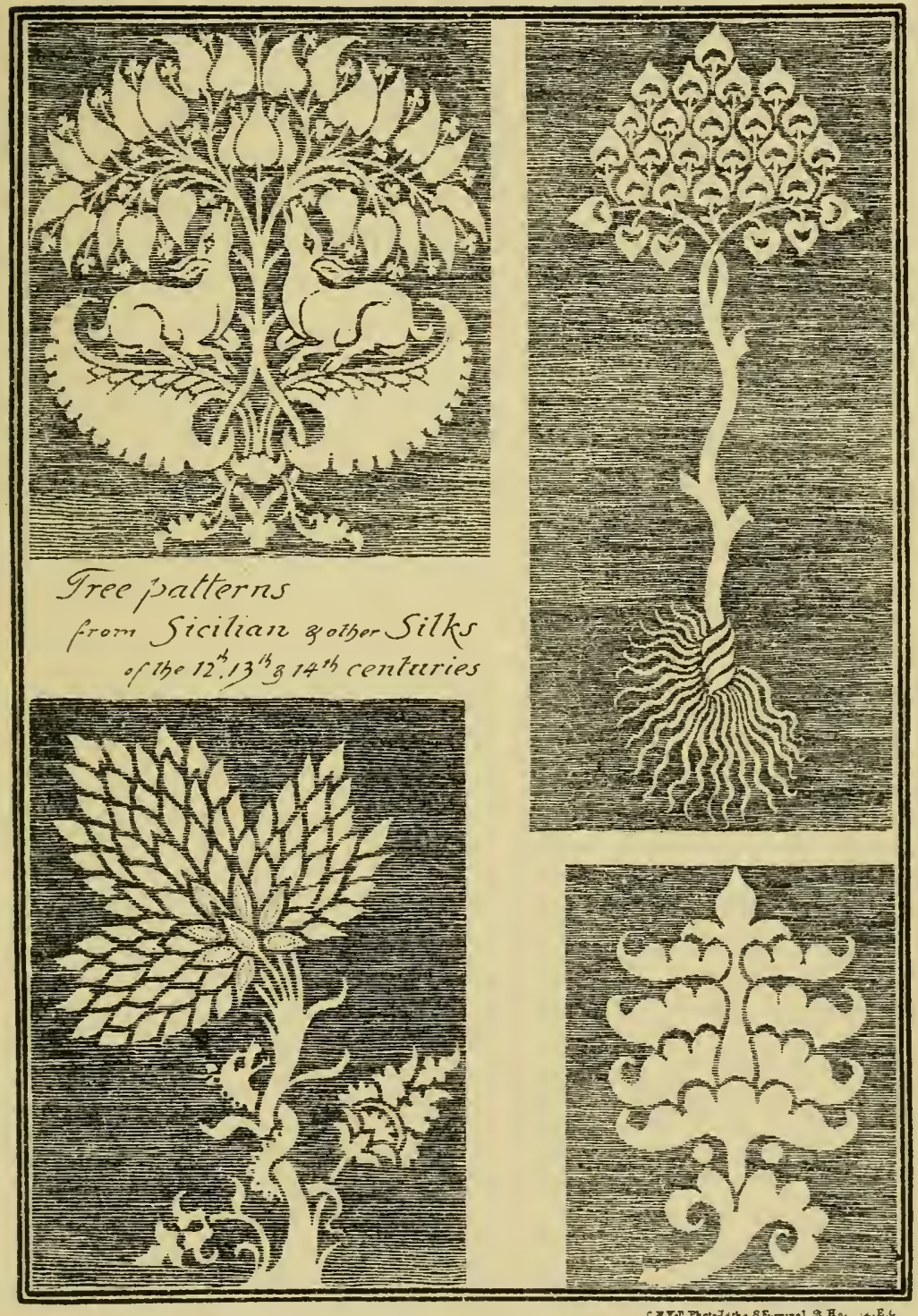

Conventional Trees. 



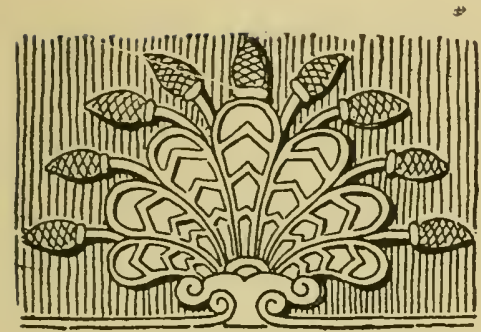

183. Assyrian sacred tree.

(Plate I I9) to the cross of Christianity and the crescent of Islam. (The cross is combined with the fleur-de-lis on p. 238.) The tree and serpent, and the tree alone (Plate I2O) remain indeed into mediæval times characteristic ornamental features, very common indeed in Byzantine and Romanesque ornament (p. I43); the symbol lingers in Sicilian silks down to the fourteenth century.

In the earlier rendering of the tree of life, which we see in Assyrian sculpture

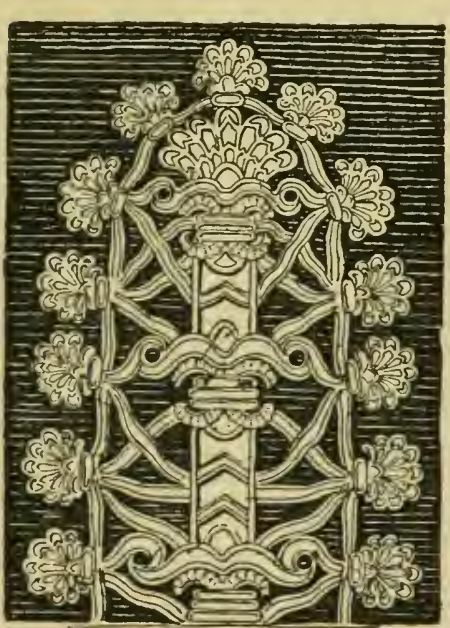

184. Assyrian sacred tree. more or less in the form of palm fronds, we have the precursor, if not the parent, of the Greek anthemion (see p. I58); and in the winged bulls which sometimes kneel in adoration on each side of it, the prototypes of the Greek gryphons. 


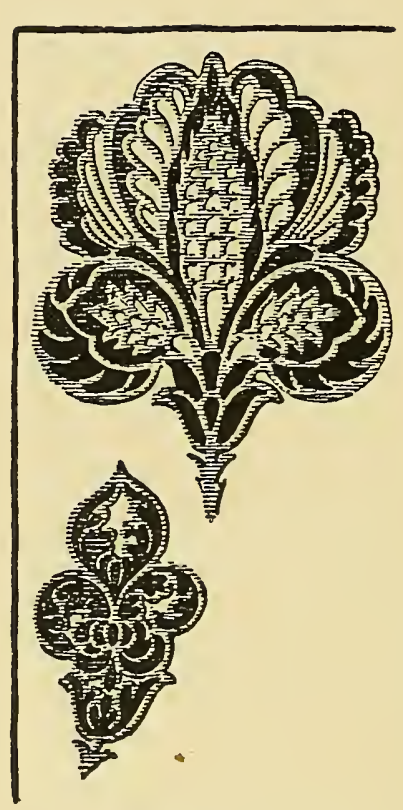

185. Iris or fleur-de-lis?Ith century Venetian.

The winged globes, the sphinxes, the sacred beetles and the like (p. 237), together with the Nile plants, determine the very character of Egyptian design.

Emblems of sovereignty again, and heraldic badges of all kinds -the rose, the lily, and the fleur-de-lis, for example (Plates 42, 43, 63, $64,121, \& c$.) - have been the "motifs" of ornament down to quite recent times, when symbolism has given way to a realism altogether inadequate to supply its place in ornament.

A symbol must be removed from nature, or it suggests not the idea symbolised but the thing used as symbol. A realistic Agnus Dei, let us say, suggesting the sheep-pen, is

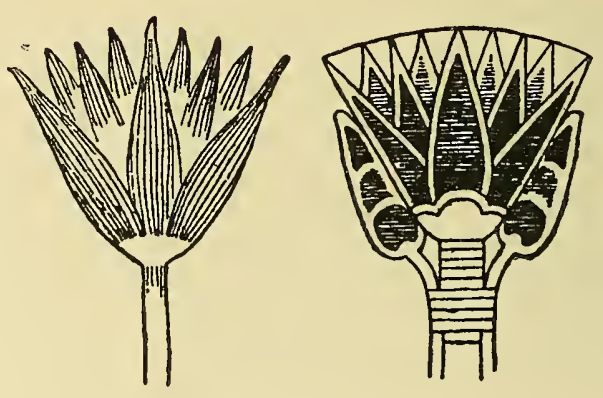
186. Egyptian symbols. 
Plate 121.
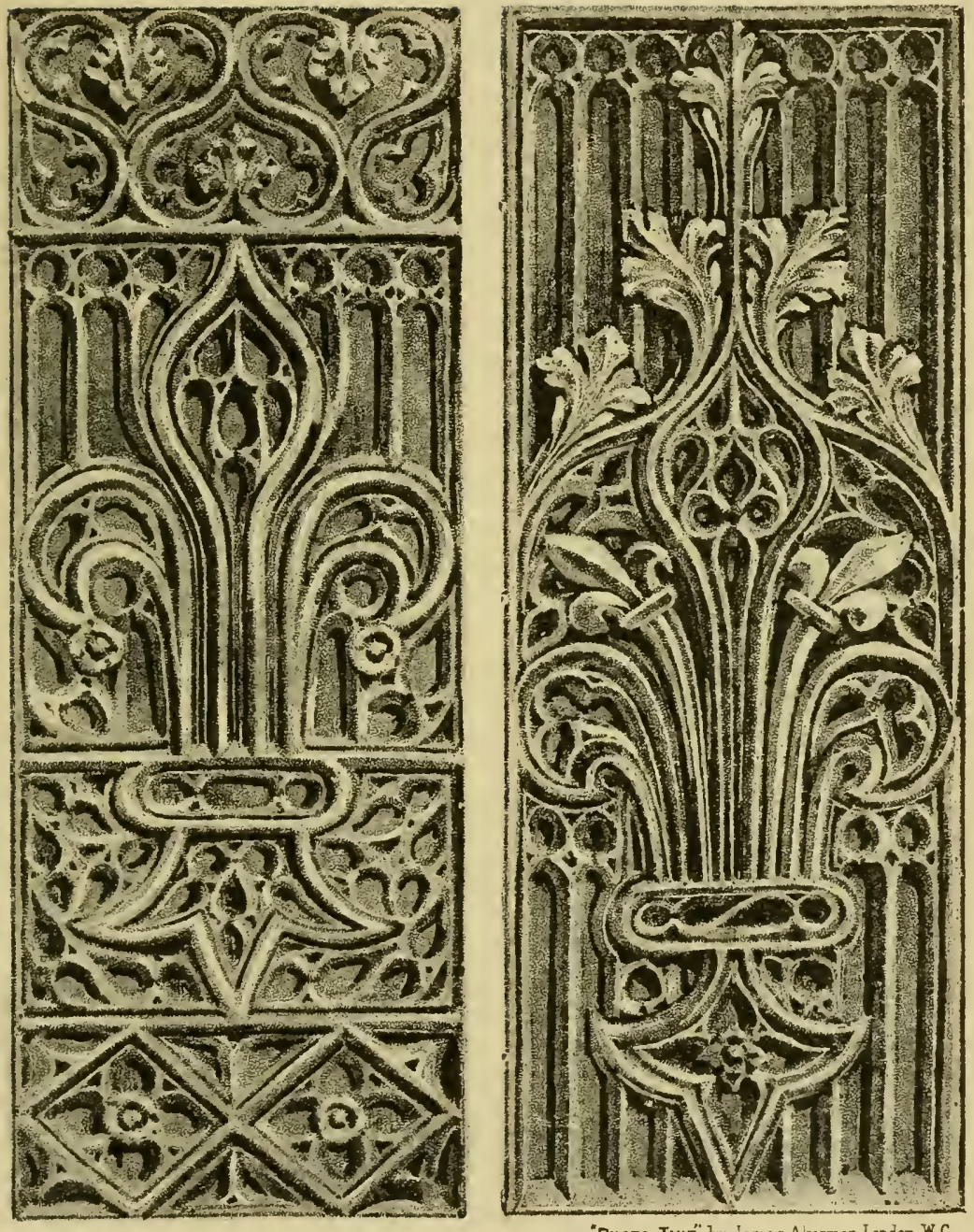

"Pnoto-Tint", by Jumes Akerman London. W. C

Late Gothic Fleur de-lis-Tracery. 

an absolutely irreverent rendering of the emblem. So, again, the uppermost of the embroidered flowers on p. 240 is clearly not so much a

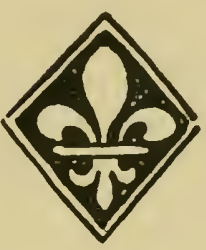
fleur-de-lis as an iris. Compare it with the one below it, with Plates 44 and I2 I, and with the flowers on p. 45, and you will see that very plainly. There are further examples of Gothic fleurs-de-lis on this page.

Of the usefulness of heraldry in ornament there is no possible doubt, not even in the minds of those who least respect the blazon of the herald as a title to distinction. The very need of introducing helmet, shield, badge, motto, or what not, has led to fresh forms of decorative design, admirable in themselves, apart from any interest there may be in tracing out their meaning. But concerning heraldry, I have already said what I had
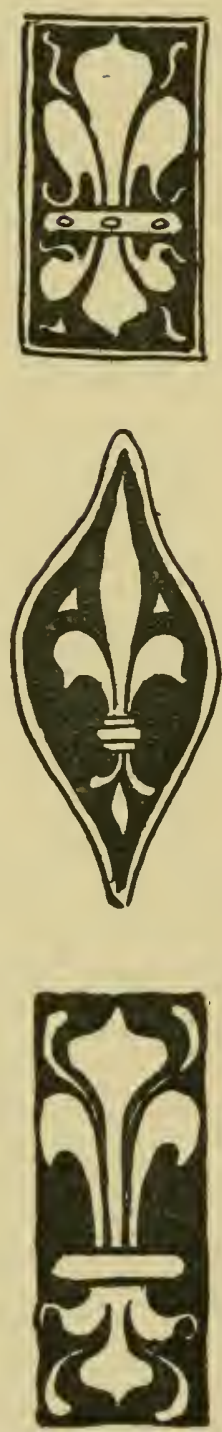

187. Gothic fleurs-de-lis. to say elsewhere.*

* 'Some Principles of Every-day Art,' p. 6.3. 
The mere repetition of symbols, even when conventionally rendered (as in the Greek border of eyes, p. 243), is not a happy form of ornament, if indeed it can be called ornament at all. But the additional interest imparted to mere foliage by the introduction of occasional badges and the like (opposite), needs no pointing out.

The quarrel we have with the modern Philistine is not that he wants something more than technique, not that he is too exacting, but that he exacts mainly the common-place.

Whether he ask
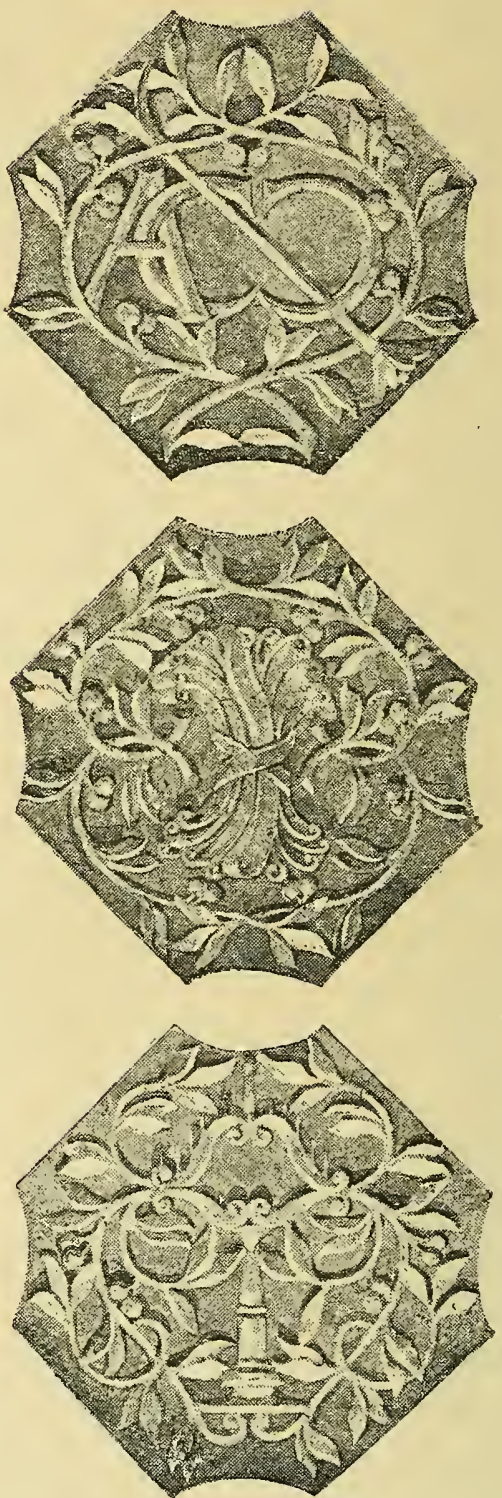

188. Heraldic badges-I6th century, Mantua. 

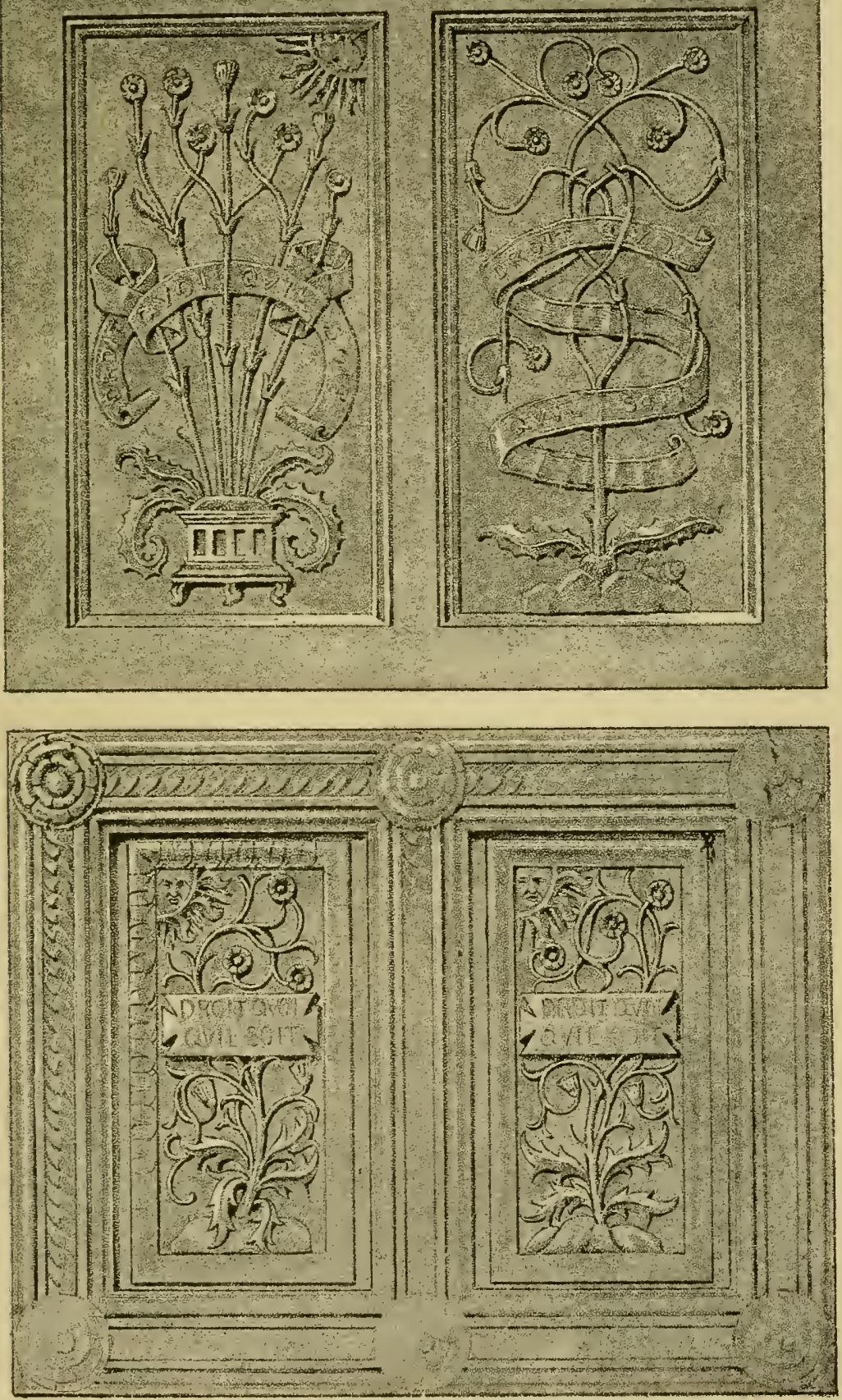

Pното-TInt, by James Akermon London W $C$,

Marguerite Panels, Wood Carvind 

for poetry or for prose, it is something very obvious that he demands. And it must be owned that we are only too ready to supply what he wants; from which readiness may be inferred

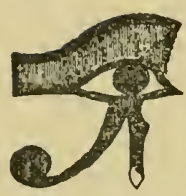

189. Symbolic eye ornamentEgyptian. that, if there is no great demand for subtle thought or graceful fancy in design, neither are thought and fancy precisely abundant in the market.

Far be it from me to urge the prosaic to try and pump up poetry. Poets will try for it, poorly as it may pay-that is in pounds, shillings, and pence. For the rest, we live in a world of prosaic people who will miss nothing in our work, be it never so uninspired.

Whatever an artist has to say he will say in his art. A thoughtful man is never content without putting meaning into his work, not that it has any commercial value, but for his own satisfaction: to him it would not be complete without it. If he make use of

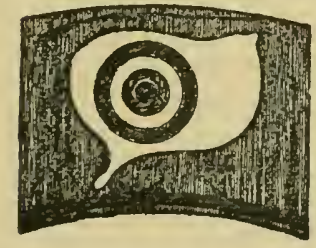

rga. Segment of Greek border of eyes-
from a painted dish. scrolls, flowers, garlands, animals, amorini, and so on, it is not as the stale "properties" of Classic or Renaissance tradition, but with significance always-a significance which would by 
no means justify poor design, but which undoubtedly enhances the pleasure we derive from good pattern.

Neither have they (if there be such) who care solely for grace and beauty of design, any just cause of complaint if the artist, over and above the full weight of decorative design, throw in, to my delight or yours, what may be to them a superfluous wealth of meaning - so long as it in no way interfere with the essentially ornamental character of the design.

That is the condition of conditions. Symbolism must not interfere with art. It will not supply its place. Yet in the hands of an artist it may be made to minister to the main purpose, and at the same time to raise design to a point of interest which pattern in itself always fails (and, as an ornamentist, I may be allowed to say very naturally fails) to awaken in the general mind.

On page 245 is a reduction from one of a series of borders framing a selection of texts "Touching the Resurrection," in which the ornament was based mainly on the idea of seed-vessels. In treating the maple seeds the intention was not only to remove them from nature but to emphasise the fact that they were "winged" seeds, and so add to their significance. 
Plate 123

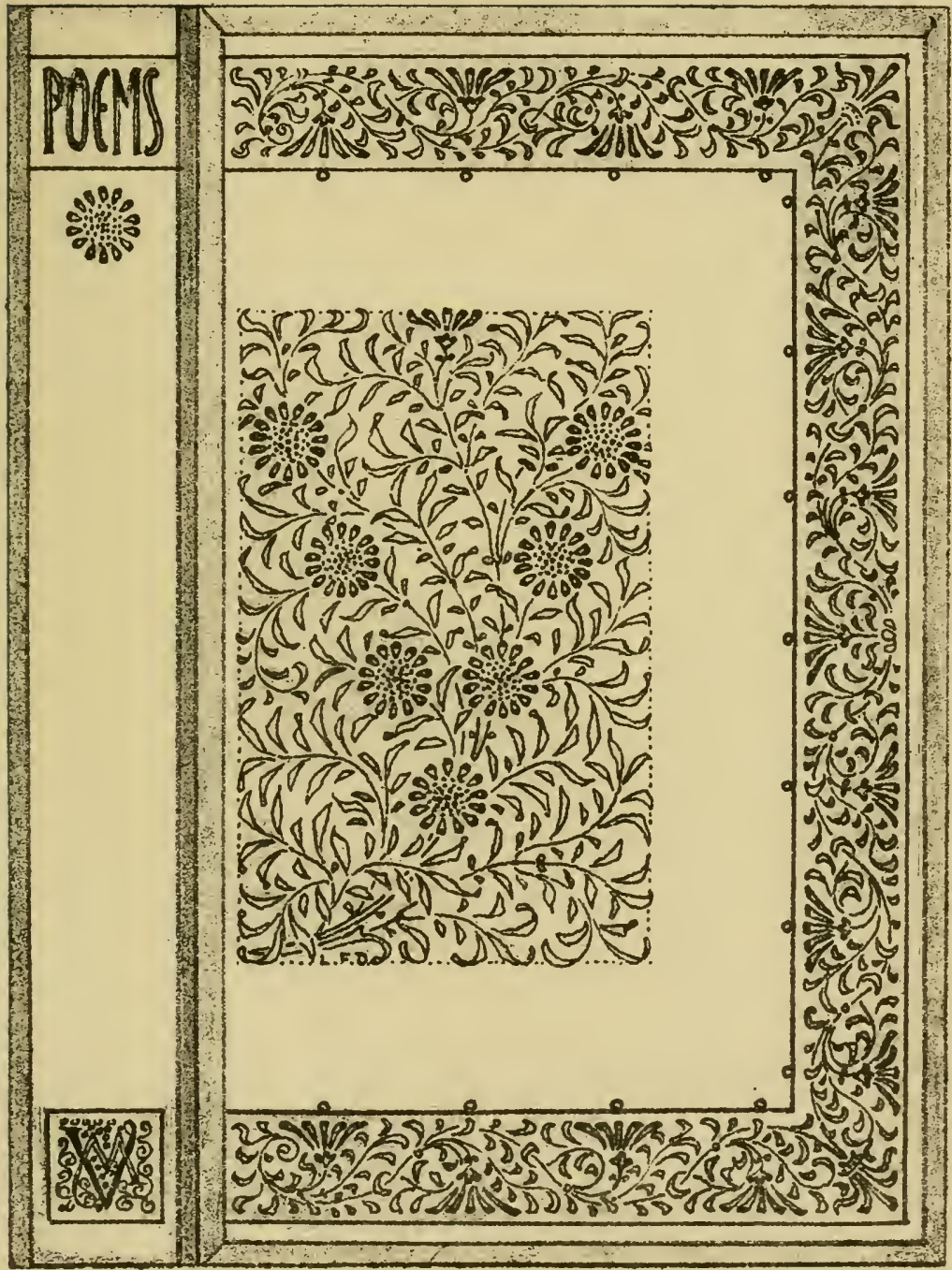

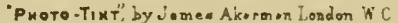

Symbolic Ornament, book cover. 



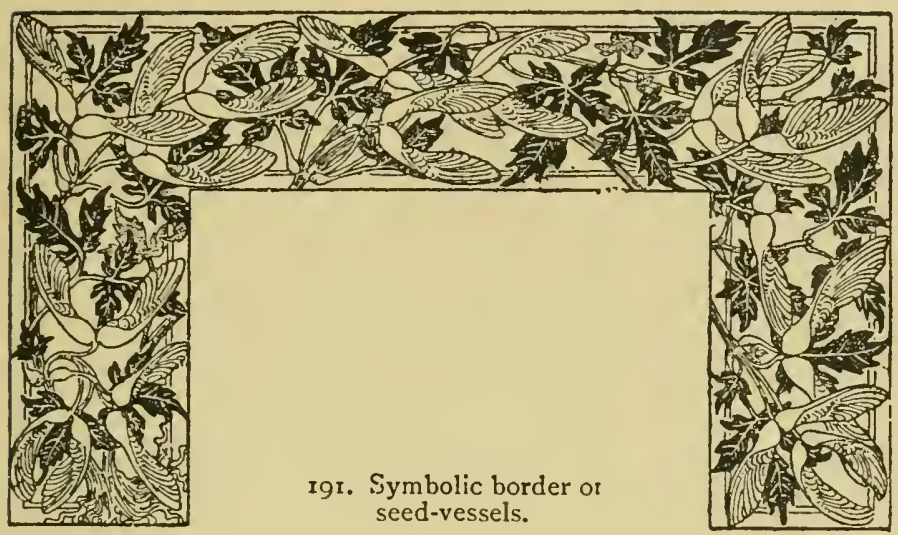

With regard further to the rendering of symbolic forms, one is justified in approaching fairly near to the natural type, so long as one does not approach so near as to substitute the thing for the symbol. The lily on Plate 75 is rather too suggestive of the garden in July to do duty for the symbol of the Virgin. A severer Gothic rendering, or at all events a more abstract representation, would more immediately call up the idea of the Annunciation.

But, however remote the emblem from actuality, there should never be any mistake about its identity. On Plate 122 are shown three very characteristic renderings of the marguerite. In the one case the growth is fairly natural, in the others the lines are much more arbitrarily disposed, but there is no mistaking the flower. 
In the rendering of the marguerite on Plate I23, the idea was that the meaning should be there (just as there is a meaning

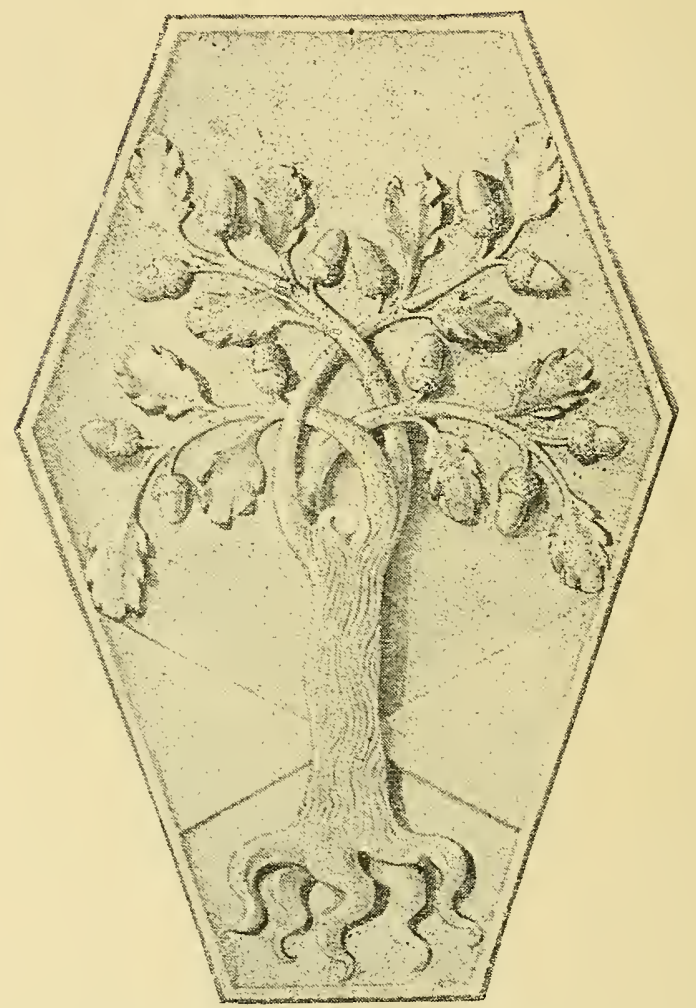

192. Heraldic oak-Italian Renaissance.

in the arrangement of the flowers) for the satisfaction of a.personal sentiment, but that it should not be too obvious. For one's own sake and for those whom it may concern, 
one may sometimes hint in ornament what one does not care to say quite plainly.

Yet, though it be essential to general interest that ornament should mean something, it may fulfil its purpose perfectly without meaning more than beauty; and, in fact, its true artistic interest is apart altogether from any thought of symbolism.

The artist, for all that, who has anything to say for himself, says it, and will say it ; and his art is by so much, not the more ornamental, but the better worth having. For which reason, as well as on account of the influence symbolism has had, and must always have, upon art-since men are something more than artists-it has seemed necessary to touch upon the inner meaning of ornament. But, once more, the art is in the saying, not in the thing said. 



\section{INDEX TO ILLUSTRATIONS.}

A.

Abstract

foliage............p. 169

ornament ...pp. 49, 152

Acanthus pp. 34, 35

Pl. 13, 14

vine-like .........p. $3^{8}$

Acorn patterns .........p. 53

Albertolli .........pp.95, I 70

Aldegrever .............. 124

Animals.................Pl. 94

Anthemion

p. 158

Gothic

p. 162

Renaissance, pp. 20, 164 Apple................Pl. 8, 82

and vine, frieze ...P1. 52 Arab vine Pl. 54

Arabesque

German ...p. 47, Pl. 20

Italian ......Pl. 17, 18, 96,100

Archaic Greek, p. 65, Pl. 4 I Artichoke. P1. 38

Artificial

grace ........pp. 90, 97 rendering ...p. $76, \mathrm{Pl} .32$ rendering of rose, $\mathrm{Pl} .62$ Ash Pl. 8 Asparagus Pl. 10
Assyrian

rosette ............ 155

symbolic ornament,

p. I 5 I

tree .........pp. I42, 239

vine .............. 106

Aster ..................... 50

Aucuba ................Pl. 5

B.

Bat

diaper ......pp. I84, I9 I embroidered .......p. I94 pattern ...........p. 2 I 6

Bay ...............Pl. 5, 8I

Beech ...............Pl. 3, 8

Beetle, Egyptian ......p. 237

Berberris ...............Pl. 5

Berries ................Pl. 37

from nature.........Pl. 5

ivy..................p. 57

Birch ................... 3

Bird

crest ..............p. 18 I

\& flower crest......p. I8I

diaper,..............p. I85

Birds ........p. 238, Pl. 94

in flight ............p. I $8 \mathrm{I}$

Blossoms, Japanesej.p. 213

Book-cover ......Pl. 22, I23 
Boragewort Pl. 6 Bouquet........p. 48, Pl. 2 I Boulle p. 4I

Briony .p. I4, Pl. 5

Brocatelle p. 140

Bronze p. 109 Pl. 4I, 63, 7 I

Broom .Pl. 7

Brunelleschi Pl. 46 Brush-work. Pl. 13

Buckwheat pp. $34,66,152$ Buddhist sculpture...p. I34 Pl. 67,119

Budding branches, from nature $\mathrm{Pl} .3$

Bud-like forms .p. 63 Buds

from nature ........Pl. 8 or fruits? ..........p. 58 or seed-vessels ? ...p. 57 Burges, W. p. 185 Butterfiies Pl. 97 Byzantine carving ...p. II5

C.

Candelabrum p. I9

Canna Pl. 4 Carpet, Italo-Persian, Pl. 65 Carrot P1. 10 Carved door. P1. 28 Carving

Gothic ...p. I19, Pl. 29 wings ............Pl. 108

Celandine ...p. r7o, Pl. 33 Chinese

butterflies Pl. 97 embroidery ...Pl. 76, 97 pp. 29, I7 I, 194
Chinese

flower forms, pp. 50, 157 foliage ........pp. 48, 5 I "kiss-me-quick," p.I7 I lotus ..............P1. 88 orchid ..........Pl. 76 pomegranates ...Pl. 73 Wistaria ............p. 29 Chrysanthemum ...p. 182 pattern ............Pl. 40

Classic

leafage, modification of .................. 39 vine Pl. 53

Cloisonné enamel ...p. I89 Cloud pattern .........p. 216 Clouds .................p. 238 Cobœa scandens ....... 14 Pl. 89

Cock Pl. 94

Colour printing ......Pl. 73 Columbine ............Pl. 83 Confusion of effect...p. IOI Coptic embroidery ......Pl.25, 49,57

feather border ...p. 227 feather diaper ...p. 227 Corn .............pp. 89, 90 Cranes, Japanese......P1. 92 Cresswort ..............Pl. 6 Cretonne ...P1. 48, 6I, 106 Crocket................Pl. 29 hawthorn...........p. 59 vine ................p. 59 Crocket-like foliage ...p. $3^{8}$ Cross of fleurs-de-lis, p. 238 Crown, imperial ....... Pl.3I 


\section{Index to Illustrations.}

D.

Damascening

Dandelion

Day, Lewis F.

Book-cover

Pl. 123

Chrysanthemum Pl. 40

Cobnea scandens, Pl. 89

Cretonne ...P1. 6I, I06

Dandelion .........Pl. 90

Fig p. 173

Frieze ...Pl. 14, 52, $8_{5}$

Grotesque scroll, Pl.Io6

Heraldic mantling,

p. 223

Inlay Pl. 31

Lily Pl. 39, 75

Linen damask ...Pl. 89, I I I, I 32, I 33

Lustre ............Pl. IO2

Narcissus ...........p. 93

Oak Pl. 9

Poppy ...p. 172, Pl. 72

Scroll ...............Pl. 48

Seaweed ...P1. I I I, II 2

Seed-vessels ......p. 245

Stained glass ......Pl. 59

Tiles ............Pl. 9, 39

Tulip .............Pl. 85

Vine ...........Pl. 59, 6r

Wall-paper ...P1. 37, 38

Denaturalised floral

details

p. 98

Diaper

of bats .....pp. I 84, rgr
of birds ..........p. 185
of dragon-flies ...p. 183
of flames..........p. 215
Gothic ..........p. 162
Diaper

Japanese ........Pl. 109

pp. 78, I 59, 182, 238

peacock-feather, Pl. I I4

of spiders' webs, p. 214

Diletra-spectabilis...p. I I I

Dolphins ............... ז 180

Dragon, Japanese ...p. 2 Io

Dragon-fly diaper ...p. 183

Drusse, Nicolaus ...Pl. II 7

Ducks ................Pl. I 29

Dürer, Albrecht ......Pl. 60

Dutch conventions ... Pl. 47

E.

Earthenware, Assyrian,

Egyptian

p. I 5 I

beetle ..............p. 237

enamel ............. I89

eyes.................p. 243

lotus ......p. 240, Pl. 79

papyrus ...p. 1 50, Pl. 79

sculpture $\quad$.........Pl. 79

vultures ...........p. I88

Eighteenth-century silk,

p.76, Pl.32, 33, 44, 62, 70

Elaborated flower,

pp. 79,80

Elm ..................Pl. 3,8

Embossed silver......Pl. 53

Embroidery ......Pl. 69, 73

Arctic..............p. 2I I

butterflies .........Pl.97

Chinese ......Pl. 76, 97

Pp. 29, I 7 I, I 94

Coptic ...Pl. 25, 49, 57 
Embroidery

German ......pp. 77, 80

Gothic ............p. 79

Indian ............ I87

Italian ........... 135

Japanese ............p. 66

Oriental, p. I3I, Pl. I I4

Turkish

Pl. II 5

Enamel, Egyptian ...p. 189 English

Gothic Pl. 29, 58

silk P1. 62, 70 Etruscan detail ........ 158 Eyes, border of ......p. 243

\section{F.}

Faience

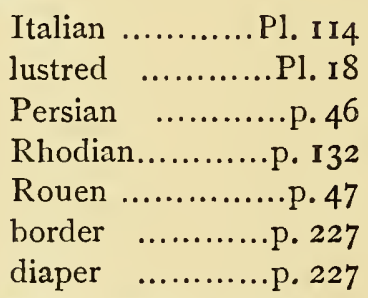

Fifteenth-century detail,

Fig

p. 157

\section{Figure}

Amorino .........Pl.99

Egyptian ........Pl. 79

Gothic ...........Pl. IOI

grotesque .........Pl. 105

Holbein .........Pl. 103

Italian ............Pl. I00

Japanese .........Pl. Io9

pattern ............p. I86

Peruvian Pl. 94
Fir

cone ......p. 157, Pl. 79

Japanese .........Pl. 109

tree ................Pl. 80

Fish

Assyrian...........Pl. 80

Japanese .........Pl. Io9

lustre ...........Fl. IO2

Flames ................p. 215

Fleur-de-lis

cross ..............p. 238

Gothic......pp. I60, 24I

Pl. $12 \mathrm{r}$

Italian ...........p. 240

Romanesque ......p. I60

tracery ............Pl. I2 I

F'leur de luce ............Pl. I

Floetner, Peter .........p. 47

Floral forms within foral,

p. 73

Footprints, Japanese, Pl. 109

Fox, George ...........p. 180

French Gothic, pp. 63, II6, 156

Frieze .........p. I8o, P1. I4

Fritillary ............ Pl. 3 I

Fruit pattern .........Pl. 87

Fruits ..................... $5^{8}$

Fungus.................Pl. 76

G.

Galls...................Pl. 9

Geese.................PI. 79

German

arabesque, p. 47, Pl. 20 conventions ......Pl. 47 embroidery ...pp. 77,80 foliage ...p. I24, $\mathrm{Hl} .83$ 
German

Gothic ......p. 8I, Pl.9I

hammered work, Pl. 36 ironwork ........p. 204 mantling ........p. 224 rosette .............p. 55 scroll Pl. I6, 19

Ghiberti Pl. 71

Giulio Romano ......Pl. I 7 Glass painting .........p. I 26 Goldsmiths' work ...p.98 PI. 2I, 53, II 7 Gooseberry ..........Pl. 98 Gothic

anthemion shape, p.162 carving ...p. I I9, Pl. 29 diaper................ 162 embroidery ......... p. 79 English. P1. 29, $5^{8}$ fleur-de-lis, pp. I60, 24I Pl. 121

French, pp. 63, II6, I56 German ...p. 8I, Pl. 9 I glass ........pp. 43, 126 inlay $\mathrm{Pl} .42$ ironwork ........Pl. 36 Italian ...p. I 20, Pl. 5 I modern .............. I 39 oak.............Pl. 29, 74 " pine " ...........Pl. 84 scroll .........Pl. I9, Iо I stencil ..............p. 60 stone-carving, pp. 63 , i 16 tiles ................p. 62 tracery ............Pl. I2 I wood-carving,

Pl. 58, 9 I, I $2 \mathrm{I}$, pp. 55, 63, 65, 8 I, I I I, I 2, I I 8,224

\section{Greek}

anthemion ........p. 158 archaic ...........Pl. 4I border ..............p. 6I detail ..............p. I6o diaper ...........Pl. I Io ivy.....p. 57, Pl. 24, 8 I scroll ..............Pl. I I that might be Gothic,

p. 65

vase Pl. 24, 81

pp. I08, I 52, I 53, 243 Gribelin, S. ...p. 98, Pl. 99 Grotesque ...........p. 202, PI. 94, 96, 102, 104 Arctic ............p.2I I figure ......PI. I03, 105 German .... ......p. 204 scroll ............. Io6 Growth

conventional ......PI.37 natural Pl. IO

$\mathrm{H}$.

Hammered iron ......Pl. 36 Hawthorn ...p. 59, P1. 3. 29 Heartsease ...........Pl. 35

Heaton, C. .............p. 89 Hemlock .................Pl. 4 Heraldry ......pp. 223, 224, 242,247 Holbein .............Pl. I03 Honeysuckle .........Pl. 44 Hop ..............pp. 8I, I Io Hopfer, D. ...........Pl. I6 Hornbeam ..............Pl. 8 Horse-chestnut .........Pl. 3 Hyacinth..... p. IOI, Pl. 3 I 


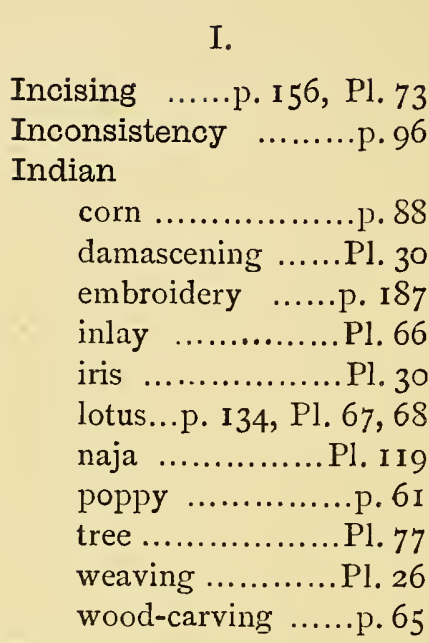

Inlay ...........p. 93, Pl. 3 I Boulle .............. 4 I Indian ..........PI. 66 Italian, P. 57, Pl. 43, 69 modern ...p. 226, Pl. 42 Persian ...........p. 169 Interlacing, Keltic...Pl. IO7 Iris................... IOI embroidery …... 135 Indian..............Pl. 30 in silk ..............Pl. 44 Japanese ...........p. 66 velvet ..............p. 240 Walter Crane ......Pl. I Iris-like ornament......p. 45 Iron grille..............p. 204 Italian

Arabesque ...Pl. I7, I8, 96,100 embroidery .....p. I35 faience ............Pl. I I 4 Gothic ..........p. 120 inlay ...p. 57, Pl. 48, 69
Italian

scroll .p. 123

silk p. 68, P1. 34 stone-carving ...... Pl. 5 I

velvet pp. 90, 247 wing-forms ......Pl. 108 wood-carving ...P1.96 pp. 88, I 10, 163, 209 Italo-Persian textile ...p. 73 P1. 65 Ivy classic ...........P1. 53 Greek, P. 57, Pl. 24, 8I

J.

Japanese

borders ......... p, 58

butterflies ........Pl. 97

cranes .............Pl. 92

dragon ..........p. 2 10

diaper, pp.I59, I9I, 215

Pl. 109

diapering ...........p. 78

embroidery .........p. 66 growth ............. Io leaf-sheaths ........Pl. 4 leather ..............p. 96 ornament, pp. 219,222 pattern ...pp. I86, 213, $214,216-220$ peacock-feather pattern, Pl. I13 roses ................Pl. 2 seed-vessels ........Pl. 6 tortoises ...........Pl. 93 wave........pp. 2r9-22I Jones, Owen .......Pl. 22 


\section{Index to Ilcustrations. $\quad 255$}

K.

Keltic interlacing ...Pl. 107 Kiss-me-quick, p.I 7I,Pl. 44

L.

Lace, ivory point ......Pl. 35 Lacquer ................ 2 I9 Larch ...................Pl. 8

Leaf sheaths ...........Pl. 4 Lemon ................Pl. 87 Lent lily .............Pl. 3 I Lily

forms p. 133 Greek .p. 6 I inlay ......Pl. 42, 43, 66 Italian .....pp. 9I, 92 lace ................Pl. 35 naturalistic, P.9I, Pl. 75 tiles Pl. 39

Lily-like details ......p. 160 Lime .Pl. 3

Linen damask, pp. I2I, I74

\section{Lotus} Pl. 89, I I I

Assyrian p. 155

Chinese Pl. 88

Egyptian, p. 240, Pl. 79 Greek ...........Pl. I Io Indian, p. I $34, \mathrm{Pl} .67,68$ Love in-a-mist .........Pl. 44 Lustre Pl. 102 Italian Pl. I8

M.

Majolica. See Faience. Maple ........p. 245, Pl. 29
Marble inlay ........PI. 66 Marco Dente da Ravenna, Pl. 105 Marguerite ..........Pl, I 22 Mino da Fiesole ......p. I64 Modern classic ..............p. 39 German ..........Pl. 98 Moorish

oak treatment ...p. I4I vine treatment, $\mathrm{PP} .113$,

114

Morris, Wm. ........Pl. 87

Mosaic

Pumpeian ........Pl. 27

Roman, pp. 36, 59, Pl.I 5 Muckley, W. J. ......Pl. 86 N.

Narcissus .............p. 93 Natural

berries ..............Pl. 5

branches ...........Pl. 3 buds ................PI. 8 foliage .............p. 63 growth ............. I 10 leaf-sheaths .........Pl. 4 pods .................Pl. 7 seed-vessels ........p. 56

Naturalism ...........Pl. 83 Naturalistic

birds ..............Pl. 100 lily ...........p. 9I, PI.75 oak ................p. 22 peony ..............Pl. 86 poppy $\ldots \ldots \ldots \ldots$.... 172 snails Pl. 9 Needlework ..........p. 136 
Niello Nightshade p. 6I, P1. 20 Ninevite sculpture ... Pl. 80 Nut Pl. 29, 45

\section{O.}

Oak

Albertolli...........p. 95

galls Pl. 9

Gothic Pl. 29, 74 heraldic. .p. 247 Moorish p. 141 natural p. 22

P. Quentel Pl. 83

Roman .p. 94

Sicilian p. 142

Oak-like leafage .....p. 37 Olive

classic Pl. 50

Greek Pl. $8 \mathrm{I}$ Olive-like leafage ......p. 37 Onion Pl. 8

Orange Pl. 87 Orchid p. 96, Pl. 76

P.

Painted wall-panel ...Pl. I7 Painting

Indian Pl. 30

Pompeian ...Pl. 27, I18 Palm tree Pl. 77 Papyrus ......p. 150, Pl. 79 Passarini, Philippo, Pl. I 6 Passion-flower ..p. 14 Pea Pl. I0, 83

Pea-pod ornament ...p. 20 Pl. 46

Peach .Pl. 87
Peacock embroidery, p. I87

\section{Peacock-feather}

diapers ............Pl. II4

inlay ..............p. 226

pattern .......Pl. I I 3, I I 5

tiles................p. 228

Peony

frieze ..............Pl. 86

stencil ..............p. 64

Persian

detail ......pp. 45, 46, 66

foliage..............Pl. 78

inlay ............... 169

porcelain, pp. $44,45,48$

scroll ..............p. 44

silk ........p. 74, Pl. 78

tiles .........pp. 101, 228

Peruvian stuffs ......Pl. 94

Phœnician wreath ...p. 23I

Pierced stone ..........Pl. 77

"Pine" ornaments ...Pl. 84 Pink

lace................Pl. 35

needlework ......p. 136

textile ......pp. 73, I49

Pl. 70

tile-painting ......p. IOI

various ...........Pl. 69

Plum ....................Pl. 3

Pods ...................Pl. 45

from nature .........Pl. 7

Pomegranate ......Pl. 73, 87 embroidery .........p. 77

modern ............p. I 39

stencil ..............p. 60

textile ...pp. 74-76, 140

Pompeian

bronze ............p. 109

candelabrum …..p. 19 


\section{Index to Illustrations.}

Pompeian

detail

painting Pl. 27, II 8

Poplar Pl. 3

Poppy

bronze

Pl. 7 I

inlay

Pl. 66

naturalistic …p. I72

niello .p. 6 I

wall-paper

Pl. 72

Porcelain ...pp. 44, 45, 48, 66,2 I $8, \mathrm{Pl} .88$

Privet Pl. 5

Pugin, A. IV. Pl. 74

Q.

Quattro-cento ...pp. 92, I23 Quentel, Peter $\mathrm{Pl} .83$

$\mathrm{R}$.

Rabbit Pl. 109 Renaissance

anthemion .........p. I64 Arabesque .........Pl. 20 German ...........p. I24 Italian ...p. I63, Pl. I04 needlework ......p. I 36 pea-pods p. 20

silk p. 149

stone-carving, Pl. 45, 46 tree .p. 247 trophies .p. 229 wing-forms Pl. 108 Rhodian faience p. I32 Rococo scroll.... Pl. I 6 Roman

candelabrum p. 133
Roman

mosaic .......pp. 36, 59 Pl. 15

naturalism, p. 94, Pì. 82 scroll ......p. 36, Pl. 12

Romanesque

detail .........pp. 42, I60 stem ................p. I 8

Rose

tree $\quad \ldots . . . \ldots \ldots \ldots$.... 143

artificial .......... Pl. 62

embroidery........p. I3I

Gothic ...........Pl. 29

Italo-Persian ..... p 130

Pl. 65

Japanese ...........Pl.

Rhedian ...........p. 132

Talbert ............Pl. 23

Tudor .........Pl. 63, 64

Rosette

Assyrian............. I 55

Gothic ......p. 55, Pl. 29

Rouen ware........p. 47

S.

Sammicheli ..........p. 9I

Sansovino ...........Pl. 104

Scratched earthenware,

Scroll

p. II 7

Boulle .............p. 4I

\& foliage...........Pl. 48

Gothic ......Pl. I9, IOI

Greek ..............Pl. I I

grotesque .........Pl. 106

Persian ............p. 44

rococo ............Pl. I 16

Roman......p. 36, Pl. 12 
Scroll

seventeenth century, P1. 99, I I7

transitional ......P1. I6 Sculpture

Assyrian...p. 106, Pl. 80 Egyptian............Pl. 79

Roman .........Pl. 55, 82 Seaweed........pp. I62, 222

P1. I I I, I I 2

Seder, Anton ........Pl. 98

Seed-vessels ......pp. 56, 57

Pl. 6

symbolic

Seventeenth-century

Boulle ..p. 4I

conventions Pl. 47 embroidery ......p. I 35 goldsmiths' work, p. 98 Pl. 2 I

scroll Pl. 99, I I 7 silk .........p. 68, Pl. 32 velvet

p. 240

Shell p. 222

Sicilian silk ......pp. 58, 142

Pl. 95

Signorelli, Luca ......p. 202 Silk p. 68

English ….Pl. 62, 70 eighteenth-century, p. 76 Pl. $32,33,44,62,70$ Italian. Pl. 34

Italo-Persian p. 149 Lyons ......p. 97, Pl. 32 Persian ...p. 74, Pl. 78 seventeenth-century, p. $68, \mathrm{Pl} .32$ Sicilian ......pp. 58, I42 P1. 95
Silver, classic ........Pl. 53 Simplified forms, pp. 54, 64 Sixteenth-century

Arabesque...P1. I8, Iоo Arabesque German,

badges p. 242 naturalisin $\mathrm{Pl} .83$ silk P1. 34 wood-carving......Pl. 96 Skull ornament ......p. 230 Snail ..................P1. 98

Snowberry .............Pl. 5 Solanum ............... Pl. 5 Spanish carving ..........p. [4I textile............... p. I4O Spiders' webs .........p. $2 \mathrm{r}_{4}$ Spindle-berry ...........P1. 5 Stained glass...p. 43, Pl. 59 Stem ................... . I8 Stencil

Gothic .............p. 60 peony ...............p. 64 Sumner ............Pl. 56

Stone-carving

archaic Greek ......p. 65 Egyptian ........Pl. 79 François $\mathrm{I}^{\mathrm{er}} \ldots \ldots \ldots$ p. 38 Gothic ......pp. 63, I 16 Indian ...p. 134, Pl. 77 Indian Buddhist, Pl. 67,68 Italian ...p. I23, Pl. 69 Renaissance...Pl. 45, 46 Storks ..p. 182 Strawberry …......... I 74 Street, G. E. ............ 54 Stucco, classic P1. 53 
Stuffs, Peruvian

Sumner, H. ...p. 64, Pl. 56 Sunflower.... Pl. 23

Swag p. 233

Sycamore Symbolic

border, Assyrian, p. I $5^{1}$ diaper...............p. 238 eye ...............p. 243 figure ..Pl. I hawk p. 189 naja Pl. I 19 ornament Pl. 123 papyrus ...pp. I 50, 240 seed-vessels .p. 245 trees Pl. 120 vulture p. 188

\section{$\mathrm{T}$.}

Talbert, B. J., pp. 139,226 $\mathrm{Pl} .23,42$

Tapestry, Gothic......Pl. I9

Tare. .p. 14

Tendrils...pp. 14, I5, Pl.60 Terra-cotta, Greek,

Pl. 24, p. 243

Thistle .....p. 54, Pl. 83, 9 I Thoroughwax Pl. 4

Tile ......Pl.9, p.62, Pl. 39 Assyrian . .........p. I 5 I

Gothic .. ...........p. 62 Persian ......p. 101, 228

Tortoises ..............Pl. 93 Tracery, Gothic......Pl. I2 I Traditional, Indian...P1. 26 Tree Pl. 120

Greek Pl. 24 Indian Pl. 77
Tree

of life ......pp. I42, 143

Roman..............p. 59

sacred..............p. 239

Sicilian..............p. $5^{8}$

Trophy ................p. 229

Tuberose.................Pl. 4

Tudor rose.........Pl. 63,64

Tulip .............Pl. 65, 85

Tulip-tree ..............Pl. 8

\section{V}

Velvet........pp. 73, 75, 130 Vine ..................Pl.61 Arab ............... 54 Assyrian ........p. 106 Byzantine ........p. II 5 carving …........Pl. 55 classic.............Pl. 53 Coptic ........Pl. 49, 57 cretonne ...........Pl. 29

Dürer .............Pl. 60 frieze .............Pl. 52 Gothic ..........Pl. 58 pp. 59, III, II 2, I I6, I I 8, I I9, I 2 I, I 26

Greek ...p. 108, Pl. 24 inlaid in bronze...p. 109 Italian ......pp. I 10, I23 Italian-Gothic ...p. I 20, Pl. 51 Moorish ...pp. II 3 , I 44 Roman ...........Pl. 50 sgraffitto .......... I I 7 stained glass ......Pl. 59 stencil..............Pl. $5 €$ tendrils ............... 15 
Vine-like acanthus ...p. $3^{8}$

Vultures .p. 188

W.

Wall-painting

Italian Pl. 100

Pompeian Pl. I 18

Wall-paper, W. Burges,

L.F. D....Pl. 37,3 $\mathrm{P} .185$
38,72

Wm. Morris ......Pl. 87

B. J. Talbert ......P1. 23

Walnut Pl. 3

Water, Japanese ......p. 217

Water-lilies, Japanese,

\section{Wave}

p. 217

diaper, Japanese, p. 238 Japanese p. $22 \mathrm{I}$

\& lotus diaper...PI. IIo ornament, Japanese,

p. 219
Wave

pattern, Japanese, pp. 216, 218-220

Wheat-ears..............p. 68

Wing

forms..............Pl. 108

treatment, Egyptian, pp. 188, 189 Italian ......p. 209

Wistaria .................. 29

Wood-carving

Cairene ..........P1. 28

French Renaissance,

p. 230, Pl. I22

Gothic ...Pl. 58, 9I, I2I pp. $55,63,65,8$ I, III, I I 2, I 8,224

Indian ..............p. 65

Italian........... Pl. 96

pp. 88, I ro, 163, 209

Tudor.............Pl. 64 Wreath ...............p. 23I

LONDON : PRINTED BY WILLIAM CLOWES AND SONS, LIMITED, GREAT WINDMILL STREET, W., AND DUKE STREET, STAMFORD ST., S.E. 




SMITHSONIAN INSTITUTION LIBRARIES

|||||||||||||||||||||||||||||||||||||||| उ 9088006427785 